\title{
Paleomagnetic Studies of the Late Miocene Mangapoike River Section, Northern Hawke's Bay, New Zealand
}

by

Ian Craig Wright

A thesis submitted for the degree of Doctor of Philosophy

Research School of Earth Sciences

Victoria University of Wellington

July 1986 


\section{Dedication}

This thesis is dedicated to Barby, when I should have been at home and dedicated.

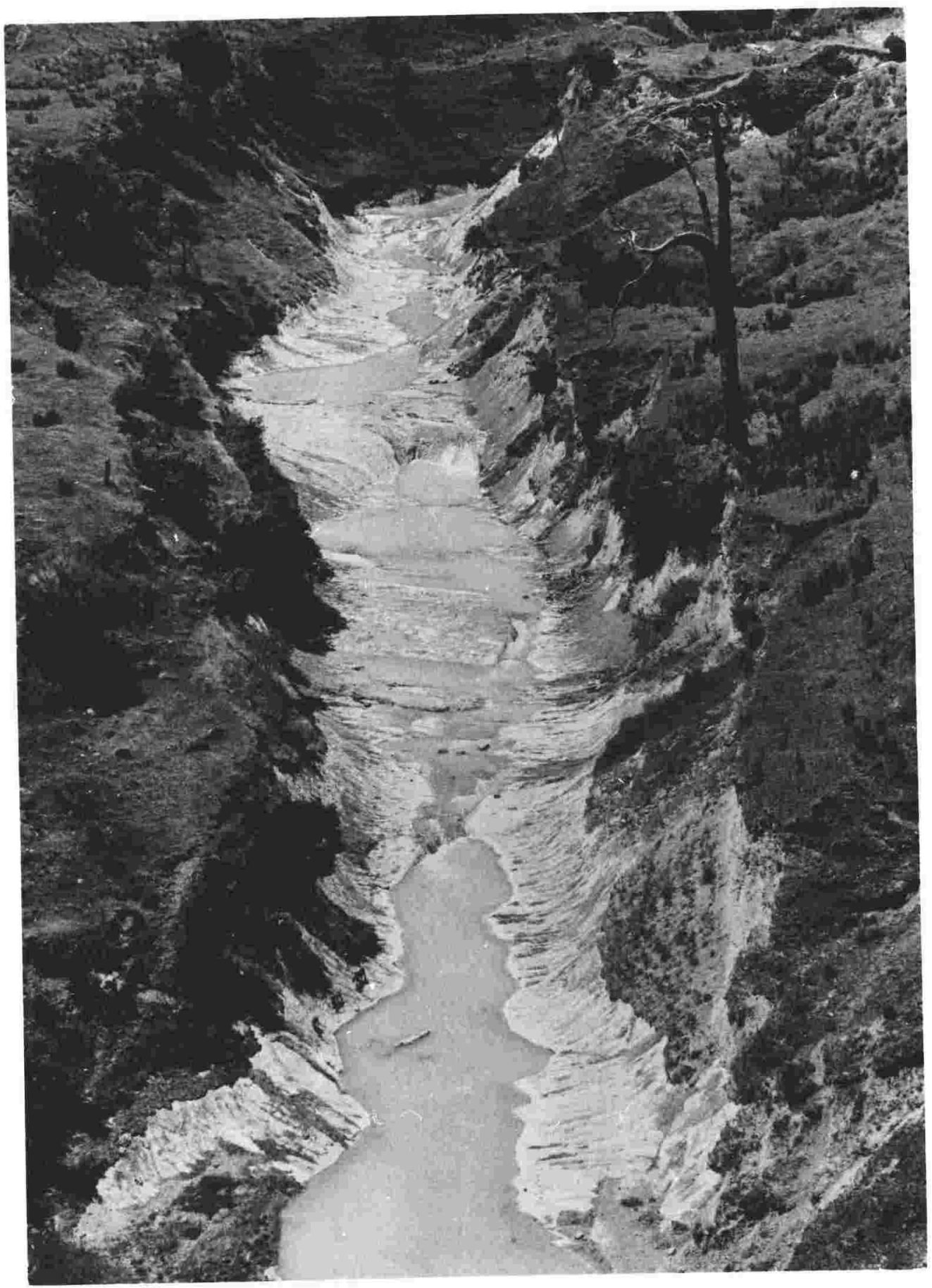

". . the increasing number of Swiss-cheese outcrops in scenic country is disturbing but perhaps unavoidable..."

Chan and Alvarez (1983). 


\section{ABSTRACT}

The Mangapoike River section $\left(38.9^{\circ} \mathrm{S}, 177.6^{\circ} \mathrm{E}\right)$, on the eastern limb of the Wairoa Syncline, northern Hawke's Bay, is a thick (> $4000 \mathrm{~m}$ ) and well exposed sequence of Waiauan to Waipipian sediments in which foraminiferal and radiolarian biostratigraphy and silicic tuff lithostratigraphy are well known. An Early Pliocene magnetostratigraphy has been determined by Kennett and Watkins (1974). The present study extends the magnetostratigraphy to the Middle - Late Miocene, and establishes a Late Miocene to Early Pliocene $3000 \mathrm{~m}$ magnetostratigraphic reference column for New Zealand.

The only identifiable remanence carrying magnetic mineral in the Mangapoike sediments is titanomagnetite. Its chemistry does not vary with grain size. Oxidation of the titanomagnetite is deuteric, and thus pre-depositional. Fluctuations of titanomagnetite concentration between $10^{-3}$ to $10^{-4} \mathrm{wt} \%$ are the main influence on the variation of NRM intensity. Viscous magnetisations characterised by both the alignment of NRM directions in a general present day field direction and remanence decay and aquisition over laboratory time were recognised in $85 \%$ of the 1204 paleomagnetic specimens. Secondary magnetisations were removed by thermal demagnetisation at temperatures varying between $200^{\circ} \mathrm{C}$ and $320^{\circ} \mathrm{C}$. AF demagnetisation was not effective in removing viscous magnetisations, even at peak alternating fields of $35 \mathrm{mT}$, since the coercivities of the primary and secondary magnetisations overlap completely. The random relationship between the degree of bioturbation and in-site dispersion at individual sites indicates the magnetisation is acquired after bioturbation, and thus is a post-depositional detrital magnetisation. The time lag between deposition and acquisition of the magnetisation is approximately 1000 yrs.

Six normal (MN1 - MN6) and seven reversed (MR1 - MR7) polarity magnetozones are identified within the late Miocene at Mangapoike. Only one normal magnetozone (MN6) is recognised in the stratigraphic interval equivalent to that from which Kennett and Watkins (1974) reported two normal zones (C1 and C2). MN6 is correlated to C2. C1 is inferred to be an uncleaned normal overprint. The magnetozones are correlated to Chrons 11 to 4 , which implies an average sedimentation rate of $64 \mathrm{~cm} / 1000 \mathrm{yrs}$. The previously known Miocene - Pliocene $3^{\circ}$ angular unconformity at Mangapoike (Hornibrook 1977) represents the period from 6.3 Ma to at least 5.41 Ma. A previously unrecognised unconformity from at least 6.86 to at least $6.42 \mathrm{Ma}$ is postulated, based on the preferred magnetostratigraphic interpretation. The presence of the unconformity is supported by radiolarian and benthic foraminiferal biostratigraphy. 
Three distinct lithological events at Mangapoike, based both on the synchroneity with deep-sea benthic $\delta^{18} \mathrm{O}$ records and unconformities of the Vail-curve, are inferred to result from glacioeustatism. At Mangapoike, the Waiauan - Tongaporutuan boundary, as defined by the incoming of Bolivinita cf pohana, has a magnetostratigraphic age of $10.3 \mathrm{Ma}$. Both the LAD of Loxostomum truncatum and the FAD of Bolivinita cf pohana are less than 42,000 yrs. younger than the late Waiauan glacioustatic event. The Waiauan Tongaporutuan boundary is thus postulated to result from glacioeustatism. Glacioeustatism may also explain the excellent age correlation between the base of the Tongaporutuan and the base of the Tortonian stratotype.

Correlation of the late Miocene and early Pliocene magnetostratigraphies and biostratigraphies of on-shore New Zealand with either of the magnetostratigraphic interpretations of DSDP Site 594 results in an unacceptably high diachroneity of some planktic taxa of $1.8 \mathrm{Ma}$ over $3.6^{\circ}$ of latitude. Of four possiblities to resolve the anomaly, incorrect magnetostratigraphic correlations at Site 594 is the most likely. The previously determined age of $6.2 \mathrm{Ma}$ for the LAD of Globoquadrina dehiscens in New Zealand is erroneous. A magnetostratigraphic age for the LAD of G. dehiscens at Mangapoike is 9.2 Ma. This age is not an extinction date for the taxon throughout New Zealand, and the LAD may well be erratic and diachronous within New Zealand.

The Wairoa Syncline, a forearc basin within the Hikurangi margin, has a rotation rate as determined from declination directions, of $7-8^{\circ} / \mathrm{Ma}$ for the last $5 \mathrm{Ma}$. Of this less than $1.5^{\circ} / \mathrm{Ma}$ is due to apparent polar wander of the Australian plate. Extrapolation of this rate towards the present is consistent with a present day rotation rate of $7^{\circ} / \mathrm{Ma}$ derived from strain analysis of geodetic data. Prior to $10 \mathrm{Ma}$ the rate of tectonic rotation is poorly constrained and may vary between $3 \% \mathrm{Ma}$ and $0 \% \mathrm{Ma}$. The change in the rate of rotation of the Wairoa Syncline around $5 \mathrm{Ma}$ is probably related to a marked change in regional tectonic regime involving opening and spreading to the north of New Zealand and compression and shortening to the south. 
Abstract.

Table of contents iii

List of figures.

List of tables

List of plates

List of appendices.

Acknowledgements $f=f$ acing

1. INTRODUCTION

Table of Contents

1.1 STUDY AIMS 1

1.2 INTRODUCTION 1

1.3 RADIOMETRIC DATING 4

1.4 MAGNETOSTRATIGRAPHY 4

1.4.1 Principles 4

1.4.2 Assumptions 4

1.4.3 Nomenclature. 5

1.5 MAGNETOSTRATIGRAPHY IN NEW ZEALAND . . . . . . . . . . . . 5

1.6 REGIONAL DEEP-SEA STRATIGRAPHY . . . . . . . . . . . . . . . 7

1.7 MAGNETOSTRATIGRAPHIC CRITERIA. . . . . . . . . . . . . . . . . 7

2. MANGAPOIKE RIVER: STRATIGRAPHY AND LITHOLOGY . . . . . . . . . 10

2.1 INTRODUCTION . . . . . . . . . . . . . . . . . . . . 10

2.2 STRATIGRAPHY . . . . . . . . . . . . . . . . . . 10

2.2.1 Previous Work . . . . . . . . . . . . . . . . . . 10

2.2.2 Stratigraphy . . . . . . . . . . . . . . . . . . . 12

2.3 LITHOLOGY . . . . . . . . . . . . . . . . . . . . . . . 15

2.4 SAMPLING AND SITE LOCATIONS . . . . . . . . . . . . . . . 15

3. ROCK MAGNETISM AND MAGNETOMINERALOGY . . . . . . . . . . . . 23

3.1 INTRODUCTION . . . . . . . . . . . . . . . . . . . . 23

3.2 DEFINITIONS AND TERMINOLOGY . . . . . . . . . . . . . . 23

3.3 GENERAL . . . . . . . . . . . . . . . . . . . . . 26

3.4 METHODS AND TECHNIQUES. . . . . . . . . . . . . . . . . 28

3.4.1 Introduction . . . . . . . . . . . . . . . . . . . . . . 28

3.4.2 Sample Storage and Preparation . . . . . . . . . . . . . . . 28

3.4.3 Electron Probe Microanalysis . . . . . . . . . . . . . . . . . 30 
3.4.4 Initial Volume Susceptibility . 30

3.4.5 Isothermal Remanence Measurements 30

3.5 MEASUREMENT OF MAGNETIC REMANENCES 33

3.6 DETRITAL MAGNETOMINERALOGY 34

3.6.1 Introduction 34

3.6.2 Chemistry . 34

3.6.3 Concentration. 39

3.6.4 Source 42

3.7 DIAGENETIC AND AUTHIGENIC MAGNETOMINERALOGY 45

3.7.1 Haematite, Maghemite and Goethite. 45

3.7.2 Pyrrhotite. 45

3.8 REMANENCE STABILITY. 45

3.8.1 Introduction 45

3.8.2 NRM Directions. 46

3.8.3 VRM Acquisition 46

3.8.4 VRM Decay .49

3.8.5 Discussion . 52

3.9 NRM INTENSITY . 57

3.9.1 Introduction 57

3.9.2 NRM Intensity 60 3.10 CONCLUSIONS

\section{DEMAGNETISATION TECHNIQUES} 62

4.1 INTRODUCTION AND PRINCIPLES . . . . . . . . . . . . . . . 62

4.2 THERMAL DEMAGNETISATION . . . . . . . . . . . . . . . . 63

4.2.1 Introduction . . . . . . . . . . . . . . . . . . . 63

4.2.2 Techniques . . . . . . . . . . . . . . . . . . . 63

4.2.3 Mineralogical Alteration. . . . . . . . . . . . . . . . . 64

4.2.4 Thermal Demagnetisation: Results . . . . . . . . . . . . . 67

4.3 AF DEMAGNETISATION . . . . . . . . . . . . . . . . . . . 72

4.3.1 Introduction . . . . . . . . . . . . . . . . . . . . 72

4.3.2 Techniques . . . . . . . . . . . . . . . . . . 73

4.3.3 AF Demagnetisation: Results . . . . . . . . . . . . . . 73

4.4 COMPARISON OF THERMAL AND AF DEMAGNETISATION. . . . . . . . 77

4.5 GENERAL DEMAGNETISATION . . . . . . . . . . . . . . . . . 83

4.5.1 General Techniques . . . . . . . . . . . . . . . . . 83

4.5.2 Selection of Representative Direction . . . . . . . . . . . . . . 83 
5. MAGNETOZONES AND CORRELATION TO THE MAGNETIC POLARITY TIMESCALE.

5.1 INTRODUCTION . . . . . . . . . . . . . . . . . . . 85

5.2 STANDARD MAGNETIC POLARITY TIMESCALE. . . . . . . . . . . . . 85

5.3 MAGNETOZONES. . . . . . . . . . . . . . . . . . . . . . . 87

5.4 CORRELATION WITH THE MAGNETIC POLARITY TIMESCALE . . . . . . . 89

5.5 SAMPLING EFFICIENCY . . . . . . . . . . . . . . . . . . . . . 95

5.6 BIOTURBATION . . . . . . . . . . . . . . . . . . . . . . . . . 98

6. LATE MIOCENE CORRELATIONS . . . . . . . . . . . . . . . . . . 101

6.1 INTRODUCTION . . . . . . . . . . . . . . . . . . . . . 101

6.2 GlaCiOEUSTATIC SEA-LEVEL CHANGES . . . . . . . . . . . . . 101

6.2.1 Introduction . . . . . . . . . . . . . . . . . . 101

6.2.2 Mangapoike Glacioeustatic Events . . . . . . . . . . . . 102

6.2.3 Discussion . . . . . . . . . . . . . . . . . . 107

6.3 NEW ZEALAND CORRELATIONS. . . . . . . . . . . . . . . . 109

6.4 BASE OF THE TONGAPORUTUAN STAGE . . . . . . . . . . . 112

6.4.1 Stratigraphy . . . . . . . . . . . . . . . . . . 112

6.4.2 Correlation and Dating . . . . . . . . . . . . . . 112

6.5 GLOBOQUADRINA DEHISCENS: LAST APPEARANCE . . . . . . . . . . 109

6.5.1 Stratigraphy . . . . . . . . . . . . . . . . . . . 114

6.5.2 Dating . . . . . . . . . . . . . . . . . . . 116

6.5.3 Discussion . . . . . . . . . . . . . . . . . . . 117

7. TECTONIC ROTATIONS. . . . . . . . . . . . . . . . . . . . 118

Manuscript entitled 'LARGE TECTONIC ROTATION OF PART OF NEW ZEALAND IN

THE LAST $5 \mathrm{Ma}^{\prime}$ submitted to Earth and Planetary Science Letters. . . . . . 119

8. MAIN CONCLUSIONS AND FUTURE WORK. . . . . . . . . . . . . 131

8.1 MAIN CONCLUSIONS . . . . . . . . . . . . . . . . . . . . . 131

8.2 FUTURE WORK . . . . . . . . . . . . . . . . . . . 133

REFERENCES . . . . . . . . . . . . . . . . . . 135

List of Figures

1.1 Chronostratigraphy of the New Zealand Neogene . . . . . . . . . . . 2

1.2 New Zealand Neogene planktic foraminiferal zones and bioevents . . . . . . . 3

1.3 Location map of New Zealand Neogene stage stratotypes . . . . . . . . . . 6

1.4 Location map of deep-sea sediment cores in the New Zealand region . . . . . . . 8 
2.1 Location and geological map of the Mangapoike River section. . . . . . . . . . 11

2.2 Chronostratigraphy and lithostratigraphy of the Mangapoike River section . . . . . 13

2.3 Stratigraphic log of the degree of bioturbation of the lower Mangapoike River section 17

3.1 Magnetic hysteresis loop . . . . . . . . . . . . . . . . . . . . . . . 25

3.2 Magnetic minerals of the $\mathrm{FeO}-\mathrm{TiO}_{2}-\mathrm{Fe}_{2} \mathrm{O}_{3}$ ternary system . . . . . . . . . . . 27

3.3 Relationship of field orientation and specimen axes . . . . . . . . . . . . . 29

3.4 Ternary plot of the 30 titanomagnetite analyses . . . . . . . . . . . . . . 35

3.5 Isothermal remanent magnetisation curves . . . . . . . . . . . . . . . 37

3.5 (continued) . . . . . . . . . . . . . . . . . . . . . . . 38

3.6 Plot of titanomagnetite $\mathrm{TiO}_{2}$ wt\% against grain size . . . . . . . . . . . . 40

3.7 Ternary plot of three major substituted cations within the titanomagnetites . . . . 44

3.8 NRM directions a) non-tectonic corrected b) tectonic corrected . . . . . . . . . . 47

3.9 Mean normal and reversed NRM directions . . . . . . . . . . . . . . . . 48

3.10 Plot of NRM declinations and core azimuths of specimens not stored in Mumetal shields . . . . . . . . . . . . . . . . . . . . . . 50

3.11 Plot of NRM declinations and core azimuths of specimens stored in Mumetal shields. 51

3.12 Plot of magnetisation intensity decay during shield storage . . . . . . . . . . 54

3.13 Stratigraphic $\log$ of volume susceptibility and NRM intensity . . . . . . . . . 58

3.14 Plot of volume susceptibilities and NRM intensities with grain size . . . . . . 59

4.1 Plot of volume susceptibility and magnetisation intensity with temperature . . . .65

4.2 Zijderveld plots of thermal pilot specimens with well defined primary magnetisations . . . . . . . . . . . . . . . . . . $68+68 \mathrm{f}$

4.3 Zijderveld plots of thermal pilot specimens with poorly defined primary magnetisations . . . . . . . . . . . . . . . . . . 69+69f

4.4 Equal-area stereographic projections of thermal specimens with poorly defined primary magnetisations . . . . . . . . . . . . . . . . . . . . . .70

4.5 Zijderveld and stereographic plots of unstable thermal pilot specimens . . . 71+71f

4.6 Zijderveld plots of AF pilot specimens with well defined primary magnetisations . . 74

4.7 Zijderveld plots of AF pilot specimens with an unrecognisable primary magnetisations . . . . . . . . . . . . . . . . . . 75+75f

4.8 Equal-area stereographic projections of $\mathrm{AF}$ pilot speciemns with an unrecognisable primary magnetisation. . . . . . . . . . . . . . . . . . . 76+76f

4.9 Equal-area stereographic projection of removed magnetisations of AF pilot specimens . 78

4.10 Zijderveld plots of unstable AF pilot specimens . . . . . . . . . . . . . . 79

4.11 VRM blocking curves under the influence of thermal and AF demagnetisation. . . 81

4.12 Comparative Zijderveld plots of thermal and AF pilot specimens from the same 
5.1 Late Miocene Mangapoike polarity magnetozones. . . . . . . . . . . . . . 88

5.2 Correlation of the Mangapoike polarity magnetozones to the magnetic polarity timescale

5.3 Inferred sedimentation rate of the Mangapoike section . . . . . . . . . . . . 92

$5.4 \delta{ }^{18} \mathrm{C}$ data bounding the Mangapoike Miocene - Pliocene angular unconformity . . . 94

5.5 Plot of $\alpha 95$ against degree of bioturbation. . . . . . . . . . . . . . . . . . . 99

6.1 Late Miocene glacioeustatic correlations . . . . . . . . . . . . . 104+104f

6.2 Mangapoike stable oxygen isotope data . . . . . . . . . . . . . . . . 108

6.3 New Zealand Late Miocene and earliest Pliocene magnetostratigraphy and biostratigraphy correlations.

$110+110 f$

7.1 Location map of the Wairoa Syncline and paleomagnetic data . . . . . 121+121f

7.2 Zijderveld plots of representative thermally demagnetised specimens . . . . . . 123

7.3 Equal-area stereographic projections of specimens from Wairoa . . . . . . . 124

7.4 Plot of age - declination of the Wairoa Syncline data . . . . . . . . . . . 127

List of Tables

3.1 Standard ilmenite microprobe analysis and statistics . . . . . . . . . . . . 31

3.2 Comparative volume susceptibilties of heated and unheated specimens below $300^{\circ} \mathrm{C}$. 32

3.3 Titanomagnetite concentration of magnetomineralogy samples . . . . . . . . . . 41

3.4 Comparative volume susceptibilties during magnetic extraction . . . . . . . . . . 43

3.5 Water content of representatitive specimens after thermal demagnetisation . . . . 53

3.6 VRM decay during Mumetal shield storage . . . . . . . . . . . . . . 55

4.1 Volume susceptibilities of thermal pilot specimens during demagnetisation . . . . . 66

5.1 Sampling efficiency calculations of Johnson and McGee (1983) . . . . . . . 97

7.1 Summary statistics of Wairoa Syncline paleomagnetic data. . . . . . . . . 126

List of Plates

2.1 Representatitive specimens showing variation of bioturbation . . . . . . . 16+16f

2.2a Locations of sites 19106-19208. . . . . . . . . . . . . . . . . . . 18+18f

2.2b Locations of sites 18994-19105. . . . . . . . . . . . . . . . . 19+19f

2.2c Locations of sites 18870-18993. . . . . . . . . . . . . . . . . 20+20f

2.3 Stratigraphic separation of cores within paleomagnetic site. . . . . . . 21+21f

$2.4 \mathrm{Fe}$ staining of silicic tuffs within the Mangapoike sequence . . . . . . . $21+21 \mathrm{f}$

3.1 Exsolved ilmenite lamellae within host titanomagnetite . . . . . . . . . 36+36f

3.2 Authigenic framboidal pyrite. . . . . . . . . . . . . . . . 36+36f

6.1 Turbidite beds of the Makaretu sandstone interpretated as resulting from 
-viii-

glacioeustatism . . . . . . . . . . . . . . . . . . 104+104f

6.2 Inferred disconformity from 6.86 to $6.42 \mathrm{Ma}$. . . . . . . . . . . . . 106+106f

6.3 Miocene-Pliocene unconformity correlated with well established late Miocene cooling . . . . . . . . . . . . . . . . . . 106+106f

Appendices

Appendix 1: Site locations and descriptions . . . . . . . . . . . . . . . . . . A1

Appendix 2: Bedding attitudes for tectonic correction . . . . . . . . . . . . . A21

Appendix 3: Magnetomineralogy samples . . . . . . . . . . . . . . . . . . A22

Appendix 4: Isothermal remanent data. . . . . . . . . . . . . . . . . . A23

Appendix 5: Electron microprobe analyses . . . . . . . . . . . . . . . . A25

Appendix 6: Thermal pilot demagnetisation data . . . . . . . . . . . . . . . A29

Appendix 7: AF pilot demagnetisation data. . . . . . . . . . . . . . . . . A29

Appendix 8: General demagnetisation data . . . . . . . . . . . . . . . A30

Appendix 9: Summary site statistics . . . . . . . . . . . . . . . . . . A44

Appendix 10: Stable oxygen and carbon isotope data . . . . . . . . . . A49

Appendix 11: Susceptiblities of Mangapoike silicic tuffs . . . . . . . . . . . A50 


\section{ACKNOWLEDGEMENTS}

This thesis was completed during tenure of a Junior Lecturer, and I thank the staff and students of the Geology Department, Victoria University of Wellington, for their support. The Internal Research Committee of Victoria University provided financial support. My supervisors, Dr P. Barrett, and Professors P. Vella and R. Walcott have been unstinting in their help and encouragement, and I thank them for their perseverance in developing my writing. Dr G. Turner and Professor D. Christoffel gave much of their time in refining my understanding of paleomagnetism and read large sections of earlier drafts. $\mathrm{Mr} \mathrm{E}$. Broughton provided technical assistance, at any hour, in the running of the cryogenic magnetometer and demagnetisation equipment. W. Mak kindly lent me his computer programmes. The Micropaleontology Section, New Zealand Geological Survey, Lower Hutt, and especially R. Hoskins and A. Edwards, have been extremely helpful in providing both biostratigraphic data and discussion. Discussions about laboratory methods with T. Mumme and P. Oliver benefited the author. C. Nelson of Waikato University organised the measurement of the isotopic data at that institution.

I greatly appreciate the kind hospitality of Mrs E. Jordan and the late Mr J. Jordan of Tukemokihi Station, and Stephen, whose understanding of two-stroke motors is far better than mine. Barby and Paul assisted with the fieldwork.

Research students in earth sciences at Victoria University, past and present, have been a great source of informed discussion and friendship. In particular, thanks are due to $\mathrm{A}$. George, I. Graham, A. Macpherson, B. Morris, P. Morris, A. Palmer, A. Pyne, B. Roser, B. Ward and P. White. The close collaboration with fellow PhD students, Jeff Ashby and Gregory Gosson, has been especially enjoyable and invaluable.

Thanks are due to J. Casey and his staff of the Photographic Facility, M. Newberry and associates of the Computer Services Centre, and D. Thompson of the Mechanical Workshop, all of Victoria University. Technicians of the Geology Department have helped in a variety of manner. Betty and Val were always supportive.

Visting scientists, Dr C. Laj, and Professors K. Hoffman and J. Kennett provided useful comments. Ms S. Guitton of Centre Fabiles des Radioactivities, Paris, measured the isothermal remanent data.

My Mum and Dad, Charles and Helen, and friends have been encouraging throughout. Finally, I thank my wife, Barby, whose support and humour has made the experience almost pleasant. I dedicate this thesis to her. 


\section{Chapter I \\ INTRODUCTION}

\subsection{STUDY AIMS}

This thesis establishes a Late Miocene (10.3 to $5.3 \mathrm{Ma}$ ) magnetostratigraphic reference column for the New Zealand region. It provides a chronology for the local biostratigraphy allowing worldwide correlation, with a precision of $10^{4}$ years. Isochroneity of planktic biostratigraphic datums is verified. Rock magnetic and microprobe data are used to determine the nature and origin of the observed magnetisation and confirm it is acquired at the time of deposition. Declination directions which are better constrained in age and direction supplement previous paleomagnetic data showing the timing and rate of tectonic rotation within the Wairoa Syncline.

\subsection{INTRODUCTION}

The thick and well-exposed marine Neogene strata of New Zealand yield an unusually complete record of temperate biostratigraphic and paleoclimatic events (Hoskins, ed. 1982, references therein, and Figs. 1.1 and 1.2). Local planktic microfossil zones (Hornibrook 1958, 1981a, 1984a; Geiger 1962; Jenkins 1967, 1971; Scott 1972; Edwards 1982a; Ashby 1985) are well developed with at least 50 bioevents now recognised within the Neogene (Jenkins 1966; Hornibrook and Edwards 1971; Hornibrook 1981b, 1984b; Edwards 1985). During the Late Cenozoic a global latitudinal provincialism of planktic taxa and the evolution of an endemic benthic fauna within New Zealand has restricted the correlation of the local biostratigraphy to overseas zonal schemes and to the international stratotypes (Hornibrook 1958, 1981b). Diachroneity of some local and international biostratigraphic planktic datums (Kennett 1968; Hornibrook 1981b; Hoskins 1982) has also impeded correlation. Previous quantitative dating of New Zealand Neogene sediments has been based on a few paleomagnetic reversal sequences and a few radiometric ( $\mathrm{K}-\mathrm{Ar}$ and fission-track ages), for most of which the stratigraphy was not rigorously controlled. 


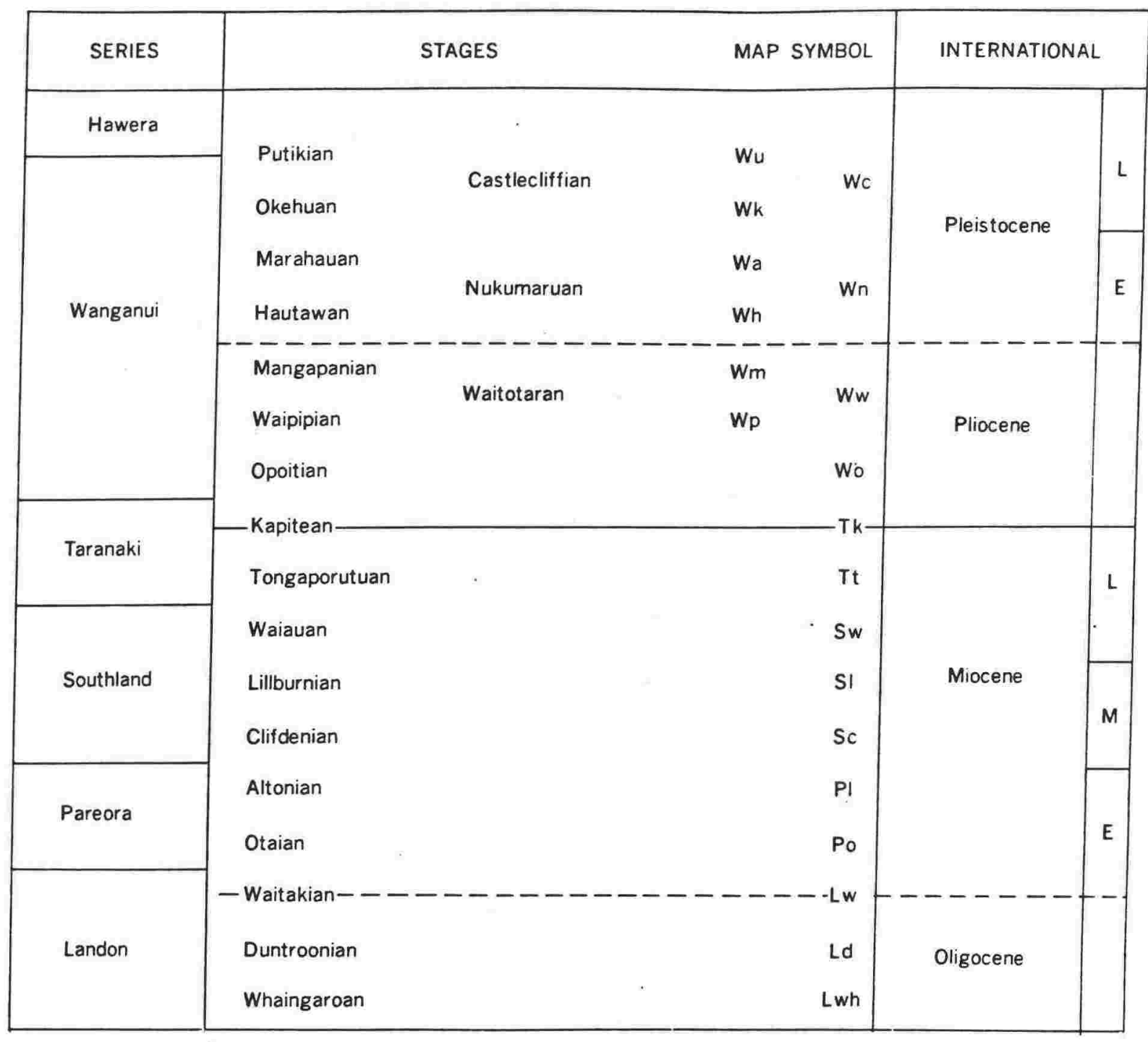

Fig. 1.1 New Zealand uppermost Paleogene and Neogene series and stages (after Hornibrook 1984b). 


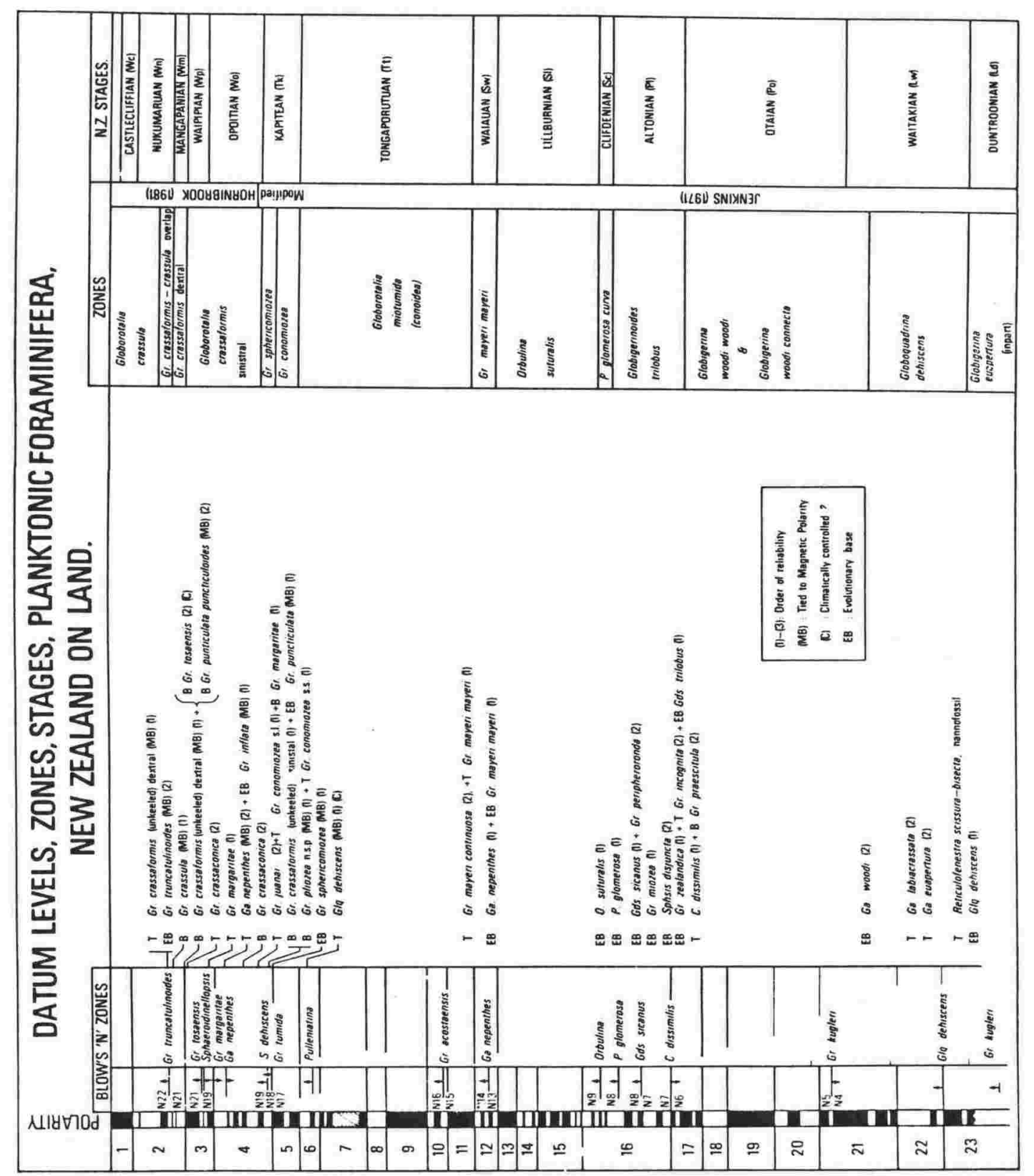

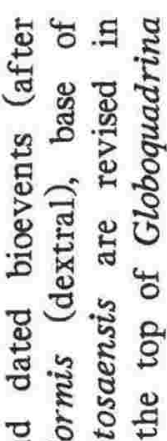

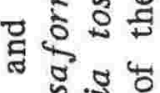

भิ

उ :

젼

荕

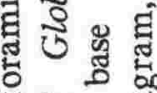

पे

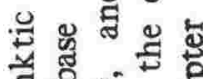

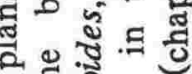

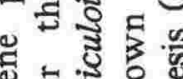

娄论 乙

这。

สี

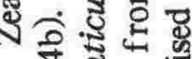
३ 乙 2

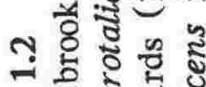

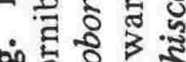

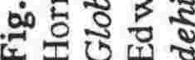




\subsection{RADIOMETRIC DATING}

Reliable radiometric ages of the New Zealand Neogene are few in number (McDougall and Page 1975; Hornibrook 1981b). The most reliable are $\mathrm{K}-\mathrm{Ar}$ ages from interbedded volcanics (Bandy et al. 1970; Stipp and Thompson 1971; Grindley et al. 1977). Not all are well controlled stratigraphically (Stipp et al. 1967; Stipp and McDougall 1968; McDougall and Coombs 1973).

Glauconite K-Ar ages (Lipson 1956, 1958; Adams 1975) have uncertainties due to argon loss in some cases and argon retention in others (Adams 1975) and in any case all are from pre-Upper Miocene strata and have no direct relevance to the present study.

Fission-track dating of tuffs has been almost totally restricted to upper Neogene sediments (Seward 1974, 1975; Hornibrook 1984b; Gosson 1986). The first fission-track ages were determined from volcanic glass (Seward 1974) but were subsequently found unreliable because of track annealling when compared with zircon fission-track ages (Seward 1979).

\subsection{MAGNETOSTRATIGRAPHY}

\subsubsection{Principles}

Magnetostratigraphy is a powerful stratigraphic technique because magnetic reversals were synchronous global events. The magnetic polarity timescale is a history and chronology of changes in the direction of the earth's magnetic field. Paleomagnetism allows the establishment of local magnetic polarity zones in a stratigraphic section. If the local zones can be compared and correlated with the currently accepted polarity timescale the local stratigraphic section can be dated. There is an important difference between the polarity timescale and magnetostratigraphy. The former was developed by organising radiometrically dated samples of known polarity according to their isotopic age and not their stratigraphic relationships.

Because of the non-unique character of individual reversals, correlation is based on the relative lengths of the polarity time-scale zones. Incomplete sequences require independent dating criteria to accurately correlate the polarity zones.

\subsubsection{Assumptions}

The following assumptions are made, with varying degrees of certainty.

1. The earth's magnetic field has always approximated a dipolar field. 
2. The mean direction of permanent magnetisation of a rock is the same as the mean direction of the geomagnetic field at the time the rock was formed. This is not always valid since the time of magnetisation may have been later.

3. The sampled specimen precisely represents the orientation of the sediment at the time of deposition.

4. The stratigraphic interval between adjacent like-polarity points has the same polarity.

5. All unconformities are recognised.

\subsubsection{Nomenclature}

A supplementary chapter of the International Stratigraphic Guide published by the IUGS International Subcommission on Stratigraphic Classification and IUGS/IAGA Subcommission on Magnetic Polarity Time Scale (Hedberg et al. 1979) proposed a magnetostratigraphic classification, which is followed here.

The basic magnetostratigraphic unit is defined as a local body of rock strata which is unified by its magnetic polarity and termed a magnetozone, with upper and lower boundaries termed transitions. Local magnetozones are designated in some manner by symbols chosen by an author for ease of discussion. Subsequent work might enable delineation of subzones or grouping of a number of magnetozones into a superzone. Geochronologic and chronostratigraphic equivalents are termed chrons and chronozones respectively.

\subsection{MAGNETOSTRATIGRAPHY IN NEW ZEALAND}

In the New Zealand Neogene, magnetostratigraphy has been examined previously in four sedimentary sections (Fig. 1.2), (Kennett et al. 1971; Lienert et al. 1972; Kennett and Watkins 1974) and three volcanic sequences (Coombs and Hatherton 1959; Evans 1970; Murphy and Seward 1981). Magnetostratigraphy by Kennett et al. (1971) has been integrated with oxygen isotope data (Devereux et al. 1970), tephrochronology (Seward 1979; Vella and Collen 1984), and that by Kennett and Watkins (1974) with oxygen and carbon isotope data (Loutit and Kennett 1979).

A spinner magnetometer was used in the early magnetic polarity measurements, with a resolution only slightly less than the average intensity of magnetisation of the sediments being measured (Kennett et al. 1971; Lienert et al. 1972; Kennett and Watkins 1974). Reliable determination of normal and reversed polarities need less 


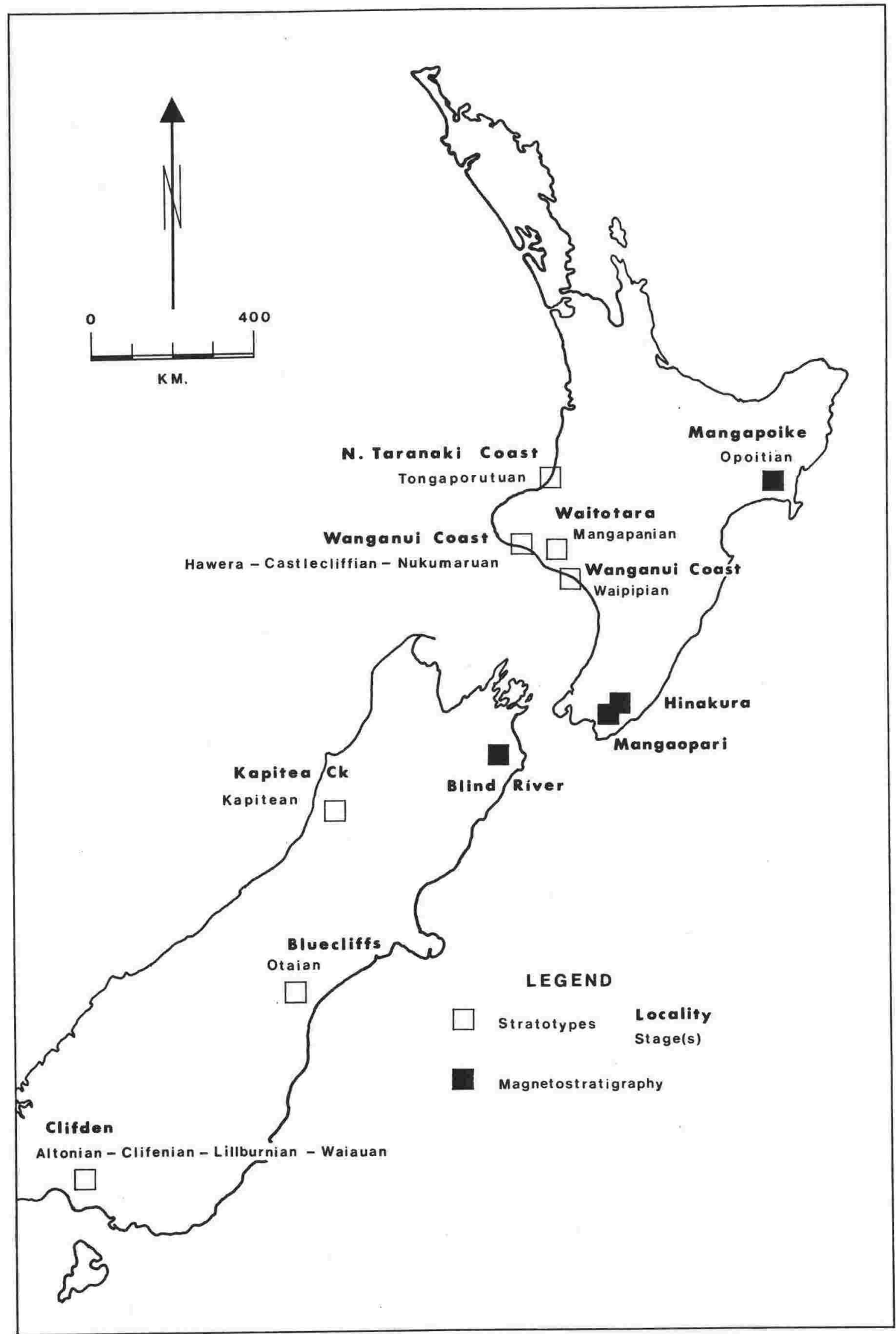

Fig. 1.3 Location map of both New Zealand Neogene stage stratotypes and localities with sedimentary magnetostratigraphies. 
precise measurment than the determination of paleopole positions, but some of the polarity measurments made using the spinner magnetometer on New Zealand marine sediments were suspect (eg. Kennett et al. 1971). This and the failure to recognise unconformities (eg. Kennett and Watkins 1974) caused problems in correlating with the magnetic polarity timescale. Subsequent reinterpretation of the polarity zones has been based on microfossil biostratigraphy (Hornibrook 1977, 1983, 1984b; Edwards 1985) and stable isotope stratigraphy (Loutit and Kennett 1979).

\subsection{REGIONAL DEEP-SEA STRATIGRAPHY}

A detailed Neogene biostratigraphy has been established from over 200 deep-sea sediment cores around New Zealand (Kennett 1970, 1973; Keany and Kennett 1975; Jenkins 1975; Edwards and Perch-Nielsen 1975; Weaver 1976; Srinivasan and Kennett 1981a, 1981b). Magnetostratigraphy has been determined in many of the cores (Hays and Opdyke 1967; Goodell and Watkins 1968; Kennett and Watkins 1970; Watkins and Kennett 1971, 1972a, 1972b; Theyer 1972; Osborn et al. 1983, Fig. 1.3). However the stratigraphy is generally limited in range. The use of piston coring to recover undisturbed continuous core for paleomagnetic measurement is mainly restricted to the latest Miocene to Recent (Chron 5? to Brunhes), with little penetration below the latest Miocene because of compaction. Even with the use of the extended core barrel (XCB) in the Deep Sea Drilling Project below the latest Miocene sediments, weak intensities of magnetisation and post-depositional chemical remanences (Barton and Bloemendal 1986) in the recovered sediments mostly restrict magnetostratigraphic determinations to the latest Miocene to Recent.

The establishment of a late Miocene magnetostratigraphic reference column from New Zealand on-land sequences provides a much needed chronology for at least part of the existing off-shore biostratigraphy.

\subsection{MAGNETOSTRATIGRAPHIC CRITERIA}

From this study a number of criteria have been developed for the selection of a sedimentary succcession for magnetostratigraphy. These are presented here as suggested guidelines for any future magnetostratigraphic study in New Zealand.

1. The section must have a well established and detailed biostratigraphy or the magnetostratigraphy must be able to be combined with a biostratigraphic study. 


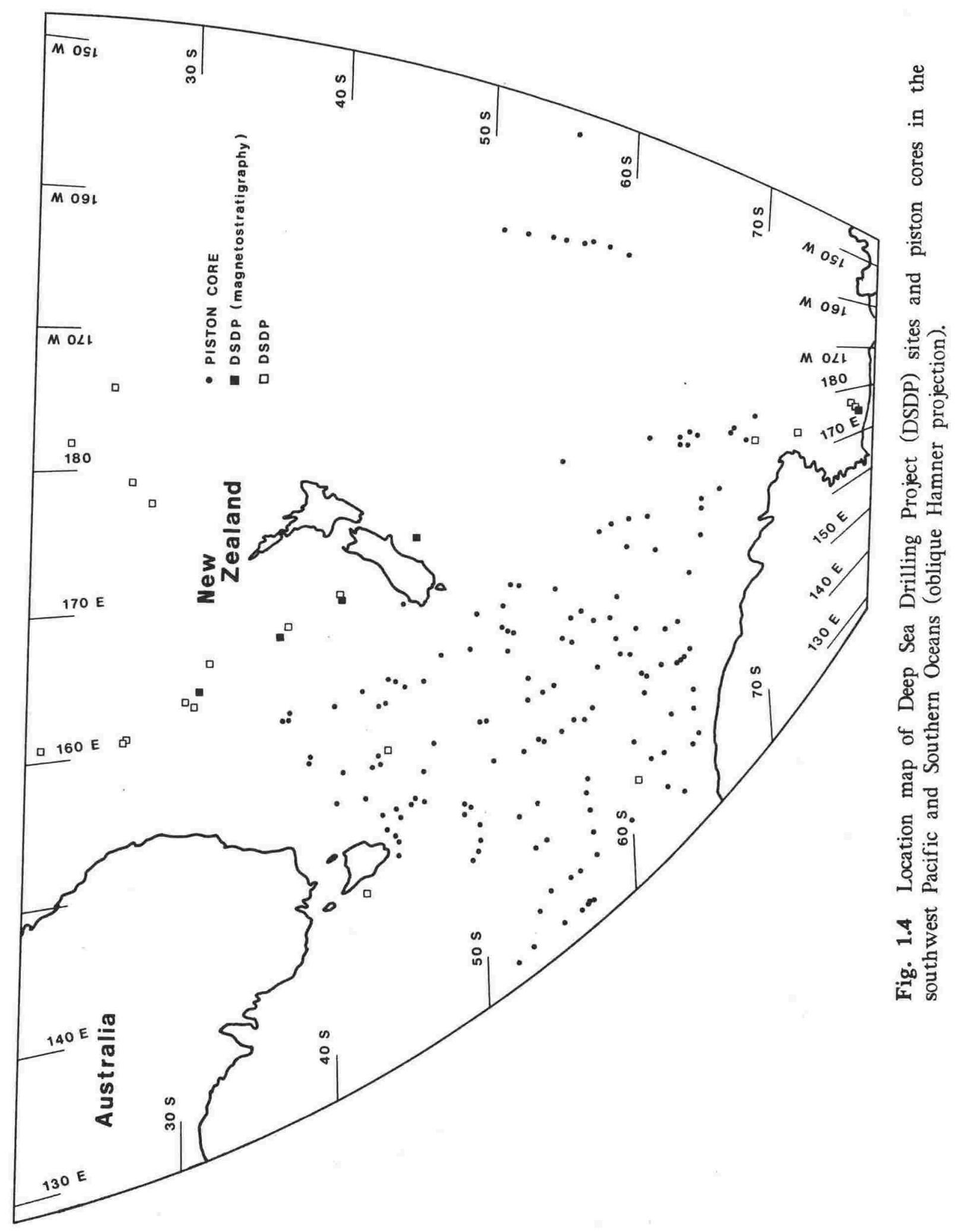


2. The lithology must have a stable and recognisable primary magnetisation.

3. The primary magnetisation must have been acquired at or close to the physical age of the rock.

4. Hiatuses in sedimentation are known and their age ranges can be accurately determined.

5. The sequence has a near uniform lithology, and sedimentation rates can be assumed to be near linear.

6. The magnetostratigraphic column can be established in one thick section to negate the problems of inter-section correlation.

7. The sequence has a sedimentation rate of at least tens of $\mathrm{cm} / 1,000$ yrs.

8. Structure of the sequence is not complex and is well understood.

9. The sequence has at least $70 \%$ exposure.

10. The sequence has a number of well-defined bedding planes to accurately determine tectonic corrections of the magnetisation directions.

11. The sequence is being actively eroded to ensure that unweathered rock can be sampled.

13. The natural remanent magnetisation (NRM) of the rocks sampled is greater than $1.5-2.0 \times 10^{-5} \mathrm{Am}^{-1}$ 


\section{Chapter II}

\section{MANGAPOIKE RIVER: STRATIGRAPHY AND LITHOLOGY}

\subsection{INTRODUCTION}

The Mangapoike River section $\left(38.9^{\circ} \mathrm{S}, 177.6^{\circ} \mathrm{E}\right)$ on the southeast limb of the Wairoa Syncline, Northern Hawke's Bay (Fig. 1.3) was selected for this study on the basis of the previously described criteria (section 1.7). The Mangapoike section is over $4000 \mathrm{~m}$ in thickness representing a period from the Lillburnian to the Mangapanian. The strata have a proven stable magnetic remanence (Kennett and Watkins 1974) in the uppermost Tongaporutuan to Opoitian.

The section extends from the base of the Makaretu sandstone in Tukemokihi Stream (NZMS 1:N106/015077)," westwards along Tukemokihi Stream and Mangapoike River, through Haupatanga Gorge to Kotare Road (NZMS 1:N106/916107, Fig. 2.1). The section is informally divided into the lower and upper Mangapoike sections by the Miocene - Pliocene boundary. The Miocene - Pliocene boundary is poorly exposed in the Mangapoike River, but a road cut exposure (N106/970086) $10 \mathrm{~m}$ above the river exposes an angular unconformity. The mapping of tuff beds above and below the unconformity from the road cut exposure to the river indicates the river section is approximately $30 \mathrm{~m}$ thicker.

The substantial logistical investment needed for magnetostratigraphy necessitated that only the Mangapoike River section was studied.

\subsection{STRATIGRAPHY}

\subsubsection{Previous Work}

The Mangapoike River was first geologically mapped by Macpherson (1927). Regional mapping in the Opoiti and Nuhaka survey districts by Ongley $(1928,1930)$ defined the Ormond, Opoiti, Mapiri and Tutamoe series, Awamoan to Taranakian in age. Osborne (1934) also defined formation names for northern Hawke's Bay including a Mangapoike Formation. Finlay (1939) designated the Opoiti survey district as the type area for the Opoitian stage and Watson (1957) proposed Mangapoike as the type section. Petroleum reports (Kicinski 1958; Wellman 1958; Haw 1959a, 1959b; Stoneley 1959; Brown 1961,

* Grid references are given as eight figures and are derived from an enlarged base map. 


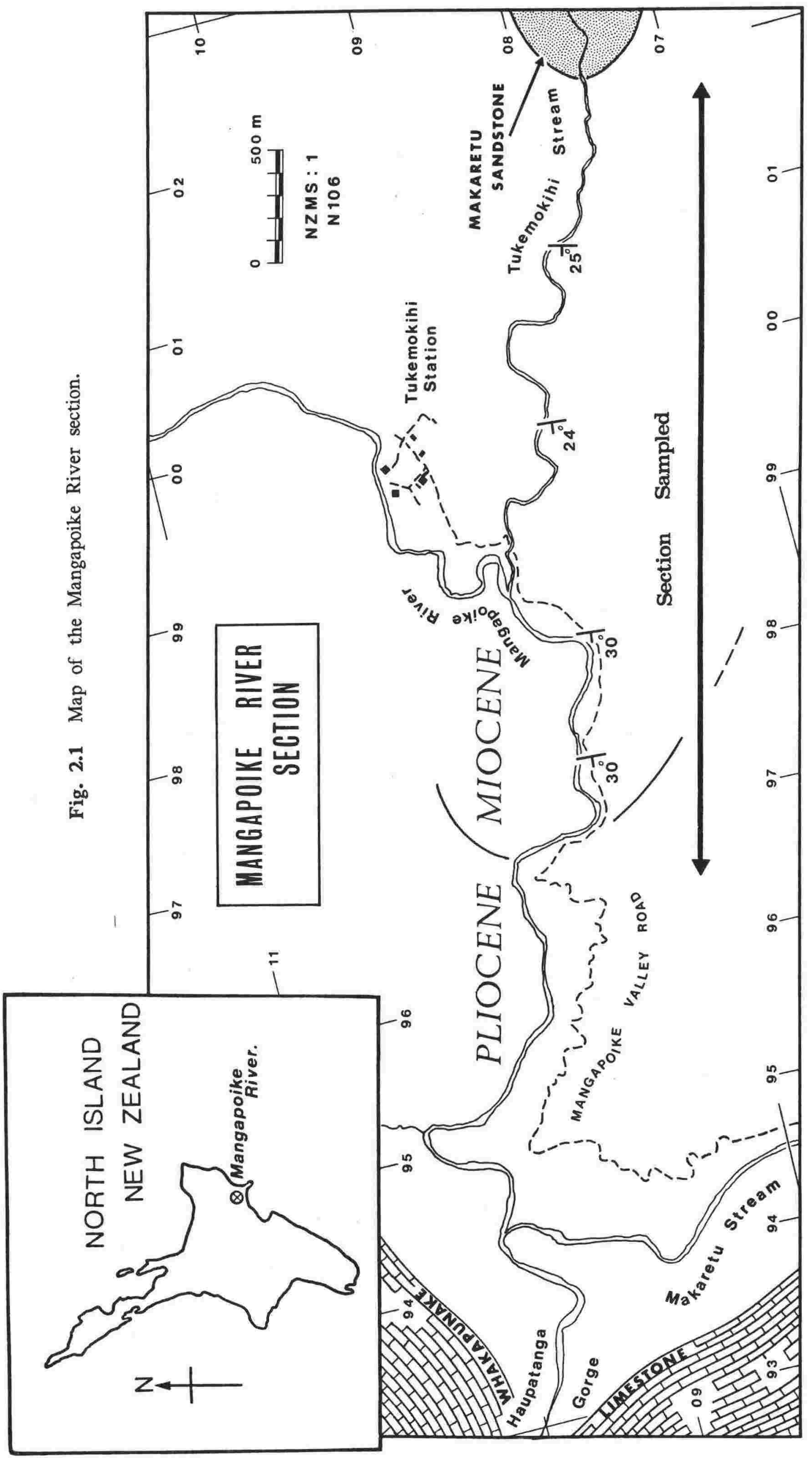


1962; Brunstroam 1962; Ferrand 1965) include paleocurrent data, structural data and isopach maps of Taranakian sediments of the Mangapoike section and surrounding areas.

McInnes (1964, 1965) described planktic foraminiferal zones which he considered to range from Tongaporutuan to Waitotaran in age. Hornibrook (1968, 1976) nominated part of the upper Mangapoike section as the Opoitian type section, but the paleontological definition of the lower boundary remained ambiguous because of transitional forms in the Globorotalia inflata lineage.

Kennett and Watkins (1974) determined magnetostratigraphic polarities in $850 \mathrm{~m}$ of mainly the upper section, in sites along the Mangapoike Valley Road. They identified Gilbert and lower Gauss ages on the evidence of the evolutionary sequence of Globorotalia miozea conoidea Walters to Globorotalia puncticulata Deshayes. They proposed an age of $4.3 \mathrm{Ma}$ for the Miocene - Pliocene boundary in New Zealand, which contrasted with the estimated $5 \mathrm{Ma}$ age for the Miocene - Pliocene boundary in Italy by biostratigraphic correlation with magnetostratigraphy in equatorial deep-sea cores (Ryan et al. 1974). Hornibrook (1977) and Hornibrook in Grindley et al. (1977) partially resolved the anomaly by recognising that most of the Globorotalia conomiozea zone is missing from the biostratigraphic sequence at Mangapoike River. His conclusion stemmed from a 5.2 Ma K-Ar age for fossiliferous basal Pliocene sediments at the Chatham Islands (Grindley et al. 1977) and the discovery of a low angle unconformity at Mangapoike (Hornibrook 1983, 1984b, Plate 6.2). Weaver (1976) had reached a similiar conclusion after reinterpreting the Mangapoike magnetostratigraphy by correlating the \% Neogloboquadrina pachyderma abundance curve at Mangapoike with the silicoflagellate paleotemperature curve of the Southern Ocean. Subsequent detailed foraminiferal biostratigraphy indicates that the uppermost Tongaporutuan and lower part of the Kapitean is missing (Hornibrook 1983, 1984a; Edwards 1985, in prep.).

Ashby (1985, 1986) described New Zealand Neogene radiolarian biostratigraphy recognising the Didymocyrtis sp. A Zone and the Lychnocanium grande Sub-Zone of the Didymocyrtis tetrathalmus tetrathalmus Zone (Ashby 1985) at Mangapoike. Tephrostratigraphy described by Gosson (1986) from the East Coast Basin, including the Mangapoike section, records Neogene silicic volcanism.

\subsubsection{Stratigraphy}

The chronostratigraphy accepted in this thesis (Fig. 2.2) is based chiefly on biostratigraphy by Hornibrook (1983, 1984a), Ashby (1986) and Hoskins (pers. comm. 1985). 


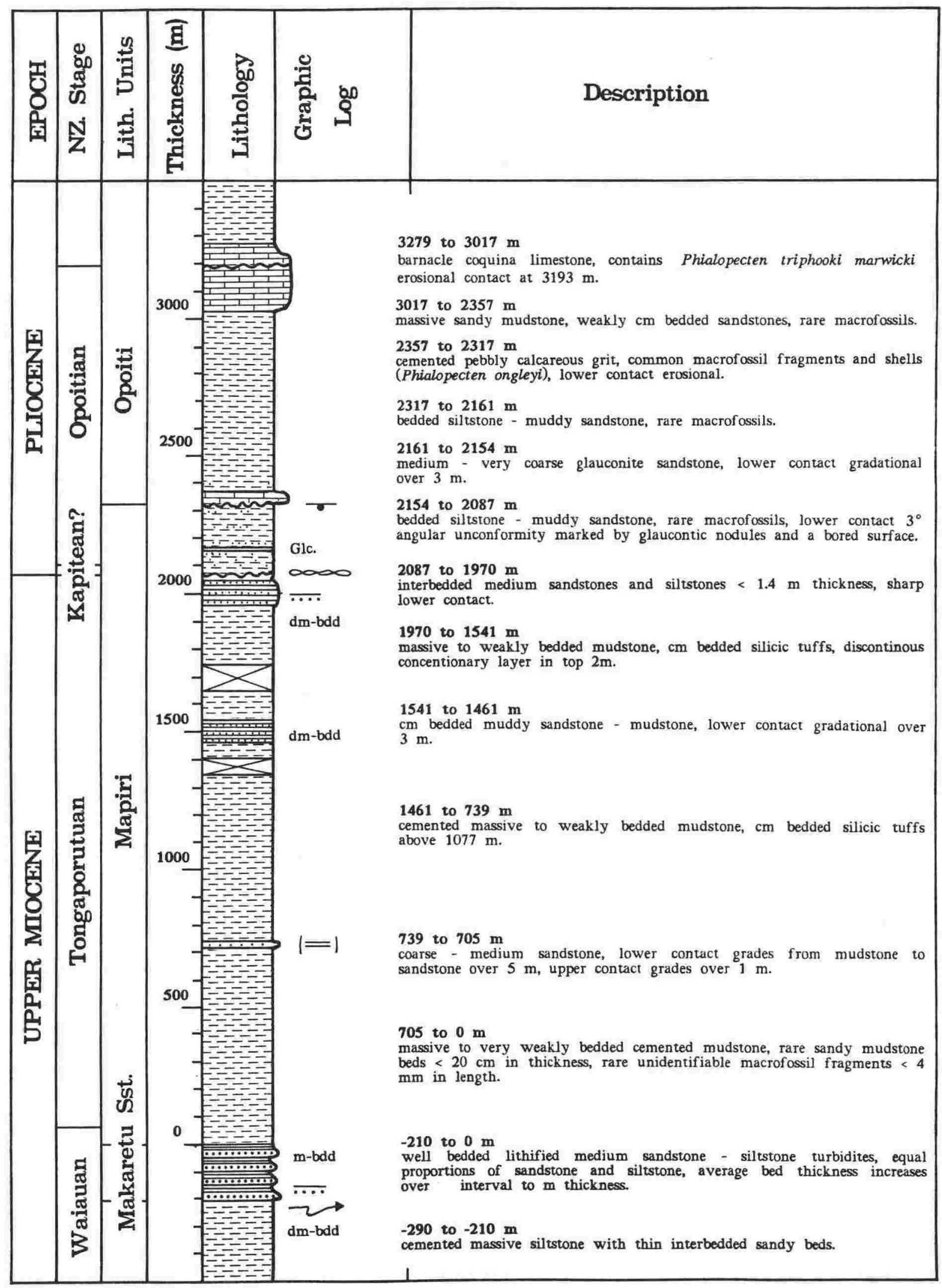

Fig. 2.2 Chronostratigraphy and lithostratigraphy of the Mangapoike River section. Stratigraphic heights are referenced to the top of the Makaretu sandstone. 


\section{Tongaporutuan}

Definition of the Tongaporutuan stage was originally based on distinct changes in mollusca (Allan 1933; Finlay and Marwick 1940). Finlay and Marwick (1940) also recognised the first appearance of the benthic foraminifera Bolivinita sp. as an important datum. Hornibrook (in Fleming, 1959) and Gibson (1967) used the first appearance of the Bolivinita quadrilatera lineage as the primary criterion for distinguishing the Tongaporotuan stage from the underlying Waiauan stage. Scott (1979a) suggested that Bolivinita quadrilatera is probably facies dependent, preferring bathyal environments, however he recommended the continued use of $B$. quadrilatera at the present time.

The base of the Tongaporutuan in the Mangapoike sequence as recognised by the incoming of B. quadrilatera lineage is $27 \mathrm{~m}$ above the Makaretu sandstone.

\section{Kapitean}

The base of the Kapitean stage was defined by the first appearance of the mollusca Sectipecten wollastoni, Struthiolaria cincta and Austrofusus coerulescens (=tuberculatus) (Finlay and Marwick 1947). Foraminiferal definition (Kennett 1966a, 1966b, 1967) was based on the plantkic Globorotalia conomiozea-puncticulata bioseries. Subsequent taxonomic review (Scott 1976, 1979b, 1979c, 1980, 1982a; Hornibrook 1981a, 1982) allowed finer biostratigraphic definition (Hornibrook 1983, 1984a; Scott 1983) with a gradational transition from Globorotalia conoidea to Globorotalia conomiozea as the accepted base of the Kapitean.

\section{Opoitian}

The original definition of the Opoitian stage (Finlay 1939) based on foraminiferal fossils, largely corresponded to that of the Opoiti series (Ongley 1930). Finlay and Marwick (1947) defined the Kapitean-Opoitian boundary by the first appearance of Globorotalia inflata. Again, later taxonomic revision (eg. Scott, 1976) has superceded the original paleontological definitions. A review of the Kapitean-Opoitian boundary by Scott (1982b) offered two options for consideration in defining the base of the Opoitian, with no definite acceptance of either as yet. The first is the appearance of Globorotalia puncticulata sphericomiozea and the second is the lowest joint occurrence of Globorotalia puncticulata puncticulata and Globorotalia crassaformis. Both alternatives for the base of the Opoitian are given by Hornibrook (1983, 1984a). 


\subsection{LITHOLOGY}

The Mangapoike section is dominated by massive moderately cemented mudstones. Interbedded sandy limestones, tuffs and sandstones are subordinate lithologies (Fig. 2.2), and provide the only clear bedding attitudes ranging from $356 / \mathrm{W} / 25$ to $018 / \mathrm{W} / 30$. (Appendix 2). The lithostratigraphic units recognised are a combination of formations and informal names in current usage, and although some units are not defined with respect to a type section and one is recommended to be abandoned (Gosson 1986), all have been included for the sake of completeness and to avoid ambiguity in locating paleomagnetic sites.

Thirty selected paleomagnetic specimens from Mangapoike are grouped into five classes: not bioturbated, weakly bioturbated, moderately bioturbated, strongly bioturbated and completely bioturbated (Plate 2.1), and are used as a standard of comparison for all bioturbation in the Mangapoike sequence. The classes correspond to those of Andrews (1982). A $\log$ of the degree of bioturbation through the lower part of the sequence (Fig. 2.3) shows that most of the section is weakly bioturbated. Certain stratigraphic horizons are moderately to strongly bioturbated, especially in the lower Tongaporutuan. The effects of bioturbation on the paleomagnetic data are discussed in section 5.6.

\subsection{SAMPLING AND SITE LOCATIONS}

The section sampled for the present study extends from the top of the Makaretu sandstone (N106/019076) westwards along Mangapoike River to above the Miocene Pliocene unconformity (N106/002085, Plate 2.2 a, b, c; Appendix 1), and ranges in age from latest Waiauan to early Opoitian. Three hundred and forty-three paleomagnetic sites were located at approximately $5 \mathrm{~m}$ stratigraphic intervals, over $2158 \mathrm{~m}$, using a Jacob's staff and Abney level. The sampled section includes sites which are stratigraphically equivalent to adjacent strata from which Kennett and Watkins (1974) delineated their $\mathrm{C} 1$ and $\mathrm{C} 2$ normal events. All stratigraphic heights are above the top of the Makaretu sandstone. Two intervals from 1345 to $1403 \mathrm{~m}$ and 1650 to $1751 \mathrm{~m}$ were not sampled. The first is covered, and the second was inaccessible for paleomagnetic sampling, but has no significant change in lithology.

Sites were located near water level wherever possible. The outcrop was cut back to a depth of $20-30 \mathrm{~cm}$ to eliminate surficial weathered sediment, although stream and river banks are estimated to erode $10-20 \mathrm{~cm}$ every winter. A portable motor-powered diamond drill was used and at least three cores $2.5 \mathrm{~cm}$ in diameter and an average 
Plate 2.1 Representative paleomagnetic specimens showing variation of bioturbation within the Mangapoike sediments.

Class 0: No visible bioturbation (0\%)

Class 1: Weak bioturbation ( $0-30 \%)$

Class 2: Moderate bioturbation (30-60\%)

Class 3: Strong bioturbation (60 - 95\%)

Class 4: Complete bioturbation (not seen). 

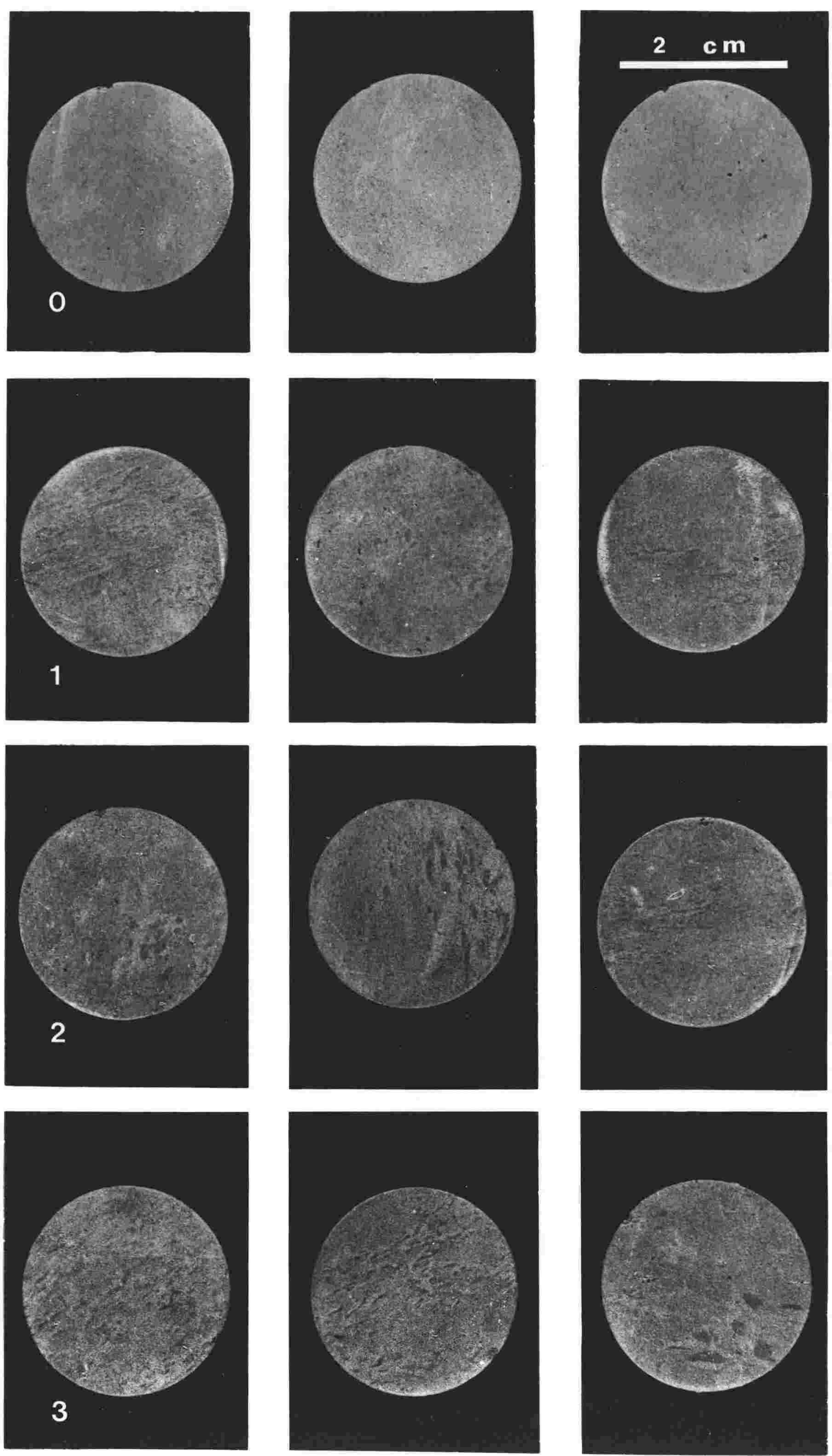


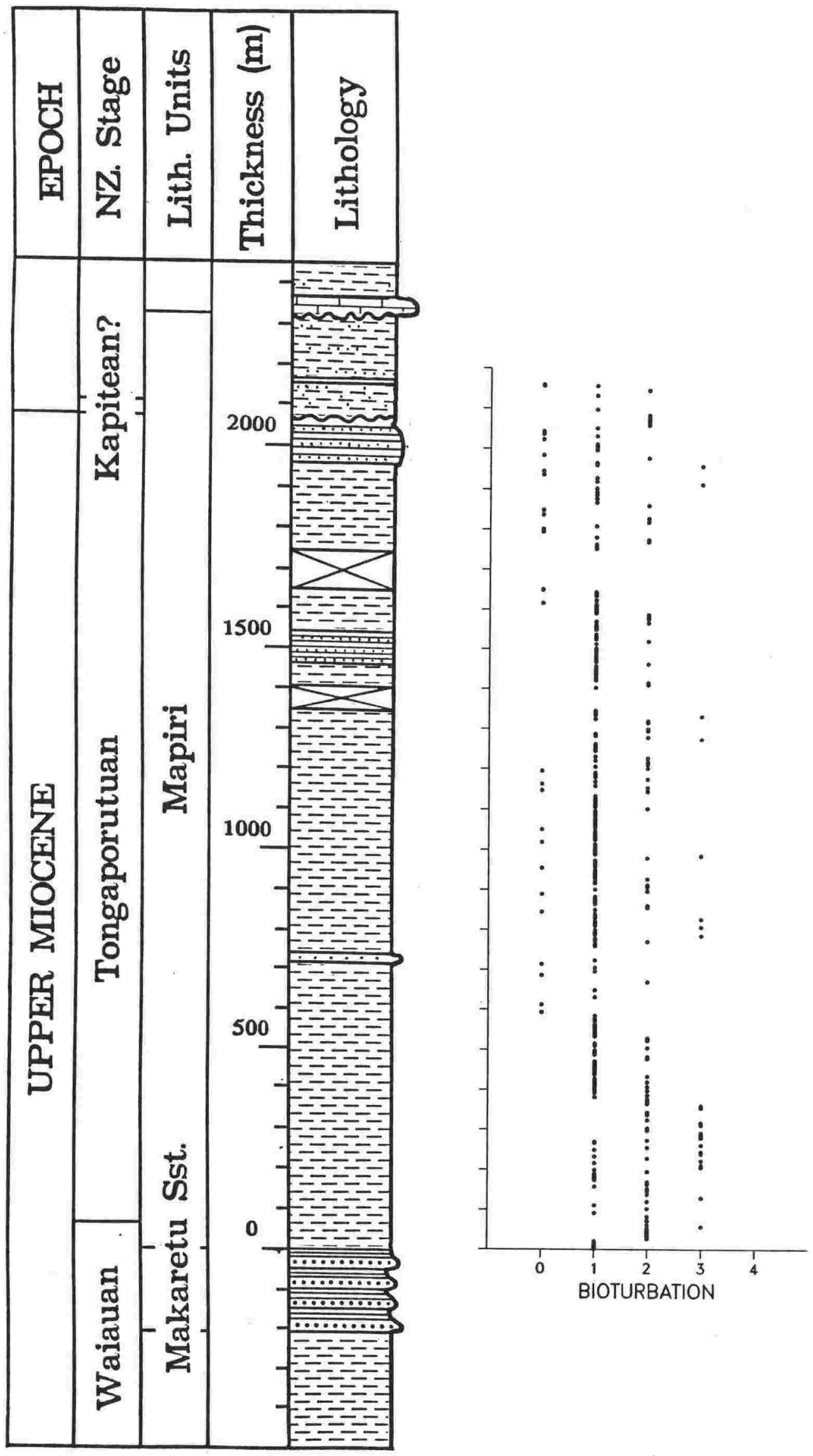

Fig. 2.3 A $\log$ of the degree of bioturbation in lower Mangapoike section. 


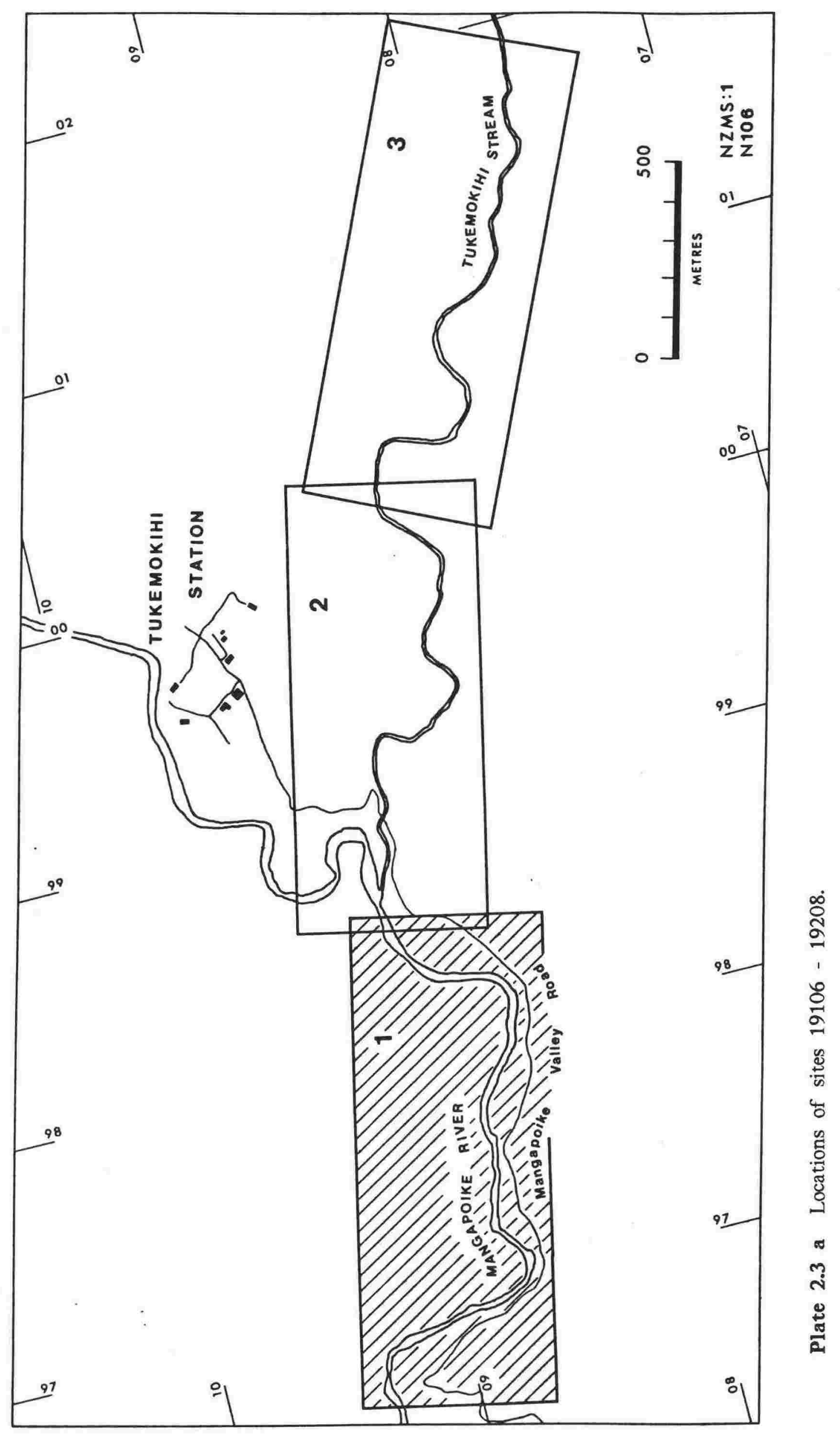




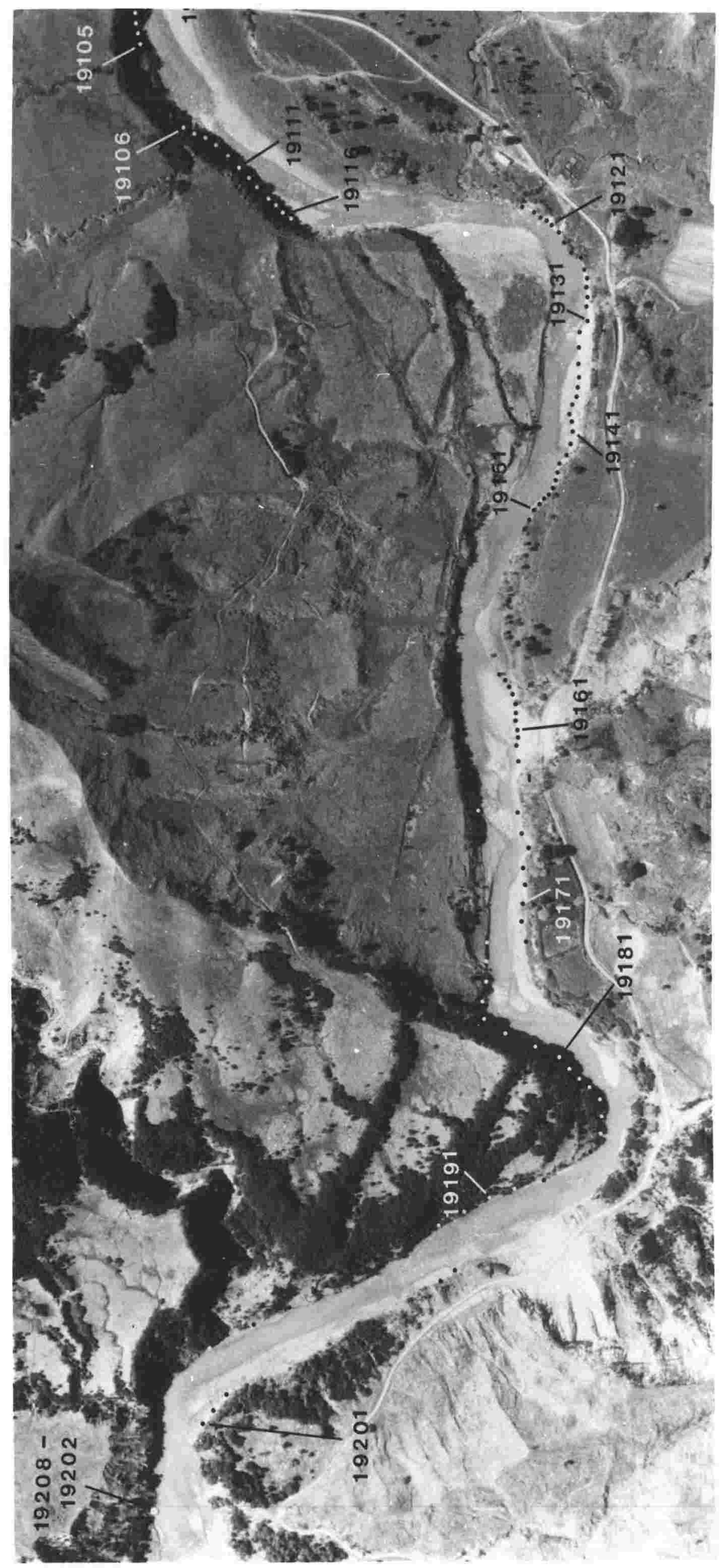




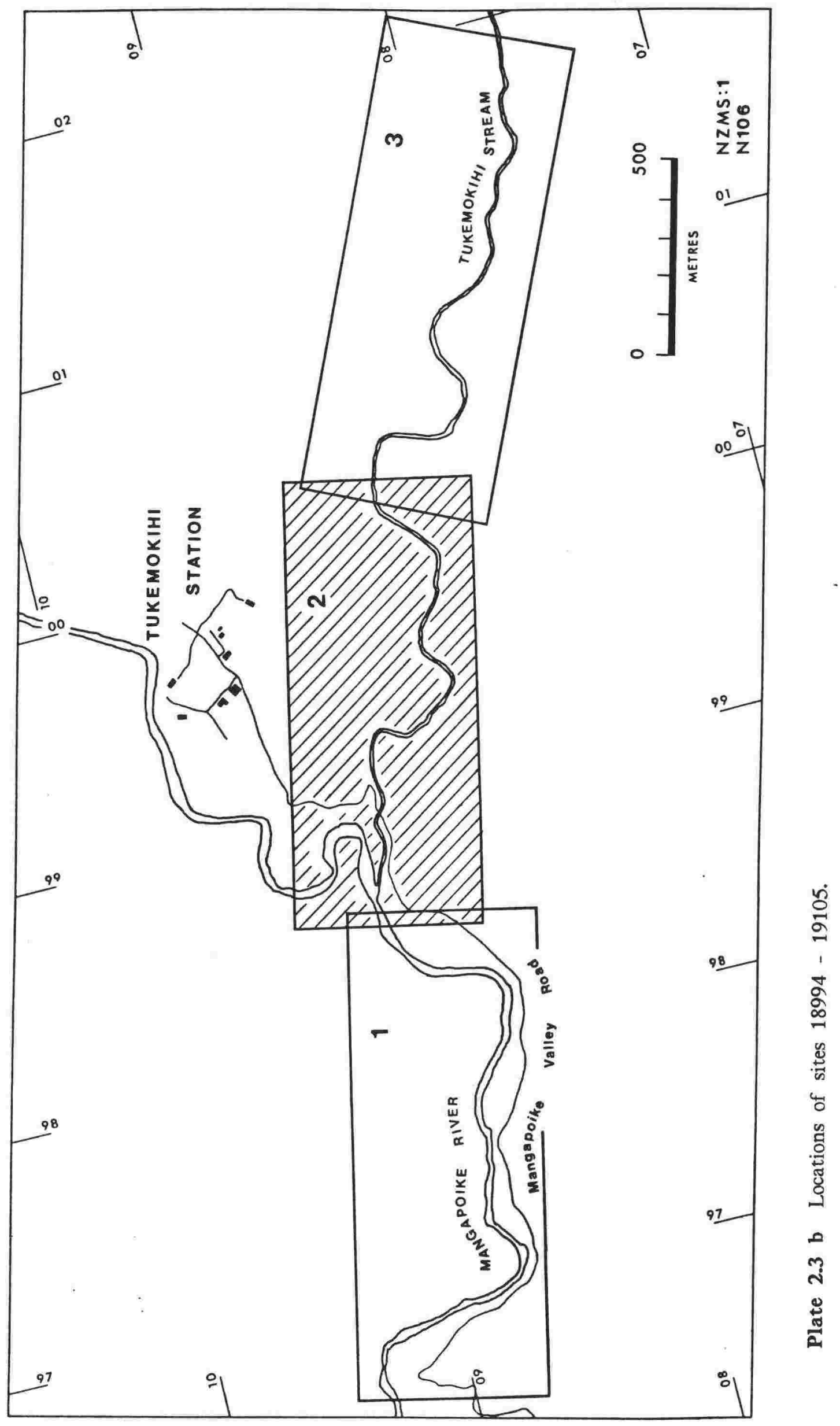




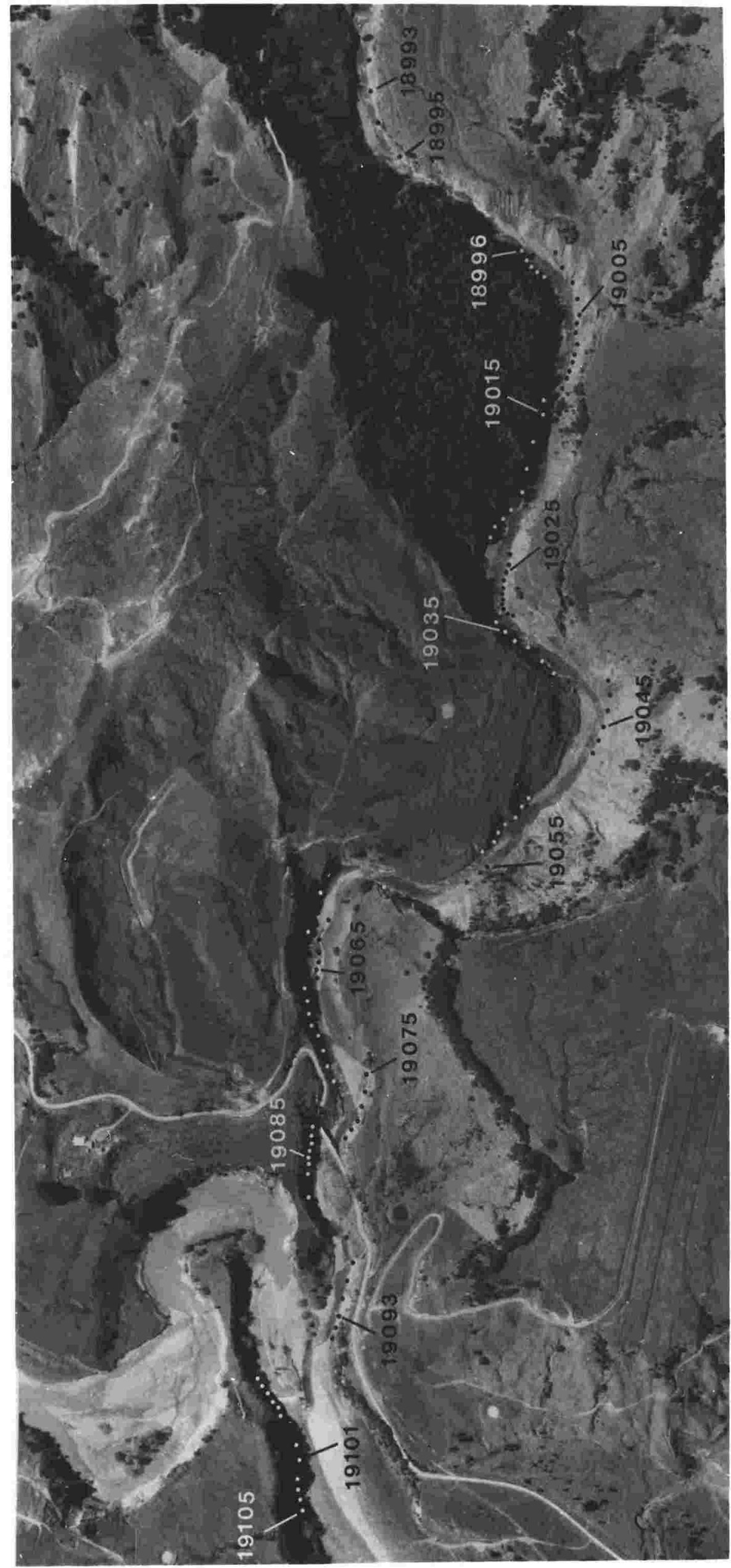




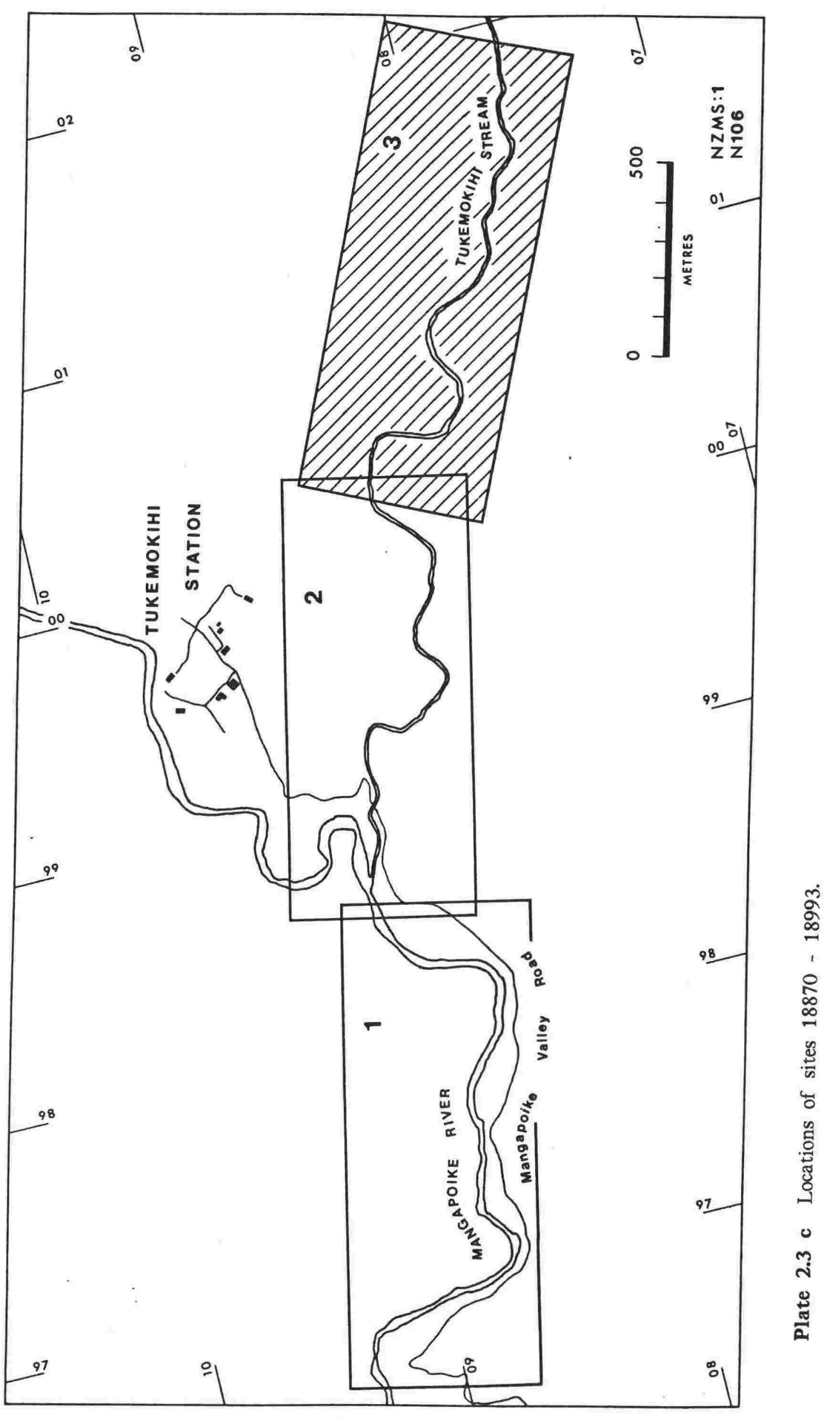




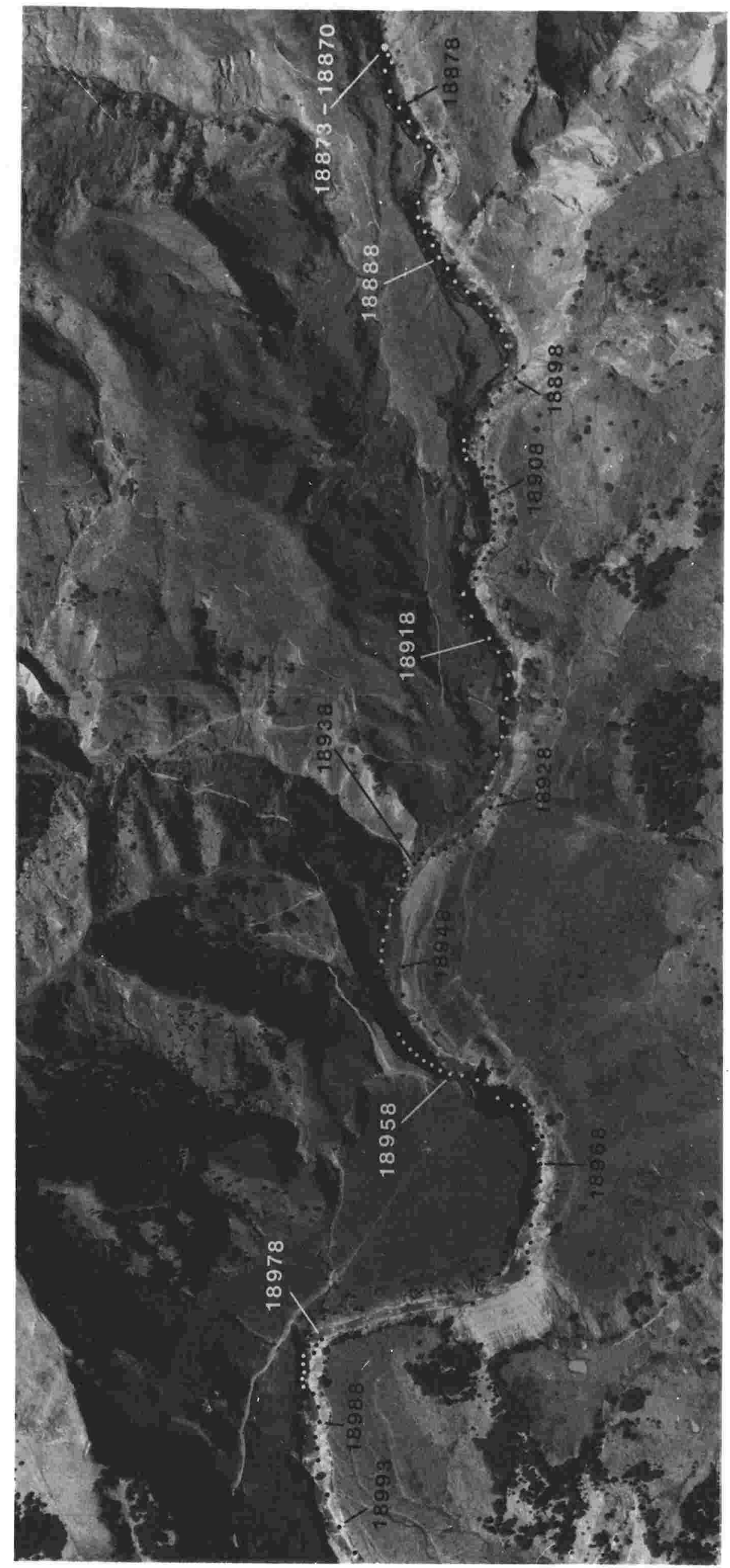


- 21f -

Plate 2.3 Stratigraphic separation of cores within a paleomagnetic site.

Plate 2.4 Iron-stained silicic tuff. 

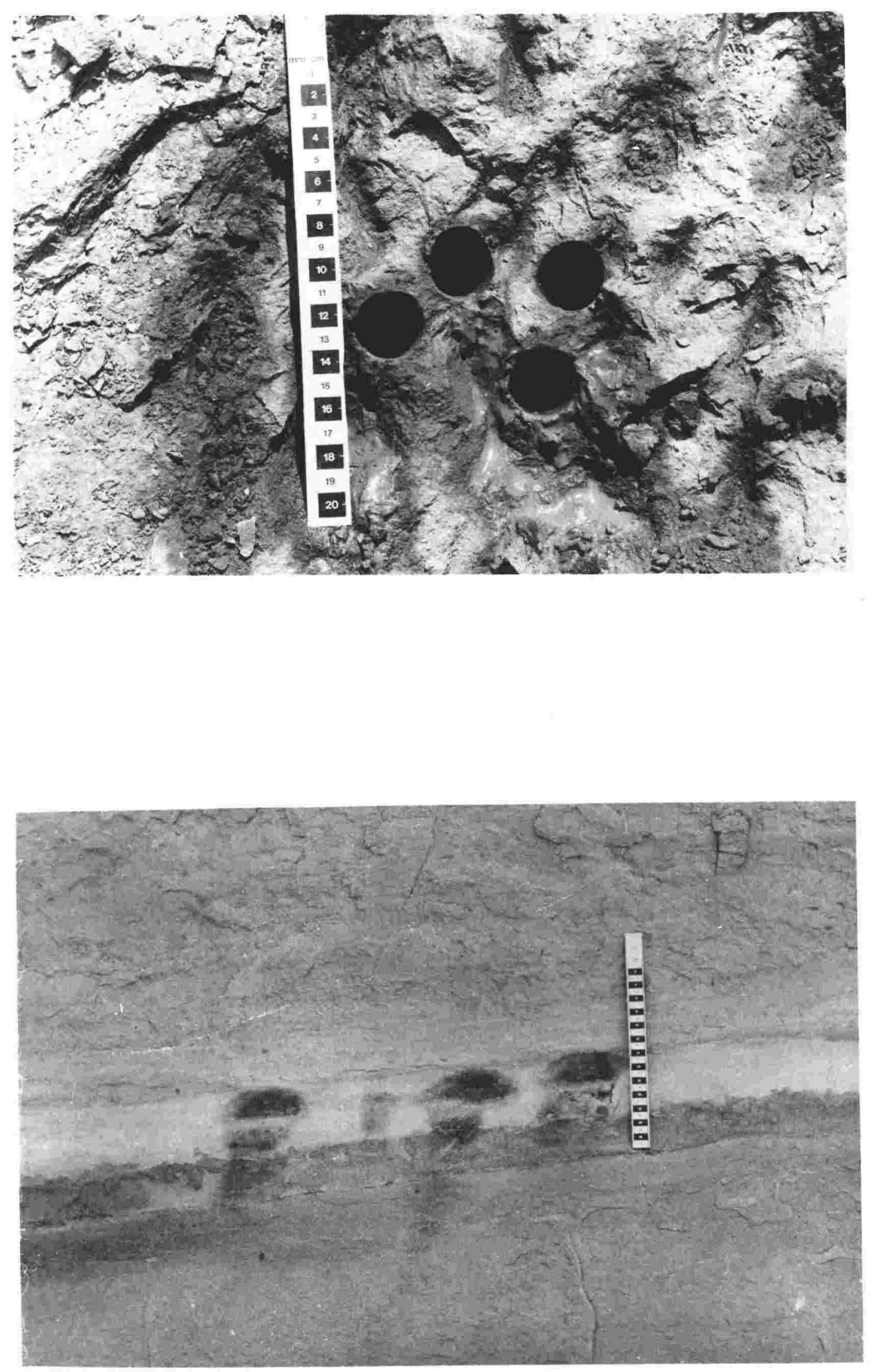
of $6 \mathrm{~cm}$ in length were taken at each site. At each site stratigraphic separation of the cores was no greater than $20 \mathrm{~cm}$ and the horizontal separation no greater than 1 $m$ (Plate 2.3). Field orientation of the cores are estimated to have errors not greater than $\pm 2^{\circ}$. Tuffs were not sampled, because they are generally coarser grained than the enclosing sediment and act as aquifers, and were consequently iron stained (Plate 2.4), although other studies (Kato et al. 1971; Yamazka et al. 1973; Wright and Mutti 1981) have obtained coherent paleomagnetic data from tuffs within marine sediments.

Ten samples (Appendix 3) were collected for magnetomineralogy. They were taken from sandstone beds for ease of disaggregation, concentration and petrographic description (chapter 3). 


\section{Chapter III}

\section{ROCK MAGNETISM AND MAGNETOMINERALOGY}

\subsection{INTRODUCTION}

Theoretical and experimental rock magnetism on both synthetic and natural minerals in the last twenty years (O'Reilly 1984, and references therein) have revealed the processes by which magnetic remanences are acquired and retained. The identification of the magnetic minerals in paleomagnetic samples (Lovlie et al. 1972; Tauxe et al. 1980; Lovlie and Larsen 1981; Papamarinopoulos et al. 1982) can provide critical data on the timing, significance and stability of the remanent magnetisations (Elston and Purucker 1979; Walker et al. 1981; Liebes and Shive 1982; McIntosh et al. 1985). Both the electron microprobe (Ade-Hall 1963, 1964; Wright and Lovering 1965; Smith 1967; Creer and Ibbetson 1970) and rock magnetic properties (Akimoto 1962; O'Reilly 1976, 1984) have been used to characterise magnetic minerals. Rock magnetic properties are especially useful in fine-grained and magnetically dilute specimens where petrological analysis is difficult (Dunlop 1971; Lowrie and Alvarez 1977).

In order to clearly demonstrate that the age of the magnetisation is the same or very close to the age of deposition of the sediments, as is required for magnetostratigraphy, chemical analyses and rock magnetic properties were used to determine the magnetic minerals. The data are discussed below and show that the only recognised magnetic mineral is titanomagnetite. The magnetisation of most specimens includes a soft viscous remanence, and a hard stable remanence.

\subsection{DEFINITIONS AND TERMINOLOGY}

There has been, and still is, considerable confusion and variation within the literature in the definition of various magnetic properties, including the units of measurement (Shive 1986). The following is a definition of parameters and terms used here. All units of measurement are SI.

All minerals have some magnetic properties (O'Reilly 1976), but the term magnetic mineral is restricted here, unless otherwise stated, to those minerals which retain a remanent magnetism. Paramagnetism is the partial alignment of magnetic moments in a mineral along an applied magnetic field direction. Spontaneous magnetisation is the property by which a magnetic vector is retained after the 
removal of an applied field. It includes ferromagnetism, ferrimagnetism and antiferromagnetism. Ferromagnetism is the parallel coupling of all unpaired electrons within a mineral, producing a very strong magnetisation which readily follows changes of the applied field. Ferrimagnetism is the net magnetisation from two antiparallel but imbalanced sublattices within a mineral. Ferrimagnetism is weaker than ferromagnetism. When the two antiparallel sublattices are identical having equal magnetic dipoles, the resultant net zero magnetism is termed antiferromagnetism. Rarely are the antiparallel lattices perfect, and they have a small residual magnetisation which is termed parasitic ferromagnetism.

Magnetic susceptibility of a sample is the proportionality constant between an applied field and the resultant magnetisation and is defined by the relation:

$$
\mathrm{M}=\mathrm{kH}
$$

where $\quad M=$ induced magnetisation per unit volume

$\mathrm{k}=$ volume magnetic susceptibility

$\mathrm{H}=$ applied field

It is termed initial susceptibility when measured in low fields $(<1 \mathrm{mT})$.

A number of useful magnetic properties can be defined from the analysis of a magnetic hysteresis loop (Fig. 3.1). A hysteresis loop traces out the induced magnetisation of a sample subjected to progressively higher applied fields; the resultant magnetisation when measured subsequently outside of the applied field, is termed an isothermal remanent magnetisation (IRM). At some point the magnetisation does not increase with higher applied fields and the sample is saturated and is termed saturation isothermal remanent magnetisation. If the induced magnetisation is saturated and measured when the sample is still within an applied field (ie not a remanent magnetisation) then it is termed a saturation magnetisation. The coercive force is the reversed field required to reduce the saturated magnetisation to zero and the coercivity of remanence is the reversed field, applied and then withdrawn, required for the isothermal magnetisation to be zero. Anhysteretic remanent magnetisation (ARM) is the magnetisation acquired in a low uniform field, within an ever decreasing alternating field.

For a more detailed account of definitions and experimental methods used in rock magnetisation the reader is referred to Banerjee (1981). 


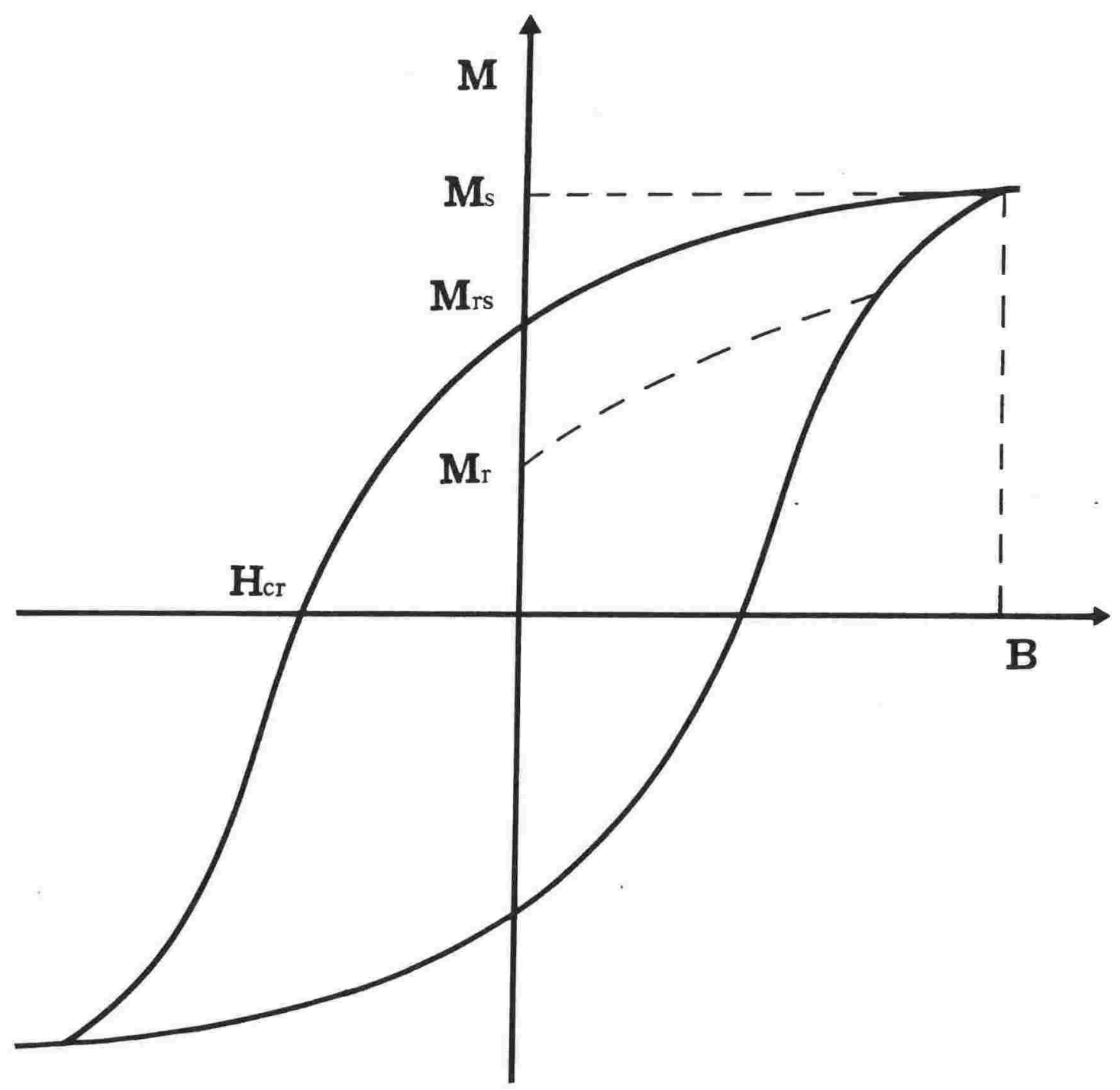

Fig. 3.1 Magnetic hysteresis loop: a graphical representation of the induced magnetisation (M) at higher applied fields $(H)$. $M_{r}$ (isothermal remanent magnetisation), $M_{r s}$ (saturation isothermal remanent magnetisation), $\mathrm{M}_{s}$ (saturation magnetisation), and $\mathrm{H}_{\mathrm{cr}}$ (coercivity of remanence). 


\subsection{GENERAL}

The most abundant terrestrial magnetic minerals are the Fe-Ti oxides within the FeO-TiO $2-\mathrm{Fe}_{2} \mathrm{O}_{3}$ ternary system (Nicholls 1955; Nagata 1961; Lindsley et al. 1966; O'Reilly 1976, 1984). Within the titanomagnetites (Fig. 3.2) solid solution of the end members, magnetite $\left(\mathrm{Fe}_{3} \mathrm{O}_{4}\right)$ and ulvospinel $\left(\mathrm{Fe}_{2} \mathrm{TiO}_{4}\right)$, only occurs above $600^{\circ} \mathrm{C}$. Naturally occurring titanomagnetites are not perfectly stoichiometric (ie the cation/anion ratio is not 3/4) and invariably $\mathrm{Mg}, \mathrm{Al}$ and $\mathrm{Mn}$ are substituted cations. Consequently the usage of the term titanomagnetite follows that of O'Reilly (1984) and is restricted to compostions where substituted cations are less than $10 \%$ of the total cations and the oxidation parameter $(z)$ is $0<z<0.1$.

Magnetism within the titanomagnetites ranges at room temperature from paramagnetism in ulvospinel to the ferrimagnetism in magnetite. Changes of bulk composition result in a steady gradation of various magnetic parameters; Curie temperature (Nagata 1961; Akimoto 1962; Stephenson 1972), saturation magnetism (Akimoto 1962; O'Reilly and Banerjee 1965; Stephenson 1969), coercive force (Robins 1972; Day et al. 1977) and susceptibility (Robins 1972; Day et al. 1977).

The metastable titanomaghemites are produced by either deuteric oxidation (Buddington and Lindsley 1964; Hauptman 1974) or low temperature oxidation (maghemitisation) (Johnson and Merrill 1973; O'Reilly 1983). Increasing non-stoichiometry (increasing $z$ ) results in a decrease in susceptibility and an increase in Curie temperature, saturation magnetisation and coercive force (Readman and OReilly 1972; O'Donovan and O'Reilly 1978; Manson et al. 1979; Keefer and Shive 1981; Ozdemir and O'Reilly 1981).

The titanohaematites $\left(y \mathrm{FeTiO}_{3}(1-y) \mathrm{Fe}_{2} \mathrm{O}_{3}\right)$ are a solid solution series between ilmenite and haematite. Magnetism of the titanohaematites varies markedly with composition (y), from the antiferromagnetism of haematite, through the ferrimagnetism of intermediate compositions to the paramagnetism of ilmenite. Variation of Curie temperature with composition is linear (Nagata and Akimoto 1956; Westcott-Lewis and Parry 1971) but other magnetic properties show far less consistent trends (Nagata and Akimoto 1956; Ishikawa and Akimoto 1958; Dunlop 1971).

Pyrrhotite $\left(\mathrm{FeS}_{1+\mathrm{x}}\right)$ and goethite $(\alpha \mathrm{FeOOH})$ are also magnetic (Neel 1955; Hedley 1968, 1971; Strangway et al. 1968; Schwarz and Vaughan 1972; Schwarz 1975). 


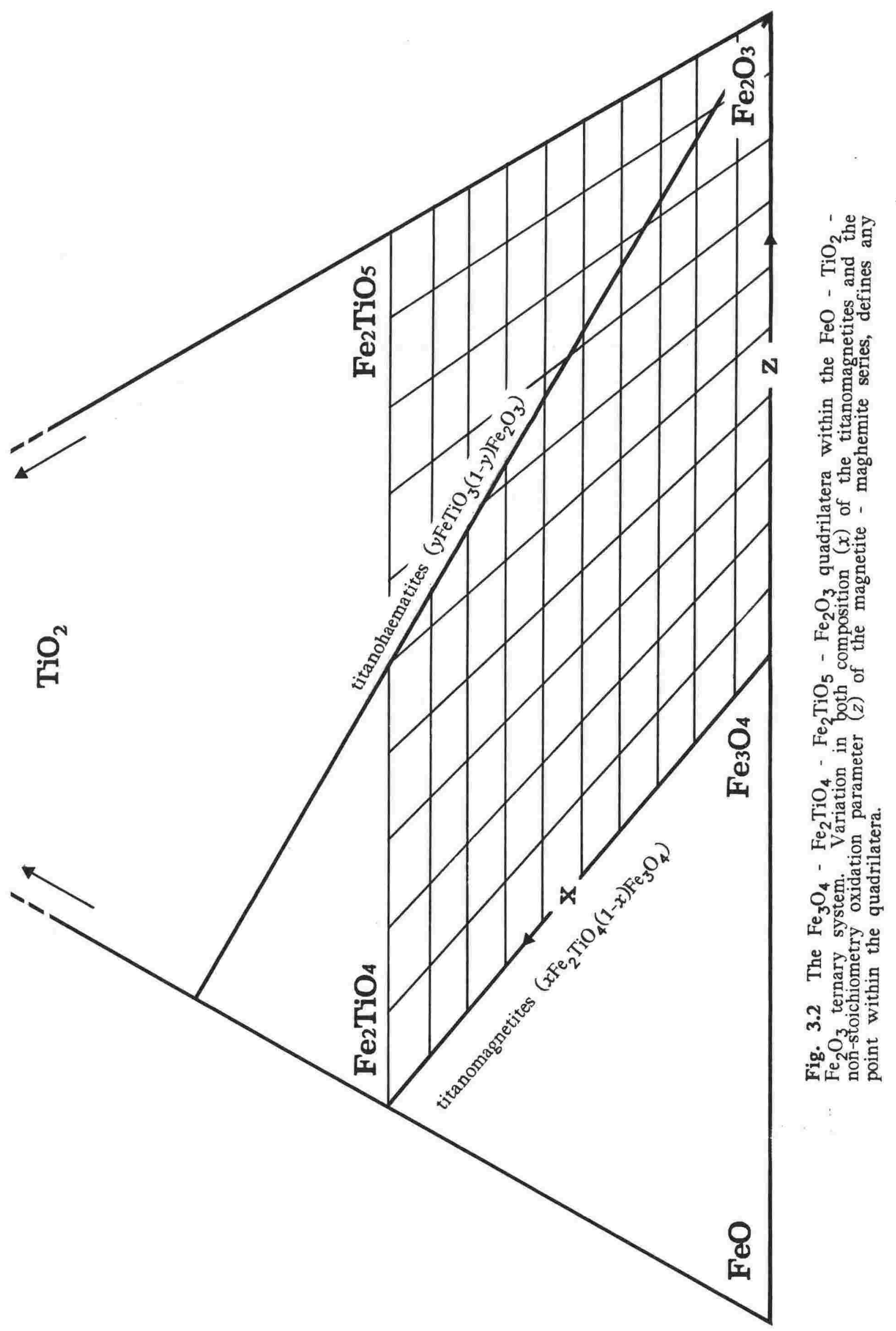




\section{4 \\ METHODS AND TECHNIQUES}

\subsubsection{Introduction}

Ten representative magnetic separates were analysed with an electron probe microanalyser. Isothermal remanent magnetisation (IRM) curves of 21 representative paleomagnetic specimens were used to confirm the electron probe microanalyser data and demonstrate their relationship to the observed remanent magnetisations. Initial susceptiblity data were used to relate variations in the concentration of magnetic minerals to fluctuations in magnetisation intensity.

Magnetic remanence measurements using the ScT magnetometer are described in section 3.5.

\subsubsection{Sample Storage and Preparation}

Most paleomagnetic cores were placed in sealed plastic bags when collected and stored in Mumetal shields, with fields of less than $50 \mathrm{nT}$, to minimise both moisture loss and the acquistion of a viscous remanence (Johnson et al. 1975; Henshaw and Merrill 1979; Verosub et al. 1979). Cores collected initially during field sampling (sites 18996-19045) were not stored in Mumetal shields and were allowed to dry in the ambient magnetic field for four months before measurement. Subsequent evidence of a post-sampling viscous remanence in Neogene sediments from the Wairoa Syncline (Walcott pers. comm. 1982; Walcott and Mumme 1982) led the author to store all cores in Mumetal shields.

Cores were cut $22 \mathrm{~mm}$ in length, with the length/radius ratio $0.80<1 / y^{d}<0.90$ so as to approximate a dipole at the specimen centre. The specimens were numbered according to stratigraphic site and core number (Fig. 3.3).

Samples of the magnetic minerals were prepared for electron microprobe analysis following, essentially, the method of Froggatt and Gosson (1982). The only difference was that in order to enable both detrital and diagenetic minerals to be recognised, samples were not chemically cleaned by reagents. All samples were wet sieved to $30 \mu$ and air dried below $30^{\circ} \mathrm{C}$ to prevent maghemitisation before analysis. The magnetic fraction was recovered with both a permanent magnet (magnetic field $5.5 \times 10^{5} \mathrm{~T}$ ) and a Frantz isodynamic separator, with a side slope of $20^{\circ} \mathrm{C}$, forward slope of $30^{\circ}$ and an amperage of 0.4. This was repeated three times for each sample. Subsequent microscopic examination of each separated 'magnetic' fraction revealed the presence of glass and micas with titanomagnetite inclusions and ilmenite. The separated 'magnetic' fraction was weighed and determined as a wt\% of the $>30 \mu$ size fraction. 


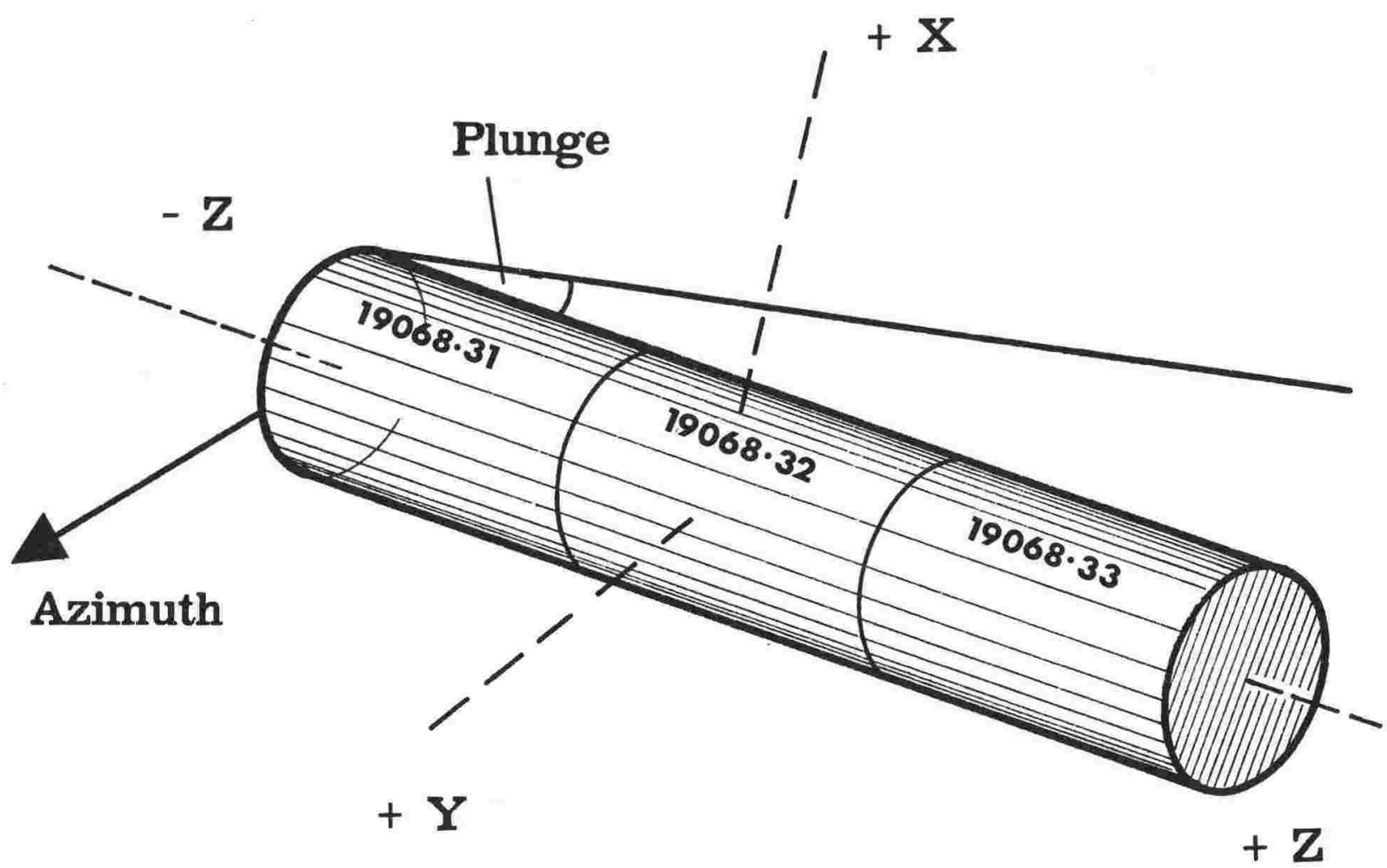

Fig. 3.3 Diagrammatic representation of numbered specimens and the relationship between field orientation and magnetometer reference axes. 


\subsubsection{Electron Probe Microanalysis}

A computer driven JEOL 733 superprobe (Analytical Facility, Victoria University of Wellington) was used for all chemical analyses. Its operation (including corrections for absorption, fluorescence and atomic number) and calibration of standards has been decribed elsewhere (Morris 1979; Watanabe et al. 1981; Froggatt and Gosson 1982; Grapes and Watanabe 1984). An accelerating potential of $15 \mathrm{kV}$, a beam current of $1.0-2.0 \times 10^{-8}$ amps and beam diameter of $3 \mu$ was used for all oxide analyses. A 25 $\mathrm{kV}$ accelerating potential was used for analysing sulphides (pyrite/pyrrhotite) to ensure the excitation of sulphur. The ilmenite standard (USNM 96819 Jarosewich et al. 1980) was analysed before and after each analysis period; the standard analysis and statistical deviations are presented in Table 3.1. All analyses with recalculated totals (Stormer 1983) in the range $99.0-101.0 \mathrm{wt} \%$ were accepted.

\subsubsection{Initial Volume Susceptibility}

Initial volume suceptibilities were measured for each specimen using a Bartington susceptibility meter. An alternating field $(0.1 \mathrm{mT})$ was applied with an operating frequency of $0.5 \mathrm{kHz}$. The meter was calibrated to $10 \mathrm{gm}$ of manganese carbonate with a known specific susceptibility of $-0.048 \times 10^{-6} \mathrm{~m}^{3} \mathrm{~kg}^{-1}$ and reset to zero before each measurement. Individual readings were corrected for specimen volume and averaged for the site (Appendix 9).

$$
\begin{aligned}
\mathrm{k} & =\mathrm{R} \times 10 \times 10^{-3} \\
\text { where } \quad \mathrm{R} & =\text { meter reading } \\
\mathrm{k} & =\text { volume susceptibility }
\end{aligned}
$$

The susceptibility meter was not available until after most specimens from sites 18996 to 19145 were thermally demagnetised. All other specimens were measured after NRM measurement and before thermal demagnetisation. A comparison of volume susceptibilities up to $300^{\circ} \mathrm{C}$ and non-demagnetised specimens (Table 3.2) indicates no significant difference.

\subsubsection{Isothermal Remanence Measurements}

Twenty-one representative specimens were given an incremental isothermal remanent, magnetisation (IRM) with a maximum direct field of $1.5 \mathrm{~T}$ (Appendix 4). All measurements were made by Dr. C. Laj and S. Guitton of Centre Des Faibles Radioactivities, Paris. 


\section{Table 3.1}

Ilmenite Standard

Microprobe Analysis

$$
\mathrm{N}=15
$$

Mean

$\mathrm{SiO}_{2}$

$\mathrm{Al}_{2} \mathrm{O}_{3}$

0.00

0.00

46.11

47.34

$\mathrm{Fe}_{2} \mathrm{O}_{3}$

\}

(17.34

$\mathrm{FeO}$

$\mathrm{MnO}$

4.47

0.31

0.00

$\mathrm{CaO}$

$\mathrm{Nb}_{2} \mathrm{O}_{5}$

Total
USNM 96819

\section{Chemical Analysis*}

Std.Dev.

0.43 45.70

0.53

$47.70\left\{\begin{array}{l}11.60 \\ 36.10\end{array}\right.$

0.21

4.77

0.31

0.00

0.92

98.24

* Jarosewich et al. (1980).

Total: not recalculated for $\mathrm{Fe}_{2} \mathrm{O}_{3}$ and $\mathrm{FeO}$.

Difference in totals between chemical analysis and microprobe analysis is $0.92 \% \mathrm{Nb}_{2} \mathrm{O}_{5}$ 
Table 3.2

Comparison of Volume Susceptibilities of Thermally Demagnetised Specimens (up to $300^{\circ} \mathrm{C}$ ) and NRM Specimens from the same Site.

(values $10^{-3}$ )

Specimen

19020.11

19020.12

19020.21

19020.22

19022.21

19022.22

19022.31

19022.32

19041.11

19041.12

19041.21

19041.22

19060.1

19060.2

19060.31

19060.32

19090.11

19090.12

19090.41

19090.42

19094.21

19094.22

19094.3

19094.4

19115.1

19115.2

19115.3

19115.4
Volume Susceptibility

of Thermally Demagnetised

Specimens

188

225

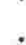

169

188

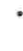

282

263
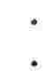

150

169

226

207

.

•

188

207
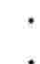

132

113
244

244

150

169

207

188

169

188
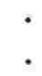

226

207

169

169

132

132
Volume Susceptibility

of NRM Specimens 


\subsection{MEASUREMENT OF MAGNETIC REMANENCES}

A two-axis ScT cryogenic magnetometer with on-line computer measured the natural remanent magnetisation. Before each period of measurement the Mylar sample holder was placed in a deionised ultrasonic water bath to dislodge any magnetic material present from previous use. The specimens were placed in the magnetometer with the positive Z-axis downwards and rotated through four $90^{\circ}$ angles. Two SQUIDs (superconducting quantum interference device) one horizontal and one vertical measured the intensities of magnetisation of the two $X$, two $Y$ and four $Z$ axis components which are averaged. The intensity of magnetisation of the previously measured sample holder without a specimen was subtracted. Because of the weak intensities of magnetisation recorded, all specimens were inverted (negative $\mathrm{Z}$-axis downwards) and remeasured, and the normal and inverted measurements again averaged.

The Fortran programme, NUCRYO.SAV was used to compute the magnetisation intensities for $\mathrm{X}, \mathrm{Y}$ and $\mathrm{Z}$ components which were recorded on floppy disks. The programme corrected for core orientation and bedding attitude (Appendix 2). Measurement of a 'zero-reference level' before and after each specimen measurement indicated any magnetic drift. When the magnetic drift exceeded $5.0 \times 10^{-6} \mathrm{Am}^{-1}$ the measurement was rejected and repeated. Helmholtz coils reduced the ambient field at the magnetometer mouth to less than $100 \mathrm{nT}$.

When measuring weakly magnetised specimens it is desirable to assess measurement quality (Heller 1977; Channell 1977; Lowrie and Alvarez 1977; Harrison 1980; Lowrie et al. 1980). Lowrie et al. (1980) showed that progressive internal dispersion ( 463$)$ of each measurement increases as magnetisation intensity decreases. However, the basis of any acceptance criterion must be the repeatability of the measurement. For these reasons criteria for initial acceptance were:

1. the averaged intensity of magnetisation of the specimen exceeded $1.5 \times 10^{-5}$ $\mathrm{Am}^{-1}$

2. the angular difference between the normal and inverted modes of measurement did not exceed $15^{\circ}$

Large angular differences between normal and inverted measurements due to specimen inhomogeneity (probably bioturbation) as opposed to inherent magnetic instability are discussed in section 5.6 . 


\subsection{1} Introduction

The only chemical data from Neogene sediments of the East Coast Deformed Belt relevant to this study is that of Gosson (1986) and Roser (unpublished). Previous studies (Orbell 1965; Bates 1967; Chaproniere 1969; Webb 1979; Kenny 1980, 1984; Blom 1982) have been petrographic descriptions where the Fe-Ti oxides have been included in the 'accessories' in modal counts. Only Ghent and Henderson (1966) detailed the mineralogy of the accessory minerals, recognising both anhedral and euhedral magnetite, the latter having an inferred volcanic source. However the 90 modal analyses from the above references give proportions of accessory minerals no greater than $4 \%$ and mostly below $1 \%$ in siltstones and sandstones. The magnetic fraction of the accesssory minerals is inferred to be $<1 \%$ within East Coast Neogene sediments. None of these petrographic studies gives chemical analyses of opaque or accessory minerals.

Gosson (1986) analysed with the microprobe volcanic glass and plagioclase from tuffs, and plagioclase and micas from the enclosing sediment. He showed that sediment from the East Coast Deformed Belt has at least three provenances; silicic volcanic tuffs and detritus, Torlesse Supergroup greywacke detritus eroded from the axial ranges and schist detritus from an as yet unrecognised source. Roser (unpublished data) analysed by X-ray fluorescence 35 Tongaporutuan siltstones from the Mangapoike section at sampled paleomagnetic sites. By titration he determined the absolute wt $\%$ of both $\mathrm{FeO}$ and $\mathrm{Fe}_{2} \mathrm{O}_{3}$ in each of the samples. The $\%$ of $\mathrm{Fe}^{3+}$ as a proportion of the total iron atoms can be expressed as an oxidation ratio, and ranges from $26.9 \%$ to $1.3 \%$, with an average of $13.5 \%$. This oxidation ratio is the whole rock $\mathrm{Fe}^{3+}$ total, in a range of different mineral species (chlorite, clays, micas and $\mathrm{Fe}-\mathrm{Ti}$ oxides). It provides a gross indication of the degree of $\mathrm{Fe}$ oxidation in the Mangapoike sediments, which on average is small.

\subsubsection{Chemistry}

Titanomagnetite $\left(x \mathrm{Fe}_{2} \mathrm{TiO}_{4}(1-x) \mathrm{Fe}_{3} \mathrm{O}_{4}\right)$ is the sole identifiable detrital magnetic mineral (Appendix 5) in the Mangapoike sequence. Titanium content varies between 5.87 wt\% and $12.82 \mathrm{wt} \%(x=0.17-0.37$, assuming impurities replace $\mathrm{Fe})$ from the 30 accepted microprobe analyses (Fig. 3.4). Substituted cations vary antipathetically and are predominantly $\mathrm{Al}, \mathrm{Mg}$ and $\mathrm{Mn}$, being always less than 0.07 of the cation total. The 


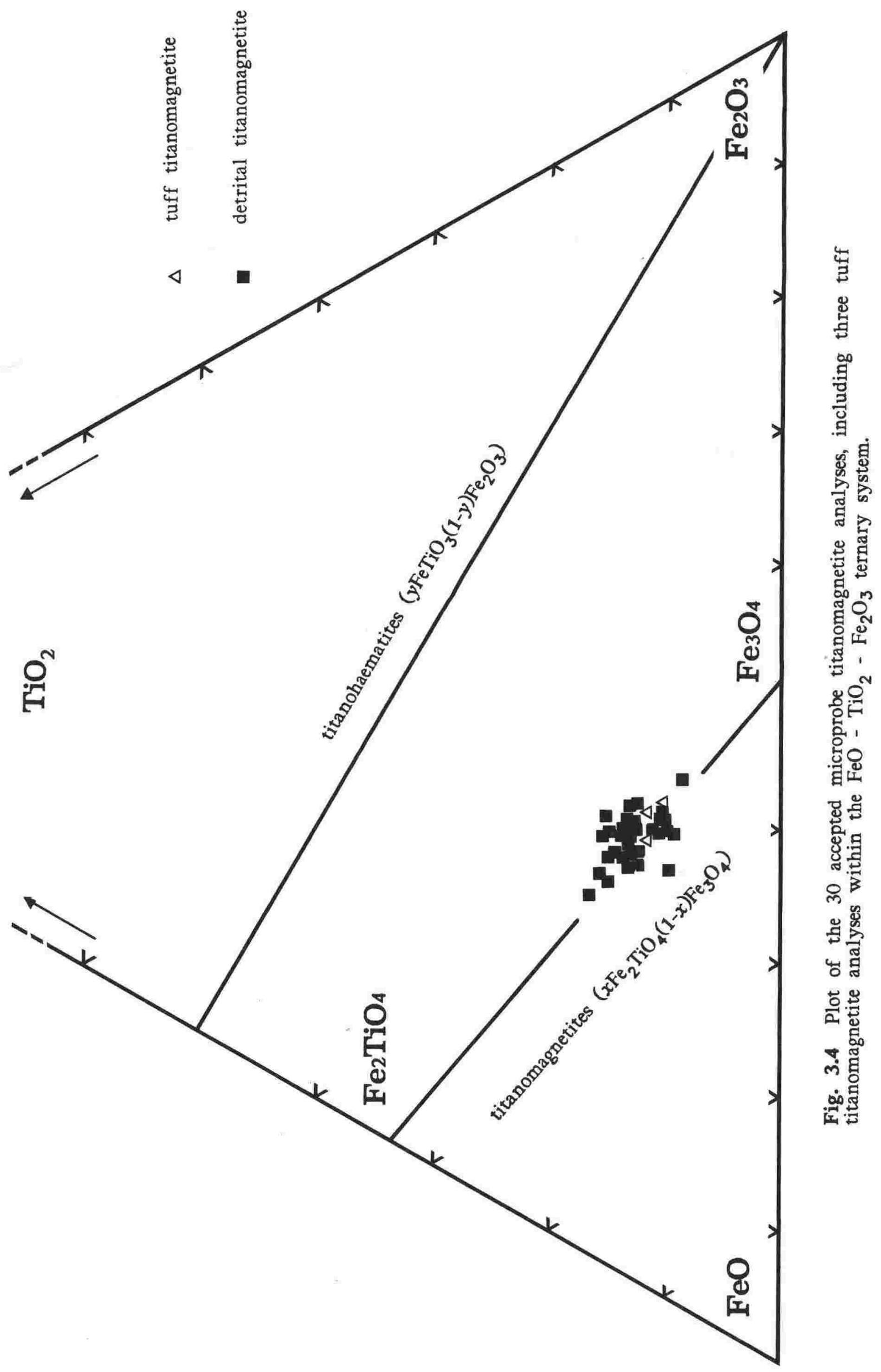


Plate 3.1 Exsolved ilmenite (Ilm) lamellae within host titanomagnetite (Mgt). Background black is the mounting epoxy resin. Scale bar (lower right) is 10 microns.

Plate 3.2 Authigenic framboidal pyrite (Pyr). Scale bar (bottom) is 100 microns. 

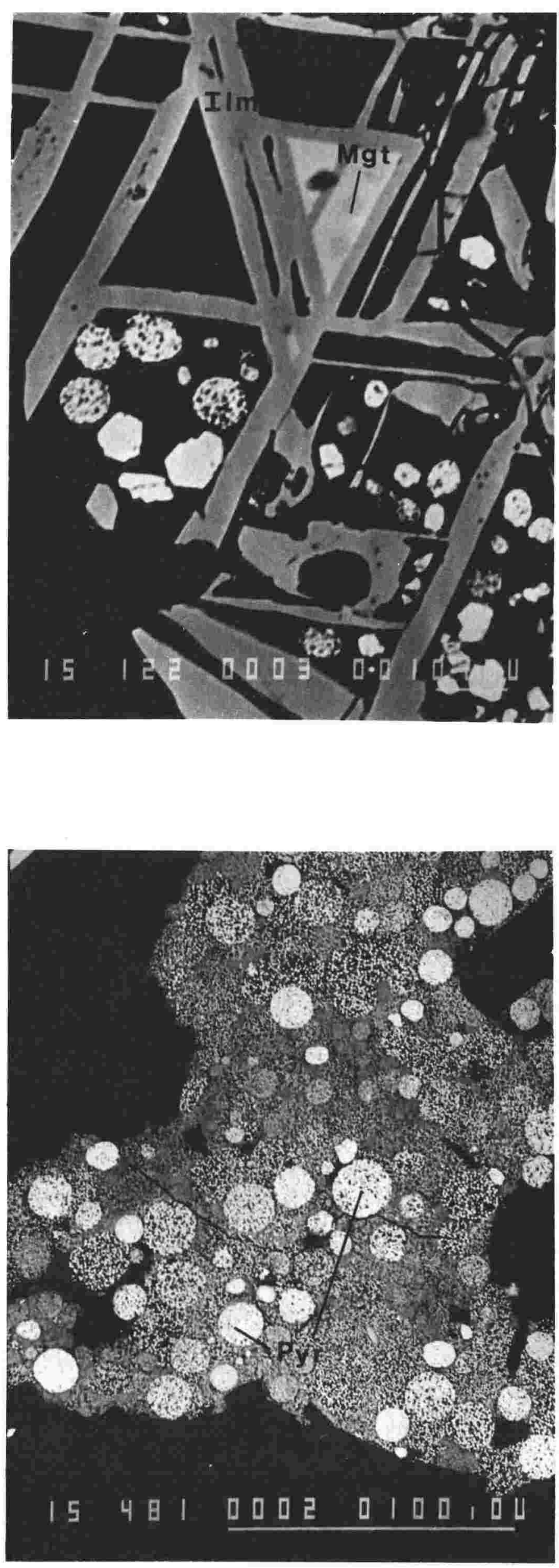

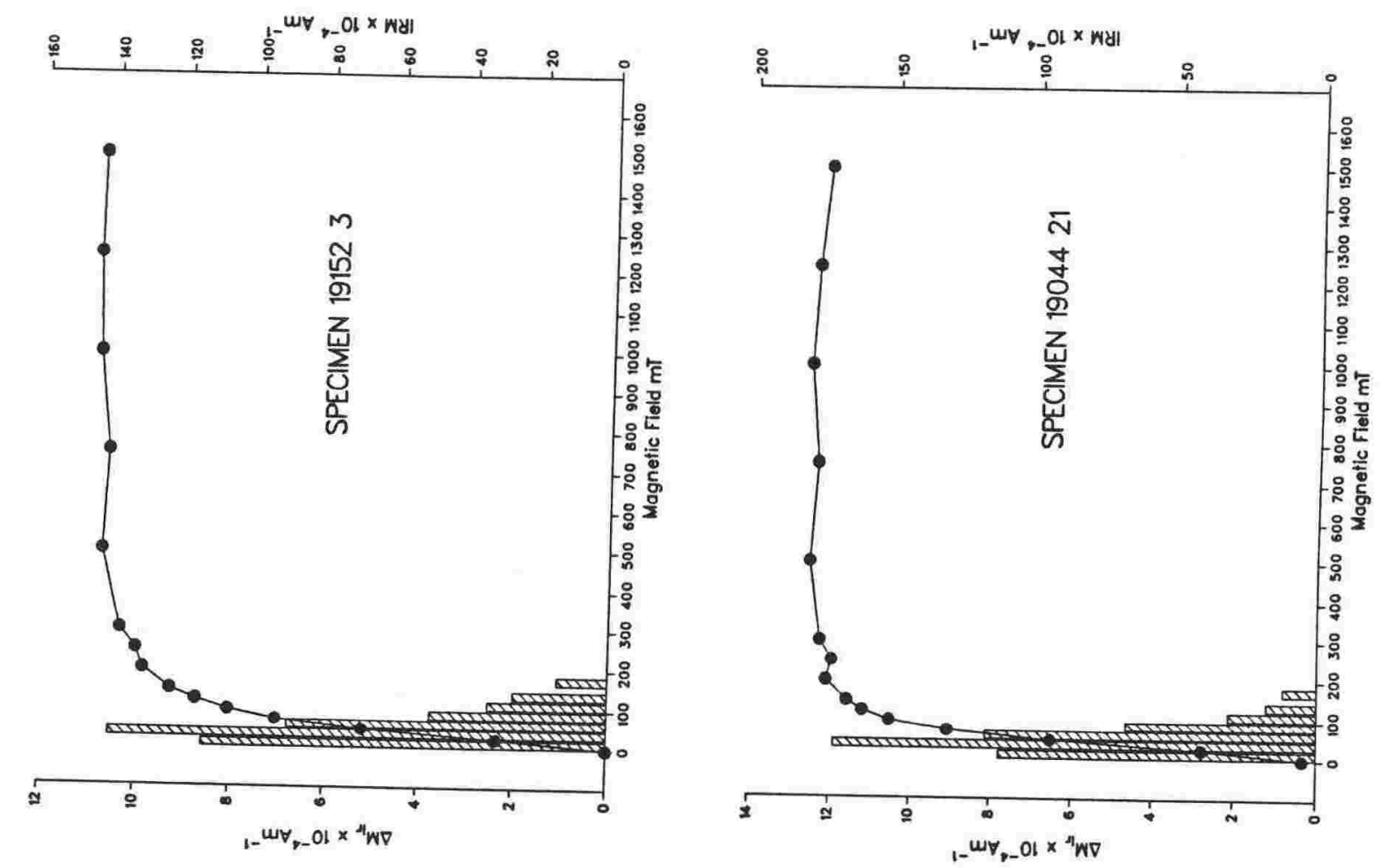

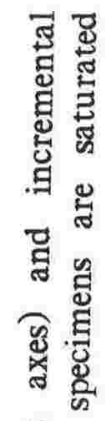

莺

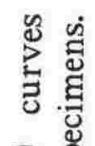

$\sum_{0}$

蛋
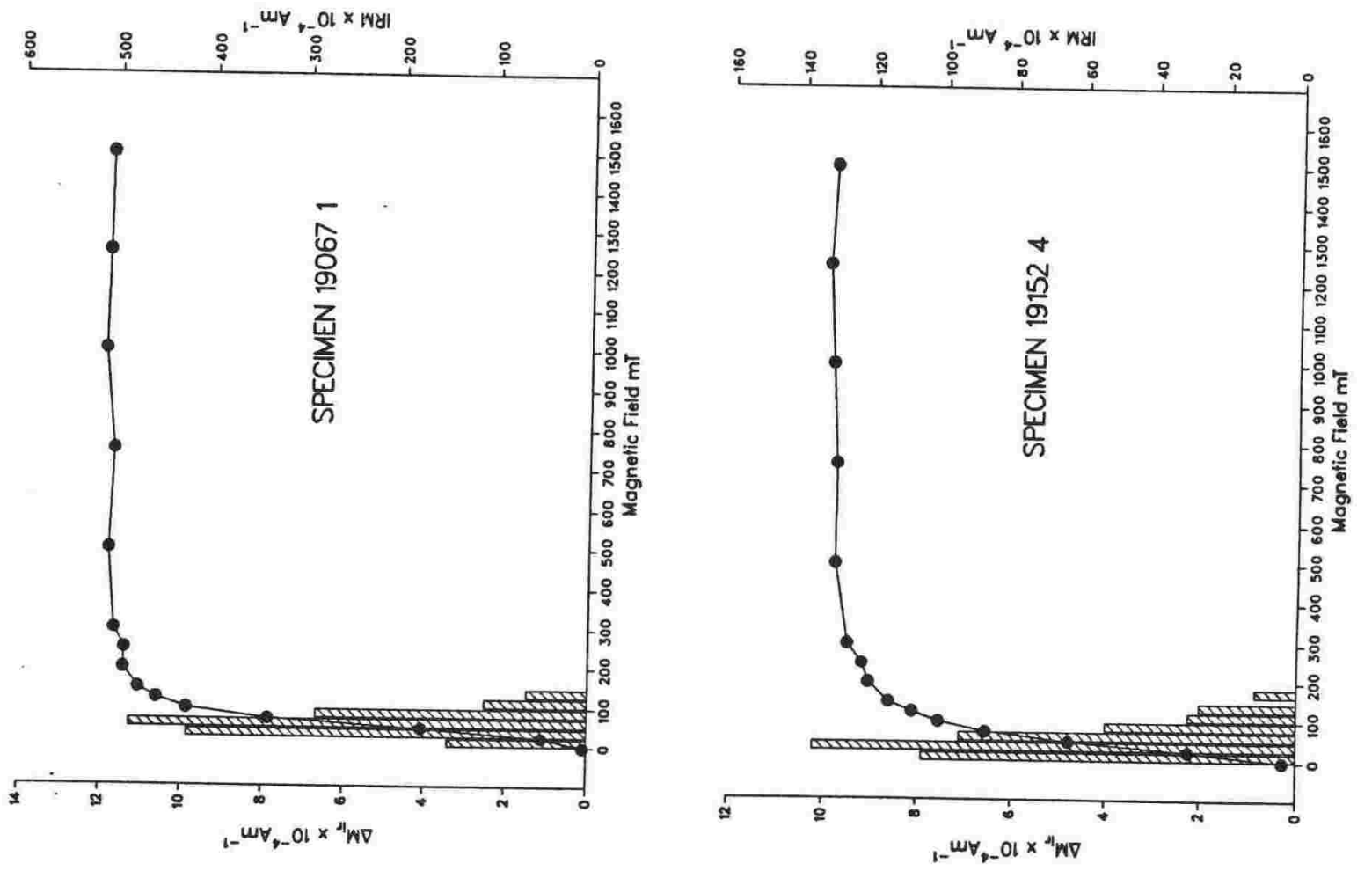

घ $\infty$

㟧

हू. छิ

藏营

ह

葛岕芯

ก 总

舟崽 

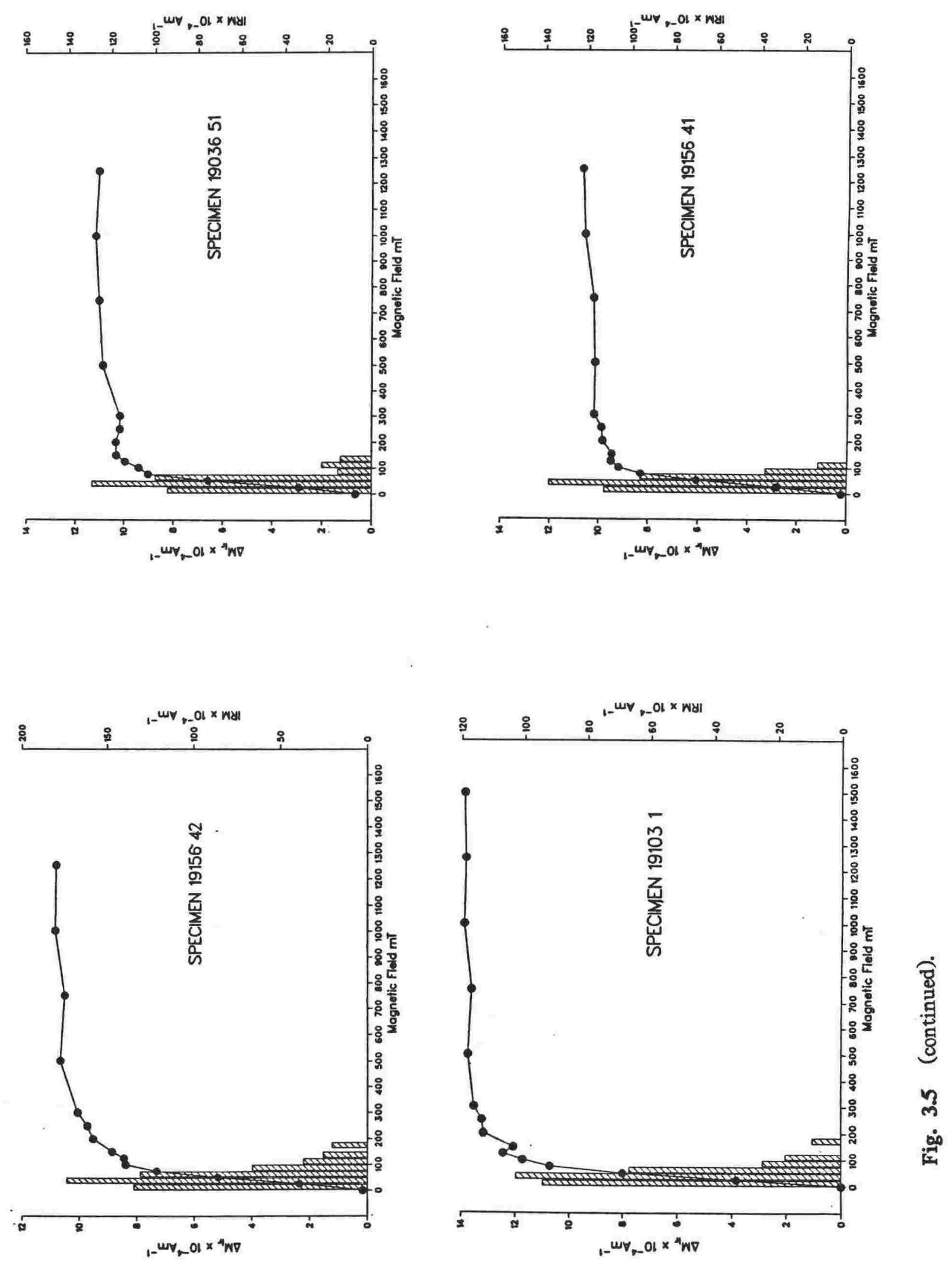
paragenesis of titanomagnetite is accepted to occur by crystallisation at magmatic temperatures (O'Reilly 1976), although Scotese et al. (1982) have suggested low temperature authigenesis of magnetite is possible. It is inferred that the identified titanomagnetite is detrital in origin, and their directions of magnetisation were aligned preferentially in the sediments at the time of or very soon after deposition. Deuteric oxidation is recognised in one titanomagnetite grain (Plate 3.1) with exsolved lamellae of ilmenite. The ilmenite lamellae are equivalent to the C3 oxidation stage of Haggerty (1976) and represent early subsolidus oxidation during magma cooling at about $600^{\circ} \mathrm{C}$ (Lindsley 1962; Buddington and Lindsley 1964; Haggerty 1976). All other titanomagnetite grains were homogeneous when viewed with back-scattered electron imagery (BEI). Ilmenite (paramagnetic) is the only other identified Fe-oxide.

Isothermal remanent magnetisation (IRM) curves support the microprobe data. Both the IRM curves and their incremental coercivity spectra (Dunlop 1972) were saturated within direct fields of $200 \mathrm{mT}$ (Fig. 3.5), in the 22 representative specimens tested (Appendix 4), indicating that magnetite, or titanomagnetite is the only magnetic mineral. Higher fields do not appear to saturate other magnetic components and it is inferred that haematite, maghemite and goethite are not present (Dunlop 1972).

Roser and Korsch (1985) and Roser and Rowe (in press) have shown that framework and matrix mineralogy and whole rock geochemistry can vary with grain size in sediments. Total $\mathrm{Fe}_{2} \mathrm{O}_{3}$ and $\mathrm{TiO}_{2}$ varied $5 \%$ and $0.6 \%$ respectively between greywacke sandstones and argillites of the Torlesse Supergroup. Similiar trends are seen within a Miocene graded bed (Roser and Korsch in prep). No such trend was shown by titanomagnetite chemistry at Mangapoike (Fig. 3.6) supporting a conclusion by Roser (pers. comm.) that hydrodynamic differentiation is minimal within a mineral species. It follows that the chemistry of the titanomagnetites within the $>30 \mu$ size fraction is representative of that of the total grain size range.

\subsubsection{Concentration}

The amount of titanomagnetite in the Mangapoike sediments is extremely low being in the order of $10^{-3}-10^{-4} \mathrm{wt} \%$. The estimate is based on the wt\% of the 'magnetic' separate and the ratio of ferrimagnetic to paramagnetic grains within the extracted fraction (Table 3.3). It assumes that there has been a complete separation of 'magnetic' and non-magnetic minerals in the $>30 \mu$ size fraction and that the concentration of 'magnetic' minerals in the $>30 \mu$ size fraction (Table 3.3) is the same as that of the < $30 \mu$ size fraction. 


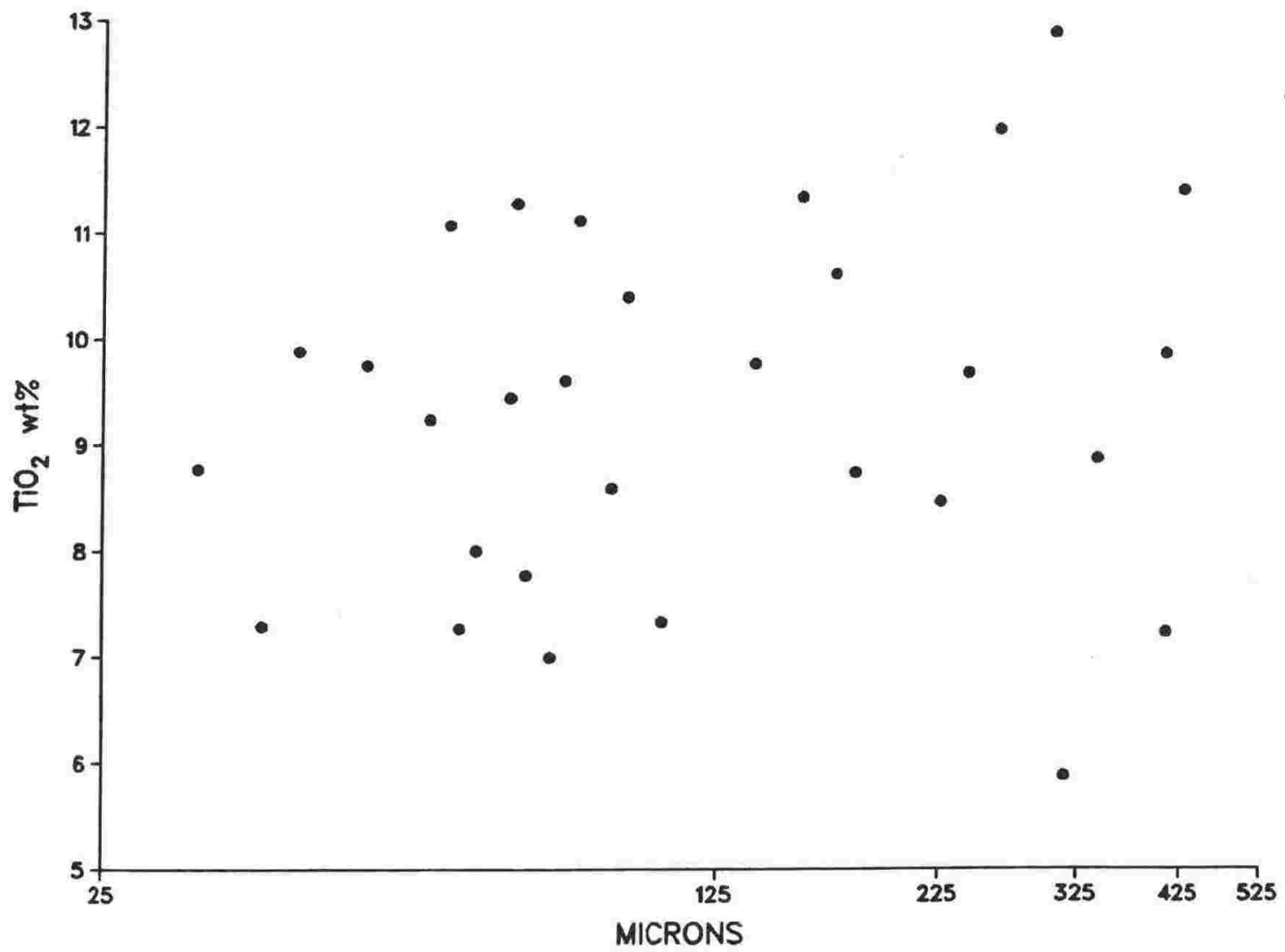

Fig. 3.6 Plot of Mangapoike titanomagnetites showing no correlation between $\mathrm{TiO}_{2}$ wt\% and grain size (microns) indicating hydrodynamic differation of the grains does not occur. 
Table 3.3

\section{Titanomagnetite Concentration}

$>30 \mu$ Size Fraction

$\begin{array}{lll}\text { Sample } & \begin{array}{c}\text { Wt\% "Magnetic" Fraction } \\ \text { of Total Sample* }\end{array} & \begin{array}{c}\text { Estimated Ratio of } \\ \text { Titanomagnetite:Ilmenite } \\ \text { in "Magnetic" Fraction }\end{array} \\ 19210 & 0.001 \% & 1: 30 \\ 19211 & 0.009 \% & 1: 50 \\ 19212 & 0.002 \% & 1: 60 \\ 19213 & 0.003 \% & 1: 100 \\ 19214 & 0.0008 \% & 1: 50 \\ 19215 & 0.004 \% & 1: 60 \\ 19216 & 0.002 \% & 1: 80 \\ 19217 & 0.003 \% & 1: 70 \\ 19218 & 0.001 \% & 1: 40 \\ 19219 & 0.0008 \% & 1: 60\end{array}$

* Includes both paramagnetic ilmenite and ferrimagnetic titanomagnetite. 
A comparison of the volume susceptibility of the original sample and the remaining non-magnetic fraction before and after extraction (Table 3.4) indicates a separation efficiency ranging from $60 \%$ to $75 \%$. Since the volume susceptibility measurements both before and after extraction have contributions from ferrimagnetic and paramagnetic minerals (Collinson 1983), volume susceptiblity is not an accurate measure of magnetic mineral content. An error of $\pm 10 \%$ is thus assigned to the separation, as measured by volume susceptibility, based on the observed ratio of paramagnetic ilmenite to ferrimagnetic titanomagnetite (Table 3.3) within the separated 'magnetic' fraction and the calculated susceptibilities of pure titanomagnetite and ilmenite, 1.0904 and 0.1900 respectively (Collinson 1983). Thus the estimated $55 \%$ to $80 \%$ separation efficiency compares favourably with other magnetic mineral extractions (Lovile et al. 1971 Kent and Lowrie 1974) which have varied between 5\% and 60\%, as measured by susceptiblity and saturation IRM data. The better extraction is ascribed to using the $>30 \mu$ size fraction since the problems of flocculation and electrostatic attraction are reduced when compared with very fine grained samples.

\subsubsection{Source}

The low $\mathrm{TiO}_{2}$ (5.87-12.82 wt\%) content of the titanomagnetites indicates one or more silicic sources (Buddington and Lindsley 1964; Carmichael 1967; Haggerty 1976). The continuum of $\mathrm{TiO}_{2}$ content over the range of wt\% (Fig. 3.4) indicates that $\mathrm{TiO}_{2}$ cannot be used as a discriminator for sediment provenance. On the basis of the three major substituted cations $\mathrm{Al}, \mathrm{Mn}$ and $\mathrm{Mg}$ within the titanomagnetites, three distinct fields are recognised (Fig. 3.7). These three fields do not represent the three sediment provenances (silicic volcanism, greywacke detritus and schist detritus) of Gosson (1986), but are a function of temporal and/or spatial variation solely within the volcanic terrane. Detrital titanomagnetite has not been identified from Torlesse greywacke rocks (Grapes pers. comm.) and phase calculations show that titanomagnetite is in disequilibrium at prehnite / pumpellyite grade metamorphism, reverting to sphene. For the same reason titanomagnetite from a schist terrane is unlikely. Metabasites within the Torlesse Supergroup (Roser 1984) can also be discounted as a titanomagnetite source, since high $\mathrm{TiO}_{2}$ (20-25 wt\%) titanomagnetites from basalts (Buddington and Lindsley 1964; Carmicheal 1967; Haggerty 1976) are not identified within the Mangapoike sediments.

Field 1 (Fig. 3.7) definitely represents titanomagnetites from a silicic volcanic source, with the three titanomagnetite analyses from a silicic tuff plotting in this field. 


\section{Table 3.4}

\section{Comparison of Volume Susceptibility during Extraction}

(values $10^{-3}$ )

Sample

Volume Susceptibility

of Original Sample

233.3

192.5

252.7

246.2

170.5

187.2

182.3

160.7

164.9

162.9
Volume Susceptibility

of Non-Magnetic Sample

after Extraction
19217

19218

19219
74.6

75.1

68.2

61.6

56.2

63.8

72.9

45.0

57.7

57.0 


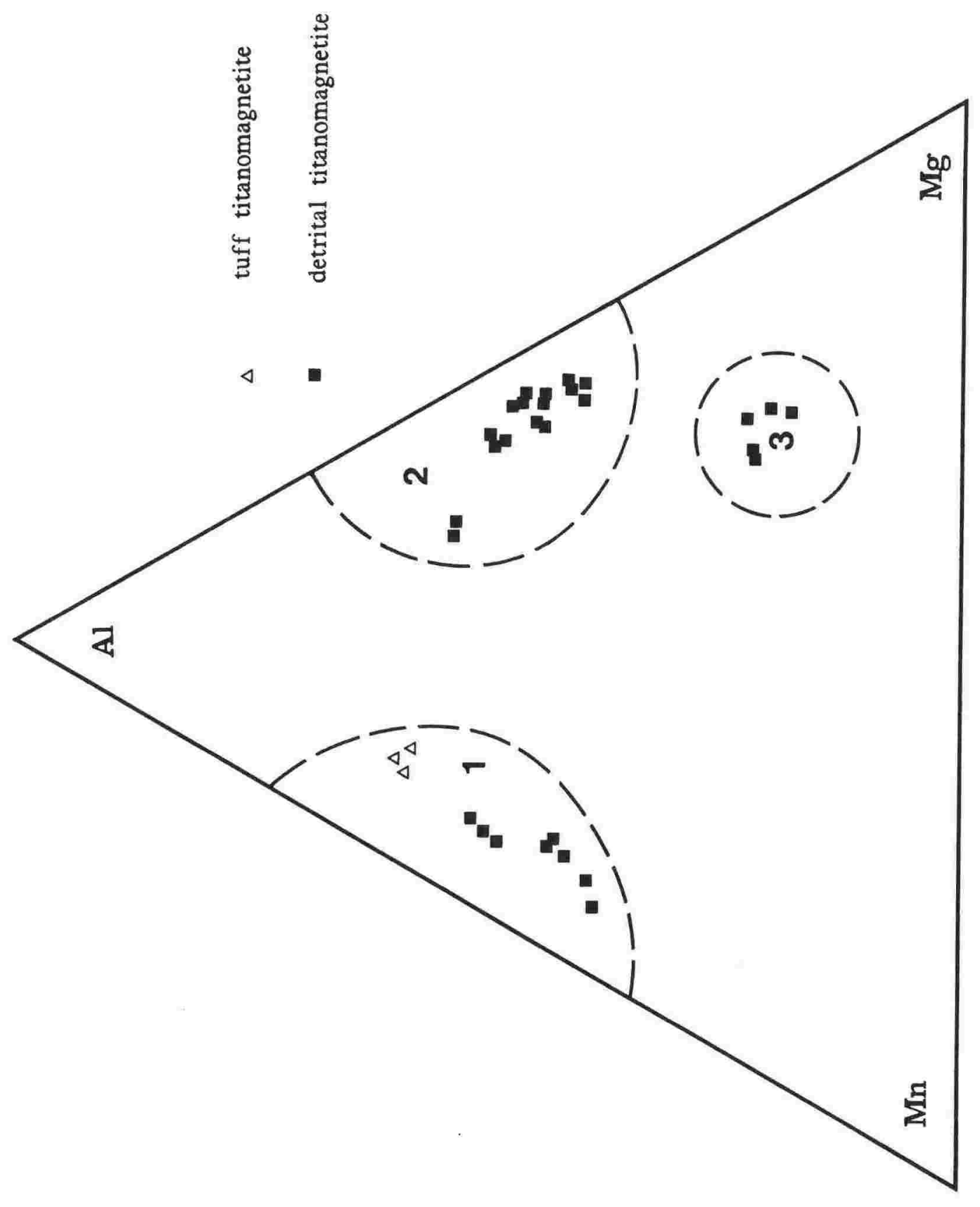

뫃

요융

若

这.

之o

믐

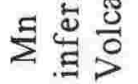

से है

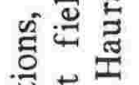

芦蔧

㶽

运营

点高

壱倦苛

娄

능 홍

을

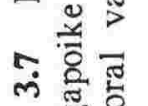

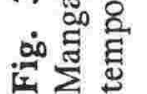


Titanomagnetite analyses comparable to those presented here have been reported from known dacitic and rhyolitic tuffs (Kohn 1970; Moll 1981; Froggatt 1982; Westgate et al. 1985). Gosson (1986) has argued convincingly that the Hauraki Volcanic Region (Skinner 1986) is the source, and his interpretation is accepted here. Fields 2 and 3 are also argued to be silicic products from the same volcanic region because of the low $\mathrm{TiO}_{2} \mathrm{wt} \%$ of the titanomagnetites and the presumed absence of titanomagnetite in either greywacke or schist terranes. Lack of comparative data from the Hauraki Volcanic Region however prevents a positive correlation of fields 2 and 3 with a Hauraki source. Compositional variabliity of substituted cations within titanomagnetites have been indicative of temporal and/or spatial variation of Quaternary pyroclastic rocks (Kohn and Topping 1978; Westgate and Evans 1978; Hodder 1985).

\subsection{DIAGENETIC AND AUTHIGENIC MAGNETOMINERALOGY}

\subsubsection{Haematite, Maghemite and Goethite}

Low temperature oxidation (maghemitisation, martitisation and oxyhydration) is not recognised in any of the analysed grains. Characteristic secondary or replacement textures (Bose 1958; Nickel 1958; Ramdor 1969; Evans and Wayman 1970; Haggerty 1976) are not recognised as inhomogeneties when viewed with back-scattered imagery. Neither haematite/maghemite nor goethite were recognised in any of the 74 oxide microprobe analyses (Appendix 5). The IRM curves (section 3.6.2) support the absence of haematite, maghemite and goethite.

\subsubsection{Pyrrhotite}

Iron sulphide (Plate 3.2) is an abundant authigenic mineral in New Zealand Cenozoic mudstones and sandstones. No pyrrhotite was detected in 40 electron probe analyses (Appendix 5).

\subsection{REMANENCE STABILITY}

\subsubsection{Introduction}

A number of field and laboratory stability tests can be used to identify viscous decay of the primary magnetisation over geologic time and/or the subsequent acquisition of a viscous magnetisation (VRM) in the present field direction. Reversed polarity directions, the fold test (Graham 1949), conglomerate test (Graham 1949), and baked contacts (Irving 1964; McElhinny 1973) have all been used as field stability tests (Irving and Runcorn 1957; Wilson 1962; Lowrie and Alvarez 1977; Purucker et al. 1980). Various 
laboratory stability test have been devised and include a comparison of induced magnetisation intensity (Konigsberger 1938; Irving 1964) and study of either induced or natural remanent coercivity (Petrova 1961; Radhakrishnamurty and Sahasrabudhe 1965; Stacey and Banerjee 1974).

\subsubsection{NRM Directions}

Most (85\%) of the NRM directions in the Mangapoike section, before tectonic correction, group near a the present field direction (declination 022, inclination -59, Fig. 3.8). The remaining $15 \%$ having reversed polarity directions. Two explanations can be made; 1 . all of the specimens have the same spectra of remanent stability, in both normal and reversed NRM directions, and coincidently lie near the present field direction; 2 . the specimens have different remanent stability spectra, and most have a secondary viscous normal overprint in the present field direction. The second explanation is favoured because of both the anomalous NRM directions, with positive inclinations but present field declinations, (Fig. 3.8) and the less than $180^{\circ}$ between mean normal and reversed NRM directions (Fig. 3.9). Both indicate the presence of a secondary component of magnetisation. Further evidence for the presence of a secondary component is the acquistion (section 3.7.3) and decay (section 3.7.4) of a viscous remanence within laboratory time.

A fold test could not be be applied to the Mangapoike data, because there are no significant variations in bedding orientation (Appendix 2). The data of Walcott and Mumme (1982) from more steeply dipping strata from the Wairoa Syncline could not be used because of the acquistion of a post-sampling viscous magnetisation.

\subsubsection{VRM Acquistion}

Viscous remanent magnetisation (VRM) acquired after sampling of New Zealand Cenozoic sediments has been described by Walcott and Mumme (1982) and Mumme and Walcott (1985). The magnetisation is aligned along the $Z$ axis of the specimen in a negative sense, while stored on end in the present magnetic field, producing a strong correlation between NRM declination and core azimuth as decsribed by the relationship: $D=\tan ^{-1}\{y /(z \cos \theta+x \sin \theta)+(\Phi-90)\}$, where $\theta$ is the core plunge and $\Phi$ is the core azimuth (Walcott and Mumme 1982, see their Fig. 3). The data could have been ascribed to a drilling induced remanence as described by Sallomy and Briden (1975), but tests by Mumme and Walcott (1985) with dry and wet specimens from the same core stored in both shielded and non-shielded states confirmed the component to be a 

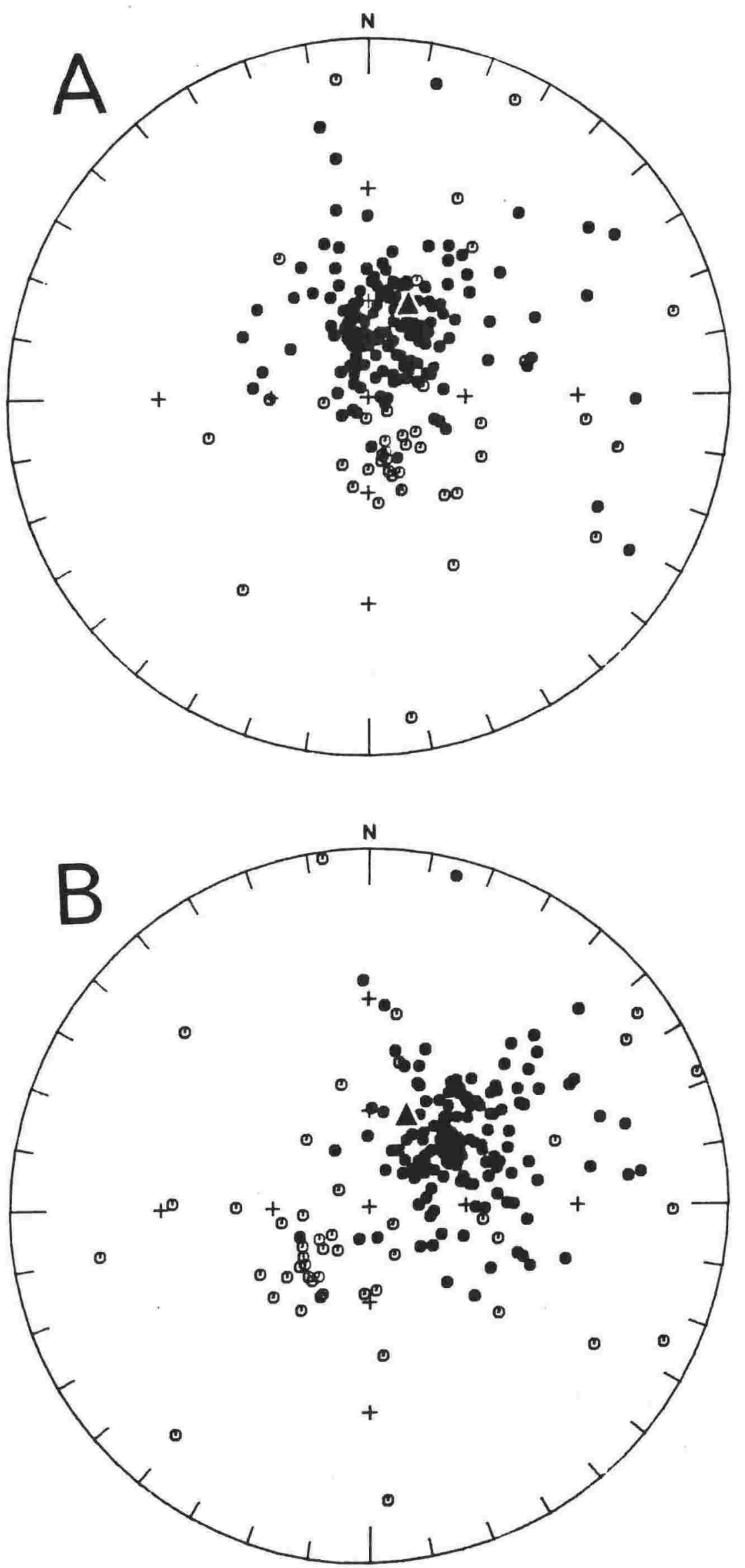

Fig. 3.8 Representative NRM directions, (a) not corrected for tectonic rotation and (b) corrected for tectonic rotation. Closed symbols upper hemisphere and open symbols lower hemisphere. Triangle, present day field direction. 


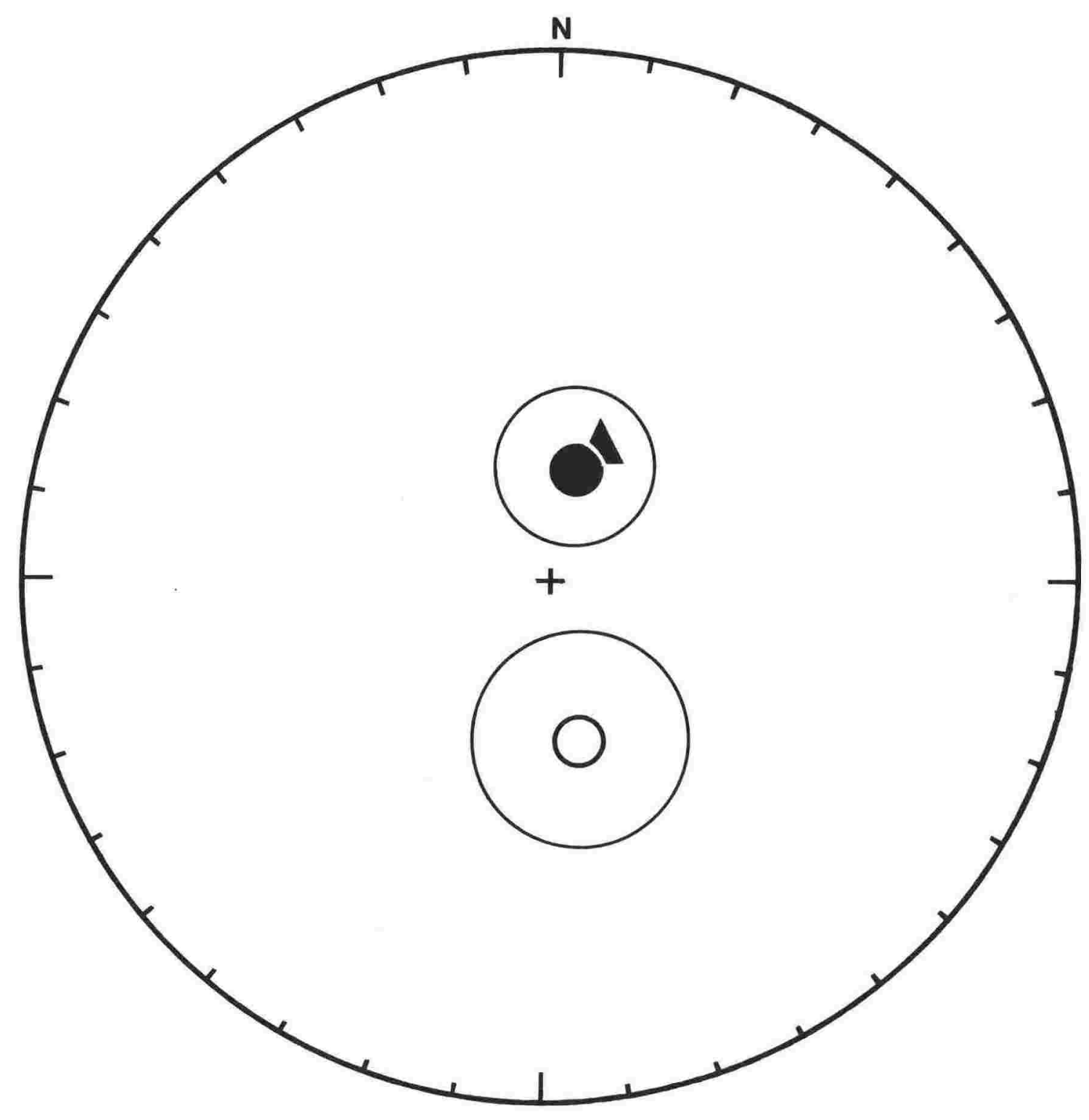

Fig. 3.9 Mean normal and reversed NRM directions, with $\alpha 95$ 's of representative specimens from Fig. 3.8. Symbol convention is that of Fig. 3.8. 
VRM, and that both drying and non-shielding were factors in its acquistion.

Similiar behaviour is recognised in Mangapoike specimens which were not stored in Mumetal shields (Fig. 3.10). The correlation between NRM declination and core azimuth is, however, not as pronounced as that of Walcott and Mumme (1982), suggesting that the post-sampling VRM component is not the predominant NRM magnetisation. Specimens stored in Mumetal shields showed no correlation between NRM declination and core azimuth (Fig. 3.11) and were inferred to have no significant post-sampling VRM component.

Drying and non-shielding are factors in imparting the post-sampling VRM (Mumme and Walcott 1985) but the physical mechanisms or phase changes in the mineralogy are unclear. Drying of sediment slurries (40-60\% water) in an applied field has imparted significant VRM components in laboratory experiments (Johnson et al. 1975; Henshaw and Merrill 1979; Verosub et al. 1979; Otofuji et al. 1982). Comparison of that drying effect with the well cemented mudstones studied here, with water contents of less than $3 \%$ (Table 3.5) is however questionable. Constant values of volume susceptibility during thermal demagnetisation at temperatures below $300^{\circ} \mathrm{C}$ (Table 3.2 and see section 4.2.3) with resultant water loss, suggest no detectable changes in the mineralogy. The magnetic characteristics of the post-sampling VRM are also unclear. It has a low coercivity of acquistion ( $0.5 \mathrm{mT}$, the earth's magnetic field) but requires either moderate temperatures $\left(200^{\circ} \mathrm{C}-250^{\circ} \mathrm{C}\right)$ or $\mathrm{AF}$ fields $(30 \mathrm{mT}$ ) for its removal (Walcott and Mumme 1982; Mumme and Walcott 1985).

\subsubsection{VRM Decay}

Zero-field demagnetisation (storage test) is the measurement of magnetisation while stored in a zero-field at progressively longer intervals of time. The decay of NRM with time indicates the presence of a viscous remanence, the contributions of which become randomised. Twelve representative specimens were placed in a Mumetal shield (field < $50 \mathrm{nT}$ ) and were initially used as an internal calibration to check SQUID orientation and sign before each measurement period.

Two types of remanent stability were recognised in these specimens over a period of 18 months. Because the magnetometer was available for use only at irregular intervals the specimens could not be measured at equal time intervals, but at 319 and 418 days of shield storage. Type I specimens show an average $45 \%$ decay in magnetisation intensity (Fig. 3.12) and thus are inferred to have a VRM component, and have magnetic viscosity coefficients $\left(S_{d}\right)$ greater than 0.250 (Table 3.6). Type II 


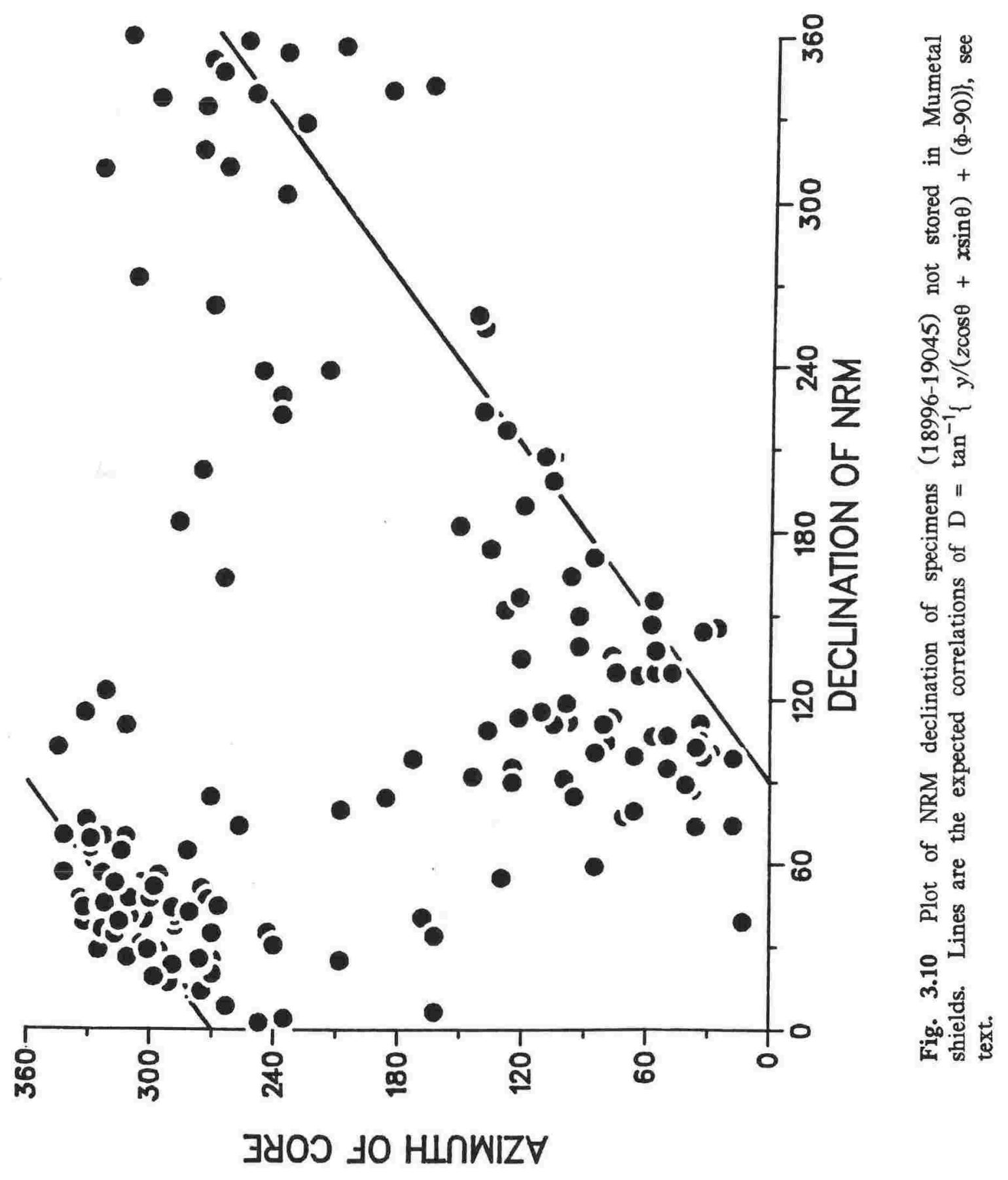




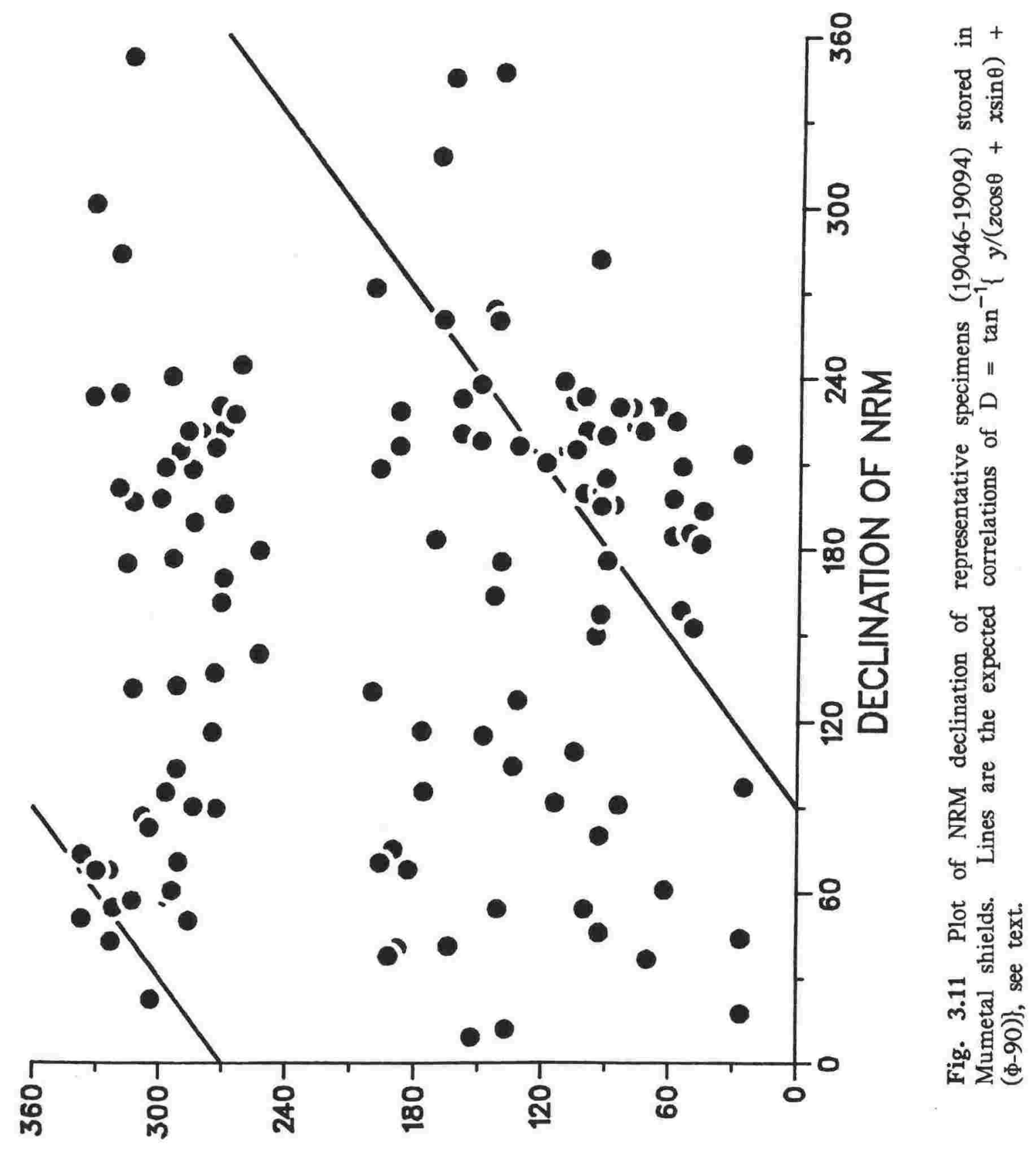

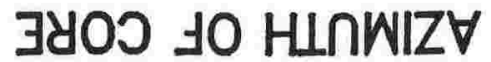


specimens showed no significant decrease in intensity, have viscosity coefficients less than 0.130 and correspondingly are assumed to have no significant VRM components.

The two types of remanent stability are related to NRM polarity. All type I specimens have normal NRM polarity, while all type II specimens have reversed NRM polarity (Table 3.5 and Fig. 3.12). Reversed NRM polarity of type II specimens is consistent with their low viscosity coefficients, which ensure that they retain their reversed polarity and do not acquire a viscous normal overprint. The converse, that all specimens with high viscosity coefficients have normal NRM polarity need not be true. It is expected that some normal NRM polarity specimens have not acquired a viscous overprint but have simply retained their normal primary magnetisation and consequently should have low viscosity coefficients. The observation that all of the high coefficient specimens have normal NRM polarity is thus considered to be a sampling problem. This is confirmed when it is observed that all of the normal NRM polarity specimens have a reversed primary magnetisation and none of the twelve specimens has a normal primary magnetisation (chapter 4 and Appendix 8).

\subsubsection{Discussion}

The acquired viscous remanent magnetisation $\left(V_{R M}\right)$ and the decaying viscous remanent magnetisation $\left(V_{R M}\right)$ as described in the previous sections are considered to be one viscous magnetisation. Both the $\mathrm{VRM}_{A}$ and the $\mathrm{VRM}_{D}$ are highly viscous over laboratory time and have similiar coercivity spectra, making it unlikely that two components with the same viscosities would resolve into two different magnetisations. The assumption that decay and acquisition viscosities are the same (ie $S_{A}=-S_{D}$ ) is supported by complementary viscous acquisition and decay experiments on the same sample made by Creer (1957). The characteristics of acquisition and decay of this viscous magnetisation are interpreted as different responses to either non-shielding or shielding with Mumetal.

The viscous magnetisation aligned in the present field direction (section 3.8.2) has a different relaxation time from the highly viscous laboratory magnetisation (cf. 720,000 yrs and 18 months) and is thus inferred to have different coercivity spectrum. Further evidence for differences in the coercivity spectra is provided in chapter 4 where evidence is shown that the viscous magnetisation aligned in the present field direction is randomised at $250-300^{\circ} \mathrm{C}$ and the laboratory magnetisation is randomised at $200-250^{\circ} \mathrm{C}$ during demagnetisation. 
Table 3.5

Water Content of Specimens \% Dry at $300^{\circ} \mathrm{C}$ (values in grams).

\begin{tabular}{|c|c|c|c|}
\hline Specimen & $20^{\circ} \mathrm{C}$ & $300^{\circ} \mathrm{C}$ & $\%$ \\
\hline & & & Dry Weight \\
\hline 18998.11 & 19.134 & 18.735 & 2.13 \\
\hline 18998.12 & 20.059 & 19.531 & 2.70 \\
\hline 19000.41 & 19.716 & 19.284 & 2.24 \\
\hline 19000.42 & 19.537 & 19.119 & 2.19 \\
\hline 19010.31 & 20.216 & 19.853 & 1.83 \\
\hline 19010.32 & 19.208 & 18.749 & 2.45 \\
\hline 19048.1 & 19.317 & 18.861 & 2.42 \\
\hline 19048.4 & 19.803 & 19.615 & 0.96 \\
\hline 19094.21 & 19.546 & 19.191 & 1.85 \\
\hline 19094.22 & 18.619 & 18.153 & 2.57 \\
\hline 19012.11 & 18.742 & 18.490 & 1.36 \\
\hline 19012.12 & 19.128 & 18.817 & 1.65 \\
\hline 19032.2 & 20.265 & 19.749 & 2.61 \\
\hline 19019.2 & 19.634 & 19.047 & 3.08 \\
\hline 19034.2 & 18.898 & 18.572 & 1.76 \\
\hline 19061.4 & 19.275 & 18.918 & 1.89 \\
\hline 19062.3 & 18.719 & 18.413 & 1.66 \\
\hline
\end{tabular}




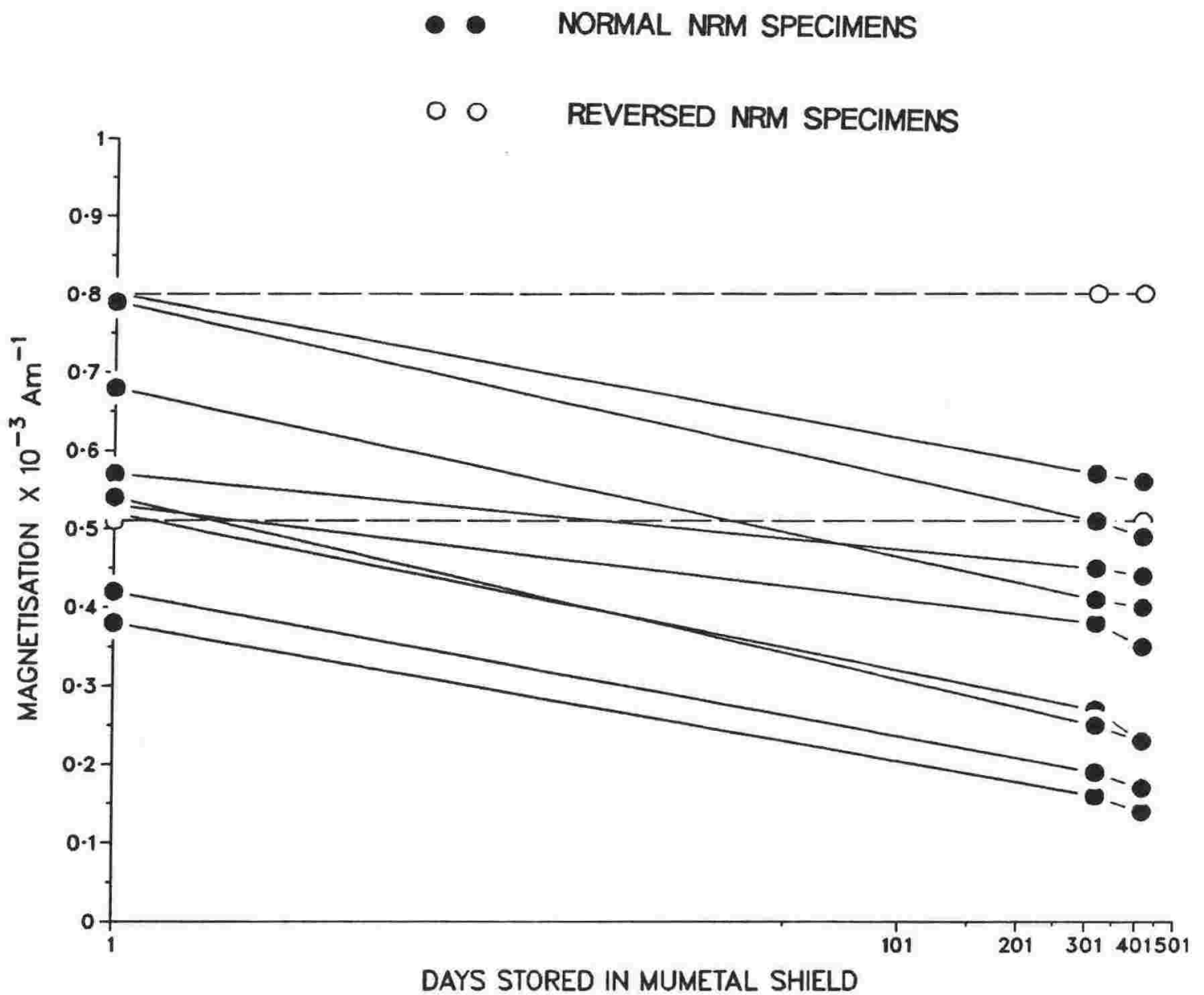

Fig. 3.12 Plot of magnetisation intensity against days of Mumetal shield storage (log scale), showing an exponential decay with time. 
Table 3.6

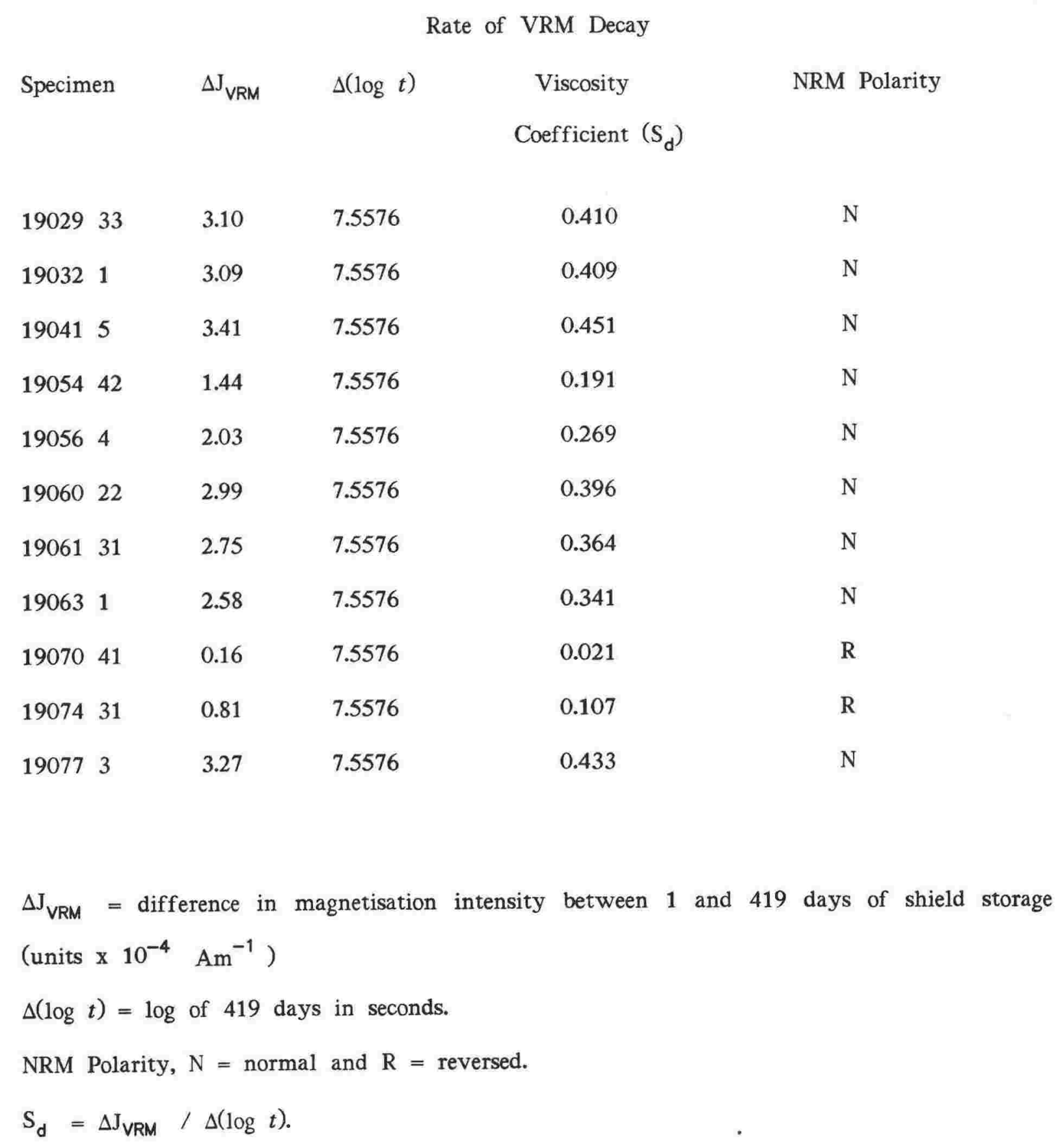


VRM, and that both drying and non-shielding were factors in its acquistion.

Similiar behaviour is recognised in Mangapoike specimens which were not stored in Mumetal shields (Fig. 3.10). The correlation between NRM declination and core azimuth is, however, not as pronounced as that of Walcott and Mumme (1982), suggesting that the post-sampling VRM component is not the predominant NRM magnetisation. Specimens stored in Mumetal shields showed no correlation between NRM declination and core azimuth (Fig. 3.11) and were inferred to have no significant post-sampling VRM component.

Drying and non-shielding are factors in imparting the post-sampling VRM (Mumme and Walcott 1985) but the physical mechanisms or phase changes in the mineralogy are unclear. Drying of sediment slurries (40-60\% water) in an applied field has imparted significant VRM components in laboratory experiments (Johnson et al. 1975; Henshaw and Merrill 1979; Verosub et al. 1979; Otofuji et al. 1982). Comparison of that drying effect with the well cemented mudstones studied here, with water contents of less than 3\% (Table 3.5) is however questionable. Constant values of volume susceptibility during thermal demagnetisation at temperatures below $300^{\circ} \mathrm{C}$ (Table 3.2 and see section 4.2.3) with resultant water loss, suggest no detectable changes in the mineralogy. The magnetic characteristics of the post-sampling VRM are also unclear. It has a low coercivity of acquistion ( $0.5 \mathrm{mT}$, the earth's magnetic field) but requires either moderate temperatures $\left(200^{\circ} \mathrm{C}-250^{\circ} \mathrm{C}\right)$ or $\mathrm{AF}$ fields $(30 \mathrm{mT})$ for its removal (Walcott and Mumme 1982; Mumme and Walcott 1985).

\subsubsection{VRM Decay}

Zero-field demagnetisation (storage test) is the measurement of magnetisation while stored in a zero-field at progressively longer intervals of time. The decay of NRM with time indicates the presence of a viscous remanence, the contributions of which become randomised. Twelve representative specimens were placed in a Mumetal shield (field < $50 \mathrm{nT}$ ) and were initially used as an internal calibration to check SQUID orientation and sign before each measurement period.

Two types of remanent stability were recognised in these specimens over a period of 18 months. Because the magnetometer was available for use only at irregular intervals the specimens could not be measured at equal time intervals, but at 319 and 418 days of shield storage. Type I specimens show an average $45 \%$ decay in magnetisation intensity (Fig. 3.12) and thus are inferred to have a VRM component, and have magnetic viscosity coefficients $\left(S_{d}\right)$ greater than 0.250 (Table 3.6). Type II 
Since titanomagnetite is the sole magnetic mineral identified by electron microprobe analysis and IRM curves, it is the magnetic carrier of both the stable and viscous magnetisations. This variation of magnetic stability within one mineral species can be attributed to either differences in particle size and domain state or variation in cation substitution within the titanomagnetite structure. The multidomain theories of VRM (Neel 1955; Stacey 1963) where viscosity (S) is particle size dependent have been confirmed by experimental data (Dunlop 1973). The correlation of coercivity and saturation remanences with cation substitution within titanomagnetites has been reported (Creer and Stephenson 1972; Richards et al. 1973). Patel and Palmer (1982) also suggested that increasing magnetic instability correlates with increasing cation substitution. In Mangapoike specimens direct correlations have not been made between magnetic viscosity and the grain size of the magnetic fraction and/or the degree of cation substitution because of a lack of data from all 343 sites. Since logarithmic decay of a VRM with time is predicted by multidomain viscous theory (Neel 1955; Stacey 1963) and such a decay is observed within the Mangapoike specimens (Fig. 3.12), it is inferred that viscous magnetisations reside in multidomain titanomagnetite.

\subsection{NRM INTENSITY}

\subsubsection{Introduction}

Variations of NRM intensity in a rock are assumed to be a function of both the strength of the geomagnetic field when the rock was formed (paleofield intensity) and the concentration of magnetic minerals in the rock. Determination of the absolute magnetic mineral content, and hence its contribution to the NRM intensity, is difficult, and especially so in fine grained sediments. A number of magnetic properties (initial susceptibility, isothermal remanent magnetisation, saturated isothermal magnetisation and anhysteretic remanent magnetisation) have been used as normalising parameters (Harrison 1966; Opdyke et al. 1973; Levi and Banerjee 1976; Johnson et al. 1975; Creer et al. 1976) assuming the measured property is proportional to the magnetic mineral content.

Initial volume susceptibility is used in this study since other magnetic properties could not be measured for all sites sampled, because of equipment limitations. Initial susceptibility is not an absolute measure of the remanent-carrying mineral content, since it has contributions from ferrimagnetic and paramagnetic minerals (Collinson 1983). This is important with the Mangapoike sediments, in which the amount of paramagnetic ilmenite and the very low concentration of titanomagnetite in the extracted 'magnetic' fraction (Table 3.7) indicates that paramagnetic susceptibility contributes up to $10 \%$ (section 3.7 .2 ) of the initial volume susceptibility. 

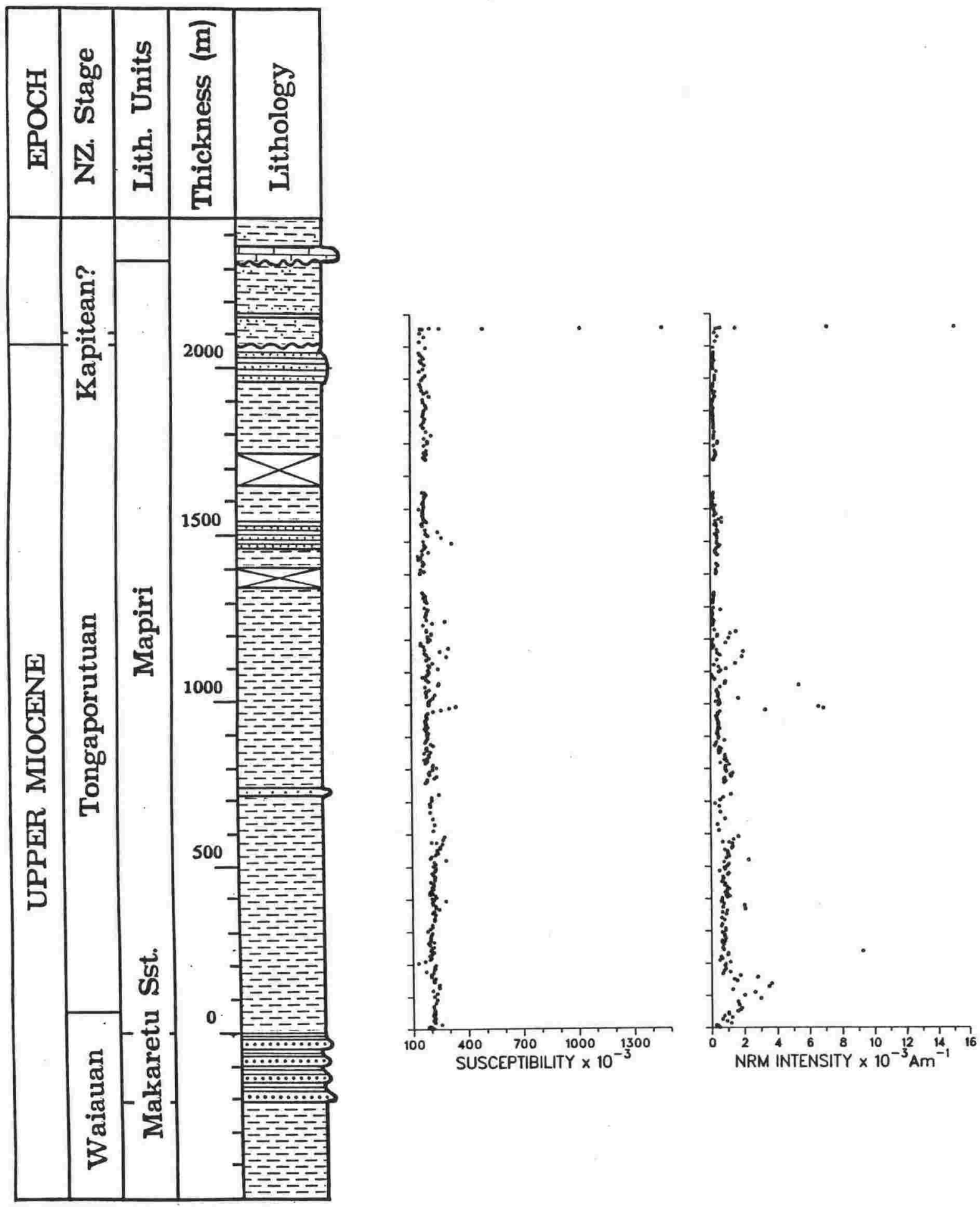

Fig. 3.13 Stratigraphic log of volume susceptibility and NRM intensity. 


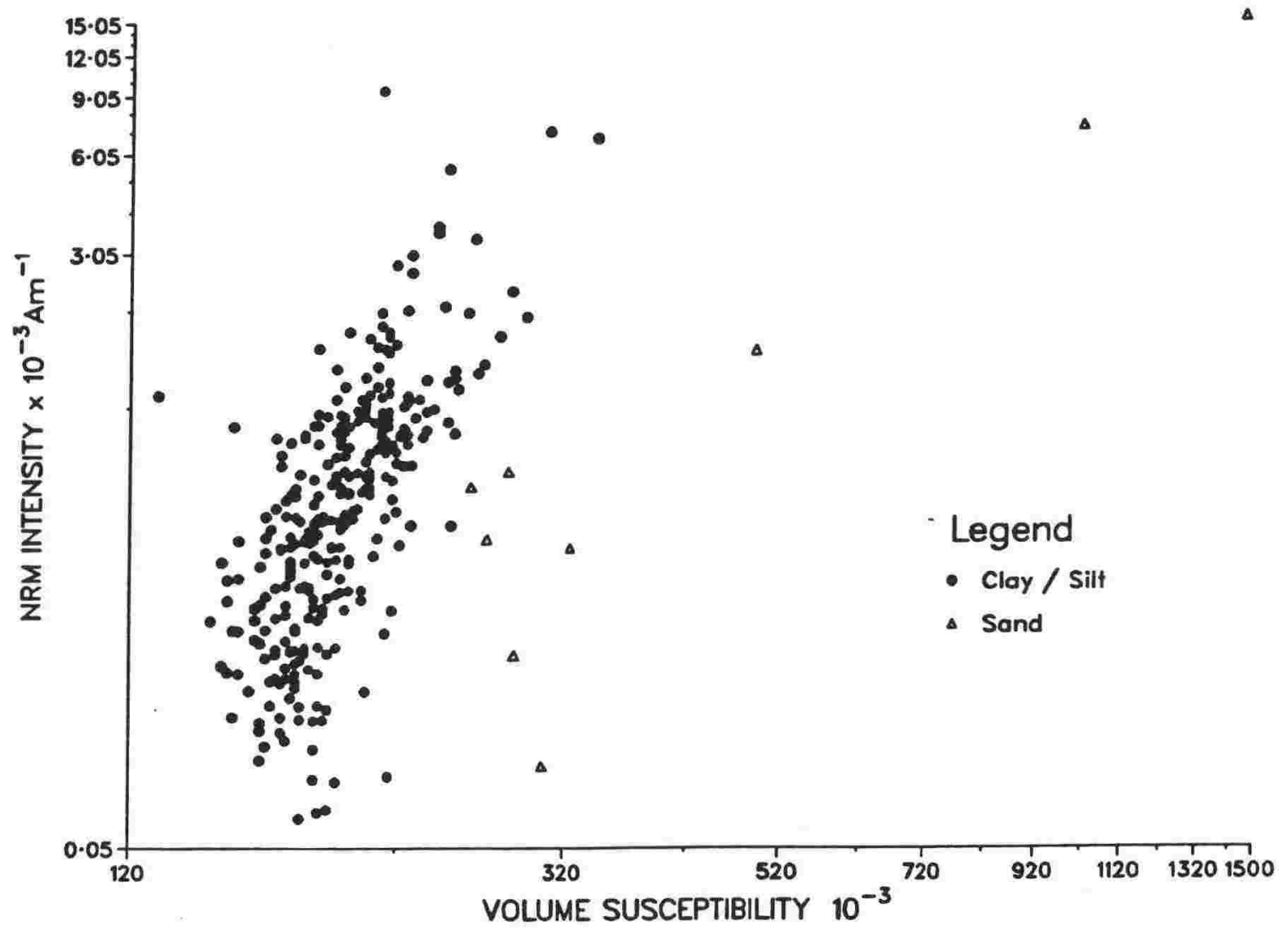

Fig. 3.14 Volume susceptibility - NRM intensity plot (log-log scale) of sandstones and mudstones (silt and claystones) from Mangapoike River. 


\subsection{2 $\quad$ NRM Intensity}

A general correlation of NRM intensity with volume susceptibility (with its paramagnetic and ferrimagnetic components) (Fig. 3.13), indicates as a first approximation, that variations of NRM intensity are lithologically controlled, and are not a function of paleofield intensity variation. Both NRM intensity and volume susceptibility show a decrease in magnitude with increasing stratigraphic height, and variations of NRM intensity are generally matched by variations of susceptibility.

The relationship between NRM intensity and volume suceptibility is complicated by grain size. Sandstones have higher susceptiblities relative to their NRM intensity (Fig. 3.14), because of domain wall movements of the multidomain components within the coarser grained size fraction during susceptibility measurement.

Previous paleomagnetic studies have generally recognised that volcanic ash has higher magnetic susceptibilities and intensities of magnetisation than the enclosing sediment (Opdkye 1972; Lovlie et al. 1971). This relationship is expected to vary with ash composition; basaltic ashes will have higher concentrations of $\mathrm{Fe}-\mathrm{Ti}$ oxides and consequently will have higher susceptiblities and magnetisation intensities than silicic ashes.

The presence of silicic volcanic detritus, including 2-30 $\mathrm{cm}$ thick tuffs (Gosson 1986) and dispersed glass shards within the enclosing sediment (Ashby 1985; Gosson 1986) above $1077 \mathrm{~m}$ within the Mangapoike sequence does not influence the general trend of decreasing volume susceptibility and NRM intensity with increasing stratigraphic height (Fig. 3.13). Average volume susceptibilities of 188 and 206 above and below $1077 \mathrm{~m}$, respectively, reflect this general trend and volume susceptibilities do not increase with the incoming of silicic volcanic detritus at $1077 \mathrm{~m}$. Measured volume susceptibilities of the tuffs themselves (Appendix 11) are similiar to those of the enclosing sediment. NRM intensity also has a similiar relationship with average values of $5.1 \times 10^{-4} \mathrm{Am}^{-1}$ and $1.1 \times 10^{-3} \mathrm{Am}^{-1}$ above and below $1077 \mathrm{~m}$. The low values of both volume susceptibility and NRM intensity above $1077 \mathrm{~m}$, where it is expected to have higher values because of the presence of volcanic detritus, cannot be solely ascribed to the silicic composition of the tuffs. Froggatt (1982) and Gosson (1986) have described abundant magnetite in Miocene - Pliocene rhyolitic pyroclastic flows. Gosson (1986) recognised the East Coast Basin tuffs to be mineral depleted (including Fe-Ti oxides) and argued that a combination of elutriation of the pyroclastic flow during eruption, aeolian fractionation with distance from source $(30-50 \mathrm{~km})$ and winnowing by fluvial processes before final deposition have produced glass enriched 
tuffs. His observation is consistent with the magnetic data presented here. Low values of volume susceptibility and NRM intensity reflect the depletion of Fe-Ti oxides from the tuffs.

\subsection{CONCLUSIONS}

The following conclusions are drawn:

1. The remanent magnetisation is carried by detrital titanomagnetite, which is the sole magnetic mineral indicated by electron microprobe analysis and isothermal remanent magnetisation curves.

2. Pre-depositional oxidation is deuteric, with ilmenite exsolution lamellae within host titanomagnetite.

3. Post-depositional oxidation (low temperature) is not recognised.

4. Chemistry $\left(\mathrm{TiO}_{2}\right)$ of the titanomagnetites is invariant with grain size.

5. The amount of titanomagnetite in the rocks is extremely small $\left(10^{-3}-10^{-4} \mathrm{wt} \%\right)$ and variations of titanomagnetite content are the main influence on NRM intensity variation. 


\section{Chapter IV}

\section{DEMAGNETISATION METHODS}

\subsection{INTRODUCTION AND PRINCIPLES}

The natural remanent magnetisation (NRM) of a rock is usually a combination of a primary magnetisation acquired at or near the time of the physical formation of the rock, and secondary magnetisations acquired subsequently. Removal of the secondary remanent magnetisation by magnetic cleaning (demagnetisation) is necessary for the identification of the primary component. Secondary magnetisations can be successfully separated only when their stabilities are lower than that of the primary magnetisation (Nagata 1961; Stacey 1963; Banerjee 1981). In rocks with multiphase magnetisations in which the magnetic components have similiar stabilities, it might not be possible to isolate the primary magnetisation (Roy and Lapointe 1978; Claesson 1978). Either an alternating magnetic field (AF demagnetisation) or heat (thermal demagnetisation) is applied to overcome the lower magnetostatic energy of the secondary magnetisations (Nagata 1961; Stacey and Banerjee 1974; Banerjee 1981; O'Reilly 1984). Thermal demagnetisation increases the temperature of the specimen in discrete steps, successively unblocking and randomising progressively higher blocking temperature components, leaving the more stable (usually primary) magnetisation intact. Cooling the rock in a zero magnetic field after each cleaning step fixes the random orientation of the unblocked magnetisation, which then no longer contributes to the rock's magnetic remanence. AF demagnetisation involves the cycling of a rock through magnetic hysteresis loops in steps of progressively higher alternating fields so as to randomise magnetic domain directions, by either domain rotation of single domain grains or domain wall movement within multidomain grains (Stacey and Banerjee 1974).

The two different demagnetisation techniques have given conflicting results. Watkins et al. (1974) were unable to identify the primary magnetisation in specimens from the Calabrian type section in Italy, because of the presence of a younger normal overprint. In the same section Nakagawa et al. (1975) identified normal and reversed magnetozones. The conflicting results were attributed to different demagnetisation methods (Kukla and Nakagawa 1977).

For any particular suite of paleomagnetic specimens the suitability of either thermal or AF demagnetisation to remove secondary magnetisations, and thus allow 
identification of the primary magnetisation can not be predicted. To determine the optimum demagnetisation method for the Mangapoike sediments 36 pilot specimens were stepwise demagnetised, 20 using thermal demagnetisation and 16 using AF demagnetisation. The 36 pilot specimens represent $3 \%$ of the total number of specimens finally measured, and $576 \mathrm{~m}$ of the total $2158 \mathrm{~m}$ sampled.

\subsection{THERMAL DEMAGNETISATION}

\subsubsection{Introduction}

Thermal demagnetisation has been the preferred method of demagnetisation in paleomagnetic studies of Cenozoic sediments in New Zealand (Lienert et al. 1972; Kennett and Watkins 1974; Walcott et al. 1981; Walcott and Mumme 1982). This has been a result of, until recently, incoherent data from the available AF demagnetising equipment. The primary component of magnetisation in these studies has been isolated at low to moderate temperatures $\left(100^{\circ} \mathrm{C}\right.$ to $\left.280^{\circ} \mathrm{C}\right)$.

\subsubsection{Techniques}

The demagnetisation equipment used in this study was developed and built by D.A. Christoffel and E. Broughton.

A horizontal cylindrical gas oven, aligned normal to the major vertical and horizontal components of the ambient field direction, enclosed in a double Mumetal shield, with a field less than $20 \mathrm{nT}$, was used for all thermal demagnetisation. Three nickel-chromium $\mathrm{v}$ copper-nickel thermocouples referenced to iced water indicated the temperature. Adjustment of the gas flame ensured the temperature difference between the front and rear of the oven was no greater than $5^{\circ} \mathrm{C}$. Specimens were held at the designated temperature for a minimum of 10 minutes, and allowed to cool to below $200^{\circ} \mathrm{C}$ before applying an air hose to accelerate cooling. After cooling to room temperature specimens were stored in a Mumetal shield until the remanence was measured.

The twenty pilot specimens were demagnetised at $50^{\circ} \mathrm{C}$ increments, up to $300^{\circ} \mathrm{C}$, and then at $320^{\circ} \mathrm{C}$ and $340^{\circ} \mathrm{C}$. Three specimens from two weakly cemented siltstones (sites 19054 and 19069) disaggregated at $200^{\circ} \mathrm{C}$ and were rejected from the analysis. 


\subsubsection{Mineralogical Alteration}

Thermal demagnetisation may cause chemical alteration of the remanent carrying minerals, and thus possibly the primary magnetisation. The mineralogical alteration may include oxidation of titanomagnetite or magnetite to haematite, dehydration of goethite to haematite or a phase change from maghemite to haematite (Buddington and Lindsley 1964; O'Reilly 1983). Alteration of the magnetic mineralogy is assumed to reflect a change in magnetic properties. Changes in magnetic properties (initial susceptibility, induced magnetisation) are thus used to detect mineralogical alteration (Stephenson 1969; Dunlop 1972). The non-repeatability of remanence measurements after a second heating to the same temperature may also indicate mineralogical alteration.

Initial susceptibility has been the most widely used magnetic property to detect mineralogical alteration (Lowrie and Heller 1982) because of the ease of measurement. Initial volume susceptibility is used in this study for the same reason, and was measured in all pilot specimens at each demagnetisation temperature, after remanence measurement.

Mineralogical alteration during thermal demagnetisation of New Zealand Cenozoic sediments has not been demonstrated in previous studies, largely because other magnetic properties were not measured, but has been assumed to have occured (Kennett and Watkins 1974; Walcott and Mumme 1982). Kennett and Watkins (1974) suggested that dehydration of goethite to haematite explained an increase in magnetisation intensity and an increase in the in-site dispersion above $300^{\circ} \mathrm{C}$ of Pliocene samples from Mangapoike River.

Similiar behaviour is recognised in the pilot specimens from the present study and is confirmed as being a result of mineralogical alteration. An increase of magnetisation intensity is matched by a 5 fold increase in the volume susceptibility at temperatures between $300^{\circ} \mathrm{C}$ and $340^{\circ} \mathrm{C}$ (Fig. 4.1). The temperature at which specimens alter (the alteration temperature) varies within a site, and even within one core (Table 4.1). This variation does not reflect varying lengths of time at a particular demagnetisation temperature, since all pilot specimens were heated within the same batch, but is inferred to reflect inhomogeneties, caused by bioturbation, in the distribution of the remanence carrying titanomagnetite. The product of the alteration is assumed to be derived from the titanomagnetite, and is most likely to be haematite, formed by oxidation of the titanomagnetite. 

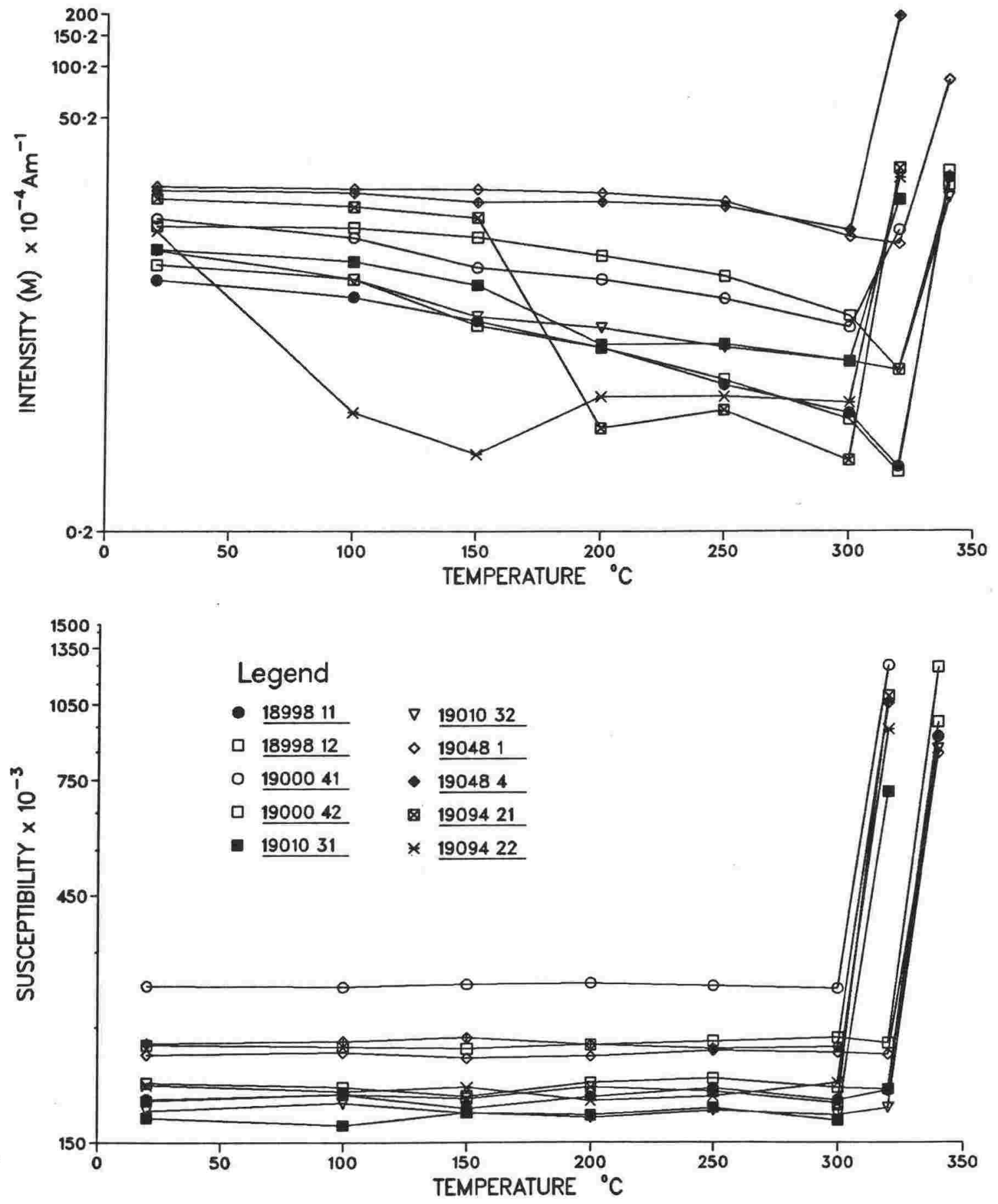

Fig. 4.1 Volume susceptibilities and magnetisation intensities of representative pilot specimens during thermal demagnetisation. 
Table 4.1

Volume Susceptibility and Magnetisation

Intensities of Representative Pilot Specimens

\begin{tabular}{|c|c|c|c|c|c|c|c|c|}
\hline SPEC & $20^{\circ} \mathrm{C}$ & $100^{\circ} \mathrm{C}$ & $150^{\circ} \mathrm{C}$ & $200^{\circ} \mathrm{C}$ & $250^{\circ} \mathrm{C}$ & $300^{\circ} \mathrm{C}$ & $320^{\circ} \mathrm{C}$ & $340^{\circ} \mathrm{C}$ \\
\hline 18998.11 & $\begin{array}{c}5.7 \mathrm{E}-04 \\
181.1\end{array}$ & $\begin{array}{c}4.5 \mathrm{E}-04 \\
185.4\end{array}$ & $\begin{array}{c}3.3 \mathrm{E}-04 \\
174.6\end{array}$ & $\begin{array}{c}2.3 \mathrm{E}-04 \\
183.6\end{array}$ & $\begin{array}{c}1.4 \mathrm{E}-04 \\
190.8\end{array}$ & $\begin{array}{c}9.6 \mathrm{E}-05 \\
181.0\end{array}$ & $\begin{array}{c}4.7 \mathrm{E}-05 \\
189.0\end{array}$ & $\begin{array}{c}1.2 \mathrm{E}-03 \\
907.2\end{array}$ \\
\hline 18998.12 & $\begin{array}{c}7.0 \mathrm{E}-04 \\
195.5\end{array}$ & $\begin{array}{c}5.7 \mathrm{E}-04 \\
191.8\end{array}$ & $\begin{array}{c}3.1 \mathrm{E}-04 \\
184.2\end{array}$ & $\begin{array}{c}2.3 \mathrm{E}-04 \\
195.5\end{array}$ & $\begin{array}{c}1.5 \mathrm{E}-04 \\
199.3\end{array}$ & $\begin{array}{r}8.8 \mathrm{E}-05 \\
191.4\end{array}$ & $\begin{array}{r}4.4 \mathrm{E}-05 \\
190.0\end{array}$ & $\begin{array}{r}1.4 \mathrm{E}-03 \\
968.4\end{array}$ \\
\hline 19000.41 & $\begin{array}{l}1.3 \mathrm{E}-03 \\
300.8\end{array}$ & $\begin{array}{c}9.9 \mathrm{E}-04 \\
298.9\end{array}$ & $\begin{array}{c}6.7 \mathrm{E}-04 \\
302.7\end{array}$ & $\begin{array}{c}5.7 \mathrm{E}-04 \\
304.6\end{array}$ & $\begin{array}{r}4.4 \mathrm{E}-04 \\
300.8\end{array}$ & $\begin{array}{c}3.0 \mathrm{E}-04 \\
297.0\end{array}$ & $\begin{array}{c}1.1 \mathrm{E}-03 \\
1247.4\end{array}$ & \\
\hline 19000.42 & $\begin{array}{l}1.7 \mathrm{E}-03 \\
231.2\end{array}$ & $\begin{array}{c}1.3 \mathrm{E}-03 \\
229.4\end{array}$ & $\begin{array}{c}1.0 \mathrm{E}-03 \\
227.5\end{array}$ & $\begin{array}{c}7.8 \mathrm{E}-04 \\
231.2\end{array}$ & $\begin{array}{c}5.9 \mathrm{E}-04 \\
235.0\end{array}$ & $\begin{array}{c}3.5 \mathrm{E}-04 \\
238.8\end{array}$ & $\begin{array}{c}1.7 \mathrm{E}-04 \\
233.1\end{array}$ & $\begin{array}{c}9.8 \mathrm{E}-03 \\
1235.5\end{array}$ \\
\hline 19010.31 & $\begin{array}{c}8.6 \mathrm{E}-04 \\
167.3\end{array}$ & $\begin{array}{c}7.2 \mathrm{E}-04 \\
161.7\end{array}$ & $\begin{array}{c}5.3 \mathrm{E}-04 \\
171.1\end{array}$ & $\begin{array}{c}2.4 \mathrm{E}-04 \\
169.2\end{array}$ & $\begin{array}{c}2.4 \mathrm{E}-04 \\
174.8\end{array}$ & $\begin{array}{c}1.9 \mathrm{E}-04 \\
165.4\end{array}$ & $\begin{array}{c}6.5 \mathrm{E}-04 \\
711.2\end{array}$ & \\
\hline 19010.32 & $\begin{array}{c}8.5 \mathrm{E}-04 \\
172.9\end{array}$ & $\begin{array}{c}5.7 \mathrm{E}-04 \\
178.6\end{array}$ & $\begin{array}{c}3.5 \mathrm{E}-04 \\
171.1\end{array}$ & $\begin{array}{c}3.0 \mathrm{E}-04 \\
167.3\end{array}$ & $\begin{array}{c}2.3 \mathrm{E}-04 \\
172.9\end{array}$ & $\begin{array}{c}1.9 \mathrm{E}-04 \\
169.2\end{array}$ & $\begin{array}{c}1.7 \mathrm{E}-04 \\
174.8\end{array}$ & $\begin{array}{c}6.8 \mathrm{E}-03 \\
856.7\end{array}$ \\
\hline 19048.1 & $\begin{array}{c}2.0 \mathrm{E}-03 \\
221.8\end{array}$ & $\begin{array}{c}1.9 \mathrm{E}-03 \\
223.7\end{array}$ & $\begin{array}{c}1.9 \mathrm{E}-03 \\
218.1\end{array}$ & $\begin{array}{c}1.8 \mathrm{E}-03 \\
219.9\end{array}$ & $\begin{array}{c}1.6 \mathrm{E}-03 \\
225.6\end{array}$ & $\begin{array}{c}1.0 \mathrm{E}-03 \\
223.7\end{array}$ & $\begin{array}{c}9.1 \mathrm{E}-04 \\
221.8\end{array}$ & $\begin{array}{c}8.1 \mathrm{E}-03 \\
842.8\end{array}$ \\
\hline 19048.2 & $\begin{array}{l}1.9 \mathrm{E}-03 \\
233.1\end{array}$ & $\begin{array}{c}1.8 \mathrm{E}-03 \\
235.0\end{array}$ & $\begin{array}{c}1.6 \mathrm{E}-03 \\
238.8\end{array}$ & $\begin{array}{c}1.6 \mathrm{E}-03 \\
231.2\end{array}$ & $\begin{array}{c}1.5 \mathrm{E}-03 \\
227.5\end{array}$ & $\begin{array}{r}1.1 \mathrm{E}-03 \\
229.4\end{array}$ & $\begin{array}{c}2.9 \mathrm{E}-02 \\
1055.2\end{array}$ & \\
\hline 19094.21 & $\begin{array}{c}1.7 \mathrm{E}-04 \\
180.5\end{array}$ & $\begin{array}{c}1.5 \mathrm{E}-04 \\
186.1\end{array}$ & $\begin{array}{c}1.3 \mathrm{E}-04 \\
182.4\end{array}$ & $\begin{array}{c}7.9 \mathrm{E}-05 \\
191.7\end{array}$ & $\begin{array}{c}1.0 \mathrm{E}-04 \\
188.0\end{array}$ & $\begin{array}{c}5.1 \mathrm{E}-05 \\
178.6\end{array}$ & $\begin{array}{c}1.9 \mathrm{E}-03 \\
1089.5\end{array}$ & \\
\hline 19094.22 & $\begin{array}{c}1.1 \mathrm{E}-04 \\
193.6\end{array}$ & $\begin{array}{c}9.7 \mathrm{E}-05 \\
188.0\end{array}$ & $\begin{array}{c}5.6 \mathrm{E}-05 \\
191.8\end{array}$ & $\begin{array}{c}1.2 \mathrm{E}-04 \\
180.5\end{array}$ & $\begin{array}{c}1.2 \mathrm{E}-04 \\
184.2\end{array}$ & $\begin{array}{c}1.1 \mathrm{E}-04 \\
195.5\end{array}$ & $\begin{array}{c}2.2 \mathrm{E}-03 \\
938.5\end{array}$ & \\
\hline
\end{tabular}

Magnetisation units $\mathrm{Am}^{-1}$

Volume Susceptibility $\left(\begin{array}{ll}x & 10^{-3}\end{array}\right)$. 
Remanence measurements were rejected for the temperatures at which volume susceptibilities increased.

\subsubsection{Thermal Demagnetisation: Results}

Thermal demagnetisation proved effective in removing secondary magnetisations at temperatures between $200^{\circ} \mathrm{C}$ and $320^{\circ} \mathrm{C}$ (Appendix 6). However the unambigious identification, from Zijderveld plots, of a primary magnetisation with both normal and reversed polarity directions, is recognised in only seven of the sixteen pilot specimens. These specimens show ideal linear decay of the horizontal and vertical components (Fig. 4.2) to the origin (Zijderveld 1967) and have well defined end-points. Two of these specimens, having reversed NRM directions, retain a clockwise deviation from the geomagnetic axial dipole in a reversed direction during demagnetisation to temperatures of $300^{\circ} \mathrm{C}$ and $320^{\circ} \mathrm{C}$ (Fig. $4.2 \mathrm{e}, \mathrm{f}$ ). This is inferred to represent a real primary direction and not a partially uncleaned overprint. The same deviation is recognised in the one specimen with a normal NRM direction and a subsequent reversed direction upon demagnetisation (Fig. $4.2 \mathrm{~g}$ ) and is interpreted in a similar manner. Remanent directions of all seven specimens show this deviation (Fig. 4.2). It is only the presence of the three reversed specimens which confirms that the magnetisation is primary and not an uncleaned hard secondary magnetisation.

A further eight of the sixteen pilot specimens (Fig. 4.3) show non-ideal linear decay during demagnetisation of the horizontal and vertical components on the Zijderveld plots. Consequently from Zijderveld plots, the primary magnetisation of these specimens could not be identified. However, these specimens are interpretated as being or very close to the primary remanent direction, based on 1) the presence of reversed remanent directions above the $200^{\circ} \mathrm{C}$ demagnetisation temperature, 2) the close proximity of these reversed directions to the reversed directions in specimens exhibiting linear decay to the Zijderveld origin, and 3) the close proximity of normal directions to the normal directions in specimens exhibiting linear decay to the Zijderveld origin (Fig. 4.4).

Demagnetisation temperatures at which the primary magnetisation is recognised varies within these fourteen specimens. The primary magnetisation of specimen 19094.21 (Fig. $4.2 \mathrm{~g}$ ) is not recognised until the $250^{\circ} \mathrm{C}$ demagnetisation temperature, whereas the primary magnetisation of specimens 19048.1 and 19048.4 (Fig. 4.2 e,f) is the respective NRM directions. The variation of the temperature at which the primary magnetisation is revealed is interpretated as resulting from the varying degrees of 


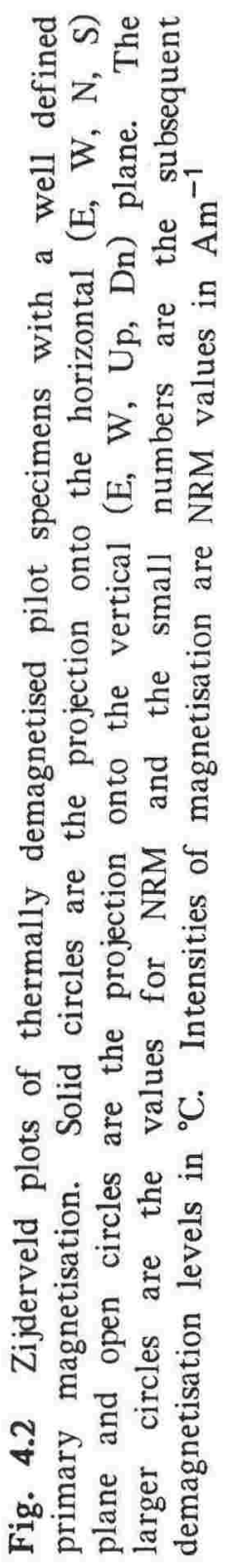



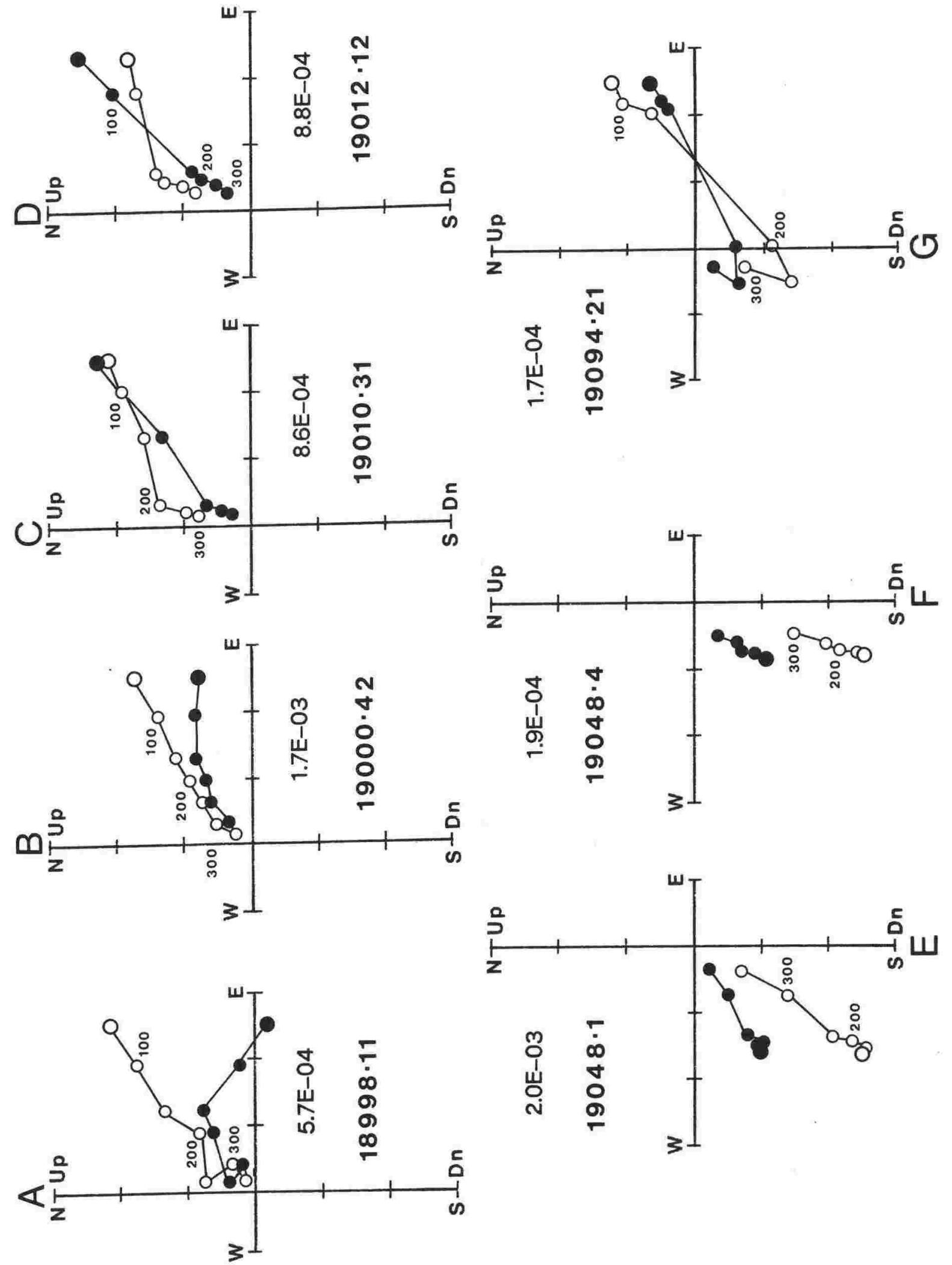
$-69 f-$

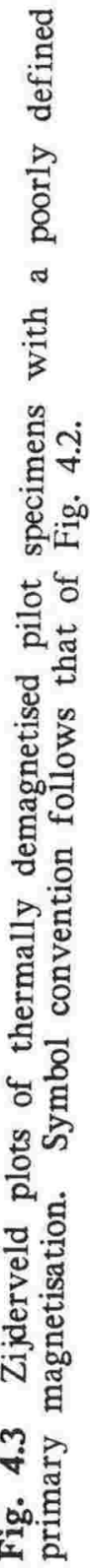



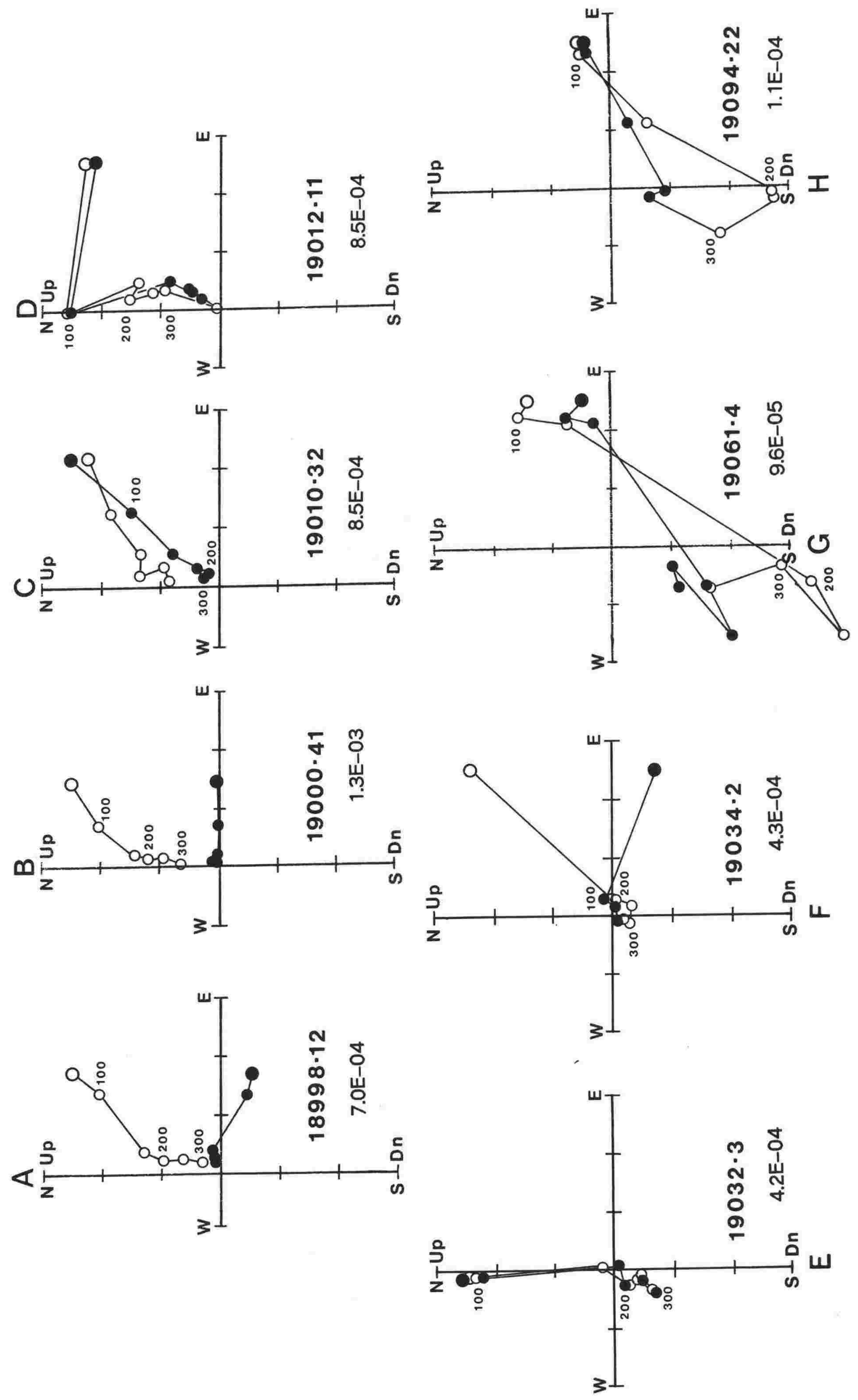


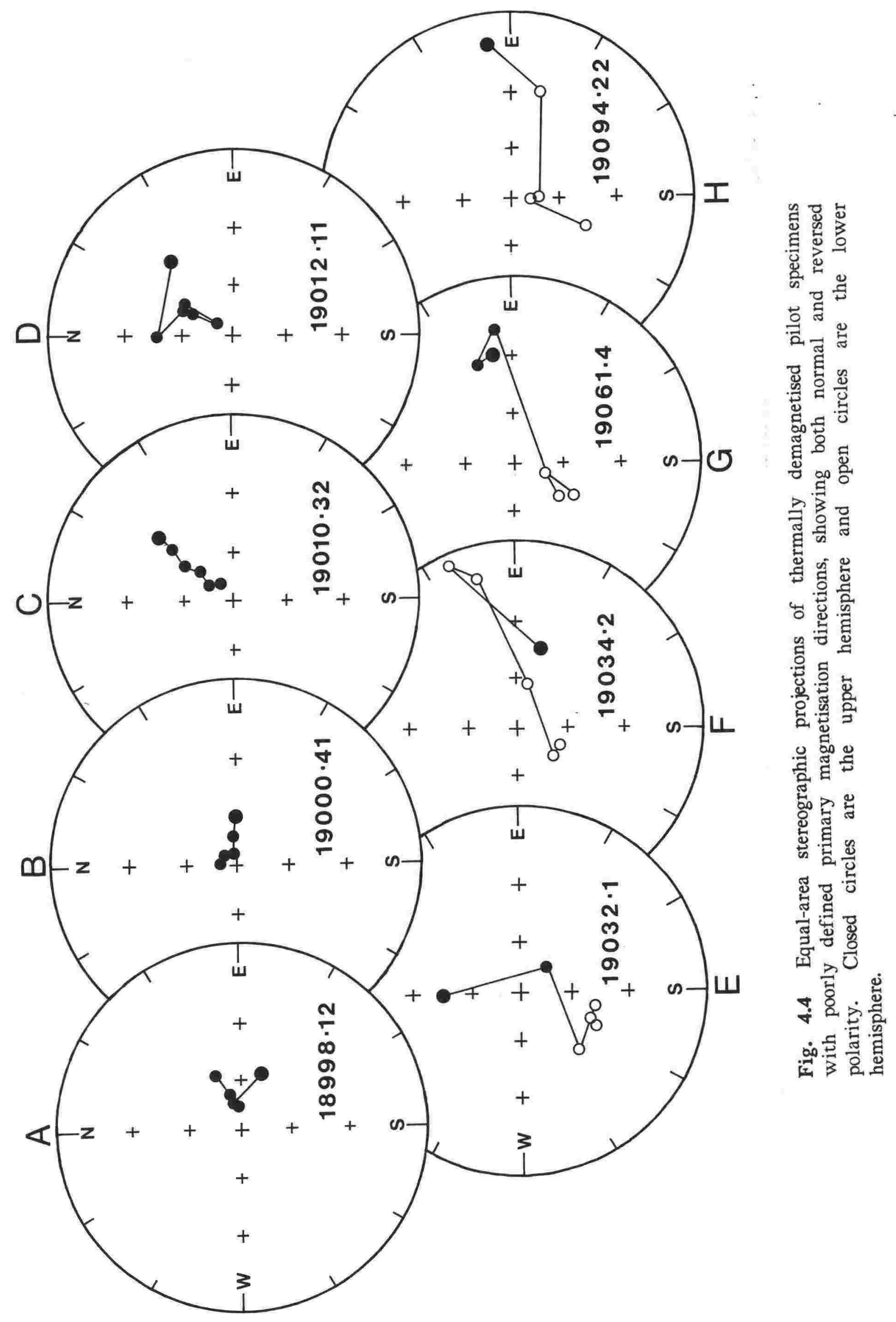




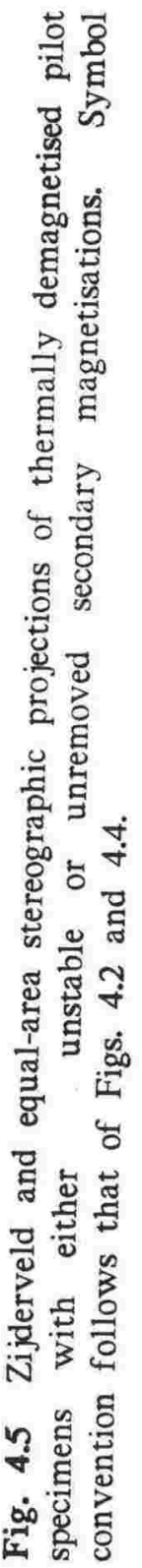



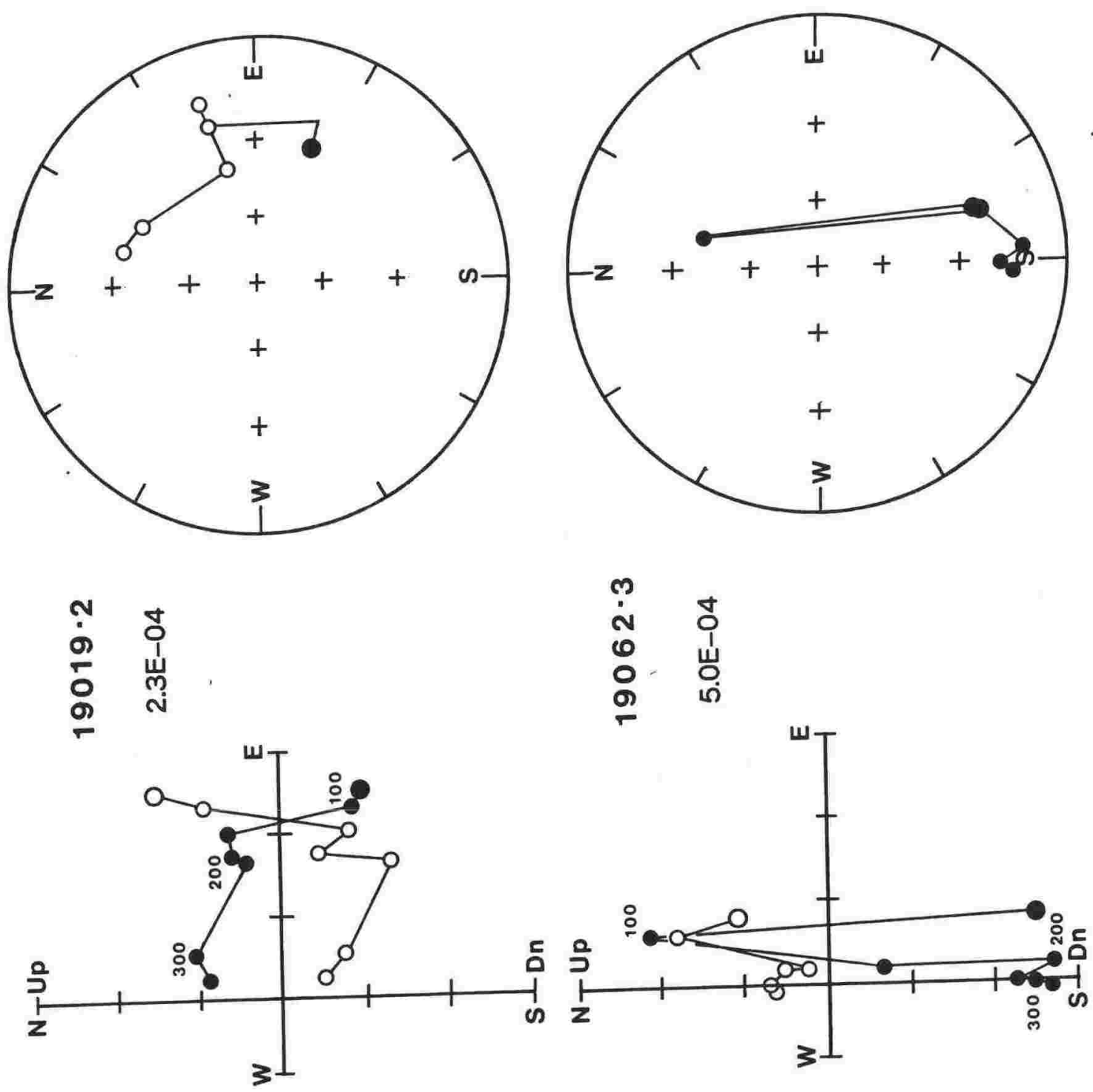

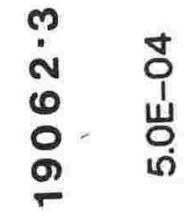

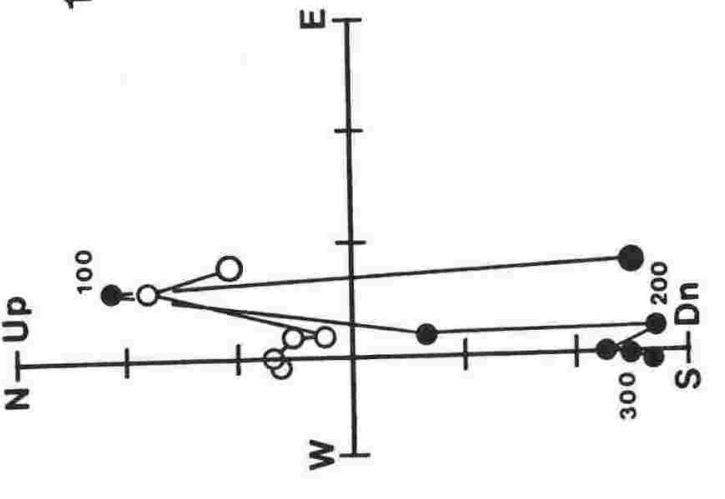


overlap of the blocking temperatures of the primary and secondary magnetisations. Specimens without a secondary magnetisation have no overlap of the blocking temperatures of the primary and secondary magnetisations and consequently the primary component can be recognised at NRM measurements. In contrast, specimens with hard secondary magnetisations where the blocking temperature almost completely overlaps that of the primary magnetisation, require higher demagnetisation temperatures for removal of the secondary magnetisations. In most specimens the primary magnetisation is recognised at temperatures of $200^{\circ} \mathrm{C}$ and above.

The remaining two specimens show neither stable demagnetisation behaviour nor normal or reversed polarity directions (Fig. 4.5) at temperatures of $300^{\circ} \mathrm{C}$. These specimens are magnetically unstable and a primary magnetisation can not be recognised.

It is concluded that:

1. Thermal demagnetisation is effective in removing secondary magnetisations.

2. Unambiguous identification of a primary magnetisation as indicated by ideal linear decay to the origin of Zijderveld plots is recognised within only half of the pilot specimens.

3. A hard and stable magnetisation which exhibits non-ideal linear decay to the Zijderveld origin is also recognised, having either normal or reversed polarity and thus is inferred to be the primary magnetisation.

4. The secondary magnetisations have variable blocking temperatures and consequently the primary magnetisation is recognised at a range of temperatures above $200^{\circ} \mathrm{C}$.

5. The removed secondary magnetisations are normal in polarity and have similiar directions, but are not specifically related to the present day geomagnetic field direction.

\subsection{AF DEMAGNETISATION}

\subsubsection{Introduction}

Alternating field (AF) demagnetisation of New Zealand Cenozoic sediments, although successful (Kennett et al. 1971; Mumme and Walcott 1985) has been restricted. At Victoria University the main problem, until recently (Christoffel pers. comm. 1985) has been incoherent data, especially at higher fields, resulting from the suspected acquisition of spurious magnetisations during $\mathrm{AF}$ cleaning with the available equipment. The successful AF cleaning programmes used peak alternating fields of $5 \mathrm{mT}$ to $30 \mathrm{mT}$ (Kennett et al. 1971; Mumme and Walcott 1985). 


\subsubsection{Techniques}

A $19 \mathrm{~cm}$ long solenoid within three orthogonal pairs of square coils one metre in length, with a residual field of less than $30 \mathrm{nT}$, was used for all AF demagnetisation. The multi-layered solenoid (2936 turns) was powered by a series tuned $50 \mathrm{~Hz}$ mains supply. Sixteen pilot specimens were demagnetised along the three orthogonal specimen axes at $5 \mathrm{mT}$ increments up to a peak alternating field of $35 \mathrm{mT}$. At progressively higher fields the decay period (ramp time) was increased. Specimens were stored in a Mumetal shield before remanence measurements.

\subsubsection{AF Demagnetisation: Results}

AF demagnetisation was ineffective in removing a secondary magnetisation aligned in a normal polarity direction and consequently a primary magnetisation was recognised in only four of the sixteen pilot specimens (Appendix 7). Two of the specimens, where the primary magnetisation was recognised, have reversed polarity NRM directions and have stable directions during demagnetisation (Fig. 4.6 a,b). However the primary magnetisation of these two specimens, as indicated by linear decay of the vertical and horizontal components of the Zijderveld plot, is not identified until peak alternating fields of 30 to $35 \mathrm{mT}$. At $40 \mathrm{mT}$ the remaining remanent intensities were below 1.5 $\mathrm{x} 10^{-5} \mathrm{Am}^{-1}$ and thus unmeasurable, indicating the coercivity spectra of the primary magnetisation is between 30 and $40 \mathrm{mT}$. The clockwise deviation from the geomagnetic axial dipole of the two reversed specimens is the same as recognised by thermal demagnetisation and is again interpreted as being a real primary direction. The other two specimens although normal in polarity show linear decay to the Zijderveld origin, having a marked decrease in intensity at peak fields of 30 and 35 $\mathrm{mT}$, and their magnetisation is interpretated as being primary (Fig. 4.6). The near zero magnetic intensity of the two specimens at fields of 30 and $35 \mathrm{mT}$ is consistent with the inference, from the reversed specimens, that the coercivity spectra of the primary magnetisation is between 30 and $40 \mathrm{mT}$.

A further eight AF pilot specimens have an inferred reversed primary magnetisation with an incompletely removed normal overprint, even at peak alternating fields of $35 \mathrm{mT}$, above which the remaining remanence is too weak to measure. Zijderveld plots reveal similiar changes of both the vertical and horizontal components during demagnetisation (Fig. 4.7), but decay to the origin is not linear. Stereographic projections (Fig. 4.8) clearly show a change of declination from normal directions at $\mathrm{NRM}$, to reversed directions at 30 to $35 \mathrm{mT}$, matched by a shallowing of the negative 


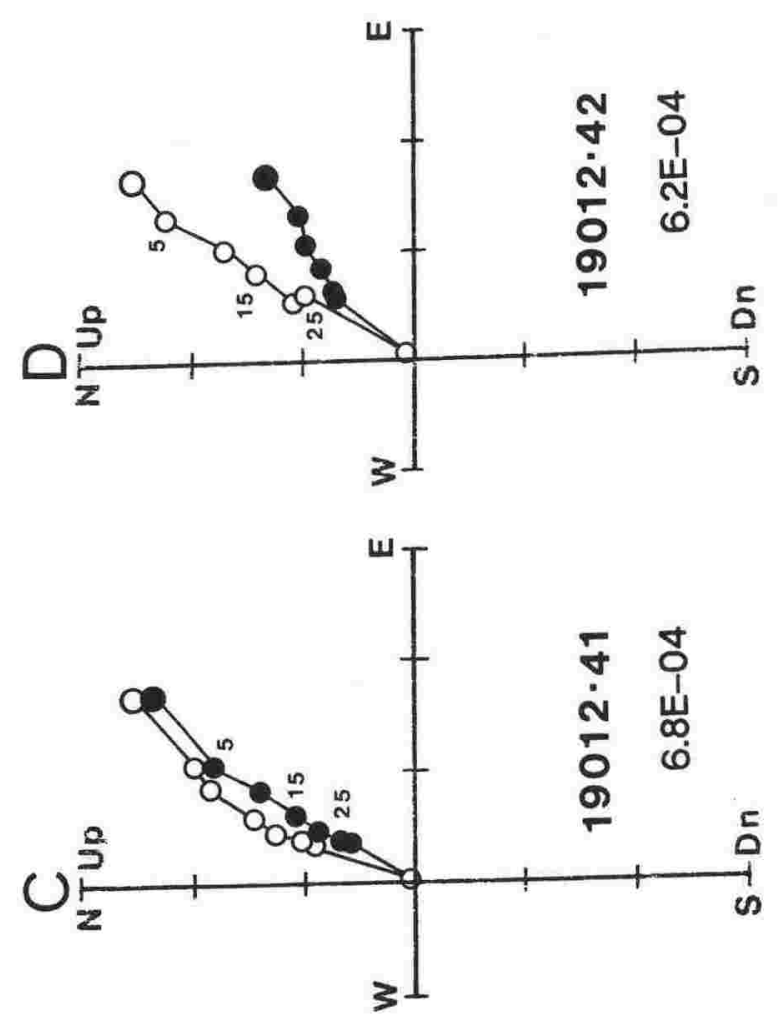

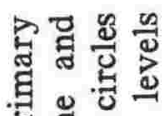

हี สี

o 20

匀尔

Z゙ 壳

हैं है

๙ เ્પी

곤

동형

औ.

हू

迢势

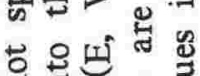

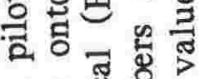

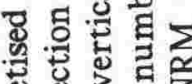

通学告

연연 클

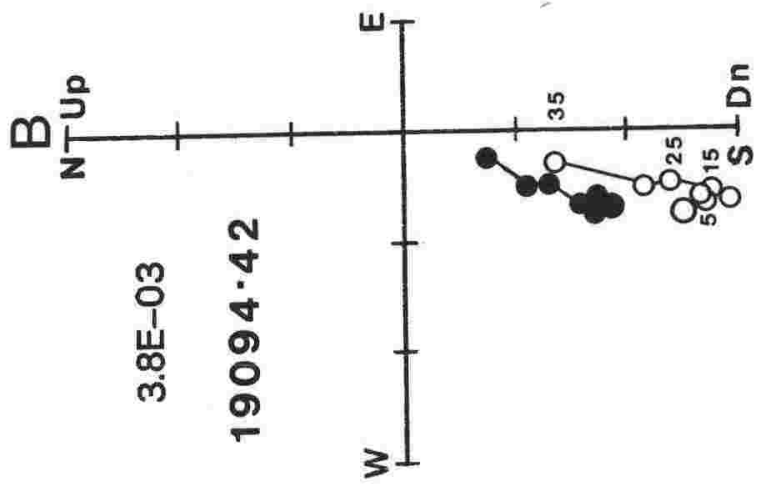

용

4 ฐิ

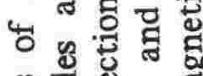
옹 은 学

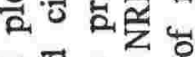
믕 긍 홍 홍 造 鬲岛

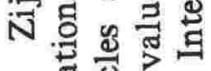
ช

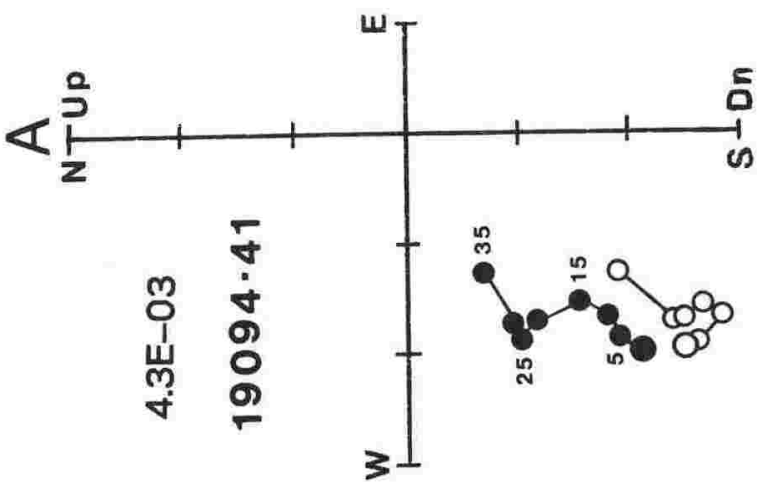

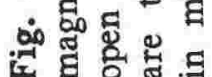




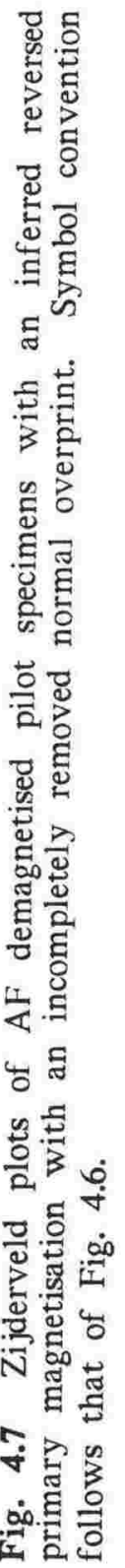



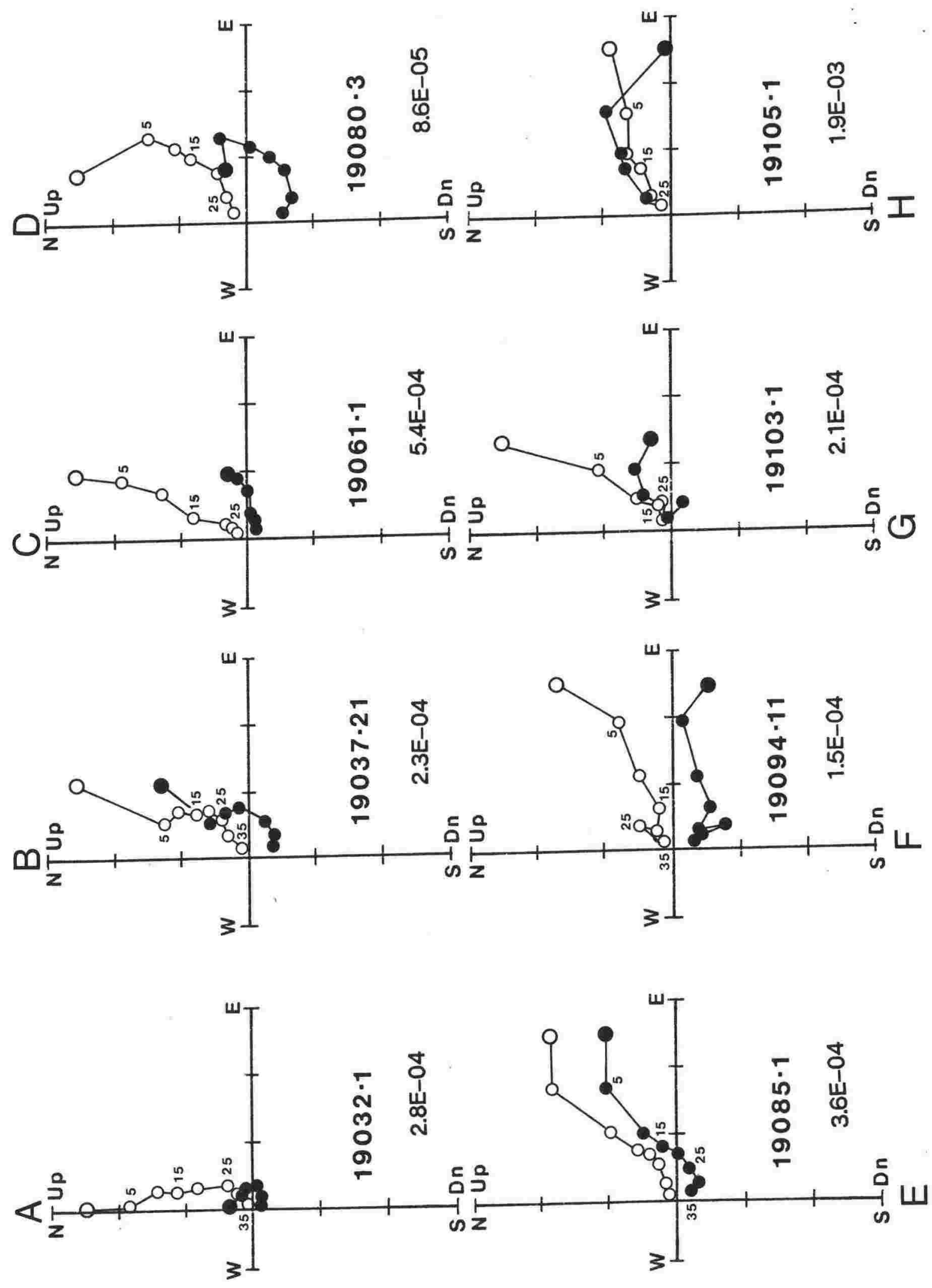
$-76 f-$

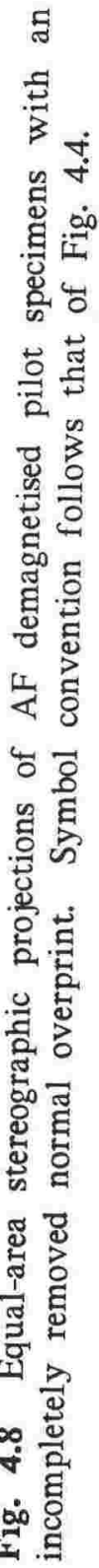




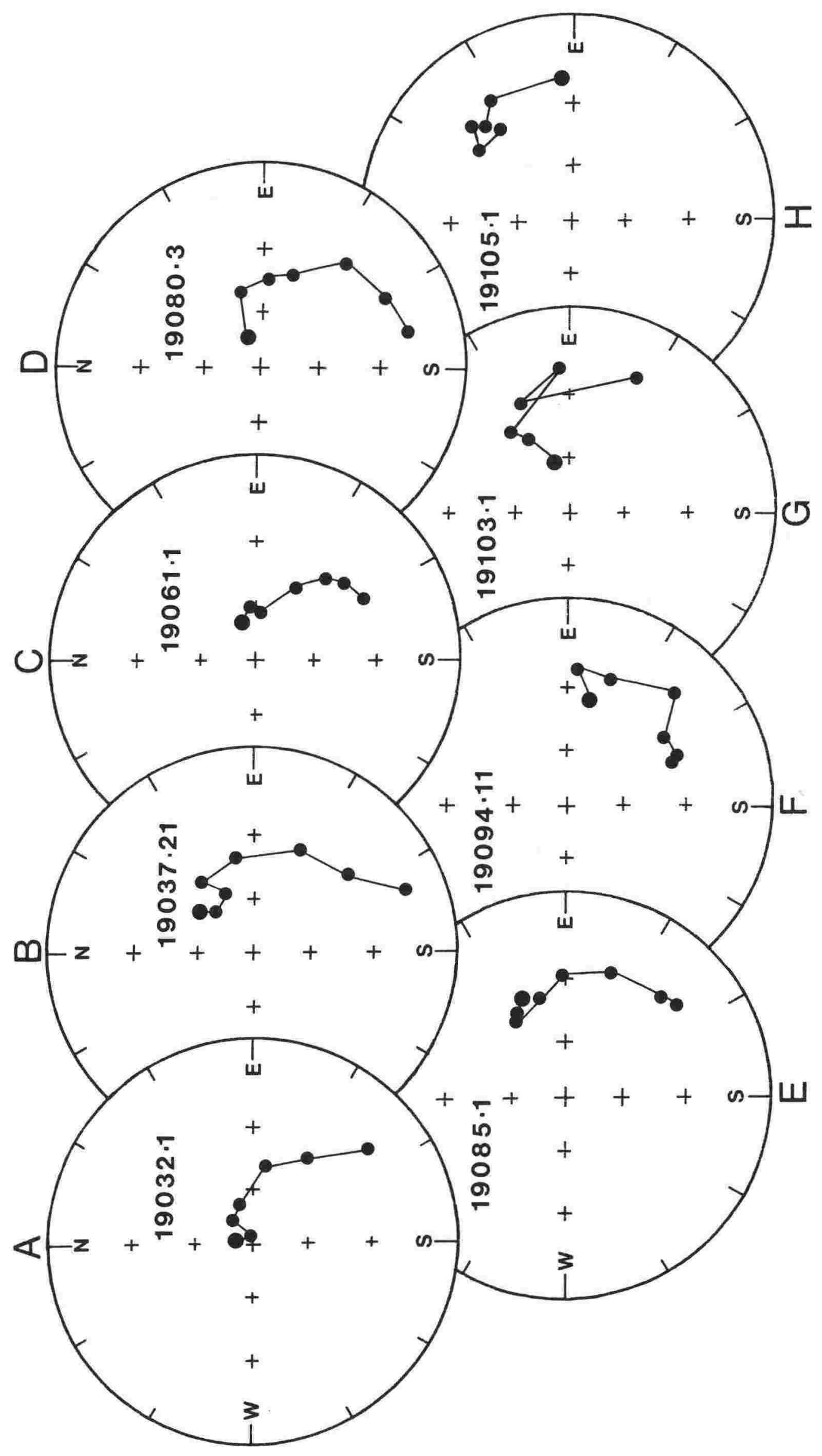


inclinations. This is interpretated as movement towards a reversed direction, as in the two reversed AF specimens, but the secondary overprint is not entirely removed before the specimens become unmeasurable. This indicates that part of the coercivity spectra of the secondary magnetisation is also between 30 and $35 \mathrm{mT}$, matching that of the primary magnetisation, and consequently the primary magnetisation can not be resolved. The partially removed secondary magnetisation, up to fields of $35 \mathrm{mT}$, has a normal direction (Fig. 4.9), but again is not specifically related to the present day field direction.

The four remaining AF pilot specimens show neither stable demagnetisation behaviour nor normal or reversed polarity directions (Fig. 4.10) even at a peak alternating field of $35 \mathrm{mT}$. These specimens are magnetically unstable and the primary magnetisation can not be recognised.

It is concluded that:

1. The primary magnetisation can not be routinely identified with AF demagnetisation.

2. The coercivity spectra of the primary and secondary magnetisations overlap even at a peak alternating field of $35 \mathrm{mT}$.

3. At fields above $35 \mathrm{mT}$ the intensity of the residual remanent magnetisation is less than $1.5 \times 10^{-5} \mathrm{Am}^{-1}$ (the accepted noise level of the cryogenic magnetometer in this study) and unmeasurable.

4. The partially removed secondary magnetisations are normal in polarity, and have similiar directions, but are not specifically related to the present day geomagnetic field direction.

\subsection{COMPARISON OF THERMAL AND AF DEMAGNETISATION}

Theoretical studies (Wilson and Smith 1968; Dunlop 1969, 1973; Biquand and Prevort 1971) predict that a viscous magnetisation (VRM) is more effectively removed by - 


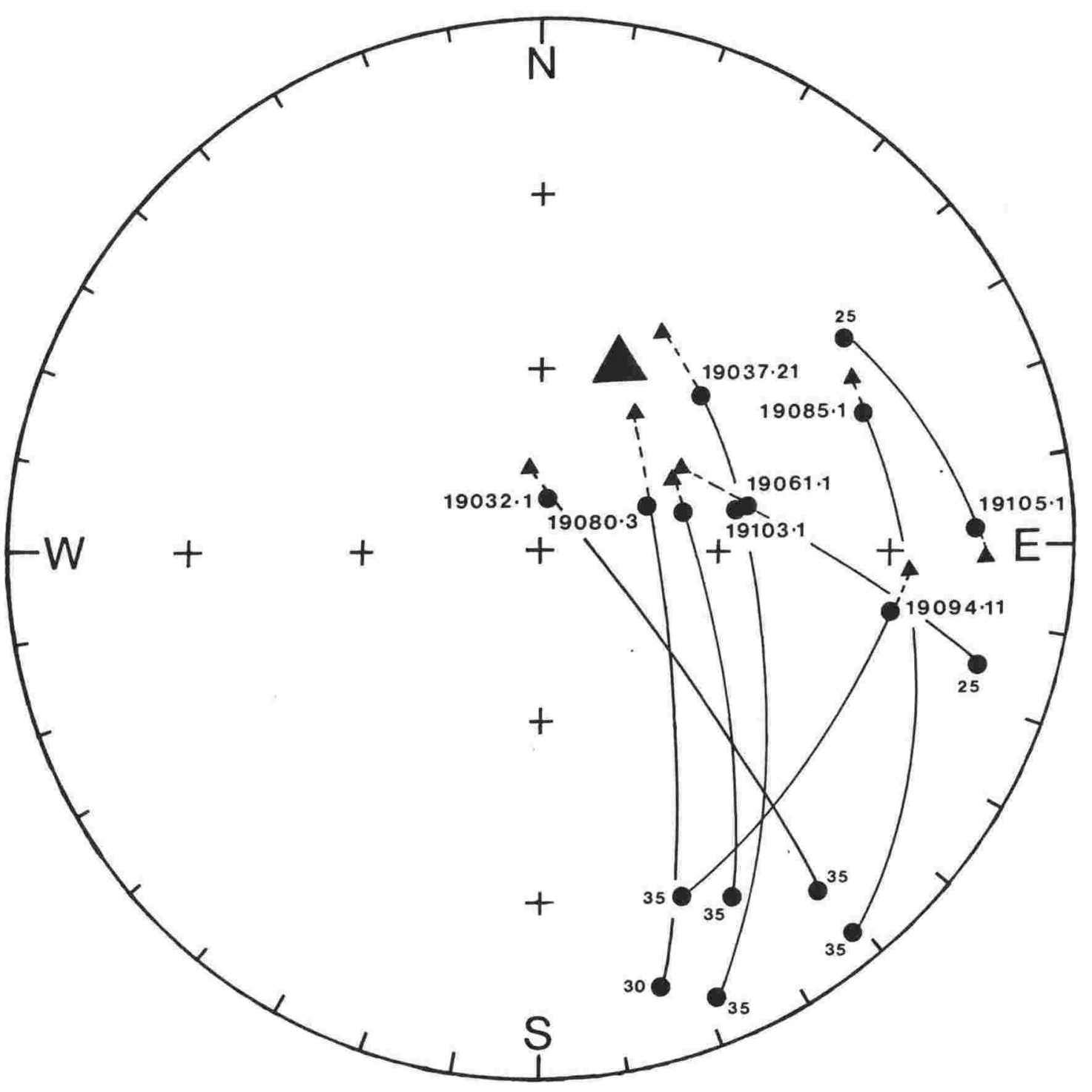

Fig. 4.9 Equal-area stereographic projection of removed components from AF demagnetised pilot specimens with an incompletely removed normal overprint. Specimen numbers are referenced to NRM directions. Circles with small numbers are the directions at the respective peak alternating fields in $\mathrm{mT}$. Small triangles are the directions of the removed magnetisation to the respective peak alternating fields. Large triangle is present day geomagnetic field direction. 


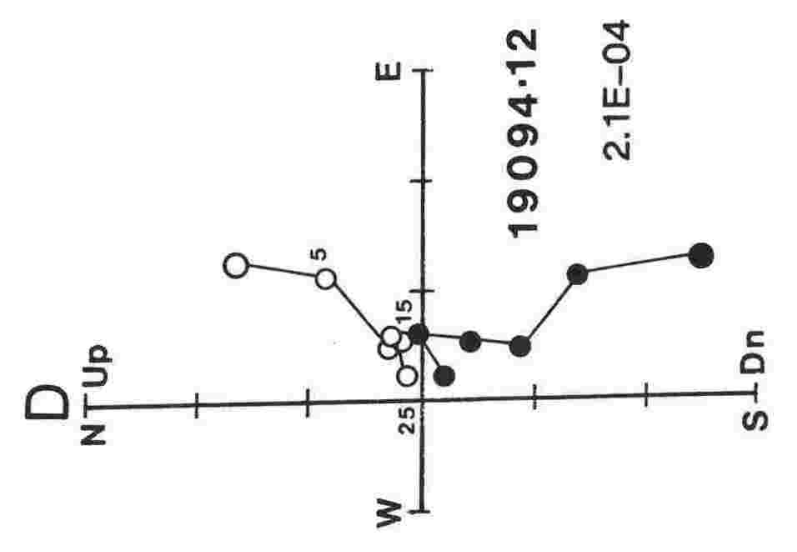

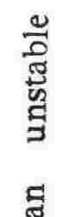

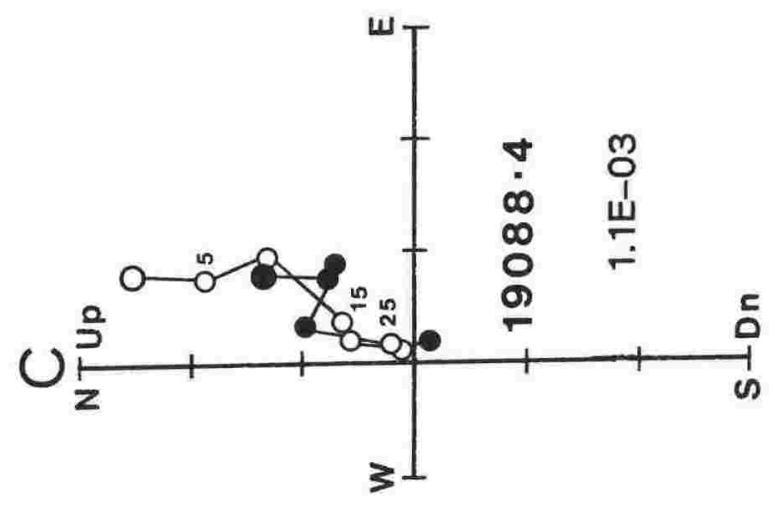

㔛

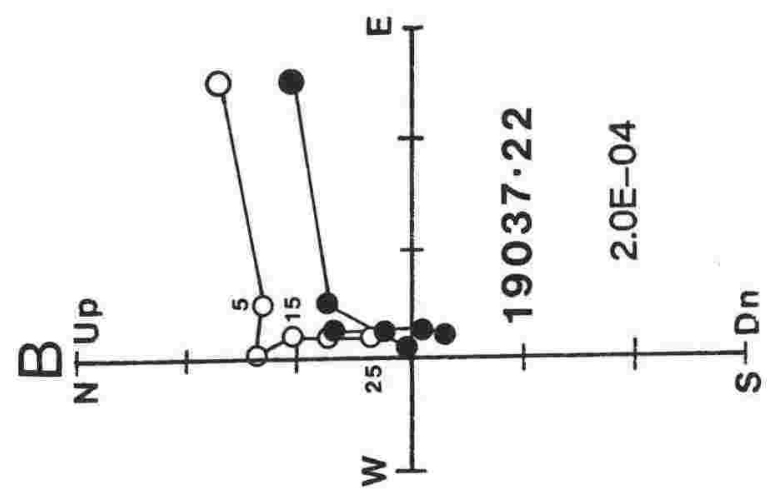

हू.

喜守

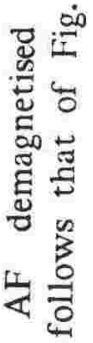

प्山े 흐

을

을 ह

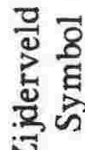

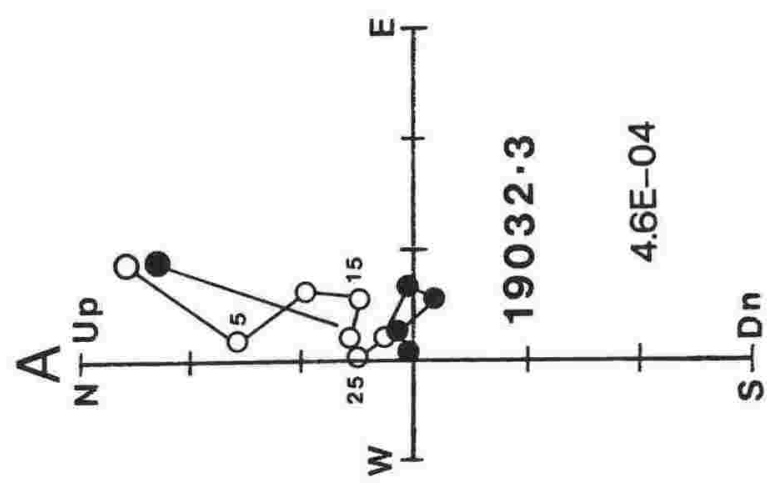

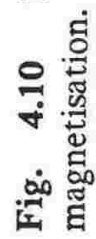




$$
\begin{aligned}
& H_{C}=\text { coercive force } \\
& Q=23.7
\end{aligned}
$$

as shown by the VRM acquisition curves of Fig. 4.11a at $t_{\ominus}$ to $t_{3}$

The unblocking curves of any subsequent zero-field demagnetisation coincide with the original blocking curves and the VRM decays logarithmically. Thermal demagnetisation of a VRM has unblocking curves also obeying the above equation, and is analogous to viscous decay (Dunlop 1973) as defined by:

$$
\frac{\partial \mathrm{J}_{\mathrm{r}}}{\partial \log t_{\mathrm{d}}} / \frac{\partial \mathrm{J}_{\mathrm{r}}}{\partial \mathrm{T}}=\frac{\mathrm{T}_{\theta}}{\mathrm{Q}+\log t_{\theta}}
$$

where

$$
\begin{aligned}
& \mathrm{J}_{\mathrm{r}}=\text { remanent magnetisation } \\
& t_{\mathrm{d}}=\text { decay time }
\end{aligned}
$$

Thus the blocking/unblocking curves for a VRM (Fig. 4.11a) are the same with either the influence of time $(t)$ or temperature $(T)$. Consequently thermal demagnetisation is efficient in removing VRM's. In contrast to viscous decay or thermal demagnetisation, unblocking curves representing $\mathrm{AF}$ demagnetisation at increasing peak fields have a different form (Fig. 4.11b). During AF demagnetisation the largest grains are demagnetised first leaving a VRM within the smaller grains as a resistent magnetisation. Higher AF peak fields are required to remove this resistant VRM. Field studies have also shown a VRM to be more effectively removed by thermal than AF demagnetisation (Ouliac 1976).

Direct comparison of thermally and AF demagnetised pilot specimens from the Mangapoike data demonstrate that VRM's are removed by thermal demagnetisation but not AF demagnetisation. Reversed remanent directions of four thermal pilot specimens from three sites are resolved at $200^{\circ} \mathrm{C}$ and above (Fig. $4.12 \mathrm{e}-\mathrm{h}$ ), but are not found in specimens from the same three sites (Fig. 4.12 a-d) following AF demagnetisation to peak fields of $35 \mathrm{mT}$. The blocking temperatures of the primary and secondary magnetisation are therefore partially overlapping, whereas the coercivities are completely × overlapping. 

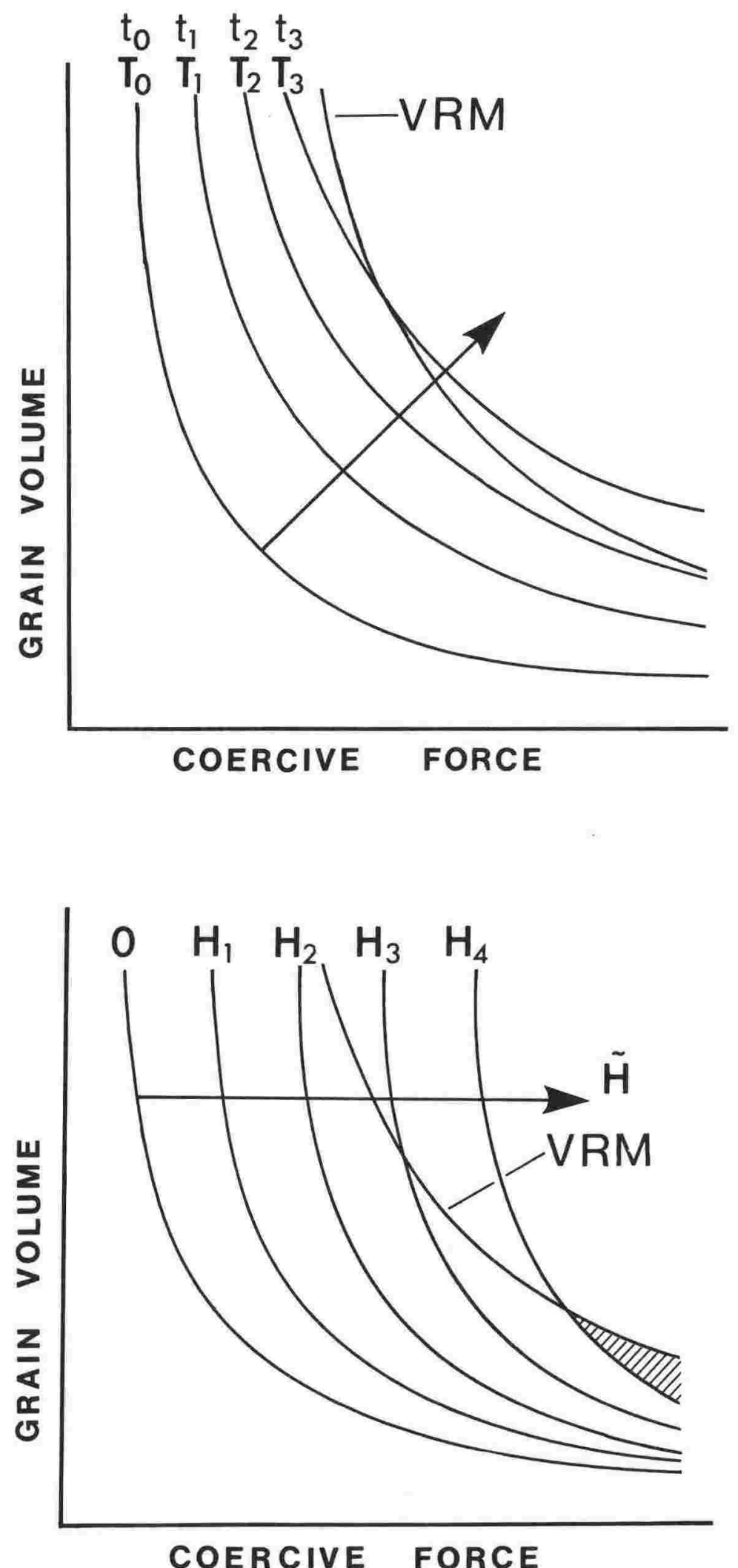

Fig. 4.11 Theoretical blocking/unblocking curves of a VRM under the influence of either thermal or AF demagnetisation. Unblocking curves under the influence of either time $(t)$ or temperature $(\mathrm{T})$ are the same, whereas the unblocking curves with an increasing coercive force $(H)$ are different. Shaded area is the resistant VRM fraction unremoved by AF demagnetisation. 


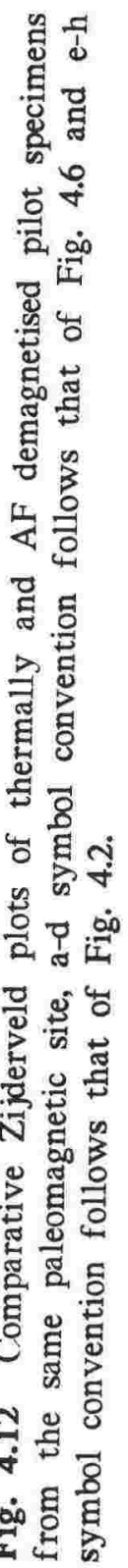



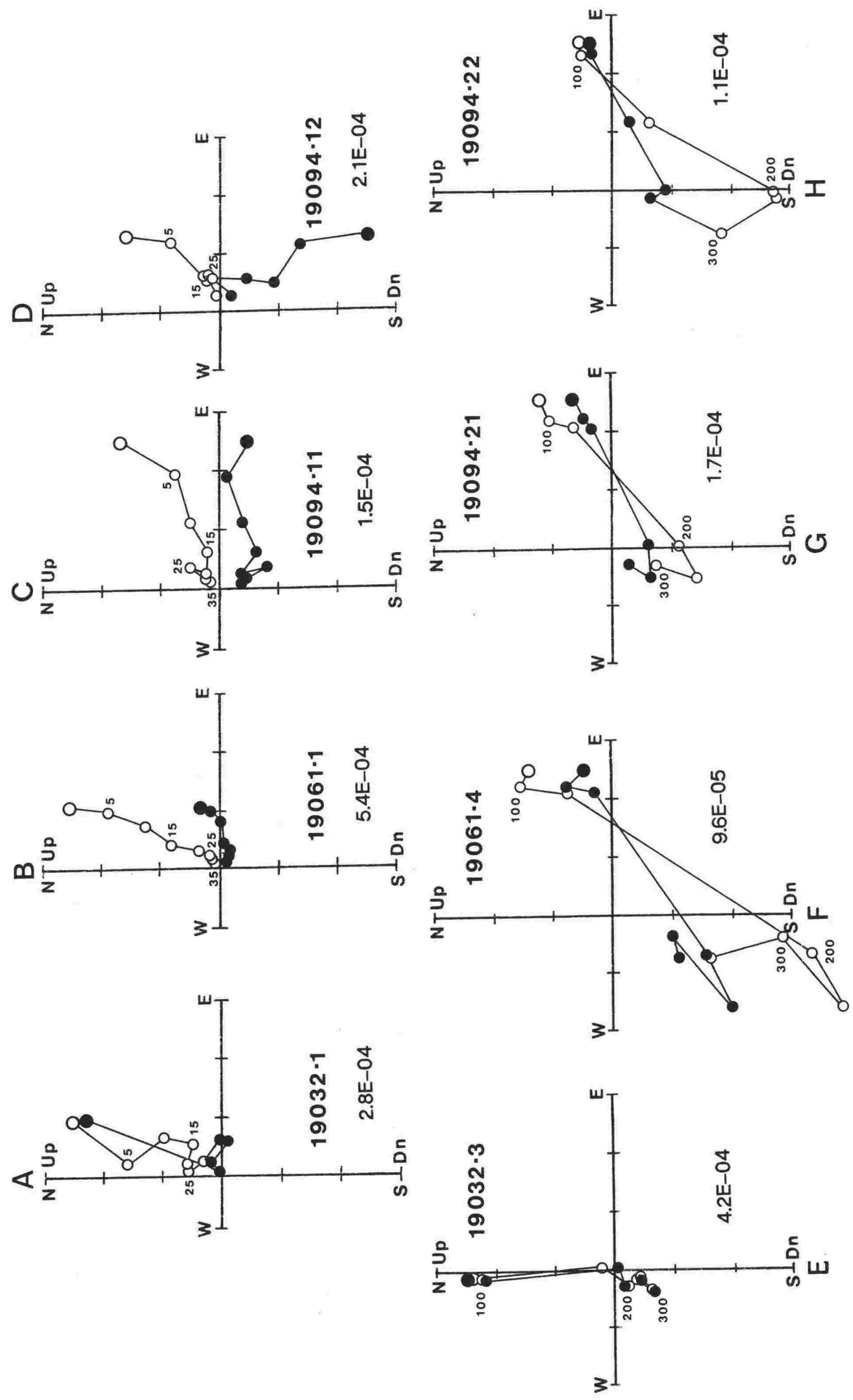


\subsection{GENERAL DEMAGNETISATION}

\subsubsection{General Techniques}

Since thermal demagnetisation was the only method capable of removing secondary magnetisations in the Mangapoike specimens, and thus allowing identification of the primary magnetisation, it was used for general demagnetisation of all remaining 1168 specimens (Appendix 8). The remanence of all specimens was measured at a minimum of three of the $200^{\circ} \mathrm{C}, 250^{\circ} \mathrm{C}, 300^{\circ} \mathrm{C}$ and $320^{\circ} \mathrm{C}$ demagnetisation temperatures. After remanence measurement, at the $300^{\circ} \mathrm{C}$ and $320^{\circ} \mathrm{C}$ temperatures, volume susceptibility was measured in order to detect mineralogical alteration: remanence measurements were discarded when a greater than $50 \%$ increase of volume susceptibility was recorded.

\subsubsection{Selection of Representative Direction}

A range of selection procedures exists to determine a representative direction from a suite of demagnetisation data. Vector diagrams (Zijderveld 1967; Dunlop 1979) remagnetisation circles (Halls 1976, 1978) vector substraction (Roy and Park 1974; Hoffman and Day 1978; Stuparsky and Symons 1978) stability indices (Tarling and Symons 1967; Briden 1972; Symons and Stuparsky 1974; Giddings and McElhinny 1976; Lowrie and Alvarez 1977) and minimum in-site dispersion have all been used to extract representative directions. Previous studies in New Zealand Cenozoic sediments have used either in-site dispersion (Kennett et al. 1971; Lienert et al. 1972; Kennett and Watkins 1974), Zijderveld plots (Walcott et al. 1981) or stability indices (Walcott and Mumme 1982; Mumme and Walcott 1985).

A two-level method using Zijderveld plots and the stability index of Lowrie and Alvarez (1977) proved effective here. Firstly the Zijderveld plot for each specimen was examined to identify the primary magnetisation indicated by linear decay of the horizontal and vertical components to the origin (Zijderveld 1967). The stability index of Lowrie and Alvarez (1977) was used to select an optimum direction from those specimens where linear decay of the primary component to the origin of the Zijderveld plot could not be demonstrated because of large secondary components or ill-defined endpoints. The Lowrie - Alvarez index defines the angle between two successive demagnetised remanent directions $i$ and $j$ as

$$
\delta \theta=\cos ^{-1}\left(l_{\mathrm{i}} l_{\mathrm{j}}+m_{\mathrm{i}} m_{\mathrm{j}}+n_{\mathrm{i}} n_{\mathrm{j}}\right) \text {. }
$$

where the direction cosines are

$$
\begin{aligned}
l & =\cos D \cos I \\
m & =\sin D \cos I
\end{aligned}
$$




$$
n=\sin I
$$

The angle $(\delta \theta)$ was divided by the increment of the demagnetising temperature $(\delta \mathrm{T})$ to obtain the average angular rate of change during the demagnetisation step. The optimum direction was the highest increment of two successive directions where $(\delta \theta / \delta \mathrm{T})$ is a minimum. Specimens with $(\delta \theta / \delta \mathrm{T})$ greater than $1^{\circ} / 1.5^{\circ} \mathrm{C}$ above the $200^{\circ} \mathrm{C}$ demagnetisation temperature were rejected from the analysis.

Since the temperature varies at which the primary magnetisation is recognised, as shown by the pilot specimens, it is expected the optimum temperature for general demagnetisation will also vary. Differences in the selected demagnetisation temperature were thus accepted, even within the same site or core. Selection of data from different demagnetisation levels within samples has been used elsewhere in paleomagnetism (Lowrie and Alvarez 1977).

Site means were calculated using Fisher statistics (Fisher 1953) from specimens accepted on the above criteria (Appendix 9). Those sites with less than three specimens were rejected from the analysis.

In summary, the following rejection criteria were used in this study:

1. The remanent magnetisation was less than $1.5 \times 10^{-5} \mathrm{Am}^{-1}$

2. The angular difference between normal and invert modes of remanent measurement was greater than $15^{\circ}$.

3. No stability of direction or change of direction where $(\delta \theta / \delta \mathrm{T})$ was greater than $1 \% 1.5^{\circ} \mathrm{C}$.

4. Less than three specimens from each site.

From these criteria, 286 specimens (24\%) were rejected from the final analysis. 


\section{Chapter V \\ MAGNETOZONES AND CORRELATION TO THE MAGNETIC POLARITY TIMESCALE}

\subsection{INTRODUCTION}

This chapter discusses the polarity magnetozones and their correlation with the magnetic polarity timescale.

Section 5.2 reviews various magnetic polarity timescales that have been published and outlines the criteria used to select the Ness et al. (1980) timescale as the best standard for comparison. Section 5.3 discusses the delineation of the magnetozones. A statistical comparison of the observed number of reversals and the expected number of reversals (section 5.5) indicates that all known polarity reversals are recognised. Section 5.4 gives the dated stratigraphic events used to correlate the magnetostratigraphic zones and also describes a previously unrecognised unconformity at Mangapoike River. The effects of bioturbation on the paleomagnetic record are discussed in the final section (5.6) concluding that the detrital magnetisation is acquired about 1000 yrs. after deposition.

\section{2 'STANDARD' MAGNETIC POLARITY TIMESCALE}

During the last 20 years progressive refinement of polarity definition (Cox 1969; Opdyke 1972; Blakely 1974) and of radiometric age determinations (McDougall and Chamalaun 1966; Harrison et al. 1979; McDougall et al. 1984) has led to a succession of slightly different magnetic polarity timescales. Reviews by Watkins (1972), McDougall (1977) and Ness et al. (1980) record the progressive development.

Published magnetic polarity timescales have been established from either radiometrically dated lava successions (McDougall and Tarling 1963; McDougall et al. 1976a; McDougall et al. 1977; Saemundsson et al. 1980; McDougall et al. 1984) or ocean-floor magnetic anomaly profiles with dated calibration points, assuming a constant spreading rate (Heirtzler et al. 1968; Talwani et al. 1971; Blakely and Cox 1972; Cande and LaBrecque 1974; LaBrecque et al. 1977; Mankinen and Dalrymple 1979; Ness et al. 1980) or biostratigraphic, chronostratigraphic and magnetostratigraphic compilations, with radiometrically dated calibration ages (Berggren 1972, 1981, 1984a; Berggren and Van Couvering 1974; Ryan et al. 1974). The various magnetic polarity timescales proposed have resulted in confusion and criticism (Berggren 1981). 
The anomaly derived timescale of Ness et al. (1980) is selected as the standard magnetic polarity timescale for this study for three reasons. Firstly it is empirically derived and is solely a 'magnetochronology' (terminology follows that of Berggren 1984a). It has a minimum number of assumptions and construction steps and hence minimises potential error. The use of a magnetochronologic timescale, as opposed to a timescale which is derived from biostratigraphic, magnetostratigraphic and $\mathrm{K}-\mathrm{Ar}$ data (a 'biomagnetoradiochronology', Berggren 1984a) is preferred here, since it avoids circular arguments. The Ness et al. (1980) timescale has been widely used in magnetostratigraphy (Berggren et al. 1984; Shibata et al. 1984; Nigrini and Lombari 1984; Hornibrook 1984a; Edwards 1985) thus allowing direct correlation to other magnetostratigraphic studies. It is detailed, and provides ages for all recognised reversals.

There is only minor disparity $( \pm 0.10 \mathrm{Ma}$ within the Late Miocene $)$ in age estimates of polarity transitions, when corrected for the new (Steiger and Jager 1977) K-Ar decay constants (cf. Cande and LaBrecque 1974; McDougall et al. 1976a; LaBrecque et al. 1977; McDougall et al. 1977; Mankinen and Dalrymple 1979; Ness et al. 1980; Berggren 1984a; Berggren et al. 1985). Only the recent timescale of McDougall et al. (1984) is different with Late Miocene polarity intervals consistently 1 Ma older. However, for the purposes of correlation in the following chapters, magnetostratigraphic age data based on polarity timescales other than Ness et al. (1980) have been corrected where possible to the Ness et al. (1980) timescale. Presented K-Ar dates have been corrected to the revised decay constants (Steiger and Jager 1977). Those data that could not be corrected to either the Ness et al. (1980) timescale or the new K-Ar decay constants are indicated with an asterix (ie $6.2 * \mathrm{Ma}$ ).

Recently published timescales (Miller et al. 1985; Berggren et al. 1985; Barron et al. 1985) have correlated Anomaly 5 with Chron 11 based on new biostratigraphic magnetostratigraphic studies from South Atlantic DSDP sites (Poore et al. 1984; Hsu et al. 1984; Khan et al. 1985) ) as opposed to the previously accepted correlation of Anomaly 5 with Chron 9 (Ryan et al. 1974; Theyer and Hammond 1974; LaBrecque et al. 1977). This alternative correlation using Anomaly $5=$ Chron 11 (Foster and Opdyke 1970) results in Chrons 7 through to Chron 14 being reassigned with magnetic anomalies; shortening Chron 7 to include only the three normal events of Anomaly 4 (Fig. 5.2). As noted by Barron et al. (1985), adoption of this revised chron - anomaly correlation results in more uniform sedimentation rates during the late Miocene than rates estimated from the traditional timescales in which Anomaly 5 was correlated 
with Chron 9. The ambiguity in using the same numbering with either the Anomaly $5=$ Chron 9 or the Anomaly $5=$ Chron 11 correlation can be circumvented by using the revised chron nomenclature of Tauxe et al. (1983). This nomenclature names chrons from correlative magnetic anomalies which extend from the youngest reversal boundary of one anomaly to the youngest reversal boundary of the next anomaly, and are prefixed with the letter $\mathrm{C}$ : ie Anomaly $6=$ Chron C6. Since a large body of literature exists using the Anomaly $5=$ Chron 9 correlation, this and both the Anomaly $5=$ Chron 11 and the Tauxe et al. (1983) correlations are presented (Fig. 5.2) for ease of reference, however all references within the text will follow the new chron nomenclature of Anomaly $5=$ Chron 11 .

\subsection{MAGNETOZONES}

The polarity magnetozones are clearly defined by the declination and inclination logs (Fig. 5.1). Virtual geomagnetic pole (VGP) latitudes were not required to determine the polarity zones. Each of the magnetozones is designated with the following notation MR1, MN1, MR2, MN2 etc (Fig. 5.1); where MR refers to Mangapoike reversed and MN to Mangapoike normal. They are numbered consecutively upward from the base of the sampled sequence. Magnetozones MR2 and MR3 are each based on only one site, but are considered to represent true geomagnetic polarity zones because they have reversed polarity after demagnetisation. Single reversed specimens are recognised at sites 18991 , 19005, 19018 (686, 805 and $868 \mathrm{~m}$ respectively) and also probably represent reversed magnetic polarity zones, but were rejected from the final analysis on the basis of the previously described criteria (sections 3.5 and 4.5 ).

Only one normal magnetozone (MN6, 1760 to $1880 \mathrm{~m}$, Fig. 5.1) was detected in the stratigraphic interval equivalent to that from which Kennett and Watkins (1974) reported two normal zones designated as C1 and C2. Magnetozone MN6 is correlated with the C2 (lowermost normal) event of Kennett and Watkins (1974) (Fig. 5.2). Their supposed C1 event is based on three low VGP latitudes that are here considered to represent reversed sites with incompletely cleaned normal overprints. Shallow inclinations in some reversed polarity sites of the present study, especially between 1500 and $2156 \mathrm{~m}$, are also attributed to incomplete cleaning of specimens with weak primary magnetisations. 

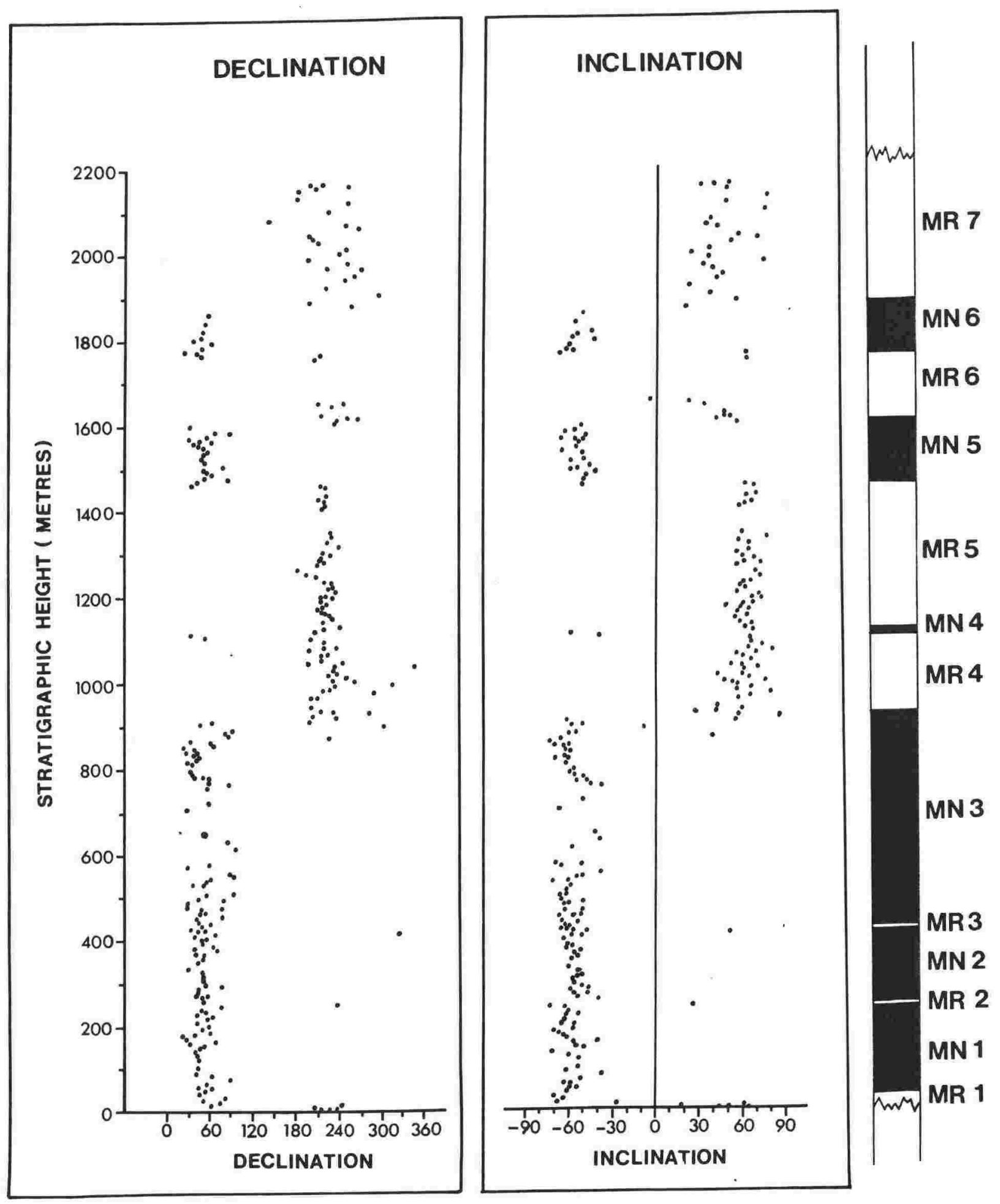

Fig. 5.1 Late Miocene Mangapoike polarity magnetozones. For notation of MR1, MN1 etc refer to text. Black is normal polarity. 


\subsection{CORRELATION WITH THE MAGNETIC POLARITY TIMESCALE}

The following biostratigraphic datums and fission-track age from the Mangapoike sequence are used as preliminary approximate dating.

1. The first appearance datum (FAD) of Globigerina nepenthes Todd is $300 \mathrm{~m}$ below the base of the paleomagnetically sampled sequence (Hoskins pers. comm.) The FAD of G. nepenthes in New Zealand is a well established biostratigraphic datum (Jenkins 1966, 1967; Hornibrook and Edwards 1971; Hornibrook 1981b, 1984b) coinciding with the base of the Waiauan Stage (Hoskins 1982). Elsewhere the FAD of G. nepenthes defines the base of Zone N14 in the late Middle Miocene (Banner and Blow 1965; Blow 1969) in the tropics, correlating to the upper parts (Srinivasan and Kennett 1981a) of the cool subtropical Globorotalia mayeri Zone (Jenkins 1971, 1975; Kennett 1973) and the warm subtropical Globorotalia mayeri Zone (Srinivasan and Kennett 1981a). Hornibrook (1981b, 1984b) suggested a $12.7^{*}$ $\mathrm{Ma}$ age for the G. nepenthes datum in New Zealand based on the stratigraphic position of Loxostomum truncatum to the $\mathrm{K}-\mathrm{Ar}$ dated Dunedin Volcanics (McDougall and Coombs 1973). Elsewhere the $G$. nepenthes datum has age estimates ranging from 12.7 to $11.6 \mathrm{Ma}$ (Berggren and Van Couvering 1974, 1978; Van Couvering and Berggren 1977; Saito 1977; Chiji and Konda 1978; Takayanagi et al. 1978; Keller 1980; Miller et al. 1985; Berggren et al. 1985).

2. The last appearance datum (LAD) of Globoquadrina dehiscens (Chapman, Parr and Collins) is at $759 \mathrm{~m}$ in the sampled sequence (Hoskins pers. comm. 1985). The disappearance of G. dehiscens in New Zealand within the Tongaporutuan is generally accepted (Kennett 1968; Hornibrook and Edwards 1971; Jenkins 1971; Hornibrook 1984b) although younger occurrences have been recorded (Hornibrook 1961; Collen and Vella 1973). Diachroneity of this datum within New Zealand is probable (Kennett 1968; Kennett and Watkins 1974), but as yet undetermined. The G. dehiscens datum in New Zealand has been dated magnetostratigraphically at Blind River at 6.2* Ma (Hornibrook 1981b, 1984b) and in equatorial regions at about 5.3 Ma (Saito et al. 1975), thus having a known diachroneity (Hornibrook 1981b, 1984b; Berggren 1984b) between temperate and tropical regions. Provisionally a $6.2 \% \mathrm{Ma}$ age for this datum in New Zealand is accepted here for preliminary dating. Inconsistent ages of the $G$. dehiscens LAD within New Zealand are described in the following chapter.

3. A fission track age of $5.80 \pm 0.55 \mathrm{Ma}$ from zircons in a tuff below the Miocene - Pliocene unconformity (Seward in Hornibrook 1984a) in an adjacent road 
exposure is equivalent to a stratigraphic height of $2070 \mathrm{~m}$ in the sampled sequence.

4. The first appearance datum (FAD) of Globorotalia sphericomiozea Walters is at $2088 \mathrm{~m}$ (the Miocene - Pliocene unconformity) in the sampled sequence. $G$. sphericomiozea is part of the Globorotalia miozea plexus (Scott 1979b, 1980; Hornibrook 1984a) having a short range within the Kapitean - Opoitian in both on land sequences and DSDP 284 (Hornibrook 1981a, 1982, 1983, 1984a; Scott 1983). An estimated age of $5.4 \mathrm{Ma}$ (Hornibrook 1981a, 1981b, 1984a; Edwards 1985) for the FAD of G. sphericomiozea is based on its occurrence just above Chron 5 from the reinterpreted magnetostratigraphy of Blind River (Loutit and Kennett 1979).

The above data constrain correlation of the magnetozones to a time interval between 11.0 and $5.0 \mathrm{Ma}$.

Individual magnetozones are correlated with chrons by their relative lengths, assuming a constant or nearly constant sedimentation rate. The long interval of normal polarities (MN1, MN2, MN3) interrupted by the very thin reversed intervals (MR1, MR2) are correlated with Chron 11. The remaining magnetozones up to MN5 are progressively correlated up the polarity timescale with Chrons 10 and 9 (Fig. 5.). This implies an average sedimentation rate of $64 \mathrm{~cm} / 1000 \mathrm{yr}$. MR2 and MR3 are correlated with the two lower reversed subchrons in Chron 11 . Above $1857 \mathrm{~m}$ only one recognised normal magnetozone $(\mathrm{MN} 6)$ is present whereas the polarity timescale contains three normal subchrons of Chron 7 and the one normal subchron of Chron 6 . From this a significant unconformity is inferred in the upper Tongaporutuan at Mangapoike. At present two interpretations (A and $B$ ) are considered for the correlation of MN6 with the polarity timescale (Fig. 5.2). Interpretation A follows the progressive correlation up the polarity timescale, correlating MN6 with the short subchron (7.44 to $7.39 \mathrm{Ma}$ ) in lower Chron 7, and gives a sedimentation rate of 200 $\mathrm{cm} / 1000 \mathrm{yr}$ for MN6. From this the non-appearance of the higher normal subchrons indicates the period from at least 7.34 to $6.42 \mathrm{Ma}$ is missing in the unconformity. Interpretation B correlates MN6 with the longer subchron (7.34 to $6.94 \mathrm{Ma}$ ) in upper Chron 7, and the shorter normal subchron below it with the unsampled interval from 1650 to $1751 \mathrm{~m}$ (Fig. 5.2). This interpretation gives a $26 \mathrm{~cm} / 1000 \mathrm{yr}$ sedimentation rate for MN6. The non-appearance of the higher normal subchrons indicates the absence of strata representing the period from at least 6.86 to $6.42 \mathrm{Ma}$. From the comparison of the sedimentation rates (200 and $26 \mathrm{~cm} / 1000 \mathrm{yr}$ ) from the two 

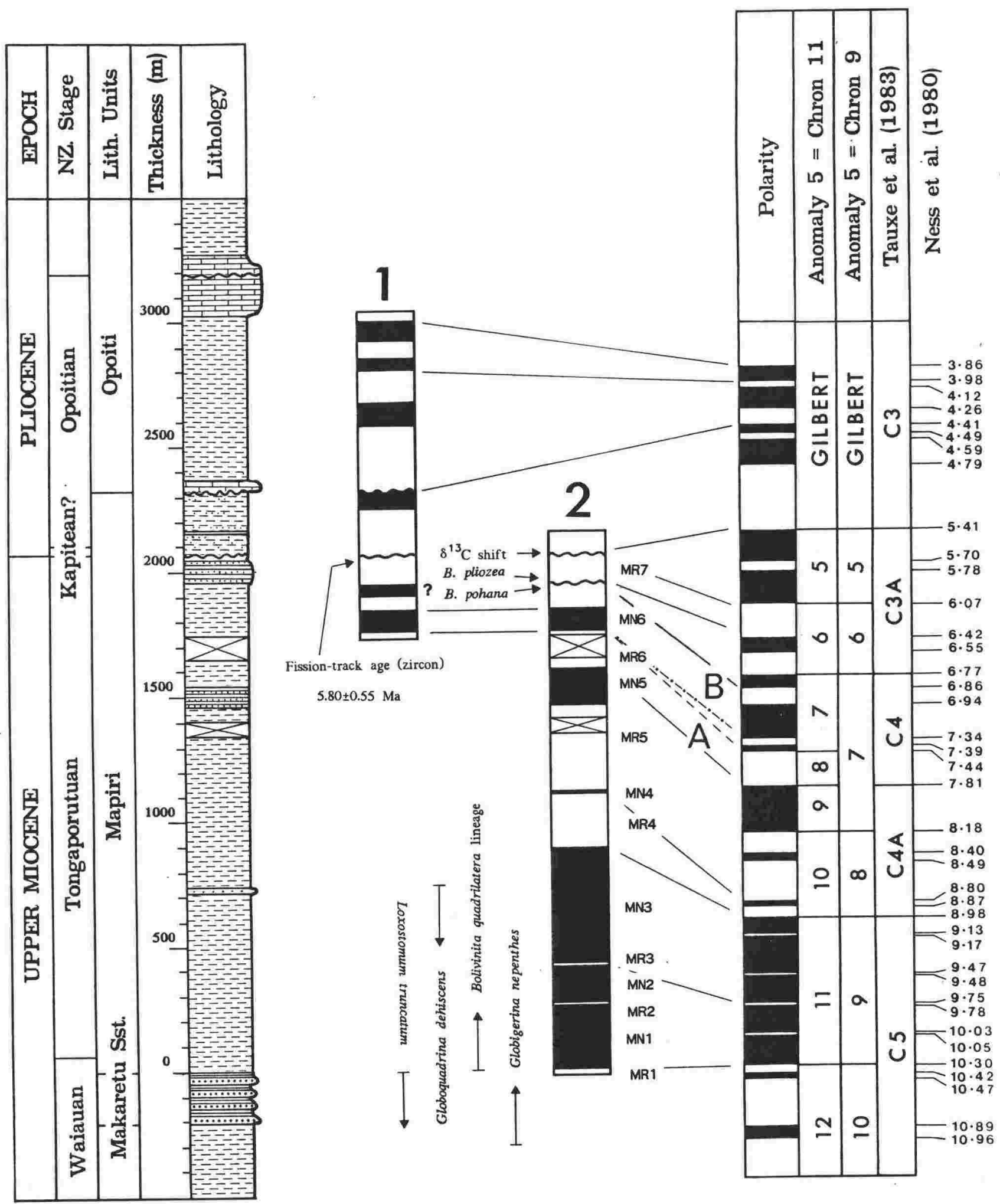

Fig. 5.2 Correlation of the Mangapoike magnetozones to the magnetic polarity timescale of Ness et al. (1980). Black is normal polarity. Column 1: magnetic polarities determined by Kennett and Watkins (1974) and reinterpreted by Edwards (1985, in prep.) Fission-track age from Hornibrook (1984b). Column 2: magnetozones and correlations determined in this thesis. Bolivinita pohana - pliozea transition determined by Scott (1978). Other foraminiferal datums determined by Hoskins (pers. comm. 1985). A and B refer to the respective magnetostratigraphic correlations described in the text. 


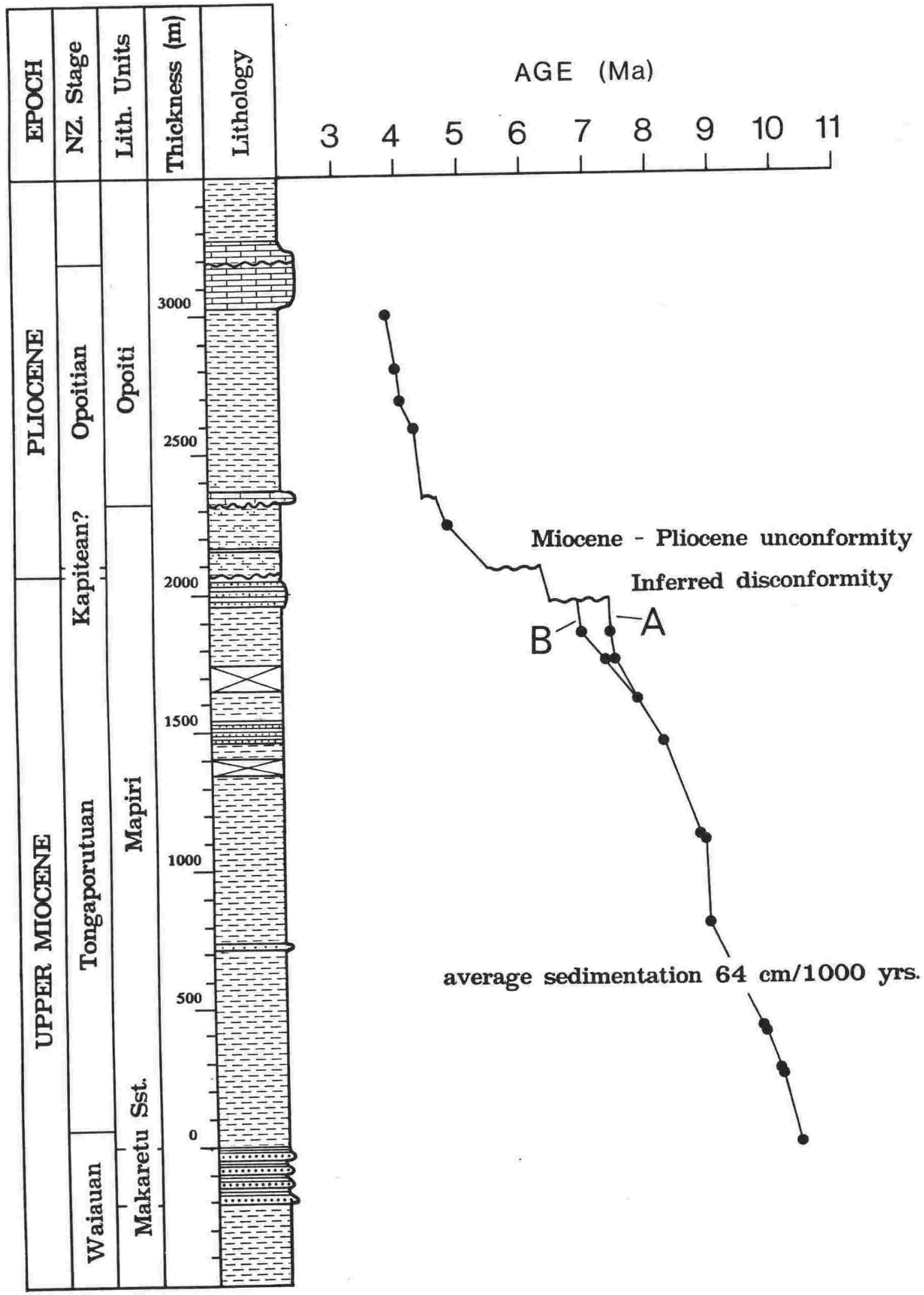

Fig. 5.3 Sedimentation rate of the Mangapoike section based on the magnetostratigraphic correlations of Edwards (1985) for the upper Mangapoike section and this thesis for the lower Mangapoike section. A and $\mathrm{B}$ refer to the respective magnetostratigraphic correlations described in the text. 
interpretations with the average sedimentation rate $(64 \mathrm{~cm} / 1000 \mathrm{yr})$ from the lower part of the section (Fig. 5.3), the second interpretation (B) is preferred.

The inferred unconformity mentioned above is assumed to be at $1970 \mathrm{~m}$ where a lithological change from massive mudstones to bedded turbidites occurs (Fig. 2.2 and Plate 6.2). Biostratigraphic evidence supports the presence of the unconformity. The Bolivinita pohana - pliozea "transition", although not yet phylogenetically understood, is a gradual but recognisable change in Bolivinita test morphology within the upper Tongaporutuan in New Zealand. As reported by Edwards (1985) the B. pohana pliozea 'transition' at Blind River (Scott 1978) occurs with the normal event of Chron 6 (6.55 to $6.42 \mathrm{Ma}$ ) of the revised Blind River magnetostratigraphy (Loutit and Kennett 1979). The morphological change of $B$. pohana to $B$. pliozea at Mangapoike, as determined by Scott (1978) does not coincide with any normal event recognised in the present study. The sampling sites used by Scott (1978), were located on the large base map used for the present study, and the morphological change from $B$. pohana to B. pliozea was found to occur between two samples at $1964 \mathrm{~m}$ and $2023 \mathrm{~m}$ (Fig. 5.2), the stratigraphic interval containing the inferred unconformity at $1970 \mathrm{~m}$. Thus as inferred solely from the biostratigraphic correlation, both the normal event of Chron 6 and the coincident B. pohana - pliozea 'transition' as recognised from Blind River, are missing at Mangapoike, indicating that at a minimum the period from 6.55 to $6.42 \mathrm{Ma}$ is missing, and that the hiatus occurs between $1964 \mathrm{~m}$ and $2023 \mathrm{~m}$.

Ashby (1986) tabulated nine radiolarian taxa (Cladococcus dentata, Antarctissa conradae, Desmospyrs sp. A, Cyrtocapsella japonica, Cyrtocapsella tetrapera, Lampromita tiara, Lamprocyclas sp. E, Phormostichoartus sp. A, and Siphosticharctus corona) with local disappearances at or just below the inferred unconformity. The most distinctive disappearances are Cyrtocapsella japonica and Cyrtocapsella tetrapera, which show persistent records below the unconformity and only one positive identification of C. tetrapera above.

The gradational change in lithology, over $3 \mathrm{~m}$, from massive mudstone to bedded sandstones and mudstones at $1461 \mathrm{~m}$ may represent a break in sedimentation. The lithological change is at or very close to the polarity reversal from MR5 to MN5. At present without further evidence, it is assumed that there is no unconformity at this stratigraphic interval.

The angular unconformity ( $3^{\circ}$ discordance) at the Miocene - Pliocene boundary (Hornibrook 1977, 1981b, 1983, 1984a) is within the reversed magnetozone MR7 at 


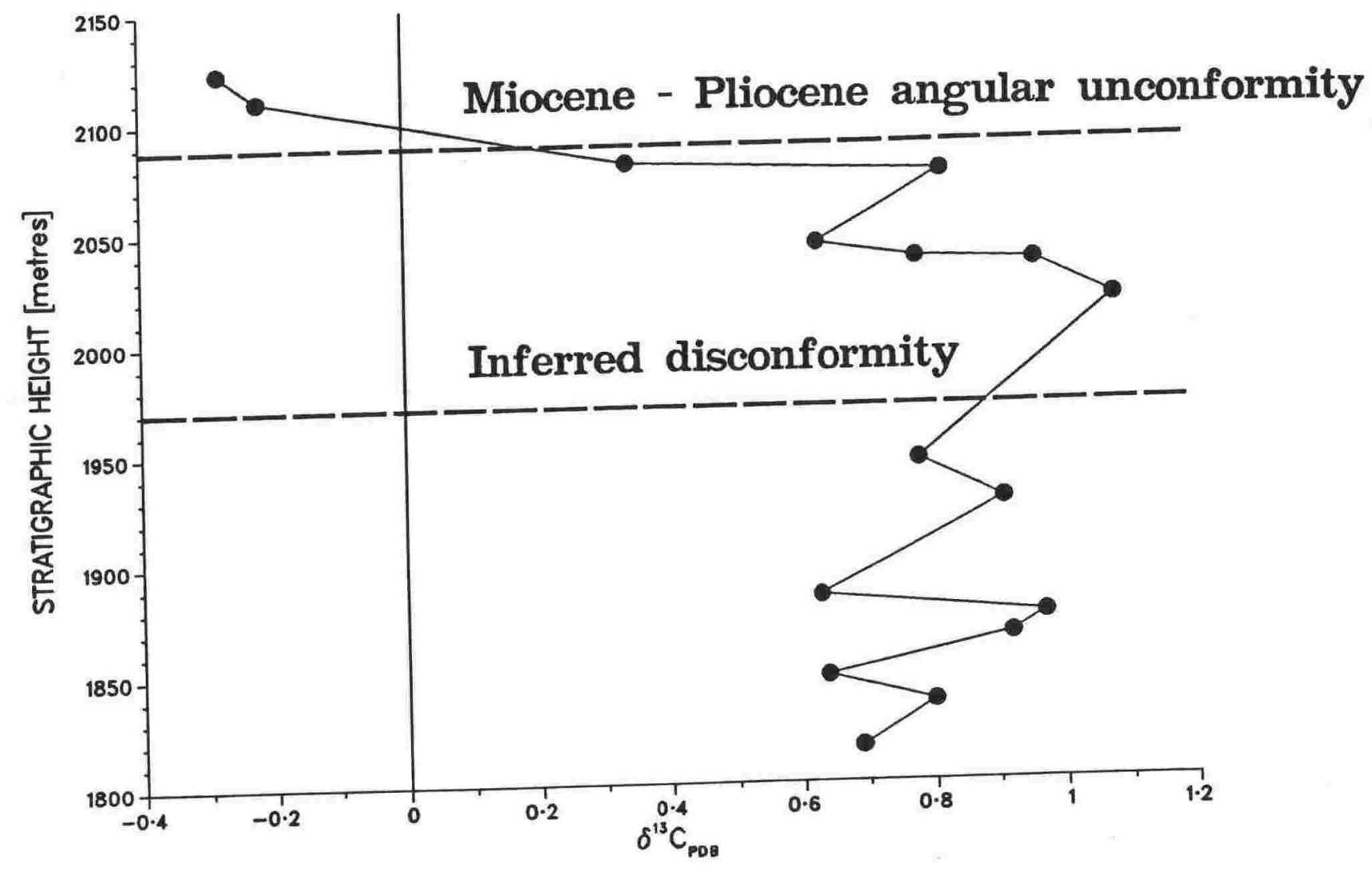

Fig. 5.4 Mangapoike $\delta^{13} \mathrm{C}$ data bounding the Miocene - Pliocene angular unconformity. $\delta^{13} \mathrm{C}$ values have been normalised to Cibicidoides wuellerstorfi (Savin et al. 1981) to correct for the disequilibrate fractionation of carbon in Uvigerina spp. 
$2088 \mathrm{~m}$. Based on the foraminiferal biostratigraphy, as discussed previously, and the magnetostratigraphic correlations outlined above, the reversed polarity zone below the unconformity is correlated with the upper reversed subchron of Chron 6 and the reversed polarity zone above the unconformity is correlated with the lower reversed subchron of the Gilbert (Fig. 5.2). This correlation follows that of Edwards, in Hornibrook (1984a, 1984b) and Edwards (1985). The implied absence of the normal subchrons of Chron 5 indicates that the minimum time missing (6.07 to $5.41 \mathrm{Ma})$ is $660,000 \mathrm{yrs}$ at the Miocene - Pliocene boundary in the Mangapoike sequence.

Carbon isotopic data based on analyses of Uvigerina spp. from the Mangapoike sequence (Appendix 10) indicates that the Miocene - Pliocene unconformity is significantly longer in time than estimated from the magnetostratigraphy. The Late Miocene carbon 'shift' is a significant -0.5 to -1.0 depletion in $\delta^{13} \mathrm{C}$ as determined from benthic foraminifera (Keigwin 1979; Kennett et al. 1979; Loutit and Kennett 1979; Loutit et al. 1983) and is accepted as an isochronous datum dated at $6.2 \mathrm{Ma}$ (Haq et al. 1980; Vincent et al. 1980; Keigwin and Shackleton 1980). Examination of the limited $\delta^{13} \mathrm{C}$ data from the Mangapoike (Fig. 5.4) indicates that the depletion occurs across the Miocene - Pliocene unconformity, although it is suggested that the early part of the carbon shift is recorded at $2080 \mathrm{~m}$. Consequently it is inferred that the greater part of the carbon 'shift' is within the unconformity and thus it is concluded from the combined evidence of the magnetostratigraphy and the carbon isotope stratigraphy that the Miocene - Pliocene unconformity at Mangapoike represents a time interval of at least 890,000 yrs. from $<5.41$ Ma to $6.3 \mathrm{Ma}$.

\subsection{SAMPLING EFFICIENCY}

Statistical evaluation of magnetostratigraphic studies for sampling efficiency and stratigraphic completeness (Sadler 1981; Johnson and McGee 1983; Hall and Butler 1983; May et al. 1985) is a recent adjunct in paleomagnetism. Cox $(1968,1981)$ defined reversals of the geomagnetic field as an exponential probability distribution function with $\mathrm{P}(\tau)=\lambda \exp (-\lambda \tau)$

where $\tau=$ time between reversals

$\lambda=$ mean frequency of reversals over time

$\mathrm{P}(\tau)=$ proportion of polarity intervals whose lengths lie between $\tau$ and $\tau+\partial \tau$

assuming that the length of successive polarity intervals is statistically independent and that the reversals have a Poisson distribution with time. Johnson and McGee (1983) 
used this distribution function to statistically define, with error limits, the number of expected reversals within a given time interval with $\mathrm{N}$ sampling sites, using a uniform, random or exponential sampling strategy. Hall and Butler (1983) defined a stochastic model to evaluate stratigraphic completeness and thus the reliability of the magnetostratigraphy. Using the technique of Sadler (1981), May et al. (1985) showed that, within different depositional environments, stratigraphic completeness at different timescales could be evaluated and used as a test of the magnetostratigraphic correlation. The statistical procedures of Sadler (1981), Hall and Butler (1983) and May et al. (1985) are not used in the present study since firstly, the Mangapoike sequence is mostly massive in lithology (section 2.3 and Appendix 1), with little or no bedding, and breaks in deposition between successive beds (Ager 1973; Dott 1983) are considered to be minimal, apart from the two unconformities (Fig. 5.2) and secondly the recognition of MR2 and MR3 indicates stratigraphic completeness, when correlated with the timescale of Ness et al. (1980), at a scale of at least $10^{4}$ years.

The Johnson and McGee (1983) model is used here to calculate the expected success of the Mangapoike sampling programme given the number of paleomagnetic sites (N), the distribution of the sites, an estimate of the geologic time span sampled $(\Delta t)$, and the mean length of the magnetic polarity zone $(\tau)$. From those data it is possible to compare the number of observed and expected reversals. Accepting the quantitatively dated biostratigraphic datums and the magnetostratigraphic correlation as discussed (section 5.3) an estimated time span for the sampled sequence of $4.9 \mathrm{Ma}$ can be derived from the base of Chron $9(10.30 \mathrm{Ma})$ and the base of the Gilbert $(5.41 \mathrm{Ma})$. The mean length of magnetic polarity zones for the Late Neogene is $0.12 \mathrm{Ma}$ (Harrison 1969; Lowrie and Kent 1983; Johnson and McGee 1983 based on data from Watkins and Walker 1977). Assuming a uniform sampling distribution, the expected number of reversals (Table 5.1a) of $17.1 \pm 4.03$ is greater than the 12 reversals observed. The discrepancy is attributed to the unconformities in the sequence (section 5.4). The estimated $0.89 \mathrm{Ma}$ represented by the Miocene - Pliocene angular unconformity, the 0.44 Ma represented by the inferred unconformity at $1970 \mathrm{~m}$, and the $0.10 \mathrm{Ma}$ within the total of $108 \mathrm{~m}$ of covered and non-sampled intervals greater than $5 \mathrm{~m}$ (based on the average sedimentation rate of $64 \mathrm{~cm} / 1000 \mathrm{yrs}$ ) totals $1.2 \mathrm{Ma}$. Subtracting $1.2 \mathrm{Ma}$ from the inferred total time span of $4.9 \mathrm{Ma}$ represented by the section leaves $3.7 \mathrm{Ma}$ which has been sampled. The expected number of reversals is $12.0 \pm 3.4$ (Table 5.1b) which is in agreement with the 12 observed reversals. It is concluded that the sampling programme (chapter 2) and the demagnetisation techniques (chapter 4) have recognised all of the polarity reversals within the section sampled. 


\section{Table 5.1}

Johnson and McGee (1983) Model Calculations

a) Uniform Sampling

$$
\begin{gathered}
\Delta \mathrm{t}=4.9 \mathrm{Ma} \\
\mathrm{N}=343 \\
\tau=1.2 \times 10^{5} \\
\mathrm{p}=1 / 2\left(1-\mathrm{e}^{-2 \Delta \mathrm{t} / \tau \mathrm{N}}\right)=0.05 \\
\mathrm{R}=\mathrm{p}(\mathrm{N}-1)=17.10 \\
\sigma=1 / 2(\mathrm{p}(1-\mathrm{p})(\mathrm{N}-1))=4.03
\end{gathered}
$$

ie Expected Reversals $17.10 \pm 4.03$

b) Uniform Sampling

$$
\begin{gathered}
\Delta t=3.47 \mathrm{Ma} \\
\mathrm{N}=343 \\
\tau=1.2 \times 10^{5} \\
\mathrm{p}=y_{2}\left(1-\mathrm{e}^{-2 \Delta t / \tau \mathrm{N}}\right)=0.035 \\
\mathrm{R}=\mathrm{p}(\mathrm{N}-1)=12.0 \\
\sigma=y_{2}(\mathrm{p}(1-\mathrm{p})(\mathrm{N}-1))=3.40
\end{gathered}
$$

ie Expected Reversals $12.0 \pm 3.40$

$\mathrm{N}=$ number of paleomagnetic sites placed within $\Delta t$

$\mathrm{p}=$ probability that a given sample set will cross magnetic reversal

$\mathrm{R}=$ expected number of reversals discovered by the sample set

$\tau=$ mean time length of polarity intervals over a long time period

$\Delta \mathrm{t}=$ time increment of stratigraphic interval 


\subsection{BIOTURBATION}

The possible effects of bioturbation, by a benthic fauna, on the paleomagnetism of sediments has been recognised (Keen 1963; Harrison 1966; Watkins 1968). The main concerns have been the vertical mixing of sediment with the consequent alteration or obliteration of polarity events (Watkins 1968) and the primary magnetic fabric in susceptibility anisotropy studies (Rees et al. 1968, 1982; Kent and Lowrie 1975) and the time lag between deposition of the sediment and acquisition of the final magnetisation (Lowrie 1975). It is recognised that detrital remanent magnetisation (DRM) can be a combination of grain alignment during settling through the water column (Nagata 1953; Graham 1949; King 1955; Griffths et al. 1960) and also subsequent alignment within the sediment slurry by grain rotation (Graham 1954; Irving 1957; Irving and Major 1964; Kent 1973; Otofuji and Sasajima 1981) termed as depositional DRM and postdepositional DRM, respectively (Verosub 1977).

Keen (1963) and Harrison (1966) recognised that extensive bioturbation of deep-sea sediments would obliterate the depositional DRM, and the observed magnetisation must be postdepositional in origin. Verosub (1977) in his review of sediment magnetisation concluded that the directional coherence of deep-sea cores as documented by Opdyke (1972) supported a postdepositional origin of magnetisation. It is argued further here that varying degrees of bioturbation, as described (section 2.7), will result in a positive correlation with direction dispersion, as measured by $\alpha 95$, if the magnetisation is a depositional DRM. If no such correlation is exhibited, and bioturbation is obvious in the sediment at the site(s) sampled then it is concluded that the magnetisation post dates the bioturbation and thus is post-depositional in origin. The Mangapoike data exhibit no correlation between the amount of visible bioturbation and $\alpha 95$ (Fig. 5.5) and thus the magnetisation is considered to be a post-depositional DRM.

An estimate of the time lag between deposition and magnetisation acquisition can be derived from the sedimentation rate and the depth from the sediment/water interface of the faunal mixing zone. A maximum bioturbation depth of $60 \mathrm{~cm}$ determined by measurements on deep-sea sediments (Ninkovich et al. 1966; Glass 1969; Ruddiman and Glover 1972; Rhoads and Boyer 1982) combined with the average Mangapoike sedimentation rate of $64 \mathrm{~cm} / 1000$ yrs indicates an approximate 1000 year lag between deposition and magnetisation in the Mangapoike sediments. This could be an over estimate of the time lag, since the maximum known depth of bioturbation in the Mangapoike sequence is $25 \mathrm{~cm}$, measured by a burrow from the base of a tuff. However the burrow itself is incomplete, by an unknown amount, with the top 
O NOT BIOTURBATED

1 WEAKLY BIOTURBATED

2 MODERATELY BIOTURBATED

3 STRONGLY BIOTURBATED

4 COMPLETELY BIOTURBATED

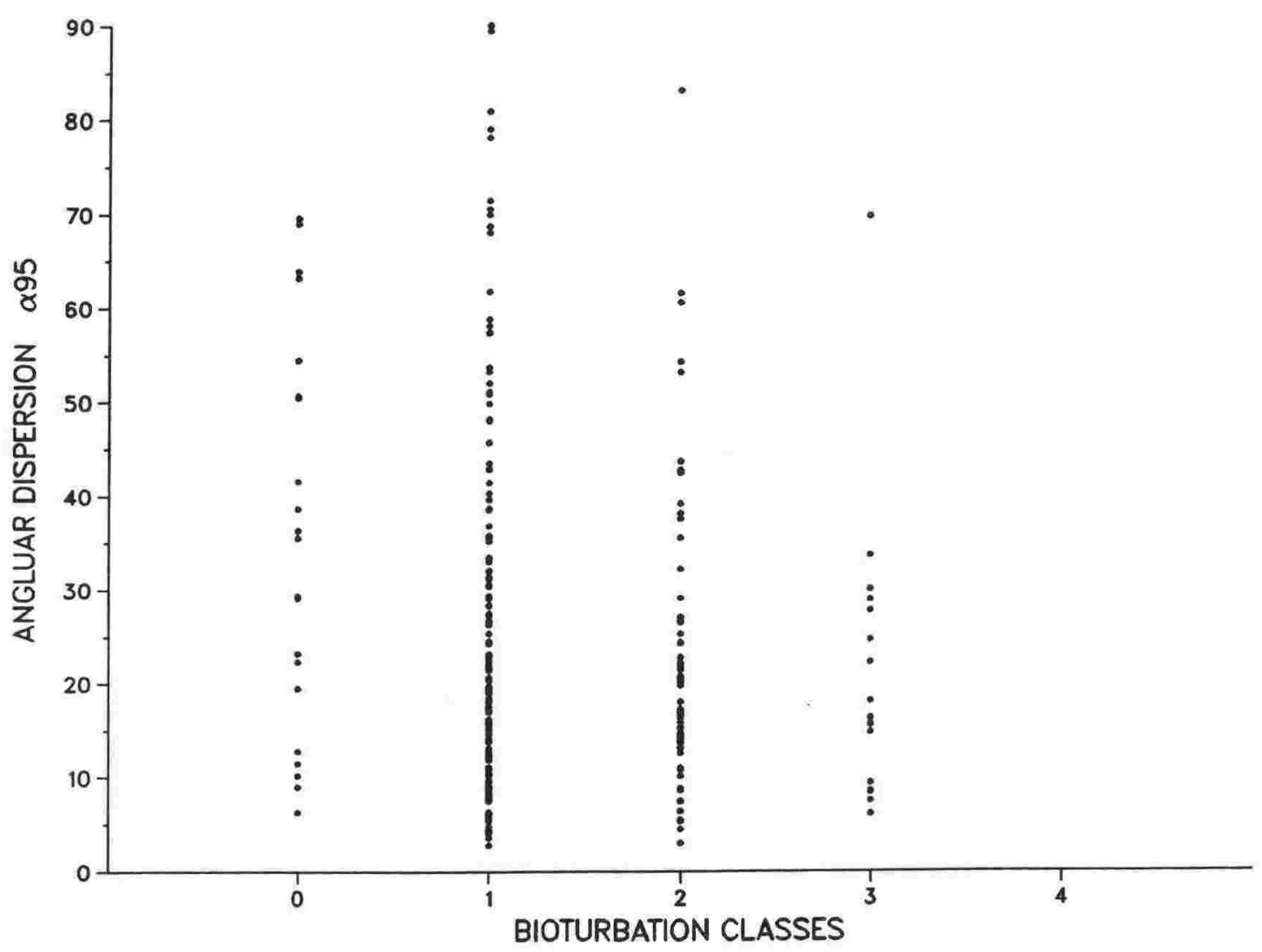

Fig. 5.5 Plot of $\alpha 95$ 's against the degree of bioturbation. 
unlocated, and for the present 1000 years remains the best estimate of the time lag between deposition and magnetisation of the Mangapoike sediments.

Modification of polarity events by bioturbation as described by Watkins (1968) is considered not to be significant, in the Mangapoike paleomagnetic record. Accepting both that polarity reversals occur on a timescale of $10^{4}$ to $10^{6}$ years and that the shortest recognised polarity event in the Late Miocene from Ness et al. (1980) is 14000 yrs and the maximum interval of bioturbation of the Mangapoike sediments is 1000 yrs, then theoretically all polarity events should be recorded. The admixture of reversed and normal polarity specimens at sites 18991, 19005 and 19018, which were rejected from the final analysis, could be attributed to inhomogeneous vertical mixing by a benthic fauna soon after a polarity transition. However, the post-bioturbation timing of magnetisation of the Mangapoike sediments, as described, indicates that mixed polarities are not a function of bioturbation, and are more likely to be product of incomplete demagnetisation of some specimens at sites where a normal overprint is superimposed on a primary reversed magnetisation. 


\section{Chapter VI \\ LATE MIOCENE CORRELATIONS}

\subsection{INTRODUCTION}

This chapter discusses Late Miocene glacioeustatic, magnetostratigraphic, biostratigraphic and chronostratigraphic correlations derived from the Mangapoike magnetostratigraphy. Section 6.2 describes three inferred glacioeustatic events within the late Waiauan to earliest Opoitian interval of the Mangapoike section, which are synchronous with positive deep-sea benthic $\delta^{18} \mathrm{O}$ values and with low sea-levels postulated by Vail et al. (1977). The three events could be attributed to relative sea-level changes caused by intermittent temporary reversals of tectonic subsidence to tectonic uplift, but there is no supporting evidence for such tectonic reversals. Section 6.3 shows the correlation of the Mangapoike magnetostratigraphy to other Late Miocene - Early Pliocene magnetostratigraphies of New Zealand, including DSDP Site 594. Sections 6.4 and 6.5 discuss the age determinations from Mangapoike, for the first appearance datum (FAD) of the Bolivinita quadrilatera lineage (the base of the Tongaporutuan Stage) and the last appearance datum (LAD) of Globoquadrina dehiscens. The former is correlated to the base of the international Tortonian stratotype and associated tropical microfossil zones.

\subsection{GLACIOEUSTATIC SEA-LEVEL CHANGES}

\subsubsection{Introduction}

Eustatic sea-level control of marine sedimentation has been recognized from the presence of sedimentary cycles and bounding uncomformities within the rock record (Wells 1960; Vella 1965; Rona 1973). Turbidites also may often correlate to low sea level (Shanmugan and Moiola 1982). Interludes of coastal onlap and offlap sedimentation, as shown by seismic profiles, have been interpreted as eustatic rises and falls, respectively, of sea-level, resulting chiefly from glaciation (Vail et al. 1977; Vail and Hardenbol 1979). The Phanerozoic eustatic sea-level curve of Vail and Hardenbol has been criticised with respect to the methodology of its construction (Maill 1986), the implied relative rates of sea-level rise and fall (Hallam 1981) and the significant lack of a glacial record, especially within the Triassic and Jurassic when large sea-level changes are postulated. Other mechanisms causal to sea-level flucuations have been suggested (Russell 1968, Valentine and Moore 1970; Hays and Pitman 1973; Pitman 1978). 
The oxygen and carbon isotope stratigraphy for the Neogene (Savin et al. 1981) is interpreted as an ice volume record (Woodruff et al. 1981) showing that at least from the middle Miocene to the present, sea-level changes shown on the Vail curve are probably truly glacioeustatic.

Within New Zealand, chronostratigraphic subdivision of the Cenozoic was originally defined by mollusca and benthic foraminifera (Allan 1933; Finlay and Marwick 1940, 1947); taxa which are influenced by eustatic sea-level changes. By implication the New Zealand stages are possibly related to eustatism (Loutit and Kennett 1981).

\subsubsection{Mangapoike Glacioeustatic Events}

Event 1: <10.3 Ma (upper Chron 12) Turbidites.

The $210 \mathrm{~m}$ thick Makaretu sandstone (Plate 6.1) immediately below the sampled sequence is tentatively identified as resulting from glacioeustatism, based on lithological inferences and the near age synchroneity with other known glacioeustatic events (Fig. 6.1). The 'sandstone' is a series of rhythmically bedded turbiditic sandstones and mudstones. Sandstones and mudstones are equal in proportion, and sandstones beds have erosional bases. Flute casts are commonly observed. The unit is bounded stratigraphically, grading over 9-6 $\mathrm{m}$ at both the base and top, by at least $300 \mathrm{~m}$ thick massive to very weakly bedded mudstone. The Makaretu sandstone is recognised throughout the Wairoa Syncline (Wellman 1958).

Increased frequency and magnitiude of turbidite deposition has been correlated to low eustatic sea-levels (Damuth 1977; Vail and Hardenbol 1979; Shanmugan and Moiola 1982). Increased erosion due to glaciation and exposure of the continental shelf results in larger volumes of coarse detritus being fed to bathyal sites.

The Makaretu sandstone (latest Waiauan) is within upper Chron 12, immediately below the Chron 11 - Chron 12 transition, and has an estimated age of 11 to 10.3 Ma. A significant glacioeustatic event has been inferred to occur between 11 and 9 Ma. Vail et al. (1977) and Vail and Hardenbol (1979) recognised a major uncomformity attributed to a low eustatic sea-level at $9.92 \mathrm{Ma}$ ( $=9.8 \mathrm{Ma}$ of Blakely 1974; timescale in Vail and Hardenbol 1979). Two episodes of marked $\delta^{18} \mathrm{O}$ enrichment in benthic foraminifera have been recognised close to the middle - late Miocene boundary (Savin et al. 1981; Burckle et al. 1982; Kennett 1986) and are interpreted as the result of increases in ice volume on Antarctica (Woodruff et al. 1981). Savin et al. (1981) estimated an age of 11.8 to $10.5 \mathrm{Ma}$ for the younger $\delta^{18} \mathrm{O}$ enrichment, on the evidence of foraminiferal, coccolith, radiolarian and diatom 
$-103 f-$

Plate 6.1 Glacioeustatic event 1: turbidite beds of the Makaretu sandstone. 


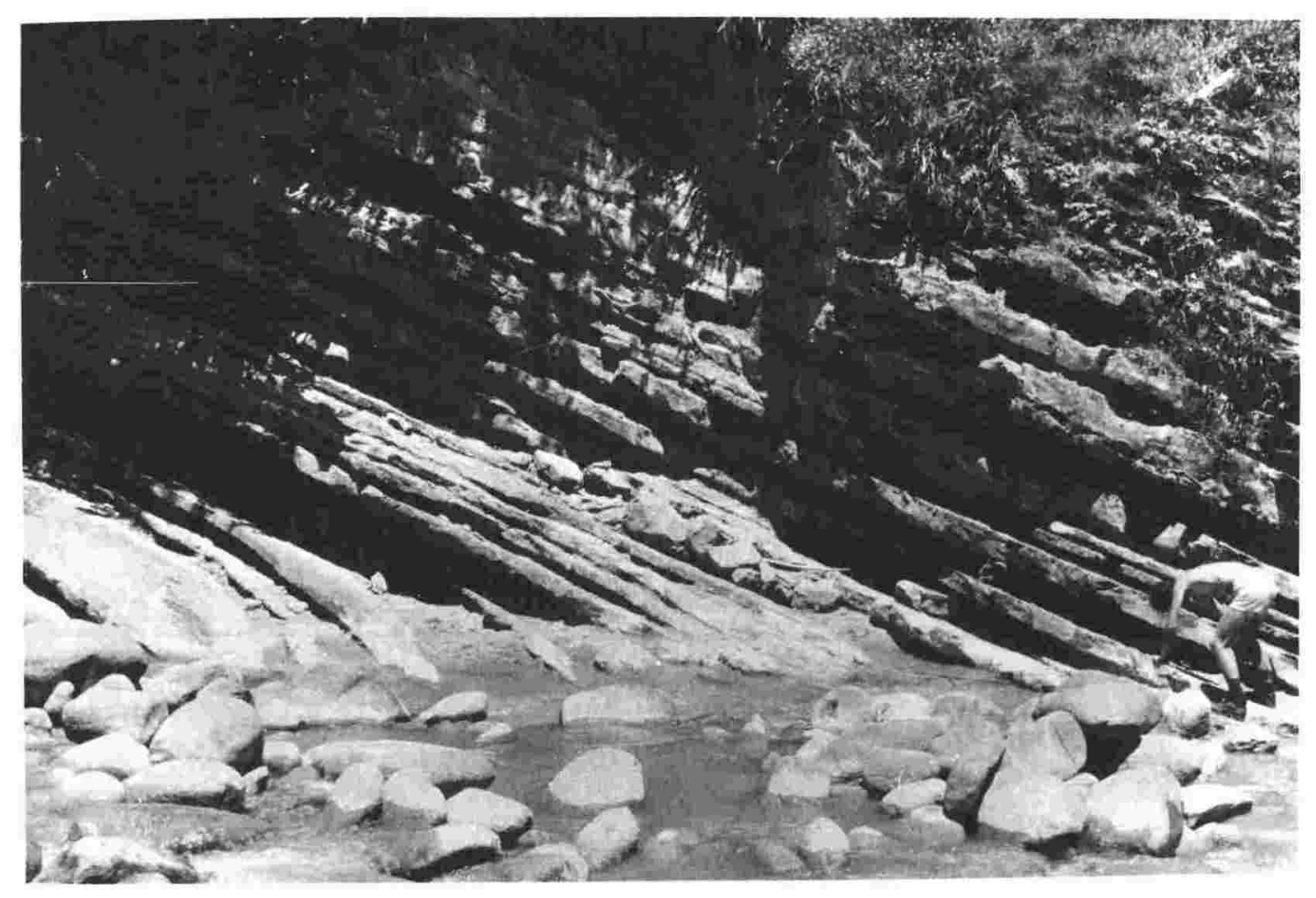


- 104f -

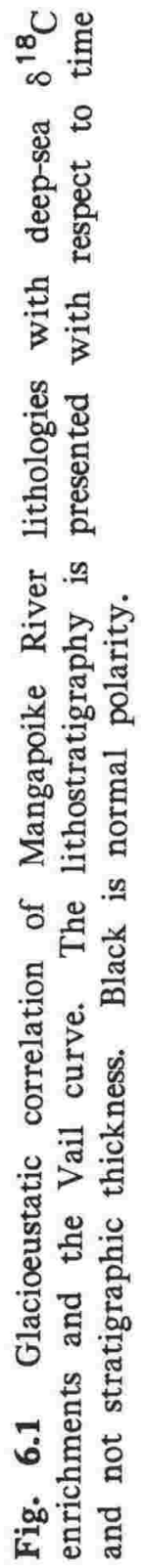



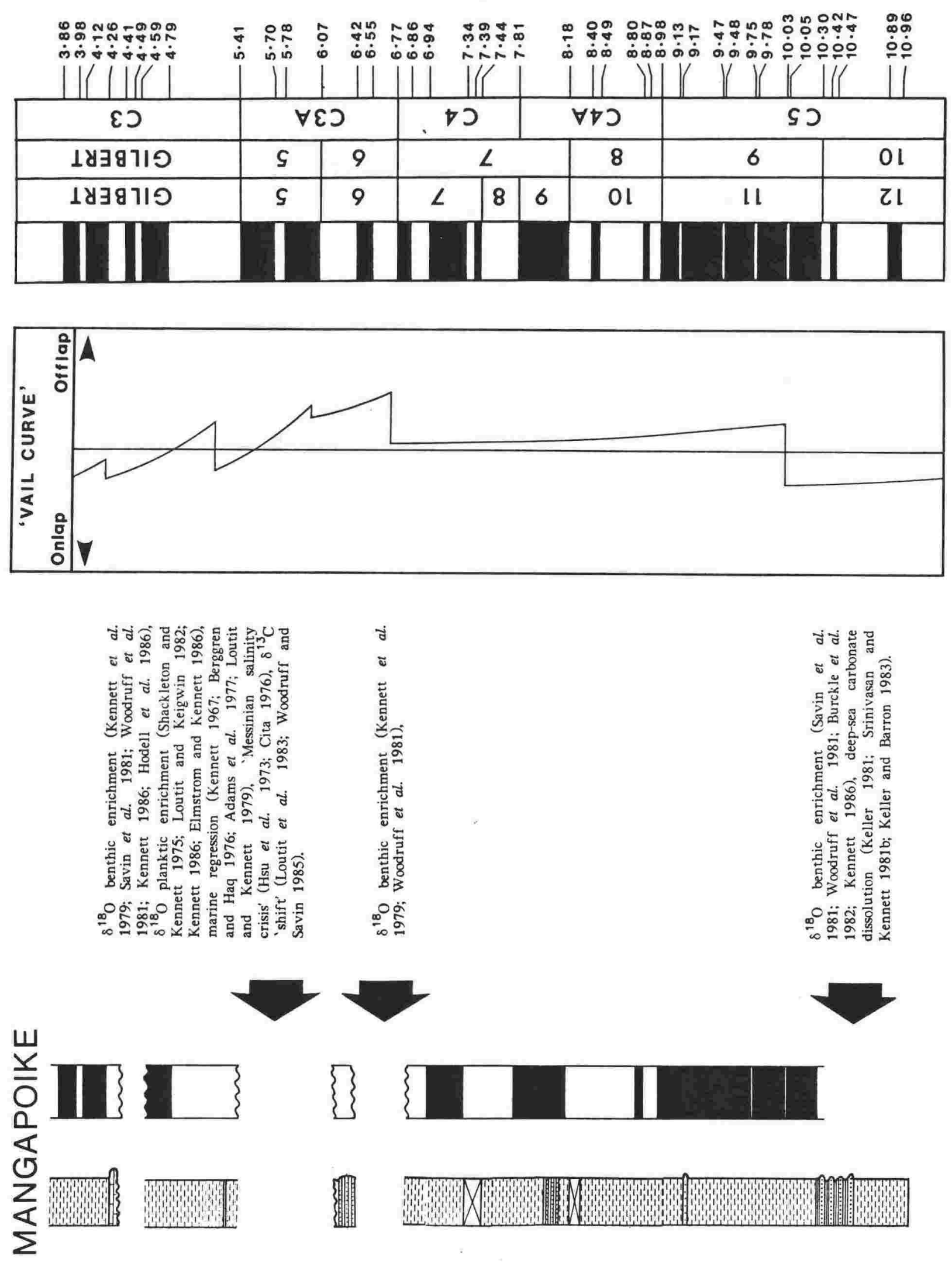
correlations. Burckle et al. (1982) identified the same isotopic event within Chron 12 ( $=$ Chron 10 of their paper). An increase in carbonate dissolution within deep-sea sediments occurred at the same time (Keller 1981; Srinivasan and Kennett 1981b) and is inferred to represent increased erosive intensity and corrosiveness of bottom waters due to increasing Antarctic glaciation (Keller and Barron 1983). Based on the inferred correlation of low glacioeustatism being causal to increased turbidite deposition and the near temporal synchroneity with a marked $\delta^{18} \mathrm{O}$ enrichment, deep-sea carbonate dissolution, and a major unconformity of the Vail curve, the Makaretu sandstone, with fair confidence, is interpreted as resulting from glacioeustatism.

Hoskins (1978) recognised a marine shallowing during the late Waiauan throughout New Zealand, and this correlated to the inferred glacioeustatic event.

Sudden uplift immediately followed by sudden subsidence to produce a coarse grained well-bedded unit sharply bounded by fine grained detritus is unlikely in both mechanism and product. Consequently tectonism is discounted as causal to the Makaretu sandstone.

\section{Event 2: 6.86 to 6.42 Ma Disconformity}

The unconformity placed at the distinct lithological change at $1970 \mathrm{~m}$, as inferred from the preferred magnetostratigraphic correlation and the biostratigraphy has a minimum period of non-deposition from 6.86 to $6.42 \mathrm{Ma}$.

Vail et al. (1977) and Vail and Hardenbol (1979) infer a low sea-level at 6.7 Ma (= 6.6 Ma of Talwani et al. 1971; timescale in Vail and Hardenbol 1979). A small $\delta^{18} \mathrm{O}$ enrichment in benthic foraminifera has been recognised by Kennett et al. (1979) and Woodruff et al. (1981), at both equatorial and temperate sites, within planktic foraminiferal zone N17 (upper Tongaporutuan), and has estimated age of 7 to $6 \mathrm{Ma}$.

The unconformity is interpreted as resulting from glacioeustatism based solely on the age synchroneity of these events. The disappearance of the radiolaria Cyrtocapsella japoncia and $C$. tetrapera at the unconformity, which are generally accepted to be warm water taxa, supports a climatic cooling and associated sea-level fall at this horizon. The stratigraphic position of the unconformity within the bedded sandstones interval is not precisely defined by either the biostratigraphy or the magnetostratigraphy, and placing it at the base of the sandstone is solely for convenience.

\section{Event 3: 5.41 to 6.3 Ma Miocene - Pliocene Angular Unconformity}


Plate 6.2 Glacioeustatic event 2: inferred unconformity at the lithological change from massive mudstones to bedded sandstones (arrowed). The bed approximately $3-4 \mathrm{~m}$ below the lithological break is a silicic tuff. (Photo G. Gosson).

Plate 6.3 Glacioeustatic event 3 : the Miocene - Pliocene $3^{\circ}$ angular unconformity (arrowed). (Photo G. Gosson). 

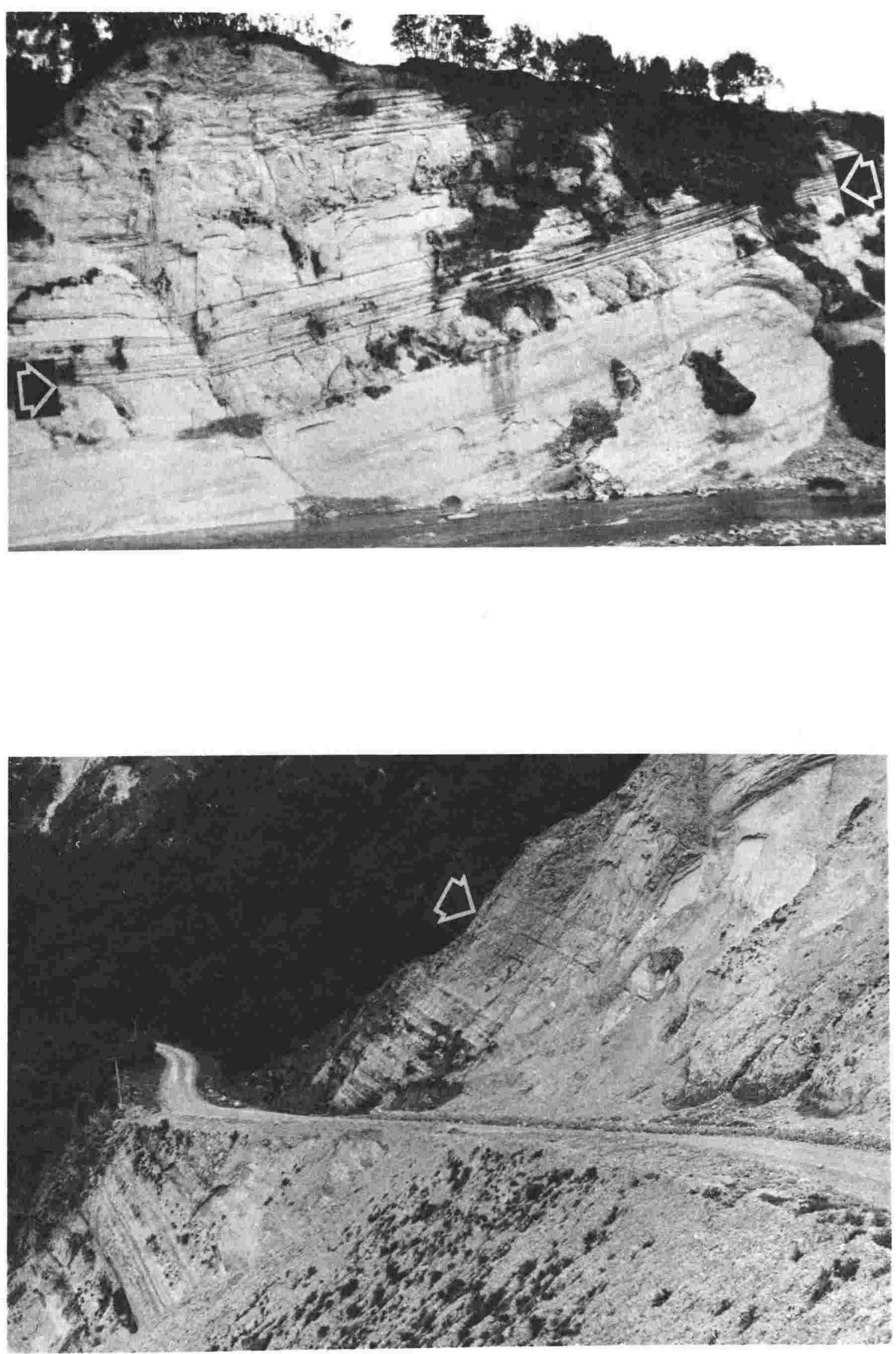
The Miocene - Pliocene angular unconformity at Mangapoike (Hornibrook 1977, 1983) is correlated to the latest Miocene climatic cooling and its associated low eustatic sea-level.

Global cooling during the latest Miocene that has been inferred from biogeography is well documented (Ingle 1967; Kennett 1967). Large but variable benthic $\delta^{18} \mathrm{O}$ values between 6.5 to $4.5 \mathrm{Ma}$ (Kennett et al. 1979; Savin et al. 1981; Woodruff et al. 1981; Kennett 1986) associated with a synchronous enrichment of planktic $\delta^{18} \mathrm{O}$ (Shackleton and Kennett 1975; Loutit and Keigwin 1982; Kennett 1986; Elmstrom and Kennett 1986) are interpreted as the result of a major expansion of Antarctic ice cover (Hodell et al. 1986). A marine regression of 40 - $80 \mathrm{~m}$ (Kennett 1967; Berggren and Haq 1976; Adams et al. 1977; Loutit and Kennett 1979; Vail and Hardenbol 1979) at this time (6.0 to $5.2 \mathrm{Ma}$ ) was sufficient to isolate the Mediterranean, initiating the 'Messinian salinity crisis' between 5.7. and 5.2 Ma (Hsu et al. 1973; Cita 1976). The late Miocene carbon 'shift' has also been ascribed as resulting from this regression (Loutit et al. 1983; Woodruff and Savin 1985). Kennett (1986) has described a mechanism whereby fractionation between continental and oceanic organic carbon reservoirs could increase at times of regression when continental shelves are exposed.

Based on synchroneity and the proposed causal mechanism of the $\delta^{13} \mathrm{C}$ 'shift', the Mangapoike Miocene - Pliocene unconformity is correlated with the latest Miocene cooling.

\subsubsection{Discussion}

The glacioeustatic correlations are based primarily on the synchroneity of both the benthic $\delta^{18} \mathrm{O}$ record and the Vail curve with distinct lithological events within the Mangapoike sequence. The inferred unconformity ( $0.44 \mathrm{Ma}$ time-break) and the Miocene - Pliocene unconformity ( $0.89 \mathrm{Ma}$ time-break) at the periods of inferred glacioeustatism will severely restrict the establishment a more direct record of glacioeustatism/cooling at Mangapoike. Isotopic $\left(\delta^{18} \mathrm{O}\right)$ data from Mangapoike (Fig. 6.2) may also prove to be ambiguous. The limited benthic $\delta{ }^{18} \mathrm{O}$ data obtained from Mangapoike, in association with determining the $\delta^{13} \mathrm{C}$ shift, do not record significant periods of cooling in the late Miocene. The only significant climatic change recorded from the Mangapoike $\delta{ }^{18} \mathrm{O}$ data is an earliest Pliocene warming. $\delta^{18} \mathrm{O}$ data from benthic tests records ocean bottom-water temperature and is inferred to be a direct record of continental ice volume (Woodruff et al. 1981), whereas planktic $\delta^{18} \mathrm{O}$ data may also record seasonal temperature fluctuations. For this reason, benthic $\delta^{18} \mathrm{O}$ data is more readily interpreted as reflecting periods of warming (depletion of $\delta^{18} \mathrm{O}$ ) and cooling (enrichment of $\delta^{18} \mathrm{O}$ ). 


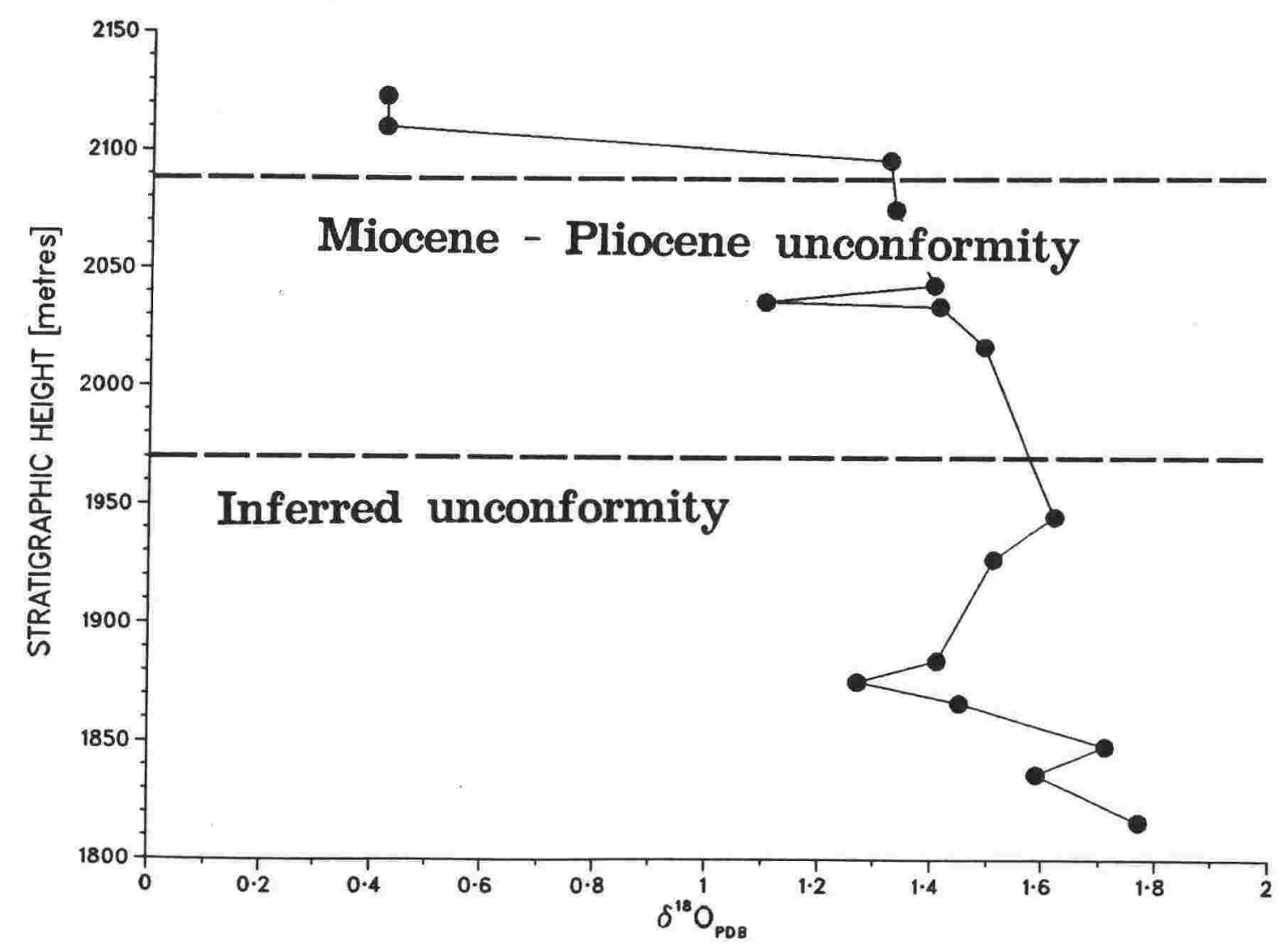

Fig. 6.2 Stable oxygen isotope data bounding the Mangapoike Miocene - Pliocene unconformity and the inferred unconformity. 
Benthic data from neritic depths of deposition (ie Mangapoike) will not however truly reflect the temperature of bottom water and thus ice volume. Loutit and Kennett (1979) described a mechanism whereby a warming of the neritic benthos results from a reduced water depth due to a glacioeustatic cooling to explain the absence of a $\delta^{18} \mathrm{O}$ enrichment within the latest Miocene of Blind River. A similiar mechanism may need to be invoked for Mangapoike.

\subsection{NEW ZEALAND CORRELATIONS}

Integration of biostratigraphic, lithostratigraphic, magnetostratigraphic, radiometric and stable isotope data by Edwards (1985, in prep.) including data from DSDP Site 284 in the Tasman Sea, has produced a coherent correlation model for the latest Miocene to Pleistocene in New Zealand. This model is followed here for the magnetostratigraphy and biostratigraphy of the Hinakura Road and Blind River sections. The independently derived and correlated Late Miocene Mangapoike magnetostratigraphy and carbon isotope stratigraphy in this thesis does not conflict with the correlation model of Edwards (1985). Consequently the magnetostratigraphies and biostratigraphies of Mangapoike River, Hinakura Road and Blind River show a high level of consistency (Fig. 6.2).

Correlation of the biostratigraphy derived from New Zealand, including DSDP Site 284, to either of the magnetostratigraphic interpretations at DSDP Site 594 (Barton and Bloemendal 1986), $200 \mathrm{~km}$ southeast of Blind River, results in a marked diachroneity of foraminiferal, radiolarian and calcareous nannofossil bioevents. Four possibilities can be proposed to resolve the anomaly.

1. The diachroneity between New Zealand and Site 594 biostratigraphy is real, and results from the position of the Subtropical Convergence zone between the two locations.

2. The first and last appearance datums (FAD's and LAD's) recognised at a number of on-shore sections are not at their true stratigraphic position at Site 594 due to poor preservation or reworking, and thus the inferred diachroneity is an artifact.

3. The integration of biostratigraphy, magnetostratigraphy and isotope stratigraphy from the on-shore sections and DSDP Site 284 is wrong and one or the other of the magnetostratigraphic interpretations at Site 594 is correct.

4. Both of the magnetostratigraphic interpretations of Site 594 are wrong and the integration of on-shore data is correct.

The FAD's of Globorotalia conomiozea conomiozea and Globorotalia sphericomiozea have been dated at Blind River (Loutit and Kennett 1979) at 6.1 and $5.4 \mathrm{Ma}$, and are 


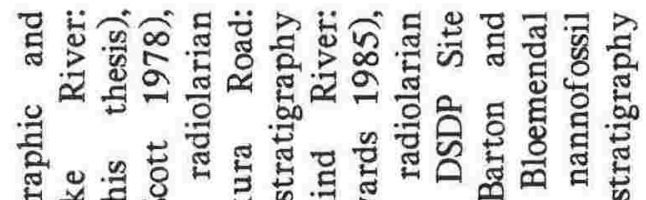

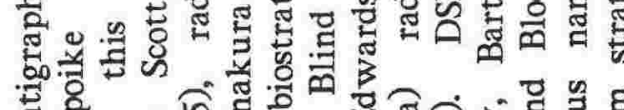

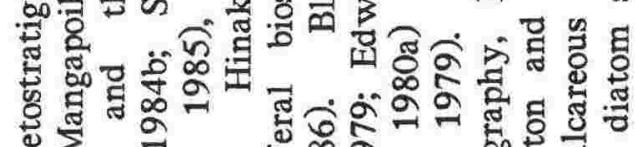
屯ू घ घ.

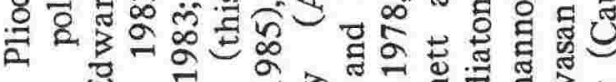

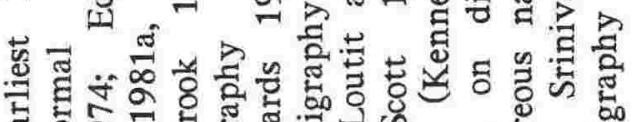

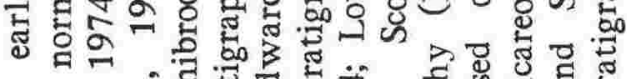
ซ. .

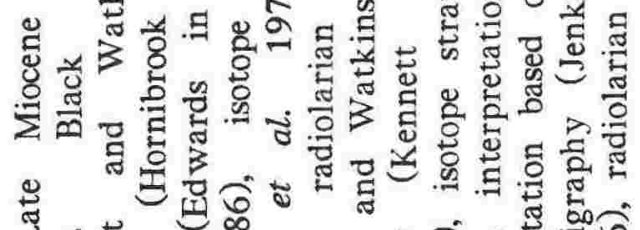

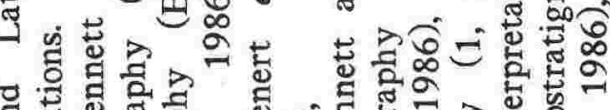

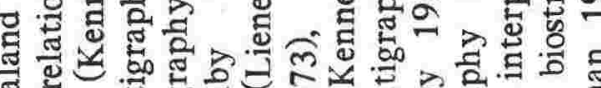

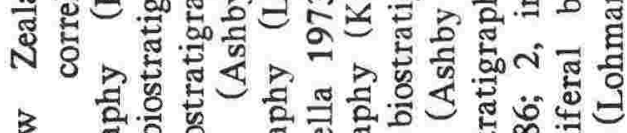

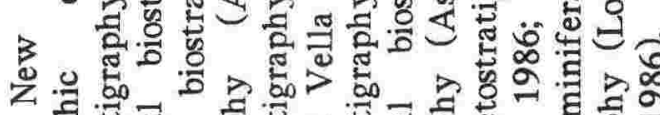

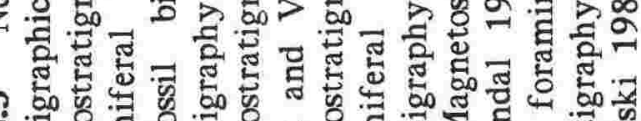

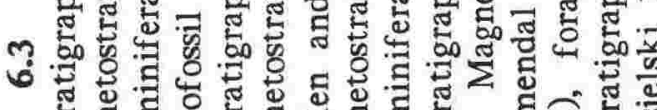

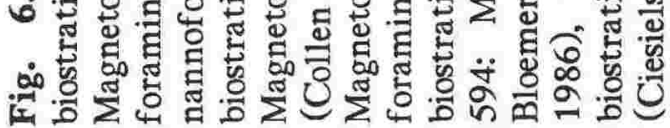




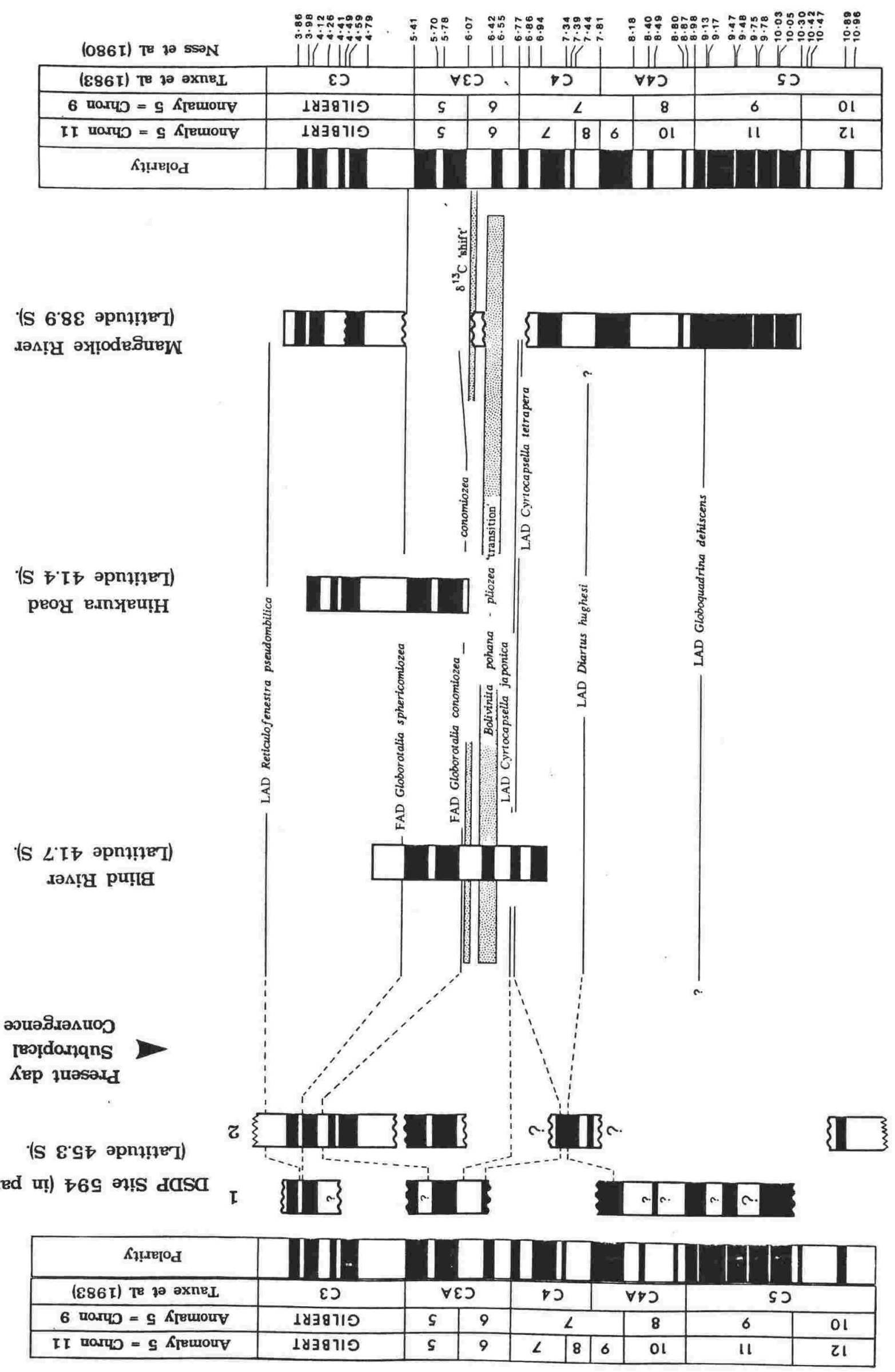


accepted within New Zealand as reliable datums (Hornibrook 1981b, 1984b; Edwards 1985). At Site 594, depending on the magnetostratigraphic interpretation the FAD'S of the G. conomiozea group (= G. conomiozea conomiozea) and G. sphericomiozea can have inferred ages of 4.3 and $3.9 \mathrm{Ma}$, resulting in a maximum of $1.8 \mathrm{Ma}$ diachroneity over $3.6^{\circ}$ of latitude, (Fig. 6.2). If that degree of diachroneity is real then it is the largest recorded, being one order of magnitude greater than the largest previously recorded: the 1.7 Ma diachroneity of the FAD of the Globorotalia truncatulinoides between equatorial and subantarctic regions (Kennett 1970). The inferred diachroneity cannot be ascribed to Blind River and Site 594 being in two different water masses, since during the latest Miocene and early Pliocene the Subtropical Convergence may have lain to the north of Blind River (Kennett and Watkins 1974) and both locations were under subantarctic waters. There is no apparent diachroneity of G. conomiozea conomiozea and G. sphericomiozea between Mangapoike River and Blind River, (Fig. 6.2) across the Subtropical Convergence. That there was diachroneity of planktic taxa within the same water mass in the order of 2 to $1 \mathrm{Ma}$ over the $3.6^{\circ}$ latitude between New Zealand and Site 594 is unacceptable.

It can not be assumed that the FAD's and LAD's of calcareous and siliceous microfossils at Site 594 have been displaced stratigraphically higher or lower because of poor preservation or reworking. From late middle Miocene to Pleistocene the planktic foraminifera at Site 594 are well preserved (Kennett, von der Borch et al. 1986) and have clearly identified zonal markers including the FAD of the G. conomiozea group. Radiolaria are rare but are well preserved throughout the core. Calcareous nannoplankton and diatoms are variable in abundance but again are well preserved. The displacement of six bioevents from their true stratigraphic position at Site 594 is thus considered unlikely.

The magnetostratigraphy of DSDP Site 594 is poorly defined and ambiguous (Barton and Bloemendal 1986). Both magnetostratigraphic interpretations proposed by Barton and Bloemendal are therefore suspect, and in view of the biostratigraphic evidence are considered to be incorrect. The Edwards (1985, in prep.) correlation model, including his magnetostratigraphic interpretations are here considered to be the best possible at present. 


\subsection{BASE OF THE TONGAPORUTUAN STAGE}

\subsubsection{Stratigraphy}

The Tongaporutuan Stage was formally defined by Finlay and Marwick (1940) with its type section at the Tongaporutu Coast, north Taranaki. Paleontological definition from the then underlying Awamoan Stage and the overlying Urenian Stage was primarily based on molluscan fossils, and amongst the foraminifera only the first appearance of the benthic Bolivinita spp. was recognised as an important datum. Further chronostratigraphic division of the Cenozoic (Finlay and Marwick 1947) defined the Waiauan Satge immediately underlying the Tongaporutuan and the replacement of the Urenuian with the Kapitean Stage. The Waiauan was defined by the presence of the benthic foraminifer Loxostomum truncatum and the Kapitean was defined by the presence of the mollusca Sectipectán wollastoni and Austrofusus coerulescens (= tuberculatus).

Further foraminiferal biostratigraphy (Hornibrook 1958; Gibson 1967; Kennett 1966a, 1966b, 1966c, 1967a, 1967b), including a three-fold subdivision of the Tongaporutuan by Vella (1954), confirmed the incoming of the Bolivinita quadrilatera lineage as the primary criterion for recognising the base of the Tongaporutuan.

\subsubsection{Correlation and Dating}

To date, correlation of the Tongaporutuan Stage to overseas stratotypes and fossil zones has been primarily based on foraminiferal biostratigraphy. When defining the Tongaporutuan, Finlay and Marwick (1940) considered it to be Late Miocene in age. Subsequent foraminiferal biostratigraphy (Finaly 1947; Hornibrook 1958; Gibson 1967; Kennett 1967a, 1967b; Jenkins 1967, 1971; Hornibrook and Edwards 1971) paralled by similar work in the Mediterranean and tropics (Banner and Blow 1965; Blow 1969; Cita and Blow 1969; Bolli 1970) has confirmed the Late Miocene age. Only a few bioevents are useful for correlation. From biostratigraphic correlation, age estimates for the base of the Tongaporutuan have ranged from 12.0 to $9.8 \mathrm{Ma}$ (Berggren 1972, 1981, Berggren and Van Couvering 1974; Edwards and Hornibrook 1980; Loutit and Kennett 1981; Edwards 1982b). Previous to this study the only radiometric age relevant in determining an age for the Waiauan - Tongaporutuan, is a $12.9 \mathrm{Ma} \mathrm{K}$-Ar whole rock date from the Dunedin Volcanics (McDougall and Coombs 1973). The dated volcanics occur within the overlap zone of Globorotalia peripheroronda and Globorotalia mayeri (Hornibrook 1977). Hornibrook (1981b) indirectly related the volcanics above the FAD of Globigerina nepenthes, by the appearance of the Waiauan index species Loxostomum 
truncatum, and based on the relative stratigraphic position, estimated a $11.7^{*} \mathrm{Ma}$ for the Waiauan - Tongaporutuan boundary.

At Mangapoike the LAD of Loxostomum truncatum (X19/f100) and the FAD of Bolivinita cf pohana (X19/f98) occur $5 \mathrm{~m}$ below and 15 above, respectively, the Chron 12 - Chron 11 transition dated at 10.3 Ma. Hoskins (pers. comm. 1985) has not recognised Bolivinita quadrilatera within the Mangapoike section. This may not invalidate the biostratigraphic definition of the Tongaporutuan at Mangapoike as Scott (1979a) recognises morphological similarity of $B$. quadrilatera and B. cf pohana and suggests they are closely related. Further Scott (1979a) has recognised B. cf pohana in other lowermost Tongaporutuan sections, suggesting that the Tongaporutuan invasion by Bolivinita may have included both species. The LAD of Loxostomum truncatum and the FAD of B. cf pohana are within 32,000 yrs. of each other, as derived from the sedimentation rate. The base of the Tongaporutuan is placed at the FAD of $B . c f$ pohana, which at Mangapoike is dated at 10.3 Ma.

The Waiauan - Tongaporutuan boundary is postulated to result from glacioeustatism. Both the LAD of $L$. truncatum and the FAD of $B . c f$ pohana are less than 42,000 yrs. younger than the top of the Makaretu sandstone: the late Waiauan glacioeustatic event.

The type section of the Late Miocene Tortonian stratotype is at Rio Mazzapiedi, northern Italy. The base of the tropical foraminiferal Zone N16 (Blow 1969), the FAD of Neogloboquadrina acostaensis, occurs slightly above the base of the section (Cita and Blow 1969). The base of the Tortonian can also be placed within the calcareous nannofossil Zone NN9 (Martini 1971), on the evidence of Discoaster hamatus in the lower Tortonian section. Indistinct microfossil assemblages in the lowest Tortonian however may mean the occurrences of $N$. acostaensis and D. hamatus may not be true appearance and disappearance datums. Consequently, Ryan et al. (1974) and Berggren et al. (1985), with supporting data from Berggren and Van Couvering (1978), have placed the base of the Tortonian at the base of the underlying Zone N15 (LAD of Globorotalia mayeri) and within the NN8 (D. coalitus). Recent DSDP data (Poore et al. 1984; Hsu et al. 1984; Miller et al. 1985; Khan et al. 1985) has required a revised correlation of nannofossil zones with the magnetic polarity timescale, which in turn results in a revised age estimate for the base of the Tortonian. In detailing the new correlations, Berggren et al. (1985) places the Serravallian - Tortonian boundary at the base of Chron 11, giving an age 10.3 Ma (=10.4 Ma of Berggren et al. 1985). Accepting this correlation, the base of the Tongaporutuan is the same age as 
the base of the Tortonian. This magnetostratigraphic correlation is very close to a previous biostratigraphic correlation (Berggren 1972) suggesting the Serravallian Tortonian and the Waiauan - Tongaporutuan boundaries were isochronous at $10.5 \mathrm{Ma}$. Glacioeustatism may account for their isochroneity. The base of the Tongaporutuan is thus also correlated with the base of foraminiferal Zone N15 and with an horizon within calcareous nannofossil Zone NN8.

This magnetostratigraphic correlation of the base of the Tongaporutuan equating with the base of N15 agrees with previous biostratigraphic correlations. When defining New Zealand Neogene foraminiferal zones, Jenkins (1967) considered the Globorotalia miotumida miotumida Zone to be broadly equivalent to the Tongaporutuan, with the base of the zone (the LAD of Globorotalia mayeri) at or very close to the base of the stage. This is still accepted at present (Hoskins 1982). The base of N15, also defined by the LAD of $G$. mayeri has been correlated (Srinivasan and Kennett 1981b) via intermediate zonal schemes to the base of the temperate G. miotumida miotumida Zone (ie approximate base of the Tongaporutuan).

\subsection{GLOBOQUADRINA DEHISCENS: LAST APPEARANCE}

\subsubsection{Stratigraphy}

The last appearance of Globoquadrina dehiscens (Chapman, Parr and Collins) is the most widely used planktic foraminiferal datum within the Tongaporutuan Stage in New Zealand. Low extinction and speciation rates of taxa within the Tongaporutuan, especially within the foraminiferas (Hoskins 1982; Hornibrook 1984b) and the recognition that the Tongaporutuan is the longest Neogene stage (approximatley $4.5 \mathrm{Ma}$ ) has made the last appearance of $G$. dehiscens a significant biostratigraphic datum in New Zealand Neogene stratigraphy. A late Tongaporutuan age for the disappearance of G. dehiscens has been generally determined (Gibson 1963, 1967; Kennett 1965, 1966a, 1966b, 1967a, 1967b; Jenkins 1967, 1971) and has been accepted as a last appearance datum (LAD) by Kennett (1968), Hornibrook and Edwards (1971), Jenkins (1971) and Hornibrook (1981b, 1984b). Within the Tongaporutu type section, a mid to late Tongaporutuan age can be inferred for $G$. dehiscens from the relative stratigraphic thicknesses of Tongaporutuan strata above and below the datum (Gibson 1963, 1967). The LAD of G. dehiscens is one of a number of warm-water planktic foraminifera inferred by Kennett (1968) and Kennett and Watkins (1974) to be diachronous within New Zealand, due to the northward movement of the Antarctic Convergence associated with a climatic cooling in the uppermost Tongaporutuan and Kapitean (Kennett 1967c). 
Younger sporadic records have been reported from Kapitean and Opoitian sediments from three localities (Kennett 1965; Hornibrook 1961; Collen and Vella 1973). The record of G. dehiscens from Blind River by Kennett (1965) is discussed in section 6.5.2. Hornibrook (1961) described G. dehiscens from Kaawa Creek, west Auckland from lower Opoitian sediments. Collen and Vella (1973) tabulated records of $G$. dehiscens from Hinakura Road, south Wairarapa, from Kapitean sediments. These sporadic records of $G$. dehiscens have been interpreted either as reworking, especially those of Kaawa Creek (Hornibrook 1961; Kennett 1968; Jenkins 1971) or as warm-water re-entrants (Collen and Vella 1973; Wright et al. 1985) and have cast some doubt on whether the disappearance of $G$ dehiscens within the Tongaporutuan is a reliable biostratigraphic datum in New Zealand. Recent re-examination of Kaawa Creek and Hinakura Road samples (Hornibrook pers. comm. 1985; Scott pers. comm. 1985; Edwards in prep.) concludes that these records of $G$. dehiscens have been reworked and misidentified, respectively, as previously interpreted (Hornibrook 1961; Kennett 1968; Jenkins 1971).

Scott (1985) has reported from an off-shore well, in the south Taranaki Basin, rare non-typical G. dehiscens morphotypes $100 \mathrm{~m}$ above the extinction of typical $G$. dehiscens specimens within the Tongaporutuan. He has suggested that the rare non-typical forms were warm water re-entrants appearing after the extinction of the typical G. dehiscens population in New Zealand.

Although not clearly established, the last appearance of G. dehiscens within New Zealand seems to be erratic and possibly diachronous. Rare non-typical forms are recorded in the New Zealand region and may represent one or more periods of warm-water re-entry. Dating of the taxon's last appearance within any one section may thus not represent the age of disappearance throughout New Zealand.

Elsewhere a similar erratic termination of $G$. dehiscens is recorded (Berggren 1984b) and has been used as a biostratigraphic datum in middle to late Miocene sediments (Jenkins and Orr 1972; Berggren 1973; Kennett 1973; Jenkins 1975; Kennett and Srinivasan 1981a, 1981b; Keller et al. 1982; Saito 1984). Early Pliocene records of G. dehiscens have also been reported (Blow 1970; Srinivasan and Srivastava 1974; Kennett and Srinivasan 1975). 


\subsubsection{Dating}

The last appearance of G. dehiscens in New Zealand has been paleomagnetically dated from only Blind River previous to this study. The age was based on rare occurrences of G. dehiscens as tabulated by Kennett (1965). Polarity determinations were by Kennett and Watkins (1974) which were subsequently reinterpreted by Loutit and Kennett (1979) using the Late Miocene carbon shift $\left(\delta^{13} \mathrm{C}\right)$. Based on the revised magnetostratigraphy, Hornibrook (1981b, 1984b) reported a $6.2 *$ Ma age for the last appearance of $G$. dehiscens in New Zealand. Re-examination of Kennett's original material, including faunal slides and washes (Hornibrook pers. comm. 1985; Vella pers. comm. 1985) and subsequent resampling of the Blind River section (Scott 1976, 1979b, 1980; Morgans 1980) has not verified the presence of G. dehiscens. Thus as concluded by Edwards (1985) and Wright et al. (1985), G. dehiscens is not present at Blind River and consequently the last appearance is older than 6.6 Ma (Edwards 1985), and the reported age of $6.2 \mathrm{Ma}$ (Hornibrook 1981b, 1984b) is erroneous.

A 9.2 Ma magnetostratigraphic age (Wright et al. 1985) for the last appearance of G. dehiscens at Mangapoike is presented. Correlation of the magnetozones (MN1, MN2, MN3) to the magnetic polarity timescale (Ness et al. 1980), at the disappearance of $G$. dehiscens is confidently placed to the base of Chron 11 through to the base of Chron 10 (Fig. 5.2). The age is derived by the interpolation, over $906 \mathrm{~m}$, from the six accepted polarity transitions within Chron 10 implying a sedimentation rate of $68 \mathrm{~cm} / 1000$ yrs. This rate is extrapolated downwards from the nearest polarity transition (Chron 11 - Chron 10 at $8.98 \mathrm{Ma}$ ) through a uniform lithology of mudstone, giving an age of $9.2 \mathrm{Ma}$ for the datum (X19/f98). The datum was derived from closely spaced samples (Hoskins pers. comm. 1985), and based on the average sedimentation rate, the disappearance of $G$. dehiscens occurs within a period of 25,000 yrs.

The disappearance of $G$. dehiscens at Mangapoike is postulated to be a function of changing climatic conditions (Wright et al. 1985). The stratigraphic position of the datum is $3 \mathrm{~m}$ above a medium-coarse sandstone (Fig. 5.2). This $34 \mathrm{~m}$ thick sandstone is the only lithological change in an otherwise monotonous $1450 \mathrm{~m}$ thick sequence of mudstone. It is suggested here that the sandstone represents a response to a period of cooling with a lowering of sea-level, and that the disappearance of G. dehiscens is related to a corresponding change in paleoceanographic conditions.

Elsewhere, the last appearance of G. dehiscens has been magnetostratigraphically dated from 18.3* to 5.3* (Saito et al. 1975; Keller 1980; Berggren et al. 1983; Poore et al. 1983). 


\subsubsection{Discussion}

The 9.2 Ma date is considered to be the age of the last appearance of G. dehiscens at Mangapoike, and not an extinction date for the taxon throughout New Zealand. Tongaporutuan sections, other than Mangapoike, have ratios of stratigraphic thickness of the 'lower' to 'upper' Tongaporutuan (pre- and post last appearance of G. dehiscens, respectively) of $2: 1$ to $3: 1$. In contrast the ratio at Mangapoike is $1: 3$, indicating the stratigraphic position of the datum is lower within the Tongaporutuan at Mangapoike, and consequently older than elswhere in New Zealand. Acceptance of the Mangapoike date as a synchronous extinction age within the Gisborne region, less than $100 \mathrm{~km}$ northeast of Mangapoike, requires sedimentation rates of $140 \mathrm{~cm} / 1000 \mathrm{yr}$ and 18 $\mathrm{cm} / 1000 \mathrm{yr}$ for 'lower' and 'upper' Tongaporutuan, respectively (Francis pers. comm. 1986). This disparity in the sedimentation rate is not reflected by changes in lithology. Within the Tongaporutu type section similiar changes in the sedimentation rate are implied if the Mangapoike date is accepted as a synchronous extinction age.

The older disappearance of $G$. dehiscens at Mangapoike need not be inconsistent with the inference that it is related to a climatic cooling at that locality. The Mangapoike foraminiferal fauna indicates a restricted oceanic circulation (Hoskins pers. comm. 1985) and as suggested by Ashby (1986) the Wairoa Syncline could well have had a structure similiar to the present day, with closure to the north. A restricted circulation may have produced paleoceanographic conditions close to the ecological threshold of G. dehiscens. Further restriction of circulation, resulting from the inferred cooling event and associated sea-level drop, would intensify the unfavourable paleoceanographic conditions and result in the disappearance of the taxon from Mangapoike. At other localities (ie Gisborne, Tongaporutu Coast) the same cooling event does not result in the disappearance of $G$. dehiscens at this time, due to their presumed open oceanic circulation.

Thus it is suggested the last appearance of G. dehiscens in New Zealand is erratic, and at present the age range of this event is between 9.2 and $>6.6 \mathrm{Ma}$. 


\section{Chapter VII \\ TECTONIC ROTATIONS}

This chapter is a co-authored manuscript discussing the tectonic rotations of the Wairoa Syncline as submitted to the journal Earth and Planetary Science Letters. The second author collected and measured cores from locality 13, and contributed to sections 5 and 6 of the paper. The paper was written by the first author and jointly edited. 
LARGE TECTONIC ROTATION OF PART OF NEW ZEALAND IN THE LAST 5 Ma.

Wright, I. C. and Walcott, R. I.

Research School of Earth Sciences

Victoria University of Wellington

Wellington, New Zealand. 


\section{Abstract}

Detailed paleomagnetic data from the Wairoa Syncline, a middle to late Miocene forearc basin on the East Coast of the North Island, New Zealand, show that the rate of clockwise rotation for the last $5 \mathrm{Ma}$ has been $7-8 \% \mathrm{Ma}$ of which less than $1.5^{\circ} / \mathrm{Ma}$ is due to apparent polar wander. This rotation is similar to a present day rate of $7 \% / \mathrm{Ma}$ determined from geodetic data. Between 5 and $20 \mathrm{Ma}$ ago the rate of tectonic rotation is poorly determined and may be between $0^{\circ}$ and $2^{\circ} / \mathrm{Ma}$.

The change in the rate of rotation of the Wairoa Syncline around $5 \mathrm{Ma}$ is probably related to a markedly different tectonic style in the New Zealand region within the last $5 \mathrm{Ma}$, associated with a change in position of the Euler poles of rotation for the Pacific - Australian plates.

\section{Introduction}

Substantial rotation of the Hikurangi - Kermadec subduction zone between $40 \mathrm{Ma}$ and the present day is suggested by plate reconstructions of the New Zealand region [1,2] based on finite rotations of identified magnetic anomalies along the Antarctic Plate boundary [3]. The position and orientation of the major Kermadec zone is determined by the age of oceanic crust whereas the Hikurangi margin is defined by a zone of deformation in the New Zealand land area (Fig. 1). Paleomagnetic studies of New Zealand Late Cenozoic sediments $[4,5,6]$ have identified a clockwise tectonic rotation of the Hikurangi margin. This zone of Late Cenozoic rotation coincides with a zone of high shear strain rate of $>3 \times 10^{-6} / \mathrm{a}[7,8]$ indicating this deformation continues at present. These data give the orientation and sense of rotation of the Hikurangi plate margin during the Late Cenozoic. The main emphasis of the earlier work has been determining the geographic extent of the deforming zone. The purpose of this paper is to present detailed paleomagnetic data from part of the East Coast of the North Island, New Zealand in the Wairoa Syncline (Fig. 1). These are better constrained in both age and declination and show an increase in the rate of rotation towards the present.

\section{Sampling}

Data from localities $1-6,11$ and 12 (Fig. 1) have been reported previously [5,6] but are included here in the final analysis. The new localities (7-10) are situated within the Mangapoike River section $\left(38.9^{\circ} \mathrm{S}, 177.6^{\circ} \mathrm{E}\right)$, northern Hawkes Bay (Fig. 1) apart from locality 13 which is situated at Waihua Valley, $40 \mathrm{~km}$ southeast of Mangapoike River. 


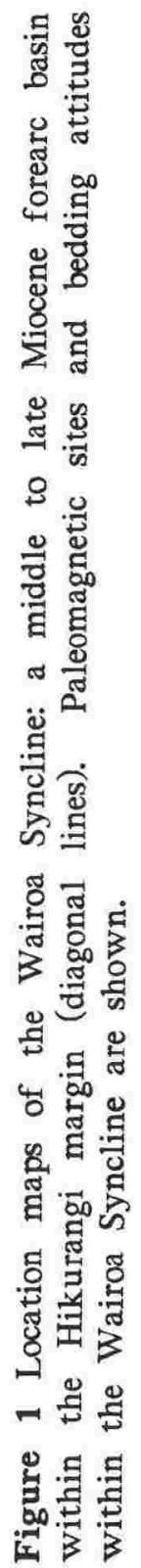




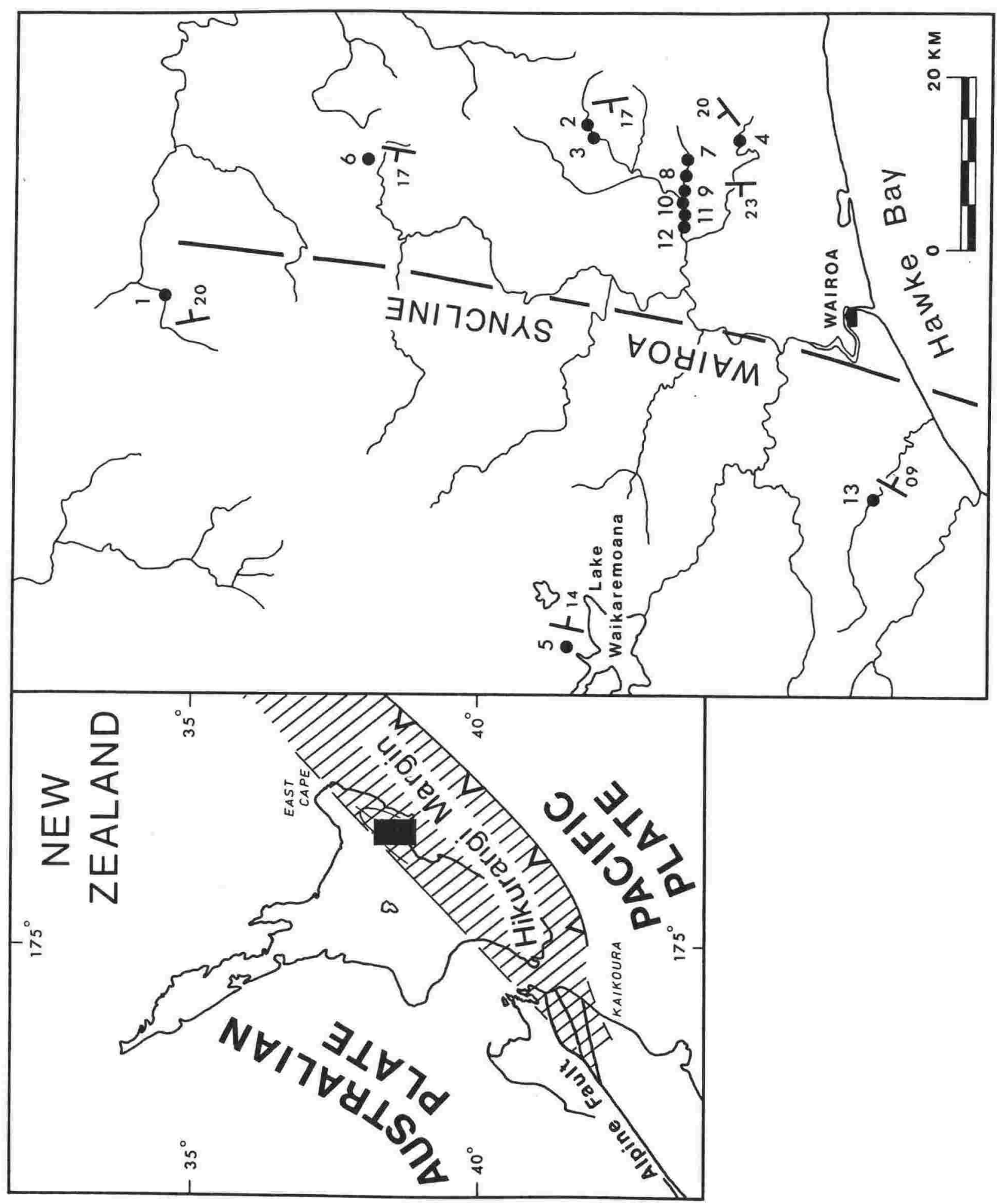


The Mangapoike section is a $5000 \mathrm{~m}$ thick clastic sequence on the eastern limb of the Wairoa Syncline extending from NZMS 1 N106/088177 westwards to N106/916107. The predominant lithology of mudstone is interbedded with sandstones, tuffs and limestones and ranges in age from the Clifdenian Stage (16 Ma) to the Mangapanian Stage (2 Ma). Localities 7-10 are derived from 343 paleomagnetic sites (having at least 3 cores per site) sampled every $5 \mathrm{~m}$ stratigraphically over a $2200 \mathrm{~m}$ part of the Mangapoike sequence where a Late Miocene (10-5 Ma) magnetostratigraphy is being established [9]. Precise site locations and bedding corrections are given in Wright [10]. Locality 10 is the mean of new data and that previously reported [5] from Mangapoike River. Magnetostratigraphic sites were grouped at $1 \mathrm{Ma}$ intervals into localities 7-10 with ages derived from the magnetostratigraphic correlation (Table 1).

The Waihua locality (NZMS 1 N115/641939) on the western limb of the Wairoa Syncline consists of ten cores (thirty-one specimens) sampled over a $10 \mathrm{~m}$ stratigraphic interval from metre bedded calcareous mudstones and sandstones. Bedding is 252/SE/09 in attitude. The first appearance of the planktic foraminifera Globorotalia crassula (base of the Nukumaruan Stage) occurs within $20 \mathrm{~m}$ stratigraphically above the sampled site and an age of 2.4-2.2 Ma for this locality is assigned accordingly [11].

\section{Paleomagnetic Measurements}

All of the orientated specimens (23-25 mm in length) were measured on the two axis ScT cryogenic magnetometer at Victoria University of Wellington. Specimens were measured positive $\mathrm{Z}$-axis down (normal) and negative $\mathrm{Z}$-axis down (inverted) and the four independent $\mathrm{X}$ components, four $\mathrm{Y}$ components and eight $\mathrm{Z}$ components averaged. If the angular difference between normal and inverted modes exceeded $15^{\circ}$ the specimen was rejected. Measurements with magnetisation intensities less than $1.5 \times 10^{-5} \mathrm{Am}^{-1}$ were also rejected. A set of Helmholtz coils reduced the ambient field at the magnetometer mouth to less than $100 \mathrm{nT}$.

Specimens from localities $7-10$ were thermally demagnetised at $200^{\circ} \mathrm{C}, 250^{\circ} \mathrm{C}, 300^{\circ} \mathrm{C}$, $320^{\circ} \mathrm{C}$ and $340^{\circ} \mathrm{C}$, with a viscous magnetisation aligned in the present field direction being removed between $250^{\circ} \mathrm{C}$ and $320^{\circ} \mathrm{C}$ (Fig. 2). Data from mineralogically altered specimens at the $320^{\circ} \mathrm{C}$ and $340^{\circ} \mathrm{C}$ increments, as inferred from a 5 fold increase in volume susceptibility and a 3 fold increase in the magnetisation intensity, were rejected from the analysis. Zijderveld plots were used to assess the optimum demagnetisation step for each individual specimen, and a site mean was calculated using Fisher statistics. Specimens without a clearly established stable end-point were rejected. 

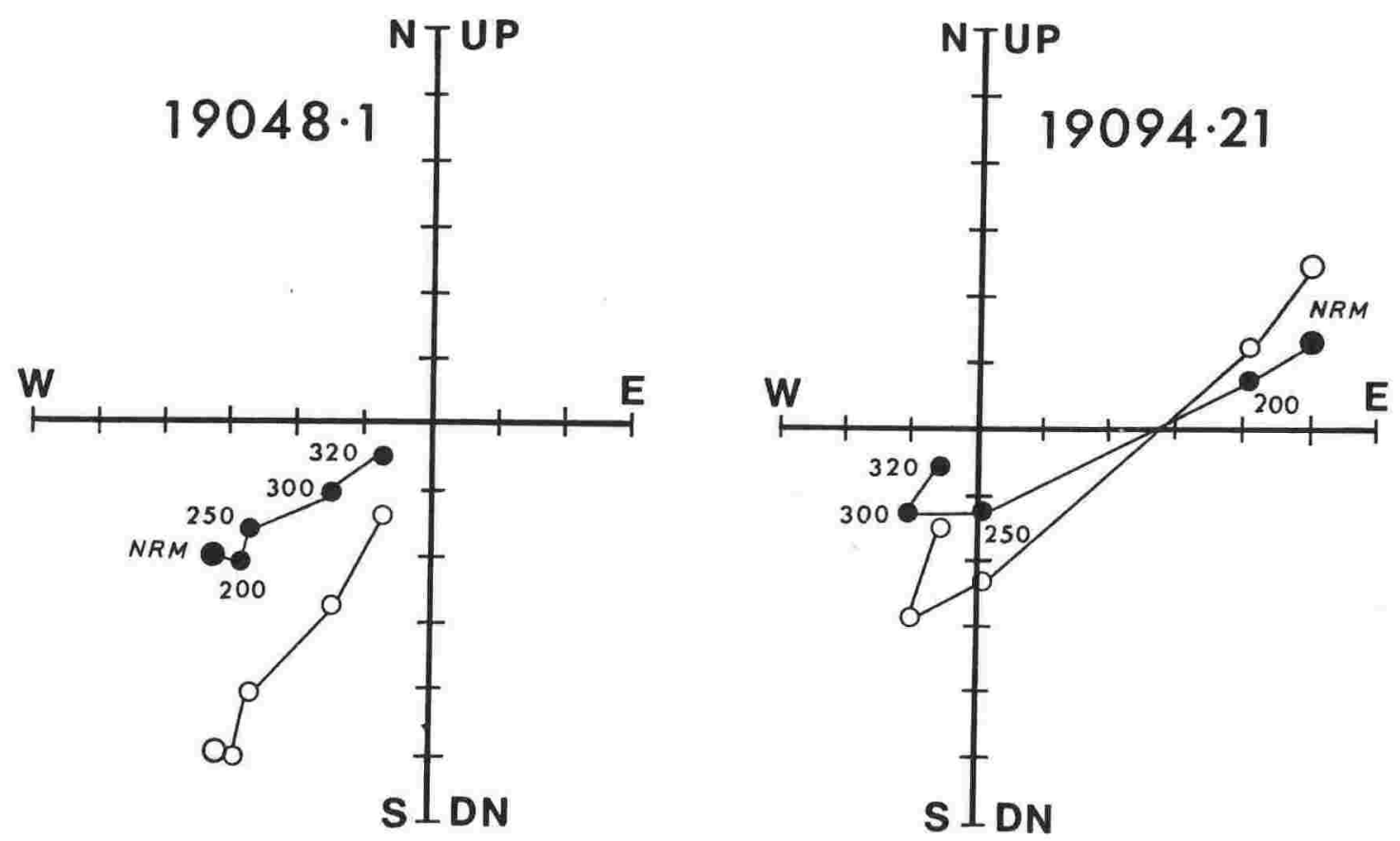

Figure 2 Zijderveld plots of thermally demagnetised specimens. Closed symbols are the projection onto the horizontal plane $(\mathrm{E}, \mathrm{W}, \mathrm{N}, \mathrm{S})$ and open symbols are the projection onto the vertical plane (E,W,Up,Dn). Larger symbols are NRM values, with smaller symbols subsequent demagnetisation levels in ${ }^{\circ} \mathrm{C}$. Intensities are units of $2.5 \times 10^{-4} \mathrm{Am}^{-1}$

Specimen numbers refer to the VUW collection. 


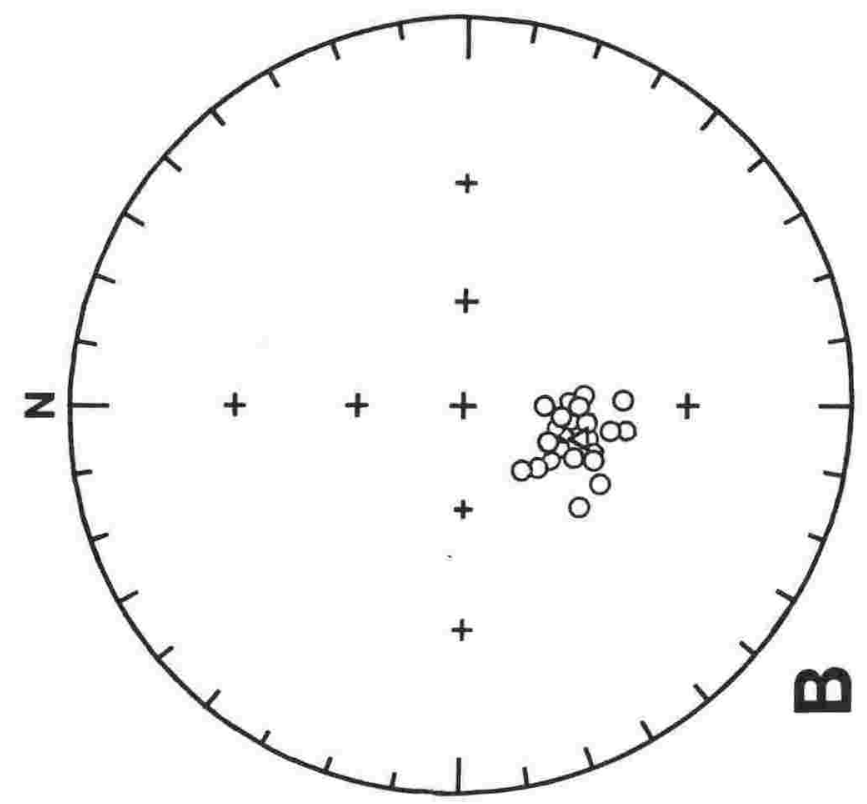

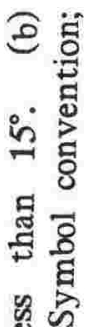

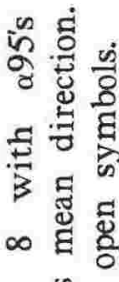

돈

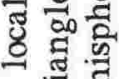

4 要

ङै

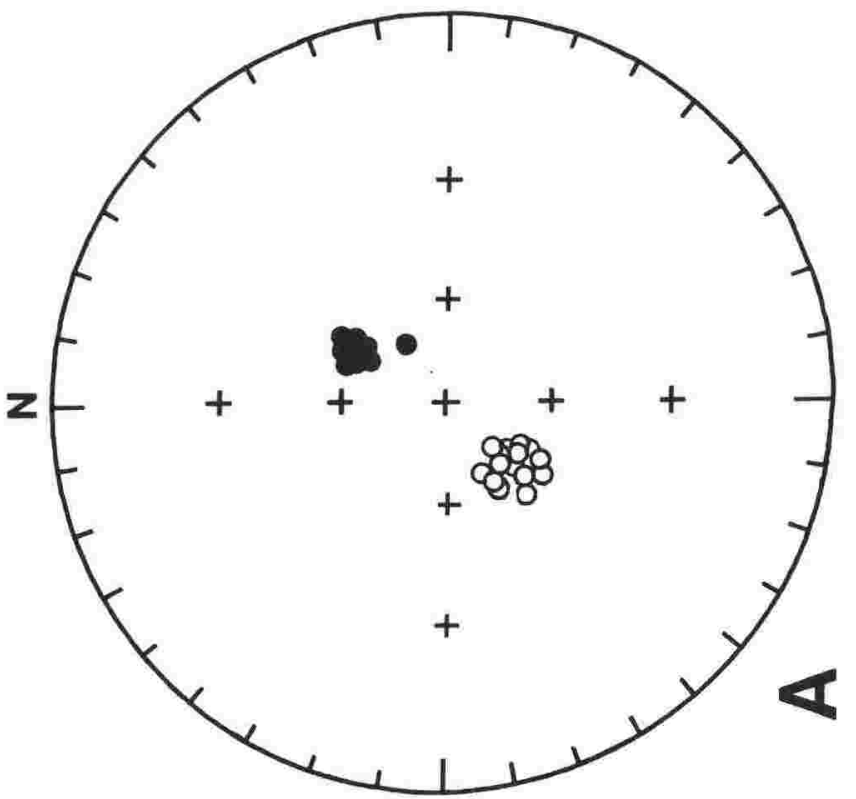

क요응

跑

事

을

สี สี है

丞㟧兽

之 :

Э

o के है

造宽

证害 
Normal and reversed polarity sites with $\alpha 95^{\prime}$ s less than $15^{\circ}$ (Fig. 3a), within each 1 Ma interval (localities 7-10), were again averaged to produce a mean locality direction.

Locality 13 specimens were AF demagnetised at peak fields of 5, 10, 20 and 30 mT. NRM directions were not measured. The minimal scatter of reversed directions at the $20 \mathrm{mT}$ increment (Fig. 3b) was accepted as the representative direction, and were averaged for the locality mean.

\section{Results}

Mean directions and associated Fisher statistics of the thirteen localities, including those reported previously are given in Table 1. Localities dated by foraminifera have been assigned age error limits consistent with the present knowledge of New Zealand Late Cenozoic biostratigraphy. Deviation in the strike of bedding from the regional trend, at locality 4, indicates localised deformation [5] which could explain the anomalously large declination.

\section{Interpretation}

The mean declination direction (Table 1) is the result of both tectonic rotation and any apparent polar wander of the reference geomagnetic pole. A revised Australian Cenozoic apparent polar wander path [13] shows northern apparent movement along the $120^{\circ} \mathrm{E}$ meridian with increasing age. For localities on the Australian plate in New Zealand with a latitude of $38.9^{\circ} \mathrm{S}$ a $1.5^{\circ} / \mathrm{Ma}$ and $1 \% \mathrm{Ma}$ clockwise rotation of the declination is calculated for rocks $12-0 \mathrm{Ma}$ and 26-12 $\mathrm{Ma}$ in age respectively. Pacific paleomagnetic pole positions at $35 \mathrm{Ma}$ and $5 \mathrm{Ma}$ show no apparent polar wander [14] and consequently the expected declination at localities within New Zealand on the Pacific plate is north/south. As the sampling localities lie in the plate boundary zone it is not clear which polar wander path is applicable. The data are presented as the total declination for an axial dipole, (Fig. 4) of which the apparent polar wander for points within the plate boundary zone could be equal to or less than $1.5 \% \mathrm{Ma}$. The paleomagnetic data extrapolated towards the present is consistent with a present day rotation rate of $7^{\circ} / \mathrm{Ma}$, derived from the strain analysis of geodetic data which integrating gives a differential velocity of $75 \mathrm{~mm} / \mathrm{a}$ directed perpendicular to the Hikurangi margin [2]. Comparison of three discrete time intervals at 25-23 Ma, 10-8 $\mathrm{Ma}$ and 2-0 Ma shows the rates of rotation are $2 \% \mathrm{Ma}, 3-4^{\circ} / \mathrm{Ma}$ and $7-8^{\circ} / \mathrm{Ma}$, respectively, of which less than $1.5^{\circ} / \mathrm{Ma}$ is apparent pole rotation. 


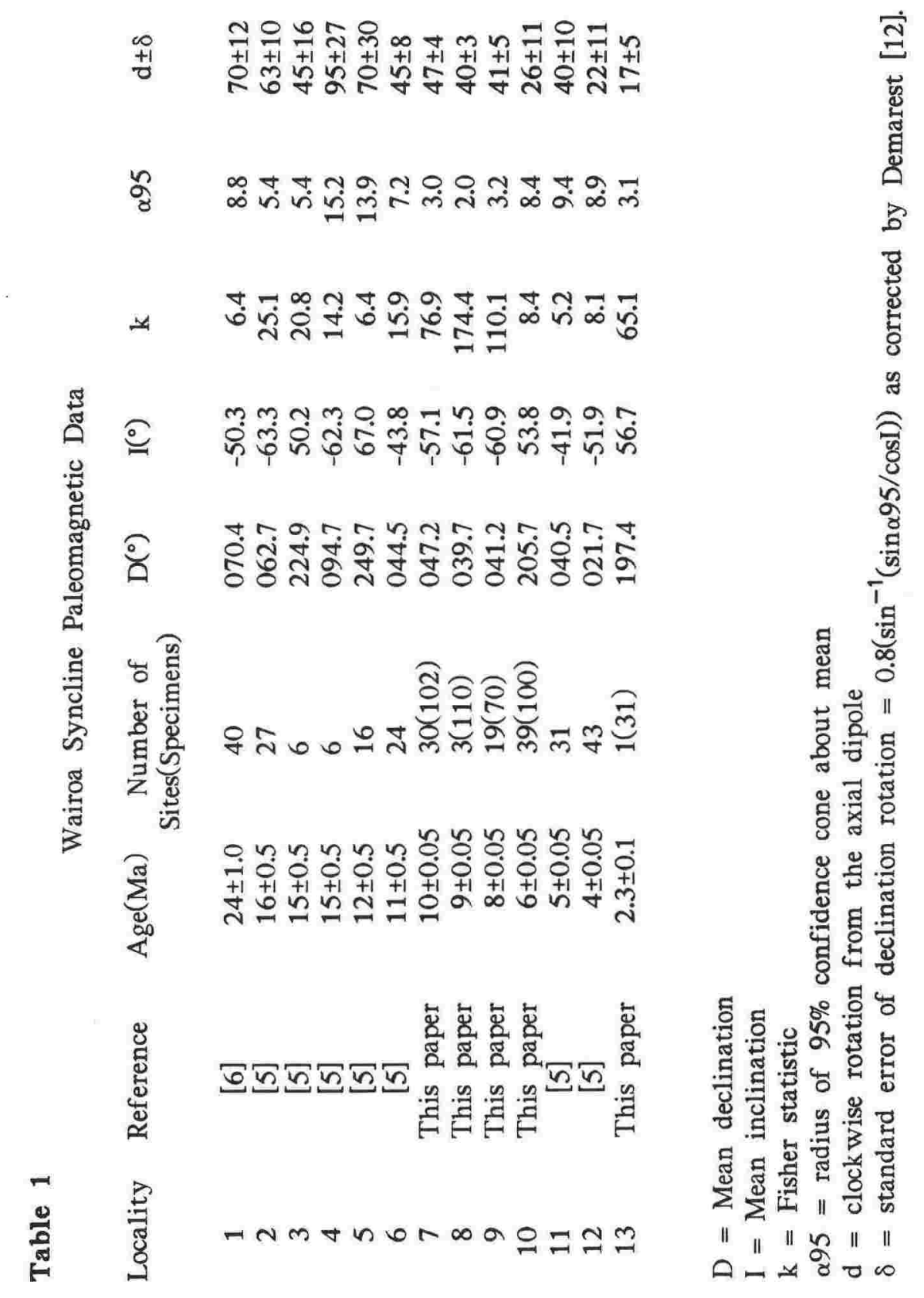




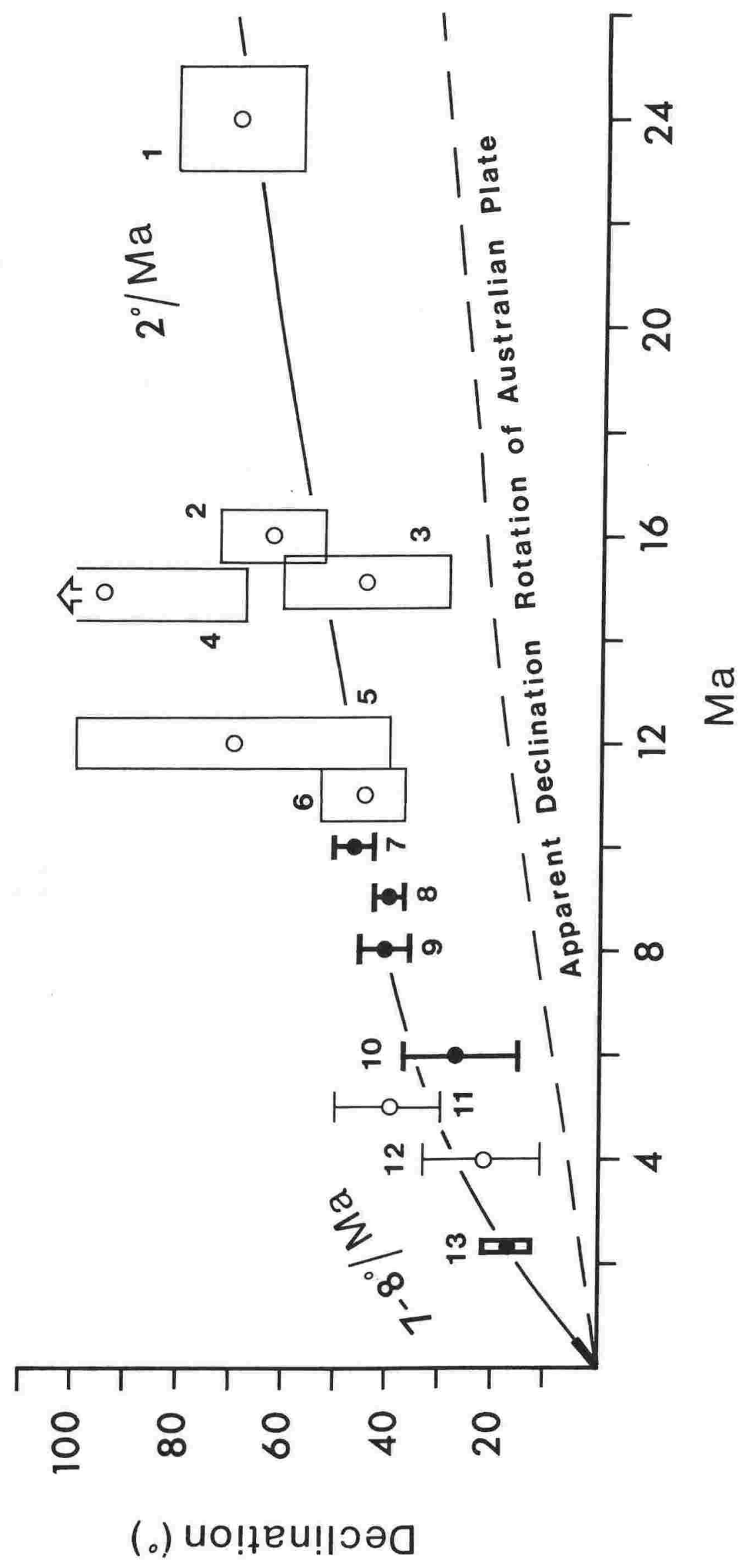

哥急芯

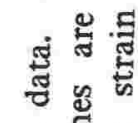

音离

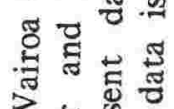

总总

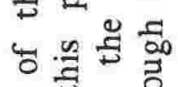

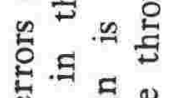

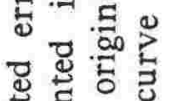

苋这击

要要

며

종

옥

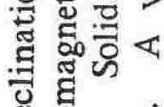

ปู

, 范

舟了。

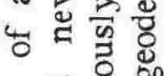

萑若总

- 总吉

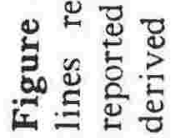




\section{Conclusions}

The Wairoa Syncline, within the Hikurangi margin, shows an increasing rate of clockwise rotation towards the present. The uncertainties in the older data from the Wairoa Syncline are sufficiently large that the rate of rotation prior to about $5 \mathrm{Ma}$ ago could be anywhere between $0^{\circ}$ and $2 \%$ Ma. Indeed, all of the tectonic rotation of some $35^{\circ}$ seen in the Mangapoike River section could have occurred in the last $5 \mathrm{Ma}$ ie. at the same rate as that shown at the present day from geodetic data. Although all of the Hikurangi margin appears to have experienced clockwise rotation, it is possible that the rate may vary from locality to locality.

There is a markedly different tectonic style today than that of the greater part of the Cenozoic which is expressed most generally by the shift in poles of rotation of the Pacific with respect to the Australian Plate. The Euler vector of present day rotation $[15,16]$ is located some $12^{\circ}$ to the southwest of the Euler poles of finite rotation for anomalies 5, 6, 13 and 18, all of which are located within $5^{\circ}$ one another [3]. The shift in the Euler vectors describing the instantaneous rotation will have been even greater.

Major tectonic features of the New Zealand region that have been developing since anomaly 5 (8.9 Ma ago) and which are continuing to develop today include opening of the Lau and Havre Basins [17] starting around $4 \mathrm{Ma}$; opening and volcanicity of the Taupo Volcanic Zone [18] starting about $1 \mathrm{Ma}$; and the growth of the axial ranges of the North Island [19] starting around 0.3 Ma, and the Southern Alps [20] around 2 Ma. To this list we may add the transcurrent faults of the North Island and the Marlborough region, which also possibly started less than $10 \mathrm{Ma}$.

The change in rate of rotation of the Wairoa Syncline around $5 \mathrm{Ma}$ ago (Fig. 4) may represent a much more general change in tectonism of the New Zealand region, involving opening and spreading to the north of New Zealand and compression and shortening to the south. In this sense the rotation of the Wairoa Syncline is a rotation of the whole of the Hikurangi margin.

\section{Acknowledgements}

This work was supported by the Internal Research Committee of Victoria University of Wellington. Thanks are due to J. Cole, S. Lamb and A. Smith for critical comments of earlier drafts of the manuscript. 


\section{REFERENCES}

1 R.I. Walcott, The kinematics of the plate boundary zone through New Zealand: a comparison of short and long-term deformation, Geophys. J. R. astr. Soc. 79, 613-633, 1984.

2 R.I. Walcott, Geodetic strain and the deformational history of the North Island of New Zealand during the Late Cenozoic, Proc. R. Soc. Lon. in press.

3 J. Stock and P. Molnar, Uncertainties in the relative positions of the Australia, Antarctica, Lord Howe and Pacific Plates since the Late Cretaceous, J. Geophys. Res. 87, 4679-4714, 1982.

4 R.I. Walcott, D.A. Christoffel and T.M. Mumme, Bending within the axial tectonic belt of New Zealand in the last 9 Ma from paleomagnetic data, Earth Planet. Sci. Lett. 52, 427-434, 1981.

5 R.I. Walcott and T.M. Mumme, Paleomagnetic study of the Tertiary sedimentary rocks from the East Coast of the North Island, New Zealand, Dept. Sci. Ind. Res. Geophys. Div. Rep. 189, 44pp, 1982.

6 T.M. Mumme and R.I. Walcott, Paleomagnetic studies at Geophysics Division 1980-1983. Dept. Sci. Ind. Res. Geophys. Div. Rep. 204, 62pp, 1985.

7 R.I. Walcott, Present tectonics and Late Cenozoic evolution of New Zealand, Geophys. J. R. astr. Soc. 52, 137-164, 1978.

8 H.M. Bibby, Geodetically determined strain across the southern end of the Tonga Kermadec - Hikurangi subduction zone, Geophys. J. R. atr. Soc. 66, 513-533, 1981.

9 I.C. Wright, Mangapoike River: A Late Miocene magnetostratigraphic reference column for New Zealand, Hornibrook Symposium, extended abstracts, N.Z. Geol. Surv. Rec. 9, 105-107, 1985.

10 I.C. Wright, Paleomagnetic studies of the Late Miocene Mangapoike River section, northern Hawke's Bay, New Zealand, Unpublished PhD thesis, Victoria University of Wellington, in prep.

$11 \mathrm{~N}$ de B. Hornibrook, Globorotalia (planktic Formainiferida) in the Late Pliocene and Early Pleistocene of New Zealand, N.Z. J. Geol. Geophys. 24, 263-292, 1981.

12 H.H. Demarest, Error analysis for the determination of tectonic rotation from paleomagnetic data, J. Geophys. Res. 88, 4321-4328, 1983.

13 M. Idnurm, Late Cretaceous and Cenozoic paleomagnetism of Australia -I. a redetermined apparent polar wander path, Geophys. J. R. astr. Soc. 83, 399-418, 1985.

14 G.W. Grindley, C.J.D. Adams, J.L. Lumb and W.A. Watters, Paleomagnetism, K-Ar dating and tectonic interpretation of Upper Cretaceous and Cenozoic volcanic rocks of the Chatham Islands, N.Z. J. Geol. Geophys. 20, 425-467, 1977. 
15 C.J. Chase, Plate kinematics: the Americas, East Africa and the rest of the world, Earth Planet. Sci. Lett. 37, 353-368, 1978.

16 J.B. Minster and T.H. Jordan, Present-day plate motions, J. Geophys. Res. 83, 5331-5354, 1978.

17 A. Malahoff, R.H. Foden and H.S. Fleming, Magnetic anomalies and tectonic fabric of marginal basins north of New Zealand, J. Geophys. Res. 87, 4109-4125, 1982.

18 J.W. Cole, Distribution and tectonic setting of Late Cenozoic volcanism in New Zealand, in: Late Cenozoic Volcanism in New Zealand, I.E.M. Smith, ed., Roy. Soc. of N.Z. Bull. 23, pp 8-20, 1986.

19 M.A. Ghani, Late Cenozoic vertical crustal movements in the central part of New Zealand, N. Z. J. Geol. Geophys. 21, 117-125, 1978.

20 R.I. Walcott, Plate motion and shear strain rates in the vicinity of the Southern Alps, in: The Origin of the Southern Alps, R.I. Walcott and M.M. Cresswell, eds., Roy. Soc. of N.Z. Bull. 18, pp 5-12, 1979. 


\section{Chapter VIII \\ MAIN CONCLUSIONS AND FUTURE WORK}

\subsection{MAIN CONCLUSIONS}

1. At present, magnetostratigraphy is the most effective means of establishing a chronology for New Zealand's Cenozoic fauna.

2. The Mangapoike River section, northern Hawke's Bay, is an extremely thick and well exposed record of Neogene sedimentation. The finely delineated biostratigraphy of a number of taxa, combined with a magnetostratigraphy, makes the Mangapoike section an important reference sequence in New Zealand Neogene stratigraphy.

3. Titanomagnetite $(x=0.17-0.37)$, is the sole identifiable remanent magnetic mineral in the Mangapoike sediments, the chemistry of which does not vary with grain size. Oxidation of the titanomagnetite is deuteric, and thus pre-depositional. Authigenic or diagenetic remanent carrying minerals are not recognised.

4. Fluctuations of titanomagnetite concentration between $10^{-3}$ to $10^{-4} \mathrm{wt} \%$ are the main influence on NRM intensity variation. The presence of silicic tuffs, within the Mangapoike sequence, does not influence either volume susceptibility of NRM intensity.

5. A viscous remanence is recognised within the NRM measurements of some specimens, and is characterised by both viscous decay and acquisition over laboratory time. A viscous magnetisation aligned in the present field direction is also recognised. These viscous magnetisations are residing in either multidomain titanomagnetite or titanomagetite with a high degree of cation substitution. Some specimens have reversed polarity NRM directions and thus a remanent stability at least greater than $0.72 \mathrm{Ma}$.

6. Secondary magnetisations are removed by thermal demagnetisation at variable temperatures between $200^{\circ} \mathrm{C}$ and $320^{\circ} \mathrm{C}$. Mineralogical alteration occurred at temperatures between $300^{\circ} \mathrm{C}$ and $340^{\circ} \mathrm{C}$ as indicated by both a five fold increase in volume susceptibility and a three fold increase in magnetisation intensity.

7. Six normal (MN1 - MN6) and seven reversed (MR1 - MR7) polarity magnetozones are identified within the late Miocene at Mangapoike. Only one normal magnetozone (MN6) is recognised in the stratigraphic interval equivalent to that from which Kennett 
and Watkins (1974) reported two normal zones, correlated as C1 and C2. MN6 is correlated to C2. Magnetozone C1 of Kennett and Watkins (1974) is inferred to be an uncleaned normal overprint.

8. Biostratigraphic data and a fission-track age at Mangapoike constrain correlations of the magnetozones to a time interval between 11 and $5 \mathrm{Ma}$. The magnetozones are correlated to Chrons 11 to 4 , with an average sedimentation rate of $64 \mathrm{~cm} / 1000$ yrs. Based on the preferred magnetostratigraphic interpretation, a previously unrecognised unconformity is inferred from at least 6.86 to at least $6.42 \mathrm{Ma}$. The presence of the unconformity is supported by benthic foraminiferal and radiolarian biostratigraphy. The Miocene - Pliocene $3^{\circ}$ angular unconformity at Mangapoike represents the period from $6.3 \mathrm{Ma}$ to at least $5.41 \mathrm{Ma}$.

9. The random relationship between the degree of bioturbation and in-site dispersion at individual sites indicates that the magnetisation is acquired after bioturbation, and thus is a post-depositional detrital magnetisation. The time lag between deposition and magnetisation acquistion is about 1000 yrs. Bioturbation has not modified the reversal stratigraphy.

10. Three distinct lithological events at Mangapoike, based on the age synchroneity with both deep-sea benthic $\delta^{18} \mathrm{O}$ records and the 'Vail - curve', are inferred to result from glacioeustatism. Confirmation of the three postulated correlations from a direct record of glacioeustatism at Mangapoike may prove difficult.

11. Correlation of the late Miocene and early Pliocene magnetostratigraphies and biostratigraphies of on-shore New Zealand with either of the magnetostratigraphic interpretations of DSDP Site 594 produces an unacceptably high diachroneity of some planktic taxa of $1.8 \mathrm{Ma}$ over $3.6^{\circ}$ of latitude. Of four possiblities, to resolve the anomaly, incorrect magnetostratigraphic correlations at Site 594 is the most likely.

12. The last appearance datum (LAD) of Globoquadrina dehiscens is an important bioevent in New Zealand's Neogene biostratigraphy. The previous age of $6.2 \mathrm{Ma}$ for this datum in New Zealand is erroneous. A magnetostratigraphic age for the LAD of G. dehiscens at Mangapoike is $9.2 \mathrm{Ma}$. This age is not the extinction date for the taxon throughout New Zealnd. The datum may also be diachronous within New Zealand. 
13. The Waiauan - Tongaporutuan boundary, as recognised by the incoming of Bolivinita cf pohana lineage, has a magnetostratigraphic age of 10.3 Ma. Both the LAD of Loxostomum truncatum and the FAD of Bolivinita $c f$ pohana are less than 42,000 yrs. younger than the late Waiauan glacioeustatic event. The Waiauan Tongaporutuan boundary is thus postulated to result from this glacioeustatic event. Based on age synchroneity, the base of the Tongaporutuan is correlated with the base of the Tortonian stratotype, base of foraminiferal Zone N15 and within calcareous nannofossil Zone NN8. Glacioeustatism may explain the excellent age correlation between the base of the Tongaporutuan and the base of the Tortonian stratotype.

14. Declination directions from the Wairoa Syncline show the rate of clockwise rotation for the last $5 \mathrm{Ma}$ has been $7-8^{\circ} / \mathrm{Ma}$ of which less than $1.5 \% \mathrm{Ma}$ is due to apparent polar wander. Extrapolation of the $7-8^{\circ} / \mathrm{Ma}$ rotation rate for the last $5 \mathrm{Ma}$ towards the present, is consistent with a present day rate of $7 \%$ Ma derived from strain anaylsis of geodetic data. The rotation rate prior to $10 \mathrm{Ma}$ is not well constrained and may vary between $3 \% \mathrm{Ma}$ and $0 \% \mathrm{Ma}$. The change in the rate of rotation at about $5 \mathrm{Ma}$ is associated with a markedly different tectonic regime in New Zealand, and in particular a shift in the Euler pole of rotation for the Australian - Pacific plates.

\subsection{FUTURE WORK}

Further magnetostratigraphic study of New Zealand Cenozoic sediments is critical in establishing a reliable local chronology for Cenozoic biostratigraphy and paleoclimatology. This is especially important, with respect to the present correlation programme of the New Zealand Geological Survey's Upper Cretaceous and Cenozoic Project (CCP). To date, correlation of New Zealand's Cenozoic marine and terrestrial sequences has been difficult, and magnetostratigraphy may prove to be the only means of precise correlation. The assumed isochroneity of certain taxa and the diachroneity of others has not been fully tested within New Zealand, even though these taxa are used extensively in biostratigraphic correlation. A local chronology would validate these assumptions. The development of an older magnetostratigraphy in New Zealand would provide chronological constraint on the regional off-shore deep-sea stratigraphy. New Zealand's exposed Cenozoic sequences may also provide the only means of establishing a detailed record of paleoceanographic and paleoclimatic changes associated with Antarctic glaciation.

The integration of future magnetostratigraphy with stable isotope stratigraphy, lithostratigraphy and detailed macro and micro biostratigraphy in a co-operative project 
is strongly recommended. Relevant data on the mineralogy, timing and stability of the remanent magnetisation must also be an integral part of any future magnetostratigraphic study. A clear understanding of the origin of the remanent magnetisations may result in a need for varied demagnetisation proceedures and the recognition of magnetozones in other wise rejected sections.

The following suggestions for future research are ranked in importance and are:

1. Establish magnetostratigraphic reference columns for each of the New Zealand Cenozoic stages in both marine and terrestrial sequences. Although ambitious, such a long term study would provide a precise chronology for paleoceanographic, paleoclimatic and paleogeographic studies of the New Zealand Cenozoic. Specific problems in New Zealand stratigraphy would also be resolved (ie the position of the Oligocene - Miocene boundary in New Zealand.

2. Establish a Tongaporutuan magnetostratigraphy in the southern South Island. A Tongaporutuan magnetostratigraphy at a higher paleolatitude would validate the isochroneity of planktic and benthic datums in New Zealand. The assumed diachroneity of the last appearnace of Globoquadrina dehiscens within New Zealand could also be demonstrated.

3. Establish a oxygen and carbon isotope stratigraphy at Mangapoike from both planktic and benthic taxa. This would provide the first dated and quantitative paleoclimatic record for the Tongaporutuan. Such an isotopic record may also validate the postulated glacioeustatic correlations.

4. Establish a magnetostratigraphy in the Tongaporutuan type section. An age for the Waiauan - Tongaporutuan boundary, as defined by the incoming of Bolivinita quadrilatera in the type section would reveal any diachroneity of this taxon between the east and wast coasts of the North Island. The erratic and assumed diachroneity of the last appearance of Globoquadrina dehiscens would also be established. 


\section{REFERENCES}

Adams, C.G., Benson, R.H., Kidd, R.B. Ryan, W.B.F. and Wright, R.C., 1977. The Messinian salinity crisis and evidence of late Miocene eustatic changes in the world ocean. Nature 269: 383-386.

Adams, C.J.D., 1975. New Zealand potassium-argon age list - 2. New Zealand Journal of Geology and Geophysics 18: 443-467.

Ade-Hall, J.M., 1963. Election probe microanalyses of basaltic titanomagnetites and their significance to rock magnetism. Geophysical Journal of the Royal Astronomical Society 8: 301-312.

Ade-Hall, J.M., 1964. A correlation between remanent magnetisation and petrology and chemical properties of Tertiary basalts from Mull, Scotland. Geophysical Journal of the Royal Astronomical Society 8: 403-423.

Ager, D.V., 1973. The Nature of the Stratigraphic Record. New York, Macmillan. $114 \mathrm{p}$.

Akimoto, S., 1962. Magnetic properties of $\mathrm{FeO}-\mathrm{Fe}_{2} \mathrm{O}_{3}-\mathrm{TiO}_{2}$ system as a basis of rock magnetism. Journal of the Physical Society of Japan 17: 706-710.

Allan, R.S., 1933. On the System and Stage names applied to subdivisions of Tertiary strata in New Zealand. Transactions of the New Zealand Institute 63: 81-108.

Andrews, P.B., 1982. Revised guide to recording field observations in sedimentary sequences. New Zealand Geological Survey Report 102. 74pp.

Ashby, J.N., 1985. Upper Neogene radiolarian zonation for the East Coast Deformed Belt, New Zealand. In: Hornibrook Symposium, 1985, extended abstracts, New Zealand Geological Record 9: 5-7.

Ashby, J.N., 1986. Upper Neogene Radiolarian from the East Coast Deformed Belt, New Zealand. Unpublished $\mathrm{PhD}$ Thesis, Victoria University of Wellington.

Bandy, O.L., Hornibrook, N. de B. and Schofield, J.C., 1970. Age relationships of the Globigerinoides trilobus zone and the andesite at Muriwai Quarry, New Zealand. New Zealand Journal of Geology and Geophysics. 13: 980-995.

Banerjee, S.K., 1981. Experimental methods of rock magnetism and paleomagnetism. In: Saltzman (Ed.) Advances in Geophysics 23: 25-99.

Banner, F.T. and Blow, W.H., 1965. Progress in the planktic foraminiferal biostratigraphy of the Neogene. Nature 208: 1164-1166.

Barron, J.A., Keller, G. and Dunn, D.A., 1985. A multiple microfossil biochronolgy for the Miocene. In Kennett, J.P. (Ed.) The Miocene Ocean: Paleoceanography and Biogeography. Geological Society of America Memoir 163: 21-36.

Barton, C.E. and Bloemendal, J., 1986. Paleomagnetism of sediments collected during Leg 90, Southwest Pacific. In: Kennett, J.P., von der Borch, C.C., et al., Initial Reports DSDP, 90: Washington (US Government Printing Office) pp 1273-1316. 
Bates, T.E., 1967. The geology of the northern Aorangi Range and part of the Palliser Bay Sheet N165. Unpublished MSc Thesis, Victoria University of Wellington.

Berggren, W.A., 1972. A Cenozoic time-scale: some implications for regional geology and paleobiogeography. Lethaia 5: 195-215.

Berggren, W.A., 1973. The Pliocene Time Scale: Calibration of planktonic foraminiferal and calcareous nannoplankton zones. Nature 243: 391-397.

Berggren, W.A., 1981. Correlation of Atlantic, Mediterranean and Indo-Pacific Neogene stratigraphies: Geochronology and chronostratigraphy. Proceedings of the International Correlation Programme (IGCP 114) International Workshop on Pacific Neogene Biostratigraphy. 6th International Working Group Meeting 1981, Osaka, Japan.

Berggren, W.A., 1984a. Correlation of Atlantic, Mediterranean, and Indo-Pacific Neogene stratigraphies: Geochronology and chronostratigraphy. In: Ikebe, N. and Tsuchi, R. (Eds.), Pacific Neogene Datum Planes: Contributions to Biostratigraphy and Chronology (IGCP -114). University of Tokyo Press. pp 93-110.

Berggren, W.A., 1984b. Neogene planktonic foraminiferal biostratigraphy and biogeography: Atlantic, Mediterranean, and Indo-Pacific regions. In: Ikebe, N. and Tsuchi, R. (Eds.), Pacific Neogene Datum Planes: Contributions to Biostratigraphy and Chronology (IGCP -114). University of Tokyo Press. pp 111-161.

Berggren, W.A., Aubry, M-P. and Hamilton, N., 1983. Neogene magnetostratigraphy of DSDP Site 516 (Rio Grande Rise, South Atlantic). In: Barker, P., Johnson, D., et al., Initial Reports DSDP, 72: Washington (US Government Printing Office). pp 675-706.

Berggren, W.A. and Haq, B.U., 1976. The Andalusian Stage (late Miocene): biostratigraphy, biochronology and paleoecology. Palaeogeography, Palaeoclimatology, Palaeoecology 20: 67-129.

Berggren, W.A., Kent, D.V. and Van Couvering, J.A., 1985. Neogene geochronology and chronostratigraphy. In: Snelling, N.J., (Ed.) Geochronology and the geologic time scale. Geological Society of London, Memior 20. pp 211-260.

Berggren, W.A., Nakagawa, N., Saito, T., Shackleton, N.J. and Shibata, K., 1984. Neogene magnetostratigraphy and chronostratigraphy. In: Ikebe, N. and Tsuchi, R. (Eds.), Pacific Neogene Datum Planes: Contributions to Biostratigraphy and Chronology (IGCP -114). University of Tokyo Press. pp 83-84.

Berggren, W.A. and Van Couvering, J.A., 1974. The Late Neogene: biostratigraphy, geochronology, and paleo-climatology of the last 15 million years in marine and continential sequences. Palaeogeography, Palaeoclimatology, Palaeoecology 16: 1-216.

Berggren, W.A. and Van Couvering, J.A., 1978. Biochronology. In Cohee, G.V., Glaessner, M.F. and Hedberg, H.D. (Eds.) Contributions to the Geologic Timescale. American Association of Petroleum Geologists, Studies in Geology 6: 39-55.

Biquand, D. and Prevort, M. 1971. AF demagnetisation of viscous remanent magnetisation in rocks. Journal of Geophysics 37: 471-485.

Blakely, R.J., 1974. Geomagnetic reversals and crustal spreading rates during the Miocene. Journal of Geophysical Research 79: 2979-2985.

Blakely,. R.J. and Cox, A., 1972. Evidence for short geomagnetic polarity intervals in the early Cenozoic. Journal of Geophysical Research 77: 7065-7072. 
Blom, W.M., 1982. Sedimentology of the Tokomaru Formation, Waiapu Subdivision, Raukumara Peninsular. Unpublished Msc Thesis, University of Auckland.

Blow, W.H., 1969. Late middle Eocene to Recent planktic foraminiferal biostratigraphy. In: Bronnimann, P. and Renz, H.H., (Eds.) First International Conference on Planktic Microfossils Geneva. pp 199-421.

Blow, W.H., 1970. Deep Sea Drilling Project, Leg 3 , foraminifera In: Maxwell, A.E., et al., Initial Reports DSDP, 3: Washington (US Govermnet Printing Office) pp 629-661.

Briden, J.C., 1972. A stability index of remanent magnetism. Journal Geophysical Research 77: 1401-1405.

Brown, B.R., 1961. Mangaone-1. BP Shell and Todd Development LTD. Petroleum Report No. 320.

Brown, B.R., 1962. Miocene sedimentation in the Wairoa Basin and adjacent areas. BP Shell and Todd Development LTD. Petroleum Report No. 372.

Brunstrom, R.G.W., 1962. Isopach/facies maps of the region from Te Aute to East Cape, North Island, New Zealand. BP Shell and Todd Development LTD. Petroleum Report No. 374.

Bolli, H.M., 1970. The foraminifera of Sites 23-31. In: Bader, R.G., et al., Initial Reports DSDP, 4: Washington (US Government Printing Office) pp 577-643.

Bose, M.K., 1958. Goethite-hematite relation - an ore microscope observation. American Mineralogist. 43: 989.

Buddington, A.F. and Lindsley, D.H., 1964. Iron-titanium oxide minerals and synthetic equivalents. Journal of Petrology 5: 310-357.

Burckle, L.H., Keigwin, L.D. and Opdyke, N.D., 1982. Middle and late Miocene stable isotope stratigraphy: correlations to the paleomagnetic reversal record. Micropaleontology 28: 329-324.

Cande, S. and LaBrecque, J.L., 1974. Behaviour of the earth's paleomagnetic field from small scale marine magnetic anomalies. Nature 247: 26-28.

Carmicheal, I.S.E., 1967. The iron-titanium oxides of salic volcanic rocks and their associated ferromagnesian silicates. Contributions to Mineralogy and Petrology 14: 36-64.

Caulet, J.P., 1986. Radiolarians from the southwest Pacific. In: Kennett, J.P., von der Borch, C.C., et al., Initial Reports DSDP, 90: Washington (US Government Printing Office) pp 835-861.

Ciesielski, P.F., 1986. Middle Miocene to Quaternary diatom biostratigraphy of Deep Sea Drilling Project Site 594, Chatham Rise, southwest Pacific. In: Kennett, J.P., von der Borch, C.C., et al., Initial Reports DSDP, 90: Washington (US Government Printing Office) pp 863-885.

Channell, J.E.T., 1977. Paleomagnetism of limestones from the Gargano Peninsula (Italy) and the implications of these data. Geophysical Journal of the Royal Astronomical Society 51: 605-616.

Chaproniere, G.C.H., 1969. Geology of the Te Araroa Area, East Cape. Unpublished MSc Thesis, University of Auckland. 146pp. 
Chiji, M. and Konda, I., 1978. Planktic foraminiferal biostratigraphy of the Tomioka Group and the Nishiyatsushiro and Shizukawa Groups, Central Japan, with some considerations of the Kaburan Stage (Middle Miocene). Cenozoic Geology of Japan. Osaka. pp 73-92.

Cita, M.B., 1976. Biodynamic effects of the Messinian salinity crisis on the evolution of planktic foraminifers in the Mediterranean. Palaeogeography, Palaeoclimatology, Palaeoecology 20: 23-42.

Cita, M.B. and Blow, W.H., 1969. The biostratigraphy of the Langhian, Serravallian and Tortonian Stages in the type sections in Italy. Rivista Italiana Paleontologia 75: 549-603.

Claesson, C., 1978. Swedish Ordovician limestones: problems in clarifying their directions of magnetisations. Physics of Earth and Planetary Interiors 16: 65-72.

Collen, J.D. and Vella, P.P., 1973. Pliocene planktonic foraminifera, southern North Island, New Zealand. Journal of Foraminiferal Research 3: 13-29.

Collinson, D.W., 1983. Methods In Rock Magnetism and Paleomagnetism: Techniques and Instrumentation. Chapman and Hall, New York, 503pp.

Coombs, D.S. and Hatherton, T., 1959. Paleomagnetic studies of Cenozoic volcanic rocks in New Zealand. Nature 184: 883-884.

Cox, A., 1968. Lengths of geomagnetic polarity intervals. Journal of Geophysical Research 73: $3247-3260$.

Cox, A., 1969. Geomagetic reversals. Science 163: 237-245.

Cox, A., 1981. A stochastic approach towards understanding the frequency and polarity bias of geomagnetic reversals. Physics of Earth and Planetary Interiors 24: $178-190$.

Creer, K.M., 1957. The remanent magnetisation of unstable Keuper marls. Philosophical Transactions of the Royal Society of London A250: 130-143.

Creer, K.M., Anderson, T.W. and Lewis, C.M.F., 1976. Late Quaternary geomagnetic stratigraphy recorded in Lake Erie sediments. Earth and Planetary Science Letters 31: 37-47.

Creer, K.M. and Ibbetson, J., 1970. Electron microprobe analyses and magnetic properties of non-stoichiometric titanomagnetites in basaltic rocks. Geophysical Journal 21: 485-511.

Creer, K.M. and Stephenson, A., 1972. Some consequences of aluminium and magnesium impurities in naturally occurring titanomagnetites. Journal of Geophysical Research 77: 3698-3710.

Damuth, J.E., 1977. Late Quaternary sedimentation in the western equatorial Atlantic. Geological Society of America Bulletin 88: 695-710.

Day, R., Fuller, M. and Schmidt, V.A., 1977. Hysteresis properties of titanomagnetites: grain size and compositional dependence. Physics of Earth and Planetary Interiors 13: 260-267.

Devereux, I., Hendy, C.H. and Vella, P.P., 1970. Pliocene and early Pleistocene sea temperature fluctuations, Mangaopari Stream, New Zealand. Earth and Planetary Science Letters 8: 163-168. 
Dott, R.H. Jr., 1983. Episodic sedimentation-How normal is average? How rare is rare? Does it matter? Journal of Sedimentary Petrology 53: 5-23.

Dunlop, D.J., 1969. Comments on a paper by R.L. Wilson and P.J. Smith: The nature of secondary natural magnetisations in igneous and baked rocks. Journal of Geomagnetism and Geoelectricity 21: 797-799.

Dunlop, D.J., 1971. Magnetic properties of fine-particle haematite. Annales de Geophysique 27: 269-293.

Dunlop, D.J., 1972. Magnetic mineralogy of unheated and heated red sediments by coercivity spectrum analysis. Geophysical Journal Royal Astronomical Society 27: $37-55$.

Dunlop, D.J., 1973. Theory of the magnetic viscosity of lunar and terresterial rocks. Reviews of Geophysics and Space Physics 11: 855-901.

Dunlop, D.J., 1979. On the use of Zijderveld vector diagrams in multicomponent paleomagnetic studies. Physics of the Earth and Planetary Interiors 20: 12-24.

Edwards, A.R., 1982a. International correlation. In: Hoskins, R.H. (Ed.) Stages of the New Zealand marine Cenozoic: A synopsis. New Zealand Geological Survey Report 107. pp 18-22.

Edwards, A.R., 1982b. Caleareous nannofossils. In: Hoskins, R.H. (Ed.) Stages of the New Zealand Marine Cenozoic: A synopsis. New Zealand Geological Survey Report 107. pp 23-27.

Edwards, A.R., 1985. A new integrated stratigraphy model for the Late Neogene of New Zealand. In Hornibrook Symposium, 1985, extended abstracts. New Zealand Geological Survey Record 9: 41-43.

Edwards, A.R., in prep. An integrated biostratigraphy, magnetostratigraphy and oxygen isotope stratigraphy for the late Neogene of New Zealand.

Edwards, A.R. and Hornibrook, N. de B., 1980. An integrated bio- and magnetostratigraphy of the Late Miocene to Pleistocene of the New Zealand Region. abstract. Geological Society of New Zealand, Christchurch Conference 1980. p 35 .

Edwards, A.R. and Perch-Nielsen, K., 1975. Calcareous nannofossils from the southern southwest Pacific. In: Kennett, J.P., Houtz, R.E. et al. Initial Reports DSDP, 29: Washington (US Government Printing Office) pp 469-539.

Elmstrom, K.M. and Kennett, J.P., 1986. Late Neogene paleoceanographic evolution of Site 590: southwest Pacific. In Kennett, J.P., von der Borch, C.C. et al., Initial Reports DSDP, 90: Washington (US Government Printing Office) pp 1361-1381.

Elston, D.P. and Purucker, M.E., 1979. Detrital magnetisation in red beds of the Moenkopi Formation (Triassic), Gray Mountain, Arizona. Journal of Geophysical Research. 84: 1653-1665.

Evans, A.L., 1970 Geomagnetic polarity reversals in a Late Tertiary lava sequence from the Akaroa volcano, New Zealand. Geophysical Journal of the Royal Astronomical Society 21: 163-183.

Evans, M.E. and Wayman, M.L., 1970. An investigation of small magnetic particles by means of electron microscopy. Earth and Planetary Science Letters 9: 365-370. 
Ferrand, J., 1965. The Mangaone - Morere uplift; geology and oil prospects. NZ Aquitaine Petroleum LTD. Petroleum Report No. 470.

Finlay, H.J., 1939. New Zealand foraminifera: Key species in the stratigraphy. Royal Society New Zealand Transactions 68: 530.

Finlay, H.J. and Marwick, J., 1940. The division of the Upper Cretaceous and Tertiary in New Zealand. Transactions of the Royal Society of New Zealand 70: 77-135.

Finlay, H.J. and Marwick, J., 1947. New divisions of the New Zealand Upper Cretaceous and Tertiary. New Zealand Journal of Science and Technology 28: 228-236.

Fisher, R.A., 1953. Dispersion on a sphere. Proceedings of the Royal Society of London 217: 295.

Foster, J.H. and Opdyke, N.D., 1970. Upper Miocene to Recent magnetic stratigraphy in deep-sea sediments. Journal of Geophysical Research 75: 4465-4473.

Froggatt, P.C., 1982. A study of some aspects of the volcanic history of the Lake Taupo area, North Island, New Zealand. Unpublished PhD Thesis, Victoria University of Wellington.

Froggatt, P.C. and Gosson, G.J., 1982. Techniques for the preparation of tephra samples for mineral and chemical analysis and radiometric dating. Geology Department Internal Publication No. 23, VUW. 12pp.

Geiger, M.E., 1962. Planktic foraminiferal zones in the Upper Tertiary of Taranaki, New Zealand. New Zealand Journal of Geology and Geophysiscs 5: 304-308.

Ghent, E.D. and Henderson, R.A., 1966. Petrology, sedimentation and paleontology of Middle Miocene graded sandstones, and mudstones, Kaiti Beach, Gisborne. Transactions of the Royal Scoiety, Geology 4: 147-169.

Gibson, G.W, 1963. Some Miocene stratigraphy and paleontology: the Tongaporutuan Stage. Unpublished $\mathrm{PhD}$ Thesis, Victoria University of Wellington.

Gibson, G.W., 1967. Foraminifera and stratigraphy of the Tongaporutuan Stage in the Taranaki Coast and six other sections. Transactions of the Royal Society of New Zealand, Geology 5: 1-70.

Giddings, J.W. and McElhinny, M.W., 1976. A new index of paleomagnetic stability for magnetite bearing rocks. Geophysical Journal of the Royal Astronomical Society 44: 239-252.

Glass, B.P., 1969. Reworking of deep-sea sediments as indicated by the vertical dispersion of the Australian and Ivory Coast microtektite horizons. Earth and Planetary Science Letters 6: 409-415.

Goodell, H.G. and Watkins, N.D., 1968. The paleomagnetic stratigraphy of the Southern Ocean. Deep-Sea Research 15: 89-112.

Graham, J.W., 1949. The stability and significance of magnetism in sedimentary rocks. Journal of Geophysical Research 54: 131-167.

Graham, J.W., 1954. Rock magnetism and the earth's magnetic field during the Paleozoic time. Journal of Geophysical Research 59: 215-222. 
Grapes, R.H. and Watanabe, T., 1984. $\mathrm{Al}^{-\mathrm{Fe}^{3+}}$ and $\mathrm{Ca}-\mathrm{Sr}^{2+}$ epidotes in metagreywackequartzfeldspathic schist, Southern Alps, New Zealand. American Mineralogist 69: 490-498.

Griffiths, D.H., King, R.F., Rees, A.I. and Wright, A.E., 1960. The remanent magnetism of some recent varved sediments. Proceedings of the Royal Society of London A256: $359-383$.

Grindley, G.W., Adams, C.J.D., Lumb, J.T. and Watters, W.A., 1977. Paleomagnetism, $\mathrm{K}-\mathrm{Ar}$ dating and tectonic interpretation of Upper Cretaceous and Cenozoic volcanic rocks of the Chatham Islands, New Zealand. New Zealand Journal of Geology and Geophysics 20: 425-467.

Gosson, G.J., 1986. Miocene and Pliocene silicic tuffs in marine sediments of the East Coast Basin, New Zealand. Unpublished $\mathrm{PhD}$ thesis, Victoria University of Wellington. $137 \mathrm{pp}$.

Haggerty, S.E., 1976. Oxidation of opaque mineral oxides in basalts In: Rumble, D. (Ed.), Oxide Minerals. Mineralogy Society of America. Short Course Notes No. 3. pp $\mathrm{Hg} 1-\mathrm{Hg} 98$.

Hall, S.A. and Butler, J.C., 1983. Potential problems in the magnetostratigraphic studies of shallow water sequences. Journal of Geology 91: 693-705.

Hallam, A., 1981. A revised sea-level curve for the early Jurassic. Geological Society of London Journal 138: 735-743.

Halls, H.C., 1976. A least-squares method to find a remanence direction from converging remagnetisation circles. Geophysical Journal of the Royal Astronomical Society 45: 297-304.

Halls, H.C., 1978. The use of converging remagnetisation circles in paleomagnetism. Physics of the Earth and Planetary Interiors 16: 1-11.

Haq, B.U., 1980. Biogeographic history of Miocene calcareous nannoplankton and paleoecology of the Atlantic Ocean. Micropaleontology 26: 414-443.

Haq, B.U., Worsley, J.R., Burckle, L.H., Douglas, R.G., Keigwin, L.D., Opdyke, N.D., Savin, S.M., Sommer, M.A., Vincent, E. and Woodruff, F., 1980. Late Miocene marine carbon-isotope shift and synchroneity of some phytoplanktic biostratigraphic events. Geology 8: 427-431.

Harrison, C.G.A., 1966. The paleomagnetism of deep-sea sediments. Journal of Geophysical Research 71: 3033-4043.

Harrison, C.G.A., 1969. What is the true rate of reversals of the Earth's magnetic field? Earth Planetary Sciences Letters 6: 186-188.

Harrison, C.G.A., 1980. Analysis of the magnetic vector in a single rock specimen. Geophysical Journal of the Royal Astronomical Society 60: 489-492.

Harrison, C.G.A., McDougall, I. and Watkins, N.D., 1979. A geomagnetic field reversal timescale back to 13.0 million years before present. Earth and Planetary Science Letters 42: 143-152.

Hauptman, Z., 1974. High temperature oxidation, range of non-stoichiometry and Curie point variation of cation deficient titanomagnetite $\mathrm{Fe}_{2} 4 \mathrm{Ti}_{0} 6 \mathrm{O}_{4+Y}$

Geophysical Journal of the Royal Astronomical Society 38: 29-47. 
Haw, D., 1959a. Compilation report on the Kauhauroa structure. BP Shell and Todd Development LTD. Petroleum Report No. 309.

Haw, D., 1959b. Geological compilation report on the Mangaone - Waingake uplift, including the Waerenga-o-kuri culmination. BP Shell and Todd Development LTD. Petroleum Report No. 315.

Hays, J.D.and Opdyke, N.D., 1967. Antarctic Radiolaria, magnetic reversals, and climatic change. Science 158: 1001-1011.

Hays, J.D. and Pitman, W.C., 1973. Lithospheric plate motion, sea-level changes and climatic and ecological consequences. Nature 246: 18-22.

Hedberg, H.D., Salvador, A. and Opdyke, N.D., 1979. Magnetostratigraphic polarity units - A supplementary chapter of the ISSC International Guide. Geology 7: 578-583.

Hedley, I.G., 1968. Chemical remanent magnetisation in the $\mathrm{FeOOH}, \mathrm{Fe}_{2} \mathrm{O}_{3}$ system. Physics of Earth Planetary Interiors 1: 103-121.

Hedley, I.G., 1971. The weak ferromagnetism of goethite (FeOOH). Journal of Geophysics 37:409-420.

Heirtzler, J.R., Dickson, G.O., Herron, E.J., Pitman, W.C. and LePichon, X., 1968. Marine magnetic anomalies, geomagnetic field reversals, and motions of the ocean floor and continents. Journal of Geophysical Research 73: 2119-2136.

Heller, F., 1977. Paleomagnetism of Upper Jurassic limestones from Southern Germany. Journal of Geophysics 42: 475-488.

Henshaw, P.C. and Merrill, R.T., 1979. Characteristics of drying remanent magnetisation in sediments. Earth and Planetary Science Letters 43: 315-320.

Hodder, P., 1981. Titanomagnetites in tephras : some implications from crystal field theory. Chemical Geology 32: 103-118.

Hodell, D.A., Elmstrom, K.M. and Kennett, J.P., 1986. Latest Miocene benthic $\delta^{18} \mathrm{O}$ changes, global ice volumes, sea level and the Messinian salinity crisis. Nature 320: $411-414$.

Hoffman, K.A. and Day, R., 1978. Separation of multicomponent NRM: a general method. Earth and Planetary Science Letters 40: 433-438.

Hornibrook, N. de B., 1958. New Zealand Upper Cretaceous and Tertiary foraminiferal zones and some overseas correlations. Micropaleontology 4: 25-38.

Hornibrook, N. de B., 1959. Tongaporutuan Stage. In: Fleming, C.A., ed., Lexique Strati. Inter. Oceanie, fascicule 4 New Zealand.

Hornibrook, N. de B., 1961. Tertiary Foraminifera from Oamaru District (NZ) Part 1. Sysematics and distribution. New Zealand Geological Survey Paleontology Bulletin $34192 \mathrm{pp}$.

Hornibrook, N. de B., 1968. Stratotypes of New Zealand Tertiary stages. Stage Conference, Christchurch.

Hornibrook, N. de B., 1976. Kapitean - Opoitian boundary. Geological Society of New Zealand Abstracts Hamilton Conference 1976. 
Hornibrook, N. de B., 1977. The Neogene (Miocene-Pliocene) of New Zealand. In: Proceedings, First International Congress on Pacific Neogene Stratigraphy. Tokyo. Kaiyo Shuppan Co. pp 145-150.

Hornibrook, N. de B., 1981a. Globorotalia (planktic foraminiferida) in the late Miocene and early Pleistocene of New Zealand. New Zealand Journal of Geology and Geophysics 24: 263-292.

Hornibrook, N. de B., 1981b. Evaluation of Pacific southern mid latitude and equatorial latitude planktic foraminiferal datum levels. New Zealand Geological Survey. Paleontology Report 42.13 pp. For: Proceedings of the International Geological Correlation Programme (IGCP) Project 114 International Workshop on Pacific Neogene Biostratigraphy. 6th International Working Group Meeting, 1981, Osaka, Japan.

Hornibrook, N. de B., 1982. Late Miocene to Pleistocene Globorotalia (Foraminiferida) from DSDP Leg 29, Site 284, southwest Pacific. New Zealand Journal of Geology and Geophysics 25: 83-99.

Hornibrook, N. de B., 1983. Guide Book for Tour B1, Neogene Geology-North Island East Coast Basin. In: 15th Pacific Science Congress and 3rd International Meeting on Pacific Neogene Stratigraphy, Dunedin, 1983. 28pp.

Hornibrook, N. de B., 1984a. Globorotalia (Planktic foraminifera) at the Miocene/Pliocene boundary in New Zealand. Palaeogeography, Palaeoclimatology, Palaeoecology 46: 107-117.

Hornibrook, N. de B., 1984b. Neogene stratigraphy and planktic foraminiferal datum planes in New Zealand. In: Ikebe, N. and Tsuchi, R. (Eds.), Pacific Neogene datum Planes: Contributions to Biostratigraphy and Chronology (IGCP - 114). University of Tokyo Press. pp 179-186.

Hornibrook, N. de B. and Edwards, A.R., 1971. Integrated planktonic foraminiferal and calcareous nannoplankton datum levels in the New Zealand Cenozoic. In: Farinacci, A. (Ed.) Proceedings of II Planktonic Conference. Roma, pp 649-657.

Hoskins, R.H., 1978. New Zealand Middle Miocene foraminifera: the Waiauan Stage (2 volumes) Unpublished $\mathrm{PhD}$ Thesis. University of Exeter. 388pp.

Hoskins, R.H., 1982. (Ed.). Stages of the New Zealand marine Cenozoic: A synopsis. New Zealand Geological Survey Report 107. 74pp.

Hsu, K.J., Cita, M.B. and Ryan, W.B.F., 1973. The origin of the Mediterranean evaporites. In Ryan, W.B.F., Hsu, K.J. et al., Initial Reports DSDP, 13: Washington (US Government Printing Office) pp 1203-1231.

Hsu, K.J., LaBrecque, J., Percival, S.F., Wright, R.C., Gombos, A.M., Pissiotto, K., Tucker, P., Petersen, N., McKenzie, J.A., Weissert, H., Karpoff, A.M., Carman, M.F. and Schreiber, E., 1984. Numerical ages of Cenozoic biostratigraphic datum levels: Results of South Atlantic Leg 73 drilling. Geological Society of America Bulletin 95: 863-876.

Ingle, J.C., 1967. Foraminiferal biofacies variation and the Miocene - Pliocene boundary in Southern California. Bulletin of American Paleontology 52: 217-394.

Irving, E., 1957. The origin of the paleomagnetism of the Torridonian sandstone series of North-West Scotland. Philosophical Transactions of the Royal Society of London A250: 100-110. 
Irving, E., 1964. Paleomagnetism and its Applications to Geological and Geophysical Problems. John Wiley and Sons Inc., New York.

Irving, E. and Major, A., 1964. Post-depositional detrital remanent magnetisation in a synthetic sediment. Sedimentology 3: 135-143.

Irving, E. and Runcorn, S.K., 1957. Analysis of the paleomagnetism of the Torridonian sandstone series of North-West Scotland. Philosophical Transactions of the Royal Society of London A250: 83-99.

Ishikawa, Y. and Akimoto, S., 1958. Magnetic property and crystal chemistry of ilmenite $\left(\mathrm{MeTiO}_{3}\right)$ and haematite $\left(\mathrm{Fe}_{2} \mathrm{O}_{3}\right)$ system, 2: Magnetic property. Journal of the Physics Society of Japan 13: 1298-1310.

Jarosewich, E., Nelen, J.A. and Norberg, J.A., 1980. Reference samples for Electron microprobe analysis. Geostandards Newsletter 4: 43-47.

Jenkins, D.G., 1966. Planktic foraminiferal datum planes in the Pacific and Trinidad Tertiary. New Zealand Journal of Geology and Geophysics 9: 424-427.

Jenkins, D.G., 1967. Planktic foraminiferal zones and new taxa from the Lower Miocene to the Pleistocene of New Zealand. New Zealand Journal of Geology and Geophysics 10: 1064-1078.

Jenkins, D.G., 1971. New Zealand Cenozoic planktic foraminifera. New Zealand Geological Survey Paleontology Bulletin 42: 278 pp.

Jenkins, D.G., 1975. Cenozoic planktic foraminiferal biostratigraphy of the southwestern Pacific and Tasman Sea -DSDP Leg 29. In: Kennett, J.P., Houtz, R.E., et al., Initial Reports DSDP, 29: Washington (US Government Printing Office) pp 449-467.

Jenkins, D.G. and Orr, W., 1972. Planktonic foraminiferal biostratigraphy of the eastern equatorial Pacific. In: Hays, J.D., et al., Initial Reports DSDP, 9: Washington (Us Government Printing Office) pp 1059-1193.

Jenkins, D.G. and Srinivasan, M.S., 1986. Cenozoic planktic foraminifera from the equator to the subantarctic of the Southwest Pacific. In Kennett, J.P., von der Borch, C.C. et al., Initial Reports DSDP, 90: Washington (US Government Printing Office) pp 795-834.

Johnson, H.P., Kinoshita, H. and Merrill, R.T., 1975. Rock magnetism and paleomagnetism of some North Pacific deep-sea sediments. Geological Society of America Bulletin 86: 412-420.

Johnson, H.P. and Merrill, R.T., 1973. Low-temperature oxidation of titanomagnetite and the implications for paleomagnetism. Journal of Geophysical Research 78: 4938-4949.

Johnson, N.M. and McGee, V.E., 1983. Magnetic polarity stratigraphy: stochastic properties of data, sampling problems, and the evaluation of interpretations. Journal of Geophysical Research 88: 1213-1221.

Kato, I., Muroi, I., Yamazaki, T., and Abe, M., 1971. Subaqueous pyroclastic flow deposits in the Upper Donzurubo Formation, Nijosan District, Osaka, Japan. Journal of the Geological Society of Japan 77: 193-206.

Keany, J. and Kennett, J.P., 1975. Pliocene-Pleistocene radiolarian biostratigraphy and paleoclimatology at DSDP Site 278 on the Antarctic Convergence. In: Kennett, J.P. and Houtz, R.E., et al., Initial Reports DSDP, 29 Washington (US Government Printing Office) pp 757-767. 
Keefer, C.M. and Shive, P.N., 1974. Curie temperature and lattice constant reference contours for synthetic titanomagnetites. Journal of Geophysical Research 86: 987-998.

Keen, M.J., 1963. The magnetisation of sediment cores from the eastern basin of the North Atlantic Ocean. Deep-Sea Research 10: 607-622.

Keigwin, L.D. Jr., 1979. Late Cenozoic stable isotope stratigraphy and paleoceanography of DSDP sites from the east equatorial and central North Pacific Ocean. Earth and Planetary Science Letters 45: 361-382.

Keigwin, L.D. Jr. and Shackleton, N.D., 1980. Uppermost Miocene carbon isotope stratigraphy of a piston core in the equatorial Pacific. Nature 284: 613-614.

Keller, G., 1980. Early to Middle Miocene planktonic foraminiferal datum levels of the equatorial and subtropical Pacific. Micropaleontology 26: 372-391.

Keller, G., 1981. Miocene biochronology and paleoceanography of the North Pacific. Marine Micropaleontology 6: 249-281.

Keller, G. and Barron, J.A., 1983. Paleoceanographic implications of Miocene deep-sea hiatuses. Geological Society of America Bulletin 94: 590-613.

Keller, G., Barron, J.A. and Burckle, L.H., 1982. North Pacific Late Miocene correlations using microfossils, stable isotopes, percent $\mathrm{CaCO}_{3}$ and magnetostratigraphy. Marine Micropaleontology 7: 327-357.

Kennett, J.P., 1965. The Kapitean Stage (Upper Miocene) of New Zealand. Unpublished $\mathrm{PhD}$ Thesis. Victoria University of Wellington.

Kennett, J.P., 1966a. The Globorotalia crassaformis bioseries in North Westland and Marlborough, New Zealand. Micropaleontology 12: 235-245.

Kennett, J.P., 1966b. Stratigraphy and fauna of the type section and neighbouring sections of the Kapitean Stage, Greymouth, New Zealand. Transactions of the Royal Society of New Zealand, Geology 4: 83-102.

Kennett, J.P., 1966c. Faunal succession in two Upper Miocene - Lower Pliocene sections, Marlborough, New Zealand. Transactions of the Royal Society of New Zealand, Geology 3:197-213.

Kennett, J.P., 1966d. Four Upper Miocene to Lower Pliocene sections, Hawke's Bay to East Cape, New Zealand. Transactions of the Royal Society of New Zealand, Geology 4:109-209.

Kennett, J.P., 1967a. Recognition and correlation of the Kapitean Stage (Upper Miocene, New Zealand). New Zealand Journal of Geology and Geophysics 10: 1051-1063.

Kennett, J.P., 1967b. Planktonic foraminiferal zones and new taxa from the Danian to Lower Pliocene of New Zealand. New Zealand Journal of Geology and Geophysics 8: 1088-1126.

Kennett, J.P., 1968. Paleo-oceanographic aspects of the foraminiferal zonation in the Upper Miocene - Lower Pliocene of New Zealand. In: Proceedings IV Session, Bolonga 1967, Giornale di Geologia 35: 143-156.

Kennett, J.P., 1970. Pleistocene paleoclimates and foraminiferal biostratigraphy in subantarctic deep-sea cores. Deep-Sea Research 17: 125-140. 
Kennett, J.P., 1973. Middle and Late Miocene planktic foraminiferal biostratigraphy of the southwest Pacific - DSDP Leg 21. In: Burns, R.E., Andrews, J.E., et al., Initial Reports DSDP, 21 Washington (US Government Printing Office) pp 575-639.

Kennett, J.P., 1986. Miocene to Early Pliocene oxygen and carbon isotope stratigraphy in the southwest Pacific, Deep Sea Drilling Project Leg 90. In: Kennett, J.P., von der Borch, C.C., et al., Initial Reports DSDP, 90: Washington (US Government Printing Office) pp 1383-1411.

Kennett, J.P., Shackleton, N.J., Margolis, S.V., Goodney, D.E., Dudley, W.C. and Kroopnick, P.M., 1979. Late Cenozoic oxygen and carbon isotope history and volcanic ash stratigraphy: DSDP site 284, South Pacific. American Journal of Science 279: 52-69.

Kennett, J.P. and Srinivasan, M.S., 1975. Stratigraphic occurrences of the Miocene planktic foraminifera Globoquadrina dehiscens in early Pliocene sediments of the Indian Ocean. Revista Espanola Micropaleontologia 7: 5-14.

Kennett, J.P., von der Borch, C.C., et al., 1986. Initial Reports DSDP, 90: Washington (US Government Printing Office).

Kennett, J.P. and Watkins, N.D., 1970. Geomagnetic polarity change, volcanic maxima and faunal extinction in the South Pacific. Nature. 227: 930-934.

Kennett, J.P. and Watkins, N.D., 1974. Late Miocene - Early Pliocene paleomagnetic stratigraphy, paleoclimatic and biostratigraphy in New Zealand. Geological Society of America Bulletin 85: 1385-1398.

Kennett, J.P., Watkins, N.D. and Vella, P., 1971. Paleomagnetic chronology of Pliocene - early Pleistocene climates and the Plio-Pleistocene boundary in New Zealand. Science 171: 276-279.

Kenny, J.A., 1980. Geology of the Ihungia Catchment, Raukumara Peninsula. Unpublished Msc Thesis, University of Auckland.

Kenny, J.A., 1984. Petrography of Cretaceous and Tertiary sedimentary rocks of the Ihungia catchment, Raukumara Peninsular, North Island, New Zealand. New Zealand Journal of Geology and Geophysics 27: 291-298.

Kent, D.V., 1973. Post-depositional remanent magnetisation in deep-sea sediment. Nature 246: 32-34.

Kent, D.V. and Lowrie, W., 1974. Origin of magnetic instability in sediment cores from central North Pacific. Journal of Geophysical Research 79: 2987-3000.

Kent, D.V. and Lowrie, W., 1975. On the magnetic susceptibility anisotropy of deepsea sediments. Earth Planetary and Science Letters 28: 1-12.

Khan, M.J., Kent, D.V. and Miller, K.G., 1985. Magnetostratigraphy of Oligocene to Pleistocene sediments, Sites 558 and 563. In: Bougault, H., Cande, S.C. et al., Initial Reports DSDP, 82: Washington (US Government Printing Office). pp 385-392.

Kicinski, F.M., 1958. Report on correlation of stratigraphic columns from north-east coast of the North Island, New Zealand. BP Shell and Todd Development LTD. Petroleum Report No. 306.

King, R.F., 1955. Remanent magnetism of artificially deposited sediments. Monthly Notices of the Royal Astronomical Society, Geophysical Supplement 7: 115-134. 
Kohn, B.P., 1970. Studies of New Zealand Quaternary Pyroclastic Rocks. Unpublished $\mathrm{PhD}$ thesis, Victoria University of Wellington.

Kohn, B.P. and Topping, W.W., 1978. Time-space relationships between late Quaternary rhyolitic and andesitic volcanism in the southern Taupo zone, New Zealand. Geological Society of America Bulletin 89: 1265-1271.

Konigsberger, J.G., 1938. Natural residual magnetism of eruptive rocks. I Terrestrial Magnetism and Atmospheric Electricity 43: 119-127.

Kukla, G. and Nakagawa, H., 1977. Late Cenozoic magnetostratigraphy: comparisons with bio-, climato-, and lithozones. Quaternary Research 7: 283-293.

LaBrecque, J.L., Kent, D.V. and Cande, S.C., 1977. Revised magnetic polarity timescale for Late Cretaceous and Cenozoic time. Geology 5: 330-335.

Levi, S. and Banerjee, S.K., 1976. On the possibility of obtaining relative intensities from lake sediments. Earth and Planetary Science Letters 29: 219-226.

Liebes, E. and Shive, P.N., 1982. Magnetisation acquisition in two Mesozoic red sandstones. Physics of Earth and Planetary Interiors 30: 396-404.

Lienert, B.R., Christoffel, D.A. and Vella, P., 1972. Geomagnetic dates on a New Zealand Upper Miocene-Pliocene section. Earth and Planetary Science Letters 16: 195-199.

Lindsley, D.H., 1962. Investigations in the system $\mathrm{FeO}-\mathrm{Fe}_{2} \mathrm{O}_{3}-\mathrm{TiO}_{2}$ Carnegie Institute Year Book. Washington.

Lindsley, D.H., Anderson, G.E. and Balsley, J.R., 1966. Magnetic properties of rocks and minerals. Geological Society of America Bulletin 97: 544-552.

Lipson, J., 1956. K-Ar dating of sediments. Geochimica et Cosmochimica Acta 10: 149-151.

Lipson, J., 1958. Potassium-argon dating of sedimentary rocks. Geological Society of America Bulletin. 69: 137-150.

Lohman, W.H., 1986. Calcareous nannoplankton biostratigraphy of the southern Coral Sea, Tasman Sea, and southwestern Pacific Ocean, Deep Sea Drilling Project Leg 90: Neogene and Quaternary. In: Kennett, J.P., von der Borch, C.C., et al., Initial Reports DSDP, 90: Washington (US Government Printing Office) pp 763-793.

Loutit, T.S. and Keigwin, L.D., 1982. Stable isotopic evidence for latest Miocene sealevel fall in the Mediterranean region. Nature 300: 163-166.

Loutit, T.S. and Kennett, J.P., 1979. Application of carbon isotope stratigraphy to late Miocene shallow marine sediments, New Zealand. Science 204: 1196-1199.

Loutit, T.S. and Kennett, J.P., 1981. Australasian Cenozoic sedimentary cycles, global sea level changes and the deep sea sedimentary record. Oceanologica Acta, 26th International Geological Congress, Paris, 1980. 18pp.

Loutit, T.S., Pisias, N.G. and Kennett, J.P., 1983. Pacific Miocene carbon isotope stratigraphy using benthic foraminifera. Earth and Planetary Science Letters 66: 48-62.

Lovlie, R. and Larsen, E., 1981. Paleomagnetism and magnetomineralogy of a Holocene lake sediment from Vagsoy, western Norway. Physics of the Earth and Planetary Interiors 27: 143-150. 
Lovlie, R., Lowrie, W. and Jacobs, M., 1972. Magnetic properties and mineralogy of four deep-sea cores. Earth Planetary Science Letters 15: 157-168.

Lowrie, W. and Alvarez, W., 1977. Late Cretaceous polarity sequence: Detailed rock and paleomagnetic studies of the Scaglai Rossa limestone at Gubbio, Italy. Geophysical Journal of the Royal Astronomical Society 51: 561-582.

Lowrie, W., Channell, J.E.T. and Heller, F., 1980. On the credibility of remanent magnetisation measurements. Geophysical Journal of the Royal Astronomical Society 60: 493-496.

Lowrie, W. and Heller, F., 1982. Magnetic properties of marine limestones. Reviews of Geophysics and Space Physics 20: 171-192.

Lowrie, W. and Kent, D.V., 1983. Geomagnetic reversal frequency since the Late Cretaceous. Earth and Planetary Science Letters 62: 305-313.

Macpherson, E.O., 1927. Geological report on area 15 (Morere) and area 20 (Mangaone). Taranaki Oilfields LTD. Petroleum Report No. 87.

Mankinen, E.A. and Dalrymple, G.B., 1979. Revised geomagnetic polarity timescale for the interval 0 to 5 my B.P. Journal of Geophysical Research 84: 615-626.

Martini, E., 1971. Standard Tertiary and Quaternary calcareous nannoplankton zonation. In: Farinacci, A. (Ed.) Proceedings of II Planktonic Conference. Roma, pp 739-785.

Manson, A.J., O'Donovan, J.B. ans O'Reilly, W., 1979. Magnetic rotational hysteresis loss in titanomagnetites and titanomaghemites- application to non-destructive mineral identification in basalts. Journal of Geophysics 46: 185-199.

May, S.R., Butler, R.F. and Roth, F.A., 1985. Magnetic polarity stratigraphy and stratigraphic completeness. Geophysical Research Letters 12: 341-344.

McDougall, I., 1977, The present status of the geomagnetic polarity timescale. In McElhinny, M.E. (Ed.) The Earth: Its Origin, Structure and Evolution. New York. Academic Press. pp 543-565.

McDougall, I. and Chamalaun, F.H., 1966. Geomagnetic polarity scale of time. Nature 212: $1415-1418$.

McDougall, I. and Coombs, D.S., 1973. Potassium-argon ages for the Dunedin Volcano and out-lying volcanics. New Zealand Journal of Geology and Geophysics 16: 179-188.

McDougall, I., Kristjannson, L. and Saemundsson, K., 1984. Magnetostratigraphy and geochronology of northwest Iceland. Journal of Geophysical Research 89: 7029-7060.

McDougall, I. and Page, R.W., 1975. Toward a physical time-scale for the Neogene-Data from the Australian region. In: Saito, T. and Burckle, L.H., (Eds.) Late Neogene Epoch Boundaries. Micropaleontology Press, New York. pp 75-84.

McDougall, I., Salmundson, K., Johanneson, H., Watkins, N.D. and Kristjansson, L., 1977. Extension of the geomagnetic polarity timescale to $6.5 \mathrm{myr}$ K-Ar dating, geological and paleomagnetic study of a $3500 \mathrm{~m}$ lava succession in Western Iceland. Geological Society of America Bulletin 88: 1-15.

McDougall, I. and Tarling, D.H., 1963. Dating of polarity zones in the Hawaiian Islands. Nature 200: 54-56. 
McDougall, I., Watkins, N.D. and Kristjansson, L., 1976a. Geochronology and paleomagnetism of a Miocene - Pliocene lava sequence at Bessastada, Eastern Iceland. American Journal of Science 276: 1078-1095.

McDougall, I., Watkins, N.D., Walker, G.P.L. and Kristjansson, L., 1976b. Potassium-argon and paleomagetic analysis of Icelandic lava flows: on the age of anomaly 5. Journal Geophysical Research 81: 1505-1512.

McElhinny, M.E., 1973. Paleomagnetism and Plate Tectonics. Cambridge University Press.

McInnes, B.A., 1964. A detailed examination of microfaunas from a Miocene-Pliocene (Taranakian-Opoitian-Waitotaran) section on the Mangapoike River,Northern Hawkes Bay. B.P. Shell and Todd Petroleum Development LTD Paleontological Note. 32.

McInnes, B.A., 1965. Globorotalia miozea Finlay as an ancestor of Globorotalia inflata (d'Orbigny). New Zealand Journal of Geology and Geophysics. 8: 104-108.

McIntosh, W.C., Hargraves, R.B. and West, C.L., 1985. Paleomagnetism and oxide mineralogy of Upper Triassic to Lower Jurassic red beds and basalts in the Newark Basin. Geological Society of the America Bulletin. 96: 463-480.

Miall, A.D., 1986. Eustatic sea level changes interpretated from seismic stratigraphy: A critique of the methodology with particular reference to the North Sea Jurassic record. American Association of Petroleum Geologists 70: 131-137.

Miller, K.G., Aubry, M.P., Khan, M.J., Melillo, A.J., Kent, D.V. and Berggren, W.A., 1985. Oligocene-Miocene biostratigraphy, magnetostratigraphy and isotopic stratigraphy of the western North Atlantic. Geology 13: 257-261.

Moll, E.J., 1981. Geochemistry and petrology of mid-Tertiary ash flows tuffs from the Sierra el Virulento area, eastern Chihuahua, Mexico. Journal of Geophysical Research 86: 10321-10334.

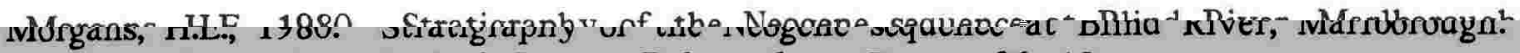
New Zealand Geological Survey Paleontology Report 36. 18pp.

Morris, P., 1979. Electron microprobe analyses of minerals from volcanic rocks from the Cñatham ıs̉ıảnas'. 'Geology Department Iñternal' Yüblićcation Nó. 12, VUW:

Mumme, T.C. and Walcott, R.I., 1985. Paleomagnetic studies at Geophysics Division 1980-1983. Geophysics Division Report 204. 62pp. Department of Scientific and Industrial Research, New Zealand.

Murphy, R.P. and Seward, D., 1981. Stratigraphy, lithology, paleomagnetism, and fission track ages of some ignimbrite formations in the Matahana Basin, New Zealand. Nèw Léalảna' Journal'oj 'Geolỏgy and Geophysics 24: 325-331.

Nagata, T., 1961. Rock Magnetism. Maruzen, Tokyo. 350pp.

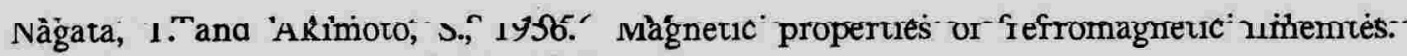
Geofis. Pura e Appl 34: 35-50.

Nakagawa, H., Niistsuma, N., Kitamura, N. Matoba, Y., Takayama, T. and Asano, K., 1974. Preliminary results on magnetostratigraphy of Neogene stage stratotypes sections in Italy. Rivista Italiana Paleontologia 80: 615-630.

Neel, L., 1955. Some theoretical aspects of rock magnetism. Advances in Physics 4: 191-243. 
Ness, G., Levi, S. and Couch, R., 1980. Marine magnetic anomaly timescales for the Cenozoic and Late Cretaceous: a precis, critique and synthesis. Reviews of Geophysics and Space Physics 18: 753-770.

Nicholls, G.D., 1955. The mineralogy of rock magnetism. Advances in Physics 4: 113-190.

Nickel, E.H., 1958. The composition and microtexture of an ulvospinel-magnetite intergrowth. Canadian Mineralogist 6: 191-199.

Nigrini, C. and Lombari, G., 1984. A Guide to Miocene Radiolaria. Cushman Foundation for Foraminiferal Research Special Publication 22. 308 pp.

Ninkovich, D., Opdyke, N.D., Heezen, B.C. and Foster, J.H., 1966. Paleomagnetism stratigraphy, rates of deposition and tephrochronolgy in North Pacific deep-sea sediments. Earth and Planetary Science Letters 1: 476-492.

O'Donovan, J.B. and O'Reilly, W., 1978. Cation distribution in synthetic titanomagnetites. Physics of Earth and Planetary Interiors 16:200-208.

Ongley, M., 1928. Wairoa Subdivision. New Zealand Geological Survey 22nd Annual Report: 7.

Ongley, M., 1930. Wairoa subdivision. New Zealand Geological Survey 24th Annual Report: 9.

Opdyke, N.D., 1972. Paleomagnetism in deep sea cores. Reviews of Geophysics and Space Physics 10: 213-249.

Opdkye, N.D., Kent, D.V. and Lowrie, W., 1973. Details of magnetic polarity transitions recorded in a high deposition rate deep-sea core. Earth and Planetary Science Letters 20: 315-324.

Orbell, G.E., 1965. Petrology and clay mineralogy of some sedimentary rocks from the Mauriceville District. New Zealand Journal of Geology and Geophysics 8: 548-559.

O'Reilly, W., 1976. Magnetic minerals in the crust of the Earth. Reports on Progress in Physics 39: 857-908.

O'Reilly, W., 1983. The identification of titanomaghemites: model mechanisms for the maghemisation and inversion processes and their magnetic consequences. Physics of the Earth and Planetary Interoirs 31: 65-76.

O'Reilly, W., 1984. Rock and Mineral Magnetism. Chapman and Hall, New York. $220 \mathrm{pp}$.

O'Reilly, W. and Banerjee, S.K., 1965. Cation distribution in titanomagnetites. Physics Letters 17: 237-238.

Osborn, N.I., Ciesielski, P.F. and Ledbetter, M., 1983 Disconformities and paleoceanography in the south east Indian Ocean during the past 5.4 million years. Geological Society of American Bulletin. 94: 1345-1358.

Osborne, N., 1934. Report on the geology of the north east portion of the Hawke Bay depression, New Zealand. Vacuum Oil Co. Petroleum Report No. 122.

Otofuji, Y., Katsura, I. and Sasjima, S., 1982. Decay of a post-depositional remanent magnetisation in wet sediment due to the effect of drying. Geophysical Journal of the Royal Astronomical Society 70: 191-203. 
Otofuji, Y. and Sasajima, S., 1981. A magnetisation process of sediments: laboratory experiments on post-depositional remanent magnetisation. Geophysical Journal of the Royal Astronomical Society 66: 241-259.

Ouliac, M., 1976. Removal of secondary magnetisation from natural remanent magnetisation of sedimentary rocks: Alternating field of thermal demagnetisation technique? Earth and Planetary Science Letters 29: 65-70.

Ozdemir, O. and O'Reilly, W., 1981. Laboratory synthesis of aluminium-substituted titanomagnetites and their characteristic properties. Journal of Geophysics 49: 93-100.

Papamarinopoulous, S., Readman, P.W., Maniatis, Y. and Simopoulosa, A., 1982. Magnetic characterization and Mossbauer spectroscopy of magnetic concentrates from Greek lake sediments. Earth and Planetary Science Letters 57: 173-181.

Patel, J.P. and Palmer, H.C., 1982. Chemical magnetic overprinting in the Ordovician redbeds of Bucaco (Portugal). abstract. Physics of the Earth and Planetary Interiors 30: 373 .

Petrova, G.N., 1961. Various laboratory methods of determining the geomagnetic stability of rocks. Bulletin of the Academy of Sciences (USSR), Geophysical Series 703-709.

Pitman, W.C., 1978. Relationships between eustacy and stratigraphic sequences of passive margins. Geological Society of America Bulletin 89: 1389-1403.

Poore, R.Z., Tauxe, L., Percival, S.F., LaBrecque, J.P., Wright, R., Petersen, N.P., Smith, C.C., Tucker, P. and Hsu, K.J., 1983. Late Cretaceous - Cenozoic magnetostratigraphic and biostratigraphic correlations of the South Atlantic Ocean: DSDP Leg 73. Palaeogeography, Palaeoclimatology, Palaeoecology 42: 127-149.

Purucker, M.E., Elston, D.P. and Shoemaker, E.M., 1980. Early acquisition of characteristic magnetisation in red beds of the Moenkopi Formation (Triassic). Journal of Geophysical Research 85: 997-1001.

Radhakrishnamurty, C. and Sahasrabudhe, P.W., 1965. Instruments and techniques for the study of magnetic stability in rocks. Journal of the Indian Geophysical Union 2: 5-15.

Ramdohr, P., 1969. The Ore Minerals and Their Intergrowths. Pergamon Press.

Readman, P.W. and O'Reilly, W., 1972. Magnetic properties of oxidised (cation deficient) titanomagnetites $(\mathrm{Fe}, \mathrm{Ti})_{3} \mathrm{O}_{4}$. Journal of Geomagnetism and Geoelectricity 24: 69-90.

Rees. A.I., Brown, C.M., Hailwood, E.A. and Riddy, P.J., 1982. Magnetic fabric of bioturbated sediment from the Northern Rockall Trough: comparison with modern currents. Marine Geology 46: 161-173.

Rees, A.I., Von Rad, U. and Shepard, F.P., 1968. Magnetic fabric of sediments from the La Jolla submarine canyon and fan, California. Marine Geology 6: 145-178.

Richards, J.W., O'Donovan, J.B., Hauptman, Z., O'Reilly, W. and Creer, K.M., 1973. A magnetic study of titanomagnetite substituted by magnesium and aluminium. Physics of the Earth and Planetary Interiors 7: 437-444.

Robins, B.W., 1972. Remanent magnetisation in spinel iron oxides. Unpublished PhD Thesis, University of New South Wales. 
Rona, P.A., 1973. Worldwide uncomformities in marine sediments related to eustatic changes of sea-level. Nature 244: 25-26.

Roser, B.P., 1983. Comparative studies of $\mathrm{Cu}$ and $\mathrm{Mn}$ mineralisation, Torlesse, Waipapa and Haast Schist terranes, New Zealand. (2 volumes). Unpublished $\mathrm{PhD}$ Thesis. Victoria University of Wellington.

Roser, B.P. and Korsch, R.J., 1985. Plate tectonics and geochemical composition of sanstones: A discussion. Journal of Geology 93: 81-84.

Roser, B.P. and Korsch, R.J., in prep. A graded Miocene bed: Geochemistry and petrography.

Roy, J.L. and Lapointe, P.L., 1978. Multiphase magnetisations: problems and implications. Physics of the Earth and Planetary Interiors 16: 20-37.

Roy, J.L. and Park, J.K., 1974. The magnetisation process of certain red beds: vector analysis of chemical and thermal results. Canadian Journal of Earth Science 11: 437-471.

Ruddiman, W.F. and Glover, L.K., 1972. Vertical mixing of ice-rafted volcanic ash in North Atlantic sediments. Geological Society of America Bulletin 83: 2817-2836.

Russell, K.L., 1968. Oceanic ridges and eustatic changes in sea level. Nature 218: 861-862.

Ryan, W.B.F., Cita, M.B., Rawson, M.D., Burkle, L.H. and Saito, T., 1974. A paleomagnetic assignment of Neogene stage boundaries and the development of isochronous datum planes between the Mediterranean, the Pacific and Indian Oceans in order to investigate the response of the world to the Mediterranean "salinity crisis". Rivista Italiana Paleontologia 80: 631-688.

Sadler, P.M., 1981. Sediment accumulation rates and the completeness of stratigraphic sections. Journal of Geology 89: 569-584.

Saemundsson, K., Kristiansson, L., McDougall, I. and Watkins, N.D., 1980. K-Ar dating, geological and paleomagnetic study of a $5 \mathrm{~km}$ lava succussion in Northern Iceland. Journal of Geophysical Research 85: 3628-2646.

Saito, T., 1977. Late Cenozoic planktonic foraminiferal datum levels: The present state of knowledge towards accomplishing pan-Pacific stratigraphic correlation.

Proceedings, First International Congress on Pacific Neogene Stratigraphy. Tokyo, Kaiyo Shuppan Co. pp 61-80.

Saito, T., 1984. Planktonic foraminiferal datum planes for biostratigraphic correlation of Pacific Neogene sequences - 1982 status report. In: Ikebe, N. and Tsuchi, R. (Eds.), Pacific Neogene Datum Planes: Contributions to Biostratigraphy and Chronology (IGCP -114). University of Tokyo Press. pp 3-10.

Saito, T., Burckle, L.H. and Hays, J.D., 1975. Late Miocene to Pleistocene biostratigraphy of equatorial Pacific sediments. In: Saito, T. and Burckle, L.H., (Eds.) Late Neogene Epoch Boundaries Micropaleontology Press, New York. pp 226-244.

Sallomy, J.T. and Briden, J.C., 1975. Paleomagnetic studies of Lower Jurassic rocks in England and Wales. Earth and Planetary Science Letters 24: 369-376.

Savin, S.M., Douglas, R.G., Keller, G. Killingley, J.S., Shanghnessy, L., Sommer, M.A., Vincent, E. and Woofruff, F., 1981. Miocene benthic foraminiferal isotope records: A synthesis. Marine Micropaleontology 6: 423-450. 
Schwarz, E.J., 1975. Magnetic properties of pyrrhotite and their use in applied geology and geophysics. Geological Survey of Canada, Paper 74.

Schwarz, E.J. and Vaughan, D.J., 1972. Magnetic phase relations of pyrrhotite. Journal of Geomagnetism and Geoelectricity 22: 463-470.

Scotese, C.R., Van der Voo, R. and McCabe, C., 1982. Paleomagnetism of the Upper Silurian and Lower Devonian carbonates of New York State: evidence for secondary magnetisation residing in magnetite. Phyiscs of Earth and Planetary Interiors 30: $385-395$.

Scott, G.H., 1972. Revision of Hutchinsonian, Awamoan and Altonian stages (Lower Miocene, New Zealand -2). New Zealand Journal Geology and Geophysics 15: 49-70.

Scott, G.H., 1976. Variation in Globorotalia punticulata sphericomiozea from New Zealand (Foraminiferida, Neogene). New Zealand Journal Geology and Geophysics 19: $855-869$.

Scott, G.H., 1978. Early history of Bolivinita pliozea Finlay (Foraminiferida, Neogene, New Zealand). New Zealand Journal of Geology and Geophysics 21: 717-634.

Scott, G.H., 1979a. Variation in Bolivinita quadrilatera (Foraminiferida, upper Neogene, New Zealand). New Zealand Journal of Geology and Geophysics 22: 509-519.

Scott, G.H., 1979b. The late Miocene to early Pliocene history of the Globorotalia miozea plexus from Blind River, New Zealand. Marine Micropaleontology 4: 341-361.

Scott, G.H., 1979c. Variation in Globorotalia puncticulata sphericomiozea from New Zealand(Foraminiferida, Neogene) New Zealand Journal of Geology and Geophyiscs 19: $855-869$.

Scott, G.H., 1980. Globorotalia inflata lineage and G. crassaformis from Blind River, New Zealand: recognition, relationship and use in uppermost Miocene - Lower Pliocene biostratigraphy. New Zealand Journal of Geology and Geophyiscs 23: 665-677.

Scott, G.H., 1982a. Tempo and stratigraphic record of speciation in Globorotalia puncticulata. Journal of Foraminiferal Research 12: 1-12.

Scott, G.H., 1982b. Review of Kapitean stratotype and boundary with Opoition Stage (upper Neogene, New Zealand). New Zealand Journal of Geology and Geophysics 25: $475-485$.

Scott, G.H., 1983. Biostratigraphy and histories of Upper Miocene - Pliocene Globorotalia, south Atlantic and southwest Pacific. Marine Micropaleontology 7: 364-383.

Scott, G.H., 1985. Biostratigraphic revision of Maui-2 offshore well south Taranaki Basin. New Zealand Geological Survey Paleontology Report 99. 44pp.

Seward, D. 1974. Age of New Zealand Pleistocene substages by fission-track dating of glass shards from tephra horizons. Earth and Planetary Science Letters 24: 242-248.

Seward, D., 1975. Fission track ages of some tephras from Cape Kidnappers, Hawkes Bay, New Zealand. New Zealand Journal of Geology and Geophysics 18: 507-510. 
Seward, D., 1979. Comparison of zircon and glass fission-track ages from tephra horizons. Geology 7: 479-482.

Shackleton, N.J. and Kennett, J.P., 1975. Late Cenozoic oxygen and carbon isotope changes at DSDP 284: implications for glacial history of the Northern Hemisphere and Antarctica. In: Kennett, J.P., Houtz, R.E., et al., Initial Reports DSDP 29: Washington (US Government Printing Office) pp 801-807.

Shanmugam, G. and Moiola, R.J., 1982. Eustatic control of turbidites and winnowed turbidites. Geology 10: 231-235.

Shibata, K., Nishimura, S. and Chinzei, K., 1984. Radiometric dating related to Pacific Neogene planktic datum planes. In: Ikebe, N. and Tsuchi, R. (Eds.), Pacific Neogene Datum Planes: Contributions to Biostratigraphy and Chronology (IGCP -114). University of Tokyo Press. pp 85-89.

Shive, P.N., 1986. Suggestions for the use of SI units in magnetism. Eos January, p 25.

Skinner, D.N.B., 1986. Neogene volcanism of the Hauraki Volcanic Region. In: Smith, I.E.M. (Ed.) Late Cenozoic Volcanism in New Zealand. Royal Society of New Zealand Bulletin 23. pp 21-47.

Smith, P.J., 1967. The intensity of the ancient geomagnetic field: A review and analysis. Journal of Geophysics 12: 321-362.

Srinivasan, M.S. and Kennett, J.P., 1981a. Neogene planktonic foraminiferal biostratigraphy and evolution: equatorial to subantarctic, South Pacific. Marine Micropaleontology 6: 499-533.

Srinivasan, M.S. and Kennett, J.P., 1981b. A review of Neogene planktonic foraminiferal biostratigraphy: applications in the equatorial and South Pacific. In: Warme, J.E., Douglas, R.G. and Winterer, E.L., (Eds.) The Deep Sea Drilling Project: A Decade of Progress. Society of Economic Paleontologists and Mineralogists. Special Publication No. 32. pp 395-432.

Srinivasan, M.S. and Srivastava, S.S., 1974. Sphaeroidinella dehiscens datum and the Miocene - Pliocene boundary. American Association of Petroleum Geologists Bulletin 58: 304-311.

Strangeway, D.W., Honea, R.M., McMahon, B.E. and Larson, E.E., 1968. The magnetic properties of naturally occurring goethite. Geophysical Journal of the Royal Astronomical Society 15: 345-359.

Stacey, F.D., 1963. The physical theory of rock magnetism. Advances in Physics 12: 45-133.

Stacey, F.D. and Banerjee, S.K., 1974. The Physical Principles of Rock Magnetism. Elsevier, Amsterdam.

Steiger, R.H. and Jager, E., 1977. Subcommission on Geochronology: Convention on the use of decay constants in geo- and cosmochronolgy. Earth and Planetary Science Letters 36: 359-362.

Stephenson, A., 1969. The temperature dependent cation distribution in titanomagnetite. Geophysical Journal of the Royal Astronomical Society 18: 199-210.

Stephenson, A., 1972. Spontaneous magnetisation curves and Curie points of spinels containing two types of magnetic ion. Philosophical Magazine 25: 1213-1232. 
Stipp, J.J., Chappel, J.M.A. and McDougall, I., 1967. K/Ar age estimates of the Pliocene - Pleistocene boundary in New Zealand. American Journal of Science 265: 462-474.

Stipp, J.J. and McDougall, I., 1968. Geochronology of the Banks Peninsula volcanoes, New Zealand. New Zealand Journal of Geology and Geophysics 11: 1239-1260.

Stipp, J.J. and Thompson, B.N., 1971. K/Ar ages from the volcanics of Northland, New Zealand. New Zealand Journal of Geology and Geophysics 14: 403-413.

Stoneley, H.M.W., 1959. Report on the paleontological examination of samples from Mangaone - Waingake uplift, including the Waerega-o-kuri culmination. BP Shell and Todd Development LTD. Petroleum Report No. 340.

Stormer, J.C.(Jr.), 1983. The effects of recalculation on estimates of temperature and oxygen fugacity from analyses of multicomponent iron-titanium oxides. American Mineralogist 68: 586-594.

Stupavsky, M. and Symons, D.T.A., 1978. Separation of magnetic components from AF step demagnetisation data by least-squares methods. Journal of Geophysical Research 83: 4925-4931.

Symons, D.T.A. and Stupavsky, M., 1974. A rational paleomagnetic stability index. Journal of Geophysical Research 79: 1718-1720.

Takayangi, Y., Sakai, T., Oda, M. Takayama, T., Oriyama, J. and Kaneko, M., 1978. Problems relating to the Kaburan Stage. Cenozoic Geology of Japan. Osaka. pp 93-111.

Talwani, M., Windisch, C.C and Langseth, M.G., 1971. Reykjanes Ridge Crest: A detailed geophysical study. Journal of Geophysical Research 76: 473-517.

Tarling, D.H. and Symons, D.T.A., 1967. A stability index of remanence in paleomagnetism. Geophysical Journal of the Royal Astronomical Society 12: 443-448.

Tauxe, L., Kent, D.V. and Opdyke, N.D., 1980. Magnetic components contributing to the N.R.M. of Middle Siwalik Red Beds. Earth Planetary Science Letters 47: 279-284.

Tauxe, L., Tucker, P., Petersen, N.P. and LaBrecque, J.P., 1983. The magnetostratigraphy of Leg 73 sediments. Palaeogeography, Palaeoclimatology, Palaeoecology 42: 65-90.

Theyer, F., 1972. Paleomagnetism and planktonic zonation of late Neogene subantarctic cores. Antarctic Journal of the United States 7: 195-197.

Theyer, F. and Hammond, S.R., 1974. Paleomagnetic polarity sequence and radiolarian zones, Brunhes to Polarity Epoch 20. Earth and Planetary Science Letters 22: 307-319.

Vail, P.R., Mitchum, R.M. and Thompson, S.III, 1977. Global cycles of relative changes of sea level. In: Seismic stratigraphy- applications to hydrocarbon exploration: American Association of Petroleum Geologists Memoir 26: 83-97.

Vail, R.R. and Hardenbol, J., 1979. Sea-level changes during the Tertiary. Oceanus 22: 71-79.

Valentine, J.W. and Moores, F.M., 1970. Plate-tectonic regulation of faunal diversity and sea-level: A model. Nature 228: 657-659. 
Van Couvering, J.A. and Berggren, W.A., 1977. Biostratigraphic basis of the Neogene timescale. In: Kauffman, E.G. and Hazel, J.E. (Eds.) Concepts and Methods in Biostratigraphy. Dowden, Hutchinson and Ross, Stroudsburg. pp 283-306.

Vella, P.P., 1954. Tertiary mollsuca from southeast Wairarapa. Transactions of Royal Society of New Zealand 81: 539-555.

Vella, P.P., 1965. Sedimentary cycles correlation and stratigraphic classification. Transactions of Royal Society of New Zealand, Geology 3: 1-9.

Vella, P.P. and Collen, J.D., 1984. Four rhyolitic tuff marker beds, Lower Pliocene, Wairarapa, New Zealand. Journal of the Royal Society of New Zealand 14: 133-138.

Verosub, K.L., 1977. Depositional and postdepositional processes in the magnetisation of sediments. Reviews of Geophysics and Space Physics 15: 129-143.

Verosub, K.L., Ensley, R.A. and Ulrick, J.S., 1979. The role of water content in the magnetisation of sediments. Geophysical Research Letters 6: 226-228.

Vincent, E., Killingley, J.S. and Berger, W.H., 1980. The magnetic epoch 6 carbon shift: A change in the ocean's ${ }^{13} \mathrm{C} /{ }^{12} \mathrm{C}$ ratio 6.2 million years ago. Marine Micropaleontolgy 5: 185-203.

Walcott, R.I., Christoffel, D.A. and Mumme, T.C., 1981. Bending within the axial tectonic belt of New Zealand in the last 9 My from paleomagnetic data. Earth and Planetary Science Letters 52: 427-434.

Walcott, R.I. and Mumme. T.C., 1982. Paleomagnetic study of the Tertiary sedimentary rocks from the east coast of the North Island, New Zealand. Geophysics Division Report 189, Department of Scientific and Industrial Research, New Zealand. 44pp.

Walker, T.R., Larson, E.E. and Hoblitt, P.R., 1981. The nature and origin of haematite in the Moenkopi Formation (Triassic), Colorado Plataeu: A contribution to the origin of magnetisation in red beds. Journal of Geophysical Research 86: 317-333.

Watanabe, T., Grapes, R.H. and Palmer, K., 1981. Quantitative analyses of rock forming minerals by JXA-733 electron probe x-ray microanalyser. JEOL News 19e: $15-19$.

Watkins, N.D., 1968. Short period geomagnetic polarity events in deep-sea sedimentary cores. Earth and Planetary Science Letters 4: 341-349.

Watkins, N.D., 1972. A review of the development of the geomagnetic polarity timescale and a discussion of prospects for its finer definition. Geological Society of America Bulletin 83: 551-574.

Watkins, N.D. and Kennett, J.P., 1971. Antarctic bottom water: Major change in velocity during the late Cenozoic between Australia and Antarctica. Science 173: 813-818.

Watkins, N.D. and Kennett, J.P., 1972a. Continuing paleomagnetic and micropaleontological dating of Eltanin deep-sea sedimentary cores. Antarctic Journal of the United States 7: 202-203.

Watkins, N.D. and Kennett, J.P., 1972b. Regional sedimentary disconformities and Upper Cenozoic changes in bottom water velocities between Australia and Antarctica. Americian Geophysical Union: Antarctic Research Series 19: 273-293. 
Watkins, N.D., Kester, D.R. and Kennett, J.P., 1974. Paleomagnetism of the type Pliocene - Pleistocene boundary section at Santa Maria De Catanzaro, Italy, and the problem of post-depositional precipitation of magnetic minerals. Earth and Planetary Science Letters 24: 113-119.

Watkins, N.D. and Walker, G.P.L., 1977. Magnetostratigraphy of eastern Iceland. American Journal of Science 277: 513-584.

Watson, J.F., 1957. The Opoitian Stage: A proposal for a type section. BP Shell and Todd Development LTD. Petroleum Report No. 355.

Weaver, F.M., 1976. Late Miocene and Pliocene radiolarian paleobiogeography and biostratigraphy of the Southern Ocean. Unpublished Ph.D. thesis, Florida State University. $175 \mathrm{pp}$.

Webb, C., 1979. The geology of eastern Mahia Peninsula, Hawke's Bay. Unpublished MSc Thesis. Auckland University.

Wells, A.J., 1960. Cyclic sedimentation: A review. Geological Magazine 97: 389-403.

Wellman, H.W., 1958. Flute cast directions in the middle and upper Miocene and in the Cretaceous, upper Senonian, Raukumara Series. BP Shell and Todd

Development LTD. Petroleum Report No. 361.

Westcott-Lewis, M.F. and Parry, L.G., 1971. Magnetism in rhombohedral iron-titanium oxides. Australian Journal of Physics 24: 719-734.

Westgate, J.A. and Evans, M.E., 1978. Compositional variability of Glacier Peak tephra and its stratigraphic significance. Canadian Journal of Earth Sciences 15: 1554-1567.

Westgate, J.A., Walter, R.C., Pearce. G.W., and Gorton, M.P., 1985. Distribution, stratigraphy, petrochemistry, and paleomagnetism of the late Pleistocene Old Crow tephra in Alaska and the Yukon. Canadian Journal of Earth Sciences 22: 983-906.

Wilson, R.L., 1962. The paleomagnetism of baked contact rocks and reversals of the Earth's magnetic field. Geophysical Journal of the Royal Astronomical Society 7: 194-202.

Wilson, R.L. and Smith, P.J., 1968. The nature of secondary natural magnetisation in some igneous and baked rocks. Journal of Geomagnetism and Geoelectricity 20: 367-380.

Woodruff, F. and Savin, S.M., 1985. $\quad \delta^{13} \mathrm{C}$ values of Miocene Pacific benthic foraminifera: correlations with sea level and biological productivity. Geology 13: 119-122.

Woodruff, F., Savin, S.M. and Douglas, R.G., 1981. Miocene stable isotope record: A detailed deep Pacific Ocean Study and its paleoclimatic implications. Science 212: 665-668.

Wright, I.C., 1985. Mangapoike River: A late Miocene magnetostratigraphic reference column for New Zealand. In: Hornibrook Symposium, 1985, extended abstracts, New Zealand Geological Record 9: 105-107.

Wright, I.C., Ashby, J.N. and Hoskins, R.H., 1985. An age for the sudden disappearance of Globoquadrina dehiscens from Mangapoike River. In: Hornibrook Symposium, 1985, extended abstracts, New Zealand Geological Record 9: 102-104. 
Wright, J.B. and Lovering, J.F., 1965. Electron probe microanalysis of iron-titanium oxides in some New Zealand ironsands. Mineral Magazine 35: 604-621.

Wright, J.V. and Mutti, E., 1981. The Dali Ash, Island of Rhodes, Greece: a problem in interpreting submarine volcanigenic sediments. Bulletin Volcanology 44: 153-167.

Yamazka, T., Kato, I. and Abe, M., 1973. Textural anaylsis and flow mechanism of the Donzurubo subaqueous pyroclastic flow deposits. Bulletin Volcanology 37: 231-244.

Zijderveld, J.D.A., 1967. AC demagnetisation of rocks: analysis of results. In: Collinson, D.W., Creer, K.M. and Runcorn, S.K. (Eds.), Methods in Paleomagnetism. Elsevier, Amsterdam. pp 254-286. 


\section{APPENDIX 1: SITE LOCATIONS AND DESCRIPTIONS.}

SITES

All paleomagnetic sites sampled are described, including those with an unstable and/or weak intensity of magnetisation. Some sites were inaccessible for sampling, but numbering was kept consectutive so as to indicate the stratigraphic interval not sampled.

\section{LOCATIONS}

Sites are located in both imperial and metric grid references. Imperial coordinates refer to sheet N106 (NZMS 1) and metric coordinates refer to the unpublished sheet X19. A map based on an enlarged aerial photograph, with an approximate scale of $1: 10,500$ allowed coordinates to be given as eight figure references.

\section{DESCRIPTIONS}

Lithological descriptions are based on field observations, including relevant data on outcrop condition and suitability for paleomagnetic study. Grain size classification and abbreviations follow Andrews (1982) NZGS Report 102, Revised Guide To Recording Field Observations In Sedimentary Sequences and are:

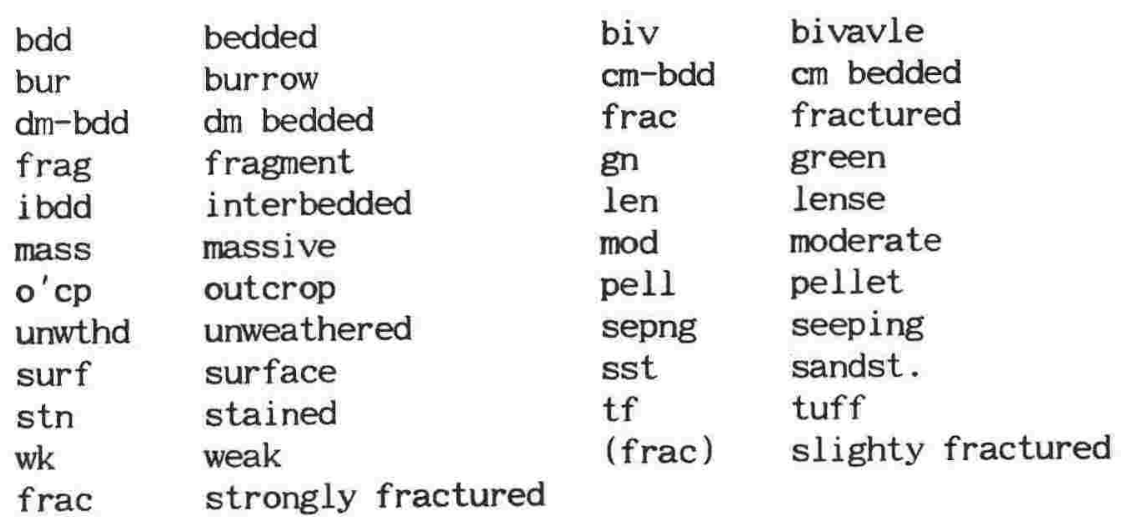




\begin{tabular}{|c|c|c|c|}
\hline SITE & $\begin{array}{l}\text { IMPERIAL GRID } \\
\text { REF. }\end{array}$ & $\begin{array}{l}\text { METRIC GRID } \\
\text { REF. }\end{array}$ & DESCRIPTION \\
\hline 18870 & N106/01930757 & $\mathrm{X} 19 / 11354386$ & $\begin{array}{l}\text { clay siltst. } \\
\text { LB. unwthd, } 2 m \text { below site } \\
18871 \text { same grd bd, (frac) }\end{array}$ \\
\hline 18871 & N106/01930757 & $\mathrm{X} 19 / 11354386$ & $\begin{array}{l}\text { clay siltst. } \\
\text { LB.unwthd, } 5.5 \mathrm{~m} \text { grd bd, } \\
\text { (frac). }\end{array}$ \\
\hline 18872 & N106/01930757 & X19/11354386 & $\begin{array}{l}\text { clay siltst. } \\
\text { LB.unwthd, } 1 \mathrm{~m} \text { grd bd, } \\
\text { (frac). }\end{array}$ \\
\hline 18873 & N106/01920757 & X19/11344386 & $\begin{array}{l}\text { silty clayst. } \\
\text { LB. unwthd, } 1.2 \mathrm{~m} \text { grd bd, } \\
\text { frac. }\end{array}$ \\
\hline 18874 & N106/01910757 & X19/11334386 & $\begin{array}{l}\text { clay siltst. } \\
\text { LB.unwthd, } 1.5 \mathrm{~m} \text { grd bd, } \\
\text { frac. }\end{array}$ \\
\hline 18875 & N106/01890757 & $\mathrm{X} 19 / 11324386$ & $\begin{array}{l}\text { clay siltst. } \\
\text { LB. unwthd, } 2.5 \mathrm{~m} \text { grd bd, } \\
\text { frac. }\end{array}$ \\
\hline 18876 & N106/01870759 & $\mathrm{X} 19 / 11304388$ & $\begin{array}{l}\text { clay siltst. } \\
\text { RB. unwthd, mass, frac. }\end{array}$ \\
\hline 18877 & N106/01850759 & $\mathrm{X} 19 / 11284388$ & $\begin{array}{l}\text { clay siltst. } \\
\text { RB.unwthd,mass, frac. }\end{array}$ \\
\hline 18878 & N106/01830759 & $\mathrm{X} 19 / 11264388$ & $\begin{array}{l}\text { clay siltst. } \\
\text { RB.unwthd, mass, frac. }\end{array}$ \\
\hline 18879 & N106/01810760 & $\mathrm{X} 19 / 11244389$ & $\begin{array}{l}\text { clay siltst. } \\
\text { RB.unwthd, mass, frac, } \\
\text { biotur. }\end{array}$ \\
\hline 18880 & N106/01790760 & X19/11224389 & $\begin{array}{l}\text { clay siltst. } \\
\text { RB. unwthd, mass, frac. }\end{array}$ \\
\hline 18881 & N106/01760760 & X19/11204389 & $\begin{array}{l}\text { clay siltst. } \\
\text { RB.unwthd, mass, frac. }\end{array}$ \\
\hline 18882 & N106/01730760 & $\mathrm{X} 19 / 11174389$ & $\begin{array}{l}\text { clay siltst. } \\
\text { RB. unwthd, mass, frac. }\end{array}$ \\
\hline 18883 & N106/01710760 & X19/11154389 & $\begin{array}{l}\text { clay siltst. } \\
\text { RB. unwthd, mass, frac, Fe } \\
\text { stn frac surf, biotur. }\end{array}$ \\
\hline 18884 & N106/01680762 & X19/11134391 & $\begin{array}{l}\text { clay siltst. } \\
\text { RB. unwthd, mass, frac. }\end{array}$ \\
\hline 18885 & N106/01670763 & $\mathrm{X} 19 / 11124392$ & $\begin{array}{l}\text { clay siltst. } \\
\text { RB. unwthd, mass, frac. }\end{array}$ \\
\hline 18886 & N106/01660763 & $\mathrm{X} 19 / 11114392$ & $\begin{array}{l}\text { clay siltst. } \\
\text { RB. unwthd, bdd, frac. }\end{array}$ \\
\hline 18887 & N106/01640764 & X19/11094394 & $\begin{array}{l}\text { clay siltst. } \\
\text { RB. unwthd, bdd, frac. }\end{array}$ \\
\hline 18888 & N106/01620764 & X19/11074394 & $\begin{array}{l}\text { clay siltst. } \\
\text { RB. unwthd, bdd, frac. }\end{array}$ \\
\hline
\end{tabular}




\begin{tabular}{|c|c|c|c|}
\hline 18889 & N106/01600764 & X19/11054394 & $\begin{array}{l}\text { clay siltst. } \\
\text { RB. unwthd, bdd, frac. }\end{array}$ \\
\hline 18890 & N106/01580764 & X19/11034394 & $\begin{array}{l}\text { clay siltst. } \\
\text { RB. unwthd, mass, frac. }\end{array}$ \\
\hline 18891 & $\mathrm{~N} 106 / 01560764$ & X19/11014394 & $\begin{array}{l}\text { clay siltst. } \\
\text { RB. unwthd, mass, frac, } \\
\text { Fe stn frac surf. }\end{array}$ \\
\hline 18892 & N106/01530764 & $\mathrm{X} 19 / 10984394$ & $\begin{array}{l}\text { clay siltst. } \\
\text { RB. unwthd, mass, frac, } \\
\text { Fe stn frac surf. }\end{array}$ \\
\hline 18893 & N106/01510763 & X19/10964392 & $\begin{array}{l}\text { silty clayst. } \\
\text { RB. unwthd, mass, frac. }\end{array}$ \\
\hline 18894 & $\mathrm{~N} 106 / 01480762$ & X19/10944391 & $\begin{array}{l}\text { clay siltst. } \\
\text { RB.unwthd, bdd, frac, } \\
\text { biotur. }\end{array}$ \\
\hline 18895 & N106/01460763 & X19/10924392 & $\begin{array}{l}\text { clay siltst. } \\
\text { RB. unwthd, bdd, frac, } \\
\text { biotur. }\end{array}$ \\
\hline 18896 & $\mathrm{~N} 106 / 01450763$ & X19/10914392 & $\begin{array}{l}\text { clay siltst. } \\
\text { RB. unwthd, mass, frac. }\end{array}$ \\
\hline 18897 & $\mathrm{~N} 106 / 01450762$ & X19/10914391 & $\begin{array}{l}\text { silty clayst. } \\
\text { LB.unwthd, mass, frac. }\end{array}$ \\
\hline 18898 & $\mathrm{~N} 106 / 01430763$ & X19/10894392 & $\begin{array}{l}\text { clay siltst. } \\
\text { LB.unwthd, mass, (frac), } \\
\text { biotur. }\end{array}$ \\
\hline 18899 & N106/01410765 & $\mathrm{X} 19 / 10874394$ & $\begin{array}{l}\text { clay siltst. } \\
\text { LB.unwthd, mass, (frac), } \\
\text { biotur. }\end{array}$ \\
\hline 18900 & N106/01390767 & $\mathrm{X} 19 / 10854396$ & $\begin{array}{l}\text { clay siltst. } \\
\text { LB.unwthd, mass, (frac). }\end{array}$ \\
\hline 18901 & N106/01370769 & $X 19 / 10844398$ & $\begin{array}{l}\text { clay siltst. } \\
\text { LB.unwthd, mass, (frac). }\end{array}$ \\
\hline 18902 & $\mathrm{~N} 106 / 01370770$ & X19/10844399 & $\begin{array}{l}\text { silty clayst. } \\
\text { LB.unwthd, mass, frac, } \\
\text { Fe stn frac surf. }\end{array}$ \\
\hline 18903 & $\mathrm{~N} 106 / 01370772$ & $\mathrm{X} 19 / 10844401$ & $\begin{array}{l}\text { silty clayst. } \\
\text { RB.unwthd, mass, frac, } \\
\text { Fe stn frac surf. }\end{array}$ \\
\hline 18904 & N106/01350773 & $X 19 / 10824402$ & $\begin{array}{l}\text { silty clayst. } \\
\text { RB. unwthd, mass, frac, } \\
\text { Fe stn frac surf. }\end{array}$ \\
\hline 18905 & N106/01340775 & $\mathrm{X} 19 / 10814404$ & $\begin{array}{l}\text { clay siltst. } \\
\text { RB. unwthd, wk bddd, frac. }\end{array}$ \\
\hline 18906 & N106/01330774 & $\mathrm{X} 19 / 10804403$ & $\begin{array}{l}\text { clay siltst. } \\
\text { LB. unwthd, mass, frac. }\end{array}$ \\
\hline
\end{tabular}




\begin{tabular}{|c|c|c|c|}
\hline 18907 & N106/01320774 & $\mathrm{X} 19 / 10794403$ & $\begin{array}{l}\text { clay siltst. } \\
\text { LB. unwthd, mass, frac. }\end{array}$ \\
\hline 18908 & N106/01300774 & $\mathrm{X} 19 / 10774403$ & $\begin{array}{l}\text { clay siltst. } \\
\text { LB. unwthd, mass, frac. }\end{array}$ \\
\hline 18909 & N106/01280774 & $\mathrm{X} 19 / 10754403$ & $\begin{array}{l}\text { silty clayst. } \\
\text { LB.unwthd,mass, frac, } \\
\text { Fe stn frac surf. }\end{array}$ \\
\hline 18910 & N106/01260775 & X19/10734404 & $\begin{array}{l}\text { clay siltst. } \\
\text { LB. unwthd, mass, frac. }\end{array}$ \\
\hline 18911 & N106/01240776 & $\mathrm{X} 19 / 10724405$ & $\begin{array}{l}\text { clay siltst. } \\
\text { LB. unwthd, mass, frac. }\end{array}$ \\
\hline 18912 & N106/01230777 & X19/10714406 & $\begin{array}{l}\text { clay siltst. } \\
\text { LB.unwthd, wk bdd, frac, } \\
\text { biotur. }\end{array}$ \\
\hline 18913 & N106/01210778 & $\mathrm{X} 19 / 10694407$ & $\begin{array}{l}\text { clay siltst. } \\
\text { LB. unwthd, mass, frac. }\end{array}$ \\
\hline 18914 & N106/01200779 & $\mathrm{X} 19 / 10684408$ & $\begin{array}{l}\text { clay siltst. } \\
\text { LB.unwthd, mass, frac. }\end{array}$ \\
\hline 18915 & N106/01190780 & $\mathrm{X} 19 / 10674409$ & $\begin{array}{l}\text { clay siltst. } \\
\text { LB. unwthd, mass, frac, } \\
\text { (Fe stn frac surf). }\end{array}$ \\
\hline 18916 & N106/01180782 & $\mathrm{X} 19 / 10664411$ & $\begin{array}{l}\text { clay siltst. } \\
\text { RB.unwthd, mass, frac. }\end{array}$ \\
\hline 18917 & N106/01170783 & X19/10654412 & $\begin{array}{l}\text { silty clayst. } \\
\text { RB.unwthd, mass, frac, } \\
\text { Fe stn frac surf. }\end{array}$ \\
\hline 18918 & N106/01130783 & $\mathrm{X} 19 / 10624412$ & $\begin{array}{l}\text { clay siltst. } \\
\text { RB. unwthd, mass, frac, } \\
\text { biotur. }\end{array}$ \\
\hline 18919 & N106/01100783 & $\mathrm{X} 19 / 10594412$ & $\begin{array}{l}\text { clay siltst. } \\
\text { RB.unwthd, mass, frac. }\end{array}$ \\
\hline 18920 & N106/01070783 & $\mathrm{X} 19 / 10574412$ & $\begin{array}{l}\text { clay siltst. } \\
\text { RB.unwthd, mass, frac. }\end{array}$ \\
\hline 18921 & N106/01060783 & X19/10564412 & $\begin{array}{l}\text { clay siltst. } \\
\text { RB.unwthd, mass, frac, } \\
\text { biotur. }\end{array}$ \\
\hline 18922 & N106/01030785 & $\mathrm{X} 19 / 10534414$ & $\begin{array}{l}\text { clay siltst. } \\
\text { RB. unwthd, mass, frac, } \\
\text { biotur. }\end{array}$ \\
\hline 18923 & N106/01010786 & X19/10514415 & $\begin{array}{l}\text { clay siltst. } \\
\text { RB.unwthd, mass, (frac), } \\
\text { biotur. } \\
\text { clay siltst. } \\
\text { RB.unwthd, mass, (frac). }\end{array}$ \\
\hline
\end{tabular}


$18925 \quad \mathrm{~N} 106 / 00980789 \quad \mathrm{X} 19 / 10494418$

$18926 \quad \mathrm{~N} 106 / 00950791$

$\mathrm{X} 19 / 10474420$

$18927 \quad \mathrm{~N} 106 / 00940791$

$\mathrm{X} 19 / 10474420$

$18928 \quad \mathrm{~N} 106 / 00930793$

$\mathrm{X} 19 / 10464422$

$18929 \quad \mathrm{~N} 106 / 00930794$

$18930 \quad \mathrm{~N} 106 / 00920795$

$18931 \quad \mathrm{~N} 106 / 00920796$

$18932 \mathrm{~N} 106 / 00910797$

$18933 \mathrm{~N} 106 / 00910799$

18934 N106/00910802

$18935 \mathrm{~N} 106 / 00900802$

$18936 \quad \mathrm{~N} 106 / 00910804$

18937 N106/00910805

18938 N106/00910806

18939 N106/00900807

$18940 \quad \mathrm{~N} 106 / 00890808$

18941
X19/10454424

X19/10454425

$\mathrm{X} 19 / 10454426$

$\mathrm{X} 19 / 10454427$

X19/10454429

$\mathrm{X} 19 / 10444430$

$\mathrm{X} 19 / 10454432$

$\mathrm{X} 19 / 10454433$

$\mathrm{X} 19 / 10454434$

X19/10444435

$\mathrm{X} 19 / 10434436$

$\mathrm{X} 19 / 10424437$ clay siltst.

RB. unwthd, mass, frac, biotur.

clay siltst. RB. unwthd, mass, frac.

clay siltst. LB. unwthd, mass, frac, $\mathrm{Fe}$ stn frac surf.

silty clayst. LB. unwthd, mass, frac, Fe stn frac surf.

silty clayst.

LB. unwthd, mass, frac, Fe stn frac surf, biotur.

silty clayst.

LB. unwthd, mass, frac, $\mathrm{Fe}$ surf stn, biotur.

clay siltst.

LB. unwthd, mass, frac.

clay siltst.

LB. unwthd, mass, frac.

clay siltst.

LB. unwthd, mass, frac.

clay siltst.

LB. unwthd, mass, frac.

clay siltst.

LB. unwthd, mass, frac, (Fe stn frac surf).

silty clayst. RB. unwthd, mass, frac, biotur.

clay siltst.

RB. unwthd, mass (frac), biotur.

clay siltst. RB. unwthd, mass (frac), biotur.

clay siltst.

RB. unwthd, mass, frac, biotur.

silty clayst. RB. unwthd, mass, frac.

silty clayst. RB. unwthd, mass, frac. 


\begin{tabular}{|c|c|c|c|}
\hline 18942 & $\mathrm{~N} 106 / 00870810$ & $X 19 / 10414438$ & $\begin{array}{l}\text { clay siltst. } \\
\text { RB.unwthd, mass, (frac). }\end{array}$ \\
\hline 18943 & N106/00860811 & X19/10404439 & $\begin{array}{l}\text { clay siltst. } \\
\text { RB.unwthd, mass, frac. }\end{array}$ \\
\hline 18944 & N106/00850812 & $\mathrm{X} 19 / 10394440$ & $\begin{array}{l}\text { silty clayst. } \\
\text { RB.unwthd, mass, frac. }\end{array}$ \\
\hline 18945 & N106/00840813 & X19/10384441 & $\begin{array}{l}\text { silty clayst. } \\
\text { LB.unwthd, mass, frac, } \\
\text { (Fe stn frac surf). }\end{array}$ \\
\hline 18946 & N106/00830814 & $\mathrm{X} 19 / 10374442$ & $\begin{array}{l}\text { silty clayst. } \\
\text { RB.unwthd, mass, frac, } \\
\text { Fe stn frac surf. }\end{array}$ \\
\hline 18947 & N106/00820814 & $\mathrm{X} 19 / 10364442$ & $\begin{array}{l}\text { clay siltst. } \\
\text { Rb.unwthd, mass, frac. }\end{array}$ \\
\hline 18948 & N106/00820813 & $\mathrm{X} 19 / 10364441$ & $\begin{array}{l}\text { clay siltst. } \\
\text { LB.unwthd, mass, frac, } \\
\text { (Fe stn frac surf). }\end{array}$ \\
\hline 18949 & N106/00810813 & $\mathrm{X} 19 / 10354441$ & $\begin{array}{l}\text { clay siltst. } \\
\text { LB. unwthd, mass, frac. }\end{array}$ \\
\hline 18950 & N106/00790813 & $\mathrm{X} 19 / 10334441$ & $\begin{array}{l}\text { clay siltst. } \\
\text { LB.unwthd, mass, frac. }\end{array}$ \\
\hline 18951 & N106/00790815 & $\mathrm{X} 19 / 10334443$ & $\begin{array}{l}\text { clay siltst. } \\
\text { RB.unwthd, mass, (Fe surf } \\
\text { stn. }\end{array}$ \\
\hline 18952 & N106/00780815 & $\mathrm{X} 19 / 10324443$ & $\begin{array}{l}\text { clay siltst. } \\
\text { RB. unwthd, mass, (Fe surf } \\
\text { stn. }\end{array}$ \\
\hline 18953 & N106/00760815 & $\mathrm{X} 19 / 10304443$ & $\begin{array}{l}\text { clay siltst. } \\
\text { RB. unwthd, mass, frac. }\end{array}$ \\
\hline 18954 & N106/00750815 & $\mathrm{X} 19 / 10294443$ & $\begin{array}{l}\text { clay siltst. } \\
\text { RB.unwthd, mass, frac. }\end{array}$ \\
\hline 18955 & N106/00730815 & $\mathrm{X} 19 / 10274443$ & $\begin{array}{l}\text { clay siltst. } \\
\text { RB.unwthd, mass, frac. }\end{array}$ \\
\hline 18956 & N106/00720815 & $\mathrm{X} 19 / 10264443$ & $\begin{array}{l}\text { clay siltst. } \\
\text { RB.unwthd, mass, (frac). }\end{array}$ \\
\hline 18957 & N106/00710815 & $\mathrm{X} 19 / 10254443$ & $\begin{array}{l}\text { clay siltst. } \\
\text { RB.unwthd, mass, (frac). }\end{array}$ \\
\hline 18958 & N106/00700814 & $\mathrm{X} 19 / 10244442$ & $\begin{array}{l}\text { clay siltst. } \\
\text { RB.unwthd, mass, (frac). }\end{array}$ \\
\hline 18959 & N106/00680814 & $\mathrm{X} 19 / 10224442$ & $\begin{array}{l}\text { clay siltst. } \\
\text { RB.unwthd,mass, (frac). }\end{array}$ \\
\hline 18960 & $\mathrm{~N} 106 / 00650811$ & $\mathrm{X} 19 / 10194439$ & $\begin{array}{l}\text { clay siltst. } \\
\text { RB.unwthd, mass, (frac). }\end{array}$ \\
\hline
\end{tabular}




\begin{tabular}{|c|c|c|c|}
\hline 18961 & N106/00620809 & X19/10164437 & $\begin{array}{l}\text { clay siltst. } \\
\text { RB.unwthd, mass, (frac), } \\
\text { water sepng o'cp. }\end{array}$ \\
\hline 18962 & N106/00570807 & $\mathrm{X} 19 / 10134435$ & $\begin{array}{l}\text { clay siltst. } \\
\text { RB.unwthd, mass, (frac). }\end{array}$ \\
\hline 18963 & N106/00570806 & $\mathrm{X} 19 / 10134434$ & $\begin{array}{l}\text { clay siltst. } \\
\text { LB.unwthd, mass, (frac). }\end{array}$ \\
\hline 18964 & N106/00560806 & $\mathrm{X} 19 / 10124434$ & $\begin{array}{l}\text { clay siltst. } \\
\text { LB.unwthd, mass, (frac), } \\
\text { Fe stn frac surf. }\end{array}$ \\
\hline 18965 & N106/00540806 & $\mathrm{X} 19 / 10104434$ & $\begin{array}{l}\text { clay siltst. } \\
\text { LB.unwthd, mass, (frac). }\end{array}$ \\
\hline 18966 & N106/00520807 & $\mathrm{X} 19 / 10084435$ & $\begin{array}{l}\text { clay siltst. } \\
\text { LB. unwthd, mass, frac. }\end{array}$ \\
\hline 18967 & N106/00500809 & $\mathrm{X} 19 / 10064437$ & $\begin{array}{l}\text { clay siltst. } \\
\text { RB.unwthd, mass, (frac). }\end{array}$ \\
\hline 18968 & N106/00480809 & $\mathrm{X} 19 / 10044437$ & $\begin{array}{l}\text { clay siltst. } \\
\text { RB.unwthd, mass, (frac). }\end{array}$ \\
\hline 18969 & N106/00470810 & $\mathrm{X} 19 / 10034438$ & $\begin{array}{l}\text { clay siltst. } \\
\text { LB. unwthd, mass, (frac). }\end{array}$ \\
\hline 18970 & $\mathrm{~N} 106 / 00450812$ & $\mathrm{X} 19 / 10014440$ & $\begin{array}{l}\text { clay siltst. } \\
\text { LB. unwthd, mass, (frac). }\end{array}$ \\
\hline 18971 & $\mathrm{~N} 106 / 00440813$ & $\mathrm{X} 19 / 10004441$ & $\begin{array}{l}\text { clay siltst. } \\
\text { LB. unwthd, mass, (frac). }\end{array}$ \\
\hline 18972 & $\mathrm{~N} 106 / 00430814$ & X19/09994442 & $\begin{array}{l}\text { clay siltst. } \\
\text { LB. unwthd, mass, (frac). }\end{array}$ \\
\hline 18973 & $\mathrm{~N} 106 / 00410815$ & $\mathrm{X} 19 / 09974443$ & $\begin{array}{l}\text { clay siltst. } \\
\text { LB. unwthd, mass, (frac). }\end{array}$ \\
\hline 18974 & $\mathrm{~N} 106 / 00400816$ & $\mathrm{X} 19 / 09964444$ & $\begin{array}{l}\text { clay siltst. } \\
\text { LB. unwthd, mass, (frac). }\end{array}$ \\
\hline 18975 & N106/00390818 & $\mathrm{X} 19 / 09954446$ & $\begin{array}{l}\text { clay siltst. } \\
\text { LB. unwthd, mass, (frac). }\end{array}$ \\
\hline 18976 & N106/00400821 & X19/09964449 & $\begin{array}{l}\text { clay siltst. } \\
\text { RB.unwthd, mass, frac. }\end{array}$ \\
\hline 18977 & N106/00380825 & $\mathrm{X} 19 / 09944453$ & $\begin{array}{l}\text { clay siltst. } \\
\text { LB.unwthd, mass, frac. }\end{array}$ \\
\hline 18978 & N106/00450843 & $\mathrm{X} 19 / 10014471$ & $\begin{array}{l}\text { siltst. } \\
\text { LB.unwthd, mass, (frac), } \\
\text { cem. }\end{array}$ \\
\hline 18979 & N106/00440844 & $\mathrm{X} 19 / 10004472$ & $\begin{array}{l}\text { siltst. } \\
\text { LB.unwthd, mass, (frac). }\end{array}$ \\
\hline 18980 & N106/00430845 & $\mathrm{X} 19 / 09994473$ & $\begin{array}{l}\text { siltst. } \\
\text { LB.unwthd, mass, (frac). }\end{array}$ \\
\hline
\end{tabular}




\begin{tabular}{|c|c|c|c|}
\hline 18981 & $\mathrm{~N} 106 / 00440846$ & $\mathrm{X} 19 / 10004474$ & $\begin{array}{l}\text { silty fine sandst. } \\
\text { RB.unwthd, mass. }\end{array}$ \\
\hline 18982 & N106/00430847 & $\mathrm{X} 19 / 09994474$ & $\begin{array}{l}\text { clay siltst. } \\
\text { RB.unwthd, mass, frac. }\end{array}$ \\
\hline 18983 & $\mathrm{~N} 106 / 00420848$ & $\mathrm{X} 19 / 09984475$ & $\begin{array}{l}\text { clay siltst. } \\
\text { RB.unwthd, mass, frac, } \\
\text { Fe stn frac surf. }\end{array}$ \\
\hline 18984 & N106/00410848 & $\mathrm{X} 19 / 09974475$ & $\begin{array}{l}\text { clay silst. } \\
\text { RB.unwthd, mass, frac. }\end{array}$ \\
\hline 18985 & N106/00390849 & $\mathrm{X} 19 / 09954476$ & $\begin{array}{l}\text { clay siltst. } \\
\text { RB.unwthd, mass, frac, } \\
\text { (Fe surf stn). }\end{array}$ \\
\hline 18986 & N106/00380849 & X19/09944476 & $\begin{array}{l}\text { clay siltst. } \\
\text { LB. unwthd, mass, frac. }\end{array}$ \\
\hline 18987 & N106/00360849 & $\mathrm{X} 19 / 09924476$ & $\begin{array}{l}\text { clay siltst. } \\
\text { LB. unwthd, mass, frac, } \\
\text { biotur. }\end{array}$ \\
\hline 18988 & $\mathrm{~N} 106 / 00340850$ & $\mathrm{X} 19 / 09904477$ & $\begin{array}{l}\text { clay siltst. } \\
\text { LB. unwthd, mass, frac. }\end{array}$ \\
\hline 18989 & N106/00320851 & X19/09884478 & $\begin{array}{l}\text { clay siltst. } \\
\text { LB. unwthd, mass, frac. }\end{array}$ \\
\hline 18990 & N106/00300852 & X19/09864479 & $\begin{array}{l}\text { clay siltst. } \\
\text { LB. unwthd, mass, frac. }\end{array}$ \\
\hline 18991 & N106/00290852 & $\mathrm{X} 19 / 09854479$ & $\begin{array}{l}\text { clay siltst. } \\
\text { LB.unwthd, mass, (frac), } \\
\text { Fe surf stn. }\end{array}$ \\
\hline 18992 & N106/00260852 & X19/09824479 & $\begin{array}{l}\text { clay siltst. } \\
\text { LB.unwthd, mass, frac, } \\
\text { Fe surf stn. }\end{array}$ \\
\hline 18993 & $\mathrm{~N} 106 / 00230850$ & $\mathrm{X} 19 / 09794480$ & $\begin{array}{l}\text { clay siltst. } \\
\text { LB.unwthd, wk bdd, (frac). }\end{array}$ \\
\hline 18994 & N106/00190853 & $\mathrm{X} 19 / 09764480$ & $\begin{array}{l}\text { clay siltst. } \\
\text { LB. unwthd, mass, (frac), } \\
\text { Fe stn frac surf. }\end{array}$ \\
\hline 18995 & $\mathrm{~N} 106 / 00150853$ & $\mathrm{X} 19 / 09724480$ & $\begin{array}{l}\text { clay siltst. } \\
\text { LB.unwthd, wk bdd, (frac). }\end{array}$ \\
\hline 18996 & N106/00080847 & $\mathrm{X} 19 / 09674474$ & $\begin{array}{l}\text { silty fine sandst. } \\
\text { RB.unwthd, wk dm-bdd, } \\
\text { (frac). }\end{array}$ \\
\hline 18997 & N106/00030843 & $\mathrm{X} 19 / 09634471$ & $\begin{array}{l}\text { silty clayst. } \\
\text { RB.unwthd, mass. }\end{array}$ \\
\hline 18998 & N106/00010841 & $\mathrm{X} 19 / 09614469$ & $\begin{array}{l}\text { silty clayst. } \\
\text { RB.unwthd, mass, (frac). }\end{array}$ \\
\hline
\end{tabular}




\begin{tabular}{|c|c|c|c|}
\hline 18999 & N106/99990839 & $\mathrm{X} 19 / 09594466$ & $\begin{array}{l}\text { silty clayst. } \\
\text { RB.unwthd, mass, mod frac. }\end{array}$ \\
\hline 19000 & N106/99960838 & $\mathrm{X} 19 / 09554465$ & $\begin{array}{l}\text { silty clayst. } \\
\text { RB.unwthd, mass. }\end{array}$ \\
\hline 19001 & N106/99960834 & $\mathrm{X} 19 / 09554461$ & $\begin{array}{l}\text { silty clayst. } \\
\text { LB.unwthd, mass, (Fe stn } \\
\text { frac surf). }\end{array}$ \\
\hline 19002 & N106/99950833 & $\mathrm{X} 19 / 09544460$ & $\begin{array}{l}\text { silty clayst. } \\
\text { LB.unwthd, mass. }\end{array}$ \\
\hline 19003 & N106/99930832 & $\mathrm{X} 19 / 09534459$ & $\begin{array}{l}\text { silty clayst. } \\
\text { LB.unwthd, mass, (frac). }\end{array}$ \\
\hline 19004 & N106/99900832 & $\mathrm{X} 19 / 09504459$ & $\begin{array}{l}\text { silty clayst. } \\
\text { LB. unwthd, mass. }\end{array}$ \\
\hline 19005 & N106/99880834 & X19/09494461 & $\begin{array}{l}\text { silty clayst. } \\
\text { LB.unwthd, mass. }\end{array}$ \\
\hline 19006 & N106/99870837 & X19/09484464 & $\begin{array}{l}\text { silty clayst. } \\
\text { LB.unwthd, mass. }\end{array}$ \\
\hline 19007 & N106/99850837 & $\mathrm{X} 19 / 09454464$ & $\begin{array}{l}\text { silty clayst. } \\
\text { LB.unwthd, mass. }\end{array}$ \\
\hline 19008 & N106/99300838 & $\mathrm{X} 19 / 09434465$ & $\begin{array}{l}\text { silty clayst. } \\
\text { LB. unwthd, mass, (frac). }\end{array}$ \\
\hline 19009 & N106/99820839 & $\mathrm{X} 19 / 09424466$ & $\begin{array}{l}\text { silty clayst. } \\
\text { LB.unwthd, mass, (frac). }\end{array}$ \\
\hline 19010 & N106/99790839 & $\mathrm{X} 19 / 09404466$ & $\begin{array}{l}\text { silty clayst. } \\
\text { LB.unwthd, len gn } \\
\text { cm-bdd sst. }\end{array}$ \\
\hline 19011 & N106/99780841 & $\mathrm{X} 19 / 09394469$ & $\begin{array}{l}\text { silty clayst. } \\
\text { LB. unwthd, mass, (frac). }\end{array}$ \\
\hline 19012 & N106/99760841 & $\mathrm{X} 19 / 09394469$ & $\begin{array}{l}\text { silty clayst. } \\
\text { LB.unwthd, len mm-bdd } \\
\text { zst. }\end{array}$ \\
\hline 19013 & N106/99740841 & X19/09344469 & $\begin{array}{l}\text { silty clayst. } \\
\text { LB.unwthd, mass, (frac). }\end{array}$ \\
\hline 19014 & N106/99740844 & $\mathrm{X} 19 / 09344472$ & $\begin{array}{l}\text { clay siltst. } \\
\text { RB.unwthd, ibdd } \\
\text { cm-bdd sst. }\end{array}$ \\
\hline 19015 & N106/99730844 & $\mathrm{x} 19 / 09334472$ & $\begin{array}{l}\text { clay siltst. } \\
\text { RB.unwthd,mass. }\end{array}$ \\
\hline 19016 & N106/99710845 & $\mathrm{X} 19 / 09324473$ & $\begin{array}{l}\text { clay siltst. } \\
\text { RB.unwthd, mass, (frac). }\end{array}$ \\
\hline 19017 & N106/99700845 & $\mathrm{X} 19 / 09314473$ & $\begin{array}{l}\text { clay siltst. } \\
\text { RB.unwthd,mass. }\end{array}$ \\
\hline
\end{tabular}




\begin{tabular}{|c|c|c|c|}
\hline 19018 & N106/99690846 & X19/09304474 & $\begin{array}{l}\text { silty clayst. } \\
\text { RB.unwthd, mass, (frac). }\end{array}$ \\
\hline 19019 & N106/99680847 & X19/09294474 & $\begin{array}{l}\text { silty clayst. } \\
\text { RB. unwthd, mass. }\end{array}$ \\
\hline 19020 & N106/99660848 & X19/09274475 & $\begin{array}{l}\text { silty clayst. } \\
\text { RB.unwthd, mass, mod frac. }\end{array}$ \\
\hline 19021 & N106/99650849 & X19/09264476 & $\begin{array}{l}\text { silty clayst. } \\
\text { RB. unwthd, mass, (frac). }\end{array}$ \\
\hline 19022 & N106/99630850 & $\mathrm{X} 19 / 09244477$ & $\begin{array}{l}\text { silty clayst. } \\
\text { RB. (wthd), mass, Fe stn } \\
5 \mathrm{~cm} \text { bd. }\end{array}$ \\
\hline 19023 & N106/99600848 & $\mathrm{X} 19 / 09204475$ & $\begin{array}{l}\text { silty clayst. } \\
\text { LB. unwthd, mass. }\end{array}$ \\
\hline 19024 & N106/99590848 & X19/09214475 & $\begin{array}{l}\text { clay siltst. } \\
\text { LB. unwthd, mass. }\end{array}$ \\
\hline 19025 & N106/99580848 & X19/09204475 & $\begin{array}{l}\text { clay siltst. } \\
\text { LB. unwthd, mass. }\end{array}$ \\
\hline 19026 & N106/99570848 & $\mathrm{X} 19 / 09184475$ & $\begin{array}{l}\text { clay siltst. } \\
\text { LB. unwthd, mass. }\end{array}$ \\
\hline 19027 & N106/99560848 & X19/09174475 & $\begin{array}{l}\text { silty clayst. } \\
\text { LB. unwthd, mass, biv frag. }\end{array}$ \\
\hline 19028 & N106/99560848 & $\mathrm{X} 19 / 09174475$ & $\begin{array}{l}\text { silty clayst. } \\
\text { LB. unwthd, mass. }\end{array}$ \\
\hline 19029 & N106/99550848 & $\mathrm{X} 19 / 09164475$ & $\begin{array}{l}\text { silty clayst. } \\
\text { LB. unwthd, mass. }\end{array}$ \\
\hline 19030 & N106/99550849 & X19/09164476 & $\begin{array}{l}\text { silty clayst. } \\
\text { LB. unwthd, mass. }\end{array}$ \\
\hline 19031 & N106/99550850 & $\mathrm{X} 19 / 09164477$ & $\begin{array}{l}\text { siltst. } \\
\text { LB. unwthd, mass, biv frag, } \\
\text { ibdd cm-bdd sst. }\end{array}$ \\
\hline 19032 & N106/99540850 & X19/09154477 & $\begin{array}{l}\text { silty clayst. } \\
\text { LB. unwthd, mass. }\end{array}$ \\
\hline 19033 & N106/99540851 & X19/09154478 & $\begin{array}{l}\text { silty clayst. } \\
\text { LB. unwthd, mass. }\end{array}$ \\
\hline 19034 & N106/99550851 & X19/09164478 & $\begin{array}{l}\text { silty clayst. } \\
\text { RB. unwthd, mass. }\end{array}$ \\
\hline 19035 & N106/99530852 & X19/09144479 & $\begin{array}{l}\text { siltst. } \\
\text { RB.unwthd, wk bdd, biv } \\
\text { frag. }\end{array}$ \\
\hline 19036 & N106/99510848 & $\mathrm{X} 19 / 09124475$ & $\begin{array}{l}\text { clay siltst. } \\
\text { RB. unwthd, mass. }\end{array}$ \\
\hline
\end{tabular}




\begin{tabular}{|c|c|c|c|}
\hline 19037 & N106/99480846 & $\mathrm{X} 19 / 09114474$ & $\begin{array}{l}\text { siltst. } \\
\text { RB. (wthd), wk bdd, biv } \\
\text { frag,Fe stn bur, Fe stn } \\
\text { tf bd. }\end{array}$ \\
\hline 19038 & N106/99460844 & X19/09104472 & $\begin{array}{l}\text { siltst. } \\
\text { RB. (wthd), wk bdd, (frac), } \\
\text { surf Fe stn. }\end{array}$ \\
\hline 19039 & N106/99440843 & $\mathrm{X} 19 / 09084471$ & $\begin{array}{l}\text { fine silty sandst. } \\
\text { RB. (wthd), wk bdd, ( } F e \\
\text { stn bur). }\end{array}$ \\
\hline 19040 & N106/99430842 & $\mathrm{X} 19 / 09074470$ & $\begin{array}{l}\text { fine silty sandst. } \\
\text { RB. (wthd), wk bdd, (Fe } \\
\text { stn frac surf). }\end{array}$ \\
\hline 19041 & N106/99420841 & $\mathrm{X} 19 / 09064469$ & $\begin{array}{l}\text { siltst. } \\
\text { RB. (wthd), ibdd cm-bdd } \\
\text { sst. }\end{array}$ \\
\hline 19042 & N106/99420837 & $\mathrm{X} 19 / 09064464$ & $\begin{array}{l}\text { clay siltst. } \\
\text { LB.unwthd, mass. }\end{array}$ \\
\hline 19043 & N106/99400838 & $\mathrm{X} 19 / 09054465$ & $\begin{array}{l}\text { clay siltst. } \\
\text { LB. unwthd, wk bdd, biv } \\
\text { frag. }\end{array}$ \\
\hline 19044 & N106/99390840 & $\mathrm{X} 19 / 09044468$ & $\begin{array}{l}\text { clay siltst. } \\
\text { LB. unwthd, ibdd cm-bdd } \\
\text { yel sst. }\end{array}$ \\
\hline 19045 & N106/99380841 & $X 19 / 09034469$ & $\begin{array}{l}\text { clay siltst. } \\
\text { LB.unwthd, wk bdd, mod } \\
\text { frac,Fe stn sst pell. }\end{array}$ \\
\hline 19046 & N106/99370842 & X19/09024470 & $\begin{array}{l}\text { silty clayst. } \\
\text { LB. unwthd, mass. }\end{array}$ \\
\hline 19047 & N106/99340844 & $\mathrm{X} 19 / 08994472$ & $\begin{array}{l}\text { silty clayst. } \\
\text { LB. unwthd, mass, frac. }\end{array}$ \\
\hline 19048 & N106/99310850 & $\mathrm{X} 19 / 08964477$ & $\begin{array}{l}\text { silty clayst. } \\
\text { RB.unwthd, mass. }\end{array}$ \\
\hline 19049 & N106/99310852 & X19/08964479 & $\begin{array}{l}\text { silty clayst. } \\
\text { RB. unwthd, mass, water } \\
\text { sepng o'cp. }\end{array}$ \\
\hline 19050 & N106/99300854 & $\mathrm{X} 19 / 08954481$ & $\begin{array}{l}\text { silty clayst. } \\
\text { RB.unwthd, mass, biv frag. }\end{array}$ \\
\hline 19051 & N106/99290856 & $\mathrm{X} 19 / 08944483$ & $\begin{array}{l}\text { silty clayst. } \\
\text { RB.unwthd, mass. }\end{array}$ \\
\hline 19052 & N106/99280856 & $\mathrm{X} 19 / 08934483$ & $\begin{array}{l}\text { silty clayst. } \\
\text { RB.unwthd, mass, biv frag. }\end{array}$ \\
\hline 19053 & N106/99270858 & $\mathrm{X} 19 / 08924485$ & $\begin{array}{l}\text { silty clayst. } \\
\text { RB.unwthd, mass. }\end{array}$ \\
\hline
\end{tabular}




\begin{tabular}{|c|c|c|c|}
\hline 19054 & N106/99260860 & X19/08914487 & $\begin{array}{l}\text { fine silty sandst. } \\
\text { RB. unwthd, mass, frac. }\end{array}$ \\
\hline 19055 & N106/99240862 & X19/08894489 & $\begin{array}{l}\text { clay siltst. } \\
\text { LB.unwthd, mass, mod frac. }\end{array}$ \\
\hline 19056 & N106/99230863 & $\mathrm{X} 19 / 08884490$ & $\begin{array}{l}\text { clay siltst. } \\
\text { LB.unwthd, mass. }\end{array}$ \\
\hline 19057 & N106/99220864 & $\mathrm{X} 19 / 08874491$ & $\begin{array}{l}\text { silty clayst. } \\
\text { LB.unwthd, mass, mod frac. }\end{array}$ \\
\hline 19058 & N106/99260872 & $\mathrm{X} 19 / 08914497$ & $\begin{array}{l}\text { silty clayst. } \\
\text { LB.unwthd, mass. }\end{array}$ \\
\hline 19059 & N106/99280880 & X19/08934506 & $\begin{array}{l}\text { sandy siltst. } \\
\text { RB. unwthd, mass, mod frac. }\end{array}$ \\
\hline 19060 & N106/99250878 & $\mathrm{X} 19 / 08904503$ & $\begin{array}{l}\text { clay siltst. } \\
\text { LB.unwthd, mass. }\end{array}$ \\
\hline 19061 & N106/99260881 & X19/08914507 & $\begin{array}{l}\text { clay siltst. } \\
\text { RB.unwthd,mass. }\end{array}$ \\
\hline 19062 & N106/99240879 & $\mathrm{X} 19 / 08894504$ & $\begin{array}{l}\text { clay siltst. } \\
\text { LB. unwthd, mass, mod frac. }\end{array}$ \\
\hline 19063 & N106/99220880 & $\mathrm{X} 19 / 08874506$ & $\begin{array}{l}\text { clay siltst. } \\
\text { LB.unwthd, mass, mod frac. }\end{array}$ \\
\hline 19064 & N106/99210880 & $\mathrm{X} 19 / 08864506$ & $\begin{array}{l}\text { clay siltst. } \\
\text { LB. unwthd, mass, mod frac. }\end{array}$ \\
\hline 19065 & N106/99190882 & $\mathrm{X} 19 / 08844509$ & $\begin{array}{l}\text { clay siltst. } \\
\text { LB.unwthd, mass, (frac). }\end{array}$ \\
\hline 19066 & N106/99170882 & $X 19 / 08824509$ & $\begin{array}{l}\text { clay siltst. } \\
\text { LB. unwthd, mod frac, } \\
\text { (Fe stn frac surf). }\end{array}$ \\
\hline 19067 & N106/99160883 & $\mathrm{X} 19 / 08814510$ & $\begin{array}{l}\text { silty clayst. } \\
\text { RB. unwthd, mod frac. }\end{array}$ \\
\hline 19068 & N106/99140883 & $\mathrm{X} 19 / 08794510$ & $\begin{array}{l}\text { silty clayst. } \\
\text { RB. unwthd, mod frac. }\end{array}$ \\
\hline 19069 & N106/99130883 & $\mathrm{X} 19 / 08784510$ & $\begin{array}{l}\text { clay siltst. } \\
\text { RB. unwthd, mass, cem. }\end{array}$ \\
\hline 19070 & N106/99110883 & $\mathrm{X} 19 / 08764510$ & $\begin{array}{l}\text { silty clayst. } \\
\text { RB.unwthd, mass, cem, } \\
\text { (frac). }\end{array}$ \\
\hline 19071 & N106/99100883 & $\mathrm{X} 19 / 08754510$ & $\begin{array}{l}\text { clay siltst. } \\
\text { RB.unwthd, mass, (frac). }\end{array}$ \\
\hline 19072 & N106/99070883 & $\mathrm{X} 19 / 08734510$ & $\begin{array}{l}\text { clay siltst. } \\
\text { RB. unwthd, mass, frac. }\end{array}$ \\
\hline 19073 & N106/99050883 & $\mathrm{X} 19 / 08714510$ & $\begin{array}{l}\text { clay siltst. } \\
\text { RB.unwthd, mass, frac. }\end{array}$ \\
\hline
\end{tabular}




\begin{tabular}{|c|c|c|c|}
\hline 19074 & N106/99030883 & $\mathrm{X} 19 / 08694510$ & $\begin{array}{l}\text { clay siltst. } \\
\text { RB. unwthd, mass, (frac). }\end{array}$ \\
\hline 19075 & N106/99020878 & $\mathrm{X} 19 / 08694503$ & $\begin{array}{l}\text { clay siltst. } \\
\text { LB. (wthd), mass, (frac), } \\
\text { (Fe stn). }\end{array}$ \\
\hline 19076 & N106/98990880 & $\mathrm{X} 19 / 08684506$ & $\begin{array}{l}\text { clay siltst. } \\
\text { LB. unwthd, mass, frac. }\end{array}$ \\
\hline 19077 & N106/98980881 & $\mathrm{X} 19 / 08674507$ & $\begin{array}{l}\text { clay siltst. } \\
\text { LB. unwthd, mass, (frac). }\end{array}$ \\
\hline 19078 & N106/98970882 & $\mathrm{X} 19 / 08864509$ & $\begin{array}{l}\text { clay siltst. } \\
\text { LB. unwthd, mass, (frac). }\end{array}$ \\
\hline 19079 & N106/98960883 & $\mathrm{X} 19 / 08654510$ & $\begin{array}{l}\text { clay siltst. } \\
\text { LB. unwthd, mass, (frac). }\end{array}$ \\
\hline 19080 & N106/98950883 & $\mathrm{X} 19 / 08644510$ & $\begin{array}{l}\text { clay siltst. } \\
\text { LB. unwthd, mass, (frac). }\end{array}$ \\
\hline 19081 & N106/98960885 & $\mathrm{X} 19 / 08654512$ & $\begin{array}{l}\text { clay siltst. } \\
\text { RB. unwthd, mass, frac. }\end{array}$ \\
\hline 19082 & $\mathrm{~N} 106 / 98950885$ & $\mathrm{X} 19 / 08644512$ & $\begin{array}{l}\text { clay siltst. } \\
\text { RB.unwthd, mass, mod frac, } \\
\text { Fe surf stn. }\end{array}$ \\
\hline 19083 & N106/98940886 & $\mathrm{X} 19 / 08634513$ & $\begin{array}{l}\text { siltst. } \\
\text { RB.unwthd, mass, (frac), } \\
\text { cem. }\end{array}$ \\
\hline 19084 & N106/98930886 & $\mathrm{X} 19 / 08624513$ & $\begin{array}{l}\text { clay siltst. } \\
\text { RB.unwthd, mass, (frac), } \\
\text { cem. }\end{array}$ \\
\hline 19085 & N106/98920887 & $\mathrm{X} 19 / 08614514$ & $\begin{array}{l}\text { clay siltst. } \\
\text { RB.unwthd, mass, (frac), } \\
\text { biv frag. }\end{array}$ \\
\hline 19086 & N106/98910887 & $\mathrm{X} 19 / 08604514$ & $\begin{array}{l}\text { clay siltst. } \\
\text { RB. unwthd, mass, mod frac. }\end{array}$ \\
\hline 19087 & N106/98900887 & $\mathrm{X} 19 / 08594514$ & $\begin{array}{l}\text { clay siltst. } \\
\text { RB.unwthd, mass, mod frac. }\end{array}$ \\
\hline 19088 & N106/98880887 & $\mathrm{X} 19 / 08574514$ & $\begin{array}{l}\text { clay siltst. } \\
\text { RB. unwthd, wk bdd, mod } \\
\text { frac. }\end{array}$ \\
\hline 19089 & N106/98850884 & $\mathrm{X} 19 / 08544511$ & $\begin{array}{l}\text { clay siltst. } \\
\text { LB.unwthd, mass, cem. }\end{array}$ \\
\hline 19090 & N106/98820884 & $\mathrm{X} 19 / 08514511$ & $\begin{array}{l}\text { silty clayst. } \\
\text { LB. unwthd, mass. }\end{array}$ \\
\hline 19091 & N106/98790884 & $\mathrm{X} 19 / 08494511$ & $\begin{array}{l}\text { clay siltst. } \\
\text { LB.unwthd,wk bdd, (frac). }\end{array}$ \\
\hline
\end{tabular}


19092

N106/98730888

X19/08434515

$19093 \quad$ N106/98700889

X19/08404516

$19094 \quad \mathrm{~N} 106 / 98680889$

X19/08384516

19095 N106/98660890

X19/08364517

$19096 \quad \mathrm{~N} 106 / 98750898$

19097 N106/98720898

$19098 \quad$ N106/98700897

$19099 \quad \mathrm{~N} 106 / 98650896$

$19100 \quad \mathrm{~N} 106 / 98640896$

19101

N106/98630895

19102

N106/98610895

$19103 \quad$ N106/98600894

19104 N106/98650894

19105 N106/98580894

$19106 \quad$ N106/98390889

$19107 \quad$ N106/98380888

19108 N106/98360888
X19/08294521

$\mathrm{X} 19 / 08454525$

X19/08424525

$\mathrm{X} 19 / 08404524$

X19/08354523

$\mathrm{X} 19 / 08344523$

X19/08334522

$\mathrm{X} 19 / 08314522$

X19/08304521

X19/08284521

$\mathrm{X} 19 / 08144516$

X19/08134515

$\mathrm{X} 19 / 08114515$ silty clayst.

LB. unwthd, mass, frac, Fe stn frac surf.

silty clayst.

LB. unwthd, mass, mod frac, (sl Fe stn).

silty clayst.

LB. unwthd, wk bdd, (frac).

clay siltst.

LB. unwthd, wk bdd, mod

frac.

clay siltst.

RB. unwthd, mass, (frac).

silty clayst.

RB. unwthd, mass, frac, (sl Fe stn), biotur.

silty clayst.

RB. unwthd, wk bdd, frac, biotur.

silty clayst.

RB. unwthd, mass, frac, biotur.

clay siltst.

RB. unwthd, wk bdd, (frac).

clay siltst.

RB. unwthd, wk bdd, frac.

clay siltst.

RB. unwthd, mass, biotur.

clay siltst.

RB. unwthd, wk bdd, mod

frac, biv frag.

silty clayst.

RB. unwthd, wk bdd, frac,

(sl Fe stn).

clayst.

RB. unwthd, mass, frac.

silty clayst.

RB. unwthd, mass, frac,

$\mathrm{Fe}$ stn frac surf.

clay siltst.

RB. unwthd, mass, frac,

$\mathrm{Fe}$ stn frac surf.

clay siltst.

RB. unwthd, mass. 


\begin{tabular}{|c|c|c|c|}
\hline 19109 & N106/98340887 & $\mathrm{X} 19 / 08094514$ & $\begin{array}{l}\text { clay siltst. } \\
\text { RB.unwthd, mass, frac. }\end{array}$ \\
\hline 19110 & N106/98330877 & $X 19 / 0804514$ & $\begin{array}{l}\text { clayst. } \\
\text { RB.unwthd, mass, frac, } \\
\text { Fe stn frac surf. }\end{array}$ \\
\hline 19111 & N106/98320886 & $\mathrm{X} 19 / 08074513$ & $\begin{array}{l}\text { clay siltst. } \\
\text { RB. unwthd, mass, mod frac. }\end{array}$ \\
\hline 19112 & N106/98320886 & $\mathrm{X} 19 / 08074513$ & $\begin{array}{l}\text { clay siltst. } \\
\text { RB. unwthd, wk bdd, mod } \\
\text { frac,Fe stn frac surf. }\end{array}$ \\
\hline 19113 & N106/98310885 & $\mathrm{X} 19 / 08064512$ & $\begin{array}{l}\text { clay siltst. } \\
\text { RB. unwthd, wk bdd, Fe stn } \\
\text { frac surf. }\end{array}$ \\
\hline 19114 & N106/98300884 & X19/08054511 & $\begin{array}{l}\text { silty clayst. } \\
\text { RB.unwthd, wk bdd, frac, } \\
\text { Fe stn frac surf. }\end{array}$ \\
\hline 19115 & N106/98290883 & $\mathrm{X} 19 / 08044510$ & $\begin{array}{l}\text { clayst. } \\
\text { RB.unwthd, wk bdd, frac, } \\
\text { Fe stn frac surf. }\end{array}$ \\
\hline 19116 & N106/98280882 & $\mathrm{X} 19 / 08034509$ & 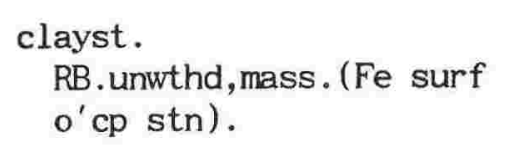 \\
\hline 19117 & N106/98270881 & $\mathrm{X} 19 / 08024507$ & $\begin{array}{l}\text { silty clayst. } \\
\text { RB.unwthd, mass, (frac), } \mathrm{Fe} \\
\text { stn, biotur. }\end{array}$ \\
\hline 19118 & N106/98170849 & $\mathrm{X} 19 / 07924476$ & $\begin{array}{l}\text { silty clayst. } \\
\text { LB.unwthd, bdd, (frac). }\end{array}$ \\
\hline 19119 & N106/98160849 & X19/07914476 & $\begin{array}{l}\text { silty clayst. } \\
\text { LB.unwthd, bdd, (frac), Fe } \\
\text { stn frac surf. }\end{array}$ \\
\hline 19120 & N106/98150848 & $\mathrm{X} 19 / 07904475$ & $\begin{array}{l}\text { fine sandst. } \\
\text { LB. unwthd, (frac), cem. }\end{array}$ \\
\hline 19121 & N106/98140848 & $\mathrm{X} 19 / 07984475$ & $\begin{array}{l}\text { fine sandst. } \\
\text { LB. (wthd), (frac), Fe stn. }\end{array}$ \\
\hline 19122 & N106/98130848 & $\mathrm{X} 19 / 07884475$ & $\begin{array}{l}\text { silty clayst. } \\
\text { LB. unwthd, mass, mod frac, } \\
\text { Fe stn frac surf. }\end{array}$ \\
\hline 19123 & N106/98120848 & $\mathrm{X} 19 / 07874475$ & $\begin{array}{l}\text { clay siltst. } \\
\text { LB.unwthd, wk bdd, mod } \\
\text { frac, biotur. }\end{array}$ \\
\hline 19124 & N106/98110848 & $\mathrm{X} 19 / 07864475$ & $\begin{array}{l}\text { silty clayst. } \\
\text { LB.unwthd, wk bdd, mod } \\
\text { frac,Fe stn frac surf. }\end{array}$ \\
\hline 19125 & N106/98100848 & $\mathrm{X} 19 / 07854475$ & $\begin{array}{l}\text { silty clayst. } \\
\text { LB.unwthd, wk bdd, mod } \\
\text { frac. }\end{array}$ \\
\hline
\end{tabular}




\begin{tabular}{|c|c|c|c|}
\hline 19126 & N106/98090848 & $\mathrm{X} 19 / 07844475$ & $\begin{array}{l}\text { clay siltst. } \\
\text { LB.unwthd, wk bdd, mod } \\
\text { frac. }\end{array}$ \\
\hline 19127 & N106/98080849 & $\mathrm{X} 19 / 07834476$ & $\begin{array}{l}\text { clay siltst. } \\
\text { LB. unwthd, wk bdd, mod } \\
\text { frac. }\end{array}$ \\
\hline 19128 & N106/98070849 & $\mathrm{X} 19 / 07824476$ & $\begin{array}{l}\text { silty clayst. } \\
\text { LB.unwthd, wk bdd, mod } \\
\text { frac. }\end{array}$ \\
\hline 19129 & N106/98060849 & $\mathrm{X} 19 / 07814476$ & $\begin{array}{l}\text { silty clayst. } \\
\text { LB. unwthd, wk bdd, mod } \\
\text { frac. }\end{array}$ \\
\hline 19130 & N106/98060850 & $\mathrm{X} 19 / 07814477$ & $\begin{array}{l}\text { silty clayst. } \\
\text { LB. unwthd, wk bdd, frac. }\end{array}$ \\
\hline 19131 & N106/98050850 & $\mathrm{X} 19 / 07804477$ & $\begin{array}{l}\text { silty clayst. } \\
\text { LB. unwthd, wk bdd, (frac), } \\
\text { Fe stn frac surf. }\end{array}$ \\
\hline 19132 & N106/98040850 & $\mathrm{X} 19 / 07794477$ & $\begin{array}{l}\text { silty clayst. } \\
\text { LB. unbwthd, mass, frac. }\end{array}$ \\
\hline 19133 & N106/98030851 & $\mathrm{X} 19 / 07784478$ & $\begin{array}{l}\text { silty clayst. } \\
\text { LB.unwthd, wk bdd, mod } \\
\text { frac, (Fe stn). }\end{array}$ \\
\hline 19134 & $\mathrm{~N} 106 / 98020851$ & $\mathrm{X} 19 / 07774478$ & $\begin{array}{l}\text { clayst. } \\
\text { LB: unwthd, wk bdd, (frac). }\end{array}$ \\
\hline 19135 & N106/98010851 & $\mathrm{X} 19 / 07764478$ & $\begin{array}{l}\text { silty clayst. } \\
\text { LB.unwthd, mass, (frac), } \\
\text { (Fe stn). }\end{array}$ \\
\hline 19136 & $\mathrm{~N} 106 / 98010851$ & $\mathrm{X} 19 / 07764478$ & $\begin{array}{l}\text { silty clayst. } \\
\text { LB.unwthd, wk bdd, mod } \\
\text { frac, (Fe stn). }\end{array}$ \\
\hline 19137 & N106/98000852 & $\mathrm{X} 19 / 07754478$ & $\begin{array}{l}\text { clay siltst. } \\
\text { LB.unwthd, mass, mod frac, } \\
\text { biotur. }\end{array}$ \\
\hline 19138 & N106/97980852 & $\mathrm{X} 19 / 07734479$ & $\begin{array}{l}\text { clay siltst. } \\
\text { LB. unwthd, mass, (frac), } \\
(\mathrm{Fe} \text { stn). }\end{array}$ \\
\hline 19139 & $\mathrm{~N} 106 / 97970852$ & $\mathrm{X} 19 / 07724479$ & $\begin{array}{l}\text { clay siltst. } \\
\text { LB. unwthd, mass, (frac), } \\
\text { biotur. }\end{array}$ \\
\hline 19140 & $\mathrm{~N} 106 / 97960852$ & $\mathrm{X} 19 / 07714479$ & $\begin{array}{l}\text { clay siltst. } \\
\text { LB.unwthd, mass, (frac), } \\
\text { Fe stn frac surf. }\end{array}$ \\
\hline 19141 & N106/97959852 & $\mathrm{X} 19 / 07704479$ & $\begin{array}{l}\text { clay siltst. } \\
\text { LB.unwthd, mass, (frac), } \\
\text { (Fe stn). }\end{array}$ \\
\hline
\end{tabular}


19142 N106/97940852

X19/07694479

$19143 \quad \mathrm{~N} 106 / 97930852$

X19/07684479

$19144 \quad \mathrm{~N} 106 / 97920853$

$19145 \quad \mathrm{~N} 106 / 97910854$

$19146 \quad \mathrm{~N} 106 / 87890855$

$19147 \quad \mathrm{~N} 106 / 97880856$

$19148 \quad \mathrm{~N} 106 / 97870856$

$19149 \quad \mathrm{~N} 106 / 97860857$

$19150 \quad$ N106/97850858

$19151 \quad \mathrm{~N} 106 / 97840859$

19152 N106/97830860

$19153 \quad$ N106/97820861

$19154 \quad$ N106/97820863

19155 N106/97810864

$19156 \quad \mathrm{~N} 106 / 97590870$

19157 N106/97590869

$19158 \quad \mathrm{~N} 106 / 97580869$
$\mathrm{X} 19 / 07674480$

X19/07664481

$\mathrm{X} 19 / 07654482$

X19/07644483

$\mathrm{X} 19 / 07634483$

X19/07624484

$\mathrm{X} 19 / 07624485$

X19/07614486

X19/07604487

X19/07604488

X19/07604490

X19/07594491

X19/07394497

X19/07394496

X19/09384496 silty clayst.

LB. unwthd, mass, mod frac, Fe stn, biotur, biv frag.

clay siltst. LB. unwthd, wk bdd, mod frac.

clay siltst. LB. unwthd, wk bdd, (frac), (Fe stn), biotur.

clay siltst. LB. unwthd, mass, (frac), (Fe stn), biotur.

clay siltst. LB. unwthd, mass, (frac), (Fe stn frac surf).

clay siltst.

LB. unwthd, wk bdd, (frac), biotur.

clay siltst.

LB. unwthd, mass, frac.

clay siltst.

LB. unwthd, wk bdd, (frac), (Fe stn frac surf).

silty clayst.

LB. unwthd, mass, (frac), (Fe stn frac surf).

silty clayst.

LB. unwthd, mass, frac, Fe stn frac surf.

clay siltst. LB. unwthd, mass, frac, (Fe stn frac surf).

silty clayst. LB. unwthd, mass, frac, Fe stn frac surf.

silty clayst.

LB. unwthd, mass, frac.

clay siltst.

LB. unwthd, mass, frac.

clay siltst. LB. unwthd, wk bdd, frac, (Fe stn frac surf).

clay siltst.

LB. unwthd, wk bdd, (frac).

clay siltst.

LB. unwthd, mass, (frac), 


\begin{tabular}{|c|c|c|c|}
\hline 19159 & N106/97570870 & $\mathrm{X} 19 / 07374497$ & $\begin{array}{l}\text { clay siltst. } \\
\text { LB.unwthd, mass, (frac). }\end{array}$ \\
\hline 19160 & N106/97560870 & $\mathrm{X} 19 / 07364497$ & $\begin{array}{l}\text { clay siltst. } \\
\text { LB.unwthd, mass, frac. }\end{array}$ \\
\hline 19161 & N106/97550871 & $\mathrm{X} 19 / 07354498$ & $\begin{array}{l}\text { clay siltst. } \\
\text { LB.unwthd, wk bdd, (frac). }\end{array}$ \\
\hline 19162 & N106/97530871 & X19/0718879498 & $\begin{array}{l}\text { clay siltst. } \\
\text { LB. unwthd, wk bdd, (frac). }\end{array}$ \\
\hline 19163 & N106/97510872 & X19/0718899499 & $\begin{array}{l}\text { clay siltst. } \\
\text { LB.unwthd, mass, frac, cem, } \\
\text { biotur. }\end{array}$ \\
\hline 19164 & N106/07490872 & $\mathrm{X} 19 / 07304499$ & $\begin{array}{l}\text { clay siltst. } \\
\text { LB.unwthd, mass, frac, } \\
\text { cem, biotur. }\end{array}$ \\
\hline 19165 & N106/97480874 & X19/0718899501 & $\begin{array}{l}\text { silty clayst. } \\
\text { RB. unwthd, wk bdd, (frac), } \\
\text { biotur. }\end{array}$ \\
\hline 19166 & N106/97470872 & X19/0718889499 & $\begin{array}{l}\text { clay siltst. } \\
\text { LB.unwthd, mass, (frac), } \\
\text { biotur. }\end{array}$ \\
\hline 19167 & N106/97450872 & $\mathrm{X} 19 / 07304499$ & $\begin{array}{l}\text { clay siltst. } \\
\text { LB. unwthd, mass, (frac). }\end{array}$ \\
\hline 19168 & N106/97420872 & $\mathrm{X} 19 / 07274499$ & $\begin{array}{l}\text { clay siltst. } \\
\text { LB.unwthd, mass, (frac), } \\
\text { biotur. }\end{array}$ \\
\hline 19169 & N106/97400873 & $\mathrm{X} 19 / 07254500$ & $\begin{array}{l}\text { clay siltst. } \\
\text { LB.unwthd, mass (frac), } \\
\text { biotur. }\end{array}$ \\
\hline 19170 & N106/97370874 & $\mathrm{X} 19 / 07224501$ & $\begin{array}{l}\text { clay siltst. } \\
\text { LB. unwthd, mass, frac, } \\
\text { Fe stn frac surf. }\end{array}$ \\
\hline 19171 & N106/9718883874 & X19/07184501 & $\begin{array}{l}\text { clay siltst. } \\
\text { LB.unwthd, mass, frac, } \\
\text { Fe stn frac surf. }\end{array}$ \\
\hline 19172 & N106/97310876 & $\mathrm{X} 19 / 07164503$ & $\begin{array}{l}\text { clay siltst. } \\
\text { LB.unwthd,mass, (frac), } \\
\text { Fe stn frac surf. }\end{array}$ \\
\hline 19173 & N106/97290876 & $\mathrm{X} 19 / 07144503$ & $\begin{array}{l}\text { clay siltst. } \\
\text { LB. unwthd, mass, (frac). }\end{array}$ \\
\hline 19174 & N106/97280879 & $\mathrm{X} 19 / 07134506$ & $\begin{array}{l}\text { clay siltst. } \\
\text { RB. unwthd, mass, (frac). }\end{array}$ \\
\hline 19175 & N106/97260880 & $\mathrm{X} 19 / 07114507$ & $\begin{array}{l}\text { clay siltst. } \\
\text { RB.unwthd, mass, (frac). }\end{array}$ \\
\hline
\end{tabular}




\begin{tabular}{|c|c|c|c|}
\hline 19176 & N106/97240880 & $\mathrm{X} 19 / 07094507$ & $\begin{array}{l}\text { clay siltst. } \\
\text { RB.unwthd, mass, (frac), } \\
\text { Fe stn frac surf. }\end{array}$ \\
\hline 19177 & N106/97230880 & $\mathrm{X} 19 / 07084507$ & $\begin{array}{l}\text { clay siltst. } \\
\text { RB. unwthd, mass, frac, } \\
\text { Fe stn frac surf. }\end{array}$ \\
\hline 19178 & N106/97210880 & $\mathrm{X} 19 / 07064507$ & $\begin{array}{l}\text { clay siltst. } \\
\text { RB.unwthd, mass. }\end{array}$ \\
\hline 19179 & N106/97190877 & X19/07044504 & $\begin{array}{l}\text { clay siltst. } \\
\text { RB. unwthd, wk bdd. }\end{array}$ \\
\hline 19180 & N106/97170876 & X19/07024503 & $\begin{array}{l}\text { clay siltst. } \\
\text { RB. unwthd, bdd, (f rac). }\end{array}$ \\
\hline 19181 & N106/97150874 & $\mathrm{X} 19 / 07014501$ & $\begin{array}{l}\text { clay siltst. } \\
\text { RB.unwthd, mass. }\end{array}$ \\
\hline 19182 & N106/97108712 & X19/06994499 & $\begin{array}{l}\text { clay siltst. } \\
\text { RB.unwthd, wk bdd, (frac), } \\
\text { biotur. }\end{array}$ \\
\hline 19183 & N106/97110871 & $\mathrm{X} 19 / 06974498$ & $\begin{array}{l}\text { clay siltst. } \\
\text { RB.unwthd, wk bdd, frac, } \\
\text { surf Fe stn, biotur. }\end{array}$ \\
\hline 19184 & $\mathrm{~N} 106 / 97070870$ & $\mathrm{X} 19 / 06934497$ & $\begin{array}{l}\text { clay siltst. } \\
\text { RB.unwthd,gr bd. }\end{array}$ \\
\hline 19185 & N106/97040870 & X19/06894497 & $\begin{array}{l}\text { clay siltst. } \\
\text { RB.unwthd, inter bdd tuf, } \\
\text { biotur. }\end{array}$ \\
\hline 19186 & N106/97010871 & X19/06864498 & $\begin{array}{l}\text { clay siltst. } \\
\text { RB.unwthd, bdd, (frac), } \\
\text { bi otur. }\end{array}$ \\
\hline 19187 & N106/96990872 & X19/06844499 & $\begin{array}{l}\text { clay siltst. } \\
\text { RB.unwthd, wk bdd, (frac). }\end{array}$ \\
\hline 19188 & N106/96970874 & $\mathrm{X} 19 / 06824501$ & $\begin{array}{l}\text { silty fine sandst. } \\
\text { RB.unwthd, wk bdd, (frac), } \\
\text { carb. }\end{array}$ \\
\hline 19189 & N106/96950877 & $\mathrm{X} 19 / 06804504$ & $\begin{array}{l}\text { clay siltst. } \\
\text { RB.unwthd, mass, (frac). }\end{array}$ \\
\hline 19190 & N106/96940881 & $\mathrm{X} 19 / 06794508$ & $\begin{array}{l}\text { clay siltst. } \\
\text { RB.unwthd, mass, frac, } \\
\text { Fe stn frac surf, biotur. }\end{array}$ \\
\hline 19191 & N106/96930887 & $\mathrm{X} 19 / 06784413$ & $\begin{array}{l}\text { silty clayst. } \\
\text { RB.unwthd, mass, (frac), } \\
\text { biotur. }\end{array}$ \\
\hline 19192 & N106/96920890 & $\mathrm{X} 19 / 06774416$ & $\begin{array}{l}\text { sandy siltst. } \\
\text { RB.unwthd, bdd, (frac), } \\
\text { biotur. }\end{array}$ \\
\hline
\end{tabular}




\begin{tabular}{|c|c|c|c|}
\hline 19193 & N106/96920894 & $\mathrm{X} 19 / 06774421$ & $\begin{array}{l}\text { sandy siltst. } \\
\text { RB.unwthd, mass, (frac), } \\
\text { biotur. }\end{array}$ \\
\hline 19194 & N106/96900891 & $\mathrm{X} 19 / 06754417$ & $\begin{array}{l}\text { clay siltst. } \\
\text { LB. unwthd, grd bd, (frac). }\end{array}$ \\
\hline 19195 & N106/96900895 & $\mathrm{X} 19 / 06754422$ & $\begin{array}{l}\text { clay siltst. } \\
\text { LB. unwthd, grd bd, (frac). }\end{array}$ \\
\hline 19196 & N106/96870913 & $\mathrm{X} 19 / 06714540$ & $\begin{array}{l}\text { clay siltst. } \\
\text { RB.unwthd, bdd, (frac), } \\
\text { biotur. }\end{array}$ \\
\hline 19197 & N106/96870918 & $\mathrm{X} 19 / 06714545$ & $\begin{array}{l}\text { clay siltst. } \\
\text { RB.unwthd, mass, frac, Fe } \\
\text { stn frac surf, biotur. }\end{array}$ \\
\hline 19198 & N106/96850924 & $\mathrm{X} 19 / 06694551$ & $\begin{array}{l}\text { clay siltst. } \\
\text { RB.unwthd, mass, frac, } \mathrm{Fe} \\
\text { stn frac surf, biotur. }\end{array}$ \\
\hline 19199 & N106/96810923 & $\mathrm{X} 19 / 06664550$ & $\begin{array}{l}\text { clay siltst. } \\
\text { LB. unwthd, mass, frac, } \mathrm{Fe} \\
\text { stn frac surf, biotur. }\end{array}$ \\
\hline 19200 & N106/96800926 & $\mathrm{X} 19 / 06654553$ & $\begin{array}{l}\text { clay siltst. } \\
\text { LB.unwthd, mass, frac, Fe } \\
\text { stn frac surf, biotur. }\end{array}$ \\
\hline 19201 & N106/96790929 & $\mathrm{X} 19 / 06644556$ & $\begin{array}{l}\text { sandy siltst. } \\
\text { LB.unwthd, mass, frac, } \\
\text { Fe stn frac surf. }\end{array}$ \\
\hline 19202 & N106/96680937 & $\mathrm{X} 19 / 00574562$ & $\begin{array}{l}\text { sandy siltst. } \\
\text { RB.unwthd,grd bd,cem. }\end{array}$ \\
\hline 19203 & N106/96680937 & $\mathrm{X} 19 / 06574562$ & $\begin{array}{l}\text { sandst. } \\
\text { RB. unwthd, bdd, frac. }\end{array}$ \\
\hline 19204 & N106/96680937 & $\mathrm{X} 19 / 06574562$ & $\begin{array}{l}\text { sandst. } \\
\text { RB.unwthd, bdd, frac. }\end{array}$ \\
\hline 19205 & N106/96670937 & $\mathrm{X} 19 / 06564562$ & $\begin{array}{l}\text { sandst. } \\
\text { RB.unwthd, bdd, (frac). }\end{array}$ \\
\hline 19206 & N106/96670937 & $\mathrm{X} 19 / 06564562$ & $\begin{array}{l}\text { sandst. (glc). } \\
\text { RB.unwthd, mass. }\end{array}$ \\
\hline 19207 & N106/96670937 & $\mathrm{X} 19 / 06564562$ & $\begin{array}{l}\text { sandst. (glc). } \\
\text { RB.unwthd, mass. }\end{array}$ \\
\hline 19208 & N106/966770937 & $\mathrm{X} 19 / 06564562$ & $\begin{array}{l}\text { sandst. (glc). } \\
\text { RB.unwthd, mass. }\end{array}$ \\
\hline
\end{tabular}




\section{APPENDIX 2: BEDDING ATTITUDES FOR TECTONIC CORRECTION}

The Mangapoike River is on the eastern limb of the Wairoa Syncline, with bedding attitudes striking north/south and dipping 24-30 . A simple tectonic correction about strike is assumed. Bedding attitudes for individual site coréections are given below:

$\begin{array}{ll}18870-18884 & 199 / \mathrm{W} / 25 \\ 18885-18926 & 193 / \mathrm{W} / 25 \\ 18927-18954 & 193 / \mathrm{W} / 24 \\ 18955-18981 & 192 / \mathrm{W} / 24 \\ 18982-18995 & 191 / \mathrm{W} / 25 \\ 18996-19045 & 186 / \mathrm{W} / 25 \\ 19046-19116 & 186 / \mathrm{W} / 27 \\ 19117-19131 & 185 / \mathrm{W} / 30 \\ 19132-19144 & 185 / \mathrm{W} / 29 \\ 19145-19173 & 186 / \mathrm{W} / 30 \\ 19174-19185 & 189 / \mathrm{W} / 30 \\ 19186-19199 & 181 / \mathrm{W} / 27 \\ 19200-19208 & 183 / \mathrm{W} / 26\end{array}$




\section{APPENDIX 3: MAGNETOMINERALOGY SAMPLES}

Stratigraphic Datum $=$ Top of Makaretu Sandstones

\begin{tabular}{lcl} 
VUW No & Stratigraphic Height $(\mathrm{m})$ & \multicolumn{1}{c}{ Comments } \\
19210 & 346 & fine medium sandst. \\
19211 & 730 & $\begin{array}{l}\text { well cemented medium- } \\
\text { coarse sandst. }\end{array}$ \\
19212 & 745 & $\begin{array}{l}\text { well cemented medium- } \\
\text { coarse sandst. }\end{array}$ \\
19213 & 1257 & medium-fine sandst. \\
19214 & 1465 & coarse-medium sandst. \\
19215 & 1519 & medium-coarse sandst. \\
19216 & 1763 & medium-fine sandst. \\
19217 & 1998 & fine-medium sandst. \\
19218 & 2071 & medium sandst. \\
19219 & 2150 & medium-fine sandst.
\end{tabular}




\section{APPENDIX 4: ISOTHERMAL REMANENT DATA}

Units of magnetisation $\times 10^{-4} \mathrm{Am}^{-1}$

$\underset{(\mathrm{mT})}{\text { FIELD }} \quad$ SPECIMENS

$\begin{array}{llllll}19012.41 & 19012.42 & 19036.51 & 19036.52 & 19041.51 & 19041.52\end{array}$

$\begin{array}{lllllrr}0 & 2.3 & 3.5 & 7.3 & 2.3 & 2.7 & 4.8 \\ 25 & 40.7 & 46.2 & 33.5 & 33.6 & 246 & 219 \\ 50 & 88 & 101 & 75.2 & 76.8 & 1694 & 1348 \\ 75 & 115 & 133 & 103 & 104 & 3187 & 2507 \\ 100 & 127 & 138 & 107 & 112 & 3854 & 3162 \\ 125 & . & 146 & 114 & 116 & 3957 & . \\ 150 & 137 & 138 & 118 & 116 & 3927 & 3618 \\ 200 & 141 & 145 & 118 & 117 & 3986 & 3620 \\ 250 & 143 & 145 & 116 & 117 & 4010 & 3709 \\ 300 & 144 & 146 & 116 & 113 & 4077 & 3748 \\ 500 & 145 & 153 & 124 & 120 & 4252 & 3819 \\ 750 & 146 & 156 & 126 & 118 & 4276 & 3857 \\ 1000 & 147 & 159 & 128 & 118 & 4252 & 3856 \\ 1250 & 147 & 159 & 126 & 119 & 4275 & 3868 \\ 1500 & 149 & . & . & . & . & 3894\end{array}$

FIELD SPECIMENS

(mT)

$\begin{array}{llllll}19044.21 & 19044.22 & 19066.2 & 19067.1 & 19097.1 & 19097.2\end{array}$

$\begin{array}{lllllll}0 & 4.8 & 2.4 & 1.5 & 4.2 & 2.0 & 1.8 \\ 25 & 39.7 & 39 & 47.9 & 47.9 & 49.8 & 52.1 \\ 50 & 93 & 81 & 187 & 174 & 169 & 169 \\ 75 & 129 & 122 & 377 & 337 & 313 & 309 \\ 100 & 150 & 141 & 466 & 423 & 401 & 393 \\ 125 & 160 & - & 5 & 455 & . & 4 \\ 150 & 165 & 157 & 524 & 474 & 456 & 451 \\ 200 & 173 & 156 & 549 & 490 & 473 & 478 \\ 250 & 171 & 159 & 575 & 489 & 477 & 495 \\ 300 & 175 & 160 & 578 & 500 & 484 & 496 \\ 500 & 179 & 162 & 576 & 507 & 491 & 494 \\ 750 & 177 & 163 & 580 & 503 & 490 & 497 \\ 1000 & 179 & 163 & 583 & 513 & 497 & 504 \\ 1250 & 177 & 164 & 581 & 510 & 498 & 509 \\ 1500 & 174 & 165 & 581 & 508 & 497 & 520\end{array}$




FIELD
$(\mathrm{mT})$

$\begin{array}{lllll}19105.1 & 19103.1 & 19152.3 & 19152.4 & 19014.3\end{array}$

$\begin{array}{llllll}0 & 3.7 & 0.1 & 0.1 & 3.7 & 2.5 \\ 25 & 83 & 32.9 & 31.1 & 29.9 & 40 \\ 50 & 89 & 69 & 69 & 64 & 87 \\ 75 & 118 & 92 & 94 & 87 & 106 \\ 100 & 136 & 101 & 107 & 101 & 119 \\ 125 & . & 107 & 116 & 108 & . \\ 150 & 151 & 103 & 124 & 115 & 129 \\ 200 & 151 & 113 & 131 & 121 & 131 \\ 250 & 157 & 113 & 133 & 123 & 131 \\ 300 & 158 & 116 & 138 & 127 & 133 \\ 500 & 160 & 118 & 143 & 130 & 134 \\ 750 & 162 & 117 & 141 & 130 & 135 \\ 1000 & 161 & 120 & 144 & 132 & 135 \\ 1250 & 162 & 119 & 145 & 133 & 136 \\ 1500 & 163 & 119 & 144 & 131 & 136\end{array}$


- A25 -

APPENDIX 5: ELECTRON MICROPROBE ANALYSES

Detrital Titanomagnetite Analyses

\begin{tabular}{|c|c|c|c|c|c|c|}
\hline Sample & 19210 & 19210 & 19210 & 19211 & 19211 & 19211 \\
\hline $\mathrm{SiO} 2$ & 0.07 & 0.00 & 0.00 & 0.00 & 0.00 & 0.00 \\
\hline $\mathrm{TiO} 2$ & 9.82 & 8.44 & 8.71 & 8.56 & 9.57 & 7.75 \\
\hline $\mathrm{A} 12 \mathrm{O} 3$ & 3.11 & 4.29 & 3.01 & 3.94 & 3.17 & 2.98 \\
\hline $\mathrm{Fe} 2 \mathrm{O} 3$ & 47.47 & 48.91 & 50.11 & 49.79 & 48.80 & 52.25 \\
\hline $\mathrm{FeO}$ & 34.82 & 33.56 & 35.04 & 3.56 & 35.16 & 34.30 \\
\hline $\mathrm{MnO}$ & 0.65 & 0.55 & 0.72 & 0.63 & 0.68 & 0.53 \\
\hline $\mathrm{MgO}$ & 3.31 & 3.42 & 2.56 & 3.58 & 2.67 & 2.64 \\
\hline Total & 99.26 & 99.17 & 100.15 & 100.06 & 100.85 & 100.46 \\
\hline Usp/Mt & 0.27 & 0.24 & 0.24 & 0.24 & 0.27 & 0.22 \\
\hline $\begin{array}{l}\text { Grainsize } \\
\text { (microns) }\end{array}$ & 409 & 226 & 181 & 95 & 84 & 76 \\
\hline Sample & 19211 & 19211 & 19211 & 19212 & 19213 & 19213 \\
\hline $\mathrm{SiO} 2$ & 0.07 & 0.07 & 0.00 & 0.10 & 0.07 & 0.00 \\
\hline $\mathrm{TiO} 2$ & 9.21 & 9.72 & 8.67 & 10.57 & 8.84 & 12.84 \\
\hline $\mathrm{A} 12 \mathrm{O} 3$ & 4.05 & 3.11 & 4.47 & 1.53 & 3.24 & 1.45 \\
\hline $\mathrm{Fe} 2 \mathrm{O} 3$ & 48.35 & 47.61 & 48.56 & 46.12 & 49.29 & 42.04 \\
\hline $\mathrm{FeO}$ & 34.52 & 34.61 & 33.40 & 38.06 & 34.01 & 39.81 \\
\hline $\mathrm{MnO}$ & 0.48 & 0.65 & 0.59 & 2.48 & 0.63 & 2.84 \\
\hline $\mathrm{MgO}$ & 3.46 & 3.31 & 3.70 & 0.28 & 3.30 & 0.19 \\
\hline Total & 100.08 & 99.17 & 99.39 & 99.14 & 99.38 & 99.17 \\
\hline Usp/Mt & 0.27 & 0.24 & 0.25 & 0.31 & 0.25 & 0.37 \\
\hline $\begin{array}{l}\text { Grainsize } \\
\text { (microns) }\end{array}$ & 59 & 50 & 32 & 171 & 342 & 305 \\
\hline Sample & 19213 & 19213 & 19214 & 19214 & 19214 & 19214 \\
\hline $\mathrm{SiO} 2$ & 0.70 & 0.00 & 0.09 & 0.10 & 0.00 & 0.08 \\
\hline $\mathrm{TiO} 2$ & 10.35 & 11.07 & 7.31 & 7.98 & 11.03 & 9.86 \\
\hline $\mathrm{A} 12 \mathrm{O} 3$ & 0.71 & 0.64 & 3.57 & 1.94 & 0.76 & 3.24 \\
\hline $\mathrm{Fe} 2 \mathrm{O} 3$ & 47.41 & 47.90 & 52.09 & 51.28 & 48.16 & 47.30 \\
\hline $\mathrm{FeO}$ & 38.64 & 38.38 & 34.18 & 36.47 & 38.43 & 35.11 \\
\hline $\mathrm{MnO}$ & 0.92 & 0.79 & 0.69 & 2.10 & 0.82 & 0.53 \\
\hline $\mathrm{MgO}$ & 1.43 & 1.53 & 2.49 & 0.24 & 1.56 & 3.28 \\
\hline Total & 100.16 & 100.32 & 100.41 & 100.11 & 100.76 & 99.40 \\
\hline Usp/Mt & 0.29 & 0.30 & 0.21 & 0.24 & 0.30 & 0.28 \\
\hline $\begin{array}{l}\text { Grainsize } \\
\text { (microns) }\end{array}$ & 99 & 87 & 109 & 67 & 62 & 42 \\
\hline
\end{tabular}


Detrital Titanomagnetite Analyses

$\begin{array}{lrrrrrr}\text { Sample } & 19215 & 19217 & 19217 & 19217 & 19217 & 19217 \\ \mathrm{SiO} 2 & & & & & & \\ \mathrm{TiO} 2 & 0.12 & 0.00 & 0.10 & 0.10 & 0.09 & 0.10 \\ \mathrm{A12O3} & 11.23 & 7.21 & 9.73 & 6.98 & 7.25 & 7.28 \\ \mathrm{Fe} 2 \mathrm{O} 3 & 1.59 & 3.47 & 1.72 & 1.78 & 2.68 & 2.76 \\ \mathrm{FeO} & 45.01 & 52.26 & 48.07 & 52.83 & 51.93 & 51.51 \\ \mathrm{MnO} & 38.96 & 33.96 & 38.18 & 35.20 & 35.23 & 35.10 \\ \mathrm{MgO} & 2.37 & 0.57 & 2.00 & 2.21 & 0.82 & 0.93 \\ \text { Total } & 0.28 & 2.46 & 0.21 & 0.21 & 1.37 & 1.35 \\ & 99.56 & 99.94 & 100.01 & 99.31 & 99.37 & 99.03 \\ \text { Usp/Mt } & 0.33 & 0.21 & 0.29 & 0.21 & 0.22 & 0.22 \\ \text { Grainsize } & 74 & 410 & 138 & 81 & 64 & 38 \\ \text { (microns) } & & & & & & \\ & & & & & & \\ & & & & & & \\ \text { Sample } & 19217 & 19217 & 19218 & 19219 & 19219 & 19219 \\ & & & & & & \\ \text { SiO2 } & 0.07 & 0.00 & 0.10 & 0.00 & 0.05 & 0.00 \\ \text { TiO2 } & 11.35 & 5.87 & 9.41 & 11.93 & 9.65 & 11.29 \\ \text { A12O3 } & 0.69 & 3.52 & 1.59 & 1.51 & 3.07 & 0.57 \\ \text { Fe2O3 } & 46.65 & 55.30 & 48.25 & 43.93 & 47.78 & 47.64 \\ \text { FeO } & 38.60 & 32.63 & 37.02 & 39.00 & 34.65 & 38.55 \\ \text { MnO } & 0.95 & 0.72 & 2.39 & 2.78 & 0.79 & 0.84 \\ \text { MgO } & 1.40 & 2.56 & 0.31 & 0.26 & 3.19 & 1.54 \\ \text { Total } & 99.71 & 100.60 & 99.06 & 99.41 & 99.18 & 100.43 \\ & & & & & & \\ \text { Usp/Mt } & 0.31 & 0.17 & 0.28 & 0.35 & 0.27 & 0.31 \\ \text { Grainsize } & 428 & 315 & 73 & 263 & 243 & 156 \\ \text { (microns) } & & & & & & \\ & & & & & & \end{array}$

Tuff Titanomagnetite Analyses

$\begin{array}{lrrr}\text { Sample } & \text { G/55 } & \text { G/55 } & \text { G/55 } \\ & & & \\ \mathrm{SiO} 2 & 0.07 & 0.18 & 0.11 \\ \mathrm{TiO} 2 & 6.43 & 7.73 & 7.33 \\ \mathrm{~A} 12 \mathrm{O} 3 & 1.22 & 1.39 & 1.23 \\ \mathrm{Fe} 2 \mathrm{O} 3 & 54.65 & 51.91 & 52.45 \\ \mathrm{FeO} & 35.85 & 37.26 & 36.72 \\ \mathrm{MnO} & 0.88 & 0.21 & 0.93 \\ \mathrm{MgO} & 0.15 & 0.21 & 0.14 \\ \text { Total } & 99.19 & 99.70 & 98.91 \\ & & & \\ \text { Usp/Mt } & 0.19 & 0.23 & 0.22 \\ \text { Grainsize } & 325 & 226 & 181 \\ \text { (microns) } & & & \end{array}$


Detrital Ilmenite Analyses (Representitative)

$\begin{array}{lrrrrrr}\text { Sample } & 19219 & 19219 & 19211 & 19211 & 19211 & 19211 \\ \mathrm{SiO} 2 & & & & & & \\ \mathrm{TiO} 2 & 0.07 & 0.00 & 0.00 & 0.00 & 0.00 & 0.00 \\ \mathrm{Al} 2 \mathrm{O} 3 & 48.35 & 42.27 & 52.02 & 52.40 & 43.06 & 47.15 \\ \mathrm{Fe} 2 \mathrm{O} 3 & 0.08 & 0.21 & 0.01 & 0.00 & 0.09 & 0.21 \\ \mathrm{FeO} & 8.21 & 21.66 & 0.27 & 0.13 & 19.65 & 11.75 \\ \mathrm{MnO} & 40.22 & 33.48 & 44.71 & 45.39 & 34.99 & 37.87 \\ \mathrm{MgO} & 0.98 & 0.41 & 2.04 & 1.39 & 0.48 & 1.13 \\ \text { Total } & 1.19 & 2.31 & 0.00 & 0.18 & 1.82 & 1.90 \\ & 99.14 & 100.34 & 99.06 & 99.49 & 100.09 & 100.01 \\ \mathrm{Il} / \mathrm{Hmt} & & & & & & \\ & 0.92 & 0.78 & 0.99 & 0.99 & 0.81 & 0.88 \\ & & & & & & \\ \mathrm{Sample} & 19212 & 19212 & 19213 & 19213 & 19217 & 19217 \\ & & & & & & \\ \mathrm{SiO2} & 0.00 & 0.00 & 0.00 & 0.00 & 0.00 & 0.31 \\ \text { TiO2 } & 42.96 & 41.99 & 39.01 & 50.88 & 50.75 & 44.23 \\ \mathrm{Al2O} 3 & 0.30 & 0.29 & 0.19 & 0.05 & 0.00 & 0.29 \\ \mathrm{Fe} 2 \mathrm{O} 3 & 21.07 & 21.75 & 27.94 & 3.60 & 3.78 & 16.81 \\ \mathrm{FeO} & 32.14 & 33.81 & 30.52 & 44.40 & 44.19 & 35.73 \\ \mathrm{MnO} & 0.76 & 0.47 & 1.02 & 0.67 & 0.74 & 0.24 \\ \mathrm{MgO} & 3.21 & 1.95 & 1.98 & 0.38 & 0.39 & 2.34 \\ \text { Total } & 100.44 & 100.26 & 100.66 & 99.98 & 99.85 & 99.95 \\ & & & & & & \\ \text { Il/Hmt } & 0.78 & 0.79 & 0.99 & 0.99 & 0.96 & 0.83 \\ & & & & & & \end{array}$

$\begin{array}{lrr}\text { Sample } & 19217 & 19218 \\ & & \\ \mathrm{SiO} 2 & 0.00 & 0.00 \\ \mathrm{TiO} 2 & 44.69 & 43.51 \\ \mathrm{~A} 12 \mathrm{O} 3 & 0.16 & 0.10 \\ \mathrm{Fe} 2 \mathrm{O} 3 & 15.92 & 19.44 \\ \mathrm{FeO} & 35.84 & 35.24 \\ \mathrm{MnO} & 0.37 & 0.39 \\ \mathrm{MgO} & 2.23 & 1.96 \\ \text { Total } & 99.20 & 100.64 \\ & & \\ \text { Il/Hmt } & 0.84 & 0.81\end{array}$


Sulphide Analyses (Representitative Pyrite)

$\begin{array}{lrrrrrr}\text { Sample } & 19211 & 19211 & 19212 & 19212 & 19213 & 19213 \\ \text { Fe } & 44.39 & 46.04 & 45.29 & 44.73 & 45.34 & 44.76 \\ \text { S } & 54.07 & 53.75 & 53.38 & 54.57 & 53.20 & 54.12 \\ \text { Mn } & 0.72 & 0.69 & 0.33 & 0.62 & 0.68 & 0.48 \\ \text { Total } & 99.18 & 100.48 & 99.00 & 99.92 & 99.22 & 99.36 \\ & & & & & & \\ & & & & & & \\ \text { Sample } & 19214 & 19214 & 19215 & 19215 & 19216 & 19216 \\ \text { Fe } & 44.49 & 45.49 & 44.74 & 46.11 & 45.37 & 45.78 \\ \text { S } & 54.63 & 53.64 & 54.56 & 53.68 & 53.30 & 53.29 \\ \text { Mn } & 0.31 & 0.54 & 0.51 & 0.59 & 0.63 & 0.41 \\ \text { Total } & 99.43 & 99.67 & 99.82 & 100.38 & 99.30 & 99.48 \\ & & & & & & \\ \text { Sample } & 19217 & 19217 & 19218 & 19218 & 19219 & 19219 \\ \text { Fe } & 44.60 & 44.85 & 45.34 & 46.07 & 45.82 & 44.70 \\ \text { S } & 53.94 & 54.61 & 54.70 & 53.59 & 53.84 & 54.03 \\ \text { Mn } & 0.54 & 0.39 & 0.42 & 0.57 & 0.59 & 0.66 \\ \text { Total } & 99.08 & 99.85 & 100.46 & 100.23 & 100.25 & 99.39 \\ & & & & & & \end{array}$




\section{APPENDIX 6: THERMAL PILOT DEMAGNETISATION DATA}

\begin{tabular}{|c|c|c|c|c|}
\hline \multirow[b]{2}{*}{ SPEC. } & \multirow[b]{2}{*}{$\begin{array}{l}\text { PLUNGE/ } \\
\text { AZIMUTH }\end{array}$} & \multicolumn{3}{|c|}{ NRM } \\
\hline & & D & I & $\mathrm{J}(\mathrm{A} / \mathrm{m})$ \\
\hline 18998.11 & 31050 & 095 & -40 & 5.7E-04 \\
\hline 18998.12 & 31050 & 107 & -54 & $7.0 \mathrm{E}-04$ \\
\hline 19000.41 & 26036 & 088 & -61 & 1. $3 \mathrm{E}-03$ \\
\hline 19000.42 & 26036 & 074 & -33 & 1. $7 \mathrm{E}-03$ \\
\hline 19010.31 & 19310 & 048 & -32 & $8.6 \mathrm{E}-04$ \\
\hline 19010.32 & 19310 & 041 & -34 & 8.5E-04 \\
\hline 19012.11 & 25309 & 050 & -35 & 8. $7 \mathrm{E}-04$ \\
\hline 19012.12 & 25309 & 042 & -28 & $8.7 \mathrm{E}-04$ \\
\hline 19019.2 & $31 \quad 124$ & 112 & -29 & 2. 3E-04 \\
\hline 19032.3 & 43256 & 357 & -44 & 4. $2 \mathrm{E}-04$ \\
\hline 19034.2 & 35066 & 107 & -42 & 4. $3 \mathrm{E}-04$ \\
\hline 19048.1 & $59 \quad 111$ & 238 & 53 & $2.0 \mathrm{E}-03$ \\
\hline 19048.4 & 53085 & 219 & 63 & 1.9E-03 \\
\hline 19061.4 & 39093 & 080 & -28 & $9.6 \mathrm{E}-05$ \\
\hline 19062.3 & $49 \quad 271$ & 162 & -22 & $5.0 \mathrm{E}-04$ \\
\hline 19094.21 & $34 \quad 317$ & 075 & -25 & $1.7 \mathrm{E}-04$ \\
\hline 19094.22 & 34317 & 081 & -12 & $1.1 \mathrm{E}-04$ \\
\hline
\end{tabular}

\author{
$100 \mathrm{C}$ \\ D I $\mathrm{J}(\mathrm{A} / \mathrm{m})$
}

$083-42 \quad 4.5 \mathrm{E}-04$ $109-55 \quad 5.7 \mathrm{E}-04$ $085-72 \quad 9.9 \mathrm{E}-04$ $068-32 \quad 1.3 \mathrm{E}-03$ $047-35 \quad 7.2 \mathrm{E}-04$ $\begin{array}{lll}040 & -43 & 5.7 \mathrm{E}-04\end{array}$ $\begin{array}{lll}359 & -45 & 7.8 \mathrm{E}-04\end{array}$ $041-23 \quad 7.2 \mathrm{E}-04$ $\begin{array}{lll}110 & -20 & 2.0 \mathrm{E}-04\end{array}$ $357-45 \quad 4.0 \mathrm{E}-04$

$238 \quad 53 \quad 1.9 \mathrm{E}-03$ $222 \quad 64 \quad 1.8 \mathrm{E}-03$ $071-32 \quad 9.3 \mathrm{E}-05$ $016-40 \quad 5.0 \mathrm{E}-04$ $\begin{array}{llll}078 & -25 & 1.5 \mathrm{E}-04\end{array}$ $082-12 \quad 9.7 \mathrm{E}-05$

\begin{tabular}{lrllll}
\multicolumn{3}{c}{$150 \mathrm{C}$} & \multicolumn{3}{c}{$200 \mathrm{C}$} \\
$\mathrm{D}$ & $\mathrm{I}$ & $\mathrm{J}(\mathrm{A} / \mathrm{m})$ & $\mathrm{D}$ & \multicolumn{1}{c}{$\mathrm{I}$} & $\mathrm{J}(\mathrm{A} / \mathrm{m})$ \\
& & & & & \\
058 & -44 & $3.3 \mathrm{E}-04$ & 056 & -37 & $2.3 \mathrm{E}-04$ \\
071 & -73 & $3.1 \mathrm{E}-04$ & 074 & -76 & $2.3 \mathrm{E}-04$ \\
074 & -83 & $6.7 \mathrm{E}-04$ & 063 & -84 & $5.7 \mathrm{E}-04$ \\
060 & -35 & $1.0 \mathrm{E}-03$ & 028 & -66 & $7.8 \mathrm{E}-04$ \\
045 & -40 & $5.3 \mathrm{E}-04$ & 026 & -60 & $3.4 \mathrm{E}-04$ \\
035 & -54 & $3.5 \mathrm{E}-04$ & 046 & -79 & $3.0 \mathrm{E}-04$ \\
029 & -56 & $3.6 \mathrm{E}-04$ & 030 & -77 & $3.4 \mathrm{E}-04$ \\
& & & 029 & -56 & $3.5 \mathrm{E}-04$ \\
073 & 22 & $1.7 \mathrm{E}-04$ & 072 & 15 & $1.4 \mathrm{E}-04$ \\
137 & -68 & $2.3 \mathrm{E}-05$ & 226 & 42 & $5.0 \mathrm{E}-05$ \\
068 & 03 & $3.5 \mathrm{E}-05$ & 076 & 10 & $3.5 \mathrm{E}-05$ \\
238 & 55 & $1.9 \mathrm{E}-03$ & 235 & 53 & $1.9 \mathrm{E}-03$ \\
& & & 228 & 65 & $1.6 \mathrm{E}-03$ \\
083 & -18 & $7.4 \mathrm{E}-05$ & 204 & 70 & $1.7 \mathrm{E}-04$ \\
163 & -20 & $1.3 \mathrm{E}-04$ & 176 & -10 & $5.0 \mathrm{E}-04$ \\
080 & -17 & $1.3 \mathrm{E}-04$ & 176 & 62 & $7.9 \mathrm{E}-05$ \\
105 & 29 & $5.6 \mathrm{E}-05$ & 182 & 72 & $1.2 \mathrm{E}-04$
\end{tabular}

SPEC.

18998.11

18998.12

19000.41

19000.42

19010.31

19010.32

19012.12

19012.11

19019.2

19032.3

19034.2

19048.1

19048.4

19061.4

19062.3

19094.21

19094.22

\begin{tabular}{ccc}
\multicolumn{3}{c}{$250 \mathrm{C}$} \\
$\mathrm{D}$ & \multicolumn{1}{c}{1} & $\mathrm{~J}(\mathrm{~A} / \mathrm{m})$ \\
021 & -62 & $1.4 \mathrm{E}-04$ \\
070 & -66 & $1.5 \mathrm{E}-04$ \\
055 & -81 & $4.4 \mathrm{E}-04$ \\
043 & -65 & $5.9 \mathrm{E}-04$ \\
026 & -62 & $2.3 \mathrm{E}-04$ \\
039 & -62 & $2.3 \mathrm{E}-04$ \\
035 & -60 & $2.7 \mathrm{E}-04$ \\
028 & -62 & $2.9 \mathrm{E}-04$ \\
076 & 39 & $1.6 \mathrm{E}-04$ \\
202 & 46 & $6.6 \mathrm{E}-05$ \\
104 & 63 & $4.5 \mathrm{E}-05$ \\
239 & 52 & $1.6 \mathrm{E}-03$ \\
225 & 66 & $1.5 \mathrm{E}-03$ \\
219 & 57 & $1.6 \mathrm{E}-04$ \\
180 & -17 & $4.2 \mathrm{E}-04$ \\
218 & 61 & $1.0 \mathrm{E}-04$ \\
190 & 78 & $1.2 \mathrm{E}-04$
\end{tabular}

$300 \mathrm{C}$

D I J $(\mathrm{A} / \mathrm{m})$

$\begin{array}{lll}064 & -38 & 9.6 \mathrm{E}-05\end{array}$ $\begin{array}{llll}054 & -65 & 8.8 \mathrm{E}-05\end{array}$ $009-80 \quad 3.0 \mathrm{E}-04$ $046-49 \quad 3.5 \mathrm{E}-04$ $027-68 \quad 1.9 \mathrm{E}-04$ $\begin{array}{lll}034 & -73 & 1.9 \mathrm{E}-04\end{array}$ $\begin{array}{lll}033 & -62 & 2.1 \mathrm{E}-04\end{array}$ $\begin{array}{lll}033 & -55 & 2.4 \mathrm{E}-04\end{array}$ $028 \quad 34 \quad 1.1 \mathrm{E}-04$ $206 \quad 42 \quad 1.1 \mathrm{E}-04$ $\begin{array}{lll}220 & 62 & 3.6 \mathrm{E}-05\end{array}$ $235 \quad 57 \quad 1.0 \mathrm{E}-03$ $236 \quad 69 \quad 1.1 \mathrm{E}-03$ $20170 \quad 1.0 \mathrm{E}-04$

$\begin{array}{lll}182 & -13 & 4.9 \mathrm{E}-04\end{array}$

$\begin{array}{lll}224 & 62 & 5.1 \mathrm{E}-05\end{array}$ $201 \quad 42 \quad 1.1 \mathrm{E}-04$

\section{APPENDIX 7: AF PILOT DEMAGNETISATION DATA}

\begin{tabular}{|c|c|c|c|c|}
\hline \multirow[b]{2}{*}{ SPEC. } & \multirow[b]{2}{*}{$\begin{array}{l}\text { PLUNGE/ } \\
\text { AZIMUTH }\end{array}$} & \multicolumn{3}{|c|}{ NRM } \\
\hline & & D & I & $\mathrm{M}(\mathrm{A} / \mathrm{m})$ \\
\hline 19012.41 & 44302 & 036 & -41 & $6.8 \mathrm{E}-04$ \\
\hline 19012.42 & 44302 & 051 & -50 & -04 \\
\hline 19030.2 & $23 \quad 309$ & 021 & -46 & 4.6 \\
\hline 19032.1 & 20160 & 010 & -82 & $2.8 \mathrm{E}-04$ \\
\hline 19037.21 & 33011 & 041 & -56 & 2. $3 \mathrm{E}-04$ \\
\hline 19037.22 & 33011 & 067 & -32 & $2.0 \mathrm{E}-04$ \\
\hline 19061.1 & 34101 & 074 & -67 & $5.4 \mathrm{E}-04$ \\
\hline .3 & 49198 & 067 & -72 & 8.7E-05 \\
\hline 190 & $\begin{array}{ll}38 & 091\end{array}$ & 068 & -35 & $3.6 \mathrm{E}-04$ \\
\hline 190 & $36 \quad 098$ & 031 & -58 & 1. $1 \mathrm{E}-03$ \\
\hline 19094.11 & 45086 & 101 & -33 & 1. $5 \mathrm{E}-04$ \\
\hline 19094.12 & 45086 & 153 & -30 & $2.1 \mathrm{E}-04$ \\
\hline 19094.41 & 39086 & 223 & 41 & 4. $3 \mathrm{E}-03$ \\
\hline 19094.42 & 39086 & 202 & 52 & $3.8 \mathrm{E}-03$ \\
\hline & $49 \quad 106$ & 079 & -60 & $2.1 \mathrm{E}-04$ \\
\hline 19105.1 & 35069 & 088 & -20 & $1.9 \mathrm{E}-04$ \\
\hline
\end{tabular}

SPEC.

19012.41

19012.42

19030.2

19032.1

19037.21

19037.22

19061.1

19080.3

19085.1

19088.4

19094.11

19094.12

19091.41

19091.42

19103.1

19105.1

$$
\text { D I } 20 \mathrm{mT}
$$

$\begin{array}{lll}028 & -53 & 2.8 \mathrm{E}-04\end{array}$ $037-51 \quad 2.6 \mathrm{E}-04$ $055 \quad-66 \quad 8.0 \mathrm{E}-05$ $070-67 \quad 1.0 \mathrm{E}-04$ $\begin{array}{lll}080 & -39 & 6.8 \mathrm{E}-05\end{array}$ $\begin{array}{lll}013 & -29 & 5.4 \mathrm{E}-05\end{array}$ $119-46 \quad 8.9 \mathrm{E}-05$ $\begin{array}{lll}127 & -38 \quad 3.4 \mathrm{E}-05\end{array}$ $091-27 \quad 8.7 \mathrm{E}-05$ $\begin{array}{lll}120 & -67 & 2.2 \mathrm{E}-04\end{array}$ $\begin{array}{lll}145 & -29 & 2.6 \mathrm{E}-05\end{array}$ $091-28 \quad 4.4 \mathrm{E}-05$ $236 \quad 50 \quad 3.6 \mathrm{E}-03$ 20360 4.1E-03 $067-29 \quad 1.8 \mathrm{E}-05$ $041-31 \quad 3.7 \mathrm{E}-05$

\begin{tabular}{crr}
\multicolumn{3}{c}{$5 \mathrm{miT}$} \\
D & I & $\mathrm{M}(\mathrm{A} / \mathrm{m})$ \\
& & \\
031 & -44 & $5.2 \mathrm{E}-04$ \\
052 & -53 & $5.2 \mathrm{E}-04$ \\
034 & -78 & $2.1 \mathrm{E}-04$ \\
041 & -87 & $2.1 \mathrm{E}-04$ \\
048 & -60 & $1.1 \mathrm{E}-04$ \\
033 & -56 & $9.8 \mathrm{E}-05$ \\
082 & -63 & $4.1 \mathrm{E}-04$ \\
074 & -47 & $6.5 \mathrm{E}-05$ \\
058 & -43 & $1.6 \mathrm{E}-04$ \\
046 & -61 & $8.1 \mathrm{E}-04$ \\
094 & -21 & $1.0 \mathrm{E}-04$ \\
139 & -25 & $1.3 \mathrm{E}-04$ \\
224 & 45 & $4.3 \mathrm{E}-03$ \\
200 & 56 & $3.9 \mathrm{E}-03$ \\
062 & -45 & $1.1 \mathrm{E}-04$ \\
059 & -19 & $1.3 \mathrm{E}-04$
\end{tabular}

D I $10 \mathrm{mT}$

$031-49 \quad 4.4 \mathrm{E}-04$ $046-50 \quad 4.2 \mathrm{E}-04$ $087-57 \quad 1.5 \mathrm{E}-04$ $061-76 \quad 1.6 \mathrm{E}-04$ $\begin{array}{llll}068 & -54 & 9.7 \mathrm{E}-05\end{array}$ $088-87 \quad 8.5 \mathrm{E}-05$ $\begin{array}{lll}090 & -59 & 2.9 \mathrm{E}-04\end{array}$ $095 \quad-42 \quad 5.1 \mathrm{E}-05$ $\begin{array}{lll}075 & -35 & 1.1 \mathrm{E}-04\end{array}$ $054-48 \quad 6.6 \mathrm{E}-04$ $108-23 \quad 6.5 \mathrm{E}-05$ $149-16 \quad 6.8 \mathrm{E}-05$ $224 \quad 49 \quad 4.2 \mathrm{E}-03$ $20456 \quad 4.0 \mathrm{E}-03$ $056-37 \quad 5.7 \mathrm{E}-05$ $\begin{array}{lll}052 & -28 & 9.3 \mathrm{E}-05\end{array}$

\begin{tabular}{cccccccccc}
\multicolumn{4}{c}{$25 \mathrm{mi}$} & \multicolumn{2}{c}{$30 \mathrm{mT}$} & \multicolumn{2}{c}{$35 \mathrm{mT}$} \\
$\mathrm{D}$ & $\mathrm{I}$ & $\mathrm{M}(\mathrm{A} / \mathrm{m})$ & $\mathrm{D}$ & $\mathrm{I}$ & $\mathrm{M}(\mathrm{A} / \mathrm{m})$ & $\mathrm{D}$ & $\mathrm{I}$ & $\mathrm{M}(\mathrm{A} / \mathrm{m})$ \\
030 & -54 & $2.2 \mathrm{E}-04$ & 030 & -53 & $2.0 \mathrm{E}-04$ & 028 & -54 & $1.6 \mathrm{E}-05$ \\
038 & -44 & $2.5 \mathrm{E}-04$ & 037 & -49 & $2.0 \mathrm{E}-05$ & 040 & -50 & $1.6 \mathrm{E}-05$ \\
130 & -87 & $7.3 \mathrm{E}-05$ & 048 & -40 & $5.6 \mathrm{E}-05$ & & & \\
216 & -82 & $5.9 \mathrm{E}-05$ & 121 & -38 & $3.4 \mathrm{E}-05$ & 141 & -20 & $2.1 \mathrm{E}-05$ \\
115 & -32 & $5.0 \mathrm{E}-05$ & 141 & -28 & $4.2 \mathrm{E}-05$ & 158 & -12 & $3.2 \mathrm{E}-05$ \\
099 & -76 & $4.9 \mathrm{E}-05$ & 142 & -46 & $3.0 \mathrm{E}-05$ & & & \\
130 & -35 & $6.4 \mathrm{E}-05$ & 138 & -31 & $4.9 \mathrm{E}-05$ & 150 & -28 & $2.8 \mathrm{E}-05$ \\
150 & -21 & $2.7 \mathrm{E}-05$ & 165 & -17 & $1.9 \mathrm{E}-05$ & & & \\
110 & -23 & $6.5 \mathrm{E}-05$ & 135 & -21 & $4.7 \mathrm{E}-05$ & 141 & -19 & $2.5 \mathrm{E}-05$ \\
078 & -46 & $1.0 \mathrm{E}-04$ & 025 & -34 & $8.4 \mathrm{E}-05$ & 084 & -67 & $6.2 \mathrm{E}-05$ \\
155 & -29 & $5.1 \mathrm{E}-05$ & 155 & -33 & $2.4 \mathrm{E}-05$ & 159 & -31 & $1.7 \mathrm{E}-05$ \\
080 & -23 & $4.3 \mathrm{E}-05$ & 122 & -20 & $2.1 \mathrm{E}-05$ & & & \\
243 & 51 & $3.8 \mathrm{E}-03$ & 241 & 50 & $3.5 \mathrm{E}-03$ & 241 & 53 & $2.7 \mathrm{E}-03$ \\
201 & 60 & $3.3 \mathrm{E}-03$ & 205 & 60 & $3.3 \mathrm{E}-04$ & 202 & 61 & $1.9 \mathrm{E}-03$ \\
115 & -17 & $3.7 \mathrm{E}-05$ & & & & & &
\end{tabular}

$029 \quad-50 \quad 3.4 \mathrm{E}-04$ $044-51 \quad 3.4 \mathrm{E}-04$ $105-37 \quad 9.6 \mathrm{E}-05$ 058 - 75 1. $3 \mathrm{E}-04$ $054-44 \quad 8.4 \mathrm{E}-05$ $\begin{array}{llll}045 & -74 & 6.8 \mathrm{E}-05\end{array}$ $098-63 \quad 1.8 \mathrm{E}-04$ $109-38 \quad 4.4 \mathrm{E}-05$ $091-27 \quad 8.7 \mathrm{E}-05$ $020-30 \quad 4.4 \mathrm{E}-04$ $\begin{array}{lll}133 & -14 & 4.5 \mathrm{E}-05\end{array}$ $\begin{array}{lll}126 & -16 & 4.7 \mathrm{E}-05\end{array}$ $226 \quad 51 \quad 3.9 \mathrm{E}-03$ $19958 \quad 4.0 \mathrm{E}-03$ $\begin{array}{llll}085 & -18 & 2.9 \mathrm{E}-05\end{array}$ $\begin{array}{lll}047 & -25 & 7.5 \mathrm{E}-05\end{array}$

$\begin{array}{lll}115 & -17 & 3.7 \mathrm{E}-05\end{array}$

$056-32 \quad 2.1 \mathrm{E}-05$ 


\section{APPENDIX 8: GENERAL DEMAGNETISATION DATA}

The general demagnetisation data is presented in this appendix. Remanence measurements for each specimen are given as declination (D), inclination (I) and magnetisation intensity (M), and are corrected for tectonic tilt (Appendix 2). Only the NRM data is given for those specimens rejected from the analysis following the criteria in chapters 3 and 4 . The optimum remanence data for each specimen is marked by an asterisk. 


\begin{tabular}{|c|c|c|c|c|c|c|c|c|c|c|c|c|c|c|c|c|c|c|c|}
\hline \multirow[b]{2}{*}{ SPEC. } & \multirow{2}{*}{\multicolumn{2}{|c|}{$\begin{array}{l}\text { PLUNGE/ } \\
\text { AZIMUTH }\end{array}$}} & \multicolumn{3}{|c|}{ NRM } & \multicolumn{2}{|r|}{150} & \multicolumn{3}{|c|}{200} & \multicolumn{3}{|r|}{250} & \multicolumn{4}{|c|}{300} & \multicolumn{2}{|r|}{320} \\
\hline & & & D & I & $\mathrm{M}(\mathrm{A} / \mathrm{m})$ & D & $1 \mathrm{M}(\mathrm{A} / \mathrm{m})$ & D & I & $M(A / m)$ & D & I & $\mathrm{M}(\mathrm{A} / \mathrm{m})$ & D & I & $\mathrm{M}(\mathrm{A} / \mathrm{m})$ & D & I & $M(A / m)$ \\
\hline 18870.21 & $\begin{array}{l}51 \\
51\end{array}$ & $\begin{array}{l}312 \\
312\end{array}$ & $\begin{array}{l}038 \\
048\end{array}$ & $\begin{array}{l}-71 \\
-69\end{array}$ & $\begin{array}{l}\text { 4. 8E-04 } \\
\text { 5.1E-04 }\end{array}$ & & & $\begin{array}{l}151 \\
206\end{array}$ & $\begin{array}{l}-73 \\
-79\end{array}$ & $\begin{array}{l}7.8 \mathrm{E}-05 \\
9.5 \mathrm{E}-05\end{array}$ & $\begin{array}{l}227 \\
214\end{array}$ & $\begin{array}{l}-45 \\
-30\end{array}$ & $\begin{array}{l}\text { 8.1E-05 } \\
7.0 \mathrm{E}-05\end{array}$ & $\begin{array}{l}224 \\
173\end{array}$ & $\begin{array}{l}-06 \\
-72\end{array}$ & $\begin{array}{l}\text { 1. } 4 \mathrm{E}-04 \\
\text { 1. } 2 \mathrm{E}-04\end{array}$ & $\begin{array}{l}.212 \\
.212\end{array}$ & $\begin{array}{l}47 \\
48\end{array}$ & $\begin{array}{l}5.9 \mathrm{E}-05^{8} \\
6.1 \mathrm{E}-05^{\circ}\end{array}$ \\
\hline $\begin{array}{l}18870.22 \\
18870.3\end{array}$ & $\begin{array}{l}51 \\
52\end{array}$ & $\begin{array}{l}312 \\
293\end{array}$ & $\begin{array}{l}048 \\
089\end{array}$ & $\begin{array}{l}-69 \\
-48\end{array}$ & $\begin{array}{l}5.1 E-04 \\
4.1 E-04\end{array}$ & & & $\begin{array}{l}206 \\
076\end{array}$ & $\begin{array}{l}-79 \\
-76\end{array}$ & $\begin{array}{l}\text { 9.5E-05 } \\
9.5 \mathrm{E}-05\end{array}$ & $\begin{array}{l}214 \\
162\end{array}$ & $\begin{array}{l}-30 \\
-36\end{array}$ & $\begin{array}{l}\text { 7.0E-05 } \\
\text { 4.2E-05 }\end{array}$ & $\begin{array}{l}173 \\
287\end{array}$ & $\begin{array}{r}-72 \\
89\end{array}$ & $\begin{array}{l}\text { 1. } 2 \mathrm{E}-04 \\
5.4 \mathrm{E}-05\end{array}$ & $=313$ & $\begin{array}{l}48 \\
89\end{array}$ & $\begin{array}{l}6.1 \mathrm{E}-05^{\circ} \\
2.6 \mathrm{E}-05^{\circ}\end{array}$ \\
\hline 18871.1 & 39 & 279 & 058 & -23 & $3.5 \mathrm{E}-04$ & & & 115 & -70 & 8.5E-05 & 076 & -68 & 8.7E-05 & 222 & 25 & $9.1 \mathrm{E}-05$ & $* 218$ & 27 & 4.6E-05? \\
\hline 18871.21 & 29 & 300 & 004 & -31 & $3.9 \mathrm{E}-04$ & & & 009 & -46 & 1. $2 \mathrm{E}-04$ & 292 & -23 & 5. $3 \mathrm{E}-05$ & $* 239$ & 64 & 4. $4 \mathrm{E}-05^{*}$ & 241 & 10 & 7. $6 \mathrm{E}-05$ \\
\hline 18871.22 & 29 & 300 & 359 & -26 & 3. $9 \mathrm{E}-04$ & & & 029 & -55 & 6.7E-05 & 260 & -09 & 1.1E-04 & 221 & 28 & 4. $5 E-05$ & $\approx 228$ & 39 & 2. $7 \mathrm{E}-05^{*}$ \\
\hline 18872.21 & 36 & 300 & 047 & -13 & 2. $3 \mathrm{E}-04$ & & & 106 & -35 & 7. $3 \mathrm{E}-05$ & 291 & 37 & 1. $2 \mathrm{E}-04$ & 241 & 61 & $6.0 \mathrm{E}-05^{\circ}$ & & & \\
\hline 18872.22 & 36 & 300 & 073 & -17 & $3.0 \mathrm{E}-04$ & & & 188 & -39 & 3. $4 \mathrm{E}-05$ & 185 & 72 & $4.4 \mathrm{E}-05$ & $* 187$ & 72 & 2. $2 \mathrm{E}-05^{*}$ & & & \\
\hline 18872.31 & 38 & 310 & 010 & -43 & 3. $7 \mathrm{E}-04$ & & & 282 & -82 & 8.7E-05 & 225 & 10 & $2.8 \mathrm{E}-05$ & .261 & 56 & 2. $3 \mathrm{E}-05^{\circ}$ & 179 & 10 & $5.0 \mathrm{E}-05$ \\
\hline 18872.32 & 38 & 310 & 020 & -40 & 3. $8 \mathrm{E}-04$ & & & & & & & & & & & & & & \\
\hline 18873.1 & 40 & 348 & 084 & -18 & 2. $2 \mathrm{E}-04$ & & & 075 & -37 & 9.5E-05 & 077 & 44 & $9.2 \mathrm{E}-05$ & 237 & 45 & $2.9 \mathrm{E}-05^{*}$ & & & \\
\hline 18873.31 & 42 & 341 & 056 & -70 & 3.1E-04 & & & 078 & -65 & 8.5E-05 & 055 & -52 & $6.4 \mathrm{E}-05$ & $=238$ & 53 & 5.5E-05* & & & \\
\hline 18873.32 & 42 & 341 & 069 & -65 & 4. $6 \mathrm{E}-04$ & & & 063 & -82 & 1. $4 \mathrm{E}-04$ & 042 & -48 & $8.6 \mathrm{E}-05$ & $* 236$ & 55 & $5.9 \mathrm{E}-05^{*}$ & 240 & 57 & 4.3E-05 \\
\hline 18874.21 & 63 & 207 & 111 & -39 & 3. $3 \mathrm{E}-04$ & & & 134 & -27 & 9.7E-05 & 203 & 15 & $2.4 \mathrm{E}-05$ & $* 203$ & 16 & 2. $3 \mathrm{E}-05^{*}$ & & & \\
\hline 18874.22 & 63 & 207 & 109 & -42 & $2.8 \mathrm{E}-04$ & & & 129 & -38 & 1.1E-04 & 132 & -17 & $8.4 \mathrm{E}-05$ & ${ }^{*} 193$ & 18 & $5.8 \mathrm{E}-05^{*}$ & & & \\
\hline 18874.31 & 71 & 223 & 035 & -44 & 2.7E-04 & & & 110 & -44 & $3.2 \mathrm{E}-05$ & 038 & 50 & 5. 0 E- 05 & $\cdot 222$ & 19 & 3.8E-05* & & & \\
\hline
\end{tabular}

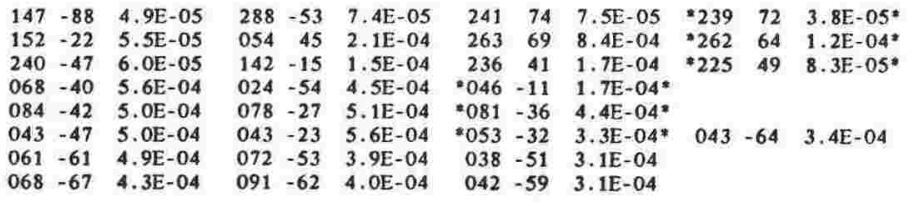
$\begin{array}{lll}061 & -61 & 4.9 \mathrm{E}-04 \\ 068 & -67 & 4.3 \mathrm{E}-04\end{array}$ $\begin{array}{llllll}18878.4 & 73 & 130 & 051 & -60 & 8.8 E-04\end{array}$ $\begin{array}{llllll}18879.21 & 63 & 151 & 359 & -68 & 7.1 \mathrm{E}-04\end{array}$ $\begin{array}{llllll}18879.22 & 63 & 151 & 330 & -69 & 7.1 \mathrm{E}-04\end{array}$ $\begin{array}{llllll}18879.31 & 61 & 144 & 108 & -59 & 6.0 \mathrm{E}-04\end{array}$ $\begin{array}{llllll}18879.32 & 61 & 144 & 131 & -48 & 5.4 \mathrm{E}-04\end{array}$ $\begin{array}{llllll}18880.1 & 43 & 081 & 108 & -43 & 1.3 \mathrm{E}-03\end{array}$ $\begin{array}{lllllll}18880.2 & 48 & 080 & 092 & -54 & 1.3 \mathrm{E}-03\end{array}$ $\begin{array}{llllll}18880.31 & 50 & 068 & 129 & -69 & 1.1 \mathrm{E}-03\end{array}$ $\begin{array}{llllll}18880.32 & 50 & 068 & 123 & -66 & 1.1 \mathrm{E}-03\end{array}$ $\begin{array}{llllll}18881.11 & 66 & 096 & 067 & -45 & 5.2 \mathrm{E}-04\end{array}$ $\begin{array}{llllll}18881.12 & 66 & 096 & 049 & -30 & 8.3 \mathrm{E}-04\end{array}$ $\begin{array}{llllll}18881.3 & 63 & 082 & 035 & -48 & 9.4 \mathrm{E}-04\end{array}$ $\begin{array}{llllll}18882.21 & 69 & 154 & 058 & -73 & 9.5 \mathrm{E}-04 \\ 18882.22 & 69 & 154 & 045 & -75 & 1.0 \mathrm{E}-03\end{array}$ $\begin{array}{llllll}18882.3 & 68 & 166 & 073 & -59 & 1.1 \mathrm{E}-03\end{array}$ $\begin{array}{llllll}18882.4 & 64 & 135 & 059 & -70 & 1.0 \mathrm{E}-0\end{array}$ $\begin{array}{llllll}18883.1 & 72 & 126 & 070 & -52 & 1.0 \mathrm{E}-03\end{array}$ $\begin{array}{llllll}18883.2 & 72 & 123 & 082 & -72 & 9.1 \mathrm{E}-0\end{array}$ $\begin{array}{llllll}18883.3 & 69 & 127 & 057 & -53 & 1.1 \mathrm{E}-0\end{array}$ $\begin{array}{llllll}18884.1 & 44 & 090 & 074 & -50 & 1.5 \mathrm{E}-03\end{array}$ $\begin{array}{lllllll}18884.2 & 56 & 115 & 100 & -71 & 1.5 \mathrm{E}-03\end{array}$ $\begin{array}{llllll}18884.3 & 52 & 107 & 071 & -48 & 1.8 \mathrm{E}-03\end{array}$ $\begin{array}{llllll}18885.11 & 49 & 082 & 066 & -61 & 2.0 \mathrm{E}-03\end{array}$ $\begin{array}{llllll}18885.12 & 49 & 082 & 063 & -58 & 1.6 \mathrm{E}-03\end{array}$ $\begin{array}{llllll}18885.2 & 53 & 062 & 067 & -62 & 1.7 \mathrm{E}-03\end{array}$ $\begin{array}{llllll}18885.2 & 53 & 062 & 067 & -62 & 1.7 \mathrm{E}-03 \\ 18886.1 & 65 & 154 & 069 & -63 & 1.6 \mathrm{E}-03\end{array}$ $\begin{array}{lllllll}18886.1 & 65 & 154 & 069 & -63 & 1.6 \mathrm{E}-03 \\ 18886.21 & 59 & 132 & 072 & -62 & 2.1 \mathrm{E}-03\end{array}$ $\begin{array}{lllllll}18886.21 & 59 & 132 & 072 & -62 & 2.1 \mathrm{E}-03 \\ 18886.22 & 59 & 132 & 064 & -62 & 1.6 \mathrm{E}-03\end{array}$ $\begin{array}{llllll}18886.22 & 59 & 132 & 064 & -62 & 1.6 \mathrm{E}-03 \\ 18886.3 & 60 & 128 & 068 & -63 & 2.0 \mathrm{E}-03\end{array}$ $\begin{array}{llllll}18886.3 & 60 & 128 & 068 & -63 & 2.0 \mathrm{E}-03 \\ 18887.1 & 58 & 131 & 076 & -56 & 1.6 \mathrm{E}-03\end{array}$ $\begin{array}{lllllll}18887.1 & 58 & 131 & 076 & -56 & 1.6 \mathrm{E}-03 \\ 18887.2 & 64 & 178 & 112 & -59 & 1.7 \mathrm{E}-03\end{array}$ $\begin{array}{llllll}18887.2 & 64 & 178 & 112 & -59 & 1.7 \mathrm{E}-03 \\ 18887.3 & 71 & 114 & 055 & -77 & 1.8 \mathrm{E}-03\end{array}$ $\begin{array}{llllll}18888.1 & 60 & 141 & 072 & -65 & 1.6 \mathrm{E}-03\end{array}$

$18888.21 \quad 64 \quad 079$ $\begin{array}{lllllll}18888.22 & 64 & 079 & 070 & -58 & 1.9 \mathrm{E}-03\end{array}$ $\begin{array}{llllll}18888.3 & 62 & 133 & 065 & -61 & 1.5 \mathrm{E}-03\end{array}$ $\begin{array}{llllll}18889.11 & 73 & 062 & 055 & -60 & 3.4 \mathrm{E}-03\end{array}$ $\begin{array}{llllll}18889.12 & 73 & 062 & 053 & -58 & 3.4 \mathrm{E}-03\end{array}$ $\begin{array}{llllll}18889.2 & 62 & 105 & 036 & -59 & 3.0 \mathrm{E}-03\end{array}$ $\begin{array}{lllllll}18889.3 & 76 & 127 & 046 & -54 & 2.1 \mathrm{E}-03\end{array}$ $\begin{array}{llllll}18890.1 & 62 & 024 & 064 & -52 & 1.8 \mathrm{E}-03\end{array}$ $\begin{array}{llllll}18890.2 & 66 & 056 & 062 & -56 & 2.2 \mathrm{E}-03\end{array}$ $\begin{array}{llllll}18890.3 & 69 & 062 & 064 & -55 & 2.0 \mathrm{E}-03\end{array}$ $\begin{array}{llllll}18891.11 & 67 & 051 & 053 & -60 & 2.0 \mathrm{E}-03\end{array}$ $\begin{array}{llllll}18891.12 & 67 & 051 & 061 & -57 & 2.6 \mathrm{E}-03\end{array}$ $\begin{array}{lllllll}18891.3 & 71 & 154 & 066 & -57 & 3.3 \mathrm{E}-03\end{array}$ $\begin{array}{lllllll}18892.1 & 58 & 066 & 076 & -58 & 1.4 \mathrm{E}-04\end{array}$ $\begin{array}{llllll}18892.2 & 53 & 062 & 065 & -43 & 1.1 \mathrm{E}-03\end{array}$ $\begin{array}{llllll}18892.3 & 50 & 060 & 071 & -55 & 1.3 \mathrm{E}-03\end{array}$ $\begin{array}{lllllll}18893.1 & 46 & 049 & 070 & -61 & 3.3 \mathrm{E}-03\end{array}$ $\begin{array}{llllll}18893.1 & 46 & 049 & 070 & -61 & 3.3 \mathrm{E}-03\end{array}$ $\begin{array}{llllll}18893.2 & 45 & 063 & 056 & -59 & 4.1 \mathrm{E}-03 \\ 18893.31 & 71 & 169 & 045 & -57 & 3.3 \mathrm{E}-03\end{array}$ $\begin{array}{lllllll}18893.31 & 71 & 169 & 045 & -57 & 3.3 \mathrm{E}-03\end{array}$ $\begin{array}{lllllll}18893.32 & 71 & 169 & 046 & -60 & 3.2 \mathrm{E}-03\end{array}$ $\begin{array}{llllll}18894.1 & 51 & 018 & 061 & -53 & 4.8 \mathrm{E}-03\end{array}$ $\begin{array}{llllll}18894.2 & 58 & 019 & 067 & -53 & 3.8 \mathrm{E}-03 \\ 18894.31 & 63 & 085 & 074 & -57 & 3.0 \mathrm{E}-03\end{array}$ $\begin{array}{llllll}18894.31 & 63 & 085 & 074 & -57 & 3.0 \mathrm{E}-03\end{array}$ $\begin{array}{lllllll}18894.32 & 63 & 085 & 069 & -56 & 2.8 \mathrm{E}-03\end{array}$ $\begin{array}{lllllll}18895.2 & 60 & 123 & 078 & -54 & 1.4 \mathrm{E}-03\end{array}$ $\begin{array}{llllll}18895.31 & 60 & 145 & 082 & -63 & 1.3 \mathrm{E}-0.3\end{array}$ $\begin{array}{llllll}18895.32 & 60 & 145 & 078 & -62 & 2.0 \mathrm{E}-03\end{array}$ $\begin{array}{llllll}18895.4 & 59 & 063 & 074 & -36 & 1.6 \mathrm{E}-03\end{array}$ $\begin{array}{llllll}18896.11 & 61 & 214 & 051 & -65 & 1.6 \mathrm{E}-03\end{array}$ $\begin{array}{llllll}18896.12 & 61 & 214 & 061 & -75 & 1.3 \mathrm{E}-03\end{array}$ $\begin{array}{llllll}18896.31 & 64 & 235 & 053 & -55 & 1.4 \mathrm{E}-03\end{array}$ $\begin{array}{llllll}18896.32 & 64 & 235 & 053 & -58 & 1.2 \mathrm{E}-03\end{array}$ $\begin{array}{llllll}18897.11 & 65 & 303 & 051 & -50 & 2.5 \mathrm{E}-03\end{array}$

$051-68 \quad 4.3 \mathrm{E}-04 \quad 076-69 \quad 3.6 \mathrm{E}-04 \quad \cdot 104-74 \quad 3.8 \mathrm{E}-04 *$

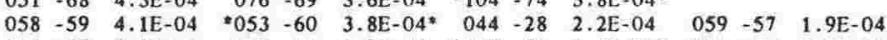
$\begin{array}{llllllllllll}014 & -77 & 3.8 \mathrm{E}-04 & 066 & -83 & 2.9 \mathrm{E}-04 & * 047 & -79 & 1.4 \mathrm{E}-04^{*} & 066 & -83 & 2.9 \mathrm{E}-04\end{array}$ $\begin{array}{llllllllll}035 & -53 & 2.7 \mathrm{E}-04 & 026 & -52 & 2.6 \mathrm{E}-04 & 045 & -54 & 1.8 \mathrm{E}-04\end{array}$

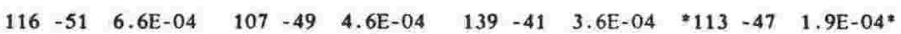
$\begin{array}{llllllllllll}074 & -70 & 4.5 \mathrm{E}-04 & 057 & -77 & 3.7 \mathrm{E}-04 & 055 & -70 & 3.2 \mathrm{E}-04 & * 058 & -75 & 2.6 \mathrm{E}-04^{*}\end{array}$ $\begin{array}{lllllllll}068 & -65 & 4.9 \mathrm{E}-04 & 047 & -68 & 3.7 \mathrm{E}-04 & * 019 & -73 & 2.4 \mathrm{E}-04^{*}\end{array}$

$025-68 \quad 4.7 \mathrm{E}-04$ $043-68 \quad 4.7 \mathrm{E}-04$ $074 \quad-63 \quad 4.7 \mathrm{E}-04$ $\begin{array}{lll}063 & -59 & 4.9 \mathrm{E}-04 \\ 053 & -56 & 5.0 \mathrm{E}-04\end{array}$ $\begin{array}{lll}053 & -56 & 5.0 \mathrm{E}-04 \\ 068 & -58 & 5.2 \mathrm{E}-04\end{array}$ 068 - 58 5. $2 \mathrm{E}-04$ 051 - $52 \quad 5.1 \mathrm{E}-04$ $\begin{array}{lll}060 & -52 & 9.8 \mathrm{E}-04\end{array}$ $\begin{array}{lll}064 & -62 & 1.1 \mathrm{E}-03 \\ 070 & -54 & 9.4 \mathrm{E}-04\end{array}$ $053-61 \quad 1.2 \mathrm{E}-03$ $\begin{array}{lll}041 & -59 & 8.4 \mathrm{E}-04\end{array}$ $\begin{array}{lll}041 & -59 & 8.4 \mathrm{E}-04 \\ 051 & -59 & 9.4 \mathrm{E}-04\end{array}$ $\begin{array}{lll}051 & -59 & 9.4 \mathrm{E}-04 \\ 055 & -58 & 8.1 \mathrm{E}-04\end{array}$ $042-60$ 1.1E-03 $\begin{array}{lll}041 & -57 & 7.6 \mathrm{E}-04\end{array}$ $\begin{array}{lll}060 & -64 & 9.2 \mathrm{E}-04\end{array}$ $\begin{array}{lll}076 & -50 & 7.3 \mathrm{E}-04 \\ 107 & -48 & 7.5 \mathrm{E}-04\end{array}$ $\begin{array}{lll}107 & -48 & 7.5 \mathrm{E}-04 \\ 070 & -50 & 7.9 \mathrm{E}-04\end{array}$ $\begin{array}{lll}070 & -50 & 7.9 \mathrm{E}-04\end{array}$ $\begin{array}{lll}063 & -59 & 8.6 \mathrm{E}-04\end{array}$ $\begin{array}{rrrrrrr}061 & -54 & 2.7 E-04 & * 037 & -63 & 2.8 E-04 *\end{array}$ $\begin{array}{lllllllll}015 & -76 & 3.7 \mathrm{E}-04 & * 029 & -67 & 3.5 \mathrm{E}-04^{*} & 076 & -45 & 1.3 \mathrm{E}-04\end{array}$ $\begin{array}{lllllllll}086 & -57 & 3.3 \mathrm{E}-04 & 077 & -80 & 4.0 \mathrm{E}-04 & * 043 & -63 & 3.2 \mathrm{E}-04^{*}\end{array}$

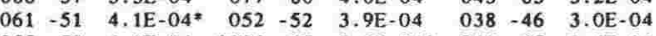
$\begin{array}{lllllllll}057 & -58 & 4.0 \mathrm{E}-04 & * 033 & -67 & 3.3 \mathrm{E}-04 & 040 & -65 & 3.4 \mathrm{E}-04\end{array}$ $\begin{array}{lllllllll}053 & -64 & 4.1 \mathrm{E}-04 & 077 & -70 & 4.0 \mathrm{E}-04 & * 064 & -60 & 3.4 \mathrm{E}-04 *\end{array}$

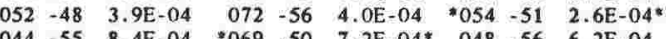
$\begin{array}{lllllllll}044 & -55 & 8.4 \mathrm{E}-04 & 069 & -50 & 7.2 \mathrm{E}-04 * & 048 & -56 & 6.2 \mathrm{E}-04\end{array}$ $\begin{array}{lllllllll}057 & -59 & 8.5 \mathrm{E}-04 & * 062 & -57 & 7.1 \mathrm{E}-04 * & 040 & -60 & 6.6 \mathrm{E}-04\end{array}$ $\begin{array}{llllll}* 051 & -58 & 7.7 \mathrm{E}-04 * & 047 & -51 & 6.9 \mathrm{E}-04\end{array}$

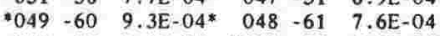
$\begin{array}{llllll}048 & -55 & 7.3 \mathrm{E}-04 & * 034 & -55 & 5.5 \mathrm{E}-04 *\end{array}$

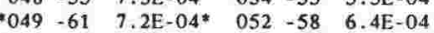

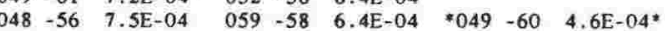
$\begin{array}{lllllll}057 & -63 & 9.0 \mathrm{E}-04 & 064 & -58 & 6.7 \mathrm{E}-04\end{array}$ $027-58 \quad 6.9 \mathrm{E}-04 \quad 040-65 \quad 6.0 \mathrm{E}-04 *$ $\begin{array}{llllll}075 & -60 & 7.8 \mathrm{E}-04 & 073 & -67 & 7.5 \mathrm{E}-04\end{array}$ $055-45 \quad 5.7 \mathrm{E}-04=064-48 \quad 4.9 \mathrm{E}-04$ $\begin{array}{llllll}089 & -43 & 6.6 \mathrm{E}-04 & * 109 & -43 & 4.8 \mathrm{E}-04\end{array}$ $\begin{array}{llllll}086 & -49 & 6.3 \mathrm{E}-04 & 085 & -61 & 5.3 \mathrm{E}-04^{*} \\ 060 & -55 & 7.6 \mathrm{E}-04 & 069 & -61 & 6.3 \mathrm{E}-04^{*}\end{array}$

$\begin{array}{llllllllllll}064 & -53 & 6.3 \mathrm{E}-04 & 062 & -41 & 5.6 \mathrm{E}-04 & 071 & -37 & 4.3 \mathrm{E}-04^{*} & 063 & -51 & 3.7 \mathrm{E}-04\end{array}$

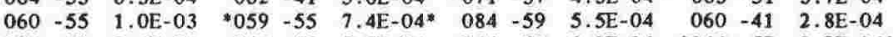
$\begin{array}{llllllllllllll}054 & -51 & 7.4 \mathrm{E}-04 & 045 & -56 & 5.7 \mathrm{E}-04 & 044 & -62 & 3.8 \mathrm{E}-04 & * 044 & -57 & 2.9 \mathrm{E}-04\end{array}$ * $\begin{array}{rrrrrrrrr}054 & -51 & 7.4 \mathrm{E}-04 & 045 & -56 & 5.7 \mathrm{E}-04 & 044 & -62 & 3.8 \mathrm{E}-04 \\ 045 & -60 & 2.1 \mathrm{E}-03 & 045 & -61 & 1.8 \mathrm{E}-03 & * 049 & -59 & 1.3 \mathrm{E}-03\end{array}$ $\begin{array}{lllllllll}045 & -60 & 2.1 \mathrm{E}-03 & 045 & -61 & 1.8 \mathrm{E}-03 & * 049 & -59 & 1.3 \mathrm{E}-03 \\ 032 & -65 & 2.2 \mathrm{E}-03 & 025 & -66 & 1.6 \mathrm{E}-03 & * 022 & -67 & 1.3 \mathrm{E}-03 *\end{array}$ $\begin{array}{llllllllll}032 & -65 & 2.2 \mathrm{E}-03 & 025 & -66 & 1.6 \mathrm{E}-03 & * 022 & -67 & 1.3 \mathrm{E}-03^{*} \\ 045 & -57 & 1.7 \mathrm{E}-03 & 038 & -58 & 1.2 \mathrm{E}-03 & .047 & -64 & 8.4 \mathrm{E}-04^{*}\end{array}$

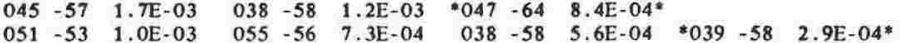
$\begin{array}{rrrrrrrrrrrrr}051 & -53 & 1.0 \mathrm{E}-03 & 055 & -56 & 7.3 \mathrm{E}-04 & 038 & -58 & 5.6 \mathrm{E}-04 & { }^{*} 039 & -58 & 2.9 \mathrm{E}-04^{*} \\ 050 & -50 & 8.2 \mathrm{E}-04 & 047 & -56 & 6.4 \mathrm{E}-04 & 069 & -54 & 5.3 \mathrm{E}-04 & * 050 & -55 & 3.1 \mathrm{E}-04^{*}\end{array}$ $054 \quad-55 \quad 1.1 \mathrm{E}-03$ $049-52 \quad 1.0 \mathrm{E}-03$ $\begin{array}{lll}038 & -56 & 1.3 \mathrm{E}-03 \\ 051 & -54 & 1.3 \mathrm{E}-03\end{array}$ $\begin{array}{llllll}046 & -55 & 8.5 \mathrm{E}-04 & * 044 & -59 & 7.5 \mathrm{E}-04 *\end{array}$

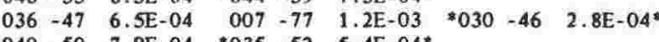
$040-50 \quad 7.9 \mathrm{E}-04 * 035 \quad-52 \quad 5.4 \mathrm{E}-04$

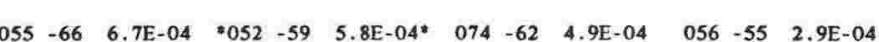
$\begin{array}{lllllllll}032 & -44 & 5.7 \mathrm{E}-04 & * 031 & -41 & 5.0 \mathrm{E}-04 * & 040 & -38 & 3.3 \mathrm{E}-04\end{array}$ $\begin{array}{lllllllll}051 & -56 & 6.8 \mathrm{E}-04 & 052 & -54 & 5.5 \mathrm{E}-04 & 054 & -58 & 3.9 \mathrm{E}-04^{*}\end{array}$ $\begin{array}{lllllllll}054 & -69 & 1.8 \mathrm{E}-03 & 056 & -72 & 1.5 \mathrm{E}-03 & * 060 & -69 & 1.2 \mathrm{E}-03\end{array}$ $\begin{array}{lllllllll}040 & -60 & 2.6 \mathrm{E}-03 & * 040 & -60 & 2.2 \mathrm{E}-03^{*} & 024 & -66 & 1.8 \mathrm{E}-03\end{array}$ $\begin{array}{lllllllllll}041 & -53 & 2.0 \mathrm{E}-03 & =040 & -53 & 1.7 \mathrm{E}-03 & 040 & -53 & 1.4 \mathrm{E}-03\end{array}$

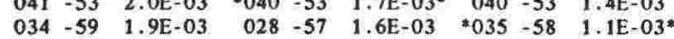

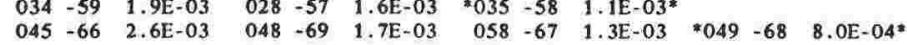
$\begin{array}{llllllllllll}055 & -62 & 1.6 \mathrm{E}-03 & 054 & -63 & 9.1 \mathrm{E}-04 & 030 & -62 & 5.3 \mathrm{E}-04 & * 055 & -63 & 4.6 \mathrm{E}-04 *\end{array}$ $\begin{array}{llllllllllll}049 & -64 & 1.5 \mathrm{E}-03 & 033 & -65 & 9.0 \mathrm{E}-04 & 021 & -75 & 7.6 \mathrm{E}-04 & * 035 & -65 & 4.5 \mathrm{E}-04 * \\ 043 & -46 & 6.0 \mathrm{E}-04 & 041 & -42 & 4.9 \mathrm{E}-04 & 041 & -33 & 2.6 \mathrm{E}-04 & * 041 & -42 & 2.4 \mathrm{E}-04 *\end{array}$ $\begin{array}{llllllllllll}056 & -58 & 9.4 \mathrm{E}-04 & 054 & -60 & 6.5 \mathrm{E}-04 & 062 & -49 & 6.1 \mathrm{E}-04 & * 057 & -60 & 3.1 \mathrm{E}-04\end{array}$ $\begin{array}{llllllllllll}044-42 & 7.0 \mathrm{E}-04 & =041 & -46 & 5.9 \mathrm{E}-04 * & 017 & -44 & 4.3 \mathrm{E}-04 & 037 & -46 & 3.1 \mathrm{E}-04\end{array}$

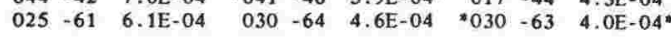
$\begin{array}{llllllllllll}058 & -49 & 6.4 \mathrm{E}-04 & 058 & -47 & 5.6 \mathrm{E}-04 & 069 & -52 & 4.8 \mathrm{E}-04 & * 057 & -44 & 2.8 \mathrm{E}-04 * \\ 051 & -56 & 3.1 \mathrm{E}-04 & 059 & -57 & 2.7 \mathrm{E}-04 & 072 & -56 & 3.6 \mathrm{E}-04 & 061 & -56 & 1.2 \mathrm{E}-04\end{array}$ 


\begin{tabular}{|c|c|c|c|c|c|c|c|c|c|c|c|c|c|c|c|c|c|c|c|}
\hline \multirow[b]{2}{*}{ SPEC. } & \multirow{2}{*}{\multicolumn{2}{|c|}{$\begin{array}{l}\text { PLUNGE/ } \\
\text { AZIMUIH }\end{array}$}} & \multicolumn{3}{|c|}{ NFM } & \multicolumn{2}{|r|}{150} & \multicolumn{3}{|c|}{200} & \multicolumn{3}{|r|}{250} & \multicolumn{3}{|r|}{300} & \multirow[b]{2}{*}{ D } & \multicolumn{2}{|r|}{320} \\
\hline & & & D & I & $\mathrm{M}(\mathrm{A} / \mathrm{m})$ & D & I $\quad M(A / m)$ & D & I & $\mathrm{M}(\mathrm{A} / \mathrm{m})$ & D & 1 & $M(A / m)$ & D & I & $\mathrm{M}(\mathrm{A} / \mathrm{m})$ & & I & $M(A / m)$ \\
\hline 18897.12 & 65 & 303 & 037 & -51 & $3.1 \mathrm{E}-03$ & & & 026 & -57 & $.21 \mathrm{E}-03$ & ${ }^{*} 020$ & -57 & 1.7E-0. $3^{*}$ & 012 & -60 & 1. $4 \mathrm{E}-03$ & 024 & -57 & 8.7E-04 \\
\hline 18897.2 & 55 & 295 & 032 & -46 & 3. $1 \mathrm{E}-03$ & & & 024 & -50 & 2. $1 \mathrm{E}-03$ & 018 & -49 & 1. $8 \mathrm{E}-03$ & $* 011$ & -48 & 1. $6 \mathrm{E}-03^{*}$ & & & \\
\hline 18897.3 & 61 & 317 & 056 & -54 & $2.4 \mathrm{E}-03$ & & & 062 & -57 & 1. $4 \mathrm{E}-03$ & 065 & -59 & 1. $2 E-03$ & $=069$ & -59 & 1.1E $-03^{*}$ & & & \\
\hline 18898.11 & 51 & 349 & 059 & -45 & 1.7E-03 & & & 050 & -63 & 7. $6 \mathrm{E}-04$ & 060 & -65 & 6.1E-04 & ${ }^{*} 063$ & -60 & 4. $8 \mathrm{E}-04^{*}$ & & & \\
\hline 18898.12 & 51 & 349 & 055 & -44 & 1.7E-03 & & & 043 & -54 & $7.9 \mathrm{E}-04$ & $* 042$ & -56 & $6.4 \mathrm{E}-04^{*}$ & 024 & -56 & 5. OE- 04 & 015 & -79 & $3.0 \mathrm{E}-04$ \\
\hline 18899.1 & 49 & 343 & 039 & -57 & $6.8 \mathrm{E}-04$ & & & 009 & -57 & 2. $2 \mathrm{E}-04$ & ${ }^{*} 014$ & -57 & 1.1E-04* & 013 & -55 & $5.6 \mathrm{E}-05$ & & & \\
\hline 18899.2 & 45 & 305 & 046 & -61 & $7.6 \mathrm{E}-04$ & & & 042 & -69 & 3. 3E-04 & 148 & -68 & 1. $7 \mathrm{E}-04$ & 080 & -53 & 8.9E-05 & ${ }^{\circ} 081$ & -53 & $4.6 \mathrm{E}-05^{*}$ \\
\hline 18899.31 & 60 & 065 & 048 & -69 & $6.1 \mathrm{E}-04$ & & & 329 & -62 & 2. $3 \mathrm{E}-04$ & 356 & -49 & 1. $6 \mathrm{E}-04$ & 277 & -01 & 1. $3 E-04$ & & & \\
\hline 18899.32 & 60 & 065 & 057 & -70 & $6.4 E-04$ & & & 325 & -58 & $2.0 \mathrm{E}-04$ & $* 345$ & -56 & 1. $3 \mathrm{E}-04^{*}$ & 338 & -49 & 1. $5 \mathrm{E}-04$ & & & \\
\hline 18900.1 & 69 & 027 & 050 & -60 & 1. $3 \mathrm{E}-03$ & & & 018 & -68 & 5. $2 \mathrm{E}-04$ & 011 & -64 & $5.7 \mathrm{E}-04$ & $*_{012}$ & -62 & 2. $8 \mathrm{E}-04^{\circ}$ & & & \\
\hline 18900.2 & 60 & 018 & 033 & -66 & $9.8 \mathrm{E} \cdot 04$ & & & 048 & -69 & 4. $6 \mathrm{E}-04$ & 037 & -68 & $3.9 \mathrm{E}-04$ & ${ }^{*} 034$ & -66 & 2. OE $-04^{*}$ & & & \\
\hline 18900.3 & 47 & 333 & 042 & -56 & 1. $2 \mathrm{E}-03$ & & & 028 & -68 & 4. $1 \mathrm{E}-04$ & $=018$ & -65 & $3.2 \mathrm{E}-04^{*}$ & 036 & -61 & 2.9E-04 & & . & \\
\hline 18901.21 & 74 & 031 & 070 & -60 & $7.9 \mathrm{E}-04$ & & & 086 & -61 & 2. $6 \mathrm{E}-04$ & 082 & -64 & 2. $3 \mathrm{E}-04$ & 055 & -74 & 1. $2 \mathrm{E}-04$ & $=055$ & -74 & $6.0 \mathrm{E}-05^{\circ}$ \\
\hline 18901.22 & 74 & 031 & 059 & -69 & $7.5 \mathrm{E}-04$ & & & 328 & -68 & $2.6 \mathrm{E}-04$ & 117 & -84 & 3. $2 \mathrm{E}-04$ & 026 & -58 & 1. $3 \mathrm{E}-04$ & $* 026$ & -58 & $6.4 \mathrm{E}-05^{\circ}$ \\
\hline 18901.31 & 67 & 348 & 052 & -54 & 7. $2 \mathrm{E}-04$ & & & 041 & -57 & 2. $4 \mathrm{E}-04$ & 034 & -70 & 2. $0 \mathrm{E}-04$ & 047 & -68 & $1.2 \mathrm{E}-04 *$ & & & \\
\hline 18901.32 & 67 & 348 & 050 & -57 & 7. $4 \mathrm{E}-04$ & & & 011 & -61 & $2.8 \mathrm{E}-04$ & 039 & -63 & $2.6 \mathrm{E}-04$ & ${ }^{*} 033$ & -63 & 1. $3 \mathrm{E}-04^{*}$ & & & \\
\hline 18902.1 & 35 & 325 & 060 & -56 & 1. $1 \mathrm{E}-03$ & & & 063 & -65 & $4.9 \mathrm{E}-04$ & 049 & -62 & $4.0 \mathrm{E}-04$ & .059 & -56 & $3.1 \mathrm{E}-04^{\circ}$ & & & \\
\hline 18902.2 & 42 & 294 & 049 & -55 & $9.8 \mathrm{E}-04$ & & & 050 & -62 & 3. $7 \mathrm{E}-04$ & 080 & -57 & 3. $2 \mathrm{E}-04$ & $=022$ & -79 & 1. $7 \mathrm{E}-04^{*}$ & & & \\
\hline 18903.2 & 49 & 112 & 078 & -55 & 5. $7 \mathrm{E}-04$ & & & 073 & -48 & 1. $3 \mathrm{E}-04$ & 101 & -71 & 1. $8 \mathrm{E}-04$ & $\cdot 102$ & -41 & 1.7E-04* & & & \\
\hline 18903.3 & 51 & 121 & 093 & -61 & $5.6 \mathrm{E}-04$ & & & 081 & -67 & 2. $3 \mathrm{E}-04$ & & & & & & & & & \\
\hline 18904.2 & 68 & 148 & 072 & -53 & 8.2E-04 & & & 053 & -45 & 3. $3 \mathrm{E}-04$ & 056 & -53 & $3.0 \mathrm{E}-04$ & .063 & -56 & 2.7E-0.* & & & \\
\hline 18904.31 & 64 & 163 & 060 & -62 & 8. $2 \mathrm{E}-04$ & & & 042 & -58 & 3. $3 \mathrm{E}-04$ & 028 & -62 & $2.9 \mathrm{E}-04$ & 053 & -62 & 2.8E-04 & 053 & -61 & $1.4 \mathrm{E}-04^{2}=$ \\
\hline 18904.32 & 64 & 163 & 056 & -60 & 7. $8 \mathrm{E}-04$ & & & 045 & -57 & 4. $2 E-04$ & $* 034$ & -54 & $2.9 \mathrm{E}-04^{*}$ & 048 & -21 & 2. $0 \mathrm{E}-04$ & & & \\
\hline 18905.1 & 59 & 134 & 068 & -66 & $8.7 \mathrm{E}-04$ & & & 066 & -65 & 4. $3 \mathrm{E}-04$ & $=063$ & -71 & $3.5 \mathrm{E}-04^{*}$ & 063 & -51 & 2. $5 \mathrm{E}-04$ & & & \\
\hline 18905.2 & 47 & 123 & 067 & -63 & $8.1 \mathrm{E}-04$ & & & 056 & -61 & $3.9 \mathrm{E}-04$ & 044 & -43 & 2. $6 \mathrm{E}-04^{*}$ & 033 & -46 & $2.6 \mathrm{E}-04$ & & & \\
\hline 18905.3 & 60 & 127 & 078 & -51 & 8. $7 E-04$ & & & 068 & -44 & $3.4 \mathrm{E}-04$ & 077 & -49 & $3.6 \mathrm{E}-04$ & $=074$ & -53 & $2.9 \mathrm{E}-04^{\prime}$ & & & \\
\hline 18906.1 & 60 & 285 & 042 & -62 & 1.1E-03 & & & 032 & -61 & $7.6 \mathrm{E}-04$ & 033 & -60 & 6.5E-04 & ${ }^{*} 028$ & -64 & 5. $2 \mathrm{E}-04^{*}$ & & & \\
\hline 18906.31 & 75 & 337 & 045 & -63 & 1. $1 \mathrm{E}-03$ & & & 050 & -65 & $7.3 \mathrm{E}-04$ & 049 & -64 & 6. $0 \mathrm{E}-04$ & $*^{*} 048$ & -68 & $4.8 \mathrm{E}-04^{*}$ & & & \\
\hline 18906.32 & 75 & 337 & 051 & -60 & 1. $2 \mathrm{E}-03$ & & & 048 & -64 & 8. $3 \mathrm{E}-04$ & 048 & -64 & $6.8 \mathrm{E}-04$ & $* 049$ & -64 & 5. $1 \mathrm{E}-04^{*}$ & & & \\
\hline
\end{tabular}

$\begin{array}{llllll}18907.1 & 61 & 236 & 035 & -62 & 3.4 \mathrm{E}-04 \\ 18907.2 & 72 & 254 & 045 & -59 & 5.0 \mathrm{E}-04 \\ 18907.3 & 62 & 263 & 039 & -62 & 5.4 \mathrm{E}-04 \\ 18907.4 & 63 & 258 & 081 & -74 & 5.9 \mathrm{E}-04 \\ 18908.1 & 62 & 244 & 068 & -65 & 5.7 \mathrm{E}-04 \\ 18908.2 & 61 & 251 & 070 & -65 & 7.0 \mathrm{E}-04 \\ 18908.3 & 72 & 235 & 068 & -60 & 6.9 \mathrm{E}-04 \\ 18908.4 & 78 & 272 & 078 & -65 & 6.6 \mathrm{E}-04 \\ 18909.1 & 46 & 343 & 041 & -47 & 5.8 \mathrm{E}-04 \\ 18909.31 & 61 & 264 & 057 & -66 & 5.3 \mathrm{E}-04 \\ 18909.32 & 61 & 264 & 046 & -70 & 6.1 \mathrm{E}-04 \\ 18910.1 & 53 & 320 & 056 & -43 & 9.8 \mathrm{E}-04 \\ 18910.2 & 52 & 316 & 302 & -77 & 9.0 \mathrm{E}-04 \\ 18910.3 & 67 & 014 & 067 & -60 & 1.1 \mathrm{E}-03 \\ 18911.1 & 57 & 008 & 067 & -53 & 8.2 \mathrm{E}-04 \\ 18911.2 & 65 & 355 & 076 & -51 & 9.6 \mathrm{E}-04 \\ 18911.31 & 70 & 009 & 075 & -53 & 1.1 \mathrm{E}-03 \\ 18911.32 & 70 & 009 & 069 & -50 & 1.2 \mathrm{E}-03 \\ 18912.1 & 44 & 345 & 060 & -44 & 9.5 \mathrm{E}-04 \\ 18912.21 & 46 & 340 & 064 & -43 & 9.9 \mathrm{E}-04 \\ 18912.22 & 46 & 340 & 061 & -56 & 9.3 \mathrm{E}-04 \\ 18912.3 & 43 & 329 & 054 & -39 & 8.3 \mathrm{E}-04 \\ 18913.11 & 64 & 216 & 042 & -69 & 6.2 \mathrm{E}-04 \\ 18913.12 & 64 & 216 & 057 & -69 & 7.4 \mathrm{E}-04 \\ 18913.31 & 61 & 254 & 040 & -51 & 9.0 \mathrm{E}-04 \\ 18913.32 & 61 & 254 & 037 & -56 & 7.4 \mathrm{E}-04 \\ 18914.11 & 65 & 215 & 057 & -44 & 5.3 \mathrm{E}-04 \\ 18914.12 & 65 & 215 & 051 & -57 & 6.7 \mathrm{E}-04 \\ 18914.2 & 67 & 231 & 069 & -65 & 7.9 \mathrm{E}-04 \\ 18915.21 & 72 & 206 & 060 & -60 & 9.5 \mathrm{E}-04 \\ 18915.22 & 72 & 206 & 066 & -70 & 8.3 \mathrm{E}-04 \\ 18915.31 & 69 & 193 & 057 & -54 & 9.0 \mathrm{E}-04 \\ 18915.32 & 69 & 193 & 052 & -52 & 9.5 \mathrm{E}-04\end{array}$

$\begin{array}{lllllll}18916.1 & 75 & 172 & 066 & -66 & 6.9 \mathrm{E}-04\end{array}$ $\begin{array}{llllll}18916.2 & 70 & 158 & 069 & -55 & 8.6 \mathrm{E}-04\end{array}$ $\begin{array}{llllll}18916.31 & 73 & 151 & 089 & -68 & 7.1 \mathrm{E}-04\end{array}$ $\begin{array}{lllllll}18916.32 & 73 & 151 & 104 & -70 & 6.8 \mathrm{E}-04\end{array}$ $\begin{array}{llllll}18917.11 & 62 & 172 & 048 & -61 & 6.6 \mathrm{E}-04\end{array}$ $\begin{array}{lllllll}18917.12 & 62 & 172 & 071 & -66 & 6.0 \mathrm{E}-04\end{array}$ $\begin{array}{lllllll}18917.31 & 64 & 201 & 074 & -56 & 6.9 \mathrm{E}-04\end{array}$ $\begin{array}{lllllll}18917.32 & 64 & 201 & 072 & -56 & 5.9 \mathrm{E}-04\end{array}$ $\begin{array}{llllll}18918.11 & 54 & 049 & 070 & -62 & 7.1 \mathrm{E}-04\end{array}$ $\begin{array}{llllll}18918.12 & 54 & 049 & 083 & -56 & 7.2 \mathrm{E}-04\end{array}$ $\begin{array}{lllllll}18918.31 & 54 & 063 & 095 & -56 & 7.0 \mathrm{E}-04\end{array}$ $\begin{array}{llllll}18918.32 & 54 & 063 & 098 & -53 & 6.4 \mathrm{E}-04\end{array}$ $\begin{array}{lllllll}18918.32 & 54 & 063 & 098 & -53 & 6.4 \mathrm{E}-04 \\ 18919.11 & 43 & 080 & 076 & -68 & 8.1 \mathrm{E}-04\end{array}$ $\begin{array}{lllllll}18919.11 & 43 & 080 & 076 & -68 & 8.1 \mathrm{E}-04 \\ 18919.12 & 43 & 080 & 075 & -65 & 9.2 \mathrm{E}-04\end{array}$ $\begin{array}{llllll}18919.12 & 43 & 080 & 075 & -65 & 9.2 \mathrm{E}-04 \\ 18919.3 & 54 & 071 & 094 & -51 & 9.2 \mathrm{E}-04\end{array}$ $\begin{array}{llllll}18919.3 & 54 & 071 & 094 & -51 & 9.2 \mathrm{E}-04 \\ 18920.11 & 63 & 066 & 072 & -55 & 7.6 \mathrm{E}-04\end{array}$ $\begin{array}{llllll}18920.11 & 63 & 066 & 072 & -55 & 7.6 \mathrm{E}-04 \\ 18920.12 & 63 & 066 & 078 & -55 & 7.9 \mathrm{E}-04\end{array}$ $\begin{array}{llllll}18920.12 & 63 & 066 & 078 & -55 & 7.9 \mathrm{E}-04 \\ 18920.2 & 64 & 216 & 115 & -62 & 7.7 \mathrm{E}-04\end{array}$ $\begin{array}{lllllll}18920.2 & 64 & 216 & 115 & -62 & 7.7 \mathrm{E}-04 \\ 18920.3 & 66 & 137 & 093 & -64 & 8.7 \mathrm{E}-04\end{array}$ $\begin{array}{lllllll}18920.3 & 66 & 137 & 093 & -64 & 8.7 \mathrm{E}-04 \\ 18921.11 & 59 & 111 & 095 & -51 & 8.0 \mathrm{E}-04\end{array}$ $\begin{array}{lllllll}18921.11 & 59 & 111 & 095 & -51 & 8.0 \mathrm{E}-04 \\ 18921.12 & 59 & 111 & 090 & -51 & 8.6 \mathrm{E}-04\end{array}$ $\begin{array}{llllll}18921.21 & 52 & 137 & 055 & -75 & 7.9 \mathrm{E}-04\end{array}$ $\begin{array}{llllll}18921.22 & 52 & 137 & 110 & -79 & 7.1 \mathrm{E}-04\end{array}$ $\begin{array}{llllll}18922.11 & 53 & 102 & 087 & -72 & 6.3 \mathrm{E}-04\end{array}$ $\begin{array}{lllllll}18922.12 & 53 & 102 & 113 & -74 & 5.9 \mathrm{E}-04\end{array}$ $\begin{array}{lllllll}18922.2 & 62 & 065 & 080 & -51 & 7.2 \mathrm{E}-04\end{array}$ $\begin{array}{lllllll}18923.11 & 60 & 162 & 071 & -65 & 9.3 \mathrm{E}-04\end{array}$ $\begin{array}{lllllll}18923.12 & 60 & 162 & 069 & -72 & 8.2 \mathrm{E}-04\end{array}$ $\begin{array}{lllllll}18923.2 & 61 & 171 & 061 & -67 & 8.3 E-04\end{array}$ $\begin{array}{lllllll}18924.11 & 68 & 097 & 047 & -78 & 8.1 \mathrm{E}-04\end{array}$ $\begin{array}{llllll}18924.12 & 68 & 097 & 047 & -78 & 8.1 E-04\end{array}$

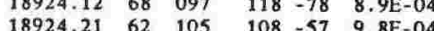
$\begin{array}{llllll}18924.21 & 62 & 105 & 108 & -57 & 9.8 \mathrm{E}-04 \\ 18924.22 & 62 & 105 & 094 & -59 & 8.0 \mathrm{E}-04\end{array}$ $\begin{array}{llllllllll}036 & -63 & 1.3 \mathrm{E}-04 & 2047 & -63 & 1.7 \mathrm{E}-04^{*} & 017 & -57 & 1.4 \mathrm{E}-04\end{array}$

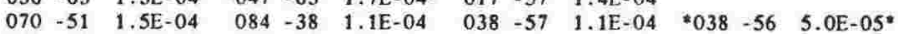
$\begin{array}{lllllllll}061 & -51 & 1.9 \mathrm{E}-04 & 094 & -65 & 1.4 \mathrm{E}-04 & * 089 & -64 & 7.5 \mathrm{E}-05^{*}\end{array}$

$\begin{array}{lllllllll}006 & -59 & 9.9 \mathrm{E}-05 & 061 & -49 & 2.1 \mathrm{E}-04 & * 051 & -47 & 9.0 \mathrm{E}-05^{*}\end{array}$

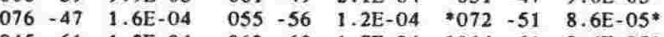
$\begin{array}{lllllllll}045 & -61 & 1.8 \mathrm{E}-04 & 062 & -63 & 1.7 \mathrm{E}-04 & =064 & -61 & 8.4 \mathrm{E}-05^{*}\end{array}$ $\begin{array}{lllllllll}050 & -61 & 3.8 \mathrm{E}-04 & 023 & -61 & 2.8 \mathrm{E}-04 & * 027 & -60 & 1.5 \mathrm{E}-04\end{array}$ $\begin{array}{llllllllll}195 & -85 & 3.2 \mathrm{E}-04 & * & 033 & -66 & 2.0 \mathrm{E}-04 * & 042 & -84 & 1.8 \mathrm{E}-04\end{array}$ $\begin{array}{lllllllll}057 & -58 & 3.3 \mathrm{E}-04 & * 060 & -58 & 2.4 \mathrm{E}-04 * & 031 & -63 & 1.6 \mathrm{E}-04 \\ 049 & -62 & 2.7 \mathrm{E}-04 & 049 & -55 & 1.9 \mathrm{E}-04 & 047 & -52 & 1.8 \mathrm{E}-04\end{array}$

$\begin{array}{lllllllll}053 & -64 & 2.7 \mathrm{E}-04 & 041 & -75 & 1.8 \mathrm{E}-04 & * 063 & -71 & 1.0 \mathrm{E}-04\end{array}$ $\begin{array}{lllllllll}062 & -54 & 3.4 \mathrm{E}-04 & * 061 & -61 & 1.9 \mathrm{E}-04 * & 045 & -66 & 2.1 \mathrm{E}-04\end{array}$ $\begin{array}{lllllllll}053 & -46 & 2.6 \mathrm{E}-04 & 016 & -51 & 2.6 \mathrm{E}-04 & 020 & -49 & 1.4 \mathrm{E}-04 *\end{array}$ $\begin{array}{lllllllll}068 & -56 & 3.2 \mathrm{E}-04 & * 063 & -54 & 2.6 \mathrm{E}-04 & 065 & -61 & 2.6 \mathrm{E}-04\end{array}$

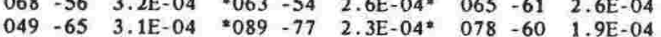

$\begin{array}{lllllllll}058 & -52 & 1.6 \mathrm{E}-04 & 092 & 076 & 6.6 \mathrm{E}-05 & * 096 & -78 & 3.4 \mathrm{E}-05^{*}\end{array}$ $\begin{array}{lllllllll}089 & -69 & 2,1 \mathrm{E}-04 & 092 & -65 & 1.4 \mathrm{E}-04 * & 057 & -41 & 8.8 \mathrm{E}-05\end{array}$ $\begin{array}{lllllllll}051 & -55 & 1.4 \mathrm{E}-04 & 041 & -60 & 1.4 \mathrm{E}-04 & * 039 & -70 & 1.2 \mathrm{E}-04 *\end{array}$ $\begin{array}{llllllllllll}086 & -06 & 2.3 \mathrm{E}-04 & 083 & -13 & 1.7 \mathrm{E}-04 & 088 & 36 & 1.5 \mathrm{E}-04 & * 237 & 23 & 2.9 \mathrm{E}-05^{*}\end{array}$

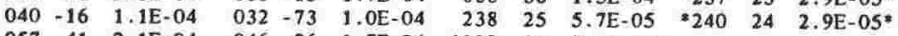
$\begin{array}{lllllllll}057-41 & 2.1 \mathrm{E}-04 & 046 & -36 & 1.7 \mathrm{E}-04 & * 229 & 30 & 7.0 \mathrm{E}-05^{*}\end{array}$ 


\begin{tabular}{|c|c|c|c|c|c|c|c|c|c|c|c|c|c|c|c|c|c|c|c|}
\hline \multirow[b]{2}{*}{ SPEC. } & \multirow{2}{*}{\multicolumn{2}{|c|}{$\begin{array}{l}\text { PLUNGE/ } \\
\text { AZIMTH }\end{array}$}} & \multicolumn{4}{|c|}{$\mathrm{NRM}$} & 150 & \multicolumn{3}{|c|}{200} & \multicolumn{3}{|r|}{250} & \multicolumn{4}{|c|}{300} & \multicolumn{2}{|r|}{320} \\
\hline & & & D & 1 & $\mathrm{M}(\mathrm{A} / \mathrm{m})$ & D & I $\quad \mathrm{M}(\mathrm{A} / \mathrm{m})$ & D & I & $\mathrm{M}(\mathrm{A} / \mathrm{m})$ & D & I & $\mathrm{M}(\mathrm{A} / \mathrm{m})$ & D & I & $M(A / m)$ & D & I & $M(A / m)$ \\
\hline 18925.1 & 49 & 123 & 090 & -62 & $7.0 \mathrm{E}-04$ & & & 051 & -49 & 2.7E-04 & 042 & -49 & 2. $5 \mathrm{E}-04$ & .047 & -46 & 1. $7 E-04^{\circ}$ & & & \\
\hline 18925.21 & 41 & 096 & 107 & -59 & $5.8 \mathrm{E}-04$ & & & 076 & -44 & $2.6 \mathrm{E}-04$ & 065 & -43 & 2.1E-04 & .063 & -20 & 1. $8 \mathrm{E}-04^{\circ}$ & & & \\
\hline 18925.22 & 41 & 096 & 089 & -43 & 5. $9 \mathrm{E}-04$ & & & & & & & & & & & & & & \\
\hline 18925.3 & 46 & 089 & 088 & -63 & 5. $3 \mathrm{E}-04$ & & & 020 & -53 & 2. $5 \mathrm{E}-04$ & ${ }^{*} 022$ & -55 & $2.4 \mathrm{E}-04^{2}$ & 012 & -68 & 1. $2 \mathrm{E}-04$ & & & \\
\hline 18926.21 & 40 & 076 & 102 & -41 & 7. $2 \mathrm{E}-04$ & & & 048 & -64 & $3.1 \mathrm{E}-04$ & 042 & -62 & 2. $1 \mathrm{E}-04$ & .052 & -57 & 1. $3 \mathrm{E}-04^{*}$ & & & \\
\hline 18926.22 & 40 & 076 & 091 & -55 & $6.4 \mathrm{E}-04$ & & & 056 & -56 & $2.5 E-04$ & 025 & -68 & 1. $7 \mathrm{E}-04$ & 9024 & -61 & 1. $5 E-04^{*}$ & & & \\
\hline 18926.31 & 29 & 086 & 100 & -48 & $6.9 \mathrm{E}-04$ & & & 059 & -55 & $2.9 \mathrm{E}-04$ & 069 & -54 & $2.6 \mathrm{E}-04$ & $=064$ & -48 & 1.5E-0. & & & \\
\hline 18926.32 & 29 & 086 & 098 & -57 & 5.5E-04 & & & 045 & -45 & $2.8 \mathrm{E}-04$ & $=049$ & -44 & $2.5 \mathrm{E}-04^{\circ}$ & 068 & -65 & 2. $1 E-04$ & & & \\
\hline 18928.1 & 47 & 346 & 064 & -44 & 8.2E-04 & & & 031 & -64 & 1.9E-04 & 046 & -28 & 1. $8 \mathrm{E}-04$ & $=034$ & -42 & 1. $5 E-04^{*}$ & & & \\
\hline 18928.2 & 45 & 339 & 051 & -41 & 7.0E-04 & & & 034 & -62 & $1.7 \mathrm{E}-04$ & $=038$ & -80 & 1. $3 E-04^{*}$ & 093 & -80 & $6.2 \mathrm{E}-05$ & & & \\
\hline 18928.31 & 55 & 325 & 047 & -51 & 8. $8 E-04$ & & & 022 & -71 & 2.7E-04 & 043 & -59 & 2. $2 \mathrm{E}-04$ & $=041$ & -59 & 1.1E-04 & & & \\
\hline 18928.32 & 55 & 325 & 059 & -40 & 8.1E-04 & & & 042 & -46 & 2. $2 \mathrm{E}-04$ & ${ }^{* 028}$ & -48 & 1. $5 \mathrm{E}-04^{*}$ & 026 & -49 & 7.5E-05 & & & \\
\hline 18929.1 & 53 & 312 & 285 & -81 & $5.4 \mathrm{E}-04$ & & & & & & & & & & & & & $=$ & \\
\hline 18929.2 & 42 & 316 & 260 & -78 & 6. $2 \mathrm{E}-04$ & & & & & & & & & & & & & & \\
\hline 18929.3 & 47 & 320 & 043 & -48 & 7. $3 \mathrm{E}-04$ & & & & & & & & & & & & & & \\
\hline 18931.21 & 59 & 354 & 065 & -46 & $9.1 \mathrm{E}-04$ & & & 064 & -51 & $3.5 \mathrm{E}-04$ & 059 & -53 & 2. $9 \mathrm{E}-04^{*}$ & 056 & -55 & $2.2 \mathrm{E}-04$ & & & \\
\hline 18931.22 & 59 & 354 & 073 & -48 & 8.5E-04 & & & 061 & -57 & $3.3 \mathrm{E}-04$ & ${ }^{*} 063$ & -59 & 2.7E-04" & 075 & -63 & 2. $8 \mathrm{E}-04$ & & & \\
\hline 18931.31 & 65 & 358 & 061 & -58 & $9.1 \mathrm{E}-04$ & & & 048 & -65 & $3.5 \mathrm{E}-04$ & 038 & -68 & $2.8 \mathrm{E}-04^{*}$ & 033 & -69 & 1. $3 \mathrm{E}-04$ & & & \\
\hline 18931.32 & 65 & 358 & 052 & -52 & $9.5 \mathrm{E}-04$ & & & 022 & -50 & $3.6 \mathrm{E}-04$ & $=023$ & -47 & $3.4 \mathrm{E}-04^{*}$ & 049 & -08 & 1.7E-04 & & & \\
\hline 18932.11 & 43 & 359 & 082 & -55 & $5.1 \mathrm{E}-04$ & & & 048 & -67 & 1.9E-04 & ${ }^{*} 077$ & -54 & 1. $7 \mathrm{E}-04^{*}$ & 068 & -52 & 1.5E-04 & & & \\
\hline 18932.12 & 43 & 359 & 059 & -42 & $6.3 \mathrm{E}-04$ & & & 030 & -66 & $2.2 \mathrm{E}-04$ & *051 & -48 & $2.1 \mathrm{E}-04^{*}$ & 049 & -46 & 1. $0 E-04$ & & & \\
\hline 18932.31 & so & 350 & 063 & -40 & $8.1 \mathrm{E}-04$ & & & 015 & -55 & 2. $2 \mathrm{E}-04$ & 356 & -56 & $2.6 \mathrm{E}-04$ & 046 & -45 & $2.1 \mathrm{E}-04$ & .044 & -45 & 1.1E-04* \\
\hline 18932.32 & 50 & 350 & 310 & -71 & $7.1 \mathrm{E}-04$ & & & & & & & & & & & & & & \\
\hline 18933.11 & 56 & 041 & 062 & -49 & $9.2 \mathrm{E}-04$ & & & 054 & -62 & 4. $8 \mathrm{E}-04$ & ${ }^{*} 056$ & -63 & 4.3E- $-04^{*}$ & 057 & -63 & $2.2 \mathrm{E}-04$ & & & \\
\hline 18933.12 & 56 & 041 & 066 & -50 & $9.6 \mathrm{E}-04$ & & & 051 & -57 & 5. OE-04 & 080 & -51 & $3.6 \mathrm{E}-04$ & 042 & -43 & 3. $3 \mathrm{E}-04$ & $\cdot 041$ & -45 & 1. $7 \mathrm{E}-04$ " \\
\hline 18933.31 & 56 & 022 & 075 & -56 & $9.2 \mathrm{E}-04$ & & & 047 & -61 & $4.8 \mathrm{E}-04$ & $* 041$ & -67 & $3.9 \mathrm{E}-04^{*}$ & 038 & -66 & $3.1 \mathrm{E}-04$ & & & \\
\hline 18933.32 & 56 & 022 & 064 & -47 & 1. $1 \mathrm{E}-03$ & & & 061 & -51 & 4. $9 \mathrm{E}-04$ & 059 & -51 & $3.8 \mathrm{E}-04^{*}$ & 050 & -64 & 2. $6 \mathrm{E}-04$ & & & \\
\hline 18934.21 & 52 & 297 & 045 & -66 & $2.2 \mathrm{E}-03$ & & & 033 & -74 & 1. $5 \mathrm{E}-03$ & ${ }^{*} 011$ & -78 & 1. $3 \mathrm{E}-03^{*}$ & 016 & -76 & $6.4 \mathrm{E}-04$ & & & \\
\hline 18934.22 & 52 & 297 & 041 & -48 & $2.1 \mathrm{E}-03$ & & & 045 & -52 & 1. $4 \mathrm{E}-03$ & ${ }^{*} 044$ & -46 & $1.1 \mathrm{E}-03^{*}$ & 044. & -46 & $8.6 \mathrm{E}-04$ & & & \\
\hline
\end{tabular}

$\begin{array}{llllll}18934.31 & 60 & 259 & 085 & -54 & 2.0 E-03\end{array}$ $\begin{array}{llllll}18934.32 & 60 & 259 & 047 & -50 & 2.0 \mathrm{E}-03\end{array}$ $\begin{array}{llllll}18935.1 & 62 & 332 & 054 & -45 & 6.4 \mathrm{E}-04\end{array}$ $\begin{array}{llllll}18935.2 & 70 & 358 & 062 & -63 & 7.2 \mathrm{E}-04\end{array}$ $\begin{array}{lllllll}18935.3 & 65 & 360 & 067 & -57 & 7.8 \mathrm{E}-04\end{array}$ $\begin{array}{llllll}18935.4 & 68 & 356 & 062 & -61 & 6.7 \mathrm{E}-04\end{array}$ $\begin{array}{llllll}18936.11 & 73 & 157 & 061 & -53 & 1.4 \mathrm{E}-03\end{array}$ $\begin{array}{lllllll}18936.12 & 73 & 157 & 072 & -63 & 1.8 \mathrm{E}-03\end{array}$ $\begin{array}{lllllll}18936.12 & 73 & 157 & 072 & -63 & 1.8 \mathrm{E}-03 \\ 18936.31 & 74 & 192 & 067 & -57 & 2.4 \mathrm{E}-03\end{array}$ $\begin{array}{llllll}18936.31 & 74 & 192 & 067 & -57 & 2.4 \mathrm{E}-03 \\ 18936.32 & 74 & 192 & 050 & -66 & 2.6 \mathrm{E}-03\end{array}$ $\begin{array}{llllll}18936.32 & 74 & 192 & 050 & -66 & 2.6 \mathrm{E}-03 \\ 18937.11 & 55 & 129 & 083 & -62 & 7.3 \mathrm{E}-04\end{array}$ $\begin{array}{llllll}18937.11 & 55 & 129 & 083 & -62 & 7.3 \mathrm{E}-04 \\ 18937.12 & 55 & 129 & 101 & -62 & 7.6 \mathrm{E}-04\end{array}$ $\begin{array}{llllll}18937.12 & 55 & 129 & 101 & -62 & 7.6 \mathrm{E}-04 \\ 18937.21 & 60 & 146 & 101 & -60 & 8.5 \mathrm{E}-04\end{array}$ $\begin{array}{lllllll}18937.21 & 60 & 146 & 101 & -60 & 8.5 \mathrm{E}-04 \\ 18937.22 & 60 & 146 & 088 & -65 & 8.0 \mathrm{E}-04\end{array}$ $\begin{array}{llllll}18937.22 & 60 & 146 & 088 & -65 & 8.0 \mathrm{E}-04 \\ 18938.21 & 61 & 003 & 068 & -46 & 7.6 \mathrm{E}-04\end{array}$ $\begin{array}{lllllll}18938.21 & 61 & 003 & 068 & -46 & 7.6 \mathrm{E}-04 \\ 18938.22 & 61 & 003 & 065 & -49 & 8.8 \mathrm{E}-0\end{array}$ $\begin{array}{llllll}18938.22 & 61 & 003 & 065 & -49 & 8.8 \mathrm{E}-04 \\ 18938.31 & 61 & 019 & 081 & -51 & 7.9 \mathrm{E}-04\end{array}$ $\begin{array}{lllllll}18938.31 & 61 & 019 & 081 & -51 & 7.9 \mathrm{E}-04 \\ 18938.32 & 61 & 019 & 075 & -44 & 8.0 \mathrm{E}-0\end{array}$ $\begin{array}{lllllll}18938.32 & 61 & 019 & 075 & -44 & 8.0 \mathrm{E}-04 \\ 18939.11 & 48 & 216 & 090 & -51 & 6.1 \mathrm{E}-0\end{array}$

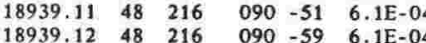
$\begin{array}{llllll}18939.21 & 54 & 219 & 086 & -59 & 6.1 \mathrm{E}-04\end{array}$ $\begin{array}{lllllll}18939.22 & 54 & 219 & 073 & -70 & 5.8 \mathrm{E}-04\end{array}$ $\begin{array}{llllll}18940.21 & 58 & 152 & 056 & -63 & 7.0 \mathrm{E}-04\end{array}$ $\begin{array}{llllll}18940.22 & 58 & 152 & 083 & -71 & 7.2 \mathrm{E}-04\end{array}$ $\begin{array}{lllllll}18940.31 & 56 & 140 & 096 & -69 & 6.0 \mathrm{E}-04\end{array}$ $\begin{array}{lllllll}18940.31 & 56 & 140 & 096 & -69 & 6.0 \mathrm{E}-04 \\ 18940.32 & 56 & 140 & 117 & -69 & 6.4 \mathrm{E}-04\end{array}$ $\begin{array}{lllllll}18940.32 & 56 & 140 & 117 & -69 & 6.4 E-04 \\ 18941.11 & 57 & 155 & 095 & -64 & 6.5 E-04\end{array}$ $\begin{array}{lllllll}18941.12 & 57 & 155 & 088 & -68 & 6.6 \mathrm{E}-04\end{array}$ $\begin{array}{lllllll}18941.12 & 57 & 155 & 088 & -68 & 6.6 E-04 \\ 18941.31 & 54 & 145 & 071 & -67 & 6.3 E-04\end{array}$ $\begin{array}{lllllll}18941.31 & 54 & 145 & 071 & -67 & 6.3 E-04 \\ 18941.32 & 54 & 145 & 080 & -67 & 6.5 \mathrm{E}-04\end{array}$ $\begin{array}{lllllll}18941.32 & 54 & 145 & 080 & -67 & 6.5 \mathrm{E}-04 \\ 18942.21 & 50 & 138 & 110 & -71 & 6.8 \mathrm{E}-04\end{array}$ $\begin{array}{llllll}18942.21 & 50 & 138 & 110 & -71 & 6.8 \mathrm{E}-04 \\ 18942.22 & 50 & 138 & 105 & -64 & 6.4 \mathrm{E}-04\end{array}$ $\begin{array}{llllll}18942.3 & 65 & 138 & 109 & -59 & 6.4 \mathrm{E}-04\end{array}$

$\begin{array}{llllll}18942.4 & 59 & 125 & 089 & -67 & 6.6 \mathrm{E}-04\end{array}$ $\begin{array}{llllll}18943.11 & 67 & 163 & 036 & -77 & 9.5 \mathrm{E}-04\end{array}$ $\begin{array}{llllll}18943.12 & 67 & 163 & 076 & -75 & 9.0 \mathrm{E}-04\end{array}$ $\begin{array}{llllll}18943.21 & 64 & 124 & 102 & -56 & 9.8 \mathrm{E}-04\end{array}$ $\begin{array}{llllll}18943.22 & 64 & 124 & 101 & -52 & 1.1 \mathrm{E}-03\end{array}$ $\begin{array}{llllll}18944.11 & 52 & 182 & 060 & -79 & 9.8 \mathrm{E}-04\end{array}$ $\begin{array}{lllllll}18944.12 & 52 & 182 & 076 & -81 & 1.0 \mathrm{E}-03\end{array}$ $\begin{array}{lllllll}18944.21 & 60 & 206 & 057 & -66 & 1.1 \mathrm{E}-03\end{array}$ $\begin{array}{lllllll}18944.22 & 60 & 206 & 052 & -68 & 1.4 \mathrm{E}-03\end{array}$ $\begin{array}{lllllll}18945.11 & 39 & 320 & 015 & 54 & 8.6 \mathrm{E}-04\end{array}$ $\begin{array}{llllll}18945.12 & 39 & 320 & 354 & 49 & 8.9 \mathrm{E}-04\end{array}$ $\begin{array}{lllllll}18945.21 & 38 & 326 & 007 & 60 & 8.9 E-04\end{array}$ $\begin{array}{lllllll}18945.22 & 38 & 326 & 358 & 51 & 9.6 \mathrm{E}-04\end{array}$ $\begin{array}{llllll}18946.1 & 72 & 060 & 043 & -16 & 4.2 \mathrm{E}-04\end{array}$ $\begin{array}{lllllll}18946.21 & 75 & 079 & 086 & -53 & 9.2 \mathrm{E}-04\end{array}$ $\begin{array}{llllll}18946.21 & 75 & 079 & 086 & -53 & 9.3 \mathrm{E}-04 \\ 18946.22 & 75 & 079 & 077 & -52 & 1.6 \mathrm{E}-03\end{array}$ $\begin{array}{llllll}18946.22 & 75 & 079 & 077 & -52 & 1.6 \mathrm{E}-03 \\ 18947.1 & 48 & 176 & 076 & -71 & 9.7 \mathrm{E}-04\end{array}$ $\begin{array}{lllllll}18947.1 & 48 & 176 & 076 & -71 & 9.7 \mathrm{E}-04\end{array}$ $\begin{array}{lllllll}18947.21 & 61 & 104 & 086 & -58 & 9.3 \mathrm{E}-04\end{array}$ $\begin{array}{lllllll}18947.22 & 61 & 104 & 090 & -59 & 9.6 \mathrm{E}-04\end{array}$ $\begin{array}{lllllll}18947.3 & 65 & 080 & 090 & -71 & 9.0 \mathrm{E}-04\end{array}$ $\begin{array}{llllll}18948.1 & 57 & 278 & 049 & -58 & 9.2 \mathrm{E}-04\end{array}$ $\begin{array}{lllllll}18948.2 & 56 & 277 & 047 & -59 & 8.8 \mathrm{E}-04\end{array}$ $\begin{array}{llllll}18948.31 & 50 & 290 & 042 & -49 & 8.0 \mathrm{E}-04\end{array}$ $\begin{array}{llllll}18948.32 & 50 & 290 & 054 & -50 & 7.6 \mathrm{E}-04\end{array}$ $\begin{array}{llllll}18949.11 & 61 & 202 & 044 & -74 & 9.8 \mathrm{E}-04\end{array}$ $\begin{array}{llllll}18949.12 & 61 & 202 & 069 & -76 & 9.1 \mathrm{E}-04\end{array}$ $\begin{array}{llllll}18949.21 & 61 & 186 & 069 & -76 & 9.2 \mathrm{E}-04\end{array}$ $\begin{array}{lllllll}18949.22 & 61 & 186 & 086 & -77 & 8.8 \mathrm{E}-04\end{array}$ $\begin{array}{llllllll}18950.11 & 54 & 194 & 034 & -76 & 8.7 \mathrm{E}-04\end{array}$ $\begin{array}{lllllll}18950.12 & 54 & 194 & 032 & -72 & 9.7 \mathrm{E}-04\end{array}$ $\begin{array}{llllll}18950.2 & 58 & 187 & 041 & -70 & 9.2 \mathrm{E}-04\end{array}$ $\begin{array}{llllll}18950.3 & 51 & 203 & 031 & -77 & 1.0 E-03\end{array}$ $\begin{array}{llllllllll}043 & -42 & 1.2 \mathrm{E}-03 & -041 & -34 & 8.4 \mathrm{E}-04 * & 041 & -34 & 7.7 \mathrm{E}-04\end{array}$

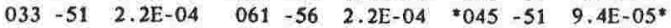

$\begin{array}{lllllllll}050 & -60 & 2.9 \mathrm{E}-04 & 036 & -73 & 1.7 \mathrm{E}-04 & * 040 & -67 & 1.6 \mathrm{E}-04\end{array}$ $\begin{array}{lllllllll}028 & -70 & 2.7 \mathrm{E}-04 & 034 & -65 & 2.3 \mathrm{E}-04 & * 022 & -71 & 1.8 \mathrm{E}-04 *\end{array}$ $\begin{array}{lllllllllll}076 & -52 & 7.0 \mathrm{E}-04 & * 082 & -47 & 5.8 \mathrm{E}-04 * & 089 & -43 & 3.6 \mathrm{E}-04\end{array}$ $\begin{array}{lllllllll}073 & -61 & 9.9 \mathrm{E}-04 & * 077 & -61 & 9.6 \mathrm{E}-04 * & 095 & -64 & 5.8 \mathrm{E}-04\end{array}$ $\begin{array}{lllllllll}068 & -56 & 1.7 \mathrm{E}-03 & * 070 & -54 & 1.5 \mathrm{E}-03 * & 073 & -55 & 1.3 \mathrm{E}-03\end{array}$ $\begin{array}{lllllllll}039 & -63 & 1.9 \mathrm{E}-03 & * 036 & -64 & 1.6 \mathrm{E}-03 * & 039 & -65 & 1.3 \mathrm{E}-03\end{array}$ $\begin{array}{llllllllllll}062 & -57 & 2.1 \mathrm{E}-04 & 026 & -54 & 1.2 \mathrm{E}-04 & -067 & -57 & 1.4 \mathrm{E}-04^{*} & 360 & -79 & 1.7 \mathrm{E}-04\end{array}$

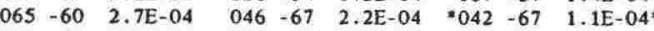
$\begin{array}{llllllllll}091 & -57 & 3.1 \mathrm{E}-04 & 084 & -52 & 2.2 \mathrm{E}-04 & * 085 & -52 & 1.1 \mathrm{E}-04 *\end{array}$ $\begin{array}{lllllllll}057 & -59 & 3.4 \mathrm{E}-04 & * 057 & -62 & 2.1 \mathrm{E}-04^{\circ} & 054 & -62 & 2.3 \mathrm{E}-04 \\ 043 & -47 & 2.3 \mathrm{E}-04 & 059 & -52 & 1.8 \mathrm{E}-04 & * 070 & -54 & 8.7 \mathrm{E}-05^{*}\end{array}$

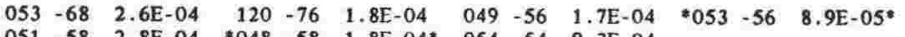
$\begin{array}{llllllllll}051 & -58 & 2.8 \mathrm{E}-04 & * 048 & -58 & 1.8 \mathrm{E}-04 * & 054 & -54 & 9.3 \mathrm{E}-04\end{array}$

$\begin{array}{llllllllllll}044 & -33 & 1.9 \mathrm{E}-04 & 050 & -40 & 1.1 \mathrm{E}-04 & =061 & -48 & 8.9 \mathrm{E}-05^{2} & 011 & -71 & 9.4 \mathrm{E}-05\end{array}$ $\begin{array}{lllllllll}062 & -62 & 2.1 \mathrm{E}-04 & 025 & -63 & 1.2 \mathrm{E}-04^{*} 011 & -72 & 1.8 \mathrm{E}-04\end{array}$

$\begin{array}{lllllllll}059 & -77 & 2.0 \mathrm{E}-04 & * 022 & -70 & 1.9 \mathrm{E}-04 * & 316 & -80 & 1.1 \mathrm{E}-04\end{array}$

$\begin{array}{lllllllll}061 & -61 & 2.7 \mathrm{E}-04 & \text { "066 } & -62 & 2.2 \mathrm{E}-04 * & 060 & -29 & 1.1 \mathrm{E}-04\end{array}$ $\begin{array}{lllllllll}050 & -50 & 2.9 \mathrm{E}-04 & * 056 & -48 & 2.2 \mathrm{E}-04^{*} & 061 & -35 & 2.0 \mathrm{E}-04 \\ 039 & -43 & 1.9 \mathrm{E}-04 & * 034 & -45 & 1.3 \mathrm{E}-04 * & 043 & -43 & 9.9 \mathrm{E}-05\end{array}$ 


\begin{tabular}{|c|c|c|c|c|c|c|c|c|c|c|c|c|c|c|c|c|c|c|c|}
\hline \multirow[b]{2}{*}{ SPEC. } & \multirow{2}{*}{\multicolumn{2}{|c|}{$\begin{array}{l}\text { PUUNGE/ } \\
\text { AZIMUTH }\end{array}$}} & \multicolumn{4}{|c|}{$\mathrm{NROM}$} & 150 & \multicolumn{4}{|c|}{200} & \multicolumn{2}{|r|}{250} & \multicolumn{4}{|c|}{300} & \\
\hline & & & D & 1 & $\mathrm{M}(\mathrm{A} / \mathrm{m})$ & D & $1 \quad M(A / m)$ & D & I & $M(A / m)$ & D & I & $\mathrm{M}(\mathrm{A} / \mathrm{m})$ & D & 1 & $M(A / m)$ & D & 1 & $M(A / m)$ \\
\hline 18951.12 & 63 & 073 & 089 & -52 & 1. $0 \mathrm{E}-03$ & & & 043 & -58 & 3. $7 \mathrm{E}-04$ & 057 & -74 & 3.0E-04 & ${ }^{*} 053$ & -67 & $2.6 \mathrm{E}-04^{\circ}$ & & & \\
\hline $\begin{array}{l}18951.31 \\
18951.32\end{array}$ & 61 & 061 & 096 & -58 & 1. $2 \mathrm{E}-03$ & & & 053 & -62 & 4. $4 \mathrm{E}-04$ & 051 & -60 & $3.6 \mathrm{E}-04$ & $=070$ & -61 & $04^{\circ}$ & & & \\
\hline 18951.32 & 61 & 061 & 097 & -50 & 1.1E-03 & & & 028 & -61 & $3.6 \mathrm{E}-04$ & $=010$ & -56 & 2.7E-04* & 017 & -47 & 2. $0 E-04$ & & & \\
\hline $\begin{array}{l}18952.11 \\
18952.12\end{array}$ & 41 & 061 & 104 & -34 & 1. $0 \mathrm{E}-03$ & & & 072 & -49 & $3.5 \mathrm{E}-04$ & *073 & -39 & $2.4 \mathrm{E}-04^{*}$ & 065 & -35 & 2. $4 \mathrm{E}-04$ & & & \\
\hline 18952.12 & 41 & 061 & 097 & -48 & 1.1E-03 & & & 064 & -62 & $3.8 \mathrm{E}-04$ & 058 & -62 & $3.5 E-04$ & $=056$ & -62 & $1.8 E-04^{*}$ & & & \\
\hline $\begin{array}{l}18952.2 \\
18953.11\end{array}$ & 48 & 052 & 097 & -34 & 8. $2 \mathrm{E}-04$ & & & 069 & -66 & 2. $1 \mathrm{E}-04$ & 052 & -60 & 1. $9 \mathrm{E}-04$ & ${ }^{*} 051$ & -60 & 9. $3 E-05^{*}$ & & & \\
\hline 18953.11 & 55 & 105 & 121 & -58 & 7.0E-04 & & & 060 & -64 & 2. $0 \mathrm{E}-04$ & 055 & -64 & $1.8 \mathrm{E}-04$ & 054 & -64 & $8.9 \mathrm{E}-05^{\star}$ & & & \\
\hline $\begin{array}{l}18953.12 \\
18953.21\end{array}$ & 55 & 105 & 108 & -58 & 8.1E-04 & & & & & & & & & & & & & & \\
\hline $\begin{array}{l}18953.21 \\
18953.22\end{array}$ & 59 & 075 & 105 & -51 & $9.2 \mathrm{E}-04$ & & & 063 & -62 & $3.2 \mathrm{E}-04$ & 056 & -56 & 2. $9 \mathrm{E}-04$ & ${ }^{*} 053$ & -57 & 2.5E-04* & & & \\
\hline $\begin{array}{l}18953.22 \\
18954.1\end{array}$ & 59 & 075 & 102 & -51 & $8.3 \mathrm{E}-04$ & & & 040 & -69 & $2.4 \mathrm{E}-04$ & 022 & -75 & 2. $4 \mathrm{E}-04$ & $=012$ & -72 & 1. $3 \mathrm{E}-04^{*}$ & & & \\
\hline $\begin{array}{l}18954.1 \\
18954.21\end{array}$ & 55 & 068 & 097 & -55 & $7.8 \mathrm{E}-04$ & & & 037 & -57 & $2.9 \mathrm{E}-04$ & 038 & -56 & 2.2E-04 & ${ }^{*} 037$ & -55 & $1.1 \mathrm{E}-04^{*}$ & & & \\
\hline $\begin{array}{l}18954.21 \\
18954.22\end{array}$ & 65 & 084 & 097 & -55 & $8.7 \mathrm{E}-04$ & & & 079 & -73 & 3. $0 \mathrm{E}-04$ & 058 & -71 & 2. 3E-04 & 047 & -63 & 2. $1 \mathrm{E}-04$ & ${ }^{*} 047$ & -62 & 1. $0 \mathrm{E}-04^{\circ}$ \\
\hline $\begin{array}{l}18954.22 \\
18954.3\end{array}$ & 65 & 084 & 099 & -49 & 8.5E-04 & & & 061 & -56 & 2. $4 \mathrm{E}-04$ & 044 & -54 & $2.1 \mathrm{E}-04$ & ${ }^{*} 043$ & -53 & 1. $0 \mathrm{E}-04^{*}$ & & & \\
\hline $\begin{array}{l}18954.3 \\
18955.11\end{array}$ & 55 & 047 & 096 & -40 & $9.3 \mathrm{E}-04$ & & & & & & & & & & & & & & \\
\hline $\begin{array}{l}18955.11 \\
18955.12\end{array}$ & $\begin{array}{l}47 \\
47\end{array}$ & 138 & 100 & -71 & $6.0 \mathrm{E}-04$ & & & 089 & -64 & 4. $2 \mathrm{E}-04$ & 051 & -52 & 1. $2 \mathrm{E}-04$ & ${ }^{*} 051$ & -49 & 7. $5 \mathrm{E}-05^{*}$ & & & \\
\hline $\begin{array}{l}18955.12 \\
18955.3\end{array}$ & $\begin{array}{l}47 \\
64\end{array}$ & $\begin{array}{l}138 \\
157\end{array}$ & 080 & -70 & $6.4 \mathrm{E}-04$ & & & 071 & -58 & $3.8 \mathrm{E}-04$ & 036 & -70 & 1. $5 E-04$ & ${ }^{*} 031$ & -71 & 7. $4 \mathrm{E}-05^{\circ}$ & & & \\
\hline 18956.11 & $\begin{array}{l}64 \\
52\end{array}$ & $\begin{array}{l}157 \\
058\end{array}$ & 103 & -66 & $7.1 \mathrm{E}-04$ & & & 010 & -62 & 4. $7 \mathrm{E}-04$ & 142 & -47 & 1. $5 \mathrm{E}-04$ & -141 & -56 & 1. $6 \mathrm{E}-04^{*}$ & & & \\
\hline 18956.12 & $\begin{array}{l}52 \\
52\end{array}$ & $\begin{array}{l}058 \\
058\end{array}$ & $\begin{array}{l}087 \\
081\end{array}$ & $\begin{array}{l}-51 \\
-56\end{array}$ & 7.2E-04 & & & 069 & -54 & $3.2 \mathrm{E}-04$ & 031 & -55 & $1.8 \mathrm{E}-04$ & "034 & -55 & $8.4 \mathrm{E}-05^{*}$ & & & \\
\hline 18956.21 & 38 & 056 & 086 & $\begin{array}{l}-56 \\
-42\end{array}$ & $\begin{array}{l}6.5 \mathrm{E}-04 \\
7.2 \mathrm{E}-04\end{array}$ & & & & & & & & & & & & & & \\
\hline 18956.22 & 38 & 056 & 085 & -40 & $\begin{array}{l}7.2 \mathrm{E}-04 \\
7.4 \mathrm{E}-04\end{array}$ & & & $\begin{array}{l}081 \\
080\end{array}$ & $\begin{array}{l}-48 \\
-43\end{array}$ & $\begin{array}{l}2.2 \mathrm{E}-04 \\
3.4 \mathrm{E}-04\end{array}$ & $\begin{array}{l}074 \\
041\end{array}$ & $\begin{array}{l}-52 \\
-45\end{array}$ & $\begin{array}{l}2.1 \mathrm{E}-04 \\
1.8 \mathrm{E}-04\end{array}$ & $\begin{array}{l}059 \\
0041\end{array}$ & $\begin{array}{l}-53 \\
-45\end{array}$ & $\begin{array}{l}\text { 1.5E-04" } \\
8.7 \mathrm{E}-05^{\circ}\end{array}$ & 109 & -86 & 7.1E-05 \\
\hline 18957.1 & 48 & 030 & 085 & -26 & 9. $3 \mathrm{E}-04$ & & & 068 & -31 & 3. $7 \mathrm{E}-04$ & 057 & -37 & $2.4 \mathrm{E}-04$ & $=058$ & -39 & 1.2E-04* & & & \\
\hline 18957.2 & 50 & 049 & 081 & -55 & 7.7E-04 & & & & & & & & & & & & & & \\
\hline 18957.31 & 48 & 052 & 082 & -43 & $6.8 \mathrm{E}-04$ & & & 078 & -59 & $2.9 \mathrm{E}-04$ & 071 & -54 & $1.7 \mathrm{E}-04$ & 073 & -52 & $8.2 \mathrm{E}-05^{*}$ & & & \\
\hline 18957.32 & 48 & 052 & 079 & -49 & $6.9 \mathrm{E}-04$ & & & 048 & -48 & 2. $0 \mathrm{E}-04$ & 022 & -57 & 1.1E-04 & ${ }^{*} 021$ & -56 & 5.3E-05* & & & \\
\hline 18958.1 & 44 & 085 & 098 & -47 & $5.8 \mathrm{E}-04$ & & & 085 & -48 & 3. $3 \mathrm{E}-04$ & 077 & -50 & 1.5E-04 & $=075$ & -49 & $7.4 \mathrm{E}-05^{\circ}$ & & & \\
\hline 18958.2 & 52 & 040 & 101 & -52 & 6. $2 \mathrm{E}-04$ & & & 096 & -51 & $2.8 \mathrm{E}-04$ & 096 & -68 & 1.1E-04 & 035 & -73 & $9.9 \mathrm{E}-05$ & 037 & -73 & $5.0 \mathrm{E}-05^{*}$ \\
\hline 18958.3 & 51 & 049 & 085 & -41 & $8.9 \mathrm{E}-04$ & & & 074 & -40 & $4.9 \mathrm{E}-04$ & 055 & -51 & $2.5 \mathrm{E}-04$ & 018 & -58 & 1. $2 \mathrm{E}-04^{*}$ & 019 & -58 & $6.0 \mathrm{E}-05$ \\
\hline 18959.11 & 48 & 064 & 091 & -44 & 1.OE-03 & & & 092 & -56 & $5.4 \mathrm{E}-04$ & 090 & -69 & $3.9 E-04$ & *103 & -75 & $2.8 \mathrm{E}-04^{*}$ & & & \\
\hline
\end{tabular}

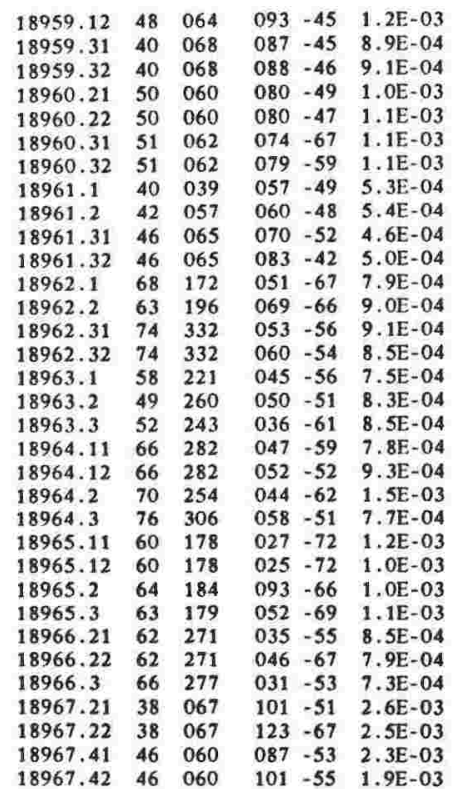

$\begin{array}{llllll}18968.1 & 50 & 124 & 107 & -72 & 8.9 \mathrm{E}-04\end{array}$ $\begin{array}{lllllll}18968.2 & 47 & 096 & 096 & -62 & 1.0 \mathrm{E}-03\end{array}$ $\begin{array}{lllllll}18968.3 & 34 & 102 & 128 & -58 & 8.2 \mathrm{E}-04\end{array}$ $\begin{array}{lllllll}18969.31 & 56 & 177 & 030 & -78 & 1.1 \mathrm{E}-03\end{array}$ $\begin{array}{llllll}18969.32 & 56 & 177 & 065 & -76 & 1.1 \mathrm{E}-03\end{array}$ $\begin{array}{lllllll}18969.41 & 59 & 189 & 014 & -81 & 1.1 \mathrm{E}-03\end{array}$ $18969.42 \quad 59 \quad 189 \quad 066-78 \quad 1.0 \mathrm{E}-03$ $18970.21 \quad 44 \quad 246 \quad 048-70 \quad 9.0 E-03$ $\begin{array}{llllll}18970.21 & 44 & 246 & 048 & -70 & 9.7 \mathrm{E}-04\end{array}$ $\begin{array}{llllll}18970.22 & 44 & 246 & 034 & -61 & 9.7 \mathrm{E}-04\end{array}$ $\begin{array}{llllll}18970.41 & 53 & 286 & 048 & -49 & 1.0 \mathrm{E}-03\end{array}$ $\begin{array}{llllll}18970.42 & 53 & 286 & 049 & -54 & 1.2 \mathrm{E}-03\end{array}$ $\begin{array}{llllll}18971.1 & 48 & 294 & 043 & -46 & 1.0 \mathrm{E}-03\end{array}$ $\begin{array}{lllllll}18971.21 & 48 & 316 & 053 & -48 & 1.4 \mathrm{E}-03\end{array}$ $\begin{array}{lllllll}18971.22 & 48 & 316 & 054 & -46 & 1.0 \mathrm{E}-03\end{array}$ $\begin{array}{llllll}18971.4 & 51 & 012 & 066 & -36 & 7.7 \mathrm{E}-04\end{array}$ $\begin{array}{llllll}18972.11 & 68 & 333 & 070 & -50 & 1.1 \mathrm{E}-03\end{array}$ $\begin{array}{llllll}18972.12 & 68 & 333 & 073 & -49 & 9.2 \mathrm{E}-04\end{array}$ $\begin{array}{llllll}18972.31 & 60 & 316 & 060 & -55 & 1.1 \mathrm{E}-03\end{array}$ $\begin{array}{lllllll}18972.32 & 60 & 316 & 039 & -50 & 9.4 \mathrm{E}-04\end{array}$ $\begin{array}{lllllll}18973.21 & 54 & 342 & 067 & -43 & 9.1 \mathrm{E}-04\end{array}$ $\begin{array}{llllll}18973.22 & 54 & 342 & 066 & -40 & 8.7 \mathrm{E}-04\end{array}$ $\begin{array}{llllll}18973.31 & 48 & 349 & 076 & -45 & 7.5 \mathrm{E}-04\end{array}$ $\begin{array}{lllllll}18973.32 & 48 & 349 & 058 & -38 & 8.6 \mathrm{E}-04\end{array}$ $\begin{array}{llllll}18974.1 & 40 & 213 & 359 & -78 & 1.3 \mathrm{E}-03\end{array}$ $\begin{array}{llllll}18974.2 & 49 & 217 & 017 & -50 & 1.3 \mathrm{E}-03\end{array}$ $18974.3 \quad 54$ 255 $042-61 \quad 1.3 \mathrm{E}-03$ $18975.31 \quad 44$ 342 $061-40 \quad 1.3 \mathrm{E}-03$ $\begin{array}{lllllll}18975.32 & 44 & 342 & 061 & -40 & 1.4 \mathrm{E}-03\end{array}$ $\begin{array}{llllll}18975.32 & 44 & 342 & 071 & -43 & 1.3 \mathrm{E}-03\end{array}$ $\begin{array}{llllll}18975.41 & 49 & 325 & 053 & -42 & 1.3 \mathrm{E}-03\end{array}$ $\begin{array}{llllll}18975.42 & 49 & 325 & 059 & -50 & 1.3 \mathrm{E}-03\end{array}$ $\begin{array}{llllll}18976.1 & 54 & 186 & 122 & -77 & 7.1 \mathrm{E}-04\end{array}$ $\begin{array}{llllll}18976.2 & 47 & 187 & 009 & -75 & 7.3 \mathrm{E}-04 \\ 18976.3 & 63 & 179 & 059 & -74 & 7.4 \mathrm{E}-04\end{array}$ $\begin{array}{llllllllllll}084 & -47 & 4.3 \mathrm{E}-04 & 061 & -52 & 4.2 \mathrm{E}-04 & 079 & -58 & 2.5 \mathrm{E}-04 & 079 & -58 & 1.3 \mathrm{E}-04 *\end{array}$ $\begin{array}{lllllllll}082 & -48 & 3.3 \mathrm{E}-04 & 070 & -54 & 2.7 \mathrm{E}-04 & * 062 & -54 & 1.3 \mathrm{E}-04 *\end{array}$

$064-52 \quad 5.7 \mathrm{E}-04 \quad 033-56 \quad 3.7 \mathrm{E}-04 * 032-56 \quad 1.9 \mathrm{E}-04 *$

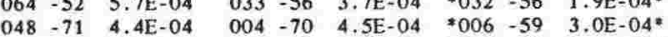

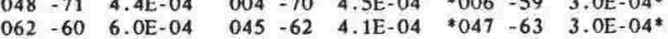

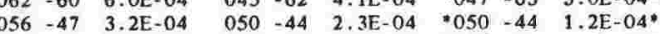
$\begin{array}{llllllllllll}052 & -49 & 2.5 \mathrm{E}-04 & 039 & -44 & 1.8 \mathrm{E}-04 & * 025 & -51 & 1.3 \mathrm{E}-04 * & 084 & -55 & 8.6 \mathrm{E}-05\end{array}$ $\begin{array}{llllllllll}062 & -53 & 1.1 \mathrm{E}-04 & 023 & -40 & 6.4 \mathrm{E}-05 & 004 & -53 & 3.2 \mathrm{E}-05 *\end{array}$

$\begin{array}{lllllllll}043 & -65 & 3.0 \mathrm{E}-04 & 015 & -68 & 2.8 \mathrm{E}-04 & =016 & -69 & 1.4 \mathrm{E}-04\end{array}$ $\begin{array}{llllllllll}065 & -63 & 3.8 \mathrm{E}-04 & 108 & -60 & 2.7 \mathrm{E}-04 & * 107 & -61 & 1.4 \mathrm{E}-04^{*} \\ 048 & -52 & 4.0 \mathrm{E}-04 & 088 & -54 & 2.6 \mathrm{E}-04 & \div 088 & -54 & 1.3 \mathrm{E}-04^{*}\end{array}$

$\begin{array}{llllllllll}042 & -60 & 3.0 \mathrm{E}-04 & 057 & -60 & 2.2 \mathrm{E}-04 & * 063 & -60 & 1.5 \mathrm{E}-04 *\end{array}$

$\begin{array}{llllllllllll}032 & -58 & 2.1 \mathrm{E}-04 & 018 & -43 & 3.0 \mathrm{E}-04 & 020 & -58 & 2.1 \mathrm{E}-04 & 020 & -58 & 1.1 \mathrm{E}-04^{*}\end{array}$

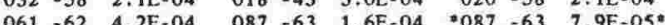

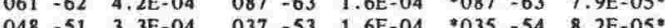
$\begin{array}{lllllllll}048 & -51 & 3.3 \mathrm{E}-04 & 037 & -53 & 1.6 \mathrm{E}-04 & * 035 & -54 & 8.2 \mathrm{E}-05^{*} \\ 043 & -64 & 4.2 \mathrm{E}-04 & 028 & -49 & 1.5 \mathrm{E}-04 & * 046 & -66 & 7.6 \mathrm{E}-05^{*}\end{array}$

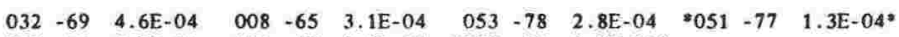

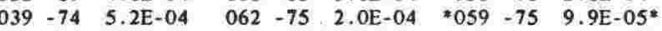
$\begin{array}{lllllllll}073 & -64 & 3.0 \mathrm{E}-04 & 089 & -18 & 2.0 \mathrm{E}-04 & \mathbf{1 0 9} & -28 & 2.9 \mathrm{E}-04 *\end{array}$

\author{
$\begin{array}{lllllllll}035 & -61 & 2.3 \mathrm{E}-04 & * 035 & -61 & 1.2 \mathrm{E}-05 * & 032 & -62 & 5.6 \mathrm{E}-05\end{array}$ \\ $\begin{array}{lllllllll}060 & -52 & 2.7 \mathrm{E}-04 & 031 & -51 & 3.1 \mathrm{E}-04 & * 029 & -44 & 1.9 \mathrm{E}-04 * \\ 076 & -65 & 2.7 \mathrm{E}-04 & 006 & -75 & 1.1 \mathrm{E}-04 & * 067 & -68 & 6.6 \mathrm{E}-05^{*}\end{array}$ \\ $032-62 \quad 4.4 \mathrm{E}-04 \quad 042-54 \quad 3.2 \mathrm{E}-04 \quad 0042 \quad-55 \quad 1.6 \mathrm{E}-04 *$ \\ $\begin{array}{lllllllll}025 & -74 & 2.1 \mathrm{E}-04 & * 026 & -73 & 1.0 \mathrm{E}-04 * & 026 & -73 & 4.9 \mathrm{E}-05\end{array}$ \\ $\begin{array}{llllllllll}074 & -49 & 3.3 \mathrm{E}-04 & 068 & -46 & 3.6 \mathrm{E}-04 & * 070 & -46 & 1.9 \mathrm{E}-04^{*}\end{array}$ \\ $\begin{array}{llllllllll}141 & -82 & 1.2 \mathrm{E}-04 & * 130 & -82 & 6.6 \mathrm{E}-05 * & 140 & -83 & 3.3 \mathrm{E}-05\end{array}$

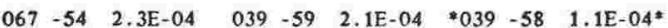 \\ $\begin{array}{llllllllll}084 & -62 & 3.1 \mathrm{E}-04 & 056 & -65 & 1.2 \mathrm{E}-04 & \approx 057 & -65 & 6.0 \mathrm{E}-05^{*}\end{array}$ \\ $\begin{array}{lllllllll}-072 & -76 & 2.8 \mathrm{E}-04^{*} & 348 & -52 & 1.4 \mathrm{E}-04 & 227 & -79 & 5.3 \mathrm{E}-05\end{array}$

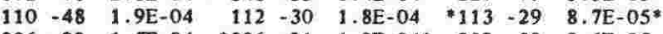 \\ $\begin{array}{lllllllll}006 & -22 & 1.5 \mathrm{E}-04 & * 006 & -21 & 1.3 \mathrm{E}-04 * & 039 & -32 & \mathbf{8 . 6 E}-05\end{array}$ \\ $\begin{array}{lllllllll}102 & -31 & 3.2 \mathrm{E}-04 & * 102 & -35 & 2.4 \mathrm{E}-0 * & 090 & -19 & 1.3 \mathrm{E}-04\end{array}$ \\ $\begin{array}{lllllllll}088 & -58 & 1.6 \mathrm{E}-04 & * 087 & -44 & 1.2 \mathrm{E}-04 * & 087 & -44 & 5.6 \mathrm{E}-05\end{array}$

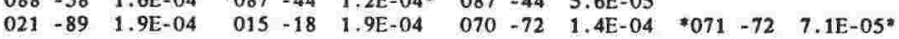

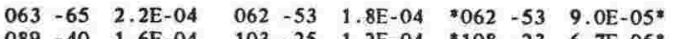

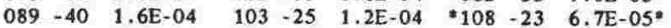

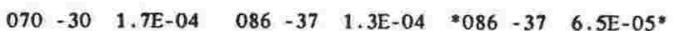

$\begin{array}{lllllllll}068 & -60 & 1.9 \mathrm{E}-04 & * 087 & -62 & 7.3 \mathrm{E}-05 * & 096 & -19 & 2.4 \mathrm{E}-04\end{array}$

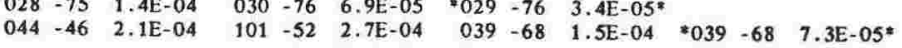




\begin{tabular}{|c|c|c|c|c|c|c|c|c|c|c|c|c|c|c|c|c|c|c|c|}
\hline \multirow[b]{2}{*}{ SPEC. } & \multirow{2}{*}{\multicolumn{2}{|c|}{$\begin{array}{l}\text { PLUNGE/ } \\
\text { AZIMUTH }\end{array}$}} & \multicolumn{3}{|c|}{ NEM } & \multicolumn{2}{|r|}{150} & \multicolumn{3}{|c|}{200} & \multicolumn{3}{|r|}{250} & \multicolumn{4}{|c|}{300} & \multicolumn{2}{|r|}{320} \\
\hline & & & D & 1 & $M(A / m)$ & D & $1 \mathrm{M}(\mathrm{A} / \mathrm{m})$ & D & 1 & $\mathrm{M}(\mathrm{A} / \mathrm{m})$ & D & I & $\mathrm{M}(\mathrm{A} / \mathrm{m})$ & D & 1 & $\mathrm{M}(\mathrm{A} / \mathrm{m})$ & D & 1 & $\mathrm{M}(\mathrm{A} / \mathrm{m})$ \\
\hline 18976.4 & 64 & 167 & 109 & -75 & 7. $0 \mathrm{E}-04$ & & & & & & & & & & & & & & \\
\hline 18977.1 & 48 & 052 & 098 & -35 & 1.1E-03 & & & 070 & -28 & 2. $4 \mathrm{E}-04$ & ${ }^{*} 023$ & -58 & 8. $8 \mathrm{E}-05^{*}$ & 023 & -59 & 4. $4 \mathrm{E}-05$ & & & \\
\hline 18977.21 & 46 & 054 & 116 & -51 & 1. $1 \mathrm{E}-03$ & & & 032 & -72 & 3. $7 \mathrm{E}-04$ & ${ }^{*} 027$ & -71 & 1. $9 \mathrm{E}-04^{\circ}$ & 029 & -72 & $9.1 \mathrm{E}-05$ & & & \\
\hline 18977.22 & 46 & 054 & 091 & -52 & 1. $5 \mathrm{E}-03$ & & & 036 & -66 & $4.6 \mathrm{E}-04$ & ${ }^{*} 037$ & -64 & 2. $3 \mathrm{E}-04^{*}$ & 037 & -66 & 1. $2 \mathrm{E}-04$ & & & \\
\hline 18977.3 & 71 & 107 & 114 & -62 & 1. $5 \mathrm{E}-03$ & & & & & & & & & & & & & & \\
\hline 18978.11 & 51 & 302 & 043 & -51 & 1. $1 \mathrm{E}-03$ & & & 037 & -63 & $2.6 \mathrm{E}-04$ & 008 & -69 & $2.4 \mathrm{E}-04$ & ${ }^{*} 012$ & -69 & 1. $2 \mathrm{E}-04^{*}$ & & & \\
\hline 18978.12 & 51 & 302 & 049 & -57 & 1. $2 \mathrm{E}-03$ & & & 042 & -46 & 2.5E-04 & 031 & -45 & 2. $1 \mathrm{E}-04$ & $* 031$ & -45 & 1. $1 \mathrm{E}-04^{*}$ & & & \\
\hline 18978.2 & 54 & 304 & 053 & -40 & 1. $2 \mathrm{E}-03$ & & & & & & & & & & & & & & \\
\hline 18978.3 & 55 & 260 & 019 & -61 & $9.7 \mathrm{E}-04$ & & & 035 & -15 & 2. OE- 04 & $\cdot 040$ & -15 & 2. $2 \mathrm{E}-04^{\mathrm{A}}$ & 072 & -17 & 1. $1 \mathrm{E}-04$ & & & \\
\hline 18980.21 & 57 & 296 & 047 & -54 & 1. $7 \mathrm{E}-03$ & & & & & & & & & & & & & & \\
\hline 18980.22 & 57 & 296 & 047 & -47 & 1. $6 \mathrm{E}-03$ & & & & & & & & & & & & & & • \\
\hline $\begin{array}{l}18980.31 \\
18980.32\end{array}$ & $\begin{array}{l}54 \\
54\end{array}$ & $\begin{array}{l}250 \\
250\end{array}$ & $\begin{array}{l}013 \\
355\end{array}$ & $\begin{array}{l}-62 \\
-74\end{array}$ & 1.2E-03 & & & & & & & & & & & & & & \\
\hline 18981.1 & 63 & 109 & 129 & -68 & 1. $8 \mathrm{E}-03$ & & & 164 & -31 & 2.1E-04 & 230 & -08 & 4. $6 \mathrm{E}-04$ & 215 & 21 & 2. $3 \mathrm{E}-04$ & $\approx 215$ & 22 & 1. $6 \mathrm{E}-05^{\circ}$ \\
\hline 18981.2 & 58 & 118 & 098 & -42 & $1.8 \mathrm{E}-03$ & & & 084 & 21 & 4.1E-04 & 098 & 01 & 3. $4 \mathrm{E}-04$ & • 186 & 24 & 1. $6 \mathrm{E}-04^{*}$ & & & \\
\hline 18981.3 & 64 & 133 & 095 & -61 & 1. $6 \mathrm{E}-03$ & & & & & & & & & & & & & & \\
\hline 18981.4 & 61 & 107 & 119 & -67 & $1.6 \mathrm{E}-03$ & & & 290 & -29 & $1.4 \mathrm{E}-04$ & 277 & -25 & $2.9 \mathrm{E}-04$ & 335 & 33 & 1. $4 \mathrm{E}-04$ & 335 & 35 & 1. $9 \mathrm{E}-05^{=}$ \\
\hline 18983.21 & 63 & 117 & 084 & 065 & 5.5E-04 & & & 037 & -52 & 1.1E-04 & 107 & -73 & 3.5E-05 & 069 & -35 & 6.3E-05 & $\$ 070$ & -34 & $3.2 \mathrm{E}-05=$ \\
\hline 18983.22 & 63 & 117 & 043 & -34 & $3.5 \mathrm{E}-04$ & & & & & & & & & & & & & & \\
\hline 18983.31 & 65 & 143 & 109 & -70 & 5. $0 \mathrm{E}-04$ & & & 137 & -48 & $9.9 \mathrm{E}-05$ & 150 & -35 & $9.5 \mathrm{E}-05$ & "148 & -39 & $5.6 \mathrm{E}-05^{*}$ & & & \\
\hline 18983.32 & 65 & 143 & 120 & -60 & $5.4 \mathrm{E}-04$ & & & 050 & -62 & 1. $4 \mathrm{E}-04$ & 030 & -70 & $8.8 \mathrm{E}-05$ & ${ }^{*} 027$ & -73 & $4.4 \mathrm{E}-05^{\star}$ & & & \\
\hline 18985.11 & 26 & 075 & 078 & -51 & $4.2 \mathrm{E}-04$ & & & & & & & & & & & & & & \\
\hline 18985.12 & 26 & 075 & 108 & -47 & $4,4 E-04$ & & & 136 & -51 & $1.1 \mathrm{E}-04$ & 128 & -26 & 1. $2 \mathrm{E}-04$ & 147 & -20 & 1. $2 \mathrm{E}-04$ & $=146$ & -20 & $5.7 \mathrm{E}-05^{\circ}$ \\
\hline 18985.21 & 23 & 085 & 104 & -56 & $3.2 \mathrm{E}-04$ & & & 037 & -52 & 1.1E-04 & 039 & -50 & 7.2E-05 & $=034$ & -57 & $6.4 \mathrm{E}-05^{*}$ & & & \\
\hline 18985.22 & 23 & 085 & 088 & -52 & 4. $3 \mathrm{E}-04$ & & & 031 & -54 & 1. $5 \mathrm{E}-04$ & 005 & -32 & 1. $0 \mathrm{E}-04$ & 057 & -13 & 7.0E-05 & ${ }^{ \pm 057}$ & -12 & 2.5E-05* \\
\hline 18987.1 & 51 & 271 & 062 & -42 & $9.8 \mathrm{E}-04$ & & & 060 & -48 & $2.1 \mathrm{E}-04$ & 022 & -58 & 1. $5 \mathrm{E}-04$ & $=026$ & -61 & $7.8 \mathrm{E}-05^{*}$ & & & \\
\hline 18987.2 & 62 & 285 & 055 & -41 & $8.7 \mathrm{E}-04$ & & & 042 & -27 & $2.3 \mathrm{E}-0.4$ & 028 & -25 & $1.8 \mathrm{E}-04$ & $=033$ & -49 & $8.1 \mathrm{E}-05^{=}$ & & & \\
\hline $\begin{array}{l}18987.3 \\
18987.4\end{array}$ & $\begin{array}{l}60 \\
65\end{array}$ & $\begin{array}{l}264 \\
300\end{array}$ & $\begin{array}{l}054 \\
026\end{array}$ & $\begin{array}{l}-53 \\
-62\end{array}$ & $7.7 \mathrm{E}-04$ & & & 055 & -45 & 1. $3 \mathrm{E}-04$ & 078 & -14 & 9.0E-05 & $* 082$ & -08 & $5.3 \mathrm{E}-05^{\circ}$ & & & \\
\hline
\end{tabular}

$\begin{array}{llllll}18989.1 & 62 & 271 & 052 & -51 & 4.3 \mathrm{E}-04 \\ 18989.2 & 62 & 302 & 083 & -51 & 4.5 \mathrm{E}-04 \\ 18989.3 & 64 & 296 & 055 & -47 & 5.9 \mathrm{E}-04 \\ 18989.4 & 61 & 271 & 058 & -54 & 5.1 \mathrm{E}-04 \\ 18991.11 & 33 & 306 & 053 & -42 & 4.7 \mathrm{E}-04 \\ 18991.12 & 33 & 306 & 054 & -30 & 5.0 \mathrm{E}-04 \\ 18991.21 & 38 & 294 & 051 & -37 & 5.9 \mathrm{E}-04 \\ 18991.22 & 38 & 294 & 060 & -43 & 5.0 \mathrm{E}-04 \\ 18992.2 & 50 & 285 & 053 & -55 & 5.4 \mathrm{E}-04 \\ 18992.3 & 49 & 276 & 134 & -24 & 1.5 \mathrm{E}-04 \\ 18992.4 & 41 & 283 & 176 & -27 & 9.0 \mathrm{E}-05 \\ 18993.11 & 37 & 242 & 035 & -54 & 5.6 \mathrm{E}-04 \\ 18993.12 & 37 & 242 & 038 & -48 & 5.2 \mathrm{E}-04 \\ 18993.21 & 40 & 228 & 026 & -52 & 5.7 \mathrm{E}-04 \\ 18993.22 & 40 & 228 & 002 & -63 & 6.6 \mathrm{E}-04 \\ 18994.11 & 36 & 229 & 030 & -69 & 7.1 \mathrm{E}-04 \\ 18994.12 & 36 & 229 & 011 & -68 & 7.7 \mathrm{E}-04 \\ 18994.2 & 44 & 264 & 029 & -60 & 7.9 \mathrm{E}-04 \\ 18995.11 & 66 & 275 & 060 & -44 & 1.4 \mathrm{E}-03 \\ 18995.12 & 66 & 275 & 063 & -45 & 1.2 \mathrm{E}-03 \\ 18995.21 & 60 & 239 & 045 & -47 & 1.2 \mathrm{E}-03 \\ 18995.22 & 60 & 239 & 052 & -64 & 1.2 \mathrm{E}-03 \\ 18996.1 & 46 & 041 & 089 & -47 & 1.0 \mathrm{E}-03 \\ 18996.2 & 41 & 036 & 103 & -28 & 6.8 \mathrm{E}-04 \\ 18996.3 & 54 & 066 & 079 & -57 & 7.4 \mathrm{E}-04 \\ 18996.5 & 24 & 097 & 164 & -64 & 7.4 \mathrm{E}-04 \\ 18997.21 & 34 & 018 & 099 & -34 & 8.3 \mathrm{E}-04 \\ 18997.22 & 34 & 018 & 074 & -41 & 1.3 \mathrm{E}-03 \\ 18997.31 & 30 & 075 & 130 & -39 & 7.5 \mathrm{E}-04 \\ 18997.32 & 30 & 075 & 131 & -45 & 7.5 \mathrm{E}-04 \\ 18998.11 & 31 & 050 & 095 & -40 & 5.7 \mathrm{E}-04 \\ 18998.12 & 31 & 050 & 107 & -54 & 7.0 \mathrm{E}-04 \\ 18998.3 & 22 & 085 & 101 & -27 & 1.2 \mathrm{E}-03 \\ & & & & & \end{array}$

$\begin{array}{llll}059 & -73 & 7.1 \mathrm{E}-04\end{array}$ $\begin{array}{lll}111 & -39 & 9.2 \mathrm{E}-04 \\ 104 & -44 & 1.1 \mathrm{E}-03\end{array}$ $\begin{array}{lll}104 & -44 & 1.1 \mathrm{E}-03 \\ 118 & -57 & 5.8 \mathrm{E}-04\end{array}$ $\begin{array}{lll}118 & -57 & 5.8 E-04 \\ 087 & -32 & 8.5 E-04\end{array}$ $080-16 \quad 1.2 \mathrm{E}-03$ $088-61 \quad 1.3 E-03$ $\begin{array}{lll}074 & -33 & 1.7 \mathrm{E}-03\end{array}$ $\begin{array}{lll}009 & -38 & 1.2 \mathrm{E}-03\end{array}$ $\begin{array}{lll}035 & -39 & 1.2 \mathrm{E}-03\end{array}$ $\begin{array}{lll}353 & -40 & 1.2 \mathrm{E}-03\end{array}$ $043-40 \quad 1.3 \mathrm{E}-03$ $\begin{array}{lll}034 & -28 & 9.8 \mathrm{E}-04\end{array}$ $\begin{array}{lll}034 & -28 & 9.8 \mathrm{E}-04 \\ 052 & -38 & 2.1 \mathrm{E}-03\end{array}$ $\begin{array}{lll}052 & -38 & 2.1 \mathrm{E}-03 \\ 004 & -64 & 1.0 \mathrm{E}-03\end{array}$ $\begin{array}{lll}004 & -64 & 1.0 \mathrm{E}-03 \\ 026 & -40 & 1.1 \mathrm{E}-03\end{array}$ $\begin{array}{lll}026 & -40 & 1.1 E-03 \\ 044 & -22 & 1.0 E-03\end{array}$ $\begin{array}{lll}044 & -22 & 1.0 E-03 \\ 023 & -31 & 9.5 E-04\end{array}$ $\begin{array}{lll}023 & -31 & 9.5 \mathrm{E}-04 \\ 029 & -38 & 1.0 \mathrm{E}-03\end{array}$ $\begin{array}{llll}029 & -38 & 1.0 \mathrm{E}-03 \\ 053 & -40 & 9.1 \mathrm{E}-04\end{array}$ $\begin{array}{lll}053 & -40 & 9.1 \mathrm{E}-04 \\ 024 & -34 & 9.5 \mathrm{E}-04\end{array}$ $\begin{array}{lll}024 & -34 & 9.5 \mathrm{E}-04 \\ 003 & -45 & 7.0 \mathrm{E}-04\end{array}$ $\begin{array}{lll}003 & -45 & 7.0 \mathrm{E}-04 \\ 355 & -74 & 1.0 \mathrm{E}-03\end{array}$ $\begin{array}{lll}355 & -74 & 1.0 \mathrm{E}-03 \\ 039 & -43 & 9.4 \mathrm{E}-04\end{array}$ $074-61 \quad 6.0 \mathrm{E}-04$ $\begin{array}{lll}065 & -62 & 8.8 \mathrm{E}-04\end{array}$ $056-32 \quad 1.1 \mathrm{E}-03$ $031-48 \quad 1.0 \mathrm{E}-03$

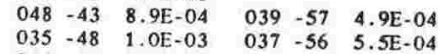

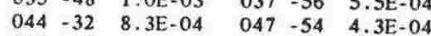
$039-46 \quad 1.1 \mathrm{E}-03 \quad 031-64 \quad 4.0 \mathrm{E}-04$ $\begin{array}{llllllllllll}069 & -58 & 3.4 \mathrm{E}-04 & 076 & -38 & 3.0 \mathrm{E}-04 & 061 & -48 & 1.2 \mathrm{E}-04^{*} & 009 & -38 & 4.2 \mathrm{E}-05\end{array}$

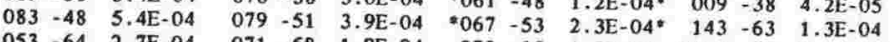

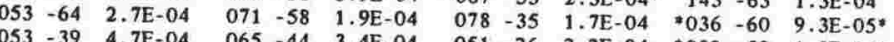
$\begin{array}{llllllllllll}073 & -83 & 6.7 \mathrm{E}-04 & * 063 & -84 & 5.6 \mathrm{E}-04 * & 055 & -81 & 4.4 \mathrm{E}-04 & 009 & -80 & 3.0 \mathrm{E}-04\end{array}$

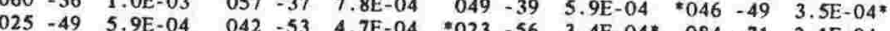

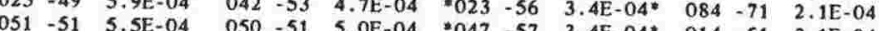

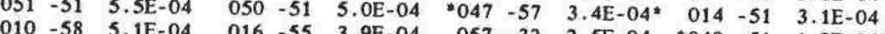

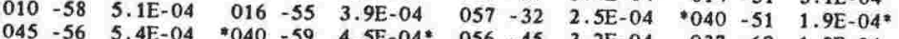
$\begin{array}{llllllllllll}045 & -56 & 5.4 \mathrm{E}-04 & * 040 & -59 & 4.5 \mathrm{E}-04 * & 056 & -45 & 3.2 \mathrm{E}-04 & 037 & -69 & 1.8 \mathrm{E}-04\end{array}$ $\begin{array}{llllllllllll}050 & -42 & 3.7 \mathrm{E}-04 & 068 & -44 & 2.7 \mathrm{E}-04 & 047 & -46 & 2.0 \mathrm{E}-04 & * 041 & -54 & 1.7 \mathrm{E}-04^{*} \\ 061 & -42 & 1.4 \mathrm{E}-03 & 061 & -44 & 1.0 \mathrm{E}-03 & 063 & -46 & 6.9 \mathrm{E}-04 & * 051 & -53 & 2.8 \mathrm{E}-04^{*}\end{array}$ $\begin{array}{llllllllllll}010 & -68 & 4.1 \mathrm{E}-04 & 003 & -66 & 3.0 \mathrm{E}-04 * & 052 & -69 & 1.7 \mathrm{E}-04 & 001 & -58 & 1.5 \mathrm{E}-04\end{array}$ $\begin{array}{llllllllllll}042 & -26 & 4.8 \mathrm{E}-04 & 047 & -33 & 3.5 \mathrm{E}-04 & 028 & -40 & 2.9 \mathrm{E}-04 & * 031 & -54 & 2.2 \mathrm{E}-04 \\ 032 & -46 & 3.5 \mathrm{E}-04 & 024 & -52 & 2 & \end{array}$

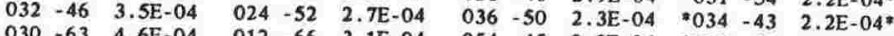

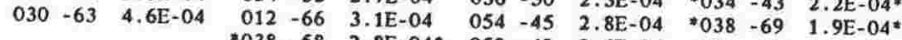

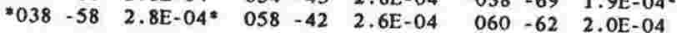




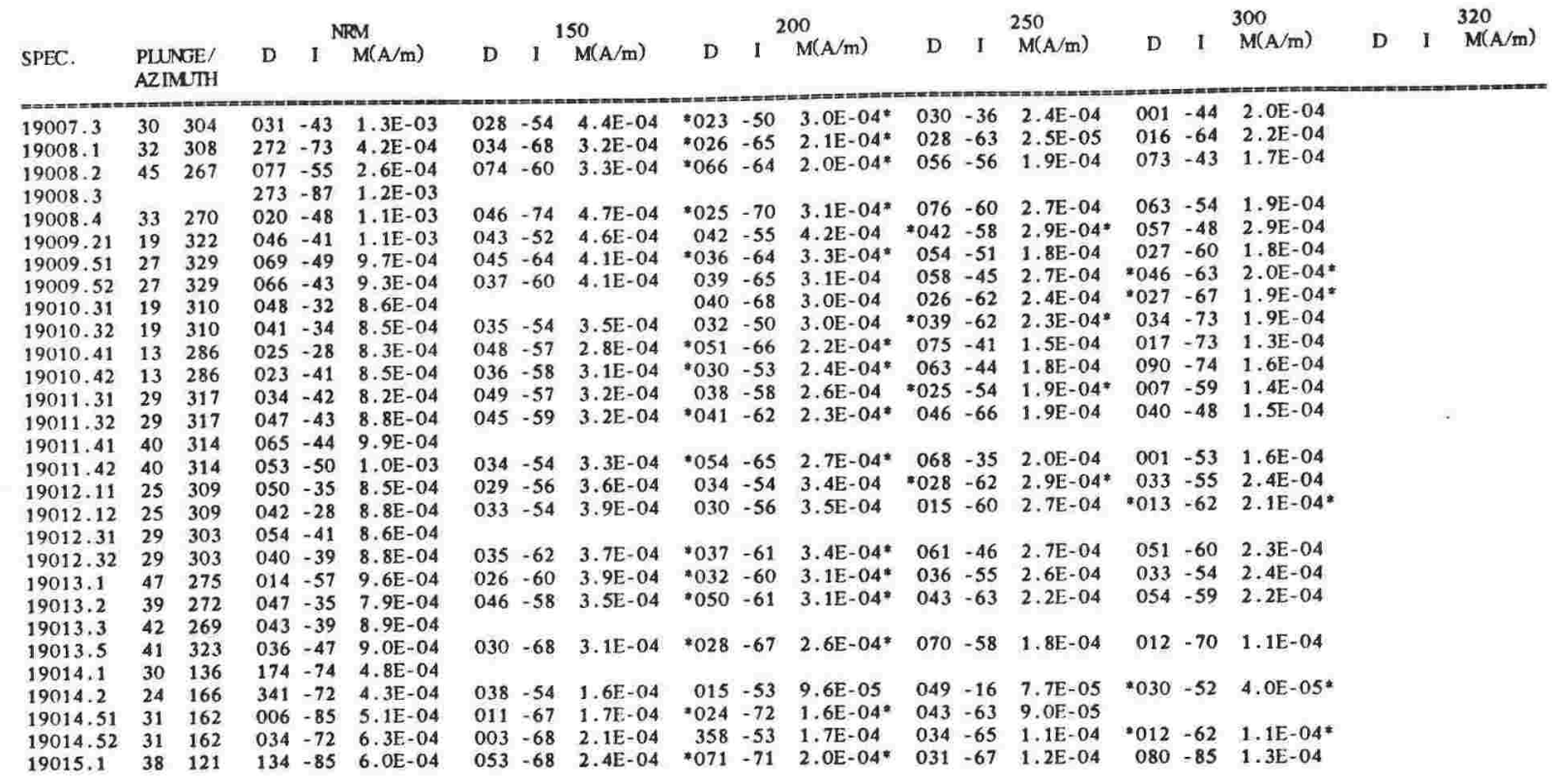

$\begin{array}{llllll}19015.2 & 54 & 130 & 055 & -67 & 7.6 \mathrm{E}-04 \\ 19015.4 & 60 & 095 & 085 & -81 & 8.4 \mathrm{E}-04 \\ 19015.5 & 55 & 144 & 092 & -64 & 8.6 \mathrm{E}-04 \\ 19016.1 & 30 & 143 & 258 & -82 & 4.6 \mathrm{E}-04 \\ 19016.3 & 29 & 140 & 223 & -77 & 4.6 \mathrm{E}-04 \\ 19016.4 & 20 & 122 & 156 & -73 & 4.2 \mathrm{E}-04 \\ 19016.5 & 27 & 110 & 207 & -78 & 6.1 \mathrm{E}-04 \\ 19017.1 & 40 & 137 & 109 & -84 & 6.5 \mathrm{E}-04 \\ 19017.2 & 25 & 111 & 115 & -72 & 7.1 \mathrm{E}-04 \\ 19017.3 & 29 & 105 & 111 & -69 & 6.3 \mathrm{E}-04 \\ 19017.4 & 34 & 122 & 113 & -74 & 5.6 \mathrm{E}-04 \\ 19018.1 & 37 & 140 & 254 & -39 & 7.9 \mathrm{E}-04 \\ 19018.2 & 29 & 151 & 182 & -48 & 5.5 \mathrm{E}-04 \\ 19018.3 & 36 & 093 & 139 & -71 & 5.7 \mathrm{E}-04 \\ 19018.4 & 34 & 120 & 189 & -27 & 2.7 \mathrm{E}-04 \\ 19019.2 & 32 & 098 & 112 & -29 & 2.3 \mathrm{E}-04 \\ 19019.3 & 23 & 086 & 171 & -82 & 3.2 \mathrm{E}-04 \\ 19019.4 & 21 & 093 & 150 & -53 & 2.2 \mathrm{E}-04 \\ 19020.11 & 14 & 208 & 080 & -80 & 3.2 \mathrm{E}-04 \\ 19020.12 & 14 & 208 & 025 & -67 & 2.7 \mathrm{E}-04 \\ 19020.21 & 19 & 129 & 217 & -72 & 3.1 \mathrm{E}-04 \\ 19020.22 & 19 & 129 & 152 & -73 & 2.9 \mathrm{E}-04 \\ 19021.1 & 43 & 168 & 041 & -70 & 3.3 \mathrm{E}-04 \\ 19021.4 & 36 & 100 & 091 & -66 & 3.1 \mathrm{E}-04 \\ 19021.51 & 39 & 186 & 339 & -81 & 3.6 \mathrm{E}-04 \\ 19021.52 & 39 & 186 & 084 & -82 & 3.5 \mathrm{E}-04 \\ 19022.21 & 38 & 125 & 090 & -12 & 1.2 \mathrm{E}-03 \\ 19022.22 & 38 & 125 & 095 & -10 & 7.8 \mathrm{E}-04 \\ 19022.31 & 24 & 173 & 098 & -41 & 9.0 \mathrm{E}-04 \\ 19022.32 & 24 & 173 & 100 & -62 & 4.2 \mathrm{E}-04 \\ 19023.21 & 37 & 325 & 311 & -52 & 7.0 \mathrm{E}-04 \\ 19023.22 & 37 & 325 & 029 & -51 & 4.8 \mathrm{E}-04 \\ 19023.41 & 47 & 342 & 071 & -28 & 3.7 \mathrm{E}-04\end{array}$

$\begin{array}{llllllllllll}054 & -66 & 3.0 \mathrm{E}-04 & 040 & -63 & 2.2 \mathrm{E}-04 & * 043 & -65 & 1.8 \mathrm{E}-04 & 359 & -75 & 1.5 \mathrm{E}-04\end{array}$ $\begin{array}{llllllllllll}083 & -67 & 2.4 \mathrm{E}-04 & * 084 & -71 & 2.5 \mathrm{E}-04 * & 062 & -47 & 1.4 \mathrm{E}-04 & 099 & -57 & 1.5 \mathrm{E}-04\end{array}$ $\begin{array}{llllllllllll}060 & -74 & 2.5 E-04 & * 092 & -69 & 1.5 E-04 * & 015 & -71 & 1.3 E-04 & 342 & -65 & 1.5 E-04\end{array}$ $\begin{array}{llllllllllll}015 & -71 & 2.2 \mathrm{E}-04 & 077 & -77 & 1.7 \mathrm{E}-04 & 031 & -78 & 1.1 \mathrm{E}-04 * & 079 & -57 & 7.3 \mathrm{E}-05\end{array}$ $\begin{array}{llllllllllll}017 & -61 & 1.7 \mathrm{E}-04 & 037 & -65 & 1.5 \mathrm{E}-04 & 077 & -61 & 1.1 \mathrm{E}-04 & * 046 & -60 & 9.0 \mathrm{E}-05^{*}\end{array}$

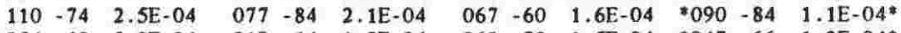
$\begin{array}{lllllllllllll}054 & -68 & 3.0 \mathrm{E}-04 & 019 & -64 & 1.8 \mathrm{E}-04 & 060 & -73 & 1.5 \mathrm{E}-04 & * 047 & -66 & 1.2 \mathrm{E}-04^{*} \\ 070 & -79 & 3 & \mathrm{E}-04 & 084 & -88 & 2.9 \mathrm{E}-04 & 035 & -65 & 1.9 \mathrm{E}-04 & * 019 & -71 & 1.5 \mathrm{E}-04^{*}\end{array}$ $\begin{array}{lllllllll}040 & -63 & 1.9 \mathrm{E}-04 & * 031 & -61 & 1.6 \mathrm{E}-04^{*} & 058 & -57 & 1.0 \mathrm{E}-04\end{array}$

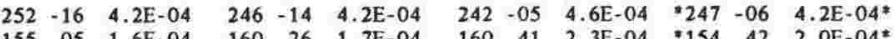

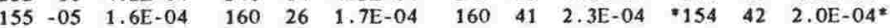
$239 \quad 55 \quad 1.8 \mathrm{E}-04 \quad 256 \quad 52 \quad 2.2 \mathrm{E}-04=250 \quad 38 \quad 2.5 \mathrm{E}-04 \quad 274 \quad 60 \quad 1.4 \mathrm{E}-04$

$\begin{array}{llllllllllll}108 & -47 & 1.2 \mathrm{E}-04 & 104 & -54 & 7.0 \mathrm{E}-05 & 128 & -43 & 4.5 \mathrm{E}-05 & * 142 & -61 & 1.6 \mathrm{E}-05 *\end{array}$ $\begin{array}{llllllllllll}097 & -45 & 8.3 \mathrm{E}-05 & 098 & -53 & 5.7 \mathrm{E}-05 * & 082 & -55 & 4.5 \mathrm{E}-05 & 349 & -46 & 4.1 \mathrm{E}-05\end{array}$

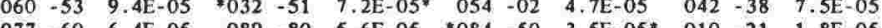
$\begin{array}{rrrrrrrrrrrr}077 & -60 & 6.4 \mathrm{E}-05 & 089 & -80 & 5.6 \mathrm{E}-05 & 084 & -50 & 3.5 \mathrm{E}-05^{*} & 010 & -21 & 1.8 \mathrm{E}-05 \\ 077 & -35 & 1.1 \mathrm{E}-04 & 074 & -53 & 8.0 \mathrm{E}-05 & 075 & -41 & 5.6 \mathrm{E}-05 & * 067 & -18 & 2.5 \mathrm{E}-05 *\end{array}$

$052-71 \quad 1.4 \mathrm{E}-04 \quad 073-74 \quad 1.1 \mathrm{E}-04 * 071 \quad-72 \quad 4.5 \mathrm{E}-05 \quad 066-64 \quad 5.8 \mathrm{E}-05$ $\begin{array}{llllllllllll}088 & -71 & 1.1 \mathrm{E}-04 & 128 & -65 & 1.0 \mathrm{E}-04 & * 122 & -65 & 4.9 \mathrm{E}-05^{*} & 140 & -58 & 4.6 \mathrm{E}-05\end{array}$ $\begin{array}{lllllllllllll}086 & -05 & 1.1 \mathrm{E}-03 & 085 & 01 & 8.4 \mathrm{E}-04 & * 084 & -02 & 4.4 \mathrm{E}-04 * & 079 & 01 & 3.3 \mathrm{E}-04\end{array}$ $\begin{array}{rrrrrrrrrrrr}088 & 04 & 6.4 \mathrm{E}-04 & 095 & 06 & 5.0 \mathrm{E}-04 & * 097 & 04 & 2.6 \mathrm{E}-04^{*} & 095 & 15 & 1.6 \mathrm{E}-04 \\ 097 & -23 & 5.8 \mathrm{E}-04 & 091 & -23 & 4.0 \mathrm{E}-04 & 064 & -42 & 1.3 \mathrm{E}-04 & =089 & -29 & 5.8 \mathrm{E}-05 *\end{array}$

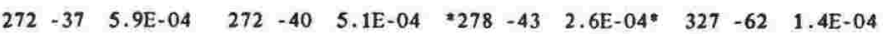

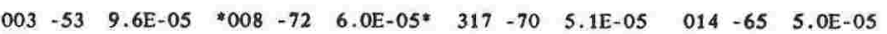

$\begin{array}{llllll}19023.42 & 47 & 342 & 057 & -37 & 3.7 \mathrm{E}-04\end{array}$ $\begin{array}{llllll}19024.21 & 33 & 323 & 044 & -33 & 4.7 \mathrm{E}-04\end{array}$ $\begin{array}{llllll}19024.22 & 33 & 323 & 057 & -20 & 5.5 E-04\end{array}$ $\begin{array}{llllll}19024.31 & 40 & 298 & 042 & -39 & 4.6 \mathrm{E}-04\end{array}$ $\begin{array}{llllll}19024.32 & 40 & 298 & 336 & -41 & 3.7 \mathrm{E}-04\end{array}$ $\begin{array}{lllllll}19025.2 & 41 & 288 & 038 & -42 & 4.1 \mathrm{E}-04\end{array}$ $\begin{array}{llllll}19025.3 & 39 & 317 & 048 & -36 & 4.5 \mathrm{E}-04\end{array}$ $\begin{array}{llllll}19025.41 & 39 & 310 & 058 & -30 & 4.6 \mathrm{E}-04\end{array}$ $\begin{array}{llllll}19025.42 & 39 & 310 & 036 & -37 & 4.2 \mathrm{E}-04\end{array}$ $\begin{array}{llllll}19026.41 & 38 & 265 & 332 & -05 & 3.2 \mathrm{E}-04\end{array}$ $\begin{array}{lllllll}19026.42 & 38 & 365 & 163 & 26 & 6.9 \mathrm{E}-04\end{array}$ $\begin{array}{llllll}19026.51 & 41 & 268 & 346 & -44 & 2.1 E-04\end{array}$ $\begin{array}{llllrl}19026.52 & 41 & 268 & 041 & 35 & 2.5 E-04\end{array}$ $\begin{array}{llllll}19027.1 & 30 & 252 & 338 & 44 & 5.6 \mathrm{E}-04\end{array}$ $\begin{array}{llllll}19027.4 & 20 & 235 & 007 & 65 & 4.6 \mathrm{E}-04\end{array}$ $\begin{array}{llllll}19027.5 & 38 & 284 & 041 & 03 & 2.3 \mathrm{E}-04\end{array}$ $\begin{array}{lllllll}19028.11 & 31 & 271 & 085 & -18 & 3.4 \mathrm{E}-04\end{array}$ $\begin{array}{lllllll}19028.12 & 31 & 271 & 262 & 41 & 2.8 \mathrm{E}-04 \\ 19028.51 & 33 & 312 & 111 & 25 & 5.3 \mathrm{E}-04\end{array}$ $\begin{array}{llllll}19028.51 & 33 & 312 & 111 & 25 & 5.3 \mathrm{E}-04 \\ 19028.52 & 33 & 312 & 359 & 53 & 5.5 \mathrm{E}-04\end{array}$ $\begin{array}{rrrrrr}19028.52 & 33 & 312 & 359 & 53 & 5.5 \mathrm{E}-04 \\ 19029.21 & 22 & 273 & 350 & -30 & 7.8 \mathrm{E}-04\end{array}$ $\begin{array}{llllll}19029.22 & 22 & 273 & 020 & -23 & 7.1 \mathrm{E}-0\end{array}$ $\begin{array}{llllll}19029.3 & 40 & 277 & 041 & -31 & 4.0 \mathrm{E}-0\end{array}$ $\begin{array}{llllll}19029.4 & 43 & 287 & 183 & -05 & 1.7 E-04\end{array}$ $\begin{array}{llllll}19030.1 & 27 & 296 & 029 & -22 & 5.0 \mathrm{E}-04\end{array}$ $\begin{array}{lllllll}19030.3 & 26 & 291 & 017 & -34 & 4.5 E-04\end{array}$ $\begin{array}{lllllll}19030.51 & 30 & 332 & 044 & -25 & 5.0 \mathrm{E}-04\end{array}$ $\begin{array}{llllll}19030.52 & 30 & 332 & 039 & -22 & 4.9 \mathrm{E}-04\end{array}$ $\begin{array}{llllll}19031.1 & 45 & 228 & 327 & -54 & 4.6 \mathrm{E}-04\end{array}$ $\begin{array}{llllll}19031.2 & 44 & 295 & 040 & -36 & 4.8 \mathrm{E}-04\end{array}$ $\begin{array}{llllll}19031.3 & 35 & 331 & 076 & -28 & 4.7 \mathrm{E}-04\end{array}$ $\begin{array}{lllllll}19031.4 & 22 & 334 & 047 & -20 & 4.9 \mathrm{E}-04 \\ 19032.2 & 44 & 283 & 022 & -28 & 3.5 \mathrm{E}-04\end{array}$

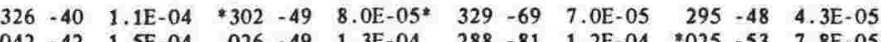
$\begin{array}{rrrrrrrrrrrr}042 & -42 & 1.5 \mathrm{E}-04 & 026 & -49 & 1.3 \mathrm{E}-04 & 288 & -81 & 1.2 \mathrm{E}-04 & * 025 & -53 & 7.8 \mathrm{E}-05 \\ 071 & -30 & 1.5 \mathrm{E}-04 & 064 & -28 & 1.3 \mathrm{E}-05 & *_{0} 073 & -11 & 8.6 \mathrm{E}-05^{*} & 081 & 01 & 6.0 \mathrm{E}-05\end{array}$ $\begin{array}{rrrrrlrrrrrr}071 & -30 & 1.5 \mathrm{E}-04 & 064 & -28 & 1.3 \mathrm{E}-05 & { }^{*} 073 & -11 & 8.6 \mathrm{E}-05^{*} & 081 & 01 & 6.0 \mathrm{E}-05 \\ 020 & -73 & 1.4 \mathrm{E}-04 & * 350 & -72 & 1.0 \mathrm{E}-04^{*} & 291 & -87 & 7.1 \mathrm{E}-05 & 327 & -76 & 4.6 \mathrm{E}-05\end{array}$

$\begin{array}{llllllllllll}045 & -60 & 9.6 \mathrm{E}-05 & 045 & -51 & 5.7 \mathrm{E}-05 & * 056 & -63 & 4.0 \mathrm{E}-05^{*} & 010 & -62 & 1.5 \mathrm{E}-05\end{array}$ $\begin{array}{llllllllllll}062 & -51 & 1.7 \mathrm{E}-04 & 045 & -57 & 1.5 \mathrm{E}-04 & * 073 & -53 & 6.2 \mathrm{E}-05^{*} & 110 & -78 & 5.4 \mathrm{E}-05 \\ 052 & -58 & 1.1 \mathrm{E}-04 & 022 & -62 & 1.0 \mathrm{E}-04 & 039 & -55 & 6.1 \mathrm{E}-05 & * 045 & -69 & 3.9 \mathrm{E}-05\end{array}$

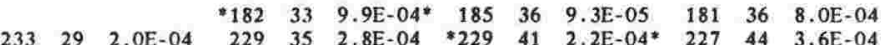

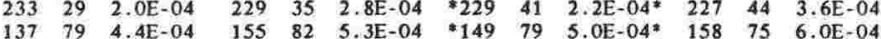
$\begin{array}{llllllllllll}137 & 79 & 4.4 \mathrm{E}-04 & 155 & 82 & 5.3 \mathrm{E}-04 & 149 & 79 & 5.0 \mathrm{E}-04 * & 158 & 75 & 6.0 \mathrm{E}-04 \\ 327 & 78 & 6.6 \mathrm{E}-04 & 304 & 76 & 7.1 \mathrm{E}-04 & 314 & 77 & 6.6 \mathrm{E}-04 * & 323 & 73 & 7.1 \mathrm{E}-04\end{array}$ $\begin{array}{llllllllllll}327 & 78 & 6.6 \mathrm{E}-04 & 304 & 76 & 7.1 \mathrm{E}-04 & 314 & 77 & 6.6 \mathrm{E}-04 * & 323 & 73 & 7.1 \mathrm{E}-04\end{array}$ $\begin{array}{lllllllllllll}139 & 85 & 4.9 \mathrm{E}-04 & * 116 & 79 & 5.3 \mathrm{E}-04^{*} & 258 & 69 & 5.4 \mathrm{E}-04 & 151 & 79 & 4.3 \mathrm{E}-04\end{array}$

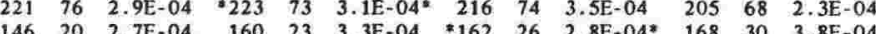

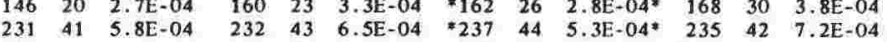
$\begin{array}{rrrrrrrrrrrr}231 & 41 & 5.8 \mathrm{E}-04 & 232 & 43 & 6.5 \mathrm{E}-04 & * 237 & 44 & 5.3 \mathrm{E}-04 * & 235 & 42 & 7.2 \mathrm{E}-04 \\ 151 & 48 & 5.4 \mathrm{E}-04 & 160 & 49 & 5.7 \mathrm{E}-04 & 169 & 54 & 6.1 \mathrm{E}-04 & * 166 & 50 & 5.1 \mathrm{E}-04^{*}\end{array}$ $\begin{array}{rrrrrrrrrrrr}151 & 48 & 5.4 \mathrm{E}-04 & 160 & 49 & 5.7 \mathrm{E}-04 & 169 & 54 & 6.1 \mathrm{E}-04 & * 166 & 50 & 5.1 \mathrm{E}-04 \\ 276 & 62 & 6.6 \mathrm{E}-04 & 285 & 61 & 7.1 \mathrm{E}-04 & * 288 & 59 & 5.8 \mathrm{E}-04^{*} & 300 & 56 & 4.7 \mathrm{E}-04\end{array}$ $\begin{array}{rrrrrrrrrrrr}276 & 62 & 6.6 \mathrm{E}-04 & 285 & 61 & 7.1 \mathrm{E}-04 & * 288 & 59 & 5.8 \mathrm{E}-04 * & 300 & 56 & 4.7 \mathrm{E}-04 \\ 346 & -24 & 4.5 \mathrm{E}-04 & 020 & -08 & 3.6 \mathrm{E}-04 & 022 & 02 & 1.1 \mathrm{E}-04 & * 301 & 16 & 3.6 \mathrm{E}-05^{*}\end{array}$

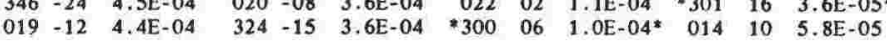

$\begin{array}{llllllllllll}178 & -33 & 5.0 \mathrm{E}-05 & 198 & 09 & 4.6 \mathrm{E}-05 & 211 & 18 & 4.9 \mathrm{E}-05 & * 216 & 42 & 5.0 \mathrm{E}-05\end{array}$

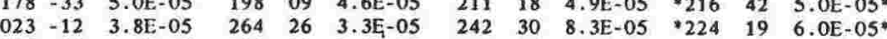
$\begin{array}{llllllllllll}233 & 24 & 6.1 \mathrm{E}-05 & 196 & 33 & 8.2 \mathrm{E}-05 & 188 & 16 & 1.2 \mathrm{E}-04 & * 194 & 28 & 9.7 \mathrm{E}-05\end{array}$ $\begin{array}{lllllllllllll}031 & -21 & 7.8 \mathrm{E}-05 & 011 & 17 & 2.1 \mathrm{E}-05 & 112 & 76 & 6.2 \mathrm{E}-05 & -257 & 48 & 7.7 \mathrm{E}-05 *\end{array}$

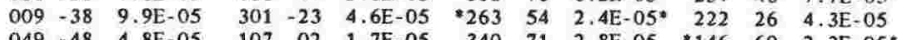

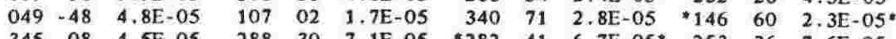
$\begin{array}{llllllllllll}345 & 08 & 4.5 E-05 & 288 & 30 & 7.1 \mathrm{E}-05 & * 282 & 41 & 6.7 \mathrm{E}-05 * & 253 & 36 & 7.6 \mathrm{E}-05\end{array}$ $\begin{array}{rrrlllllllll}131 & -07 & 5.7 \mathrm{E}-05 & 162 & 20 & 5.2 \mathrm{E}-05 & 179 & 45 & 5.4 \mathrm{E}-05 & * 177 & 47 & 4.7 \mathrm{E}-05 \\ 066 & 61 & 3.0 \mathrm{E}-05 & 204 & 75 & 5.8 \mathrm{E}-05 & 213 & 47 & 7.5 \mathrm{E}-05 & =223 & 41 & 7.8 \mathrm{E}-05\end{array}$ $\begin{array}{llllllllllll}066 & 61 & 3.0 \mathrm{E}-05 & 204 & 75 & 5.8 \mathrm{E}-05 & 213 & 47 & 7.5 \mathrm{E}-05 & * 223 & 41 & 7.8 \mathrm{E}-05^{*} \\ 294 & 33 & 9.3 \mathrm{E}-05 & 263 & 28 & 1.4 \mathrm{E}-04 & 279 & 32 & 1.5 \mathrm{E}-04 & * 270 & 34 & 1.8 \mathrm{E}-04^{*}\end{array}$ 


\begin{tabular}{|c|c|c|c|c|c|c|c|c|c|c|c|c|c|c|c|c|c|c|c|}
\hline & & & & IRM & & & 50 & & & 00 & & & 250 & & & 300 & & & 320 \\
\hline SPEC. & $\begin{array}{l}\text { PLUNGE/ } \\
\text { AZIMUTH }\end{array}$ & D & $\mathbf{I}$ & $\mathrm{M}(\mathrm{A} / \mathrm{m})$ & D & 1 & $\mathrm{M}(\mathrm{A} / \mathrm{m})$ & D & 1 & $\mathrm{M}(\mathrm{A} / \mathrm{m})$ & D & I & $M(A / m)$ & D & I & $\mathrm{M}(\mathrm{A} / \mathrm{m})$ & D & I & $\mathrm{M}(\mathrm{A} / \mathrm{m})$ \\
\hline
\end{tabular}

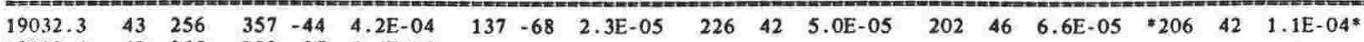

$\begin{array}{llllll}19032.4 & 40 & 265 & 008 & -35 & 4.4 \mathrm{E}-04\end{array}$

$\begin{array}{lllllll}19032.5 & 36 & 312 & 070 & -25 & 6.1 \mathrm{E}-04\end{array}$

$\begin{array}{llllll}19033.11 & 43 & 270 & 033 & -36 & 4.7 \mathrm{E}-04\end{array}$

$\begin{array}{llllll}19033.12 & 43 & 270 & 025 & -35 & 5.0 \mathrm{E}-04\end{array}$

$19033.51 \quad 40 \quad 275 \quad 051-27 \quad 4.9 \mathrm{E}-04$

$\begin{array}{lllllll}19033.52 & 40 & 275 & 041 & -34 & 5.1 E-04\end{array}$

$\begin{array}{llllll}19034.2 & 24 & 057 & 107 & -42 & 4.3 \mathrm{E}-04\end{array}$

$\begin{array}{llllll}19034.2 & 24 & 057 & 107 & -42 & 4.3 \mathrm{E}-04 \\ 19034.3 & 35 & 066 & 099 & -42 & 4.8 \mathrm{E}-04\end{array}$

$\begin{array}{llllll}19034.3 & 35 & 066 & 099 & -42 & 4.8 \mathrm{E}-04 \\ 19034.5 & 32 & 075 & 128 & -44 & 3.7 \mathrm{E}-04\end{array}$

$\begin{array}{llllll}19034.5 & 32 & 075 & 128 & -44 & 3.7 \mathrm{E}-04 \\ 19035.21 & 36 & 048 & 096 & -19 & 3.6 \mathrm{E}-04\end{array}$

$\begin{array}{llllll}19035.21 & 36 & 048 & 096 & -19 & 3.6 \mathrm{E}-04 \\ 19035.22 & 36 & 048 & 130 & -07 & 4.5 \mathrm{E}-04\end{array}$

$\begin{array}{llllll}19035.22 & 36 & 048 & 130 & -07 & 4.5 \mathrm{E}-04 \\ 19035.41 & 38 & 033 & 099 & -52 & 3.0 \mathrm{E}-04\end{array}$

$\begin{array}{llllll}19035.42 & 38 & 033 & 126 & -38 & 5.3 E-04\end{array}$

$\begin{array}{llllll}19036.11 & 46 & 077 & 113 & -29 & 3.9 \mathrm{E}-04\end{array}$

$\begin{array}{llllll}190.36 .12 & 46 & 077 & 136 & -34 & 3.6 \mathrm{E}-04\end{array}$

$\begin{array}{llllll}19036.21 & 46 & 034 & 105 & -43 & 3.6 \mathrm{E}-04 \\ 19036.22 & 46 & 034 & 111 & -17 & 3.6 \mathrm{E}-04\end{array}$

$\begin{array}{llllll}19036.22 & 46 & 034 & 111 & -17 & 3.6 \mathrm{E}-04 \\ 19037.11 & 21 & 056 & 138 & -22 & 2.0 \mathrm{E}-04\end{array}$

$\begin{array}{llllll}19037.11 & 21 & 056 & 138 & -22 & 2.0 \mathrm{E}-04 \\ 19037.12 & 21 & 056 & 130 & -32 & 2.6 \mathrm{E}-04\end{array}$

$\begin{array}{llllll}19037.12 & 21 & 056 & 130 & -32 & 2.6 \mathrm{E}-04 \\ 19037.41 & 35 & 029 & 101 & -24 & 3.2 \mathrm{E}-04\end{array}$

$\begin{array}{llllll}19037.42 & 35 & 029 & 077 & -22 & 4.5 \mathrm{E}-04\end{array}$

$\begin{array}{llllll}19038.51 & 47 & 016 & 073 & -34 & 4.6 \mathrm{E}-04\end{array}$

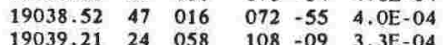

$\begin{array}{llllll}19039.21 & 24 & 058 & 108 & -09 & 3.3 \mathrm{E}-04 \\ 19039.22 & 24 & 058 & 147 & -17 & 2.7 \mathrm{E}-0\end{array}$

$\begin{array}{llllll}19039.51 & 24 & 064 & 129 & 27 & 4.7 \mathrm{E}-04\end{array}$

$19039.52 \quad 24 \quad 064 \quad 127 \quad 33 \quad 5.4 E-04$

$\begin{array}{llllll}19040.21 & 36 & 057 & 146 & 37 & 8.1 \mathrm{E}-04\end{array}$

$\begin{array}{llllllllllll}111 & -17 & 1.3 \mathrm{E}-04 & 128 & -03 & 1.1 \mathrm{E}-04 & 160 & -01 & 9.0 \mathrm{E}-05 & * 143 & 09 & 7.5 \mathrm{E}-05 *\end{array}$

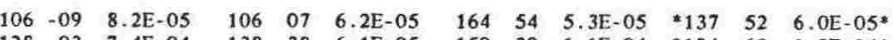
$\begin{array}{rrrrrrrrrrrr}128 & -03 & 7.4 \mathrm{E}-04 & 1.38 & 38 & 6.1 \mathrm{E}-05 & 159 & 39 & 1.1 \mathrm{E}-04 & * 184 & 60 & 1.0 \mathrm{E}-04 * \\ 117 & -42 & 4.7 \mathrm{E}-05 & 143 & -05 & 3.3 \mathrm{E}-05 & 274 & 09 & 1.9 \mathrm{E}-05 & * 245 & 25 & 3.0 \mathrm{E}-05^{*}\end{array}$ $\begin{array}{llllllllllll}154 & 35 & 5.4 \mathrm{E}-05 & 174 & 64 & 6.9 \mathrm{E}-05 & 183 & 17 & 7.6 \mathrm{E}-05 & 208 & 59 & 6.0 \mathrm{E}-05^{*} \\ 145 & 05 & 4.5 \mathrm{E}-05 & 159 & 53 & 6.9 \mathrm{E}-05 & 196 & 44 & 7.0 \mathrm{E}-05 & * 208 & 60 & 9.1 \mathrm{E}-05^{*}\end{array}$ $\begin{array}{llllllllllll}145 & 05 & 4.5 \mathrm{E}-05 & 159 & 53 & 6.9 \mathrm{E}-05 & 196 & 44 & 7.0 \mathrm{E}-05 & * 208 & 60 & 9.1 \mathrm{E}-05^{*} \\ 097 & 23 & 3.4 \mathrm{E}-05 & 084 & 78 & 5.4 \mathrm{E}-05 & * 239 & 72 & 4.9 \mathrm{E}-05^{*} & 161 & 57 & 5.5 \mathrm{E}-05\end{array}$ $13165 \quad \begin{array}{lllllllllll}1.6 \mathrm{E}-05 & 231 & 49 & 3.3 \mathrm{E}-05 & 186 & 60 & 5.4 \mathrm{E}-05 & * 209 & 59 & 4.0 \mathrm{E}-05\end{array}$

$\begin{array}{llllllllllll}021 & 46 & 9.0 \mathrm{E}-05 & 352 & 47 & 9.8 \mathrm{E}-05 & 305 & 56 & 1.3 \mathrm{E}-04 & * 311 & 53 & 1.8 \mathrm{E}-04:\end{array}$ $\begin{array}{llllllllllll}095 & 83 & 4.8 \mathrm{E}-04 & * 150 & 85 & 5.8 \mathrm{E}-04^{*} & 178 & 85 & 5.7 \mathrm{E}-04 & 137 & 81 & 3.2 \mathrm{E}-04\end{array}$ $\begin{array}{llllllllllll}171 & 50 & 5.5 E-04 & 170 & 47 & 5.2 \mathrm{E}-04 & 173 & 50 & 4.5 \mathrm{E}-04 & * 172 & 49 & 4.7 \mathrm{E}-04\end{array}$

$\begin{array}{llllrl}19040.22 & 36 & 057 & 156 & 21 & 4.8 \mathrm{E}-04 \\ 19040.4 & 36 & 026 & 146 & -02 & 4.1 \mathrm{E}-04 \\ 19040.5 & 34 & 040 & 087 & 79 & 5.2 \mathrm{E}-04 \\ 19041.11 & 41 & 106 & 198 & 49 & 3.3 \mathrm{E}-03 \\ 19041.12 & 41 & 106 & 207 & 48 & 4.0 \mathrm{E}-03 \\ 19041.21 & 42 & 112 & 205 & 59 & 2.7 \mathrm{E}-03 \\ 19041.22 & 42 & 112 & 204 & 59 & 3.3 \mathrm{E}-03 \\ 19042.2 & 18 & 247 & 238 & 46 & 5.3 \mathrm{E}-03 \\ 19042.3 & 39 & 215 & 238 & 38 & 6.5 \mathrm{E}-03 \\ 19042.41 & 17 & 238 & 222 & 64 & 9.7 \mathrm{E}-03 \\ 19042.42 & 17 & 238 & 229 & 68 & 6.1 \mathrm{E}-03 \\ 19043.11 & 46 & 276 & 333 & 48 & 8.9 \mathrm{E}-03 \\ 19043.12 & 46 & 276 & 202 & 25 & 1.9 \mathrm{E}-03 \\ 19043.2 & 51 & 237 & 302 & 42 & 6.2 \mathrm{E}-03 \\ 19043.4 & 52 & 277 & 318 & 46 & 9.5 \mathrm{E}-03 \\ 19044.41 & 16 & 280 & 023 & -07 & 5.0 \mathrm{E}-04 \\ 19044.42 & 16 & 280 & 017 & -16 & 4.4 \mathrm{E}-04 \\ 19044.51 & 15 & 323 & 070 & -13 & 4.7 \mathrm{E}-04 \\ 19044.52 & 15 & 323 & 069 & -02 & 5.1 \mathrm{E}-04 \\ 19045.2 & 37 & 345 & 103 & 12 & 3.9 \mathrm{E}-04 \\ 19045.3 & 25 & 332 & 115 & 67 & 1.0 \mathrm{E}-03 \\ 19045.5 & 40 & 322 & 123 & 53 & 3.0 \mathrm{E}-04 \\ 19046.1 & 35 & 302 & 083 & -16 & 6.1 \mathrm{E}-05 \\ 19046.2 & 34 & 294 & 061 & 67 & 3.7 \mathrm{E}-04 \\ 19046.3 & 37 & 295 & 240 & 66 & 4.4 \mathrm{E}-04 \\ 19047.3 & 50 & 294 & 177 & 11 & 2.9 \mathrm{E}-04 \\ 19047.5 & 44 & 315 & 352 & 01 & 1.3 \mathrm{E}-04 \\ 19047.7 & 43 & 265 & 227 & 50 & 1.1 \mathrm{E}-03 \\ 19048.1 & 59 & 111 & 239 & 51 & 2.0 \mathrm{E}-03\end{array}$

$\begin{array}{llllll}19048.4 & 52 & 073 & 222 & 61 & 1.9 \mathrm{E}-03 \\ 19048.5 & 53 & 085 & 230 & 62 & 1.2 \mathrm{E}-03 \\ 19049.1 & 45 & 143 & 229 & 63 & 3.4 \mathrm{E}-04 \\ 19049.2 & 36 & 159 & 233 & 63 & 4.8 \mathrm{E}-04 \\ 19049.41 & 39 & 150 & 238 & 71 & 3.6 \mathrm{E}-04 \\ 19049.42 & 39 & 150 & 218 & 61 & 5.4 \mathrm{E}-04 \\ 19050.21 & 48 & 200 & 272 & 33 & 5.3 \mathrm{E}-04 \\ 1950.22 & 48 & 200 & 130 & 40 & 5.6 \mathrm{E}-04 \\ 19050.3 & 53 & 168 & 261 & 62 & 3.0 \mathrm{E}-04 \\ 19051.1 & 42 & 137 & 012 & 45 & 5.6 \mathrm{E}-04 \\ 19051.2 & 39 & 153 & 008 & 33 & 3.9 \mathrm{E}-04 \\ 19051.3 & 40 & 141 & 347 & 51 & 3.9 \mathrm{E}-04 \\ 19052.1 & 42 & 141 & 054 & 05 & 2.1 \mathrm{E}-04 \\ 19052.2 & 38 & 148 & 115 & 06 & 2.6 \mathrm{E}-04 \\ 19052.32 & 51 & 159 & 221 & 11 & 2.8 \mathrm{E}-04 \\ 19052.4 & 59 & 140 & 178 & 64 & 5.3 \mathrm{E}-04 \\ 19053.1 & 42 & 170 & 318 & 61 & 6.3 \mathrm{E}-04 \\ 19053.2 & 42 & 142 & 260 & 16 & 1.5 \mathrm{E}-04 \\ 19053.4 & 46 & 132 & 127 & 81 & 3.2 \mathrm{E}-04 \\ 19055.1 & 65 & 197 & 208 & 59 & 5.8 \mathrm{E}-04 \\ 19055.2 & 61 & 171 & 183 & 63 & 4.9 \mathrm{E}-04 \\ 19055.31 & 58 & 188 & 216 & 63 & 6.5 \mathrm{E}-04 \\ 19055.32 & 58 & 188 & 228 & 71 & 5.4 \mathrm{E}-04 \\ 19056.2 & 38 & 298 & 209 & 58 & 3.7 \mathrm{E}-03 \\ 19056.3 & 67 & 272 & 230 & 57 & 6.1 \mathrm{E}-03 \\ 19056.4 & 53 & 027 & 214 & 52 & 6.3 \mathrm{E}-03 \\ 19057.11 & 39 & 332 & 301 & 79 & 8.2 \mathrm{E}-04 \\ 19057.12 & 39 & 332 & 233 & 64 & 1.0 \mathrm{E}-03 \\ 19057.4 & 37 & 316 & 175 & 44 & 7.7 \mathrm{E}-04 \\ 19058.1 & 44 & 025 & 097 & 55 & 6.0 \mathrm{E}-04 \\ 19058.2 & 40 & 049 & 153 & 73 & 1.0 \mathrm{E}-03 \\ 19058.3 & 34 & 043 & 271 & 49 & 1.1 \mathrm{E}-03 \\ 19059.1 & 34 & 101 & 234 & \mathbf{7 5} & 2.0 \mathrm{E}-04\end{array}$

$\begin{array}{llllllllllll}185 & 49 & 3.9 \mathrm{E}-04 & 185 & 51 & 3.7 \mathrm{E}-04 & 200 & 45 & 3.8 \mathrm{E}-04 & * 196 & 52 & 3.4 \mathrm{E}-04\end{array}$ $\begin{array}{llllllllllll}209 & 52 & 2.8 \mathrm{E}-04 & * 220 & 55 & 2.8 \mathrm{E}-04 * & 244 & 50 & 1.7 \mathrm{E}-04 & 312 & 04 & 5.5 \mathrm{E}-05 \\ 276 & 55 & 7.0 \mathrm{E}-04 & 275 & 46 & 7.0 \mathrm{E}-04 & 274 & 40 & 5.9 \mathrm{E}-04 & 267 & 41 & 2.7 \mathrm{E}-04\end{array}$ $\begin{array}{lllllllllllll}276 & 55 & 7.0 \mathrm{E}-04 & 275 & 46 & 7.0 \mathrm{E}-04 & 274 & 40 & 5.9 \mathrm{E}-04 & =267 & 41 & 2.7 \mathrm{E}-04^{*}\end{array}$ $\begin{array}{llllllllllll}214 & 59 & 3.2 \mathrm{E}-03 & 211 & 58 & 3.2 \mathrm{E}-03 & * 212 & 63 & 2.7 \mathrm{E}-03^{*} & 211 & 61 & 2.8 \mathrm{E}-03\end{array}$ $\begin{array}{llllllllllll}214 & 58 & 3.6 \mathrm{E}-03 & 214 & 57 & 4.1 \mathrm{E}-03 & * 218 & 58 & 3.4 \mathrm{E}-03^{*} & 219 & 54 & 3.7 \mathrm{E}-03\end{array}$ $\begin{array}{llllllllllll}239 & 67 & 2.7 \mathrm{E}-03 & * 239 & 66 & 2.5 \mathrm{E}-03 * & 240 & 68 & 1.9 \mathrm{E}-03 & 251 & 63 & 1.2 \mathrm{E}-03\end{array}$ $\begin{array}{llllllllllll}231 & 70 & 3.3 \mathrm{E}-03 & * 239 & 72 & 3.1 \mathrm{E}-03 & 228 & 74 & 2.3 \mathrm{E}-03 & 221 & 77 & 1.8 \mathrm{E}-03\end{array}$ $\begin{array}{llllllllllll}249 & 62 & 5.6 \mathrm{E}-03 & 146 & -53 & 5.1 \mathrm{E}-03 & 226 & 54 & 2.8 \mathrm{E}-03 & * 231 & 54 & 1.8 \mathrm{E}-03\end{array}$ $\begin{array}{llllllllllll}236 & 46 & 6.7 \mathrm{E}-03 & * 237 & 42 & 6.0 \mathrm{E}-03^{*} & 244 & 38 & 4.3 \mathrm{E}-03 & 247 & 37 & 3.1 \mathrm{E}-03\end{array}$

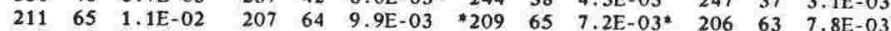

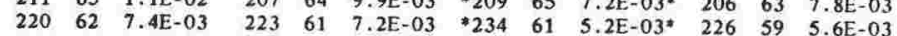

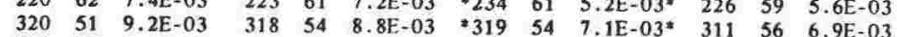

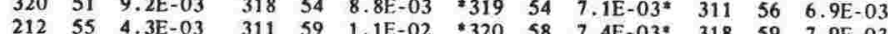

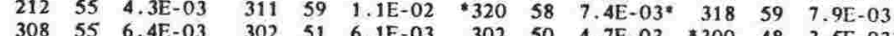

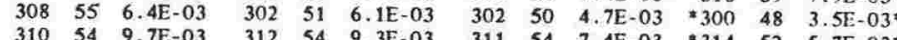
$\begin{array}{llllllllllll}310 & 54 & 9.7 \mathrm{E}-03 & 312 & 54 & 9.3 \mathrm{E}-03 & 311 & 54 & 7.4 \mathrm{E}-03 & * 314 & 52 & 5.7 \mathrm{E}-03 \\ 338 & 46 & 1.1 \mathrm{E}-04 & 326 & 54 & 1.0 \mathrm{E}-04 & 277 & 69 & 1.1 \mathrm{E}-04 & * 264 & 65 & 1.3 \mathrm{E}-04\end{array}$

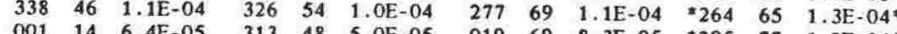
$\begin{array}{rrrrrrrrrrrr}001 & 14 & 6.4 \mathrm{E}-05 & 313 & 48 & 5.0 \mathrm{E}-05 & 019 & 69 & 8.3 \mathrm{E}-05 & * 295 & 77 & 1.2 \mathrm{E}-04^{*} \\ 104 & 75 & 6.3 \mathrm{E}-05 & =207 & 78 & 7.3 \mathrm{E}-05 & 224 & 62 & 7.7 \mathrm{E}-05 & 136 & 85 & 7.1 \mathrm{E}-05\end{array}$

$\begin{array}{llllll}201 & 37 & 2.5 \mathrm{E}-04 & 220 & 37 & 3.1 \mathrm{E}-04\end{array}$

$\begin{array}{llllllllllll}209 & 71 & 1.1 \mathrm{E}-03 & 226 & 70 & 9.2 \mathrm{E}-04 & 216 & 69 & 7.7 \mathrm{E}-04 & * 227 & 36 & 3.2 \mathrm{E}-04\end{array}$ $\begin{array}{llllllllllll}228 & 51 & 7.5 \mathrm{E}-04 & * 237 & 36 & 5.4 \mathrm{E}-04 * & 234 & 21 & 4.2 \mathrm{E}-04 & 242 & 16 & 2.7 \mathrm{E}-04\end{array}$

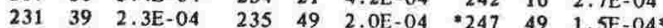
$327 \quad 85 \quad 4.3 \mathrm{E}-04 * 311 \quad 813.4 \mathrm{E}-04 \% 003 \quad 49$ 1.SE-04*

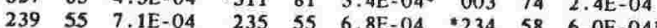

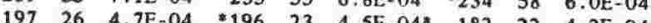

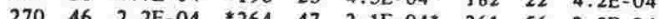

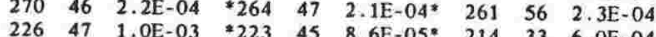
$\begin{array}{rrrrrrrrr}226 & 47 & 1.0 \mathrm{E}-03 & * 223 & 45 & 8.6 \mathrm{E}-05^{*} & 214 & 33 & 6.0 \mathrm{E}-04 \\ 236 & 51 & 1.9 \mathrm{E}-03 & 240 & 51 & 1.6 \mathrm{E}-03 & * 236 & 55 & 1.0 \mathrm{E}-03 *\end{array}$

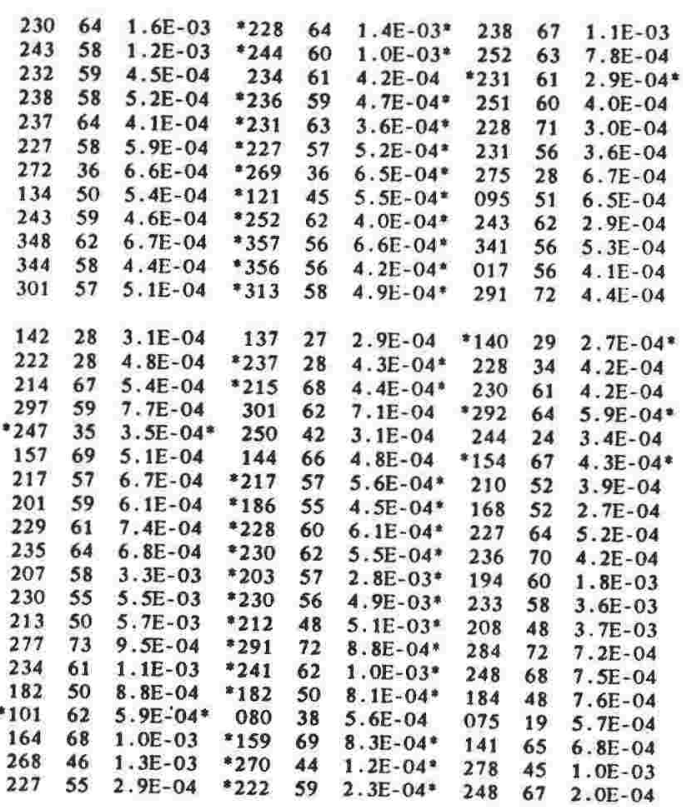




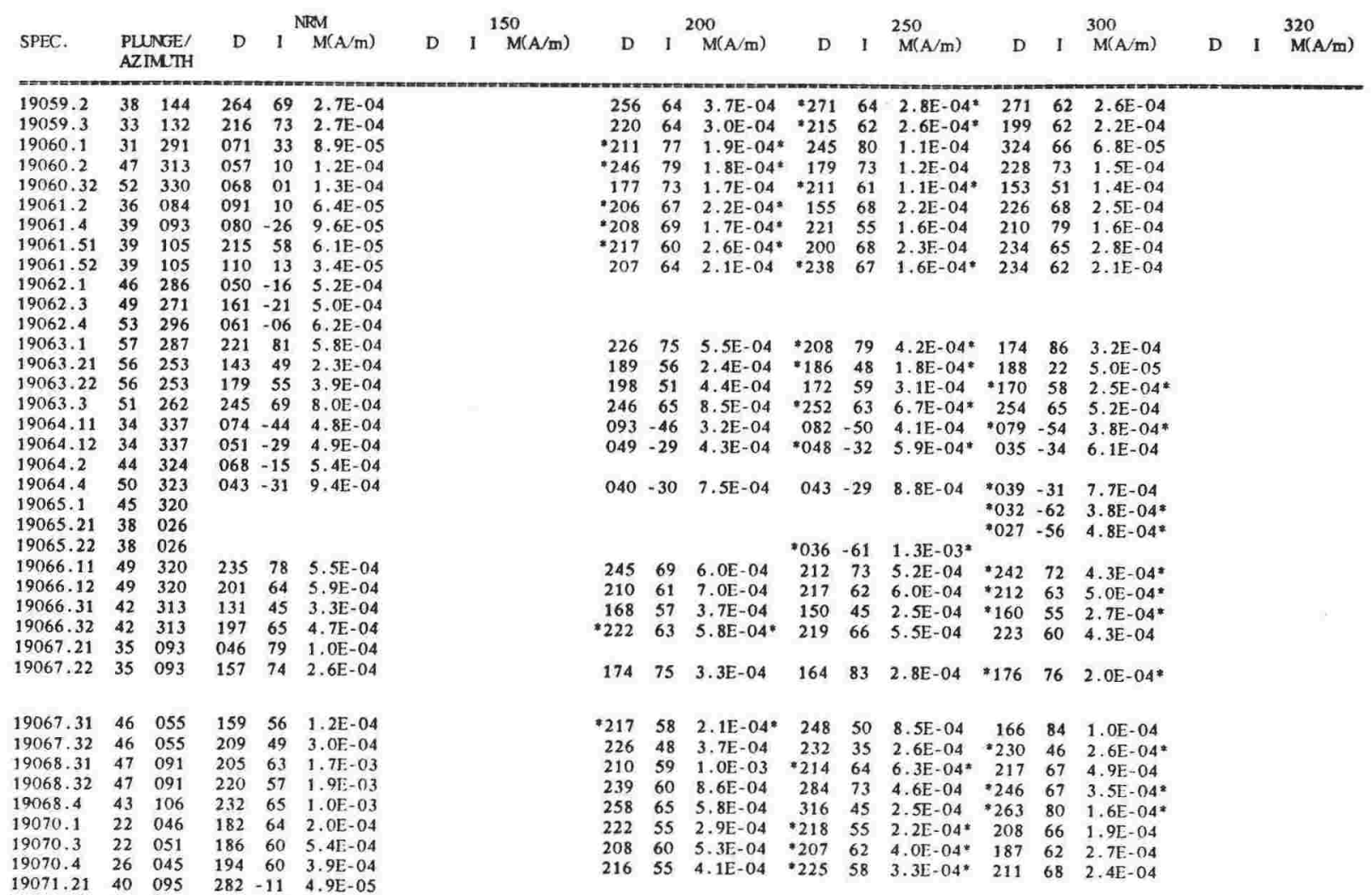

$\begin{array}{llllll}19078.4 & 59 & 300 & 198 & 68 & 2.2 \mathrm{E}-04 \\ 19079.1 & 59 & 275 & 116 & 57 & 1.1 \mathrm{E}-04 \\ 19079.2 & 63 & 273 & 090 & 69 & 1.1 \mathrm{E}-04 \\ 19079.3 & 65 & 297 & 058 & 74 & 1.3 \mathrm{E}-04 \\ 19079.41 & 69 & 292 & 104 & 63 & 1.2 \mathrm{E}-04 \\ 19079.42 & 69 & 292 & 132 & 58 & 1.5 \mathrm{E}-04 \\ 19080.1 & 48 & 196 & 071 & -36 & 8.6 \mathrm{E}-05 \\ 19080.2 & 65 & 183 & 068 & -29 & 8.5 \mathrm{E}-05 \\ 19080.4 & 68 & 190 & 075 & -42 & 9.6 \mathrm{E}-05 \\ 19080.5 & 69 & 192 & 038 & -36 & 1.0 \mathrm{E}-04 \\ 19081.21 & 66 & 164 & 041 & 77 & 9.3 \mathrm{E}-05 \\ 19081.22 & 66 & 162 & 345 & 87 & 4.2 \mathrm{E}-05 \\ 19081.32 & 52 & 188 & 040 & 22 & 1.0 \mathrm{E}-04 \\ 19082.1 & 56 & 114 & 092 & 54 & 3.6 \mathrm{E}-05 \\ 19082.2 & 63 & 134 & 105 & 68 & 3.9 \mathrm{E}-05 \\ 19082.31 & 35 & 176 & 096 & 74 & 1.0 \mathrm{E}-04 \\ 19082.42 & 34 & 177 & 117 & 88 & 8.8 \mathrm{E}-05 \\ 19083.2 & 39 & 058 & 225 & 58 & 9.0 \mathrm{E}-04 \\ 19083.3 & 41 & 070 & 221 & 56 & 1.8 \mathrm{E}-03 \\ 19083.4 & 34 & 067 & 230 & 54 & 6.3 \mathrm{E}-04 \\ 19084.1 & 32 & 090 & 176 & 63 & 3.2 \mathrm{E}-04 \\ 19084.2 & 33 & 087 & 196 & 85 & 5.4 \mathrm{E}-04 \\ 19084.4 & 33 & 100 & 054 & 17 & 3.4 \mathrm{E}-04 \\ .19085 .2 & 31 & 101 & 200 & 59 & 4.8 \mathrm{E}-04 \\ 19085.3 & 44 & 103 & 200 & 66 & 3.5 \mathrm{E}-04 \\ 19085.4 & 57 & 105 & 218 & 60 & 4.4 \mathrm{E}-04 \\ 19086.1 & 23 & 125 & 226 & 55 & 1.3 \mathrm{E}-03 \\ 19086.2 & 61 & 134 & 227 & 59 & 1.7 \mathrm{E}-03 \\ 19086.3 & 44 & 112 & 232 & 62 & 1.0 \mathrm{E}-03 \\ 19086.4 & 55 & 083 & 220 & 63 & 8.8 \mathrm{E}-04 \\ 19087.1 & 27 & 037 & 208 & 64 & 9.2 \mathrm{E}-04 \\ 19087.2 & 29 & 052 & 216 & 71 & 1.6 \mathrm{E}-03 \\ 19087.3 & 25 & 053 & 229 & 66 & 2.2 \mathrm{E}-03\end{array}$

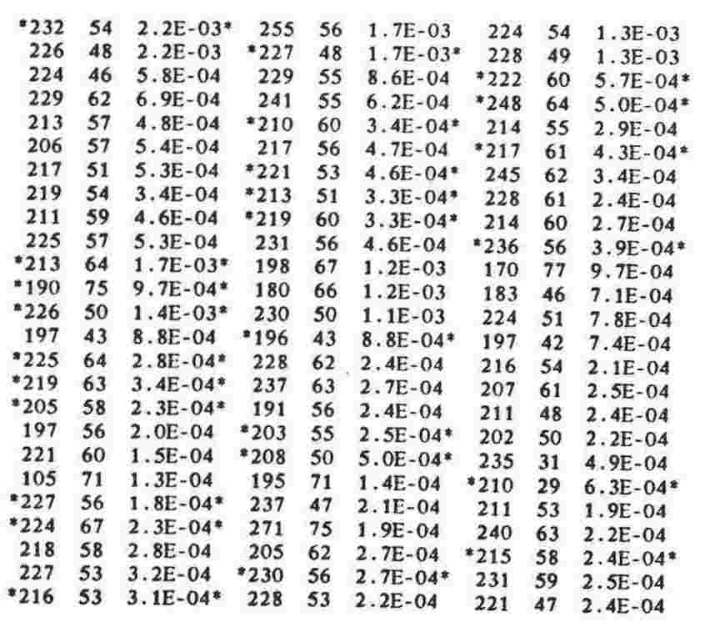

$\begin{array}{lllllllll}219 & 63 & 3.1 \mathrm{E}-04 * & 231 & 56 & 2.6 \mathrm{E}-04 & 224 & 65 & 2.5 \mathrm{E}-04\end{array}$

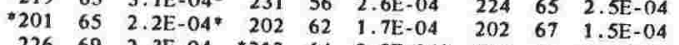
$\begin{array}{lllllllll}226 & 69 & 2.3 \mathrm{E}-04 & * 212 & 64 & 2.0 \mathrm{E}-04^{*} & 224 & 66 & 2.0 \mathrm{EE}-04 \\ 224 & 66 & 2.5 \mathrm{E}-04 & 195 & 72 & 2.04\end{array}$

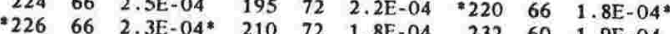
$\begin{array}{lllllllll}200 & 60 & 2.2 \mathrm{E}-04 & 219 & 53 & 1.8 \mathrm{E}-04 & 232 & 60 & 1.9 \mathrm{E}-04 \\ 210 & 62 & 1.8 \mathrm{E}-04 *\end{array}$ 20056 1.2E-04 207 47 $1.1 \mathrm{E}-04 * 199 \quad 56$ (.8E-04* *234 72 1.1E-04* $193 \quad 74$ 1.5E-04 222 61 $1.4 \mathrm{E}-04$ $\begin{array}{lllllllll}230 & 71 & 1.2 \mathrm{E}-04 & 258 & 51 & 1.5 \mathrm{E}-04 & 222 & 61 & 1.4 \mathrm{E}-04 \\ & 227 & 64 & 1.3 \mathrm{E}-04\end{array}$ $\begin{array}{lllllllll}179 & 66 & 8.3 \mathrm{E}-05 & 258 & 51 & 1.2 \mathrm{E}-04 & * 227 & 64 & 1.3 \mathrm{E}-04 * \\ 0 & 205 & 9.2 \mathrm{E}-05 & * 203 & 65 & 1.1 \mathrm{E}-04 *\end{array}$

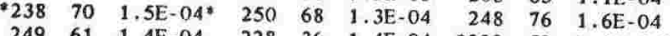
$\begin{array}{lllllllll}249 & 61 & 1.4 \mathrm{E}-04 & 228 & 36 & 1.4 \mathrm{E}-04 & * 222 & 59 & 1.4 \mathrm{E}-04 *\end{array}$ $\begin{array}{rrlllllll}298 & 82 & 1.5 \mathrm{E}-04 & 245 & 74 & 1.4 \mathrm{E}-04 & =227 & 84 & 1.7 \mathrm{E}-04 *\end{array}$

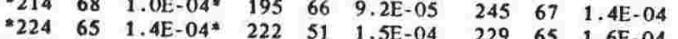
$\begin{array}{lllllllll}244 & 83 & 1.5 \mathrm{E}-04 * & 238 & 73 & 1.8 \mathrm{E}-04 & 158 & 78 & 1.7 \mathrm{E}-04\end{array}$ $\begin{array}{lllllllll}208 & 67 & 2.0 \mathrm{E}-04 & * 215 & 63 & 2.3 \mathrm{E}-04^{*} & 216 & 64 & 2.0 \mathrm{E}-04\end{array}$

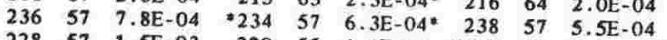
$\begin{array}{lllllllll}228 & 57 & 1.5 \mathrm{E}-03 & 220 & 55 & 1.1 \mathrm{E}-03 & * 229 & 58 & 7.5 \mathrm{E}-04^{*}\end{array}$ $\begin{array}{rrrrrlrrr}211 & 58 & 5.5 \mathrm{E}-04 & 221 & 60 & 4.4 \mathrm{E}-04 & * 216 & 59 & 3.1 \mathrm{E}-04 * \\ 210 & 71 & 3.9 \mathrm{E}-04 & * 211 & 70 & 3.4 \mathrm{E}-04^{*} & 210 & 75 & 3.0 \mathrm{E}-04 \\ 234 & 60 & 4.7 \mathrm{E}-04 & 229 & 53 & 3.8 \mathrm{E}-04 & * 233 & 51 & 3.1 \mathrm{E}-04 * \\ 224 & 56 & 1.0 \mathrm{E}-03 & 216 & 55 & 4.8 \mathrm{E}-04 & * 226 & 55 & 4.2 \mathrm{E}-04^{*} \\ 229 & 57 & 1.2 \mathrm{E}-03 & 228 & 61 & 5.7 \mathrm{E}-04 & * 232 & 59 & 4.7 \mathrm{E}-04^{*} \\ 228 & 61 & 9.0 \mathrm{E}-04 & 219 & 57 & 5.2 \mathrm{E}-04 & * 227 & 58 & 4.3 \mathrm{E}-04^{*} \\ 232 & 62 & 7.1 \mathrm{E}-04 & * 231 & 58 & 4.3 \mathrm{E}-04^{*} & 244 & 62 & 3.1 \mathrm{E}-04 \\ 217 & 60 & 8.6 \mathrm{E}-04 & 220 & 50 & 4.2 \mathrm{E}-04 & 216 & 52 & 3.2 \mathrm{E}-04 * \\ 227 & 73 & 1.3 \mathrm{E}-03 & 232 & 66 & 6.9 \mathrm{E}-04^{*} & 244 & 68 & 5.6 \mathrm{E}-04 \\ 234 & 60 & 1.7 \mathrm{E}-03 & * 237 & 57 & 8.2 \mathrm{E}-04^{*} & 238 & 59 & 7.5 \mathrm{E}-04\end{array}$ 


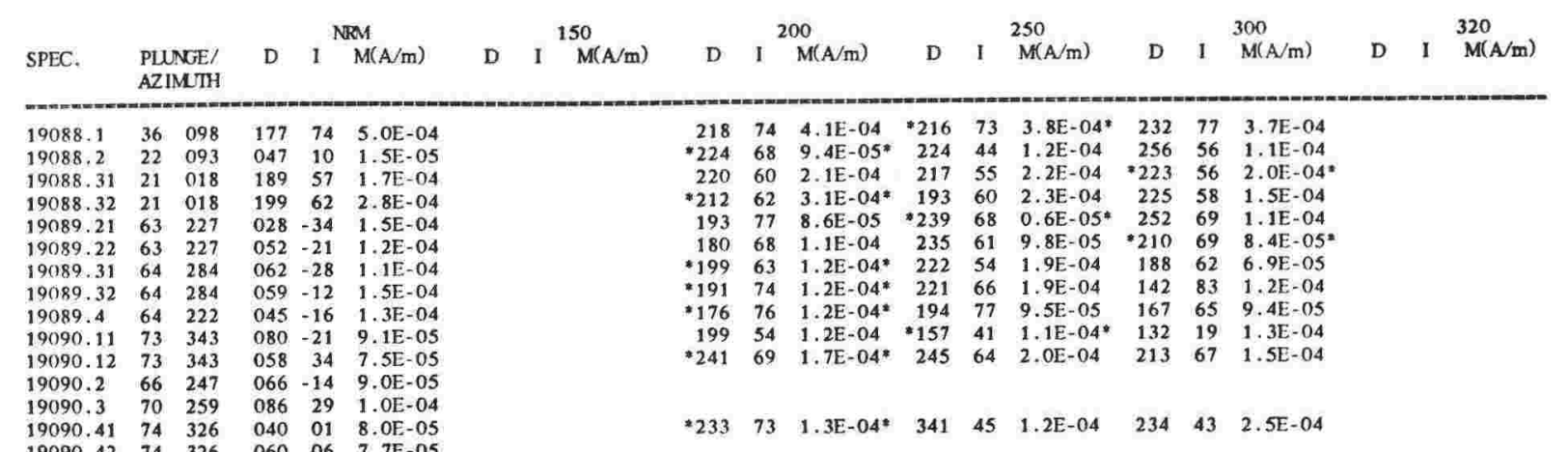

$\begin{array}{llllll}19095.12 & 39 & 282 & 123 & 56 & 9.7 \mathrm{E}-05\end{array}$ $\begin{array}{llllll}19095.2 & 28 & 329 & 057 & 27 & 1.2 \mathrm{E}-04\end{array}$ $\begin{array}{llllll}19095.3 & 38 & 301 & 028 & -28 & 7.0 \mathrm{E}-05\end{array}$ $\begin{array}{llllll}19096.11 & 52 & 051 & 081 & 22 & 9.2 \mathrm{E}-05\end{array}$ $\begin{array}{llllll}19096.12 & 52 & 051 & 113 & 26 & 6.9 \mathrm{E}-05\end{array}$ $\begin{array}{llllll}19096.21 & 45 & 059 & 118 & 17 & 4.7 \mathrm{E}-05\end{array}$

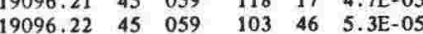
$\begin{array}{llllll}19097.1 & 29 & 067 & 224 & 54 & 4.0 \mathrm{E}-0\end{array}$ $\begin{array}{llllll}19097.2 & 22 & 038 & 222 & 68 & 6.1 \mathrm{E}-04\end{array}$ $\begin{array}{llllll}19097.31 & 24 & 009 & 224 & 63 & 5.5 \mathrm{E}-04\end{array}$ $\begin{array}{llllll}19097.32 & 24 & 009 & 222 & 59 & 7.1 \mathrm{E}-04\end{array}$ $\begin{array}{llllll}19097.41 & 25 & 056 & 228 & 56 & 5.7 \mathrm{E}-04\end{array}$ $\begin{array}{lllllll}19097.42 & 25 & 056 & 216 & 64 & 5.9 \mathrm{E}-04\end{array}$ $\begin{array}{llllll}19098.1 & 34 & 029 & 125 & 77 & 1.6 \mathrm{E}-04\end{array}$ $\begin{array}{lllllll}19098.2 & 31 & 040 & 165 & 62 & 2.3 \mathrm{E}-04\end{array}$ $\begin{array}{lllllll}19098.3 & 32 & 012 & 148 & 83 & 1.7 \mathrm{E}-04\end{array}$ $\begin{array}{llllllll}19098.41 & 31 & 030 & 121 & 71 & 2.0 \mathrm{E}-04\end{array}$ $\begin{array}{llllll}19098.42 & 31 & 030 & 214 & 74 & 1.4 E-04\end{array}$ 21474 1.4E-04 $\begin{array}{llllll}19099.2 & 65 & 060 & 076 & -08 & 1.1 E-04\end{array}$ $074-53$ 1.5E -04 $\begin{array}{llllll}19099.32 & 70 & 063 & 096 & -44 & 1.3 \mathrm{E}-04\end{array}$

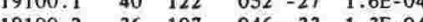
$19100.236 \quad 107-046-33 \quad 1.3 E-04$ $\begin{array}{lllllll}19100.3 & 30 & 142 & 048 & -18 & 1.2 \mathrm{E}-0\end{array}$ $\begin{array}{lllllll}19100.41 & 33 & 127 & 061 & -40 & 1.4 E-04\end{array}$ $\begin{array}{llllll}19100.42 & 33 & 127 & 059 & -39 & 1.1 \mathrm{E}-04 \\ 19101.1 & 35 & 070 & 066 & -29 & 1.8 \mathrm{E}-04\end{array}$ $\begin{array}{llllll}19101.2 & 40 & 079 & 054 & -12 & 1.6 \mathrm{E}-04\end{array}$ $\begin{array}{llllll}19101.3 & 31 & 085 & 077 & -17 & 1.8 \mathrm{E}-04\end{array}$ $\begin{array}{llllll}19102.1 & 40 & 088 & 034 & -20 & 3.0 \mathrm{E}-04\end{array}$ $\begin{array}{llllll}19102.2 & 29 & 106 & 057 & -53 & 2.0 \mathrm{E}-04\end{array}$ $\begin{array}{llllll}19102.3 & 26 & 085 & 038 & -40 & 2.3 \mathrm{E}-04\end{array}$ $\begin{array}{lllllll}19102.4 & 51 & 079 & 067 & -34 & 2.5 \mathrm{E}-04\end{array}$ $\begin{array}{llllll}19103.1 & 49 & 106 & 054 & -30 & 1.7 \mathrm{E}-04\end{array}$ $\begin{array}{lllllll}19103.21 & 47 & 114 & 053 & -43 & 2.4 \mathrm{E}-04\end{array}$ $\begin{array}{llllll}19103.22 & 47 & 114 & 046 & -49 & 1.9 E-04\end{array}$ $19103.31 \quad 37 \quad 114 \quad 069-34 \quad 2.0 \mathrm{E}-04$ $\begin{array}{llllll}19103.31 & 37 & 114 & 069 & -34 & 2.0 \mathrm{E}-04\end{array}$ $\begin{array}{llllll}19103.32 & 37 & 114 & 077 & -42 & 1.7 \mathrm{E}-04\end{array}$ $\begin{array}{llllll}19104.1 & 61 & 155 & 077 & -35 & 1.7 \mathrm{E}-04\end{array}$ $\begin{array}{lllllll}19104.21 & 64 & 118 & 063 & -37 & 1.5 \mathrm{E}-04\end{array}$ $\begin{array}{llllll}19104.22 & 64 & 118 & 048 & -32 & 1.7 \mathrm{E}-04\end{array}$ $\begin{array}{llllll}19104.3 & 64 & 110 & 072 & -53 & 1.7 \mathrm{E}-04\end{array}$ $19105.4 \quad 35 \quad 069$ 087 $-47 \quad 2.1 \mathrm{E}-04$ $\begin{array}{llllll}19105.1 & 35 & 069 & 054 & -12 & 2.1 \mathrm{E}-04\end{array}$ $\begin{array}{llllll}19105.2 & 40 & 086 & 065 & -32 & 1.5 \mathrm{E}-04\end{array}$ $\begin{array}{llllll}19105.31 & 55 & 072 & 048 & -15 & 2.3 \mathrm{E}-04\end{array}$ $\begin{array}{llllll}19105.32 & 55 & 072 & 059 & -13 & 2.1 E-04\end{array}$ $\begin{array}{llllll}19105.41 & 45 & 070 & 057 & -19 & 2.0 \mathrm{E}-04\end{array}$ $\begin{array}{lllllll}19106.1 & 63 & 178 & 054 & -45 & 2.9 \mathrm{E}-04\end{array}$ $\begin{array}{llllll}19106.2 & 62 & 166 & 069 & -38 & 3.5 \mathrm{E}-04\end{array}$ $\begin{array}{llllll}19106.3 & 70 & 239 & 055 & -47 & 3.4 \mathrm{E}-04\end{array}$ $\begin{array}{llllll}19106.4 & 70 & 217 & 059 & -52 & 3.1 \mathrm{E}-04\end{array}$ $\begin{array}{llllll}19107.2 & 45 & 058 & 058 & -39 & 3.3 \mathrm{E}-04\end{array}$ $\begin{array}{lllllll}19107.4 & 30 & 029 & 056 & -38 & 3.1 \mathrm{E}-04\end{array}$ $\begin{array}{lllllll}19107.5 & 47 & 034 & 064 & -38 & 3.4 \mathrm{E}-04\end{array}$ $\begin{array}{lllllll}19107.6 & 58 & 025 & 058 & -41 & 4.2 \mathrm{E}-04\end{array}$ $\begin{array}{lllllll}19108.1 & 52 & 030 & 067 & -57 & 3.0 \mathrm{E}-04\end{array}$ $\begin{array}{llllll}19108.2 & 66 & 026 & 073 & -47 & 3.0 \mathrm{E}-04\end{array}$ $\begin{array}{lllllllll}138 & 43 & 4.9 \mathrm{E}-05 & 201 & 50 & 7.8 \mathrm{E}-05 & * 180 & 57 & 5.1 \mathrm{E}-05^{*}\end{array}$ $\begin{array}{lllllllll}138 & 43 & 4.9 \mathrm{E}-05 & 201 & 50 & 7.8 \mathrm{E}-05 & 180 & 57 & 5.1 \mathrm{E}-05 \\ 137 & 62 & 4.2 \mathrm{E}-05 & 215 & 47 & 6.9 \mathrm{E}-05 & =217 & 48 & 1.1 \mathrm{E}-04^{*}\end{array}$ $\begin{array}{lllllllll}137 & 62 & 4.2 \mathrm{E}-05 & 215 & 47 & 6.9 \mathrm{E}-05 & 217 & 48 & 1.1 \mathrm{E}-04 \\ 143 & 45 & 4.6 \mathrm{E}-05 & 173 & 59 & 6.1 \mathrm{E}-05 & * 181 & 52 & 4.4 \mathrm{E}-05^{*}\end{array}$

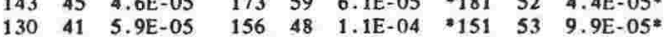
$\begin{array}{rrrrrrrrr}130 & 41 & 5.9 \mathrm{E}-05 & 156 & 48 & 1.1 \mathrm{E}-04 & 151 & 53 & 9.9 \mathrm{E}-05 \\ 167 & 71 & 1.3 \mathrm{E}-04 & 181 & 79 & 1.5 \mathrm{E}-04 & 147 & 73 & 1.1 \mathrm{E}-04\end{array}$ $195 \quad 44 \quad 9.2 \mathrm{E}-05 \quad * 211$ 46 $1.2 \mathrm{E}-04$ * $221 \quad 39 \quad 1.2 \mathrm{E}-04$ $\begin{array}{llllllllll}195 & 44 & 9.2 \mathrm{E}-05 & * 211 & 46 & 1.2 \mathrm{E}-04 & 221 & 39 & 1.2 \mathrm{E}-04 \\ 184 & 74 & 8.7 \mathrm{E}-05 & =212 & 63 & 8.9 \mathrm{E}-05 & 203 & 81 & 7.9 \mathrm{E}-05\end{array}$ $\begin{array}{rrrrrlllll}184 & 74 & 8.7 \mathrm{E}-05 & 212 & 63 & 8.9 \mathrm{E}-05^{*} & 203 & 81 & 7.9 \mathrm{E}-05 \\ 223 & 62 & 1.3 \mathrm{E}-04 & 216 & 50 & 1.4 \mathrm{E}-04 & 214 & 57 & 1.3 \mathrm{E}-04\end{array}$ $\begin{array}{rrrrrrrrr}223 & 62 & 1.3 \mathrm{E}-04 & 216 & 50 & 1.4 \mathrm{E}-04 & 214 & 57 & 1.3 \mathrm{E}-04 \\ 180 & 61 & 7.9 \mathrm{E}-05 & \approx 220 & 59 & 1.0 \mathrm{E}-04 * & 198 & 75 & 8.1 \mathrm{E}-05\end{array}$ $\begin{array}{lllllllll}180 & 61 & 7.9 \mathrm{E}-05 & * 220 & 59 & 1.0 \mathrm{E}-04^{*} & 198 & 75 & 8.1 \mathrm{E}-05 \\ 188 & 72 & 1.2 \mathrm{E}-04 & * 198 & 77 & 1.2 \mathrm{E}-04 * & 117 & 75 & 1.1 \mathrm{E}-04\end{array}$

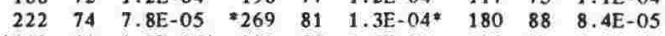
$\begin{array}{lllllllll}* 213 & 63 & 1.2 \mathrm{E}-04^{*} & 222 & 55 & 1.4 \mathrm{E}-04 & 188 & 61 & 1.1 \mathrm{E}-04 \\ * 215 & 67 & 2.7 \mathrm{E}-04^{*} & 217 & 60 & 2.5 \mathrm{E}-04 & 211 & 76 & 2.1 \mathrm{E}-04\end{array}$

$\begin{array}{lllllllll}205 & 63 & 2.5 \mathrm{E}-04 * & 217 & 58 & 2.6 \mathrm{E}-04 & 210 & 66 & 2.2 \mathrm{E}-04\end{array}$ $\begin{array}{lllllllll}221 & 68 & 2.3 \mathrm{E}-04^{*} & 219 & 74 & 2.0 \mathrm{E}-04 & 216 & 71 & 2.3 \mathrm{E}-04\end{array}$

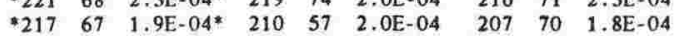
$\begin{array}{lllllllll}199 & 68 & 1.9 \mathrm{E}-04 & 224 & 63 & 2.1 \mathrm{E}-04 & 215 & 60 & 2.2 \mathrm{E}-04\end{array}$ $21455 \quad 2.0 \mathrm{E}-04.209 \quad 48$ 2.1E-04* $199 \quad 50 \quad 1.8 \mathrm{E}-04$ $\begin{array}{lllllllll}229 & 68 & 2.2 \mathrm{E}-04^{*} & 230 & 70 & 2.3 \mathrm{E}-04 & 209 & 61 & 1.8 \mathrm{E}-04\end{array}$ $215 \quad 66 \quad 2.2 \mathrm{E}-04 * 207 \quad 58 \quad 2.1 \mathrm{E}-04 * 248 \quad 61 \quad 2.0 \mathrm{E}-04$

$23356 \quad 7.2 \mathrm{E}-04 \quad 220 \quad 56 \quad 6.3 \mathrm{E}-04 \quad 221 \quad 55 \quad 5.7 \mathrm{E}-04 *$ $\begin{array}{lllllllll}226 & 53 & 8.4 \mathrm{E}-04 & * 225 & 53 & 7.6 \mathrm{E}-04 & 226 & 49 & 6.7 \mathrm{E}-04\end{array}$ $\begin{array}{lllllllll}225 & 56 & 7.6 \mathrm{E}-04 & 227 & 54 & 6.6 \mathrm{E}-04^{*} & 223 & 51 & 6.1 \mathrm{E}-04\end{array}$

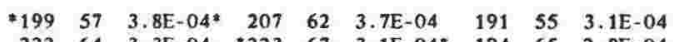
$\begin{array}{lllllllll}222 & 64 & 3.3 \mathrm{E}-04 & * 223 & 67 & 3.1 \mathrm{E}-04 * & 194 & 65 & 2.8 \mathrm{E}-04\end{array}$ $\begin{array}{llllllllll}210 & 68 & 3.2 \mathrm{E}-04 & * 209 & 66 & 3.4 \mathrm{E}-04 & 208 & 64 & 3.0 \mathrm{E}-04\end{array}$ $23259 \quad 3.0 \mathrm{E}-04=227 \quad 59 \quad 3.4 \mathrm{E}-04 * 215$ 56 $3.0 \mathrm{E}-04$

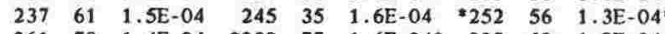
$\begin{array}{rrlrlllll}261 & 70 & 1.4 \mathrm{E}-04 & * 230 & 77 & 1.6 \mathrm{E}-04^{*} & 228 & 62 & 1.9 \mathrm{E}-04 \\ .227 & 57 & 1.5 \mathrm{E}-04 * & 250 & 60 & 1.3 \mathrm{E}-04 & 223 & 60 & 1.8 \mathrm{E}-04\end{array}$ $\begin{array}{lllllllll}218 & 84 & 9.1 \mathrm{E}-05 & 221 & 55 & 1.1 \mathrm{E}-04 & * 223 & 68 & 9.5 \mathrm{E}-05\end{array}$

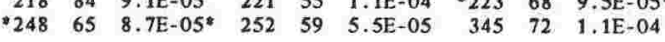

\begin{abstract}
$\begin{array}{llllllllll}255 & 52 & 8.8 \mathrm{E}-05 & 237 & 49 & 1.2 \mathrm{E}-04^{*} & 202 & 58 & 1.1 \mathrm{E}-04\end{array}$ $\begin{array}{lllllllll}156 & 73 & 6.8 \mathrm{E}-05 & * 234 & 65 & 9.5 \mathrm{E}-05^{*} & 198 & 22 & 3.8 \mathrm{E}-05\end{array}$

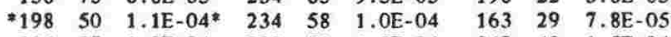
$\begin{array}{lllllllll}024 & 37 & 1.2 \mathrm{E}-04 & 020 & 51 & 1.3 \mathrm{E}-04 & 349 & 48 & 1.5 \mathrm{E}-04\end{array}$ $\begin{array}{lllllllll}214 & 42 & 2.8 \mathrm{E}-05 & 253 & 23 & 1.7 \mathrm{E}-05 & 078 & 57 & 6.9 \mathrm{E}-05\end{array}$

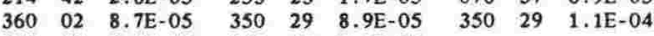
$\begin{array}{llllll}067 & 57 & 6.1 \mathrm{E}-05 & 085 & 40 & 3.9 \mathrm{E}-05\end{array}$

$\begin{array}{lllllllll}057 & 02 & 3.7 \mathrm{E}-05 & 239 & 40 & 2.4 \mathrm{E}-05 & * 223 & 68 & 7.4 \mathrm{E}-05 *\end{array}$ $\begin{array}{llllllllll}156 & 42 & 2.0 \mathrm{E}-05 & 235 & 59 & 4.6 \mathrm{E}-05 & : 223 & 72 & 6.7 \mathrm{E}-05\end{array}$

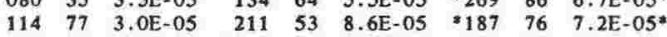
$\begin{array}{llllllllll}079 & 62 & 2.1 \mathrm{E}-05 & * 225 & 66 & 6.3 \mathrm{E}-05 * & 241 & 52 & 6.6 \mathrm{E}-05\end{array}$ $10280 \quad 3.5 \mathrm{E}-05 \quad 201 \quad 34 \quad 9.5 \mathrm{E}-05=185 \quad 60 \quad 9.3 \mathrm{E}-05^{\circ}$
\end{abstract}

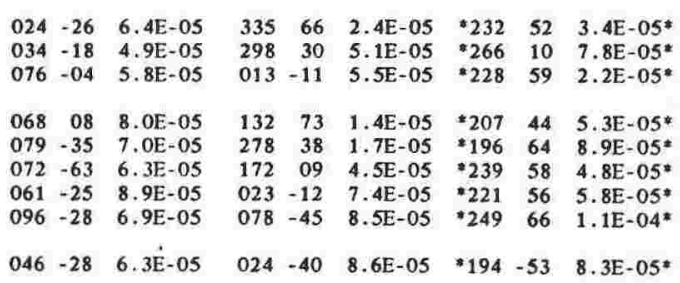

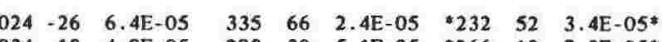
$\begin{array}{lllllllll}034 & -18 & 4.9 \mathrm{E}-05 & 298 & 30 & 5.1 \mathrm{E}-05 & * 266 & 10 & 7.8 \mathrm{E}-05 \\ *\end{array}$ $\begin{array}{lllllllll}076 & -04 & 5.8 \mathrm{E}-05 & 013 & -11 & 5.5 \mathrm{E}-05 & * 228 & 59 & 2.2 \mathrm{E}-05\end{array}$ $\begin{array}{lllllllllll}068 & 08 & 8.0 \mathrm{E}-05 & 132 & 73 & 1.4 \mathrm{E}-05 & * 207 & 44 & 5.3 \mathrm{E}-05 *\end{array}$ $\begin{array}{llllllllll}079 & -35 & 7.0 \mathrm{E}-05 & 278 & 38 & 1.7 \mathrm{E}-05 & * 196 & 64 & 8.9 \mathrm{E}-05\end{array}$

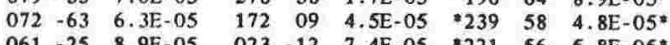
$\begin{array}{lllllllll}061 & -25 & 8.9 \mathrm{E}-05 & 023 & -12 & 7.4 \mathrm{E}-05 & * 221 & 56 & 5.8 \mathrm{E}-05^{*}\end{array}$ $\begin{array}{llllllllll}046 & -28 & 6.3 \mathrm{E}-05 & 024 & -40 & 8.6 \mathrm{E}-05 & * 194 & -53 & 8.3 \mathrm{E}-05 *\end{array}$

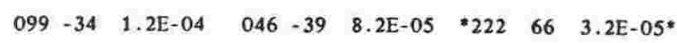




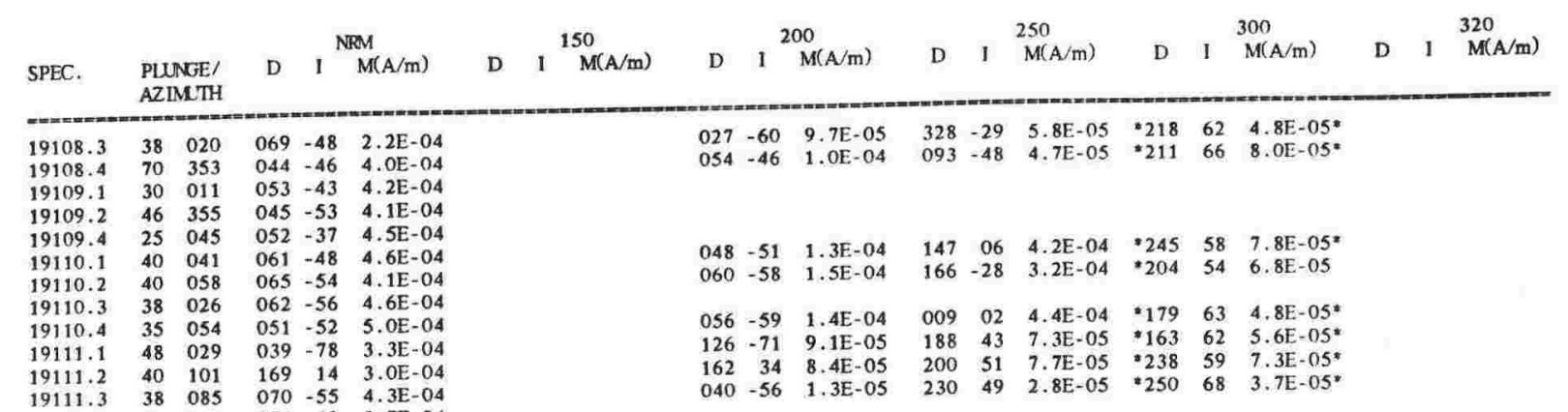

$\begin{array}{llllll}19111.3 & 38 & 085 & 070 & -55 & 4.3 \mathrm{E}-04\end{array}$

$\begin{array}{llllll}19112.1 & 50 & 067 & 053 & -49 & 3.7 \mathrm{E}-04\end{array}$

$\begin{array}{lllllll}19112.2 & 58 & 064 & 062 & -53 & 3.9 \mathrm{E}-04 \\ 19112.3 & 29 & 064 & 051 & -47 & 4.2 \mathrm{E}-04\end{array}$

$\begin{array}{lllllll}19112.41 & 34 & 071 & 056 & -55 & 4.3 \mathrm{E}-04\end{array}$

$\begin{array}{llllll}19112.42 & 34 & 071 & 052 & -55 & 4.1 \mathrm{E}-04\end{array}$

$\begin{array}{llllll}19112.42 & 34 & 071 & 052 & -55 & 4.1 \mathrm{E}-04\end{array}$

$\begin{array}{llllll}19114.31 & 34 & 043 & 059 & -42 & 3.9 E-04\end{array}$

$\begin{array}{llllll}19114.32 & 34 & 043 & 049 & -58 & 3.8 \mathrm{E}-04\end{array}$

$\begin{array}{llllll}19115.1 & 38 & 072 & 054 & -29 & 3.7 E-04\end{array}$

$\begin{array}{llllll}19115.2 & 48 & 058 & 038 & -60 & 4,0 \mathrm{E}-04\end{array}$

$\begin{array}{llllll}19115.4 & 41 & 019 & 041 & -52 & 3.6 \mathrm{E}-04 \\ 19116.1 & 44 & 057 & 035 & -28 & 5.4 \mathrm{E}-04\end{array}$

$\begin{array}{llllll}19116.1 & 44 & 057 & 035 & -28 & 5.4 \mathrm{E}-04 \\ 19116.2 & 40 & 073 & 051 & -54 & 3.7 \mathrm{E}-04\end{array}$

$19116.2 \quad 40 \quad 073 \quad 051-54 \quad 3.7 E-04$

19116.41 43 (3) $052 \quad 057 \quad-53 \quad 3.6 \mathrm{E}-04$

$\begin{array}{llllll}19116.42 & 43 & 052 & 044 & -50 & 4.4 \mathrm{E}-04 \\ 19117.11 & 37 & 037 & 066 & -37 & 2.8 \mathrm{E}-04\end{array}$

$\begin{array}{llllll}19117.11 & 37 & 037 & 066 & -37 & 2.8 \mathrm{E}-04 \\ 19117.12 & 37 & 037 & 057 & -47 & 3.3 \mathrm{E}-04\end{array}$

$\begin{array}{llllll}19117.12 & 37 & 037 & 057 & -47 & 3.3 \mathrm{E}-04 \\ 19117.2 & 50 & 044 & 052 & -38 & 2.6 \mathrm{E}-04\end{array}$

$\begin{array}{llllll}19117.4 & 49 & 034 & 051 & -44 & 3.1 \mathrm{E}-04\end{array}$

$\begin{array}{llllll}19118.2 & 65 & 199 & 052 & -46 & 3.6 \mathrm{E}-04 \\ 19118.3 & 54 & 197 & 064 & -47 & 3.2 \mathrm{E}-04\end{array}$

$\begin{array}{rrrrrrrrr}004 & -50 & 9.9 \mathrm{E}-04 & 340 & -20 & 8.2 \mathrm{E}-05 & * 269 & 63 & 4.1 \mathrm{E}-05^{*} \\ 131 & 03 & 2.0 \mathrm{E}-04 & 196 & 47 & 7.8 \mathrm{E}-05 & * 209 & 52 & 5.6 \mathrm{E}-05^{*} \\ 103 & -26 & 1.4 \mathrm{E}-04 & 160 & -10 & 5.1 \mathrm{E}-05 & * 180 & 69 & 3.0 \mathrm{E}-05^{*} \\ 120 & -14 & 1.2 \mathrm{E}-04 & 220 & 47 & 8.1 \mathrm{E}-05 & * 218 & 58 & 7.2 \mathrm{E}-05^{*} \\ 069 & -42 & 2.3 \mathrm{E}-04 & 150 & -09 & 9.2 \mathrm{E}-05 & * 225 & 64 & 6.0 \mathrm{E}-05^{*} \\ 140 & 22 & 7.2 \mathrm{E}-04 & 180 & 43 & 4.6 \mathrm{E}-05 & * 203 & 61 & 9.0 \mathrm{E}-05^{*} \\ 023 & -27 & 3.8 \mathrm{E}-04 & * 012 & -28 & 2.0 \mathrm{E}-04^{*} & 012 & -34 & 2.7 \mathrm{E}-04 \\ 043 & -61 & 1.8 \mathrm{E}-04 & -046 & -57 & 8.9 \mathrm{E}-05^{*} & 047 & -39 & 7.2 \mathrm{E}-05 \\ 036 & -64 & 1.1 \mathrm{E}-04 & 355 & -69 & 8.9 \mathrm{E}-05^{*} & * 042 & -65 & 6.4 \mathrm{E}-05^{*} \\ 080 & -64 & 3.1 \mathrm{E}-04 & 047 & -52 & 2.3 \mathrm{E}-04^{*} & 048 & -59 & 7.6 \mathrm{E}-05 \\ 047 & -42 & 8.5 \mathrm{E}-05 & 031 & -46 & 5.5 \mathrm{E}-05^{*} & 038 & -52 & 2.7 \mathrm{E}-05 \\ 049 & -62 & 7.5 \mathrm{E}-05 & 151 & -68 & 1.4 \mathrm{E}-04 & * 039 & -63 & 4.8 \mathrm{E}-05^{*} \\ 048 & -44 & 7.3 \mathrm{E}-05^{*} & 099 & -28 & 5.3 \mathrm{E}-05 & 039 & -55 & 4.8 \mathrm{E}-05 \\ 054 & -55 & 1.2 \mathrm{E}-04 & 051 & -53 & 6.3 \mathrm{E}-05 & * 049 & -56 & 5.0 \mathrm{E}-05^{*} \\ 054 & -55 & 7.7 \mathrm{E}-05^{*} & 132 & -54 & 5.9 \mathrm{E}-05 & 061 & -62 & 4.1 \mathrm{E}-05\end{array}$

$096-25 \quad 1.3 \mathrm{E}-04 \quad 108-31 \quad 8.7 \mathrm{E}-05 \quad * 111 \quad-30 \quad 5.8 \mathrm{E}-05 *$

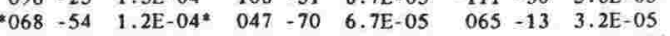

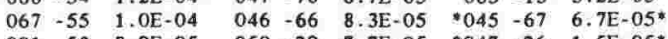
$\begin{array}{lllllllll}077 & -23 & 1.6 \mathrm{E}-04 & 074 & -26 & 9.6 \mathrm{E}-05^{*} & 080 & -15 & 6.7 \mathrm{E}-05\end{array}$ $\begin{array}{lllllllll}038 & -46 & 1.2 \mathrm{E}-04 & 056 & -19 & 3.5 \mathrm{E}-05 & * 050 & -44 & 5.3 \mathrm{E}-05 *\end{array}$

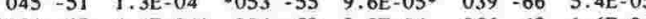

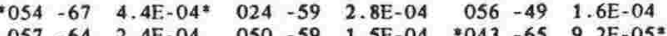
$\begin{array}{lllllllll}057 & -64 & 2.4 \mathrm{E}-04 & 050 & -59 & 1.5 \mathrm{E}-04 & * 043 & -65 & 9.2 \mathrm{E}-05^{*}\end{array}$ $\begin{array}{llllllllll}050 & -59 & 2.2 \mathrm{E}-04 & 053 & -50 & 1.1 \mathrm{E}-04 & * 058 & -47 & 7.5 \mathrm{E}-05^{*} \\ 059 & -56 & 1.7 \mathrm{E}-04 & 072 & -39 & 3.0 \mathrm{E}-04 & * 058 & -55 & 9.4 \mathrm{E}-05^{*}\end{array}$

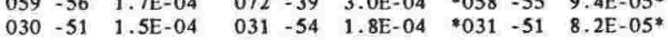

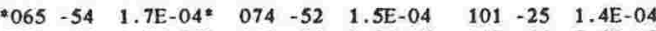

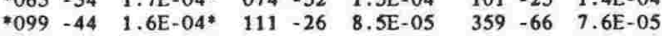
$\begin{array}{lllllllll}* 065 & -29 & 8.6 \mathrm{E}-05^{*} & 068 & -30 & 5.7 \mathrm{E}-05 & 058 & -29 & 6.5 \mathrm{E}-05\end{array}$ $\begin{array}{lllllllll}069 & -52 & 1.3 \mathrm{E}-04 & 066 & -63 & 6.8 \mathrm{E}-05 & * 063 & -63 & 4.5 \mathrm{E}-05 *\end{array}$

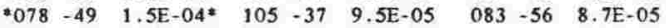
$\begin{array}{lllllllll}* 043 & -56 & 1.5 \mathrm{E}-04 * & 022 & -63 & 1.6 \mathrm{E}-04 & 041 & -54 & 7.6 \mathrm{E}-05\end{array}$ $\begin{array}{lllllllll}091 & -83 & 1.6 \mathrm{E}-04 & 020 & -63 & 1.6 \mathrm{E}-04 & * 019 & -67 & 9.1 \mathrm{E}-05 *\end{array}$ $031-55$ 1. 031 - 55 1.1E-04 044 - 44 1.1E-04 045 -43 8.2E-05* $\begin{array}{lllllllll}040 & -64 & 1.2 \mathrm{E}-04 & 085 & -60 & 1.2 \mathrm{E}-04 & 025 & -61 & 8.3 \mathrm{E}-05\end{array}$

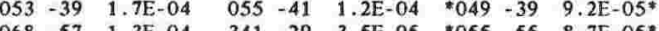
$\begin{array}{rrrrrrrrr}068 & -57 & 1.3 E-04 & 341 & -29 & 3.5 \mathrm{E}-05 & { }^{0} 055 & -55 & 8.7 \mathrm{E}-05^{\circ} \\ 089 & -74 & 9.5 \mathrm{E}-05 & 085 & -29 & 4.6 \mathrm{E}-05 & 148 & -54 & 9.6 \mathrm{E}-05\end{array}$

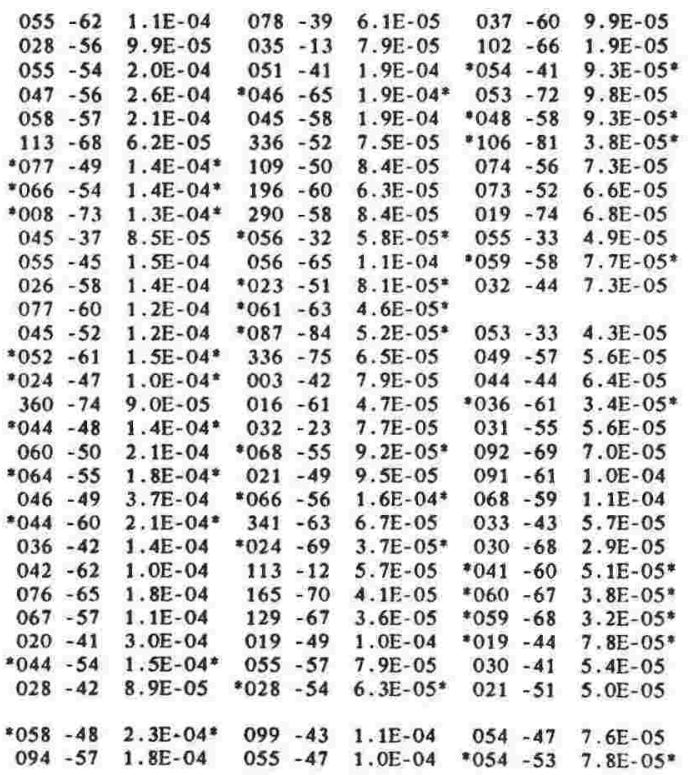




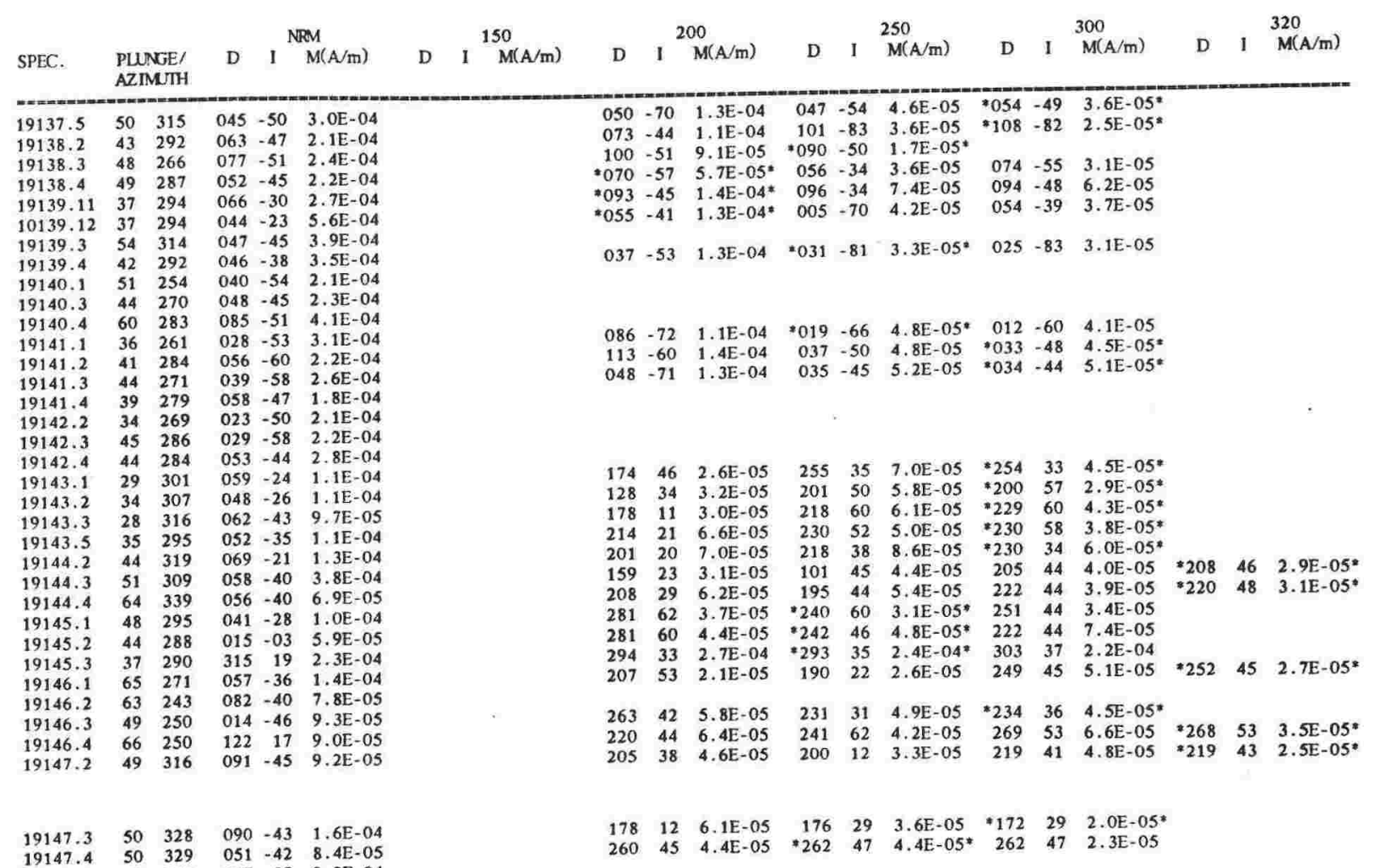

$\begin{array}{llllll}19147.4 & 50 & 329 & 051 & -42 & 8.4 \mathrm{E}-05\end{array}$

$\begin{array}{llllll}19149.1 & 49 & 259 & 037 & -37 & 2.2 \mathrm{E}-04\end{array}$

$19149.2 \quad 51 \quad 271 \quad 023 \quad-35 \quad 1.9 \mathrm{E}-04$

$\begin{array}{llllll}19149.3 & 42 & 245 & 010 & -24 & 1.4 \mathrm{E}-04\end{array}$

$\begin{array}{llllll}19149.4 & 50 & 251 & 083 & -27 & 1.1 \mathrm{E}-04\end{array}$

$19150.2 \quad 57 \quad 308 \quad 049-23 \quad 1.3 \mathrm{E}-04$

$\begin{array}{llllll}19150.41 & 62 & 252 & 056 & -43 & 1.8 \mathrm{E}-04 \\ 19150.42 & 62 & 252 & 042 & -46 & 1.6 \mathrm{E}-04\end{array}$

$\begin{array}{llllll}19150.42 & 62 & 252 & 042 & -46 & 1.6 \mathrm{E}-04 \\ 19151.1 & 47 & 356 & 072 & -33 & 1.1 \mathrm{E}-04\end{array}$

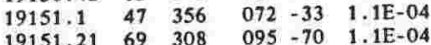

$\begin{array}{llllll}19151.21 & 69 & 308 & 095 & -70 & 1.1 E-04\end{array}$

$\begin{array}{lllllll}19151.22 & 69 & 308 & 020 & -45 & 1.7 \mathrm{E}-04\end{array}$

$\begin{array}{lllllll}19151.4 & 70 & 330 & 024 & -77 & 9.8 \mathrm{E}-04 \\ 19152.11 & 32 & 346 & 047 & -58 & 1.7 \mathrm{E}-04\end{array}$

$\begin{array}{llllll}19152.11 & 32 & 346 & 047 & -58 & 1.7 \mathrm{E}-04 \\ 19152.12 & 32 & 346 & 054 & -41 & 1.9 \mathrm{E}-04\end{array}$

$\begin{array}{llllll}19152.12 & 32 & 346 & 054 & -41 & 1.9 \mathrm{E}-04 \\ 19152.21 & 20 & 305 & 047 & -41 & 1.6 \mathrm{E}-04\end{array}$

$\begin{array}{llllll}19152.21 & 20 & 305 & 047 & -41 & 1.6 \mathrm{E}-04 \\ 19152.22 & 20 & 305 & 060 & -62 & 2.1 \mathrm{E}-04\end{array}$

$\begin{array}{lllllll}19152.22 & 20 & 305 & 060 & -62 & 2.1 E-04 \\ 19153.1 & 39 & 301 & 046 & -45 & 2.2 E-04\end{array}$

$\begin{array}{lllllll}19153.1 & 39 & 301 & 046 & -45 & 2.2 \mathrm{E}-04 \\ 19153.2 & 24 & 007 & 077 & -46 & 1.4 \mathrm{E}-04\end{array}$

$\begin{array}{llllll}19153.2 & 24 & 007 & 077 & -46 & 1.4 \mathrm{E}-04 \\ 19153.4 & 74 & 294 & 052 & -55 & 2.0 \mathrm{E}-04\end{array}$

$\begin{array}{llllll}19153.4 & 74 & 294 & 052 & -55 & 2.0 \mathrm{E}-04 \\ 19156.21 & 51 & 174 & 064 & -59 & 2.9 \mathrm{E}-04\end{array}$

$\begin{array}{lllllll}19156.21 & 51 & 174 & 064 & -59 & 2.9 \mathrm{E}-04 \\ 19156.22 & 51 & 174 & 059 & -52 & 3.2 \mathrm{E}-04\end{array}$

$\begin{array}{rrrrrr}19156.22 & 51 & 174 & 059 & -52 & 3.2 \mathrm{E}-04 \\ 19156.31 & 55 & 198 & 105 & 50 & 2.5 \mathrm{E}-04\end{array}$

$\begin{array}{llllll}19156.32 & 55 & 198 & 075 & -62 & 3.6 \mathrm{E}-04\end{array}$

$\begin{array}{llllll}19157.1 & 54 & 282 & 043 & -45 & 3.3 \mathrm{E}-04\end{array}$

$\begin{array}{llllll}19157.2 & 52 & 273 & 038 & -45 & 3.9 \mathrm{E}-04\end{array}$

$\begin{array}{llllll}19157.31 & 67 & 214 & 045 & -56 & 3.6 \mathrm{E}-04\end{array}$

$\begin{array}{llllll}19157.32 & 67 & 214 & 047 & -60 & 3.5 \mathrm{E}-04 \\ 19158.11 & 48 & 261 & 048 & -50 & 3.5 \mathrm{E}-04\end{array}$

$\begin{array}{llllll}19158.12 & 48 & 261 & 042 & -54 & 3.9 \mathrm{E}-04 \\ 19158.31 & 50 & 256 & 056 & -66 & 1.5 \mathrm{E}-04 \\ 19158.32 & 50 & 256 & 033 & -45 & 3.1 \mathrm{E}-04 \\ 19159.21 & 44 & 250 & 038 & -47 & 2.6 \mathrm{E}-04 \\ 19159.22 & 44 & 250 & 039 & -41 & 2.6 \mathrm{E}-04 \\ 19159.31 & 55 & 259 & 045 & -47 & 3.1 \mathrm{E}-04 \\ 19159.32 & 55 & 259 & 038 & -51 & 2.9 \mathrm{E}-04 \\ 19159.33 & 55 & 259 & 041 & -46 & 2.9 \mathrm{E}-04 \\ 19161.11 & 43 & 285 & 048 & -39 & 2.3 \mathrm{E}-04 \\ 19161.12 & 43 & 285 & 047 & -32 & 2.3 \mathrm{E}-04 \\ 19161.31 & 43 & 289 & 047 & -39 & 2.5 \mathrm{E}-04 \\ 19161.32 & 43 & 289 & 047 & -45 & 2.1 \mathrm{E}-04 \\ 19162.1 & 63 & 234 & 049 & -56 & 3.4 \mathrm{E}-04 \\ 19162.2 & 59 & 255 & 041 & -57 & 6.0 \mathrm{E}-04 \\ 19162.3 & 62 & 263 & 044 & -58 & 3.4 \mathrm{E}-04 \\ 19162.4 & 55 & 249 & 057 & -58 & 5.2 \mathrm{E}-04 \\ 19163.1 & 33 & 315 & 040 & -56 & 5.6 \mathrm{E}-04 \\ 19163.2 & 41 & 296 & 052 & -46 & 4.1 \mathrm{E}-04 \\ 19163.3 & 26 & 301 & 049 & -52 & 4.3 \mathrm{E}-04 \\ 19164.1 & 38 & 298 & 059 & -40 & 2.2 \mathrm{E}-04 \\ 19164.2 & 31 & 288 & 054 & -47 & 2.2 \mathrm{E}-04 \\ 19164.31 & 31 & 309 & 039 & -54 & 2.2 \mathrm{E}-04 \\ 19164.32 & 31 & 309 & 048 & -53 & 2.3 \mathrm{E}-04 \\ 19165.1 & 21 & 099 & 115 & -60 & 2.0 \mathrm{E}-04 \\ 19165.2 & 15 & 109 & 095 & -54 & 2.2 \mathrm{E}-04 \\ 19165.31 & 40 & 076 & 052 & -50 & 2.5 \mathrm{E}-04 \\ 19165.32 & 40 & 076 & 055 & -48 & 2.2 \mathrm{E}-04 \\ 19166.11 & 31 & 306 & 064 & -59 & 2.4 \mathrm{E}-04 \\ 19166.12 & 31 & 306 & 044 & -53 & 2.7 \mathrm{E}-04 \\ 19166.31 & 48 & 282 & 064 & -51 & 2.9 \mathrm{E}-04 \\ 19166.32 & 48 & 282 & 055 & -50 & 2.5 \mathrm{E}-04 \\ 19167.21 & 62 & 177 & 047 & -44 & 2.0 \mathrm{E}-04 \\ 19167.22 & 62 & 177 & 044 & -45 & 2.2 \mathrm{E}-04\end{array}$

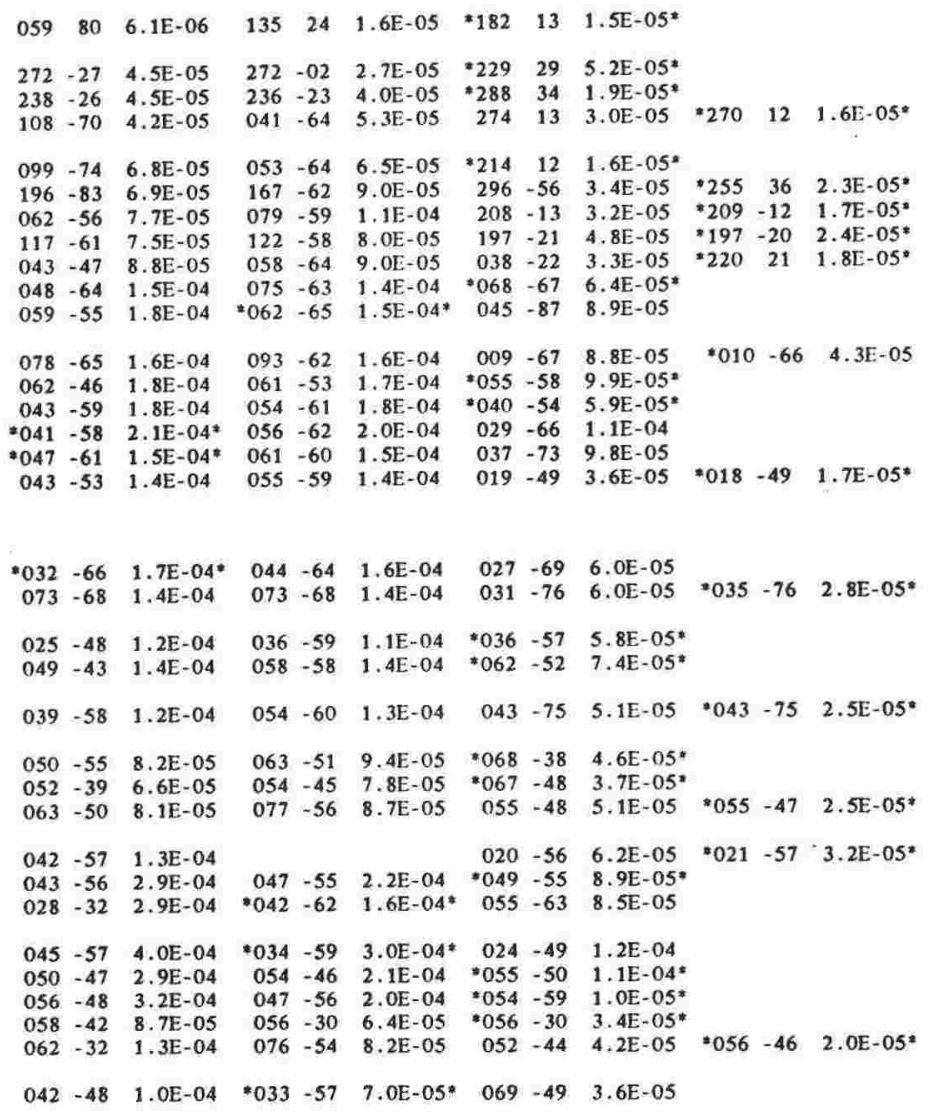

$\begin{array}{lllllllll}046 & -57 & 1.2 \mathrm{E}-04 & 056 & -58 & 8.2 \mathrm{E}-05 & * 057 & -59 & 3.7 \mathrm{E}-05 *\end{array}$

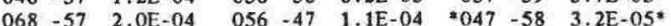
$\begin{array}{lllllllll}056 & -52 & 1.2 \mathrm{E}-04 & 055 & -54 & 9.6 \mathrm{E}-05 & =54 & -53 & 4.4 \mathrm{E}-05\end{array}$ 


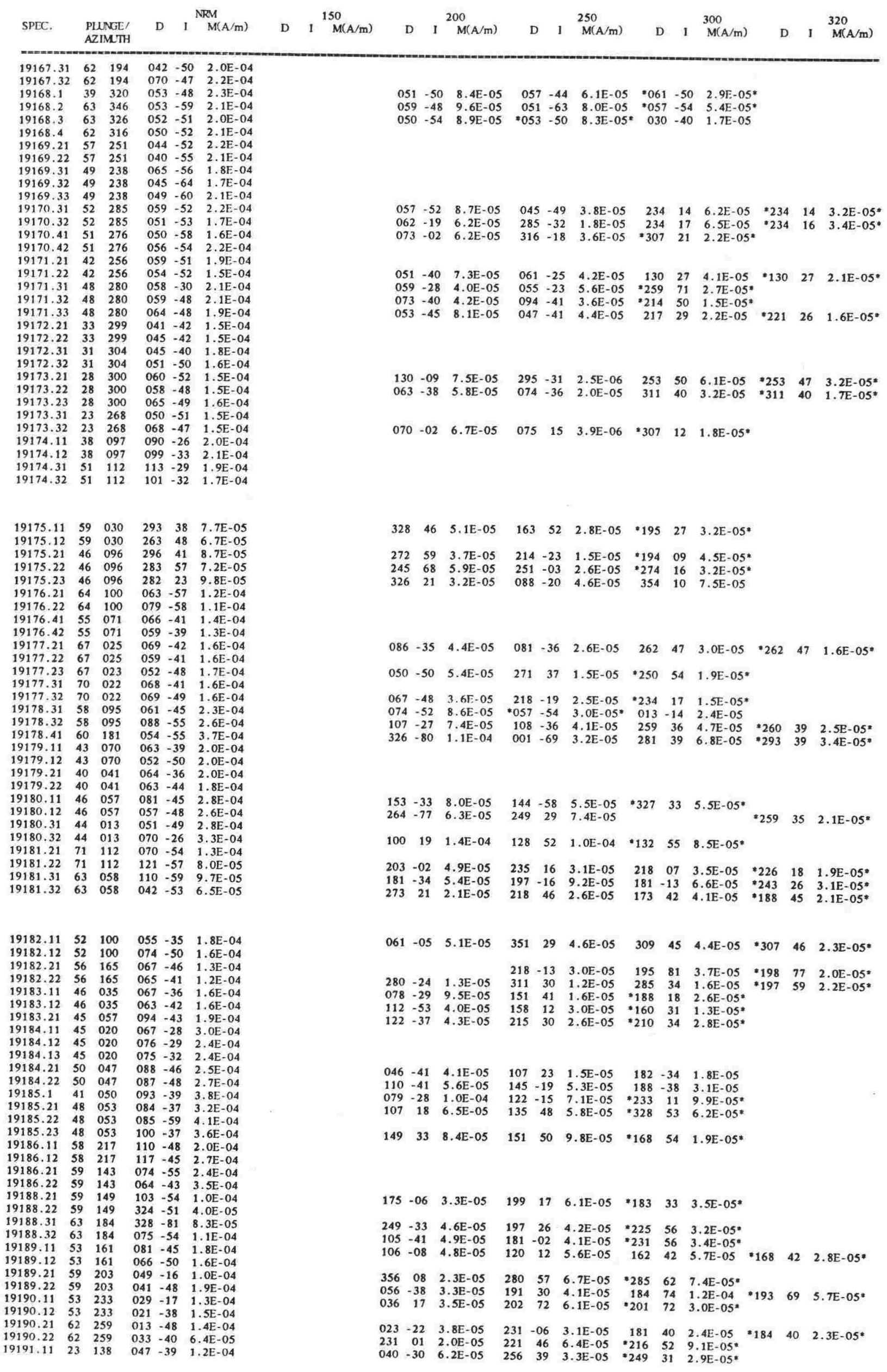




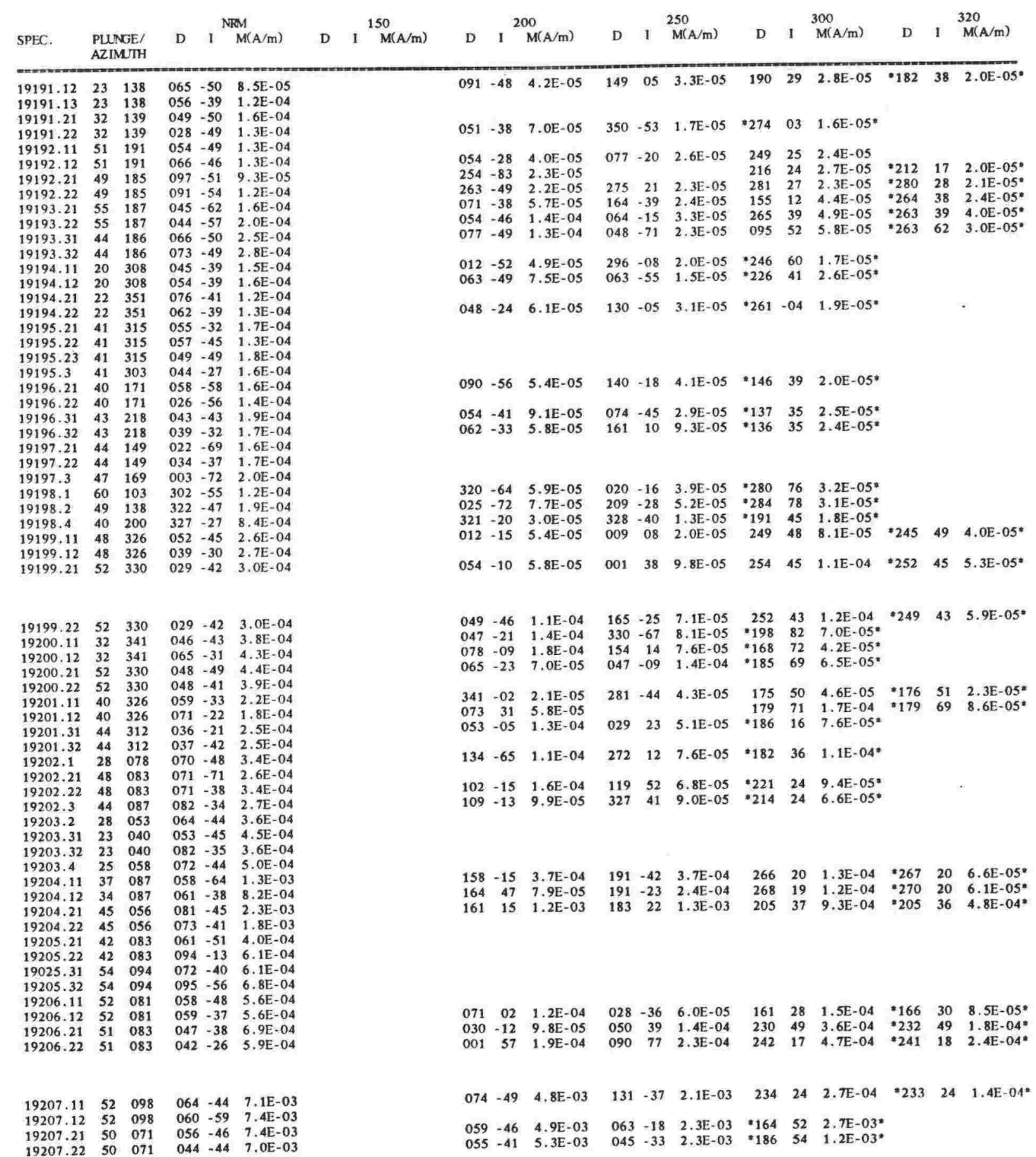




\section{APPENDIX 9: SUMMARY SITE STATISTICS}

(1) VUW collection number.

(2) Stratigraphic height $(\mathrm{m})$ above the Makaretu sandstone.

(3) Average degree of bioturbation at the site, (see Plate 2.1 and section 2.3).

(4) Number of specimens used in the final analysis and does not include those specimens which were rejected.

(5) Average initial volume susceptibility of all specimens sampled at the site (values $x$ $\left.10^{-3}\right)$.

(6) Average magnetisation intensity of all specimens sampled at the site (values $\mathrm{Am}^{-1}$ ).

(7) Mean declination $\left(^{\circ}\right)$ of specimens accepted from the site.

(8) Mean inclination $\left(^{\circ}\right)$ of specimens accepted from the site.

(9) Average magnetisation intensity of specimens accepted from the site (values $\mathrm{Am}^{-1}$ ).

(10) $k$, Fisher's precision parameter

(11) $\alpha 95$, radius $\left(^{\circ}\right)$ of the $95 \%$ confidence cone about the mean direction.

(12) $\mathrm{R}$, resultant vector length of mean direction.

(13) Polarity, $\mathrm{N}=$ normal and $\mathrm{R}=$ reversed. 


$\begin{array}{rrrr}(1) & \text { (2) } & \text { (3) } & (4) \\ 18870 & 2.0 & 1 & 3 \\ 18871 & 3.0 & 1 & 3 \\ 18872 & 4.0 & 1 & 3 \\ 18873 & 5.0 & 1 & 3 \\ 18874 & 6.0 & 1 & 3 \\ 18875 & 7.0 & 1 & . \\ 18876 & 9.0 & 1 & 3 \\ 18877 & 15.0 & 1 & 3 \\ 18878 & 21.0 & 1 & 3 \\ 18879 & 27.0 & 2 & 3 \\ 18880 & 33.0 & 2 & 3 \\ 18881 & 38.0 & 2 & \\ 18882 & 43.0 & 2 & 4 \\ 18883 & 48.0 & 2 & 3 \\ 18884 & 52.0 & 2 & 3 \\ 18885 & 57.0 & 3 & 3 \\ 18886 & 62.0 & 2 & 4 \\ 18887 & 72.0 & 2 & 3 \\ 18888 & 82.0 & 2 & 4 \\ 18889 & 92.0 & 1 & 4 \\ 18890 & 102.0 & 2 & 3 \\ 18891 & 111.0 & 1 & 5 \\ 18892 & 120.0 & 2 & 3 \\ 18893 & 129.0 & 3 & 4 \\ 18894 & 138.0 & 2 & 3 \\ 18895 & 147.0 & 2 & 3 \\ 18896 & 152.0 & 2 & 3 \\ 18897 & 158.0 & 1 & 3 \\ 18898 & 163.0 & 2 & 3\end{array}$

(5)

(6)

(7)

(8)

(9)

(10)

(11)

(12)

(13)

$\begin{array}{lll}195.52 & 4.7 \mathrm{E}-04 \quad 213.0\end{array}$

61.2
43.4

4. $9 \mathrm{E}-05$

$\begin{array}{lll}10.8 & 39.5 & 2.8149\end{array}$

$\begin{array}{lll}193.64 & 3.2 \mathrm{E}-04 & 238.0\end{array}$

$65.9 \quad 3.5 \mathrm{E}-05$

$\begin{array}{lll}16.6 & 31.2 & 2.8798\end{array}$

$\begin{array}{llrrr}50.7 & 4.8 \mathrm{E}-05 & 235.9 & 8.0 & 2.9915\end{array}$

$\begin{array}{lll}188.00 & 3.3 \mathrm{E}-04 & 237.2 \\ 180.48 & 3.0 \mathrm{E}-04 & 205.9\end{array}$

$18.1 \quad 4.0 \mathrm{E}-05$

$\begin{array}{lll}32.3 & 22.0 & 2.9382\end{array}$

$197.40 \quad 3.6 \mathrm{E}-04$

$251.92 \quad 2.5 \mathrm{E}-04$

$\begin{array}{ll}251.92 & 1.2 \mathrm{E}-03 \\ 216.20 & 9.2 \mathrm{E}-04\end{array}$

$\begin{array}{ll}216.20 & 9.2 \mathrm{E}-04 \\ 206.80 & 6.4 \mathrm{E}-04\end{array}$

$216.20 \quad 1.2 \mathrm{E}-03$

$214.32 \quad 7.6 \mathrm{E}-04$

$216.20 \quad 1.0 \mathrm{E}-03$

$210.56 \quad 1.6 \mathrm{E}-03$

$\begin{array}{ll}216.20 & 1.8 \mathrm{E}-03 \\ 212.44 & 1.8 \mathrm{E}-03\end{array}$

$206.80 \quad 1.7 \mathrm{E}-03$

$219.96 \quad 1.6 \mathrm{E}-03$

$227.48 \quad 3.0 \mathrm{E}-03$

$212.44 \quad 2.0 \mathrm{E}-03$

227.48
204.92
$24.3 \mathrm{E}-03$

$240.64 \quad 3.5 \mathrm{E}-03$

$214.32,1.6 \mathrm{E}-03$

$210.56 \quad 1.4 \mathrm{E}-03$

$219.96 \quad 2.8 \mathrm{E}-03$

239.7
58.8

62.7

8. $1 E-05$

$\begin{array}{lll}29.4 & 23.1 & 2.932\end{array}$

$73.5 \quad-27.2$

4. OE- 04

$\begin{array}{lll}15.1 & 32.9 & 2.8677\end{array}$

$\begin{array}{lll}36.9 & 20.6 & 2.9459\end{array}$

$-64.2 \quad 2.3 \mathrm{E}-04$

$\begin{array}{lll}36.9 & 20.6 & 2.9459 \\ 11.0 & 39.0 & 2.8188\end{array}$

44.5

$-61.7 \quad 3.4 \mathrm{E}-0$

60.9

43.2
54.2

$-59.6 \quad 3.1 \mathrm{E}$

$\begin{array}{ll}-59.6 & 3.1 \mathrm{E}-04 \\ -55.3 & 7.3 \mathrm{E}-04\end{array}$

$69.5 \quad 11.0 \quad 3.9569$

$54.5 \quad 16.9 \quad 2.9633$

$\begin{array}{rrrrr}-59.1 & 7.3 \mathrm{E}-04 & 210.6 & \mathbf{8 . 5} & 2.99605\end{array}$

$\begin{array}{lllll}-64.3 & 6.8 \mathrm{E}-04 & 156.2 & 7.4 & 3.980\end{array}$

86.8
61.5
39.8

-51.6 5.0E-04

$\begin{array}{ll}-37.2 & 5.2 \mathrm{E}-04\end{array}$

$\begin{array}{lll}22.0 & 27.0 & 2.9090\end{array}$

$\begin{array}{rrr}37.2 & 15.3 & 3.9193\end{array}$

$\begin{array}{lllll}-53.6 & 4.5 \mathrm{E}-04 & 79.5 & 13.9 & 2.9749\end{array}$

$\begin{array}{lll}43.6 & -53.1 & 4.9 \mathrm{E}-04\end{array}$

$42.1 \quad-60.1 \quad 1.6 \mathrm{E}-03$

$\begin{array}{lll}45.0 & -49.8 & 6.6 \mathrm{E}-04 \\ 5.8 \mathrm{E}-04\end{array}$

51.3

$-59.8$

$197.40 \quad 1.8 \mathrm{E}-03$

$-57.2$

2. $7 \mathrm{E}-04$

$\begin{array}{lll}40.3 & 19.7 & 2.9504\end{array}$

$\begin{array}{lll}97.2 & 9.4 & 3.9691\end{array}$

$54.2 \quad 16.9 \quad 2.9620$

$37.8 \quad 20.3 \quad 2.9640$

$\begin{array}{lll}20.1 & 28.2 & 2.9006\end{array}$

$\begin{array}{lll}5.1 & 61.4 & 2.6080\end{array}$

$\begin{array}{ll}18899 & 169.0 \\ 18900 & 174.0 \\ 18901 & 179.0 \\ 18902 & 184.0 \\ 18903 & 189.0 \\ 18904 & 194.0 \\ 18905 & 199.0 \\ 18906 & 205.0 \\ 18907 & 210.0 \\ 18908 & 216.0 \\ 18909 & 221.0 \\ 18910 & 227.0 \\ 18911 & 232.0 \\ 18912 & 238.0 \\ 18913 & 243.0 \\ 18914 & 249.0 \\ 18915 & 254.0 \\ 18916 & 260.0 \\ 18917 & 266.0 \\ 18918 & 272.0 \\ 18919 & 278.0 \\ 18920 & 284.0 \\ 18921 & 290.0 \\ 18922 & 297.0 \\ 18923 & 303.0 \\ 18924 & 310.0 \\ 18925 & 316.0 \\ 18926 & 323.0 \\ 18927 & 330.0 \\ 18928 & 336.0 \\ 18929 & 342.0 \\ 18930 & 348.0 \\ 18931 & 353.0 \\ & \end{array}$

$\begin{array}{ll}195.52 & 6.7 \mathrm{E}-04 \\ 206.80 & 1.1 \mathrm{E}-03 \\ 169.20 & 7.5 \mathrm{E}-04 \\ 212.44 & 8.6 \mathrm{E}-04 \\ 218.08 & 5.7 \mathrm{E}-04 \\ 216.20 & 8.1 \mathrm{E}-04 \\ 221.84 & 8.5 \mathrm{E}-04 \\ 127.84 & 1.1 \mathrm{E}-03 \\ 163.56 & 4.9 \mathrm{E}-04 \\ 191.76 & 6.5 \mathrm{E}-04 \\ 197.40 & 5.7 \mathrm{E}-04\end{array}$

$188.00 \quad 9.8 \mathrm{E}-04$

$201.16 \quad 1.0 \mathrm{E}-03$

$212.44 \quad 9.3 \mathrm{E}-03$

$195.52 \quad 7.5 \mathrm{E}-04$

$201.16 \quad 6.7 \mathrm{E}-04$

$\begin{array}{ll}212.44 & 9.1 \mathrm{E}-04 \\ 191.76 & 7.4 \mathrm{E}-04\end{array}$

$182.36 \quad 6.4 \mathrm{E}-04$

$191.76 \quad 6.4 \mathrm{E}-04$

$195.52 \quad 8.8 \mathrm{E}-04$

$\begin{array}{ll}193.64 & 8.1 \mathrm{E}-04 \\ 197.40 & 8.0 \mathrm{E}-04\end{array}$

$204.92 \quad 6.5 \mathrm{E}-04$

$178.60 \quad 8.6 \mathrm{E}-04$

193.64 8.7E-04

204.92 6.5E-04

$218.08 \quad 8.1 \mathrm{E}-04$

$218.08 \quad 6.3 \mathrm{E}-04$

$223.72 \quad 9.0 \mathrm{E}-04$

\section{2}

$-62.0 \quad 9.7 \mathrm{E}-05$

$\begin{array}{lll}9.5 & 42.4 & 2.7897\end{array}$ $\begin{array}{lll}37.6 & -65.8 & 9.3 \mathrm{E}-05\end{array}$ $-68.6 \quad 2.4 \mathrm{E}-04$

$\begin{array}{lll}90.5 & 9.7 & 3.9669\end{array}$

$\begin{array}{lll}31.3 & 22.4 & 2.9362\end{array}$

$49.9 \quad-57.3 \quad 2.3 \mathrm{E}-0$

$\begin{array}{lll}81.8 & 13.7 & 2.9756\end{array}$

$\begin{array}{lll}58.7 & -56.3 & 3.0 \mathrm{E}-0 \\ 41.3 & -65.7 & 5.0 \mathrm{E}-0\end{array}$

$\begin{array}{rrr}22.9 & 26.4 & 2.9125 \\ 218.3 & 8.4 & 2.9908\end{array}$

55.9
62.1

$-62.9 \quad 9.9 \mathrm{E}-05$

$\begin{array}{lll}37.8 & 20.3 & 2.9471 \\ 63.7 & 15.6 & 2.9686\end{array}$

$-53.2 \quad 8.7 \mathrm{E}-05$

$\begin{array}{lll}71.8 & 14.6 & 2.9721\end{array}$

$\begin{array}{lll}14.5 & 33.6 & 2.9662\end{array}$

$\begin{array}{lll}14.5 & 33.6 & 2.8625 \\ 47.5 & 18.1 & 2.9579\end{array}$

$-61.3 \quad 1.6 \mathrm{E}-04$

25.8 4.3E-05

$\begin{array}{rrr}170.6 & 9.5 & 2.9883\end{array}$

49.6

$-40.0 \quad 1.1 \mathrm{E}-04$

$\begin{array}{ll}-55.0 & 6.5 \mathrm{E}-05 \\ -47.7 & 8.8 \mathrm{E}-05\end{array}$

41.9
43.2
43.2

$-57.9 \quad 1.1 \mathrm{E}-04$

$\begin{array}{ll}-46.7 & 8.9 \mathrm{E}-05 \\ -50.9 & 2.1 \mathrm{E}-04\end{array}$

$\begin{array}{ll}-56.7 & 1.3 \mathrm{E}-04\end{array}$

$50.7 \quad-56.8 \quad 2.4 \mathrm{E}-04$

$\begin{array}{lll}49.5 & -53.2 & 2.2 \mathrm{E}-04\end{array}$

$\begin{array}{lll}50.0 & -52.2 & 1.8 \mathrm{E}-04 \\ 49.2 & -53.5 & 1.3 \mathrm{E}-04\end{array}$

$\begin{array}{lll}31.8 & 22.2 & 2.9371\end{array}$

$\begin{array}{lll}42.8 & 19.1 & 2.9532\end{array}$

$\begin{array}{rrr}217.0 & 13.1 & 2.9778 \\ 7.4 & 2.9908\end{array}$

$\begin{array}{lll}70.5 & 14.8 & 2.9716\end{array}$

$\begin{array}{lll}10.3 & 30.0 & 3.7096\end{array}$

$\begin{array}{lll}89.6 & 13.1 & 2.9777\end{array}$

$\begin{array}{lll}80.9 & 13.8 & 2.9753 \\ 4.2 & 69.7 & 2.5248\end{array}$

$\begin{array}{lll}20.8 & 27.7 & 2.9039\end{array}$

$\begin{array}{lll}44.1 & 14.0 & 3.9320\end{array}$

$\begin{array}{lll}19.3 & 21.4 & 3.8449\end{array}$

$30.2 \quad-60.1 \quad 1.7 \mathrm{E}-0$

$\begin{array}{lll}32.8 & 16.3 \quad 3.9085\end{array}$

$\begin{array}{lll}18932 & 359.0 & 3 \\ 18933 & 364.0 & 2 \\ 18934 & 370.0 & 2 \\ 18935 & 375.0 & 2 \\ 18936 & 381.0 & 1 \\ 18937 & 385.0 & 2 \\ 18938 & 269.0 & 1 \\ 18939 & 392.0 & 1 \\ 18940 & 396.0 & 2 \\ 18941 & 399.0 & 1 \\ 18942 & 403.0 & 1 \\ 18943 & 406.0 & 2 \\ 18944 & 409.0 & 1 \\ 18945 & 412.0 & 1 \\ 18946 & 415.0 & 1 \\ 18947 & 418.0 & 2 \\ 18948 & 421.0 & 1 \\ 18949 & 424.0 & 1 \\ 18950 & 427.0 & 1 \\ 18951 & 432.0 & 2 \\ 18952 & 438.0 & 1 \\ 18953 & 443.0 & 1 \\ 18954 & 449.0 & 1 \\ 18955 & 454.0 & 1 \\ 18956 & 460.0 & 1 \\ 18957 & 465.0 & 1 \\ 18958 & 470.0 & 1 \\ 18959 & 476.0 & 2 \\ 18960 & 481.0 & 2 \\ 18961 & 487.0 & 1 \\ 18962 & 492.0 & 1 \\ 18963 & 497.0 & 1 \\ 18964 & 503.0 & 2 \\ & & \end{array}$

$\begin{array}{ll}206.80 & 6.7 \mathrm{E}-04 \\ 216.20 & 9.6 \mathrm{E}-04 \\ 244.40 & 2.1 \mathrm{E}-03 \\ 227.48 & 7.0 \mathrm{E}-04 \\ 225.60 & 2.0 \mathrm{E}-03 \\ 210.56 & 7.8 \mathrm{E}-04 \\ 212.44 & 8.1 \mathrm{E}-04 \\ 206.80 & 6.0 \mathrm{E}-04 \\ 282.00 & 6.6 \mathrm{E}-04 \\ 214.32 & 6.5 \mathrm{E}-04 \\ 204.92 & 6.5 \mathrm{E}-04 \\ 229.36 & 9.7 \mathrm{E}-04 \\ 225.60 & 1.1 \mathrm{E}-03 \\ 223.72 & 9.0 \mathrm{E}-04 \\ 193.64 & 1.0 \mathrm{E}-03 \\ 208.68 & 9.4 \mathrm{E}-04 \\ 193.64 & 8.4 \mathrm{E}-04 \\ 193.64 & 9.2 \mathrm{E}-04 \\ 201.16 & 9.5 \mathrm{E}-04 \\ 212.44 & 1.1 \mathrm{E}-03 \\ 204.92 & 9.8 \mathrm{E}-04 \\ 214.32 & 8.3 \mathrm{E}-04 \\ 212.44 & 8.6 \mathrm{E}-04 \\ 197.40 & 6.5 \mathrm{E}-04 \\ 219.96 & 7.1 \mathrm{E}-04 \\ 219.96 & 7.7 \mathrm{E}-04 \\ 223.72 & 7.0 \mathrm{E}-04 \\ 212.44 & 1.0 \mathrm{E}-03 \\ 204.92 & 1.1 \mathrm{E}-03 \\ 219.96 & 5.1 \mathrm{E}-04 \\ 225.60 & 8.6 \mathrm{E}-04 \\ 225.60 & 8.1 \mathrm{E}-04 \\ 212.44 & 9.8 \mathrm{E}-04 \\ & \end{array}$

$\begin{array}{rrr}48.0 & -55.0 & 2.0 \mathrm{E}-04 \\ 49.0 & -56.7 & 3.4 \mathrm{E}-04 \\ 38.4 & -53.0 & 1.1 \mathrm{E}-03 \\ 38.5 & -62.4 & 1.7 \mathrm{E}-04 \\ 68.6 & -57.5 & 1.1 \mathrm{E}-03 \\ 65.3 & -60.3 & 1.4 \mathrm{E}-04 \\ 57.2 & -56.3 & 1.2 \mathrm{E}-04 \\ . & . & \\ 48.8 & -63.8 & 1.4 \mathrm{E}-04 \\ . & . & \\ 48.3 & -51.4 & 1.9 \mathrm{E}-04 \\ 52.3 & -51.4 & 2.6 \mathrm{E}-04 \\ 39.2 & -58.5 & 3.7 \mathrm{E}-04 \\ 320.2 & 50.4 & 5.0 \mathrm{E}-04 \\ 66.6 & -47.8 & 2.2 \mathrm{E}-04 \\ 51.1 & -57.8 & 1.7 \mathrm{E}-04 \\ 51.1 & -61.8 & 1.3 \mathrm{E}-04 \\ 43.0 & -65.4 & 1.1 \mathrm{E}-04 \\ 32.6 & -60.3 & 2.2 \mathrm{E}-04 \\ 46.5 & -63.2 & 2.4 \mathrm{E}-04 \\ 61.9 & -54.2 & 1.7 \mathrm{E}-04 \\ 43.4 & -65.1 & 1.2 \mathrm{E}-04 \\ 42.2 & -57.0 & 1.0 \mathrm{E}-04 \\ 75.8 & -67.2 & 1.0 \mathrm{E}-04 \\ 44.5 & -51.3 & 1.1 \mathrm{E}-04 \\ 52.5 & -50.9 & 8.5 \mathrm{E}-05 \\ 47.4 & -62.7 & 8.2 \mathrm{E}-05 \\ 76.1 & -62.9 & 1.8 \mathrm{E}-04 \\ 28.0 & -60.6 & 2.6 \mathrm{E}-04 \\ 27.5 & -51.0 & 1.9 \mathrm{E}-04 \\ 78.9 & -65.7 & 1.4 \mathrm{E}-04 \\ 43.7 & -66.5 & 1.4 \mathrm{E}-04 \\ 53.9 & -62.9 & 7.9 \mathrm{E}-05\end{array}$

$\begin{array}{rrrr}19.3 & 28.9 & 2.8963 & \mathrm{~N} \\ 49.1 & 13.2 & 3.9389 & \mathrm{~N} \\ 11.9 & 37.4 & 2.8325 & \mathrm{~N} \\ 38.6 & 20.1 & 2.9482 & \mathrm{~N} \\ 39.8 & 14.7 & 3.9247 & \mathrm{~N} \\ 54.2 & 12.6 & 3.9446 & \mathrm{~N} \\ 144.9 & 10.3 & 2.9862 & \mathrm{~N} \\ 22.5 & 26.6 & 2.9112 & \mathrm{~N} \\ 49.8 & 13.1 & 3.9398 & \mathrm{~N} \\ 11.6 & 38.0 & 2.8277 & \mathrm{~N} \\ 76.9 & 10.5 & 3.9696 & \mathrm{~N} \\ 105.3 & 9.0 & 3.9715 & \mathrm{R} \\ 53.7 & 17.0 & 2.9628 & \mathrm{~N} \\ 47.8 & 18.0 & 2.9582 & \mathrm{~N} \\ 22.0 & 23.0 & 2.9089 & \mathrm{~N} \\ 218.7 & 8.4 & 2.9909 & \mathrm{~N} \\ 82.1 & 10.2 & 3.9635 & \mathrm{~N} \\ 34.8 & 15.8 & 3.9139 & \mathrm{~N} \\ 30.3 & 22.8 & 2.9340 & \mathrm{~N} \\ 45.8 & 18.4 & 2.9563 & \mathrm{~N} \\ 215.5 & 8.4 & 2.9907 & \mathrm{~N} \\ 7.7 & 47.9 & 2.7401 & \mathrm{~N} \\ 71.6 & 14.6 & 2.9721 & \mathrm{~N} \\ 19.1 & 29.0 & 2.8952 & \mathrm{~N} \\ 17.4 & 30.5 & 2.8852 & \mathrm{~N} \\ 32.9 & 21.9 & 2.9390 & \mathrm{~N} \\ 56.5 & 16.6 & 2.9646 & \mathrm{~N} \\ 26.7 & 24.3 & 2.9252 & \mathrm{~N} \\ 14.7 & 33.4 & 2.8639 & \mathrm{~N} \\ 29.7 & 23.0 & 2.9326 & \mathrm{~N} \\ 32.1 & 22.1 & 2.9377 & \mathrm{~N} \\ & & & \end{array}$




\begin{tabular}{|c|c|c|c|c|c|c|c|c|c|c|c|c|}
\hline (1) & (2) & (3) & (4) & (5) & (6) & (7) & (8) & (9) & (10) & (11) & (12) & (13) \\
\hline 18965 & 509.0 & 1 & 3 & 225.60 & 1. $1 \mathrm{E}-03$ & 90.7 & -63.1 & $1.8 \mathrm{E}-04$ & 6.9 & 51.9 & 2.7098 & $\mathrm{~N}$ \\
\hline 18966 & 515.0 & 1 & . & 218.08 & $7.9 \mathrm{E}-04$ & . & . & . & . & . & . & \\
\hline 18967 & 521.0 & 2 & . & 283.88 & 2. $3 \mathrm{E}-03$ & . & . & - & . & . & & \\
\hline 18968 & 527.0 & 2 & 3 & 197.40 & $9.1 \mathrm{E}-04$ & 39.4 & -58.5 & 8. $9 \mathrm{E}-05$ & 26.7 & 24.3 & 2.9251 & $\mathrm{~N}$ \\
\hline 18969 & 532.0 & 1 & 3 & 203.04 & 1. $1 \mathrm{E}-03$ & 51.4 & -59.0 & 1. $.5 \mathrm{~F}-04$ & 20.0 & 28.3 & 2.9002 & $\mathrm{~N}$ \\
\hline 18970 & 537.0 & 1 & 3 & 223.72 & 1. $1 \mathrm{E}-03$ & 54.9 & -71.0 & 7. $9 \mathrm{E}-04$ & 23.2 & 26.2 & 2.9137 & $\mathrm{~N}$ \\
\hline 18971 & 542.0 & 1 & 3 & 238.76 & 1. $0 \mathrm{E}-03$ & 59.8 & -54.1 & 1. $7 \mathrm{E}-04$ & 2.6 & 78.9 & 2.2336 & $\mathrm{~N}$ \\
\hline 18972 & 547.0 & 1 & 3 & 235.00 & 1. $0 \mathrm{E}-03$ & 91.0 & -50.8 & 1. $4 \mathrm{E}-04$ & 14.8 & $3,3.3$ & 2.8649 & $\mathrm{~N}$ \\
\hline 18973 & 552.0 & 1 & 3 & 233.12 & 8.5E-04 & 88.4 & -38.7 & $7.4 \mathrm{E}-05$ & 12.3 & 36.7 & 2.8379 & $\mathrm{~N}$ \\
\hline 18974 & 557.0 & 1 & . & 250.04 & 1. $3 \mathrm{E}-03$ & . & . & . & . & . & . & \\
\hline 18975 & 562.0 & 1 & . & 250.04 & 1. $3 \mathrm{E}-03$ & & . & & . & . & 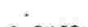 & \\
\hline 18976 & 576.0 & 1 & 3 & 204.92 & 7.2E-04 & 57.5 & -70.4 & $6.0 \mathrm{E}-05$ & 36.9 & 20.6 & 2.9459 & $\mathrm{~N}$ \\
\hline 18977 & 571.0 & 1 & 3 & 263.20 & 1. $3 \mathrm{E}-03$ & 28.6 & -64.8 & 1. $6 \mathrm{E}-04$ & 126.9 & 11.0 & 2.9842 & $\mathrm{~N}$ \\
\hline 18978 & 575.0 & 1 & 3 & 231.24 & 1. $1 \mathrm{E} \cdot 03$ & 29.6 & -51.8 & 1. $1 \mathrm{E}-04$ & 23.2 & 26.2 & 2.9139 & $\mathrm{~N}$ \\
\hline 18979 & 580.0 & . & . & . & . & . & . & . & . & . & . & \\
\hline 18980 & 584.0 & 1 & . & 266.96 & 1. $4 \mathrm{E}-03$ & . & . & $\therefore$ & . & . & . & \\
\hline 18981 & 593.0 & 0 & 3 & 276.36 & 1.7E-03 & . & . & 5.5E-05 & . & . & . & \\
\hline 18982 & 602.0 & . & . & . & . & . & & , & - & & & \\
\hline 18983 & 612.0 & 0 & 3 & 214.32 & 4. $9 \mathrm{E}-04$ & 94.5 & -58.4 & 4. $4 \mathrm{E}-05$ & 4.2 & 69.5 & 2.5272 & $\mathrm{~N}$ \\
\hline 18984 & 621.0 & . & . & . & . & . & & & $\therefore$ & . & & \\
\hline 18985 & 630.0 & 1 & 3 & 221.84 & $4.0 E-04$ & 83.1 & -39.7 & 4. $8 \mathrm{E}-05$ & 2.4 & 67.9 & 2.1634 & $\mathrm{~N}$ \\
\hline 18986 & 639.0 & . & . & . & . & . & . & . & . & . & & \\
\hline 18987 & 648.0 & 1 & 3 & 212.44 & 8.7E-04 & 54.2 & -42.6 & $7,1 \mathrm{E}-05$ & 5.1 & 61.6 & 2.6065 & $\mathrm{~N}$ \\
\hline 18988 & 658.0 & . & . & & & . & . & . & . & . & . & \\
\hline 18989 & 668.0 & 2 & 3 & 197.40 & $5.8 \mathrm{E}-04$ & . & . & 4. $2 \mathrm{E}-05$ & . & . & . & \\
\hline 18990 & 677.0 & . & & & . & . & . & . & . & & & \\
\hline 18991 & 686.0 & 0 & 3 & 199.28 & $5.1 \mathrm{E}-04$ & 125.0 & 42.9 & 4. $3 \mathrm{E}-05$ & 4.3 & 68.9 & 2.5327 & $\mathbf{R}$ \\
\hline 18992 & 695.0 & 1 & . & 195.52 & $2.6 \mathrm{E}-04$ & . & . & & . & . & & \\
\hline 18993 & 705.0 & 1 & 3 & 206.80 & 5.7E-04 & 27.0 & -66.8 & 2.5E-05 & 22.5 & 26.6 & 2.9110 & $\mathrm{~N}$ \\
\hline
\end{tabular}

$\begin{array}{lll}18994 & 714.0 & 0 \\ 18995 & 723.0 & 1 \\ 18996 & 759.0 & 1 \\ 18997 & 764.0 & 1 \\ 18998 & 769.0 & 2 \\ 18999 & 773.0 & 1 \\ 19000 & 778.0 & 1 \\ 19001 & 783.0 & 3 \\ 19002 & 788.0 & 1 \\ 19003 & 793.0 & 1 \\ 19004 & 799.0 & 1 \\ 19005 & 805.0 & 3 \\ 19006 & 810.0 & 1 \\ 19007 & 815.0 & 1 \\ 19008 & 820.0 & 1 \\ 19009 & 825.0 & 3 \\ 19010 & 830.0 & 1 \\ 19011 & 835.0 & 1 \\ 19012 & 840.0 & 1 \\ 19013 & 845.0 & 0 \\ 19014 & 850.0 & 1 \\ 19015 & 854.0 & 2 \\ 19016 & 859.0 & 2 \\ 19017 & 864.0 & 1 \\ 19018 & 868.0 & 1 \\ 19019 & 873.0 & 1 \\ 19020 & 878.0 & 1 \\ 19021 & 883.0 & 1 \\ 19022 & 889.0 & 0 \\ 19023 & 895.0 & 2 \\ 19024 & 900.0 & 1 \\ 19025 & 906.0 & 2 \\ 19026 & 911.0 & 2\end{array}$

\begin{tabular}{|c|c|}
\hline 06.80 & 7. $6 \mathrm{E}-04$ \\
\hline 246.28 & 1. $2 \mathrm{E}-03$ \\
\hline 172.96 & 8.2E-04 \\
\hline 182.36 & $9.2 \mathrm{E}-04$ \\
\hline 184.24 & 8.1E-04 \\
\hline 221.84 & 8.6E-04 \\
\hline 235.00 & 1. $3 \mathrm{E}-03$ \\
\hline 195.52 & 1. $2 \mathrm{E}-0.3$ \\
\hline 191.76 & 1. $4 \mathrm{E}-03$ \\
\hline 195.52 & $9.8 \mathrm{E}-04$ \\
\hline 212.44 & 9.1E-04 \\
\hline 235.00 & 8.9E-04 \\
\hline 212.44 & $9.2 \mathrm{E}-04$ \\
\hline 216.20 & 1. $1 \mathrm{E}-03$ \\
\hline 174.84 & 6. $0 \mathrm{E}-04$ \\
\hline 184.24 & 1. $0 \mathrm{E}-03$ \\
\hline 167.32 & 8.5E-04 \\
\hline 184.24 & $9.2 \mathrm{E}-04$ \\
\hline 193.64 & 8. $7 \mathrm{E}-04$ \\
\hline 191.76 & 8. 8E-04 \\
\hline 167.32 & 5. $2 \mathrm{E}-04$ \\
\hline 203.04 & $5,8 E-04$ \\
\hline 184.24 & 4. $9 \mathrm{E}-04$ \\
\hline 176.72 & $6.6 \mathrm{E}-04$ \\
\hline 182.36 & $5.4 \mathrm{E}-04$ \\
\hline 218.08 & 2. $6 \mathrm{E}-04$ \\
\hline 203.04 & 3. $0 E-04$ \\
\hline 172.96 & $3.4 \mathrm{E}-04$ \\
\hline 178.60 & 8. $5 \mathrm{E}-04$ \\
\hline 186,12 & 4. $7 \mathrm{E}-04$ \\
\hline 186.12 & 4. $9 \mathrm{E}-04$ \\
\hline 184.24 & $4.4 \mathrm{E}-04$ \\
\hline & \\
\hline
\end{tabular}

$\begin{array}{rrr}57.3 & -50.4 & 2.2 \mathrm{E}-04 \\ 55.9 & -38.4 & 1.2 \mathrm{E}-04 \\ 85.9 & -46.4 & 2.3 \mathrm{E}-04 \\ 56.8 & -48.0 & 1.8 \mathrm{E}-04 \\ 56.4 & -54.2 & 1.5 \mathrm{E}-04 \\ 51.9 & -50.1 & 3.0 \mathrm{E}-04 \\ 37.0 & -56.1 & 3.3 \mathrm{E}-04 \\ 35.3 & -59.2 & 2.5 \mathrm{E}-04 \\ 34.8 & -56.3 & 2.3 \mathrm{E}-04 \\ . & . & . \\ 34.7 & -62.5 & 2.9 \mathrm{E}-04 \\ 27.1 & -61.3 & 2.8 \mathrm{E}-04 \\ 39.8 & -67.3 & 2.4 \mathrm{E}-04 \\ 41.2 & -61.7 & 2.7 \mathrm{E}-04 \\ 36.2 & -62.3 & 2.2 \mathrm{E}-04 \\ 38.7 & -60.7 & 2.3 \mathrm{E}-04 \\ 26.3 & -61.7 & 2.8 \mathrm{E}-04 \\ 37.1 & -62.9 & 2.9 \mathrm{E}-04 \\ 23.0 & -61.2 & 1.0 \mathrm{E}-04 \\ 63.9 & -69.8 & 2.1 \mathrm{E}-04 \\ 61.5 & -74.1 & 1.2 \mathrm{E}-04 \\ 33.2 & -66.4 & 1.4 \mathrm{E}-04 \\ 224.4 & 38.6 & 2.8 \mathrm{E}-04 \\ . & .6 & . \\ 85.9 & -59.9 & 4.5 \mathrm{E}-05 \\ 81.5 & -55.3 & 6.0 \mathrm{E}-05 \\ 90.0 & -8.8 & 4.3 \mathrm{E}-05 \\ 300.9 & -58.7 & 1.2 \mathrm{E}-04 \\ 45.3 & -50.3 & 8.8 \mathrm{E}-05 \\ 60.5 & -62.2 & 4.7 \mathrm{E}-05 \\ 198.3 & 54.3 & 5.7 \mathrm{E}-04 \\ & & \end{array}$

$\begin{array}{rrrr}10.5 & 40.2 & 2.8093 & \mathrm{~N} \\ 34.4 & 21.4 & 2.9148 & \mathrm{~N} \\ 17.7 & 30.3 & 2.8867 & \mathrm{~N} \\ 22.9 & 26.4 & 2.9127 & \mathrm{~N} \\ 53.7 & 17.0 & 2.9628 & \mathrm{~N} \\ 5.6 & 42.8 & 3.4622 & \mathrm{~N} \\ 150.7 & 7.5 & 3.9801 & \mathrm{~N} \\ 32.3 & 22.0 & 2.9382 & \mathrm{~N} \\ 55.3 & 12.5 & 3.9460 & \mathrm{~N} \\ . & . & . & \\ 674.5 & 4.8 & 2.9970 & \mathrm{~N} \\ 61.5 & 15.9 & 2.9675 & \mathrm{~N} \\ 64.9 & 15.4 & 2.9692 & \mathrm{~N} \\ 414.3 & 6.1 & 2.9952 & \mathrm{~N} \\ 106.9 & 8.9 & 3.9719 & \mathrm{~N} \\ 77.6 & 14.1 & 2.9742 & \mathrm{~N} \\ 192.7 & 8.9 & 2.9896 & \mathrm{~N} \\ 147.7 & 10.2 & 2.9865 & \mathrm{~N} \\ 53.3 & 17.1 & 2.9625 & \mathrm{~N} \\ 88.2 & 13.2 & 2.9773 & \mathrm{~N} \\ 37.3 & 15.2 & 3.9195 & \mathrm{~N} \\ 128.3 & 10.9 & 2.9844 & \mathrm{~N} \\ 2.4 & 70.4 & 2.1665 & \mathrm{R} \\ 10.9 & 29.2 & 3.7242 & \mathrm{~N} \\ 5.7 & 57.3 & 2.6489 & \mathrm{~N} \\ 19.0 & 29.1 & 2.8946 & \mathrm{~N} \\ 9.6 & 42.3 & 2.7906 & \mathrm{~N} \\ 4.2 & 69.8 & 2.5239 & \mathrm{~N} \\ 58.6 & 16.3 & 2.9659 & \mathrm{~N} \\ 6.5 & 53.0 & 2.6913 & \mathrm{R}\end{array}$

$\begin{array}{lrl}19027 & 916.0 & 1 \\ 19028 & 921.0 & 1 \\ 19029 & 925.0 & 2 \\ 19030 & 929.0 & 1 \\ 19031 & 934.0 & 1 \\ 19032 & 939.0 & 1 \\ 19033 & 944.0 & 1 \\ 19034 & 949.0 & 1 \\ 19035 & 954.0 & 0 \\ 19036 & 958.0 & 1 \\ 19037 & 963.0 & 1 \\ 19038 & 968.0 & 1 \\ 19039 & 973.0 & 1 \\ 19040 & 978.0 & 2 \\ 19041 & 983.0 & 3 \\ 19042 & 988.0 & 1 \\ 19043 & 993.0 & 1 \\ 19044 & 998.0 & 1 \\ 19045 & 1003.0 & 1 \\ 19046 & 1008.0 & 1 \\ 19047 & 1013.0 & 1 \\ 19048 & 1019.0 & 0 \\ 19049 & 1024.0 & 1 \\ 19050 & 1030.0 & 1 \\ 19051 & 1035.0 & 1 \\ 19052 & 1040.0 & 1 \\ 19053 & 1045.0 & 1 \\ 19054 & 1050.0 & 0 \\ 19055 & 1054.0 & 1 \\ 19056 & 1060.0 & 1 \\ 19057 & 1065.0 & 1 \\ 19058 & 1071.0 & 1 \\ 19059 & 1077.0 & 1 \\ & & \end{array}$

$\begin{array}{lcc}182.36 & 4.2 \mathrm{E}-04 & 232.3 \\ 178.60 & 4.2 \mathrm{E}-04 & 201.3 \\ 171.08 & 5.5 \mathrm{E}-04 & 280.5 \\ 189.88 & 4.8 \mathrm{E}-04 & 230.0 \\ 176.72 & 4.8 \mathrm{E}-04 & 212.4 \\ 182.36 & 4.6 \mathrm{E}-04 & 200.9 \\ 174.84 & 4.9 \mathrm{E}-04 & . \\ 172.96 & 4.3 \mathrm{E}-04 & . \\ 180.48 & 4.1 \mathrm{E}-04 & . \\ 184.24 & 3.7 \mathrm{E}-04 & 198.3 \\ 178.60 & 3.1 \mathrm{E}-04 & 207.3 \\ 180.48 & 4.3 \mathrm{E}-04 & . \\ 189.88 & 4.0 \mathrm{E}-04 & 286.3 \\ 218.08 & 5.5 \mathrm{E}-04 & 214.7 \\ 261.32 & 3.3 \mathrm{E}-03 & 225.2 \\ 308.32 & 6.9 \mathrm{E}-03 & 229.3 \\ 344.04 & 6.6 \mathrm{E}-03 & 312.6 \\ 193.64 & 4.8 \mathrm{E}-04 & 259.5 \\ 193.64 & 5.8 \mathrm{E}-04 & 229.6 \\ 193.64 & 2.9 \mathrm{E}-04 & 248.3 \\ 201.16 & 5.2 \mathrm{E}-04 & 223.9 \\ 216.20 & 1.7 \mathrm{E}-03 & 236.1 \\ 182.36 & 4.3 \mathrm{E}-04 & 231.3 \\ 227.48 & 4.6 \mathrm{E}-04 & 231.5 \\ 180.48 & 4.5 \mathrm{E}-04 & 342.5 \\ 178.60 & 3.6 \mathrm{E}-04 & 195.0 \\ 197.40 & 3.7 \mathrm{E}-04 & 242.2 \\ & .94 & \\ 174.84 & 5.7 \mathrm{E}-04 & 214.2 \\ 246.28 & 5.4 \mathrm{E}-03 & 214.7 \\ 250.04 & 8.7 \mathrm{E}-04 & 223.6 \\ 193.64 & 9.0 \mathrm{E}-04 & 196.6 \\ 180.48 & 2.5 \mathrm{E}-04 & 234.4\end{array}$

$\begin{array}{cc}85.2 & 5.0 \mathrm{E}-04 \\ 56.3 & 4.8 \mathrm{E}-04 \\ 25.8 & 3.2 \mathrm{E}-04 \\ 40.5 & 7.5 \mathrm{E}-05 \\ 58.8 & 5.6 \mathrm{E}-05 \\ 41.4 & 1.3 \mathrm{E}-04 \\ . & . \\ . & . \\ 56.0 & 6.5 \mathrm{E}-05 \\ 63.8 & 6.4 \mathrm{E}-05 \\ . & . \\ 78.0 & 2.4 \mathrm{E}-05 \\ 55.0 & 3.4 \mathrm{E}-05 \\ 65.0 & 2.9 \mathrm{E}-03 \\ 55.7 & 5.1 \mathrm{E}-03 \\ 53.3 & 5.9 \mathrm{E}-03 \\ 75.6 & 1.1 \mathrm{E}-04 \\ 46.4 & 6.3 \mathrm{E}-04 \\ 64.3 & 3.6 \mathrm{E}-04 \\ 41.6 & 5.1 \mathrm{E}-04 \\ 59.9 & 1.2 \mathrm{E}-03 \\ 60.1 & 4.1 \mathrm{E}-04 \\ 69.0 & 5.1 \mathrm{E}-04 \\ 58.2 & 5.2 \mathrm{E}-04 \\ 51.1 & 3.8 \mathrm{E}-04 \\ 65.0 & 4.5 \mathrm{E}-04 \\ .04 & 5.4 \mathrm{E}-04 \\ 60.0 & 5.4 \mathrm{E}-04 \\ 54.4 & 4.3 \mathrm{E}-03 \\ 67.8 & 9.1 \mathrm{E}-04 \\ 80.0 & 5.1 \mathrm{E}-04 \\ 63.7 & 2.6 \mathrm{E}-04\end{array}$

\begin{tabular}{|c|c|c|}
\hline 24.9 & 25.3 & 2.9196 \\
\hline 4.4 & 49.7 & 3. 3168 \\
\hline 3.3 & 83.0 & 2.3942 \\
\hline 7.7 & 35.5 & 3.6087 \\
\hline 5.0 & 45.6 & 3.4047 \\
\hline 2.2 & 58.0 & 2.0826 \\
\hline - & . & . \\
\hline • & . & - \\
\hline 4.1 & 71.3 & 2.5090 \\
\hline 56.3 & 12.3 & 3.9473 \\
\hline 3 & 7 & $\therefore$ \\
\hline 12.4 & 27.2 & 3.7576 \\
\hline 9.2 & 32.1 & 3.6727 \\
\hline 95.8 & 9.4 & 3.9680 \\
\hline 45.2 & 13.8 & 3.9336 \\
\hline 137.4 & 7.9 & 3.9782 \\
\hline 40.2 & 19.7 & 2.9502 \\
\hline 18.8 & 29.3 & 2.8936 \\
\hline 15.9 & 32.0 & 2.8741 \\
\hline 7.6 & 48.1 & 2.7383 \\
\hline 187.1 & 9.0 & 2.9893 \\
\hline 659.2 & 3.6 & 3.9955 \\
\hline 3.0 & 89.4 & 2.3235 \\
\hline 36.8 & 20.6 & 2.9457 \\
\hline 3.4 & 80.8 & 2.4157 \\
\hline 5.5 & 58.7 & 2.6357 \\
\hline 53.3 & 12.7 & 3.9437 \\
\hline 78.6 & 14.0 & 2.9746 \\
\hline 10.0 & 41.3 & 2.7993 \\
\hline 4.4 & 67.9 & 2.5429 \\
\hline 33.6 & 21.6 & 2.9405 \\
\hline
\end{tabular}




$\begin{array}{cccc}(1) & (2) & (3) & (4) \\ 19060 & 1084.0 & 1 & 3 \\ 19061 & 1090.0 & 1 & 4 \\ 19062 & 1095.0 & 1 & . \\ 19063 & 1100.0 & 2 & 4 \\ 19064 & 1105.0 & 1 & 3 \\ 19065 & 1110.0 & 1 & 3 \\ 19066 & 1116.0 & 1 & 4 \\ 19067 & 1121.0 & 1 & 3 \\ 19068 & 1127.0 & 1 & 3 \\ 19069 & 1132.0 & 1 & 3 \\ 19070 & 1137.0 & . & 3 \\ 19071 & 1142.0 & 2 & 3 \\ 19072 & 1147.0 & 0 & 3 \\ 19073 & 1152.0 & 2 & 3 \\ 19074 & 1157.0 & 1 & 4 \\ 19075 & 1163.0 & 0 & 3 \\ 19076 & 1168.0 & 1 & 4 \\ 19077 & 1173.0 & 2 & 4 \\ 19078 & 1179.0 & 1 & 5 \\ 19079 & 1184.0 & 1 & 5 \\ 19080 & 1190.0 & 1 & 4 \\ 19081 & 1195.0 & 0 & 3 \\ 19082 & 1200.0 & 2 & 4 \\ 19083 & 1205.0 & 1 & 3 \\ 19084 & 1210.0 & 2 & 5 \\ 19085 & 1215.0 & 2 & 3 \\ 19086 & 1220.0 & 1 & 4 \\ 19087 & 1225.0 & 2 & 3 \\ 19088 & 1230.0 & 1 & 4 \\ & & & \end{array}$

$\begin{array}{ccr}(5) & (6) & (7) \\ 161.68 & 1.1 \mathrm{E}-04 & 217.8 \\ 184.24 & 6.4 \mathrm{E}-05 & 217.3 \\ 193.64 & 5.5 \mathrm{E}-04 & . \\ 195.52 & 5.0 \mathrm{E}-04 & 198.6 \\ 189.88 & 6.2 \mathrm{E}-04 & 52.6 \\ 246.28 & 9.4 \mathrm{E}-04 & 31.6 \\ 199.28 & 4.8 \mathrm{E}-04 & 203.6 \\ 191.76 & 2.0 \mathrm{E}-04 & 216.7 \\ 216.20 & 1.5 \mathrm{E}-03 & 239.0 \\ 182.36 & 3.8 \mathrm{E}-04 & 216.8 \\ 197.40 & 4.8 \mathrm{E}-04 & \\ 293.28 & 1.9 \mathrm{E}-03 & 227.4 \\ 184.24 & 5.7 \mathrm{E}-04 & 224.1 \\ 172.96 & 4.0 \mathrm{E}-04 & 219.4 \\ 257.56 & 2.0 \mathrm{E}-03 & 215.0 \\ 172.96 & 3.6 \mathrm{E}-04 & 208.9 \\ 304.56 & 8.8 \mathrm{E}-05 & 214.7 \\ 167.32 & 2.0 \mathrm{E}-04 & 220.6 \\ 152.28 & 1.2 \mathrm{E}-04 & 213.6 \\ 152.28 & 9.2 \mathrm{E}-04 & 213.2 \\ 191.76 & 7.9 \mathrm{E}-05 & 228.6 \\ 204.92 & 1.5 \mathrm{E}-04 & 220.5 \\ 191.76 & 1.1 \mathrm{E}-03 & 232.3 \\ 189.88 & 4.0 \mathrm{E}-04 & .3 \\ 210.56 & 4.2 \mathrm{E}-04 & 222.3 \\ 210.56 & 1.2 \mathrm{E}-03 & 228.7 \\ 184.24 & 1.6 \mathrm{E}-03 & 227.4 \\ 184.24 & 2.4 \mathrm{E}-04 & 219.0\end{array}$

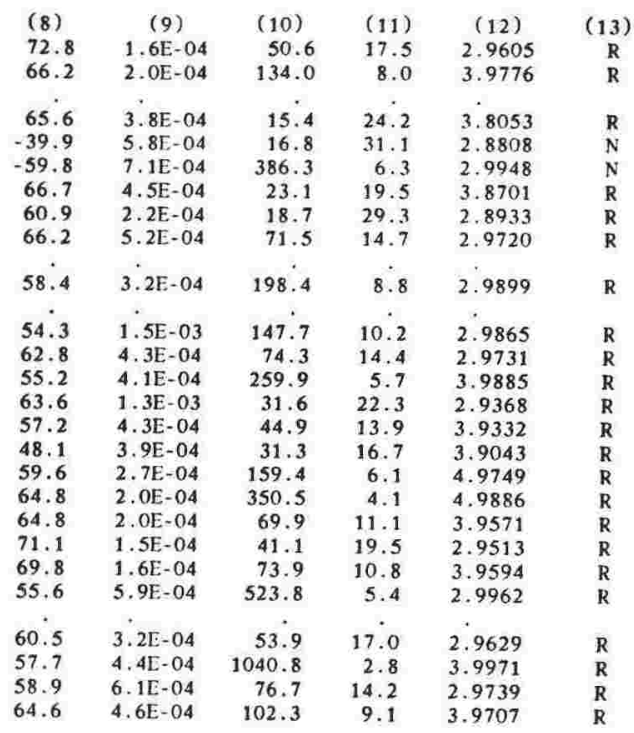

$\begin{array}{ll}19089 & 1245.0 \\ 19090 & 1250.0 \\ 19091 & 1256.0 \\ 19092 & 1261.0 \\ 19093 & 1272.0 \\ 19094 & 1277.0 \\ 19095 & 1282.0 \\ 19096 & 1287.0 \\ 19097 & 1293.0 \\ 19098 & 1298.0 \\ 19099 & 1314.0 \\ 19100 & 1319.0 \\ 19101 & 1324.0 \\ 19102 & 1329.0 \\ 19103 & 1334.0 \\ 19104 & 1339.0 \\ 19105 & 1345.0 \\ 19106 & 1403.0 \\ 19107 & 1409.0 \\ 19108 & 1415.0 \\ 19109 & 1421.0 \\ 19110 & 1427.0 \\ 19111 & 1433.0 \\ 19112 & 1439.0 \\ 19113 & 1445.0 \\ 19114 & 1450.0 \\ 19115 & 1456.0 \\ 19116 & 1461.0 \\ 19117 & 1467.0 \\ 19118 & 1473.0 \\ 19119 & 1479.0 \\ 19120 & 1485.0 \\ 19121 & 1490.0 \\ & \end{array}$

$\begin{array}{ll}165.44 & 1.3 \mathrm{E}-04 \\ 216.20 & 8.2 \mathrm{E}-05 \\ 285.76 & 1.9 \mathrm{E}-04 \\ 184.24 & 1.7 \mathrm{E}-04 \\ 176.72 & 6.1 \mathrm{E}-05 \\ 182.36 & 1.2 \mathrm{E}-04 \\ 182.36 & 9.9 \mathrm{E}-05 \\ 188.00 & 6.5 \mathrm{E}-05 \\ 193.64 & 6.0 \mathrm{E}-04 \\ 174.84 & 1.8 \mathrm{E}-04 \\ 188.00 & 1.3 \mathrm{E}-04 \\ 176.72 & 1.3 \mathrm{E}-04 \\ 180.48 & 1.7 \mathrm{E}-04 \\ 169.20 & 2.5 \mathrm{E}-04 \\ 178.60 & 2.0 \mathrm{E}-04 \\ 171.08 & 1.7 \mathrm{E}-04 \\ 161.68 & 2.1 \mathrm{E}-04 \\ 150.40 & 3.2 \mathrm{E}-04 \\ 172.96 & 3.5 \mathrm{E}-04 \\ 154.16 & 3.2 \mathrm{E}-04 \\ 158.24 & 4.3 \mathrm{E}-04 \\ 165.44 & 4.5 \mathrm{E}-04 \\ 172.96 & 3.6 \mathrm{E}-04 \\ 165.44 & 4.0 \mathrm{E}-04 \\ . & . \\ 154.16 & 4.0 \mathrm{E}-04 \\ 139.12 & 3.7 \mathrm{E}-04 \\ 163.56 & 4.3 \mathrm{E}-04 \\ 197.40 & 3.0 \mathrm{E}-04 \\ 161.68 & 2.7 \mathrm{E}-04 \\ 172.96 & 3.3 \mathrm{E}-04 \\ 182.36 & 4.7 \mathrm{E}-04 \\ 172.96 & 5.7 \mathrm{E}-04\end{array}$

205.4
193.6
182.7
207.0
218.2
212.9
213.5
224.3
214.1
237.8
221.9
227.0
226.5
214.1
217.6
217.2
210.7
218.7
.
219.2
215.1
33.4
39.5
83.9
53.2
60.3
52.9

71.

67.1 1.1E-04

$54.5 \quad 6.6 \mathrm{E}-04$

$\begin{array}{ll}59.3 & 1.1 \mathrm{E}-04 \\ 71.2 & 1.2 \mathrm{E}-04\end{array}$

$66.9 \quad 2.4 \mathrm{E}-04$

$58.8 \quad 2.1 \mathrm{E}-04$

$\begin{array}{ll}55.0 & 6.8 \mathrm{E}-04 \\ 63.1 & 3.4 \mathrm{E}-04\end{array}$

63.4 1.5E-04

$55.9 \quad 1.1 E-04$

75.8 9.5E-05

\begin{tabular}{ll}
58.8 & $7.6 \mathrm{E}-05$ \\
\hline & $2.7 \mathrm{E}-05$
\end{tabular}

$\begin{array}{ll}56.2 & 2.7 \mathrm{E}-05 \\ 56.3 \mathrm{E}-05\end{array}$

$60.0 \quad 8.2 \mathrm{E}-05$

64.7 5.3E-05

61.0 6.5E-05

67.7 5.6E-05

$65.7 \quad 4.2 \mathrm{E}-05$

$61.4 \quad 7.4 \mathrm{E}-05$

$-51.5$

$-51.5$

$-49.9$

-49.6 6. 6 - 05

$-42.3 \quad 8.2 \mathrm{E}-05$

8. $2 \mathrm{E}-05$
7. $0 \mathrm{E}-05$

$\begin{array}{rrrr}78.6 & 8.7 & 4.9491 & \mathrm{R} \\ 8.4 & 45.5 & 2.7625 & \mathrm{R} \\ 24.3 & 19.0 & 3.8763 & \mathrm{R} \\ 26.2 & 24.6 & 2.9236 & \mathrm{R} \\ 40.0 & 14.7 & 3.9251 & \mathrm{R} \\ 439.2 & 4.4 & 3.9932 & \mathrm{R} \\ 73.9 & 10.8 & 3.9594 & \mathrm{R} \\ 937.1 & 3.0 & 3.9968 & \mathrm{R} \\ 114.4 & 8.6 & 3.9738 & \mathrm{R} \\ 36.4 & 20.7 & 2.9450 & \mathrm{R} \\ 26.4 & 24.5 & 2.9244 & \mathrm{R} \\ . & . & . & \\ 63.0 & 15.7 & 2.9683 & \mathrm{R} \\ . & . & & \mathrm{R} \\ 107.6 & 11.9 & 2.9814 & \mathrm{R} \\ 26.9 & 24.2 & 2.9258 & \mathrm{R} \\ 27.0 & 24.2 & 2.9259 & \mathrm{R} \\ 535.0 & 5.3 & 2.9963 & \mathrm{R} \\ 22.4 & 26.7 & 2.9108 & \mathrm{R} \\ 16.0 & 31.9 & 2.8751 & \mathrm{R} \\ . & . & . & \\ 15.0 & 33.0 & 2.8699 & \mathrm{R} \\ 184.0 & 9.1 & 2.9891 & \mathrm{R} \\ 17.4 & 22.7 & 3.8273 & \mathrm{~N} \\ 46.8 & 18.2 & 2.9572 & \mathrm{~N} \\ 10.0 & 41.3 & 2.7998 & \mathrm{~N} \\ 13.0 & 35.7 & 2.8460 & \mathrm{~N} \\ 21.4 & 27.4 & 2.9065 & \mathrm{~N} \\ 48.1 & 18.0 & 2.9584 & \mathrm{~N}\end{array}$

\begin{tabular}{|c|c|}
\hline 19122 & 1495.0 \\
\hline 19123 & 1501.0 \\
\hline 19124 & 1507.0 \\
\hline 19125 & 1512.0 \\
\hline 19126 & 1518.0 \\
\hline 19127 & 1524.0 \\
\hline 19128 & 1530.0 \\
\hline 19129 & 1536.0 \\
\hline 19130 & 1542.0 \\
\hline 19131 & 1548.0 \\
\hline 19132 & 1552.0 \\
\hline 19133 & 1556.0 \\
\hline 19134 & 1560.0 \\
\hline 19135 & 1564.0 \\
\hline 19136 & 1569.0 \\
\hline 19137 & 1574.0 \\
\hline 19138 & 1580.0 \\
\hline 19139 & 1585.0 \\
\hline 19140 & 1590.0 \\
\hline 19141 & 1595.0 \\
\hline 19142 & 1599.0 \\
\hline 19143 & 1604.0 \\
\hline 19144 & 1608.0 \\
\hline 19145 & 1612.0 \\
\hline 19146 & 1616.0 \\
\hline 19147 & 1622.0 \\
\hline 19148 & 1627.0 \\
\hline 19149 & 1633.0 \\
\hline 19150 & 1638.0 \\
\hline 19151 & 1643.0 \\
\hline 19152 & 1649.0 \\
\hline 19153 & 1650.0 \\
\hline 9154 & \\
\hline
\end{tabular}

\begin{tabular}{ll}
325.24 & $3.9 \mathrm{E}-04$ \\
169.20 & $4.0 \mathrm{E}-04$ \\
268.84 & $4.2 \mathrm{E}-04$ \\
193.64 & $4.0 \mathrm{E}-04$ \\
182.36 & $2.8 \mathrm{E}-04$ \\
248.16 & $4.6 \mathrm{E}-04$ \\
178.60 & $4.1 \mathrm{E}-04$ \\
163.56 & $3.8 \mathrm{E}-04$ \\
159.80 & $2.4 \mathrm{E}-04$ \\
161.68 & $3.5 \mathrm{E}-04$ \\
188.00 & $7.1 \mathrm{E}-04$ \\
180.48 & $3.0 \mathrm{E}-04$ \\
171.08 & $4.9 \mathrm{E}-04$ \\
169.20 & $7.0 \mathrm{E}-04$ \\
163.56 & $2.3 \mathrm{E}-04$ \\
169.20 & $3.9 \mathrm{E}-04$ \\
163.56 & $2.8 \mathrm{E}-04$ \\
167.32 & $2.4 \mathrm{E}-04$ \\
144.76 & $2.4 \mathrm{E}-04$ \\
171.08 & $1.1 \mathrm{E}-04$ \\
172.96 & $1.9 \mathrm{E}-04$ \\
171.08 & $3.1 \mathrm{E}-04$ \\
163.56 & $1.0 \mathrm{E}-04$ \\
169.20 & $1.1 \mathrm{E}-04$ \\
174.84 & .94 \\
174.84 & $1.7 \mathrm{E}-04$ \\
186.12 & $1.2 \mathrm{E}-04$ \\
176.72 & $1.8 \mathrm{E}-04$ \\
163.56 & $1.9 \mathrm{E}-04$ \\
184.24 & $2.0 \mathrm{E}-04$ \\
\hline &
\end{tabular}

$$
7
$$

$50.6-54.4$

$\begin{array}{lll}41.1 & -59.4 & 1.3 \mathrm{E}-04 \\ 47.7 & -50.2 & 9.5 \mathrm{E}-05\end{array}$

$\begin{array}{lll}50.0 & -51.6 & 1.5 \mathrm{E}-04 \\ 53.8 & -66.1 & 1.1 \mathrm{E}-04\end{array}$

$49.0 \quad-56.0 \quad 9.0 \mathrm{E}-05$

$\begin{array}{lll}42.6 & -54.7 & 6.0 \mathrm{E}-05\end{array}$

$38.2 \quad-54.7 \quad 1.1 \mathrm{E}-04$

$\begin{array}{lll}61.0 & -56.6 & 1.6 \mathrm{E}-04\end{array}$

$46.1 \quad-66.8$

29.5
55.5

$\begin{array}{ll}55.5 & -50.1 \\ 83.5 & -63.6\end{array}$

$1.8 \mathrm{E}-05$
-1.05

9.8E-05

$\begin{array}{lll}69.6 & -57.5 & 3.6 \mathrm{E}-05 \\ & & 1.0 \mathrm{E}-04\end{array}$

$30.1 \quad-52.7 \quad 4.8 \mathrm{E}-05$

231.5

$\begin{array}{ll}53.9 & 3.9 \mathrm{E}-05 \\ 41.3 & 5.6 \mathrm{E}-05\end{array}$

$\begin{array}{ll}41.3 & 5.6 \mathrm{E}-05 \\ 50.1 & 1.0 \mathrm{E}-04\end{array}$

45 1.0E-04

$\begin{array}{ll}45.7 & 2.3 \mathrm{E}-05\end{array}$

$\begin{array}{lll}48.1 & 18.0 & 2.9584\end{array}$

N 


\begin{tabular}{|c|c|c|c|c|c|c|c|c|c|c|c|c|}
\hline (1) & (2) & (3) & (4) & (5) & (6) & (7) & (8) & (9) & (10) & (11) & (12) & (13) \\
\hline 19155 & 1757.0 & 1 & 3 & 171.08 & 2.5E-04 & 209.3 & 60.2 & 1. $8 \mathrm{E}-05$ & 241.2 & 8.0 & 2.9917 & \\
\hline 19156 & 1762.0 & 1 & 3 & 176.72 & $3.0 \mathrm{E}-04$ & 47.2 & -68.1 & 8. $5 \mathrm{E}-05$ & 41.6 & 19.4 & 2.9519 & $\mathrm{~N}$ \\
\hline 19157 & 1767.0 & 2 & 4 & 188.00 & $3.6 \mathrm{E}-04$ & 45.5 & -58.0 & 1. $3 \mathrm{E}-04$ & 275.3 & 5.5 & 3.9891 & $\mathrm{~N}$ \\
\hline 19158 & 1772.0 & 2 & 3 & 172.96 & 3. $5 E-04$ & 25.9 & -63.9 & $7.1 \mathrm{E}-05$ & 33.5 & 21.6 & 2.9404 & $\mathrm{~N}$ \\
\hline 19159 & 1779.0 & 1 & 3 & 188.00 & $2.8 \mathrm{E}-04$ & 48.7 & -62.0 & $5.2 \mathrm{E}-05$ & 33.9 & 21.5 & 2.9409 & $\mathrm{~N}$ \\
\hline $\begin{array}{l}19161 \\
19162\end{array}$ & 1794.0 & $\begin{array}{l}0 \\
0\end{array}$ & 3 & 174.84 & 2. $3 \mathrm{E}-04$ & 63.5 & -44.3 & $3.6 \mathrm{E}-05$ & 116.4 & 11.5 & 2.9828 & $\mathrm{~N}$ \\
\hline $\begin{array}{l}19162 \\
19163\end{array}$ & $\begin{array}{l}1801.0 \\
1807.0\end{array}$ & 1 & 3 & 193.64 & 4. $5 \mathrm{E}-04$ & 37.5 & -58.6 & $9.3 \mathrm{E}-05$ & 94.3 & 12.8 & 2.9788 & $\mathrm{~N}$ \\
\hline $\begin{array}{l}19163 \\
19164\end{array}$ & $\begin{array}{l}1807.0 \\
1816.0\end{array}$ & 2 & 3 & 193.64 & 4. $7 \mathrm{E}-04$ & 48.1 & -56.1 & $1.7 \mathrm{E}-04$ & 96.3 & 12.6 & 2.9793 & $\mathrm{~N}$ \\
\hline $\begin{array}{l}19164 \\
19165\end{array}$ & $\begin{array}{l}1816.0 \\
1825.0\end{array}$ & 2 & 3 & $\begin{array}{l}174.84 \\
214.32\end{array}$ & $\begin{array}{l}2.2 \mathrm{E}-04 \\
2.2 \mathrm{E}-04\end{array}$ & 50.1 & -45.0 & 4. $1 \mathrm{E}-05$ & 24.9 & 25.2 & 2.9197 & $\mathrm{~N}$ \\
\hline 19166 & 1836.0 & 0 & 3 & 186.12 & $\begin{array}{l}2.2 \mathrm{E}-04 \\
2.6 \mathrm{E}-04\end{array}$ & 52.9 & -56.9 & $3.8 \mathrm{E}-05$ & 389.8 & 6.3 & 2.9949 & $\mathrm{~N}$ \\
\hline 19167 & 1848.0 & 0 & . & 171.08 & $2.1 \mathrm{E}-04$ & . & & & . & . & & \\
\hline 19168 & 1857.0 & 2 & 3 & 159.80 & 2.1E-04 & 56.4 & -52.4 & 5. $7 E-05$ & 370.6 & 6.4 & 2.9946 & $\mathrm{~N}$ \\
\hline $\begin{array}{l}19169 \\
19170\end{array}$ & 1866.0 & 1 & i & 172.96 & 2.0E-04 & . & . & . & $\cdot$ & . & . & \\
\hline $\begin{array}{l}19170 \\
19171\end{array}$ & 1875.0 & 1 & 3 & 178.60 & $1.9 \mathrm{E}-04$ & 256.2 & 20.1 & 2.9E-05 & 4.3 & 68.6 & 2.5345 & R \\
\hline $\begin{array}{l}19171 \\
19172\end{array}$ & 1884.0 & $\begin{array}{l}1 \\
1\end{array}$ & 4 & $\begin{array}{l}167.32 \\
171.08\end{array}$ & 1.9E-04 & 197.9 & 53.2 & $2.0 E-05$ & 4.0 & 53.1 & 3.2439 & $\mathbf{R}$ \\
\hline $\begin{array}{l}19172 \\
19173\end{array}$ & $\begin{array}{l}1892.0 \\
1901.0\end{array}$ & $\begin{array}{l}1 \\
1\end{array}$ & 3 & $\begin{array}{l}171.08 \\
174.84\end{array}$ & $\begin{array}{l}\text { 1. } 6 \mathrm{E}-04 \\
\text { 1. } 5 \mathrm{E}-04\end{array}$ & 293.7 & 36.0 & $2.2 \mathrm{E}-05$ & 6.9 & 51.0 & 2.7104 & R \\
\hline 19174 & 1909.0 & 3 & . & 188.00 & 1.9E-04 & & . & . & . & & 2.1104 & \\
\hline 19175 & 1918.0 & 1 & 3 & 182.36 & 8.0E-05 & 219.3 & 21.3 & $3.6 \mathrm{E}-05$ & 3.5 & 78.9 & 2.4340 & $\mathrm{R}$ \\
\hline 19176 & 1927.0 & 1 & . & 169.20 & 1. $2 \mathrm{E}-04$ & & . & . & . & $\cdot$ & & \\
\hline 19177 & 1936.0 & 0 & 3 & 167.32 & $1.6 \mathrm{E}-04$ & 246.7 & 40.3 & 1. $7 \mathrm{E}-05$ & 12.6 & 36.3 & 2.8410 & $\mathbf{R}$ \\
\hline 19178 & 1945.0 & 0 & 3 & 203.04 & 2. $8 \mathrm{E}-04$ & 259.9 & 45.0 & $2.8 \mathrm{E}-05$ & 9.9 & 41.5 & 2.7976 & $\mathbf{R}$ \\
\hline 19179 & 1954.0 & 3 & . & 174.84 & 2.0E-04 & $\therefore$ & . & . & 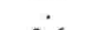 & i & . & \\
\hline 19180 & 1959.0 & 1 & 3 & 191.76 & $2.9 \mathrm{E}-04$ & 267.3 & 38.1 & $5.9 \mathrm{E}-05$ & 3.6 & 78.0 & 2.4427 & $\mathrm{R}$ \\
\hline 19181 & 1964.0 & 1 & 3 & 161.68 & 9.2E-05 & 221.9 & 31.4 & 2. $3 \mathrm{E}-05$ & 9.1 & 43.4 & 2.7809 & $\mathbf{R}$ \\
\hline 19182 & 1975.0 & 2 & 3 & 157.92 & 1.5E-04 & 250.2 & 72.2 & 2.2E-05 & 6.3 & 54.1 & 2.6803 & $\mathbf{R}$ \\
\hline 19183 & 1984.0 & 0 & 3 & 150.40 & 1. $7 \mathrm{E}-04$ & 193.9 & 34.9 & 2. 3E-05 & 4.9 & 63.1 & 2.5914 & $\mathbf{R}$ \\
\hline 19184 & 1996.0 & 1 & 3 & 159.80 & $2.6 \mathrm{E}-04$ & 239.2 & 22.7 & 2. $5 E-05$ & 5.7 & 57.2 & 2.6504 & $R$ \\
\hline 19185 & 2004.0 & 1 & 3 & 171.08 & 2.7E-04 & 247.0 & 35.4 & $6.0 \mathrm{E}-05$ & 7.0 & 50.7 & 2.7139 & $\mathbf{R}$ \\
\hline 19186 & 2010.0 & 1 & . & 182.36 & 2. $6 \mathrm{E}-04$ & . & . & . & . & - & . & \\
\hline 19187 & 2017.0 & $\therefore$ & ; & . & . & & - & & - & $355^{\circ}$ & & \\
\hline 19188 & 2023.0 & 0 & 3 & 148.52 & $3.6 \mathrm{E}-04$ & 208.5 & 50.4 & $3.4 \mathrm{E}-05$ & 13.1 & $\begin{array}{l}35.5 \\
53.6\end{array}$ & $\begin{array}{l}2.8476 \\
2.6855\end{array}$ & $\begin{array}{l}R \\
R\end{array}$ \\
\hline 19189 & 2030.0 & 1 & 3 & 169.20 & 1. $6 \mathrm{E}-04$ & 201.5 & 67.3 & $\begin{array}{l}5.3 \mathrm{E}-05 \\
4.8 \mathrm{E}-05\end{array}$ & $\begin{array}{r}6.4 \\
18.8\end{array}$ & $\begin{array}{l}53.6 \\
29.3\end{array}$ & 2.8934 & $\begin{array}{l}\mathrm{K} \\
\mathrm{R}\end{array}$ \\
\hline $\begin{array}{l}19190 \\
19191\end{array}$ & $\begin{array}{l}2036.0 \\
2043.0\end{array}$ & 0 & 3 & & $\begin{array}{l}\text { 1. } 2 \mathrm{E}-04 \\
\text { 1. } 2 \mathrm{E}-04\end{array}$ & 198.6 & 55.4 & $4.0 \mathrm{~L}-00$ &. & . & . & \\
\hline $\begin{array}{l}19192 \\
19193\end{array}$ & $\begin{array}{l}2050.0 \\
2056.0\end{array}$ & $\begin{array}{l}1 \\
2\end{array}$ & i & 154.16 & 2. $2 \mathrm{E}-04$ & 264.0 & 39.6 & $3.4 \mathrm{E}-05$ & 13.2 & 35.4 & 2.8482 & $\mathbf{R}$ \\
\hline $\begin{array}{l}19193 \\
19194\end{array}$ & 2063.0 & 2 & 3 & 172.96 & 1. $4 \mathrm{E}-04$ & 246.2 & 33.8 & $2.1 \mathrm{E}-05$ & 5.2 & 60.4 & 2.6184 & R \\
\hline 19195 & 2069.0 & 2 & . & 165.44 & $1.6 \mathrm{E}-04$ & & . & & 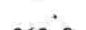 & 7 & & \\
\hline 19196 & 2075.0 & 2 & 3 & 154.16 & 1.7E-04 & 139.5 & 36.4 & $2.3 \mathrm{E}-05$ & 268.8 & 7.5 & 2.9926 & $\mathbf{R}$ \\
\hline 19197 & 2081.0 & 2 & : & 148.52 & $1.8 \mathrm{E}-04$ & . & . & . & - & ${ }^{\circ}$ & & \\
\hline 19198 & 2096.0 & 1 & 3 & 184.24 & 1. $3 \mathrm{E}-04$ & 223.6 & 72.7 & $2.7 \mathrm{E}-05$ & 9.4 & 42.7 & 2.7871 & $R$ \\
\hline 19199 & 2115.0 & . & 3 & 150.40 & $2.8 \mathrm{E}-04$ & 248.8 & 45.6 & $5.1 \mathrm{E}-05$ & 520.4 & 5.4 & 2.9962 & R \\
\hline 19200 & 2130.0 & 1 & 3 & 174.84 & 4.1E-04 & 180.6 & 74.4 & $5.9 \mathrm{E}-05$ & 109.0 & 11.9 & 2.9817 & R \\
\hline 19201 & 2142.0 & 2 & 3 & 152.28 & $2.2 \mathrm{E}-04$ & 181.5 & 45.9 & $6.2 \mathrm{E}-05$ & 9.1 & 43.5 & 2.7803 & $\mathrm{R}$ \\
\hline 19202 & 2154.0 & 1 & 3 & 167.32 & $3.0 \mathrm{E}-04$ & 206.7 & 28.8 & $7.4 \mathrm{E}-05$ & 17.5 & 30.4 & 2.8858 & $\mathbf{R}$ \\
\hline 19203 & 2155.0 & 0 & . & 154.16 & 4. $2 \mathrm{E}-04$ & & & & . & . & $\cdot$ & \\
\hline 19204 & 2156.0 & 0 & 3 & 494.44 & 1. $5 \mathrm{E}-03$ & 250.6 & 28.3 & $5.8 \mathrm{E}-05$ & 6.2 & 54.4 & 2.6778 & $R$ \\
\hline 19205 & 2156.5 & 0 & . & 259.44 & $6.0 \mathrm{E}-04$ & . & $0^{\circ}$ & & ${ }^{\circ}$ & $\cdot$ & & \\
\hline 19206 & 2157.0 & 0 & 3 & 204.92 & $6.0 \mathrm{E}-04$ & 213.4 & 37.3 & 1.7E-04 & 4.8 & 63.8 & 2.5841 & R \\
\hline 19207 & 2157.5 & 0 & 3 & 1024.60 & $7.2 \mathrm{E}-03$ & 199.7 & 47.5 & 1. $4 \mathrm{E}-03$ & 7.0 & 50.6 & 2.7144 & D \\
\hline 19208 & 2158.0 & 0 & . & 1472.04 & 1. $5 \mathrm{E}-02$ & . & . & . & . & . & . & \\
\hline
\end{tabular}




\section{APPENDIX 10: CARBON AND OXYGEN ISOTOPE DATA}

Carbon Isotope Data

$\begin{array}{cccc}\begin{array}{c}\text { VUW } \\ \text { No }\end{array} & \begin{array}{r}\text { Stratigraphic } \\ \text { Height }(\mathrm{m})\end{array} & \begin{array}{r}\text { Analytical } \\ \delta^{13} \mathrm{C}\end{array} & \begin{array}{r}\text { Corrected } \\ \delta^{13} \mathrm{C}\end{array} \\ 19221 & & & -0.28 \\ 19220 & 2123 & -0.84 & -0.22 \\ 19197 & 2110 & -0.78 & 0.34 \\ 19196 & 2081 & -0.22 & 0.82 \\ 19191 & 2075 & 0.26 & 0.63 \\ 19190 & 2043 & 0.07 & 0.78 \\ 19189 & 2036 & 0.22 & 0.96 \\ 19187 & 2030 & 0.40 & 1.08 \\ 19178 & 2017 & 0.52 & 0.78 \\ 19176 & 1945 & 0.22 & 0.91 \\ 19171 & 1927 & 0.35 & 0.63 \\ 19170 & 1884 & 0.07 & 0.97 \\ 19169 & 1875 & 0.41 & 0.92 \\ 19167 & 1866 & 0.39 & 0.64 \\ 19166 & 1848 & 0.08 & 0.80 \\ 19164 & 1836 & 0.24 & 0.69\end{array}$

Corrected values are the analytical values normalised to Cibicidoides wuellerstorfi by the addition of $0.56 \delta^{13} \mathrm{C}$.

Oxygen Isotope Data

$\begin{array}{ccc}\begin{array}{c}\text { VUW } \\ \text { No }\end{array} & \begin{array}{c}\text { Stratigraphic } \\ \text { Height }(\mathrm{m})\end{array} & \begin{array}{c}\text { Analytical } \\ \delta^{18} \mathrm{O}\end{array} \\ 19221 & 2123 & \\ 19220 & 2110 & 0.42 \\ 19197 & 2081 & 0.42 \\ 19196 & 2075 & 1.32 \\ 19191 & 2043 & 1.33 \\ 19190 & 2036 & 1.40 \\ 19189 & 2030 & 1.10 \\ 19187 & 2017 & 1.41 \\ 19178 & 1945 & 1.49 \\ 19176 & 1927 & 1.62 \\ 19171 & 1884 & 1.51 \\ 19170 & 1875 & 1.41 \\ 19169 & 1866 & 1.27 \\ 19167 & 1848 & 1.45 \\ 19166 & 1836 & 1.71 \\ 19164 & 1816 & 1.59 \\ & & 1.77\end{array}$

All samples were analysed by Dr. C. Nelson on the Waikato University VG Micromass $602 \mathrm{E}$ mass spectrometer. 
- A50 -

APPENDIX 11: SUSCEPTIBILITIES OF SILICIC TUFFS

(MANGAPOIKE)

$\begin{array}{lllll}\text { Tuff* } & \text { Value } 1 & \text { Value } 2 & \text { Value } & \text { Mean } \\ \text { G161 } & 159.2 & 164.6 & 163.2 & 162.3 \\ \text { G159 } & 190.2 & 203.4 & 191.8 & 195.1 \\ \text { G156 } & 174.5 & 174.9 & 166.0 & 171.8 \\ \text { G153 } & 173.9 & 182.8 & 178.3 & 178.3 \\ \text { G152 } & 198.7 & 184.6 & 196.8 & 193.8 \\ \text { G74 } & 163.6 & 171.2 & 170.9 & 168.6 \\ \text { G71 } & 220.8 & 224.1 & 226.5 & 223.8 \\ \text { G62 } & 180.3 & 178.4 & 187.6 & 182.1 \\ \text { G55 } & 190.8 & 192.7 & 189.4 & 191.0 \\ \text { G171 } & 213.7 & 221.4 & 209.1 & 214.7\end{array}$

Susceptibility values are $\times 10^{-3}$

* G number refers to the field numbers of Gosson (1986). 